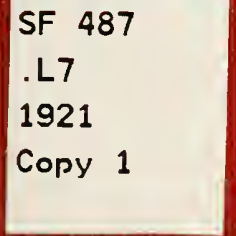



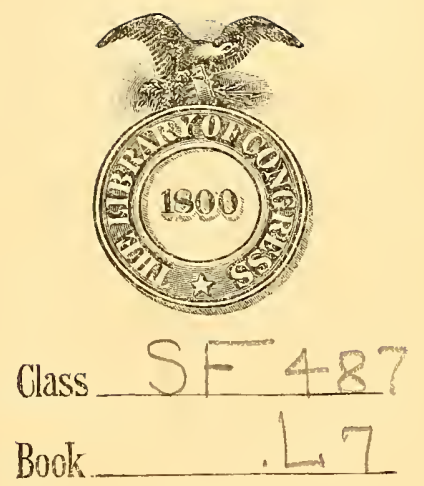

Copyight No $\quad 1921$ COYMRGHT DEPOSY. 






\section{POULTRY PRODUCTION}

BY

\section{WILLIAM ADAMS LIPPINCOTT}

II

PROFESSOR OF POULTRY HUSBANDRY, KANSAS STATE AGRICULTURAL COLLEgE

THIRD EDITION, THOROUGHLY REVISED

ILLUSTRATED WITH 243 ENGRAVINGS

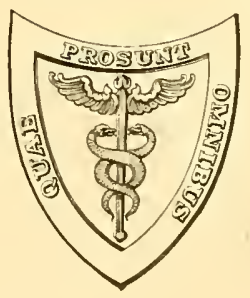

LEA \& FEBIGER

PHILADELPHIA AND NEW YORK 1921 


$$
\begin{aligned}
& =5.87 \\
& =491
\end{aligned}
$$

\section{COPY RIGHT}

LEA \& FEBIGER

1921

\section{SEP 101921}

PRINTED IN U. S. A.

(2) 4622725 
$\mathrm{TO}$

MY FATHER

JULIAN POST LIPPINCOTT

WITHOUT WHOSE ENCOURAGEMENT THIS WORK WOULD NOT HAVE BEEN UNDERTAKEN IT IS AFFECTIONATELY INSCRIBED 



\section{PREFACE TO THE THIRD EITIION.}

Twis book has been written to furnish agricultural students with a comprehensive and convenient statement of the facts and principles of Poultry Production. It is hoped that it will render a service in teaching its subject in the great producing areas where farm poultry is abundant and poultry farms rare. It is of necessity very largely a compilation, and as far as possible cousists of a systematic report of facts fully or partly established by careful experiment.

The material is largely that used by the author in courses taught at Iowa State College and Kansas State Agricultural College during the last eleven years. This has been supplemented by knowledge gleaned from the literature of the subject. Credit is given for material wherever used, when the person with whom it originated is known.

It is a pleasure to acknowledge the assistance of the following gentlemen in the preparation of this book:

Mr. J. G. Halpin, Professor of Poultry Husbandry, University of Wisconsin, made several helpful suggestions, particularly in reference to the chapters on 'The Poultry Industry, Housing and Hygiene, and Preparing for Consumption.

Mr. A. G. Philips, Professor of Poultry Husbandry, Purdue University, made several pertinent suggestions concerning the chapter on Breeding.

Messrs. George C. Bowman and I Harry Perry, of the 
Seymour Packing Company, Topeka, Kansas, and Mr. John Perry, of Perry Brothers, packers of poultry and eggs, Manhattan, Kansas, have made numerous helpful suggestions concerning the chapters on The Poultry Industry, and Preparing for Consumption.

Mr. F. E. Mussehl, Professor of Poultry Husbandry, University of Nebraska, made several suggestions concerning the chapter on Feeding, and Diseases and Parasites. He also compiled the tables of feeds in the appendix.

Dr. J. S. Hughes, Associate Professor of Chemistry, Kansas State Agricultural College, aided materially in the revision of the chapters on Feeds and Feeding.

Mr. H. A. McAleer, Chief, Foods Research Laboratory, Bureau of Chemistry, U.S. Department of Agriculture, made pertinent suggestions concerning the revision of the chapters on the Poultry Industry and the Preparation of Poultry Products.

Professor F. E. Fox, of Oregon State Agricultural College, and Professor L. H. Schwartz, of Purdue University, called the author's attention to several omissions and inaccuracies.

Messrs. W. A. Henry and F. B. Morrison, of the University of Wisconsin, very kindly gave permission for the use of the analyses found in Table LIV in the Appendix, which were taken from their volume, Feeds and Feeding.

I also desire to acknowledge my indebtedness to Mr. James E. Rice, Professor of Poultry Husbandry, Cornell University. It was my good fortune to secure my first college training in this subject under his direction. The principles which I learned from him are to be found throughout this book.

W. A. L.

Kansas State Agricultural College, 1921. 


\section{CONTENTS.}

CHAPTER I.

Poultry Production and the Poultry Industry . . . 17

CHAPTER II.

Breeds of Chichens . . . . . . . . . . . . 49

CHAPTER III.

The Breeding of Chickens . . . . . . . . 84

CHAPTER IV.

The Incubation of Hen's Eggs . . . . . . . . 175

CHAPTER V.

The Brooding of Chicks . . . . . . . . . . 230

CHAPTER VI.

Housing and Hygiene . . . . . . . . . . . . 249

CHAPTER VII.

The Nutrients and Nutrition . . . . . . . . 297

CHAPTER VIII.

The Feeds . . . . . . . . . . . . . . . . 329

CHAPTER IX.

The Compodnding of Rations 
viii

CHAPTER X.

Feeding Practices and Appliances . . . . . . . . 377

CHAPTER XI.

TURKEYS . . . . . . . . . . . . . . . 418

CHAPTER XII.

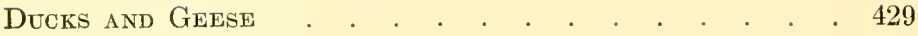

CHAPTER XIII.

Pigeons and Guinea-fowl . . . . . . . . . . 443

CHAPTER XIV.

Preparing Poultry Products . . . . . . . . . 451

CHAPTER XV.

Poultry Diseases and Parasites . . . . . . . . . 503

APPENDIX . . . . . . . . . . . . . 523

$\operatorname{INDEX}$. . . . . . . . . . . . . . . 531 


\title{
POULTRY PRODUCTION.
}

\author{
CHAPTER I.
}

\section{POULTRY PRODUCTION AND THE POULTRY INDUSTRY.}

Definition of Poultry. ${ }^{1}$ - Poultry is a term designating collectively those species of birds which render man an economic service and reproduce regularly and freely under his care. It includes chickens, turkeys, ducks, geese, swans, guineas, pigeons, pheasants, peafowl and ostriches, and refers to them whether alive or dressed.2

Relative Importance of the Different Species of Poultry.Chickens are of preëminent importance among the various species of poultry. As shown in Table I, the total number of poultry found on the farms of the United States ${ }^{3}$ April 15,1910 , was $295,876,176$ birds. Of these, almost 95 per cent $(280,340,643)$ were chickens; a little over 1.2 per cent $(3,688,688)$ were turkeys; less than 1 per cent $(2,904,359)$ were ducks; a trifle under 1.5 per cent $(4,431,623)$ were geese; while the total for guineas, pigeons, peafowl and ostriches was slightly over 1.5 per cent $(4,510,873)$.

1 Adapted from Pusch, Allgemeine Tierzucht.

2 The names of the various species of poultry also designate them respectively when dressed, there being no separate terms, as in the case of "beef," "mutton," and "pork."

${ }^{3}$ Unfortunately these figures fail to take into account the numbers of poultry under three months of age, or those which are kept in the towns and villages, and which would appreciably increase both the total numbers and the relative proportion of chickens to other species. 


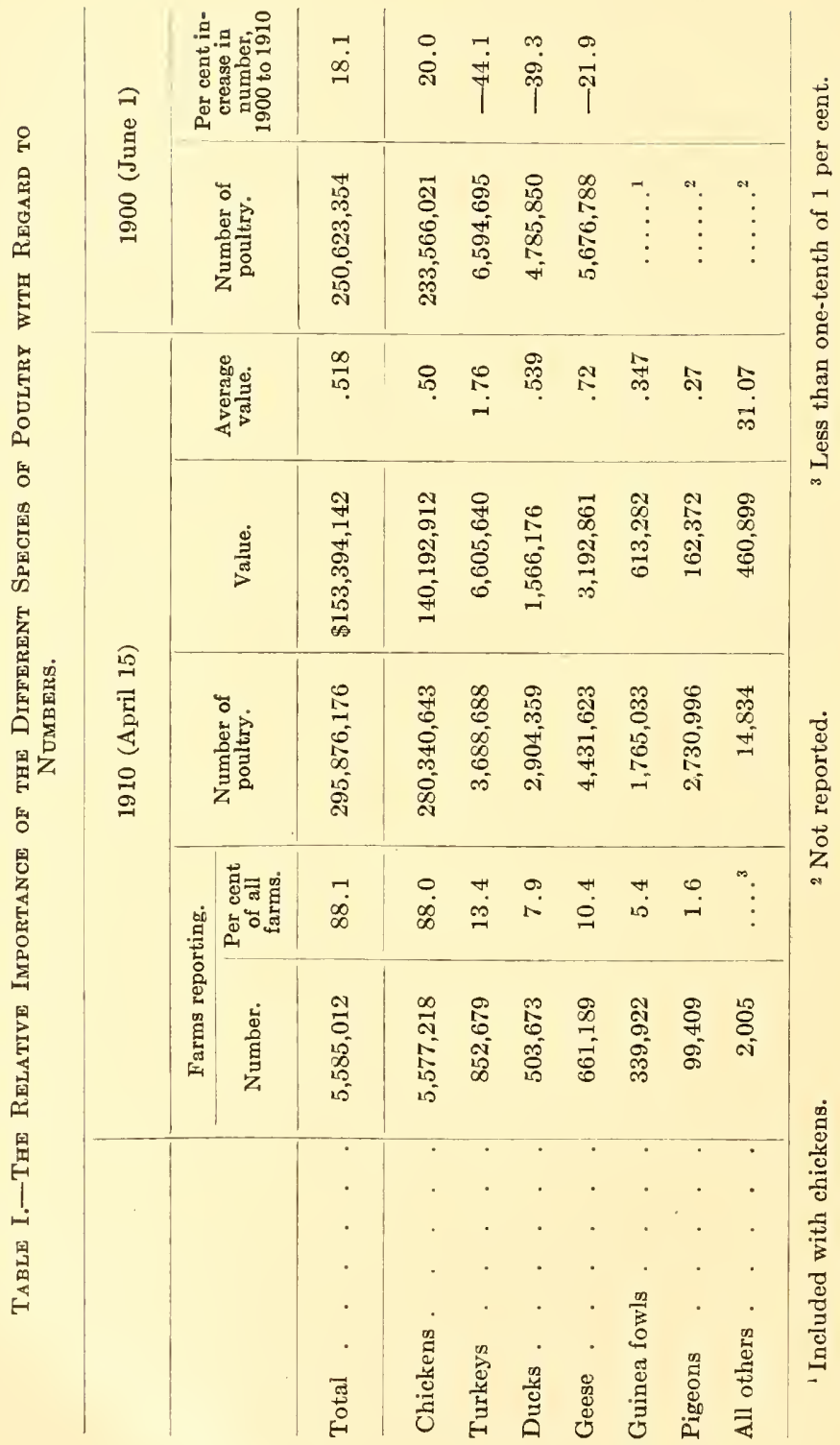


While $S S$ per cent of all the farms of the United States reported chickens, there was but 0.1 per cent that reported any species of poultry that did not report chickens. From 1900 to 1910 the number of chickens in the United States increased 20 per cent, while during the same period the number of turkeys, ducks, and geese decreased 44.1, 39.3, and 21.9 per cent respectively.

The popularity of the chicken is due to the fact that it furnishes a convenient source of fresh meat on the farm, and is, almost universally, a greater egg producer than are other sorts of poultry.

Magnitude of the Poultry Industry.-The 1911 report of the Secretary of Agriculture places the national annual income from poultry products at $\$ 750,000,000$, or approximately the combined value of the gold, silver, iron, and coal mined the same year. It exceeds the value of the wheat crop reported in the last census. While this is only an estimate, it far more nearly approximates the truth than does the report of the 1910 census, which places the national annual income from eggs and carcasses sold at a little over $\$ 256,000,000$. (See Table LI, Appendix.) The latter figures take no account of poultry and eggs produced in towns or villages, or consumed on the farm, or of birds under three months of age, all of which are highly important items, and which account somewhat for the discrepancy.

"History has shown that as the population of a country increases, the hen population outruns the population of other domestic animals. In the United States, we had two hens per person in 1880 and a little over three hens per person in 1900 and 1910. In the meantime the number of other (food) animal units . . . has decreased 30 per cent." 1

At average market values the carcasses and eggs produced on farms, as shown in Table LI (Appendix), would bring the poultry income of the nation up to $\$ 509,195,332$, leaving the production of the villages, towns, and cities unaccounted for. On this basis, however, poultry products represent 16.9 per cent of the value of all products of animal origin,

${ }_{1}^{1}$ Benjamin: Jour. Am. Assn. Inst. Invest, in Poul. Husb., vol. iv, No. 3. 
including wool and mohair, as well as the food products. The census figures for the different states, while incomplete, are fairly comparable, because of the fact that the same method was used in securing them in each state. The first ten states in point of income from poultry are shown in Table II.

\section{Table II.-The Rank of the First Ten States, with Reference to Their Total Income from Poultry. ${ }^{1}$}

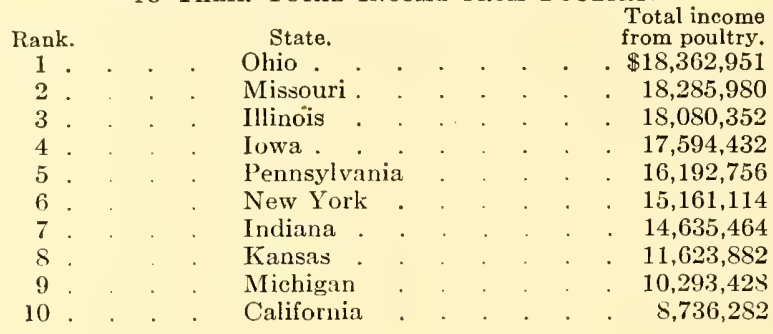

Farm Incomes from Poultry.--The importance of a state to an industry and the importance of an industry to a state may be, and in the case of poultry production are two very different matters. While Missouri, for instance, ranks second in the total income to the state, she ranks only twentyfirst in the average farm income derived from poultry. (See Table L, Appendix.)

According to the 1910 census report the average farm income from poultry products sold in the United States was $\$ 92.39$ on the basis of the total number of farms. (See Table L, Appendix.) On the basis of the total number of farms leporting poultry the average farm income for the United States is $\$ 104.98$, or about $\$ 2$ per bird. Figures are not available which show what proportion of the average total farm income the average poultry income is, but it is reasonable to suppose it will generally be greatest in those states whose average farm income from poultry is largest. 'The ten states showing the largest average farm incomes from poultry sold are listed according to their incomes in Table III.

1 Compiled from the United States Census Report for 1910. 
Table III.-The Relative Rank of the First Ten States with Reference to the Average Farm Income from Poultry. ${ }^{1}$

Rank.
1
2
3
4
5
6
7
8
9
10

State.
Rhode Island
California
New Jersey .
Massachusetts .
District of Columbia
Nevada . . .
Arizona.
Connecticut .
Delaware .
New Hampshire

Average farm income from poultry.

$\$ 267.70$

$256.43^{2}$

221.49

215.16

199.01

164.85

$156.103^{3}$

143.25

130.25

124.91

Farm Consumption of Poultry Products.-The average quantities of home produced meats (including eggs) consumed per family by 955 farm families (average size 4.8 adults or equivalent), in fourteen states was reported by Funk ${ }^{4}$ in 1920 to be as shown in Table IV. Poultry and eggs furnish 39 per cent of the home produced meat food.

Table IV.-Home-produced Meat Foods Consumed Annually by Farm Families (Data of Funk).

Pounds.

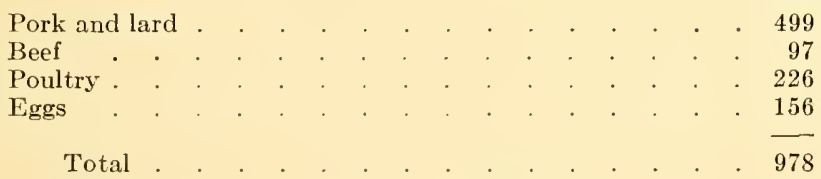

The Primary Poultry Product.-Eggs are the leading poultry product. As shown in Table LI (Appendix), the average state income from poultry products was, in $1910 \$ 5,227,403$, of which $\$ 1,536,194$ was credited to poultry carcasses sold, and $\$ 3,691,239$ was credited to eggs, or considerably over two-thirds of the total income.

At the same time the average annual farm income from eggs for all the farms in the United States was $\$ 60.57$, as shown in Table L (Appendix), while the income from carcasses sold was \$31.\$2, or slightly over half as much.

${ }^{1}$ For the average farm incomes for all the states, see Table L (Appendix).

2 These figures include the income from ten ostrich farms.

3 These figures include the income from thirteen ostrich farms.

1 U. S. Farmers' Bulletin, No. 1082. 


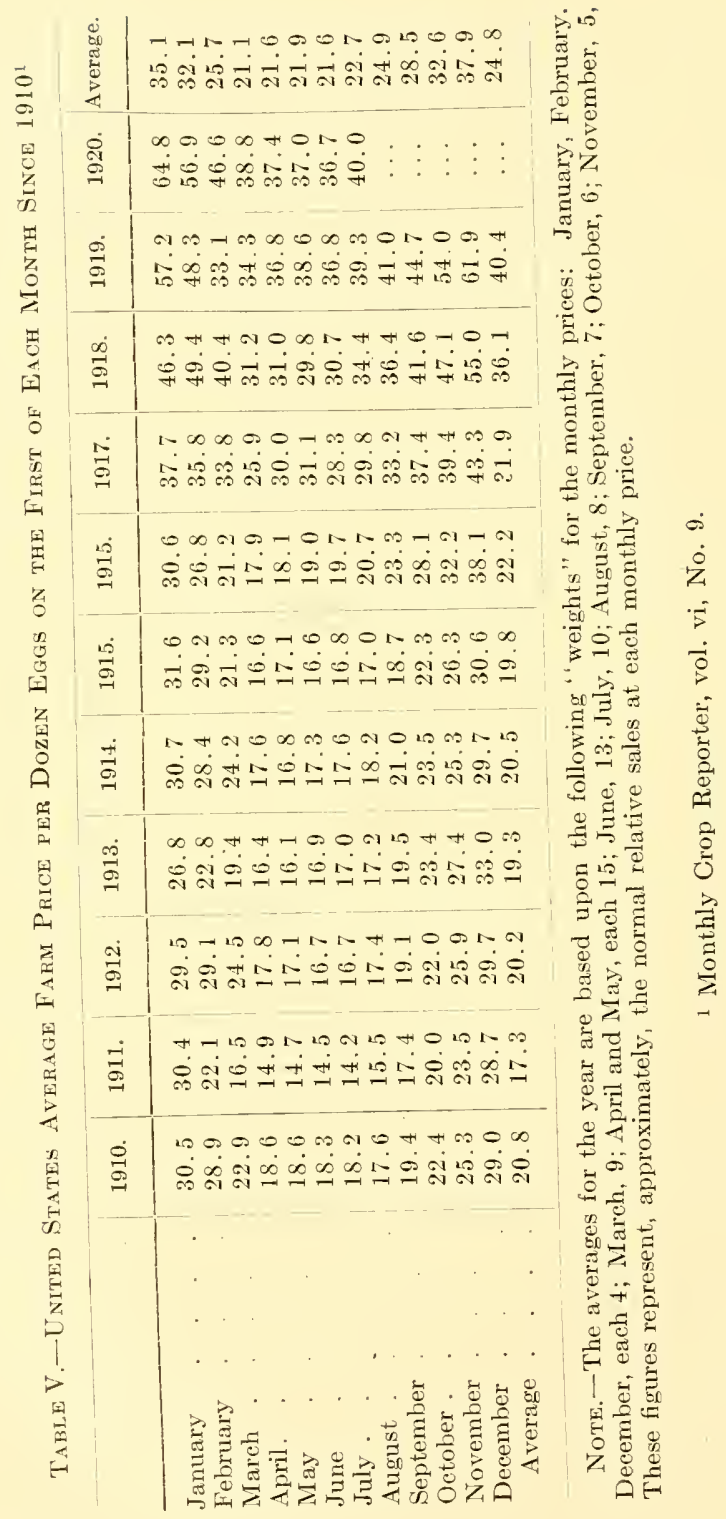


The reason for this difference probably lies in the uniqueness of eggs among human foods, their high digestibility, ${ }^{1}$ healthfulness, and general attractiveness. It is likely to continue until some economic condition arises whereby the poultry carcass becomes more highly valued by the general public, in comparison with the egg, than at present. In the light of recent discoveries concerning their content of food accessories or vitamins, eggs are likely to increase in esteem, rather than decrease.

Although the eggs of ducks and guineas find their way into the regular channels of trade, their number is so small when compared with the number of hens' eggs as to make them practically a negligible quantity. Turkey and goose eggs are used for hatching purposes only.

"The output of eggs is steadily growing, but the demand is growing even faster than the supply, due to the increased price of meat, as well as a preference for eggs as food; hence the price of eggs has risen. In 1899 the farm price was 11.15 cents per dozen, as an average for the United States; in 1909 the average was 19.7 cents, weighted according to monthly production."'2

The average farm price per dozen eggs on the first day of each month from January, 1910 to August, 1920 is shown in Table $\mathrm{V}$.

As indicative of the advance in prices of poultry as well as eggs during the last twenty-four years, the weighted average New York prices (estimated), furnished by the "Crner-Barry Company," New York City, are given in Table VI. These prices represent those paid wholesale receivers by jobbers for western products, all grades considered except extras in the case of eggs.

1 Several investigations reported by Langworthy show that 95 per cent of the dry matter of the edible portion of the egg is digested by man. In detail the digestibility of the various constituents of the edible portion was: protein, 90 to 98 per cent; lecithin, 91 per cent; neutral fat, 95 to 98 per cent: ash, 70 per cent-Farmers' Bulletin, 128.

${ }^{2}$ Pennington and Pierce, Year-book of United States Department of Agriculture, 1910. 
Table Vi.-Weighted New York Average Prices (Estimated) on Eggs, Live and Dressed Poultry for the Years 1896 to 1919 INCLUSIVE.

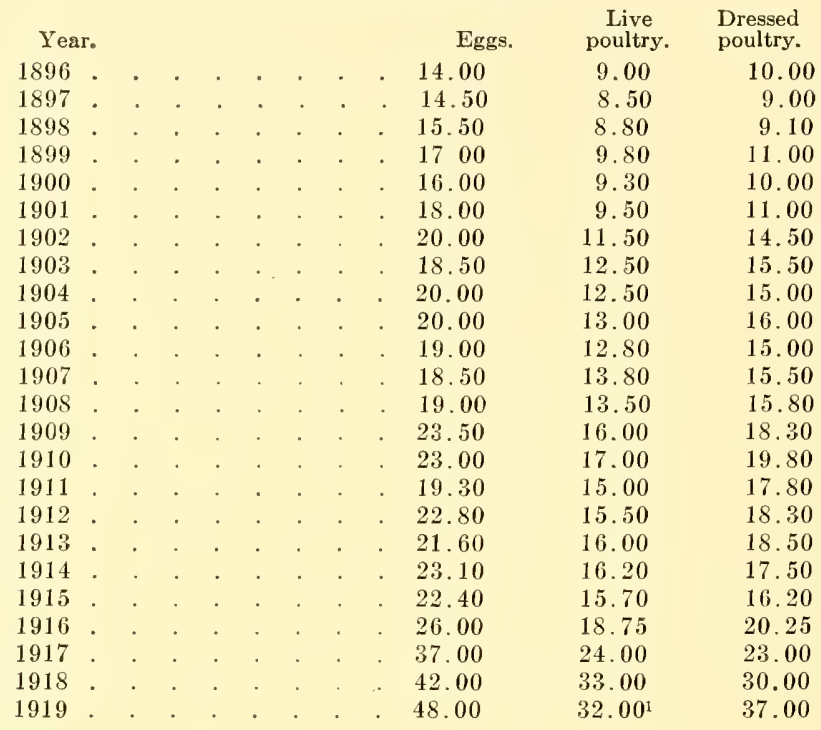

During these same years the Chicago prices of eggs into and out of storage are shown in Table VII. ${ }^{2}$

Home Demand Supplied.-For the five years ending June 30,1920 , the average annual imports of eggs were only 1,131,602 dozens (see Table LVI, Appendix). During the same period the average annual exports of eggs were 27,400,313 dozens (See Table LV, Appendix). These figures refer to eggs in the shell. A rather recent development is the importation of considerable quantities of dried and frozen eggs, chiefly from China. During the five years ending June 30, 1920, the average annual imports of this class of goods were $12, \$ 22,693$ pounds valued at $\$ 3,727,661$. During the same period the average value of the exports was only $\$ 286,425$. (See Tables LVII and LVIII in Appendix.)

I This slight decline in the price of live poultry was due to a very heavy increase (about 41 per cent) in the supply.

${ }^{2}$ Courtesy of Paul Mandeville, Merrill and Eldredge, and S. S. Borden Co., Chicago. 
Tabie ViI.-Cost of Storage Packed Egga into Store, F. O. B. Chicago.

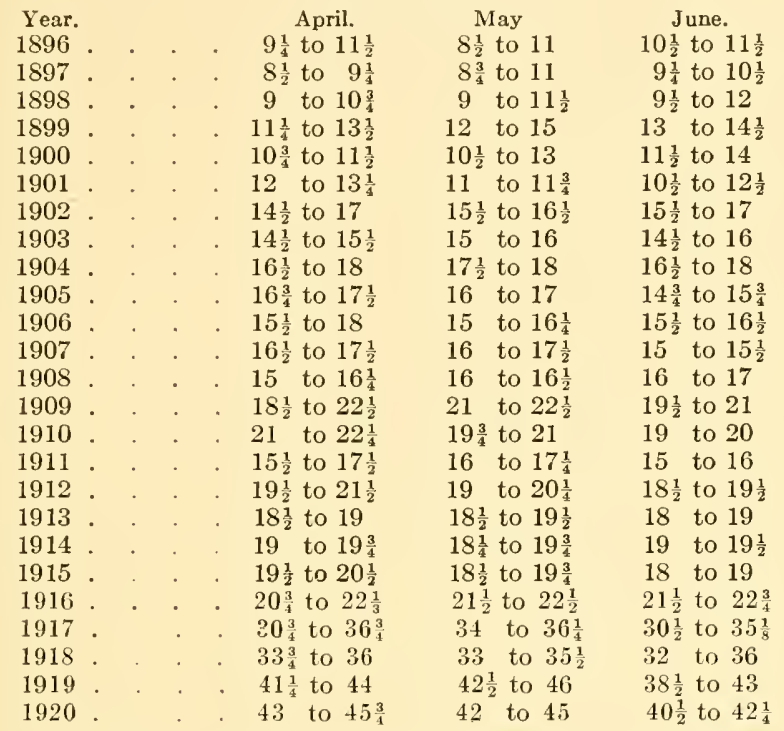

Selling Price of Aprils and Northern Mays, Including Carrying Charges F. O. B. Chicago.

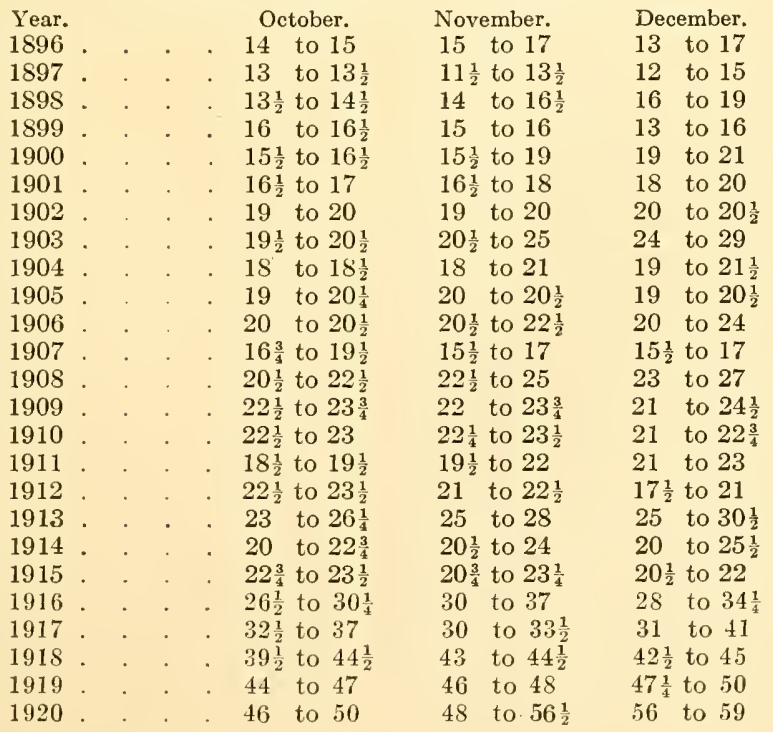


Geographical Distribution of Poultry.--"The great egg and poultry producing territories of the United States can be divided according to their geographical location and the character of the industry, into three quite distinct sections. The first of these comprises the northeastern states, including New England, New York, Pennsylvania, New Jersey, and Maryland. This is a section in which the poultry industry is one of importance and where many large and specialized poultry farms are located. Inasmuch as it also happens to be one of the greatest consuming sections of poultry products, the local supply does not supply the demand, and large quantities are brought in from other parts of the country."

"The second producing section comprises the states bordering the Pacific. Here the conditions are in many respects identical with those of the first section. The eggs produced all find a market in the cities of those states, and the quantity is not sufficient to supply the demand."2

"The third section comprises principally states lying in the Mississippi Valley. They are Minnesota, Wisconsin, Illinois, Michigan, Indiana, Ohio, Nebraska, Iowa, Kansas, Missouri, Kentucky, 'Tennessee, Oklahoma, Arkansas, and Texas. In this great section the vast majority of the eggs (and poultry) are produced; yet the character of the poultry keeping is quite different from that in the other two sections discussed. There are in this whole stretch of country few farms which can properly be termed poultry farms, or where poultry raising can properly be considered one of the main branches of the farm work.",

Over 88 per cent of all the farms in the United States reported poultry in the census of 1910 . The total number of poultry on the farms at that time was $295,876,176$, with an average of $6,038,289$ birds for each state and 53 birds to each farm, with value per bird of 52 cents. ${ }^{4}$ Nearly 54 per cent of the total number is found in ten states, which are listed according to their rank in Table VIII.

\footnotetext{
I Lamon, Year-book, United States Department of Agriculture, 1911.

${ }^{2}$ Loc. cit.

${ }^{3}$ Loc. cit.

${ }^{4}$ According to the census of 1900 it was 34 cents.
} 
Table VIII.-Showing the Comparative Rank of the First Ten States with Regard, to the Number of Poultry Kept, and Their Total Value. ${ }^{1}$

Rank. Numbers kept. Rank. Total value.

1. Iowa $23,482,880$

2. Illinois . . . . $21,409,053$

3. Missouri . . . $20,897,208$

4. Ohio . . . . $17,342,289$

5. Kansas . . . 15,736,038

6. Indiana . . . . 13,789,109

7. Texas . . . . 13,669,645

8. Pennsylvania . . $12,728,341$

9. Minnesota . . . 10,697,075

10. New York . . . $10,678,836$

\begin{tabular}{|c|c|c|}
\hline low & & \\
\hline Missouri & & \\
\hline Illinois & & 11, \\
\hline hio & & \\
\hline York & & \\
\hline & & 7, \\
\hline & & \\
\hline & & \\
\hline & & \\
\hline & & 4,807, \\
\hline
\end{tabular}

The rank of these states with reference to numbers and value differs somewhat. The causes for this difference usually lie in the quality of the poultry, the distance from market, or both. The first ten states with reference to the value of their poultry at the time of the census are also listed according to their rank in Table VIII. Nearly 56 per cent of the total valuation of poultry in the United States is found in these ten states. It will be noted that the same states are found in each list, except that Minnesota, which stands ninth in the number of poultry kept, is replaced by Michigan in the list of states whose poultry shows the greatest value.

\section{POULTRY PRODUCTION.}

Poultry production includes those operations incident to breeding and rearing domestic birds for food purposes and for pleasure and in preparing their products ${ }^{2}$ for market. These are the activities of the breeder, the producer, and the packer.

Early History of Poultry Production.-Poultry raising is essentially a home industry. It appeared in this country at least as soon as the first homes were made in Jamestown in 1607. The entire product of the flock, including the feathers, was used at home. It has, however, never been a frontier occupation in the sense that beef production and,

1 For complete statistics of all the states, see Table LII, Appendix.

2 The by-products of poultry production are feathers, fertilizer, gizzard linings as a source of commercial pepsin, and egg-shells as a source of powdered calcium carbonate for infant feeding. Of these, feathers are by far the most important being in the case of the ostrich the primary product. 
to a less degree, wheat production, which tend to be replaced by crops yielding more food units per acre, have been. Poultry and eggs have been from the first, for the most part by-products of general agriculture. It was not until long after most of the present-day industries which emanated from the farm had become fairly well established that poultry raising with its associated industries began to be accounted an industry and recognized as of any commercial importance.

This was largely due to two associated causes. The first was the high perishability of both poultry and eggs and the second the poor means of transportation in early days.

Commercially the poultry industry as a whole is dependent upon present-day improved transportation facilities, and the history of its development has very largely paralleled the history of the development of the modern common carriers and advanced with the improvement of refrigerator cars. It was not until about 1869 when the refrigerator was first brought into use for long distance hauling, that means were afforded for transporting poultry products from the farm to distant cities and production, beyond that demanded by home needs, became an object and poultry a source of any considerable money income.

Present Organization of the Poultry Industry.-The poultry industry is at present made up of several more or less clearly defined coördinate industries which have to do with growing and marketing poultry and poultry products. Taking their names from the respective industries in which they are employed, the persons engaged in the poultry industry as a whole may be designated as (1) productionbreeders; (2) fanciers and fancier-breeders; (3) producers; (4) customs hatchers and baby chick dealers; (5) buyers; (6) packers and (7) distributers.

While this classification holds true, it should be clearly recognized that there is no hard-and-fast line between the classes, and that the same person often engages in two or more lines of work. Thus the producer of the best type carries on breeding operations within certain limits. The breeder should be somewhat of a fancier, and the packer is usually a buyer and distributer as well. 


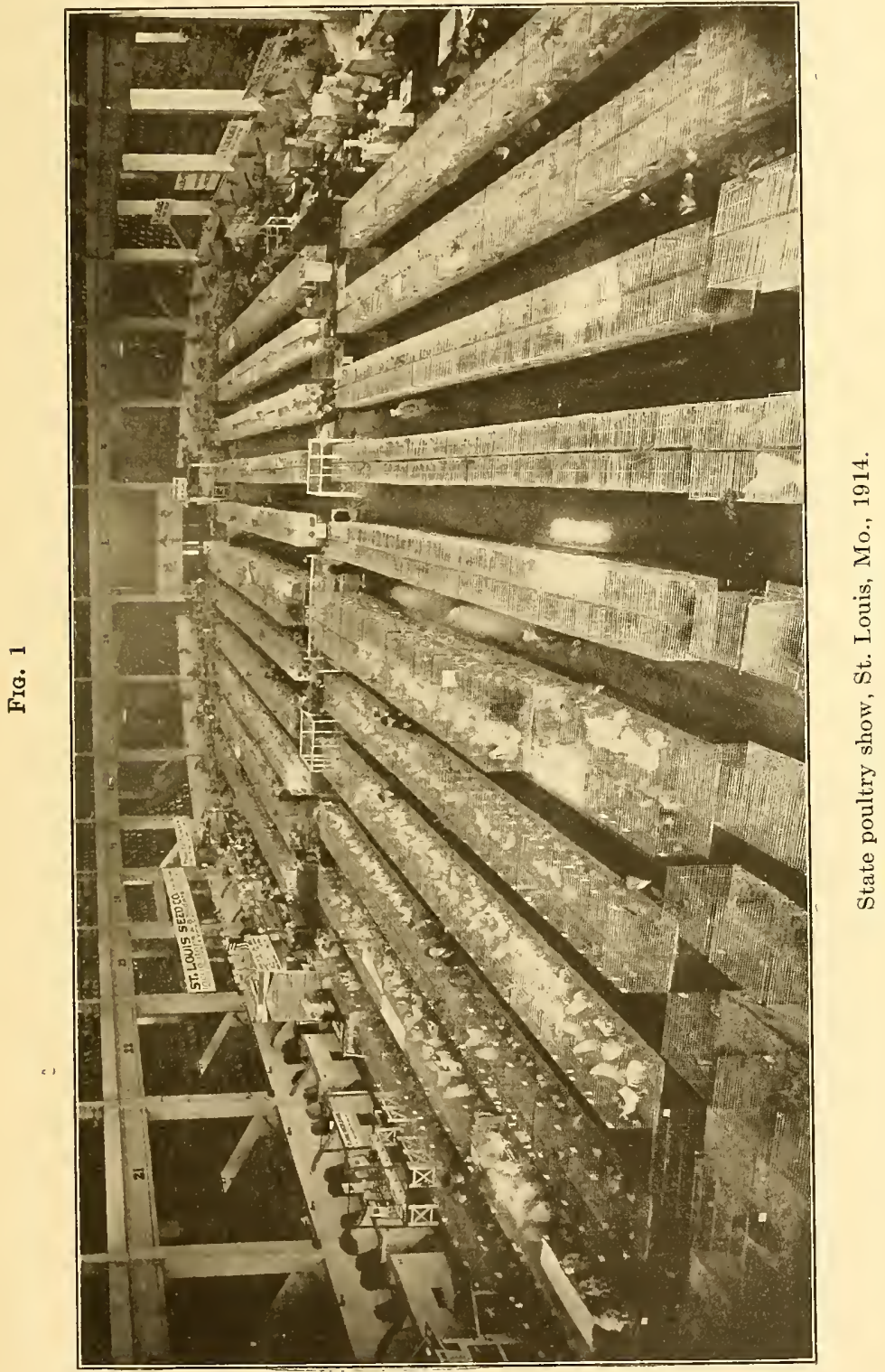


The Production-breeder.-A breeder is one who seeks to improve stock through proper selection and mating. From the standpoint of poultry production, with the exception of ostriches, improvement refers to an increased efficiency in the production of human food. A breeder whose primary aim is to raise the food manufacturing efficiency of any species of poultry may for convenience be called a "production breeder". A comparatively small, but constantly growing number of breeders are turning their attention toward production. Their principal function with regard to production is to furnish the producer with breeding males of standard varieties with which to improve his flocks whether the flocks are mongrel or pure-bred. Pedigree breeding, the only method by which prepotent males able to sire efficient producers can be produced, with any regularity is out of reach of the producer, who must make his profit by securing a narrow margin on many birds, rather than a wide one on a few. The true breeder is a producer in the very best and highest sense. The producer can follow only as far as the breeder leads the way.

Fanciers and Fancier-breeders.-The term "fancier" refers to one who keeps poultry for pleasure rather than for the production of food, while a "fancier-breeder" is one who breeds poultry for fanciers. At the present time the fancierbreeders as far outnumber the production-breeders as the fanciers are outnumbered by producers.

The preponderance of fancier-breeders over productionbreeders is largely due to three causes. The first is the elaborate poultry show system in vogue in this country, the second is the lack of anything like the general adoption of a merit system in the purchase of farm poultry products, and the third is a profound ignorance of the laws of productive breeding.

The poultry show system of America is more complete than for any other line of live stock. Nearly every city (and very many of the towns and villages), throughout the United States and Canada has its annual poultry show, at which the fanciers from a greater or less range of surrounding territory exhibit their birds in competition for premiums. 
Back of these shows, which are comparatively seldom held for profit, are usually to be found an enthusiastic group of fanciers organized into a more or less local association.

The characteristics or points by which competing birds are compared, are those beauties which, taken collectively, make up the bird representing the prevailing fashion. The useful type has not been made the basis of the show type with poultry to nearly so great a degree as with other foodproducing animals or with draft horses. Improvement in this line during the last few years, however, has been very marked, and there is a noticeable tendency for those fanciers who carry on breeding operations to become breeders from the stand-point of production.

It is to the credit of the fancier, however, that there are distinct types and breeds of poultry. Both breeders and producers are under lasting obligations to them for the possibility of that uniformity which is so essential as a basis of successful feeding in flocks, and in marketing modern high-class products.

A second reason why the fanciers outnumber the breeders is that there has been no merit system in general use for purchasing poultry products, and hence there has been little incentive toward improved products. When market poultry and eggs are universally purchased from the farmer on the basis of their quality, as cream is bought on the basis of butter-fat content in many sections, and a better price is paid for good goods than for poor goods, poultry breeding in the best sense will become a practice and the number of production-breeders will more nearly approach that of the fancier-breeders.

A third cause has been the lack of anything like definite rules of selection in production-breeding practice. There are now happily being worked out certain correlations between form and function which are giving some characteristics at least, of a producing type. With the increase in knowledge concerning the inheritance of egg production, the growth of the practice of pedigree breed $\mathrm{ng}$ and of the dependence upon the progeny test in estimating the breeding value of a given bird this cause bids fair to disappear. 
The Producer.-By a "producer," reference is made to a person who raises poultry primarily for human consumption.

During the last twenty-five years a great many attempts have been made to operate farms which had as their principal market crops, poultry and eggs. In fact, numerous attempts have been made to go beyond this and specialize on a certain sort of product, and through the nineties, broiler, egg, and roaster farms were frequently heard of and much exploited by the press.

Today farms of any considerable size that have deroted their entire attention to poultry production (aside from duck raising) and have been a business success for a period of ten years are exceptions and generally due to especially advantageous conditions of production or market, not generally available. While there are no reliable statistics covering the point, the vast majority of producers are general farmers whose poultry raising is carried on as a subordinate line in a system of diversified farming.

Hastings, ${ }^{1}$ who has had every opportunity to observe, thinks that "more than 98 per cent of the poultry and eggs are produced on the general farm," while Robinson ${ }^{2}$ hazards the opinion that "the greater part, probably over 90 per cent, of all the poultry sold in the United States is produced by poultry keepers who do not make a business of poultry culture, but keep poultry on a small scale while giving their attention chiefly to some other occupation, usually general farming."

In the extreme eastern and western states and in the vicinity of certain of the large cities in the central states, there are sections containing numerous small tracts given over to the production of eggs and poultry for specialtrades. Possibly the best known of these is the Petaluma district of California, which specializes in white eggs and broilers for the winter tourist trade. The Vineland district in New Jersey, as described by Lewis, ${ }^{3}$ furnishes new-laid white

1 Formerly with the Burcau of Animal Industry, United States Department of Agriculture.

2 Principles and Practice of Poultry Culture.

${ }^{3}$ Productive Poultry Husbandry. 
eggs for the fancy New York market. 'The Little Compton district of Rhode Island produces brown eggs for the New

F1G. 22

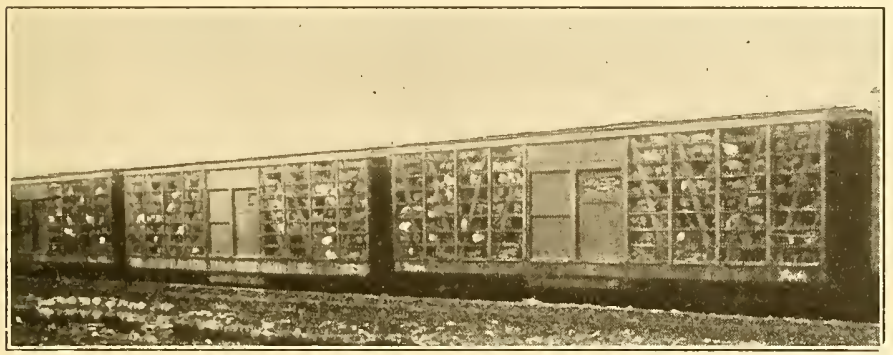

Live poultry going to the market. These birds would bring more money if they were all alike. An opportunity for community breeding. (Courtesy of United States Department of Agriculture.)

England markets. In the well-known South Shore district of Massachusetts a specialty is made of the so-called "soft roaster" for the city markets of the East, though the

FIG. 3

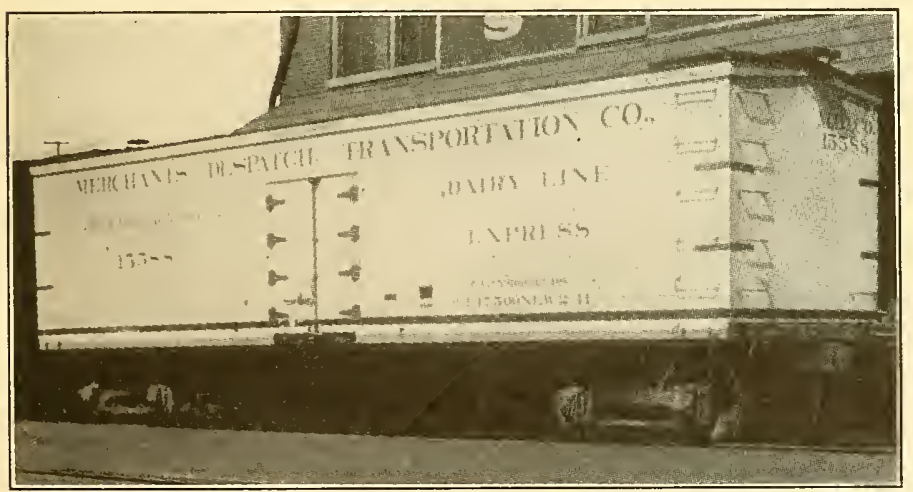

Refrigerator car. (Courtesy of United States Department of Agriculture.)

majority of these birds are grown on farms where poultry raising is not the principal occupation, 
Specialized, intensive, small poultry farms bear a similar relation to general poultry production that the greenhouse culture of vegetables does to general market gardening. They are useful for the production of out-of-season luxuries for the wealthy, but have little to do with feeding the nation. And in common with the production of luxuries generally, though large and tempting profits are sometimes made, as an exclusive occupation they are hazardous.

FIG. 4

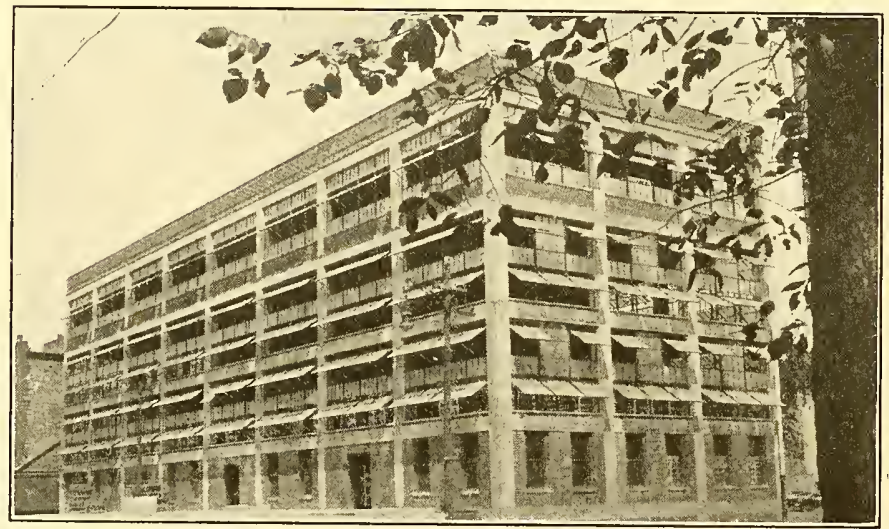

The "chicken-house" of a Western poultry-packing establishment, given over entirely to milk-feeding and dressing chickens. (Courtesy of Seymour Packing Company.)

The general farm producer usually disposes of his products as staples and his problem, since he sells at the current quotation, is to reduce the cost of production. Where the poultry or eggs are handled as specialities, the great problem is marketing, of getting a special or fancy price for each individual unit of the product.

The Customs Hatcher and Baby Chick Dealer.-A present tendency in poultry production is for the producer to depend upon a skilled hatcher to furnish him with living chicks. This practice though ages old in Egypt and China, is a comparatively recent development in America. Though 
assuming large proportions, the baby chick industry is yet in its infancy in this country, and an expansion hardly yet dreamed of is the prospect of the next few years. It is not improbable that the hatching of chicks for the surrounding territory may ultimately become one of the functions of the poultry packer just as the fattening and finishing already have.

The term customs hatcher refers to a person who incubates, for a consideration, eggs which he does not own, usually for nearby producers. Good sized centralized hatching plants are appearing in most communities where poultry forms an important item among the agricultural products. This takes the bother of hatching and the necessity of purchasing an incubator away from the farm, yet allows the producer to develop his own line of stock.

The baby chick dealer is one who owns the eggs he incubates and sells the chicks. The latter are frequently hatched by the thousand and may be shipped hundreds of miles to customers. At the present time over two-thirds of the baby chicks sold go to city or town customers.

The Buyer.-In nearly every trading point in the United States there is someone who is willing to buy eggs and poultry from the producer at any season of the year. At the smaller points this is usually the merchant of whom the farmer buys his supplies, and who pays for the poultry and eggs in trade. At larger points there is likely to be besides the merchant one or more persons who give their whole attention to buying farm produce, and in many cases to buying poultry produce alone. Such a buyer usually pays a little less than the merchant gives in trade, but is able to handle a considerable volume of business because he makes immediate payment in cash.

To be a really efficient member of the poultry industry a buyer should give his quotations only on a quality basis and provide himself with refrigerator facilities.

Whether the buyer is a merchant, an independent produce man, or an agent of the packer or distributer, his is the first step in the gathering and concentrating of a gigantic crop of highly perishable products, aggregating hundreds of millions 
in value, from very many farms whose average yearly sales probably amount to a few hundred dollars at most. As indicated in Figure 6, the original buyer may be any one of several classes of dealers, or the goods may pass through the hands of three classes of buyers before the work of distribution is begun.

The Packer.-The function of a packer is to prepare food products for preservation and consumption, and to preserve them. The home-killing of poultry for general consumption is passing just as the home slaughtering of beef and pork has largely given way to the slaughter houses of the large packing centers.

FIG. 5

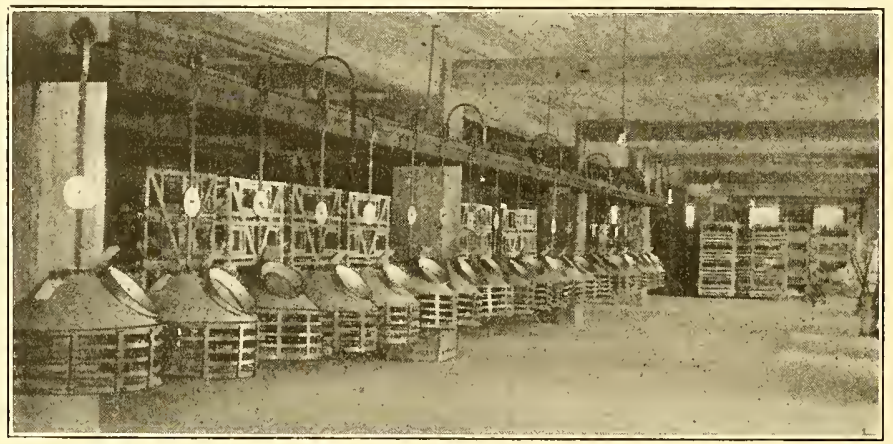

Poultry receiving-room of a Western poultry packing-house. (Courtesy of Seymour Packing Company.)

The preparing and preserving of both eggs and poultry for general consumption have been carried on for some time by firms doing a general packing business. More recently, establishments specializing on poultry products alone have been able to enter into successful competition with the organizations doing a general packing business.

The states of Kansas, Iowa, Nebraska, Missouri, Minnesota, Indiana and Tennessee are those in which the poultrypacking business has shown the greatest development. While it is carried on to a greater or less extent in all the states, most of the establishments dressing poultry or shipping eggs are 
small, without adequate equipment and employing only the crudest methods.

The present tendency is toward centralized plants having all the facilities of a first-class packing establishment, of which mechanical refrigeration is the most fundamental item.

FIG. 6

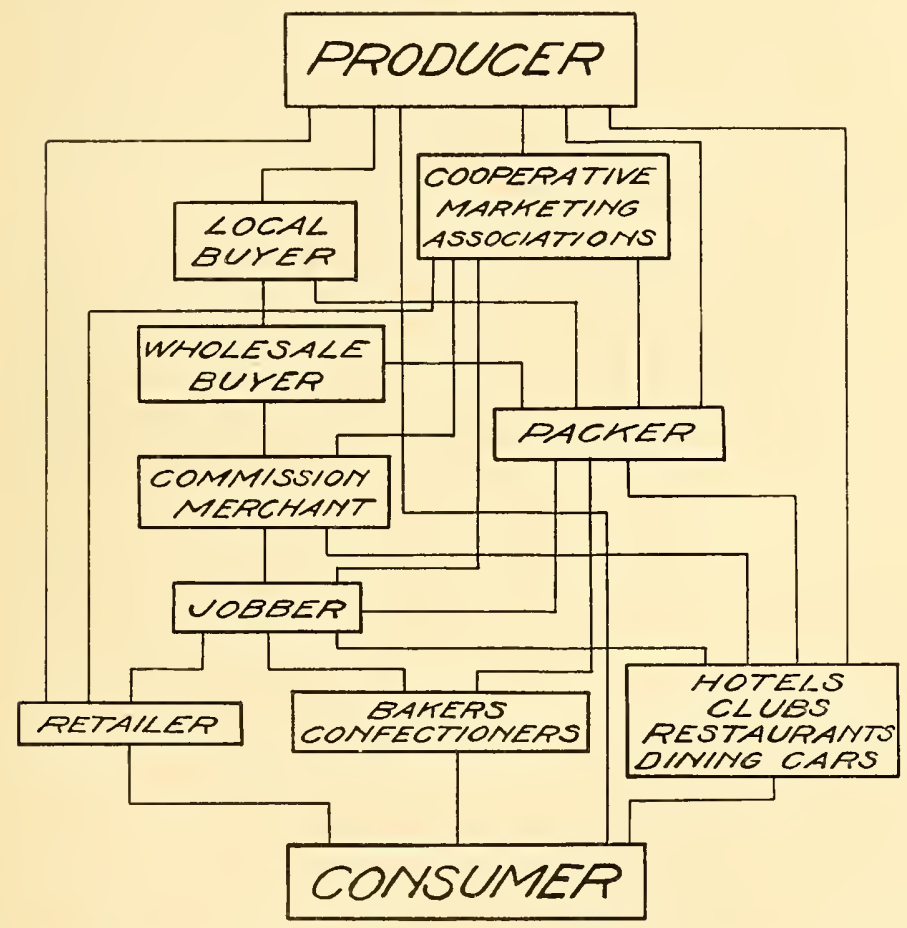

Showing routes by which poultry products reach the consumer from the producer.

Aside from dressing and preserving poultry, eliminating the bad eggs (which, under the present general system of buying eggs from producers without regard to quality, are bound to find their way into the channels of trade.), and preserving the good ones, the packer has been forced by the 
exigencies of the business to take up the work of fattening and finishing the poultry before killing it.

FIG. 8

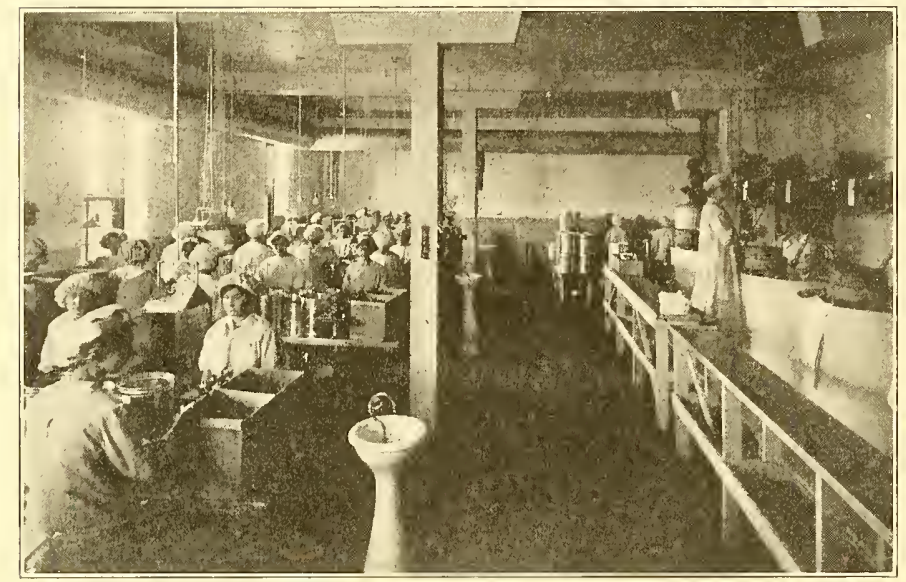

Egg-breaking room at a Western packing-house, Eggs are broken out for freezing. See egg churns at the right The ctrying of eggs in this country has largely been discontinued, owing to the fact that American capital has found it more profitable to dry the cheaper Chinese eggs in that country and ship them to America. (Courtesy of Seymour Packing Company.)

The Distributer.-As indicated in Figure 6, poultry products may reach the consumer by various routes. In a very small proportion of cases the producer deals with the consumer direct, and is also a distributer. In an increasing, though still small, number of cases, the local buyer is a merchant who retails the products at the place of production. In the great majority of cases, however, both eggs and poultry reach the consumer by a more circuitous route. After the products have been concentrated in the hands of the wholesale buyers, including the packers, they may be turned over to a commission merchant or broker, who disposes of them to the jobber in quite large quantities. The jobber in turn distributes them among the various retailing agencies, which include the retail markets, bakeries, con- 
fectioneries, hotels, clubs, restaurants, dining cars, the steamship dining service, and the like, which deal directly with the consumer.

There are numerous modifications of this route. One or more of these steps in distribution may be eliminated, as would be the case if a coöperative marketing association dealt directly with a jobber or a retailer, or the packer sold to a hotel; but the great bulk of the goods at present passes through the several steps indicated at the left of Figure 6 .

Reasons for Widespread Production. -The reasons for the widespread production of poultry are mainly as follows:

1. The first consideration in keeping poultry is often not the securing of products for sale, but for home consumption. Chickens on the general farm or the city lot furnish eggs at less cost, and because of their high perishability, of better quality, than may usually be secured from the stores. The cheapness of 'production lies, as Robinson ${ }^{1}$ points out, in the fact that chickens as well as most other poultry "may be fed largely on food wasted by man (in manufacture as well as in consumption) and on foods wasted by or not available for the larger domestic animals." At the same time, all kinds of poultry furnish a constant and convenient form of highly palatable fresh meat and they thrive nearly everywhere that man can live.

2. "Very little poultry is kept profitably in this country except on farms where it is in the strictest sense a noncompeting crop. Where it is kept in small quantities, it forages for itself, consuming mainly waste products besides destroying insects, and does not exhaust the soil at all, but tends rather to enrich it. Again it does not compete for the farmers' time, being cared for mainly by the labor of women and children. This may help to explain how difficult it is for anyone to make a living raising poultry alone in competition with farm poultry, unless one is prepared to go into business on a large scale and is equipped with thorough scientific knowledge. Where diversified farm-

${ }^{1}$ Principles and Practice of Poultry Culture. 
ing means the growing of non-competing crops specialization is a long way off." 1

3. Poultry is receiving increasing recognition as an excellent means of converting the farm and table waste into cash, particularly when this waste is supplemented by feeds furnishing certain essental ingredients that are otherwise lacking. Poultry products are crops for which a constant demand furnishes an outlet, usually at good prices, in either cash or trade. With the growth of closer relations between producers and consumers and the development of coöperative agencies for buying and distributing general farm produce, pou'try products are destined to assume a position of greater though always subordinate importance among other farm products.

4. The general farm furnishes such favorable conditions for poultry that little experience or skill is necessary to succeed in handling it in a small way. Because of the large fields and pastures which are covered with greenness and are available for ranges, the variety of grains and insects to be picked up and which demand exercise in the getting, the numerous buildings and trees for protection from the sun and wind, and the fact that the flocks are usually small and the farms so large that there are few birds to the acre, poultry thrive in spite of any lack of skill used in their care.

The late Prof. G. M. Gowell ${ }^{2}$ saw clearly when he said: "Poultry husbandry is a legitimate agricultural industry. . . . It occupies a special place in agriculture and will never displace other work except on limited areas. It requires large quantities of grains and concentrated feeding material and but small quantities of bulky foods. Larger animals will always occupy the farms and prepare the coarser crops of the land for market." Robinson ${ }^{3}$ acutely observes that "the stable factor in production is the farm flock. . . The natural tendency of the poultry industry is not to develop production on a large scale, but to extend and improve ordinary small operations as far as possible

${ }_{1}$ Carver, Principles of Rural Economics.

2 Maine Bulletin No. 144.

${ }^{3}$ Principles and Practice of Poultry Culture. 
without changing the position they occupy as subordinate to other interests of the poultry keeper and other uses of his land.'

While there will always be a place for the growing of agricultural specialities, by far the greater part of the agricultural industry must always be concerned with the production of staple crops.

General Farm Versus Intensive Conditions.-As the result of keeping complete records of eighteen farm flocks of chickens and thirteen town flocks, in Ohio, for a period of one year beginning August, 1909, Lloyd and Elser ${ }^{1}$ report some illuminating facts regarding the keeping of poultry under intensive and extensive conditions. This may be taken as representing the results to be attained under similar conditions throughout the heavy producing states.

The town flocks, excluding one owned by a commercial poultryman, varied in size from 18 to 97 birds, averaging 46 birds. These flocks gave results varying from an average loss per bird of $\$ 0.93$ to an average profit of $\$ 1.64$ per bird, under pre-war prices. The average profit per bird for all the town flocks was $\$ 0.36$ per bird for the year.

It is highly interesting to note, however, that the average profit per bird in flocks above the average size was $\$ 0.26$, while the average profit per bird in flocks below the average in size was $\$ 0.44$.

Eight of the flocks were in close confinement and had no range. The feed cost per bird was in this case $\$ 0.99$, while the feed cost for those having a limited range was $\$ 0.87$ for the year. No statement is made of the feeding of these flocks, and it is impossible to draw conclusions as to how much of this saving is due to the green feed furnished in the form of pasture to the ranging birds.

The eighteen farm flocks varied in size from 38 to 370 fowls and averaged 121. The average profit per bird in different flocks varied from $\$ 2.47$ to $\$ 0.62$, with an average profit per bird for eighteen farm flocks of $\$ 0.87$. These 
differences were probably due to the skill of the respective farmers and the comparative vigor of the flocks.

The average profit per fowl in flocks of less than average size was $\$ 0.98$, while the average profit per fowl in flocks above average size was $\$ 0.63$. This average result was in spite of the fact that because of intelligent care and rational feeding three of these flocks which exceeded 300 birds gave an average profit of $\$ 0.86$ per bird.

The marked differences between the town flocks and the farm flocks were not accounted for by greatly increased production. The average egg production per hen was 71 for the farm flocks and 70 for the town flocks. It arose rather from the fact that the farm fowls secured gleanings from grain scattered at harvest and wasted or undigested by live stock, waste from the orchard and garden, offal at butchering time, abundant pasture, weed seeds and insects, as well as sour or unused sweet milk.

During the same period the flock of a commercial poultryman residing in town, numbering 333, was kept at an average feed cost of $\$ 0 . \$ 1$ per bird, and returned a profit of $\$ 1.46$ per bird. The average egg production was 141 eggs per bird. This egg production which is double that secured in the flocks mentioned above is the result of greater skill, better stock and equipment.

In all cases, labor and purchased, or marketable, feed were charged against the flocks, but no overhead charges were included. The records in detail are shown in Tables IX and $\mathrm{X}$. It should be understood that the preceding costs and profits were made on the basis of pre-war prices. Their comparative value, however, is probably not affected.

Limiting Factors of the Future.-There are three main considerations which will define the general limits of poultry production on the farm beyond that necessary to market the waste. These are (1) the efficiency of poultry as producers of human food; (2) the relation of poultry to the conservation of soil fertility; and (3) the extent to which general methods of disease prevention may be developed that can successfully cope with the intensive conditions that progressively prevail as the number of birds on a given acreage is increased. 


\begin{tabular}{|c|c|c|}
\hline 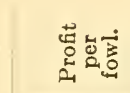 & 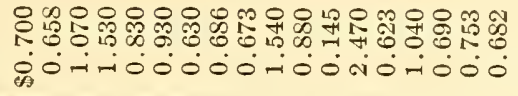 & 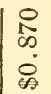 \\
\hline 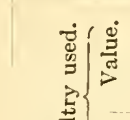 & 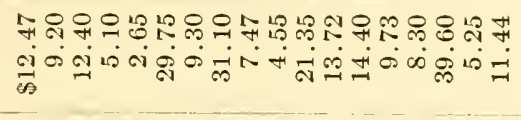 & $\stackrel{\infty}{\infty}$ \\
\hline$\dot{\bar{\theta}}$ & 쑈 & $\stackrel{\infty}{\circ}$ \\
\hline 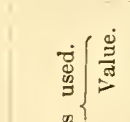 & 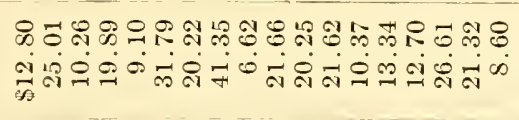 & $\underset{\oplus}{\vec{\infty}}$ \\
\hline 焉 & 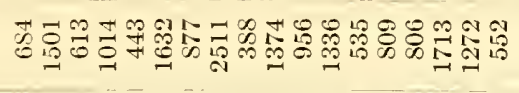 & $\stackrel{0}{\mathscr{2}}$ \\
\hline 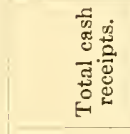 & 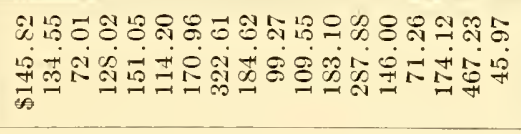 & $\begin{array}{l}\infty \\
\infty \\
0 \\
\dot{0} \\
\qquad \infty\end{array}$ \\
\hline 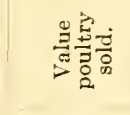 & 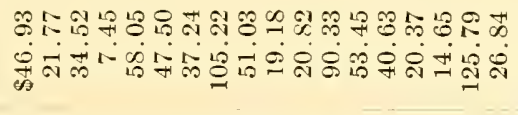 & 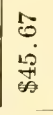 \\
\hline 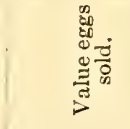 & 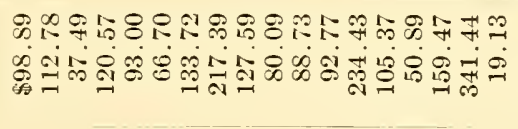 & 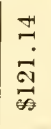 \\
\hline 总范蓆寄 & 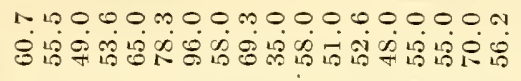 & $\stackrel{0}{-i}$ \\
\hline 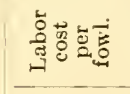 & 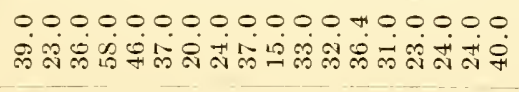 & $\underset{\infty}{\infty}$ \\
\hline 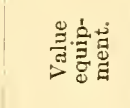 & 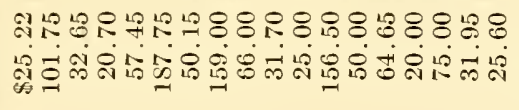 & $\begin{array}{l}0 \\
\dot{10} \\
0 \\
\oplus\end{array}$ \\
\hline 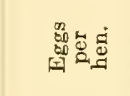 & 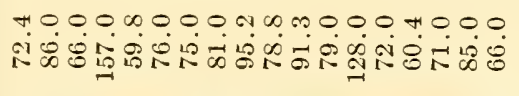 & $\stackrel{i}{i}$ \\
\hline$\dot{z} \dot{\dot{g}}$ & 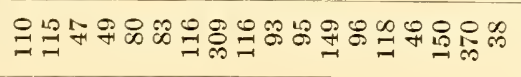 & $\overrightarrow{\mathrm{N}}$ \\
\hline $\begin{array}{l}\dot{0} \\
z \\
\dot{y} \\
\dot{0} \\
\dot{0}\end{array}$ & 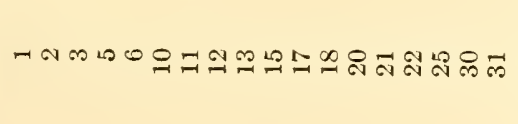 & 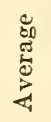 \\
\hline
\end{tabular}




\begin{tabular}{|c|c|c|c|}
\hline 5 & 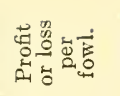 & 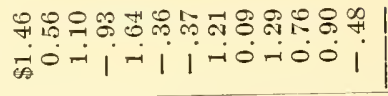 & $\vdots \stackrel{\infty}{:}$ \\
\hline 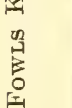 & 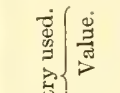 & 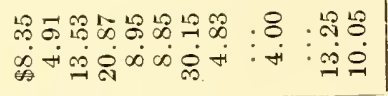 & $\begin{array}{l}\stackrel{2}{\circ}: \\
\stackrel{8}{\infty}:\end{array}$ \\
\hline & 官 & 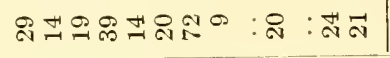 & $\vec{N}$ \\
\hline 蛋 & 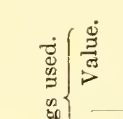 & 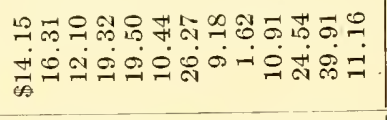 & $\underset{\oplus \infty}{\infty}:$ \\
\hline 马 & 언 & 굿요 & $\stackrel{0}{\sigma}$ \\
\hline 它 & 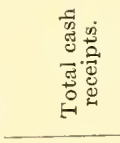 & 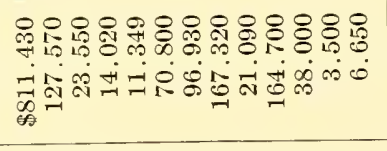 & $\begin{array}{l}\stackrel{9}{8}: \\
0 \\
0 \\
0\end{array}$ \\
\hline 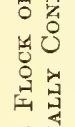 & 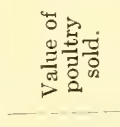 & 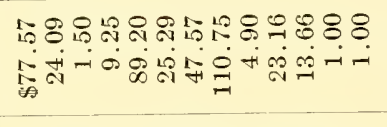 & 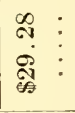 \\
\hline 淟蛋 & 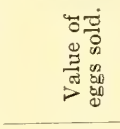 & 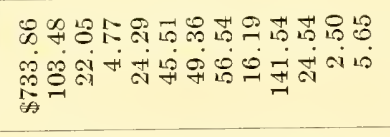 & $\begin{array}{c}\infty \\
\stackrel{\infty}{-} \vdots \\
\stackrel{-1}{\oplus}\end{array}$ \\
\hline 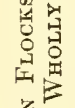 & 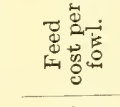 & 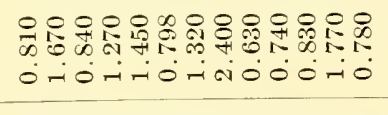 & $: \frac{8}{0}$ \\
\hline$\sum_{0}^{2}$ & 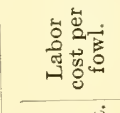 & 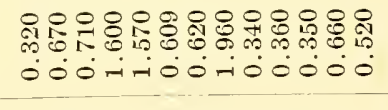 & $: \stackrel{8}{8}$ \\
\hline$\stackrel{02}{\theta}$ & 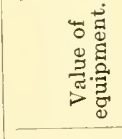 & 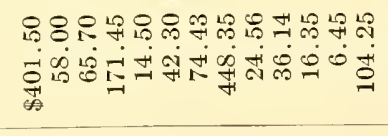 & $\begin{array}{l}\text { मे }: \\
\infty \\
\infty \\
\infty \\
\infty\end{array}$ \\
\hline 2 & 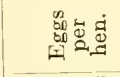 & 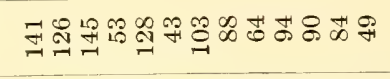 & $: R$ \\
\hline 出 & $\dot{z} \div$ & ॠ్ & $\stackrel{\infty}{\text { H : }}$ \\
\hline 舅 & $\begin{array}{l}\circ \\
z \\
\frac{y}{0} \\
\frac{0}{1}\end{array}$ & 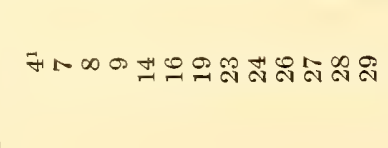 & 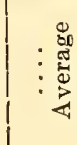 \\
\hline
\end{tabular}


For specific farms, transportation facilities and nearness to markets determine the commercial advisability of emphasizing poultry production, and unfavorable soil or climatic conditions are, of course, local limiting factors.

Food Manufacturing Efficiency of the Hen.-As the question of the food-supply becomes more and more acute and the cost of living higher, the efficiency of the various domestic animals as human food factories will be taken more and more into consideration. In the last analysis, other things being equal, the animal that manufactures the least human food from a given amount of digestible feed will be the one whose product will be the most expensive. As food becomes increasingly expensive there will be a cessation in the consumption of the more expensive kinds as articles of common diet, and they will be placed among the luxuries.

As the size of farm or even town flocks grows beyond that necessary for waste consumption, the efficiency of poultry with reference to food production is going to play a larger and larger part.

Unfortunately, data are not available which show the comparative efficiency of poultry with other animals except for the chicken. A comparison between the hen and her competitors among the larger animals, with regard to the amount of marketable product and the actual edible solids produced from one hundred pounds of digestible organic material in the ration, is shown in Table XI.

\section{Table XI.-The Amount of Human Food Produced from One Hundred Pounds of Digestible Organic Matter in THE Ration. ${ }^{1}$}

Animal.

Product.

\begin{tabular}{|c|c|c|c|c|c|c|}
\hline Animal. & & Product. & & Mar & $\begin{array}{l}\text { ketable product. } \\
\text { Pounds. }\end{array}$ & $\begin{array}{c}\text { Edible solic } \\
\text { Pounds. }\end{array}$ \\
\hline Dairy cow. & & Milk & . & . & .139 .00 & 18.00 \\
\hline Swine . & & Dressed carcass & - & . & 25.00 & 16.10 \\
\hline Calves. & . & Dressed carcass & . & . & 36.50 & 8.10 \\
\hline Fowls, large & . & Live weight & . & 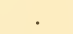 & 19.60 & \\
\hline Fowls, small & . & Live weight & 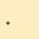 & 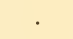 & 19.60 & \\
\hline & & d carcass & . & . & 60 & 4.20 \\
\hline & & $\mathrm{Eg}$ & . & 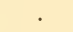 & 19 & 5.10 \\
\hline Broilers & & Live weight & . & . & 28.70 & \\
\hline & & arcass & . & . & 23 & 3.50 \\
\hline & & d carcass & . & . & 8.30 & 2.75 \\
\hline and 1 & & ed carcass & & . & 7.00 & 2.60 \\
\hline
\end{tabular}

${ }^{1}$ Adapted from figures given in Jordon's Feeding of Farm Animals, 
Conservation of Soil Fertility.-It is becoming increasingly necessary to market crops in those forms "which carry the least amount of the valuable fertilizing constituents away from the farm. It is a matter of common knowledge that live stock and their products offer the best opportunity for accomplishing this. This is owing to the fact that very much of the fertility found in the feed and totally lost if sold in the form in which it is grown, may be returned to the soil in the manure, if fed to stock.

The per cent of the fertility value of the feed required in the production of several common food products of animals origin respectively, including eggs and broilers, which is left on the farm in the form of manure is shown in Table XII. The products are arranged in order according to the per cent of the value of the fertilizing constituents left on the farm.

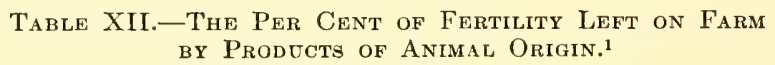
by Products of Animal Origin. ${ }^{1}$

Butter

Bacon

Beef

Eggs

Broilers

Milk

Cheese
Per cent of fertility value left on the farm.

99.83

92.24

91.94

89.56

87.20

86.24

58.03

Disease and Intensive Conditions. - That the problems of growing poultry are difficult under certain conditions and fairly simple under others is shown by the fact that while poultry-farming enterprises of any considerable proportions which have confined their efforts to production and have been profitable through a series of years are rather exceptional, the volume of poultry on farms in the [nited States increased over 18 per cent from 1900 to 1910. (See Table I.)

This means that for some reason poultrymen, who are presumably skilled in the various operations that make up

1 Compiled from various sources, chiefly Sherman, Chemistry of Food and Nutrition; and Henry and Morrison, Feeds and Feeding. 
poultry husbandry, have failed to do on a large scale what many farm folks who make no pretensions at skill are doing with at least some degree of success on a small scale.

'The majority of the very many market poultry farms that have been undertaken and have failed, have failed because they have been unable to maintain the health and productive vigor of their flocks. Where poultry is the main source of income, the conditions are likely to be those of congestion, and the methods of management intensive. If the land is good for general farming, it is so valuable that large numbers of birds must be kept on a limited area, and the labor minimized, in order that a profit may be realized above the interest on the investment in the land.

Poultry (with the exception of waterfowl), and particularly chickens and turkeys, are highly susceptible to disease. While chickens are gregarious, the natural covey is small, and the practice of congregating large numbers on a limited area permanently, renders each individual a menace to every other individual, makes sweeping epidemics possible, and renders it difficult, if not impossible, to keep the ranges and runs green. Ground so heavily stocked as to make it bare is a constant source of danger from disease infection.

In how far general hygienic measures and highly vigorous stock may be developed that will offset these dangers is yet to be seen. These are problems of management and breeding worthy of investigators' best efforts.

From the broad standpoint it is interesting to compare the fact that in 1910 there were in this country slightly over 394 fowls per square mile of improved farm land, or at the rate of one fowl for each 1.6 acres. According to King, ${ }^{1}$ Japan supports $\$ 25$ fowls per square mile of improved farm land which allows less than.$S$ of an acre per fowl. It would appear, therefore, that the poultry population of the United States may be at least doubled without serious danger of widely sweeping epidemics.

As already noted, the one exception to the foregoing is duck farming. While the total production of ducks declined 
39.3 per cent (see Table I) between 1900 and 1910, the farms devoting their entire space to duck culture increased in number and size. This was particularly true of New York, it being the only state showing an increase in the number of ducks at the taking of the last census. "There are many plants in the eastern states growing from 5000 to 10,000 or 12,000 ducks a year, a number growing up to 20,000, and some with an annual production of over 50,000."1 This has been carried on on a relatively large scale on Long Island since prior to 1860 .

That this is possible is largely due to the comparatively phlegmatic temperament of ducks, so that they are not so quarrelsome as other sorts of poultry, coupled with their lack of susceptibility to disease arising from filth in their food or quarters.

1 Robinson, Principles and Practice of Poultry Culture. 


\section{BREEDS OF CHICKENS.}

Origin of the Domestic Fowl. - When man lived in a primitive state and was a savage, all animals and birds were also wild. The first step in advance came when he began to realize the value of wealth, to bring animals under control and develop flocks and herds. He was still a wanderer and a nomad. It was probably not until the necessity of cooperative effort in protecting his wealth against enemies, coupled with the increasing population, forced him to take up settled life in villages, that birds were domesticated. Poultry production was from the first, as it is now, essentially a home industry.

While it appears likely that fowls were first captured for fighting purposes, and later domesticated for flesh and eggs, the earliest actual reference to poultry states that the Chinese Emperor Fu-Hsi, who lived from 3341 to 3227 B.C., taught his people to breed fowls. ${ }^{1}$ Cock-fighting is still a favorite pastime among the native princes of India, from whence our domestic fowls originally came.

So far as records show, fowls were taken eastward nearly a thousand years before they appeared in Europe. A Chinese encyclopedia, said to have been compiled 1400 years before Christ, makes mention of fowls as "creatures from the West." "The first actual reference in Western literature to the fowl occurs in the writings of Theognis and Aristophanes between 400 and 500 B.C."'2

Progenitors of the Breeds. - Darwin thought that all modern breeds of fowls were the offspring of a common ancestor. The differences noted between the phlegmatic Cochin and the sprightly Leghorn, he considered to have been brought

1 v. Fries, Abriss der Geschichte Chinas.

${ }^{2}$ Brown, Races of Domestic Poultry. 
about by the conditions of domestication, particularly selection and breeding.

The bird which he selected as the probable ancestor of the hen was the species of jungle fowl known as Gallus bankiva which is still to be found in the jungles of Burmah, Northern India, the Philippine Islands, and several other countries. The bankiva male very closely resembles the blackbreasted red game in color of plumage. The female has a salmon-colored breast, striped neck feathers, and stippled

FIG. 8

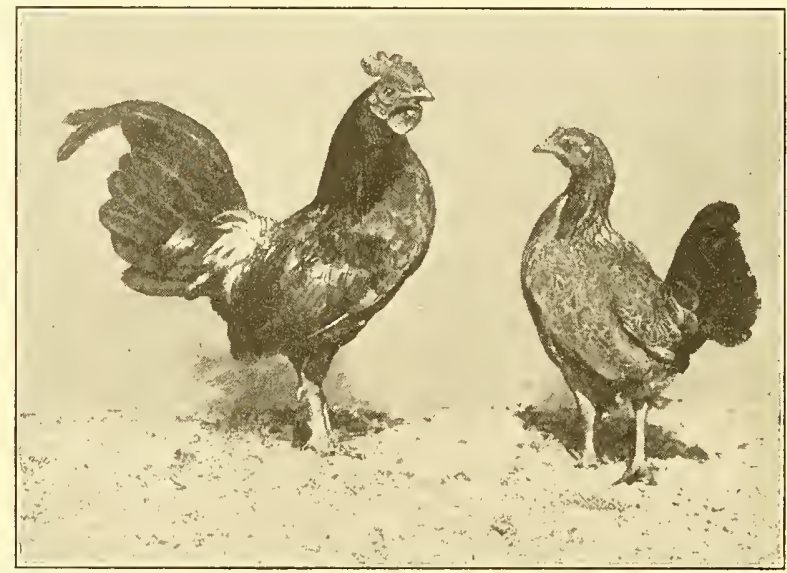

Jungle fowl (Gallus bankiva). (Courtesy of New York Zoölogical Gardens.)

body feathers almost identical with those of the modern brown Leghorn female. In voice both male and female resemble the common barnyard fowl. The crow of the wild male, however, is not so prolonged as in the case of his domesticated brother. In action they are quite similar to the modern Leghorn.

These birds cross readily with domestic breeds, producing fertile offspring and are themselves easily domesticated.

While these considerations seem to point toward the 
bankiva as one ancestor of the hen as we know her, they do not necessarily prove that it was the only ancestor of the modern fowl nor that it was necessarily a progenitor of all breeds of chickens.

FIG. 9

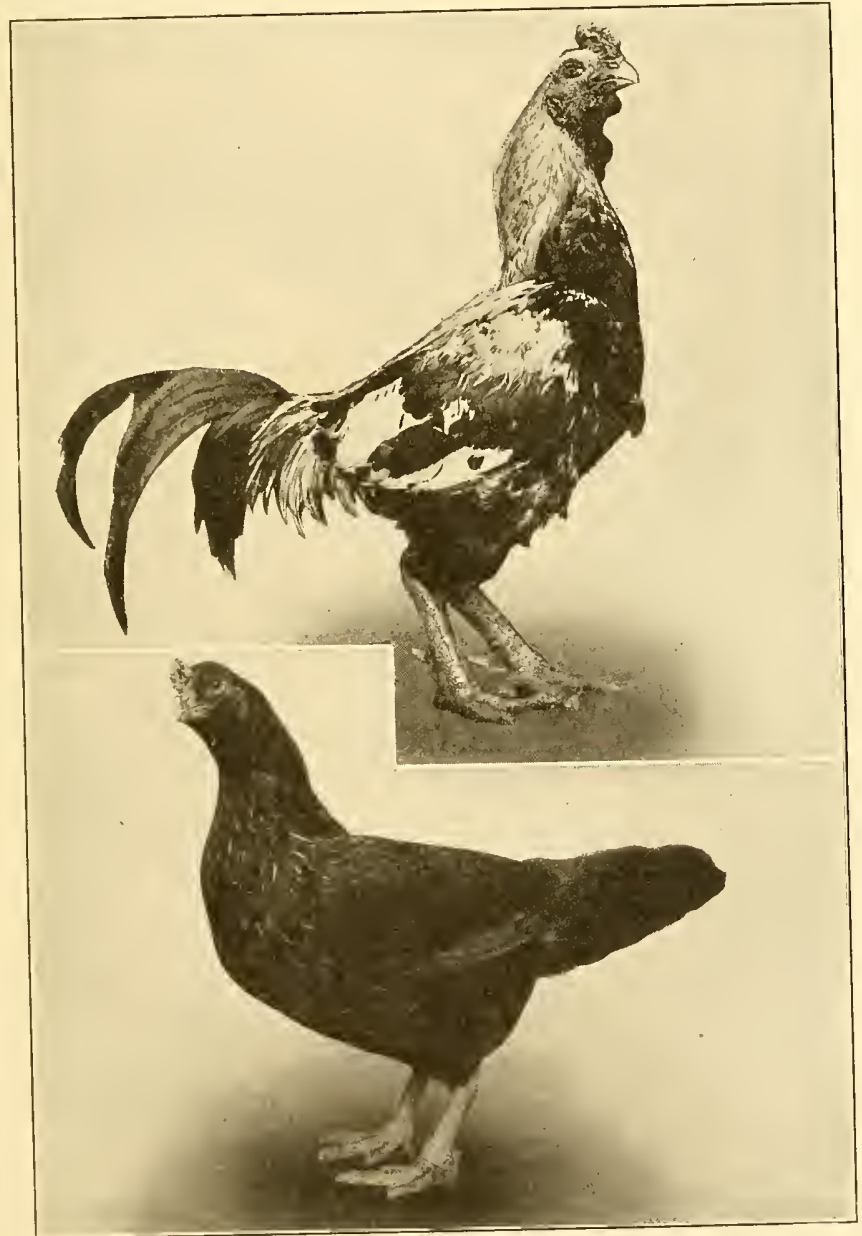

The Aseel or Malay fowl. (Courtesy of C. B. Davenport.) 
As Brown ${ }^{1}$ (whom I have largely followed) points out, there are excellent reasons for believing that such heavy, loose-feathered breeds as the Cochins and Brahmas came from an entirely different ancestry with which the Aseel or Malay fowl, domesticated over three thousand years ago, is the connecting link. In these breeds the long axis of the opening of the skull through which the spinal cord passes (occipital foramen) is perpendicular, while in both the Leghorn and bankiva it is horizontal. This is mentioned as representative of several structural differences which could not have been selected for. It can be noted only by removing the head from the neck.

Besides structural differences, there are also differences in habit which seem to indicate an ancestor far removed from the close-feathered, early-maturing, high-flying jungle fowl.

The question of just what was the forerunner of our heavy breeds is an open one. While various suggestions have been made, none have gained general acceptance, and it seems probable that it is now extinct.

Early American Poultry.-There is little information to be found concerning the status of poultry previous to the rise of the breeds in the middle of the last century. "With the exception of the turkey, ${ }^{2}$ all our farm animals and poultry were imported from the Old World. The first to reach the New World were brought by Columbus on his second voyage in 1493.*** Chickens, ducks, and geese are known to have been brought at that time." 3 According to Robinson, ${ }^{4}$ the ordinary native stocks of fowls, ducks, geese, and turkeys in America at the time of the general awakening of interest in improved poultry and for some years after, were, even when compared with the average mongrel stocks of today, small birds of distinctly inferior table qualities, and usually inferior also in egg production. This degeneracy of stock was due to the common practice of selecting for the table first.

1 Races of Domestic Poultry.

2 One breed of ducks, the Muscovy, probably originated in South America.

${ }^{3}$ Carver, Principles of Rural Economies.

${ }^{4}$ Principles and Practice of Poultry Culture. 
That such practice, persistently followed, did not quickly run the stock out was due to these saving circumstances: (1) the natural tendency of the stock to improve under the very favorable conditions which small flocks at liberty on farms enjoyed, and (2) the occasional introduction of blood of improved native stock.

Now and then a person particularly interested in poultry would breed his flock to one type or color, but the prevailing belief was that the best breeding was that which combined the greatest variety.

Results of Domestication.-The general effects of domestication upon poultry have been four in number, namely: (1) increased size of body, (2) increased fecundity, (3) a tendency toward the suspension of the maternal instinct, and (4) a lowering of the vitality of the race.

According to Brown," "the jungle fowl of India is a small bird weighing about $3 \frac{1}{2}$ pounds, but becomes heavier when brought under domestication, even though not selected for enhanced size. It does not develop much beyond six pounds, unless breeding with that object in view is adopted."

The jungle fowl usually lays two clutches of eggs a season, totalling from twenty-two to twenty-six eggs. In all the modern breeds there is a marked increase in production, most breeds probably averaging close to a hundred eggs a year. The conditions which have been responsible for this have been (1) selection, (2) supplying stimulating feeds, (3) comfortable housing, and (4) the comparatively frequent gathering of eggs. Of these, the latter has had by far the greatest influence. Pearl ${ }^{2}$ says in this connection:

"Egg-laying in wild birds is simply one phase of a cyclical process. If the cycle is not disturbed in any way the egg production is simply the minimum required for the perpetuation of the race. If, however, the cycle is disturbed, as, for example, by the eggs being removed from the nest as fast as they are laid, a very considerable increase in the total number of eggs produced will result. This is, of course, what happens under domestication. . . Austen shows

1 Races of Domestic Poultry.

2 Maine Bulletin No. 205. 
that whereas the wild Mallard duck in a state of nature lays only twelve to eighteen eggs in the year, it will lay from eighty to one hundred if they are removed as fast as laid and the bird kept confined in a pen at night. Hauke, by regularly removing the eggs, got forty-eight in succession from a common wryneck. Wenzel in the same way brought a house sparrow's productivity up to fifty-one eggs.'

It is probable, however, that the practice of frequent gathering has long since reached its limit of effectiveness and that further improvement will be reached through breeding, supplemented by proper housing and feeding.

Increased fecundity seems to have caused longer periods of time to elapse between seasons of broodiness. In general, it may be said that the broodiness of a breed is in inverse proportion to its fecundity. With the Mediterranean breeds this is true to such an extent that the Leghorns are frequently termed a non-setting breed.

The increasingly general use of the incubator is having the result of further discouraging the exercise of the maternal instinct. Where incubators are employed, the effort is likely to be to "break up" the broody hen with the hope that less time will be lost from laying.

The vitality of the race has been lowered largely through combined poor selection and inbreeding. With the breeds, the practice has been to choose as breeders those birds which show the breed type or color characteristics to the greatest degree even though they are not physically fit. Combined with this has been the effect of inbreeding these individuals to fix their characteristics and the promiscuous inbreeding that often accompanies the mongrel flock.

Classes, Breeds, and Varieties.-The breed is the basis of the classification of poultry. It may be defined as a group of domestic birds closely approaching a certain specific shape. The breed name is the one identifying any well defined and recognized type, such as Plymouth Rock, Wyandotte, Leghorn, Brahma, or Runner, and the birds conforming closely to those types are said to be members of those respective breeds.

The breeds are for convenience both subdivided and 
grouped. The subdivisions are called varieties, while the groups are referred to as classes. There are two varietal distinctions, namely, comb shape and plumage color. Either one or both may be present. 'Thus, the Rose Comb Rhode Island Red differs from the Single Comb Rhode Island Red only in comb shape. The White Wyandotte differs from the Buff Wyandotte only in color, while the Single Comb White Leghorn differs from the Rose Comb Dark Brown Leghorn in both comb and color. They are members of the same breed, however, because they approach very closely the same type or shape. The common saying among poultrymen that "shape makes the breed, and color and comb the variety" is an accurate statement of the case.

For the more common breeds of chickens the class grouping is based on similar general characteristics and place of origin. The Brahma, Cochin, and Langshan together comprise the Asiatic class. They have all come to us from or through Asia and are birds of large size, having feathered shanks and red earlobes, frequently becoming broody, and laying a dark brown egg. The Leghorns, Minorcas, Anconas, Andalusians, Spanish and Buttercups which comprise the Mediterranean class, all seem to have originated around the Mediterranean Sea. They are all nervous, active birds, stylish and sprightly in appearance, and somewhat lacking in the brooding instinct. They are layers of white eggs, comparatively small in size and carry white earlobes.

The breeds which comprise the American class are the familiar Plymouth Rock, Wyandotte, and Rhode Island Red, and the less familiar Java, Buckeye, Dominique and Fluff. These breeds were developed in America through a judicious blending of Asiatic and Mediterranean blood lines followed by rigid selection. In most characteristics they fall about half way between the two general types from which they arose.

The grouping of breeds of chickens into classes may have no other basis than that of convenience or, as in the case of the "Miscellaneous" class, which is composed of three rather curious breeds, namely, Silkies, Sultans, and Frizzles, because they do not seem to fit anywhere else. 
Turkeys, ducks, geese, and guinea fowl each comprise a class, the species being the basis of division.

Purpose of Breeds.-The purpose of forming a new breed of poultry should be to secure a bird that will yield a product of maximum value at minimum cost. It should be a means to an end.

Most of the breeds now popular for production purposes were originally brought forward to meet a real need. Many of the very numerous varieties that have appeared, often bearing no relation to the original members of the breed, have been brought forward for the purpose of "booming," to the financial advantage of their promoters. It has been toomuch a case of attractive color and markings rather than that of a more efficient food factory.

The breeds thus tend to become an end, rather than a means, and the revision of a breed standard is too often based on the effort to secure a more attractive type than a more efficient one.

Standard Breeds and Varieties. - Standard breeds and varieties are those which have been officially recognized by the American Poultry Association. Quoting from the Constitution of the American Poultry Association, "The procedure for the recognition of new breeds and varieties shall be as follows:

"A petition for recognition must be presented to the American Poultry Association at an annual meeting at least one year before the annual meeting at which action upon the application of the breed or variety is taken.

"The petition shall give:

"(a) The name of the breed or variety.

"(b) A description of the breed or variety and all ascertainable facts regarding its origin and breeding; name and address of the originator and facts of an educational or historical nature, all of which must be preserved among the records of this Association.

"(c) Certificates of not less than five members of the Association who are breeders of the breed or variety and, who have bred it for two years or more, certifying that it produces not less than 50 per cent of specimens reasonably true to type or variety. 
" $(d)$ Certificates showing that two or more specimens of the breed or variety have been exhibited in each of the classes for single birds-cock, hen, cockerel and pullet-at a show held under American Poultry Association rules in the two annual show seasons next preceding the annual meeting at which the petition for recognition is presented; such affidavits to be signed by the Secretary of each such show and by a licensed judge who officiated at it.

"(c) A staudard for a breed or variety must be in the form used in The Imerican Standard of Perfection; in case of a new variety of a Standard breed, conforming to the Standard for that breed; in case of a new breed, conforming to the general requirements of its class; and in case of a kind, not heretofore included in the Standard of Perfection, conforming to the general plan of description in the Standard, which standard is to be a provisional standard, subject to amendment by the petitioner or by the Association before the recognition of the breed or variety."

Membership in a standard breed does not necessarily imply a common or even a similar ancestry with other members, though such is usually the case. It means only that the individual considered approaches the ideal type of the breed to a considerable degree. For instance, as Brown $^{1}$ states, the Buff Orpington is the result of the systematic crossing of the Golden Spangled Hamburg, Buff Cochin, and Dark Dorking, while another variety of the same breed, the Black Crpington, traces its decent from the Black Minorca, the Black Plymouth Rock (a non-standard variety), and clean-legged Langshans (which are disqualified by the Standard).

Varieties may and often do have a common ancestry, as, for instance, the several Wyandottes. The Whites are mutations from the Silvers, and the Goldens count American Seabrights, the forerunners of the modern Silver Wyandottes, among their ancestors.

"Standard Bred" or "Pure Bred."-In poultry terminology, "pure bred," as used in reference to farm animals, is, technically at least, replaced by "standard bred."

${ }^{1}$ Races of Domestic Poultry. 
The term "pure bred" implies that a complete official record of the ancestry of the individual considered may be traced back to the individuals that are looked upon as the foundation animals of the breed, without admixture of alien

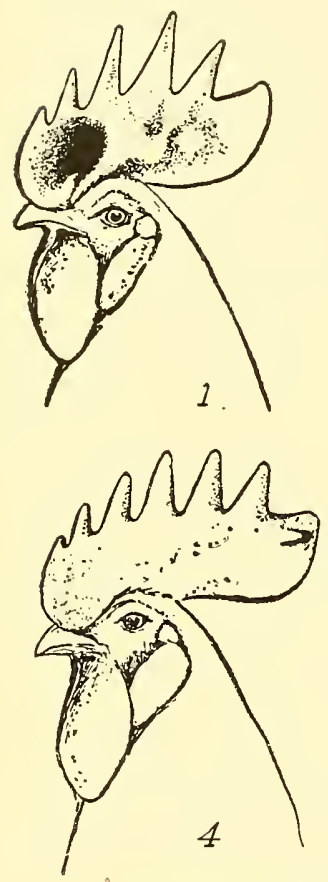

FIG. 10
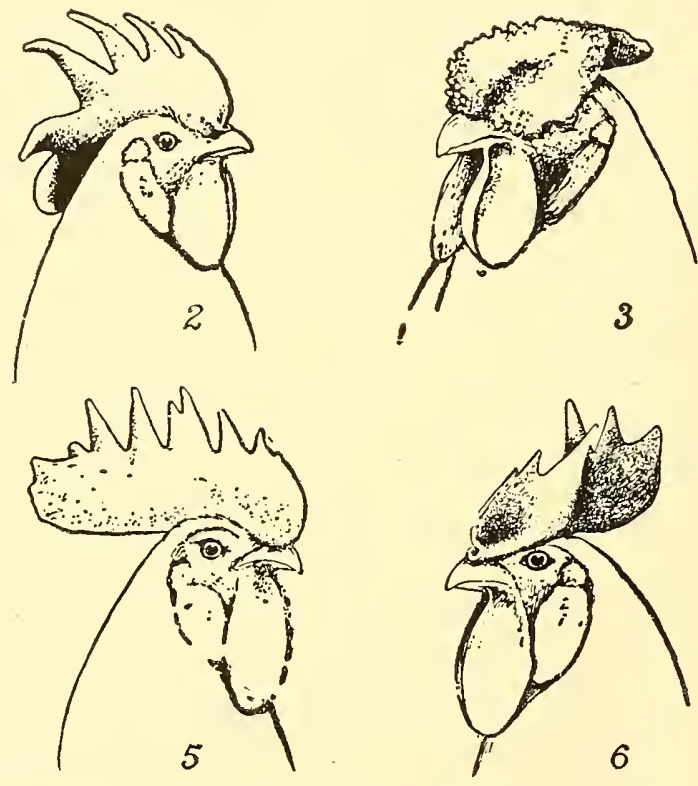

Comb defects and disqualifications. 1, Thumb mark, a defect. 2, Blade follows neck too closely; point lops; defects. 3, Rose comb showing hollow center, a defect. 4, Side sprig, a disqualification. 5, Uneven serrations, a defect. 6, Twisted comb, a defect. (After Slocum.)

blood, beyond a certain clearly defined and very small maximum, usually only in distant progenitors.

The term "standard bred" implies that in breeding practice only those individuals have been mated which conform closely to the "standard" description of the breed which 
they represent, or which, as in double mating, will produce individuals which conform closely to that description.

While technically there is no "pure-bred" poultry, in that the standard breeds cannot be demonstrated by official record and pedigree to have been bred pure for many succeeding generations, practically all the old-established breeds are as much "pure bred" as any breed of farm animal that is as many generations removed from its beginnings. ${ }^{1}$

American Standard of Perfection.-In poultry-breeding, the American Standard of Perfection takes the place which the herd book holds in the breeding of other farm animals. It safeguards the qualities of the breed, not by the exclusion

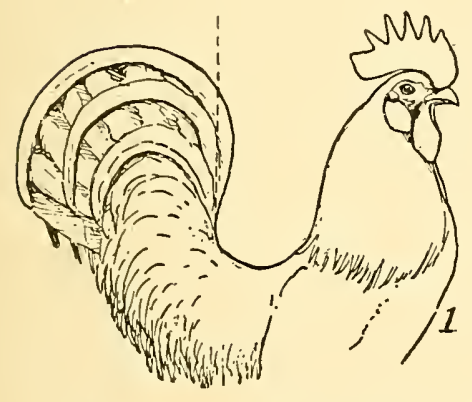

FIG. 11

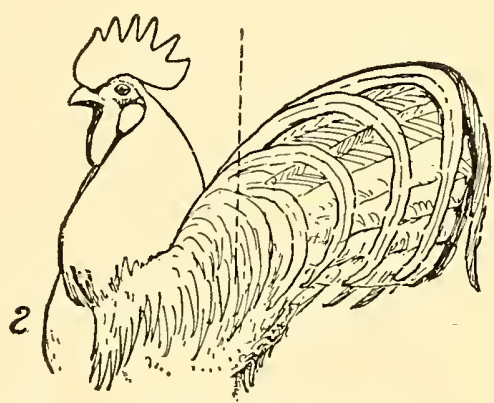

1, Squirrel tail. 2, Wry tail. Both are disqualifications. (After Slocum.)

of individuals known to carry "impure" blood, but by the disqualification ${ }^{2}$ of such birds as have defects so serious as to seem to indicate the influence of impure breeding, or to be greatly to the detriment of the breed.

This book, ordinarily spoken of as The Standard, is published by the American Poultry Association, and is revised and brought down to date once in eight years. It lists all

1 The term "thoroughbred" is frequently used in describing standardbred poultry. "Thoroughbred" is a proper name and refers to a breed of horses. It is technically as inaccurate to speak of Thoroughbred chickens as it would be to refer to Plymouth Rock horses.

2 Declaring them unworthy to be considered members of the breed. In the show room a disqualified bird is not allowed to compete for a premium. 
the recognized breeds and varieties, grouped in their proper classes, with their descriptions and disqualifications, and is the official guide by which all standard breeds are judged. Most of the well-known breeds and varieties are standard, Pit Games and Rhode Island Whites probably being the most brilliant exceptions among chickens.

A complete list of chickens, turkeys, ducks, geese and guinea fowl as recognized by the American Poultry Association includes sixteen classes, sixty-five breeds and one hundred and fifty-seven varieties. Of these, twelve classes, forty-five breeds and one hundred and twenty-seren varieties are of chickens. There are eleven breeds of ducks, grouped in one class, and subdivided into fifteen rarieties. The six breeds of geese are grouped as one class, and only one of the breeds has two varieties. Turkeys are all of the same shape and so all belong to the same breed, as well as to the same class. The breed is divided into six varieties on the basis of color. The guinea fowl has but a single breed and variety. Pigeons, pheasants, peafowl, swans, and ostriches are not dealt with by The Standard.

Breed Standards.-Each description of a breed with its several varieties is termed a "breed standard." The American Standard of Perfection is in reality a collection of breed standards. Each represents the composite ideal for the breed as formed from breeders' conceptions of usefulness and beauty. The use or harm of these standards depends upon the balance preserved between those characteristics that are of economic importance and those that are merely attractive. The standard of any breed that does not find beauty mainly in utility is a false standard and if persisted in will surely bring about the economic downfall of the breed. Strong breed characteristics, even though they add only to the attractiveness of the breed, and of themselves have no economic value, are assets to any individual and are of value to the producer. Utility points being equal, that individual which most strongly exhibits breed and variety characteristics is likely to be the individual whose pedigree, could it be examined, would show the most intelligent and careful breeding. 
Separate breed standards have been published for the Plymouth Rocks and Wyandottes.

Economic Value of Fancy Points.-Because there is little apparent value in some of the so-called "fancy points" is not just cause for condemning them wholesale. As a whole, producers have been benefited by the work of the fancierbreeder. Without it there would be no breeds, and no uniformity which is so vastly important with animals that are fed, or products that are sold, in numbers.

Other things being equal, the bird that shows most plainly breed and varietal characteristics, provided these do not conflict with indications of constitutional vigor, should be the breeder selected. Strong breed characteristics may be considered as indicating close and careful breeding and to be a mark of prepotency. The great difficulty is the tendency to overwork them and make them a fad. Their purpose is to furnish uniformity to the carcass for market purposes and to indicate internal and functional uniformity for feeding. Such a purpose does not carry the necessity for the extremes of color now somewhat in fashion. If we may learn from other live stock, we find absolute color requirements almost totally lacking. The lonely example of the Dutch-belted cattle among the dairy breeds is one where a color pattern requirement is associated with mediocrity of production.

Classification of the Breeds.-There are several ways of classifying the breeds. For our immediate purpose, they should first of all be divided into (1) the productive and (2) the ornamental breeds.

The productive breeds are those which are proving themselves such efficient manufacturers of human food that it is profitable to breed them for that purpose.

The ornamental or non-productive breeds are those which are inefficient as food producers but are bred more or less because of their general attractiveness or because of some peculiarity.

It is also customary to classify the breeds according to the purpose for which their type appears most efficient and for which they are supposedly bred. Thus we have the 
so-called (1) meat breeds, (2) the general purpose or dual purpose breeds, and (3) the egg breeds. These breed groups conform very closely to the Asiatic, American and English, and Mediterranean classes repectively. Broadly speaking the latter classification is incorrect. Aside from the more or less isolated sections where special market conditions prevail, as in the South Shore soft roaster district of the extreme East, there are no chickens that are bred primarily for meat pro-

FIg. 12

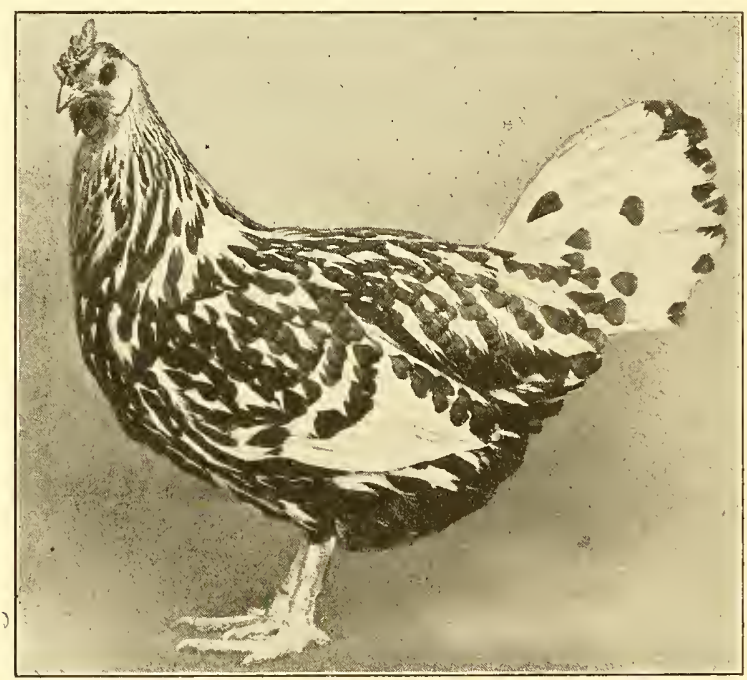

Silver Spangled Hamburg, an ornamental breed.

duction. The trend of production following the economic demand is toward eggs. The so-called meat breeds that lay comparatively few eggs, are surely and rather rapidly passing off the platform of economic importance. Good egg production (or its absence) has in the last analysis been the controlling factor in the permanence or dwindling of the popularity in which the various breeds have been held. Meat is becoming more and more a by-product of egg-production. It is 
an important by-product of the American breeds, and a relatively unimportant one of the Mediterranean varieties.

The Asiatic Class.-The classes of fowls that have played the most important part in building up the present valued breeds commercially are the Asiatics and Mediterraneans.

Of the Asiatics, the three recognized breeds are the Brahma, Cochin, and Langshan. All three were brought to this country by direct importation from China, coming from near the Brahmapootra River, from the city of Shanghai and from the district of Langshan respectively.

The forerunners of the present Brahmas were first imported in 1846. They were nearly if not fully as large as the modern Brahmas, were less heavily feathered and very much better layers. What was until recently the highest authentic egg record was made by a Light Brahma pullet in 1872, when a bird owned by I. K. Felch, of Natick, Mass., laid 313 eggs in 330 days.

The Standard Classes, Breeds, and Varieties.

Class.

Breed.

Variety.

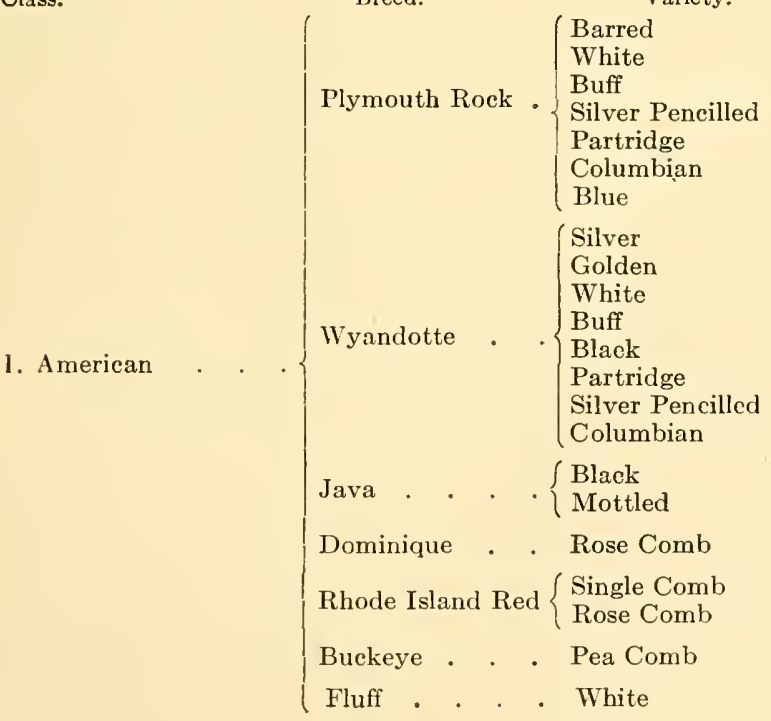


The Standard Classes, Breeds, and Varieties (Continued). Class. Breed. Variety.

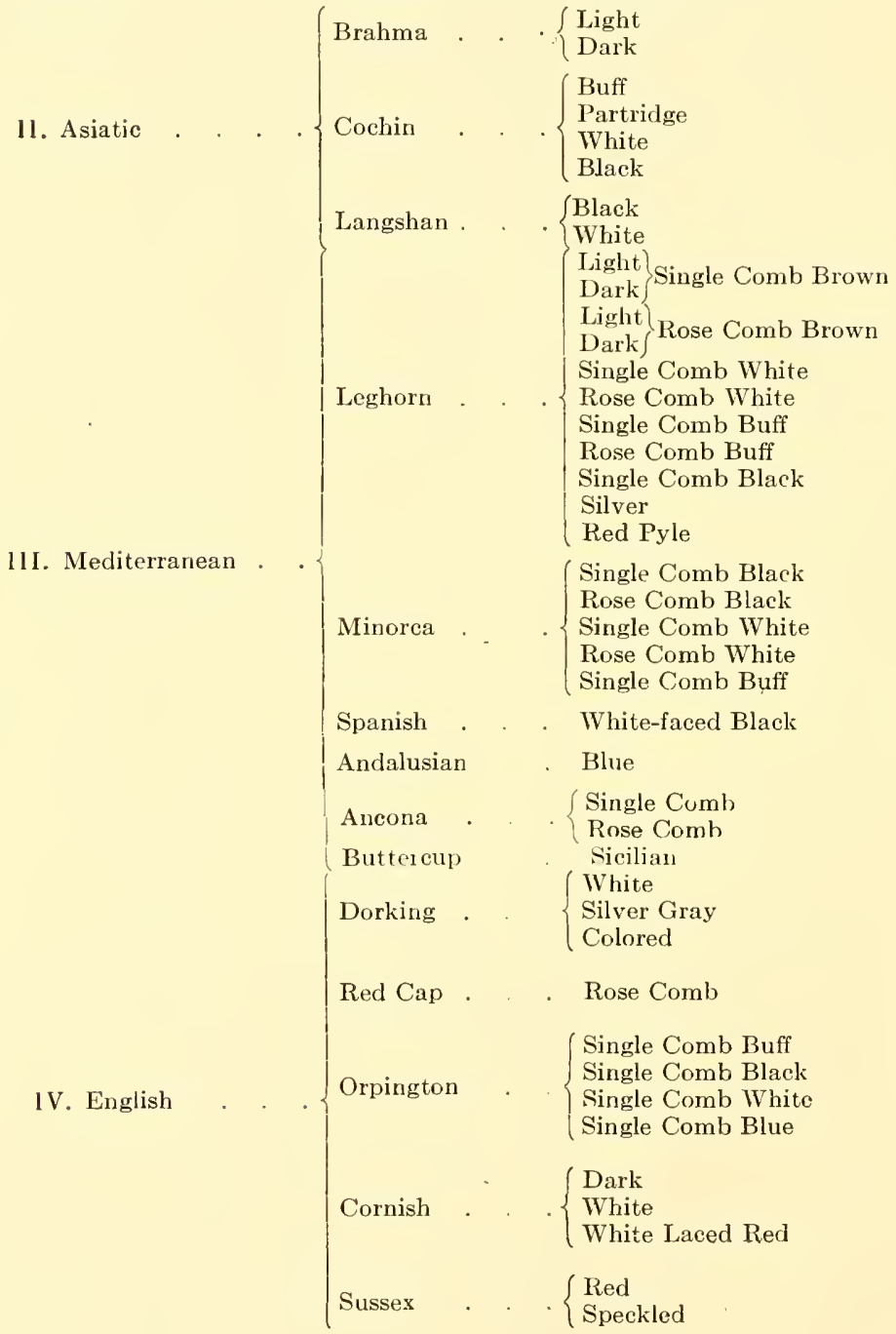


The Standard Classes, Breeds, and Varieties (Continued). Class.

Breed. Variety.

White-erested Black Bearded Golden Bearded Silver

V. Polish . . . Polish . . . Bearded White Buff Laced Non-bearded Golden Non-bearded Silver Non-bearded White Golden Spangled Silver Spangled V1. Hambur . . Hamburg. . . $\begin{aligned} & \text { Golden Pencilled } \\ & \text { Silver Peneilled }\end{aligned}$ White Black

VII. French Houdan ..$\left\{\begin{array}{l}\text { Mottled } \\ \text { White }\end{array}\right.$

Creveecur . Black La Fleehe. . . Black Faverolles . . Salmon

VIII. Continental $\begin{cases}\text { Campine } & \text { Silver } \\ \text { Rhinelander } & \text { Golden } \\ \text { Black }\end{cases}$

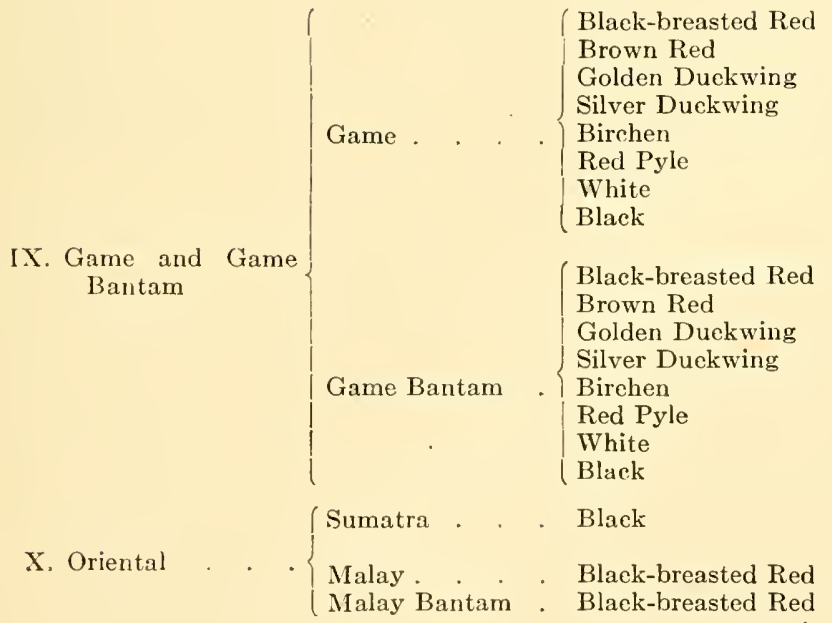


The Standard Classes, Breeds, and Varieties (Continued). Class.

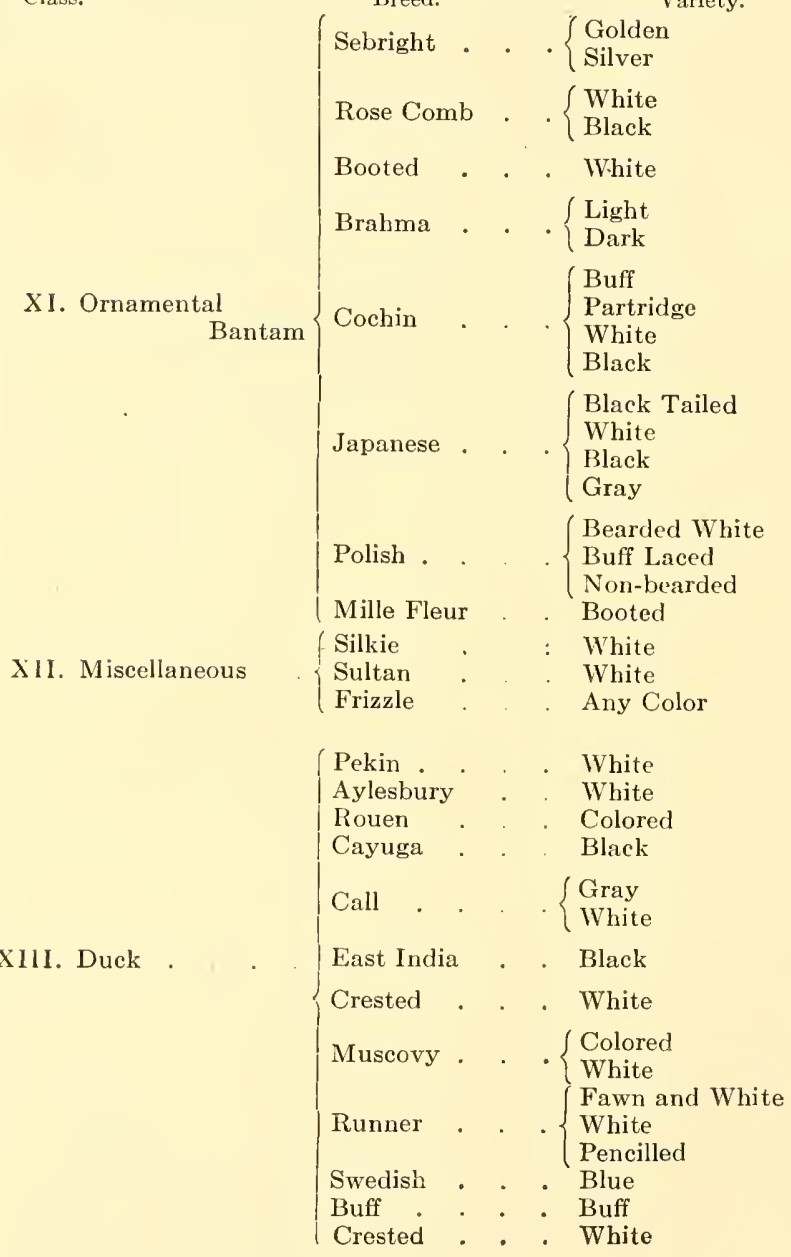


The Standard Classes, Breeds, and Varieties (Continued). Class.

Breed. Variety.

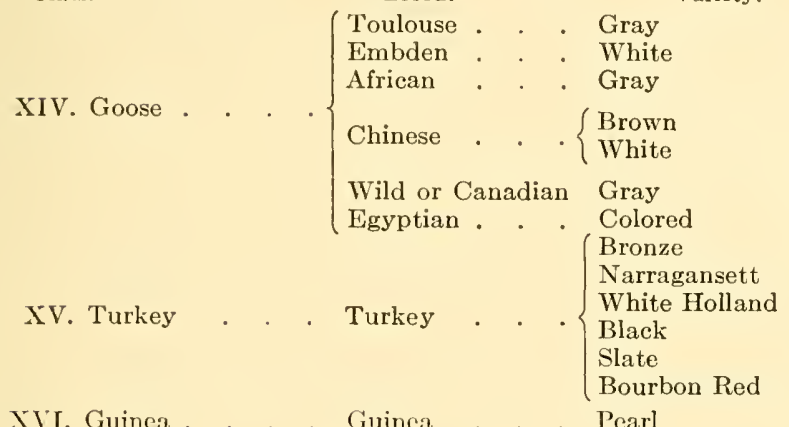

FIG. 13

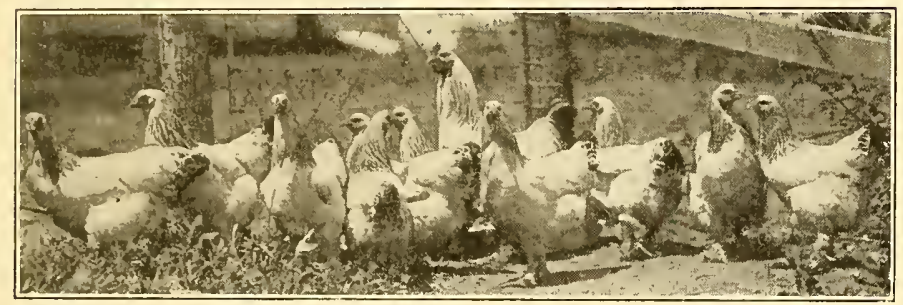

Light Brahmas (Asiatic).

The Cochins, then called Shanghais, were first imported in 1845 and, like the Brahmas, were less heavily feathered and much more fecund than now. Both of these breeds have been freely used in the formation of the American breeds now enjoying popular favor, and in spite of the general belief to the contrary, their blood in every case predominates over the Mediterranean.

The Brahmas and Cochins, as described in the present Standard, are the result of selection. That the characters selected for have not been good economic qualities would seem to be indicated by their waning popularity on the farm. The points most valued have been color, and length and heaviness of feather. The selection for color has resulted in the development of varieties when none were needed. 
Length and heaviness of feather unfortunately appear to be correlated with late maturity, general sluggishness of temperament, and low egg production. Selection for these points has had the only result possible, the production of races that are fast being relegated to the position of ornamental breeds.

FIG. 14

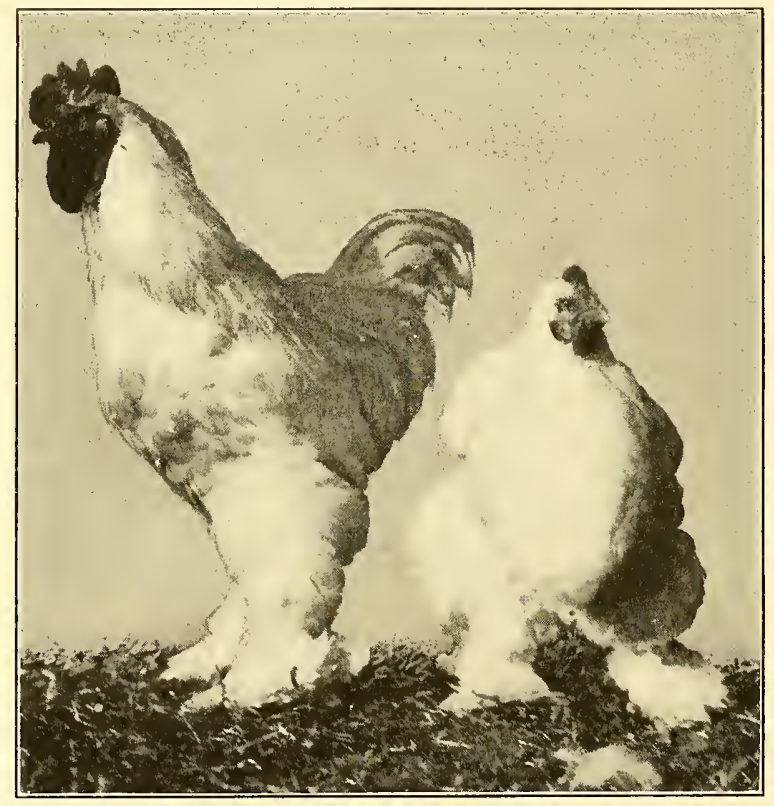

White Cochins (Asiatic).

In deploring the craze for heavy feathering, Brown ${ }^{1}$ remarks that "Feather is the most expensive material to produce, and hence the birds are slower in growth, great eaters, and distinctly inferior in egg production to the original type."

The Langshan was a later importation (1872). Like the Brahma and Cochin, its economic qualities have been injured

${ }^{3}$ Races of Domestic Poultry. 
by adhering to a false standard. Though the craze for heavy feathering has not laid its hand heavily upon it, the eagerness to make their type entirely distinct from that of the Orpington has led to the development of what Brown ${ }^{1}$ has depicted as "a leggy monstrosity, stilty, often weak legged, but naturally heavier in bone and smaller in body than of yore." In America the type has not been developed to such an extreme as in England, from which view-point Brown

FIG. 15

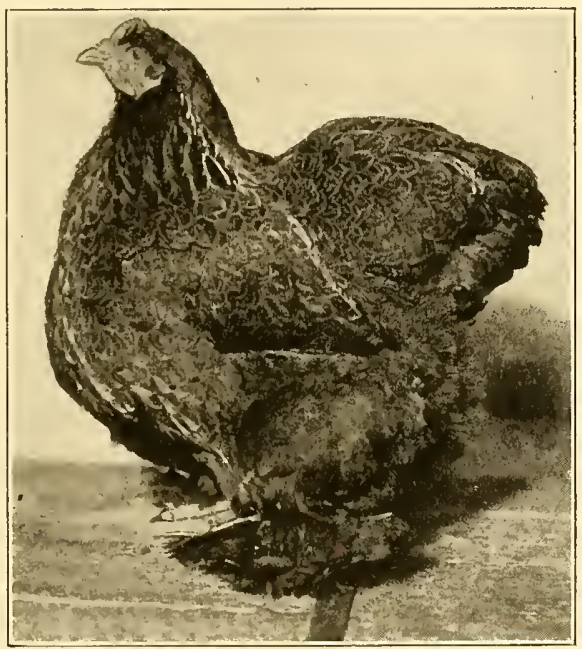

Partridge Cochin, female (Asiatic).

writes, but the development has assuredly not been toward the most desirable economic qualities.

The characteristics which these breeds have in common are: relatively large size, phlegmatic disposition, late maturity, and feathered shanks. All three of them lay an egg that is tinted a rich deep brown, and are persistent setters.

Mairs, ${ }^{2}$ in tests embracing members of the Asiatic, Ameri-

1 Races of Domestic Poultry.

2 Pennsylvania Bulletin No. 87. 
can, and Mediterranean classes, found that the chicks of the large breeds consume more feed during the growing period than do the smaller ones.

Mediterranean Class.-There are six breeds classified as Mediterranean because they originated near the shores of the Mediterranean Sea. These are:- Leghorns, Minorcas,

FIG. 16

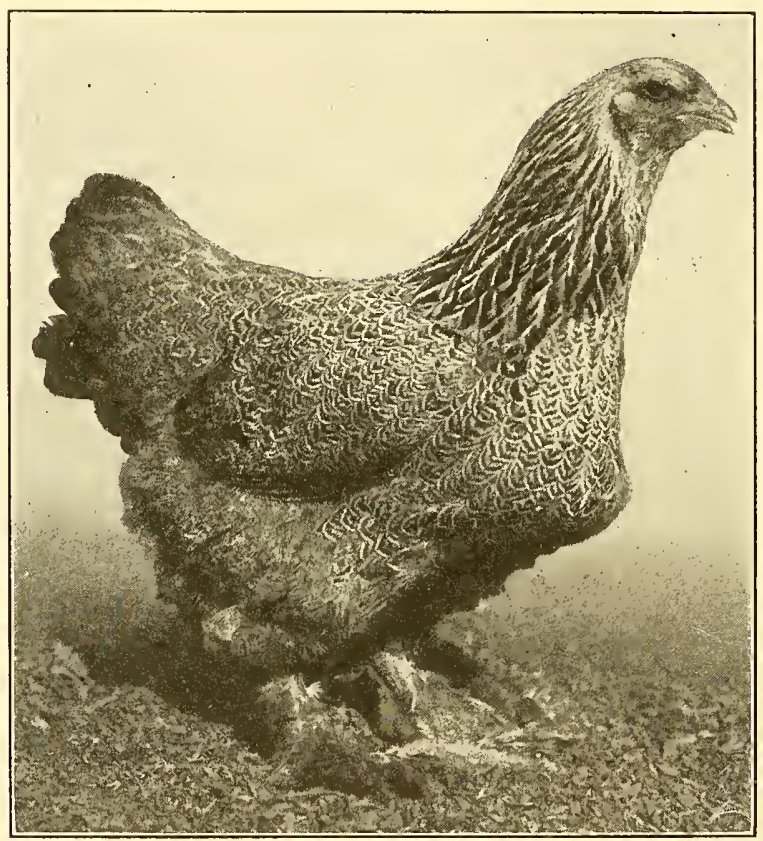

Dark Bralıma, female (Asiatic).

Spanish, Andalusians, Anconas and Buttercups. These breeds are at the opposite extreme from the Asiatic breeds in size, disposition, color of earlobe, earliness of maturity, setting tendency, and the number and color of eggs laid.

The most familiar Mediterranean breeds are the Leghorn and Minorca. Of these the Leghorn is by far the most 
popular, because of its superior reputation with regard to egg-producing qualities.

The Leghorns, named for the town of Leghorn, Italy, were first introduced into America in 1835 and have undergone a most gratifying improvement at the hands of American breeders. Whether through chance or design, they appear

FIG. 17

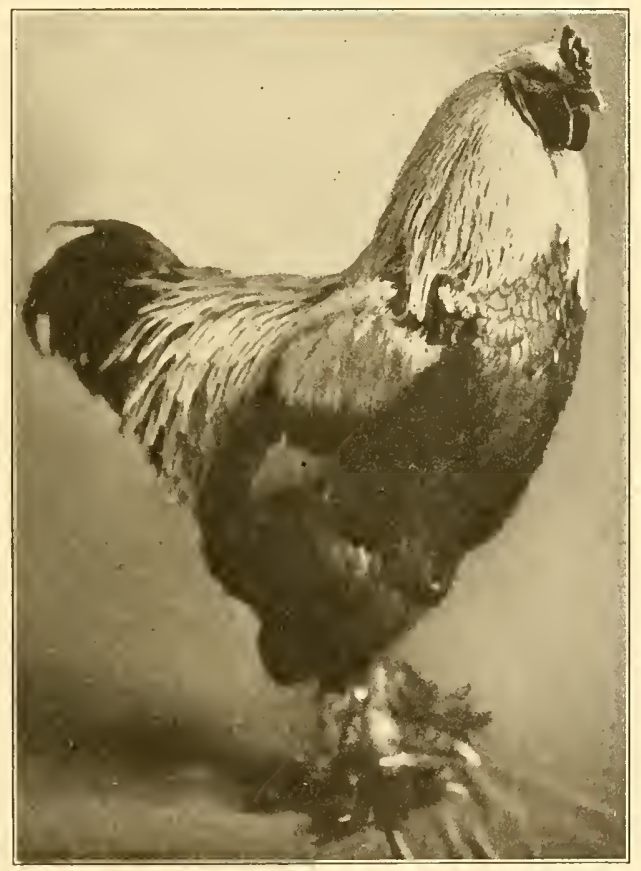

Dark Brahma, male (Asiatic).

to have been exceedingly fortunate in escaping the burden of harmful fancy fads. They are today enjoying an unexcelled popularity as egg producers. Of the several varieties, the Whites and Browns are most bred.

Their sister breed, the Minorca, is named for one of the Balearic Islands, off the east coast of Spain. This breed 
was formerly eredited with outlaying the Leghorns, where the actual pounds of eggs produced were considered, and is possibly the immediate progenitor of our modern Plymouth Rock which is responsible for its present-day tendency toward high production. It is now dropping out of favor, largely because of the diminution of that same high-producing quality.

FIG. 18

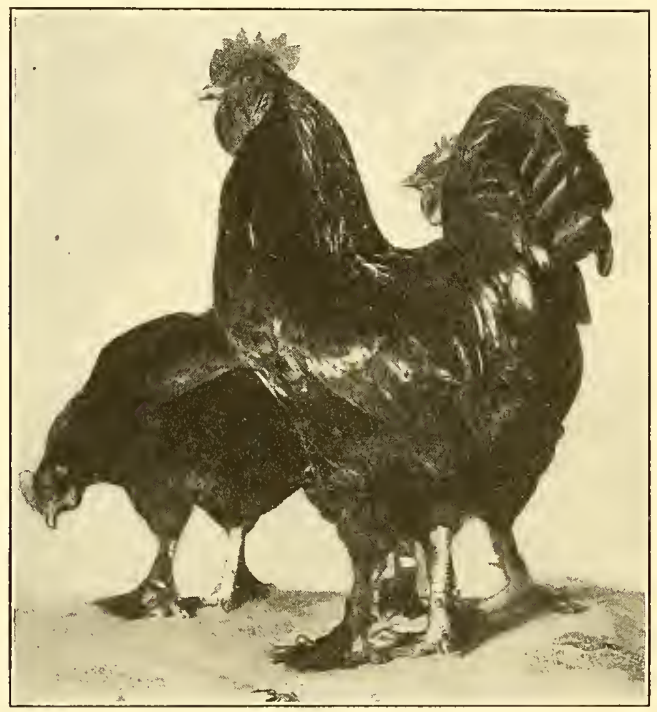

Black Langshans (Asiatic).

The reason usually ascribed for this retrogression is the fad for extreme size in comb. How or why extreme size in comb should militate against egg production is impossible to state. It may well be that the two characters are not necessarily opposed, but that in their enthusiasm for one character, breeders entirely lost sight of the other. Of the two varieties, White and Black, the Blacks predominate.

Both the Leghorn and Minorca are sprightly and stylish in type, very nervous and active in disposition, early in maturity, non-setters and layers of large white eggs. In all 
Fí. 19

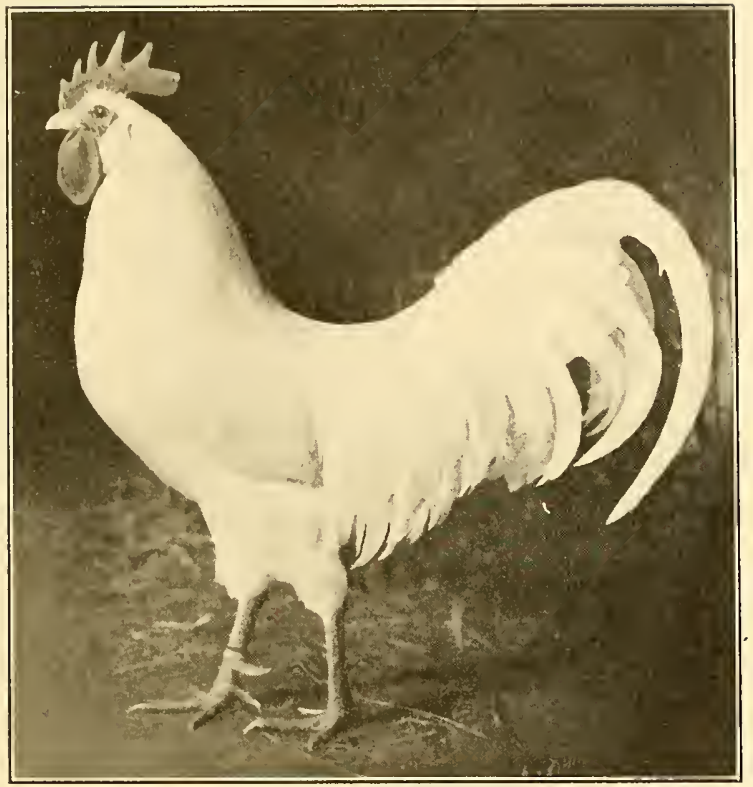

Single Comb White Leghorn. male (Mediterranean). (Courtesy of Owen Farms and Reliable Poultry Journal.)

Fig. 20

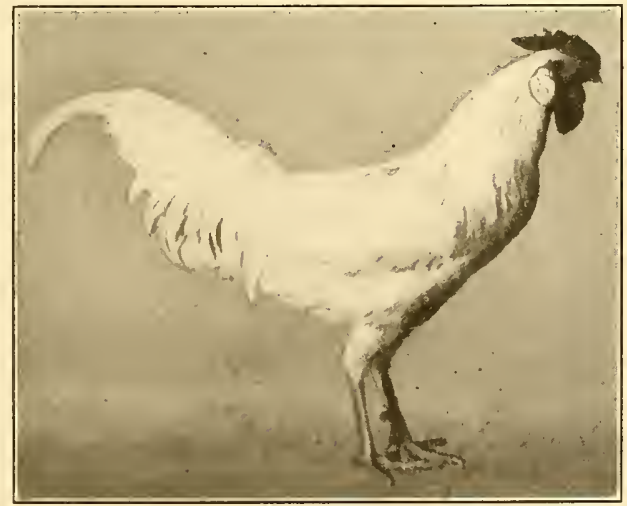

Rose Comb White Minorca, male (Mediterranean). 
these characteristics, as in fecundity, the Leghorn is more extreme save in the largeness of the egg, for which the Minorca enjoys an excellent and well-deserved reputation.

The Blue Andalusian is remarkable in that it never breeds true for color. The offspring of blue parents are, on the average, in the proportion of one black to two blue to one white, splashed with blue. The black offspring when mated together give only blacks. The white-splashed mated

FIG. 21

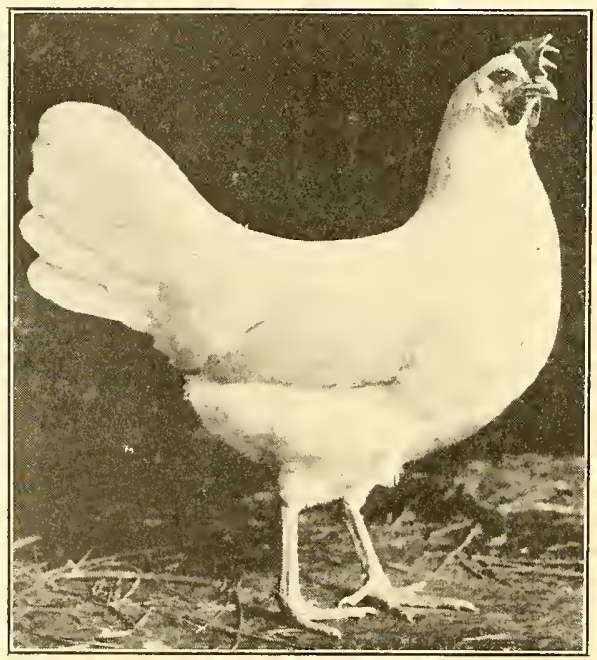

Single Comb White Leghorn, female (Mediterranean). (Courtesy of Owen Farms and Reliable Poultry Journal.)

together give all white-splashed. The blue offspring give blacks, blues and blue-splashed just as did their parents. Neither the blacks or white-splashed are recognized as standard varieties, though they breed true.

It is probable that the Blue Orpingtons and Blue Plymouth Rocks trace their ancestry to the Blue Andalusian among others and their breeding behavior corresponds to that of the Andalusian. 
The Buttercup, only recently admitted to The Standard. is as yet comparatively little known.

The American Class.-The American class as given in The Standard consists of seven breeds. These are Plymouth Rocks, Wyandottes, Javas, Dominiques, Rhode Island Reds, Buckeyes and Fluff's. Of these the Plymouth Rocks, Wyandottes, and Rhode Island Reds have found by far the most faror as farm fowls.

Fig. 22

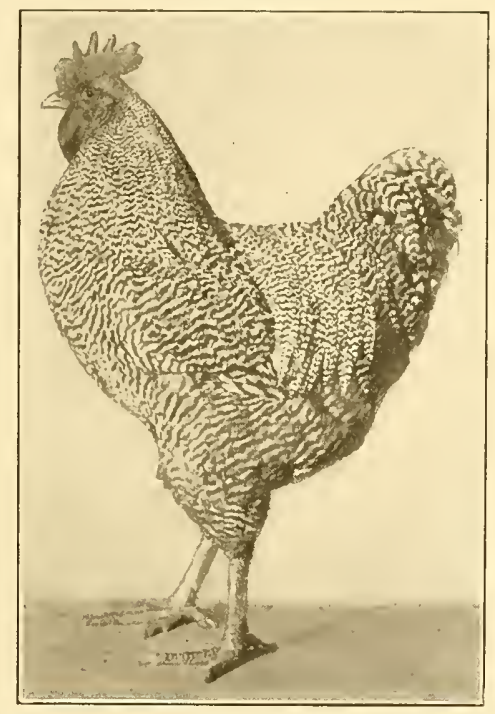

Barred Plymouth Rock, male (American).

As has been suggested, these American breeds were formed by a judicious blending of Asiatic and Mediterranean blood, in which the former predominates. The characteristics sought were hardiness of constitution, a larger frame than the Mediterranean commonly carried, a yellow skin and shank, a featherless shank, a greater activity and fecundity, and an earlier maturity than the Asiatics possessed.

According to Brown," "A fowl to which the name of

1 Races of Domestic Poultry. 
Plymouth Rock was given was introduced about 1849 by Dr. J. C. Bennett . . . but soon passed into oblivion. The present stock has no relationship or connection with it.

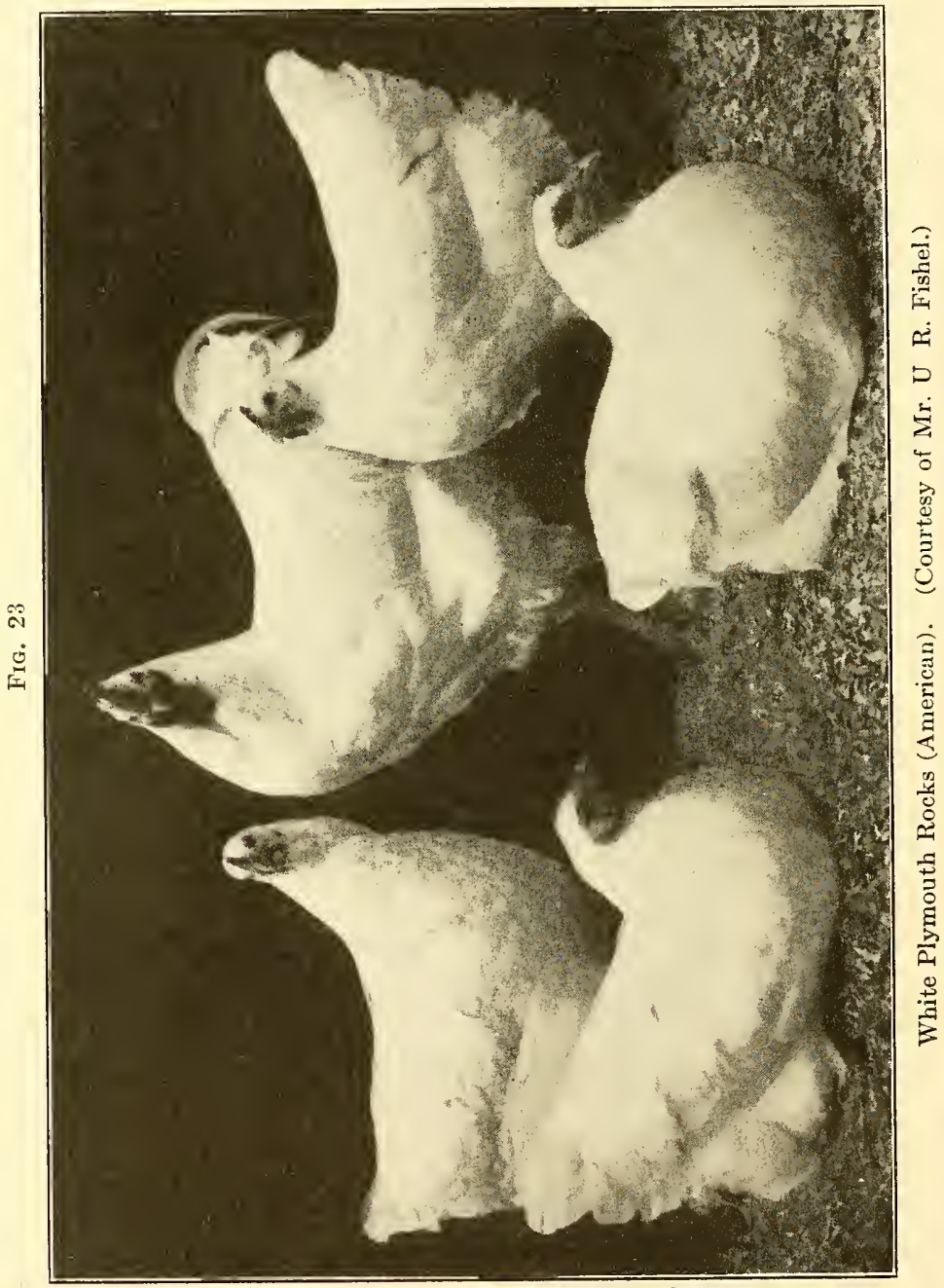


FIG. 24

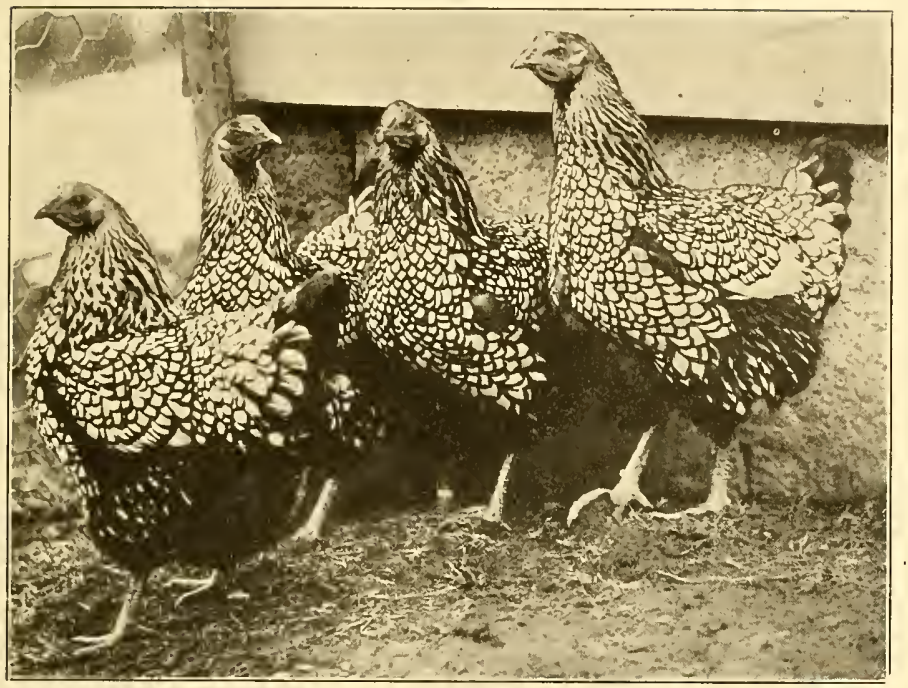

Silver Wyandottes, females (American).

Fig. 25

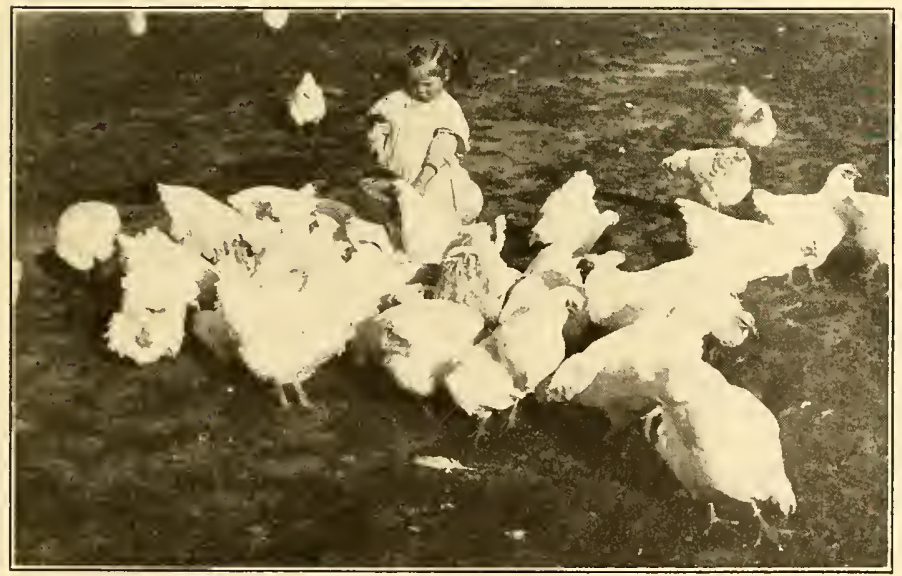

Firm flock of White Plymouth Rocks. (Courtest F. E. Colburn.) 
The first specimens leading to our present stock . . were exhibited by Mr. D. A. Upham, of Wilsonville, Conn., at Worcester, Mass., in 1869. They were originated by Mr. Joseph Spaulding, of Putnam, Conn. Much interest was manifested in them, and led to the steps which ultimated in the Essex strain nine years later. From

Fig. 26

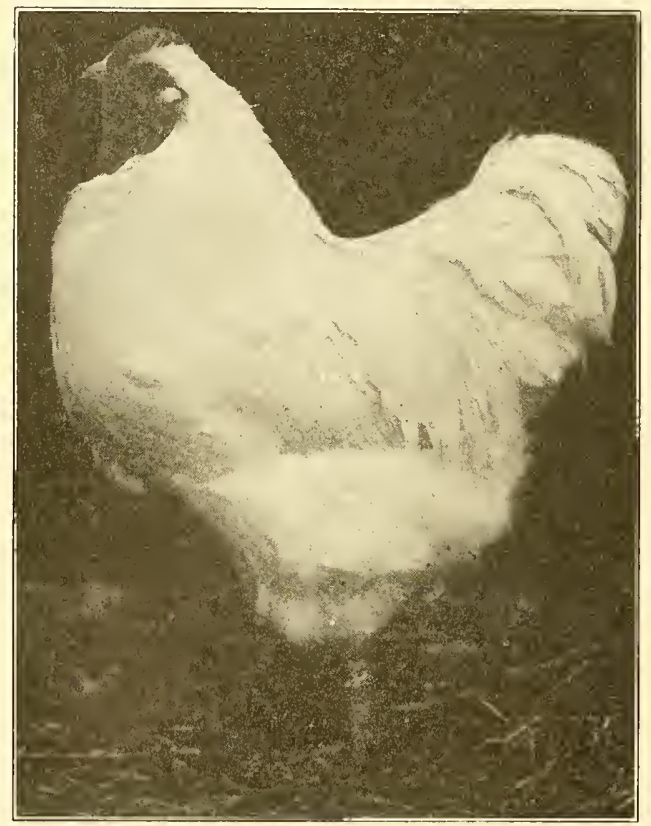

White Wyandotte, male (American).

the first they 'caught on,' both with exhibitors and practical poultry keepers. Something must be allowed for the fact that the breed was an undoubted American production. It is not too much to say that the great development of the poultry industry in America owed much to the breed."

The foregoing applies to the Barred Plymouth Rocks, at first simply called "Plymouth Rocks." The Whites were 
not introduced until $18 S 0$ and the Buffs were recognized in 1S93. The Partridge, Columbian, Silver Pencilled and Blue varieties were later additions.

"Barred Rocks were introduced into Great Britain in 1879 and speedily won a widespread popularity. For some years at exhibitions, classes of (Barred) Rocks were by far the largest. . . . But it was not only among exhibitors that the breed secured favor. Its undoubted economic qualities caused it to be spread very widely throughout the kingdom, and until the advent of the Buff Orpington its influence was more in evidence as a farmer's fowl than any other."1

FIG. 27

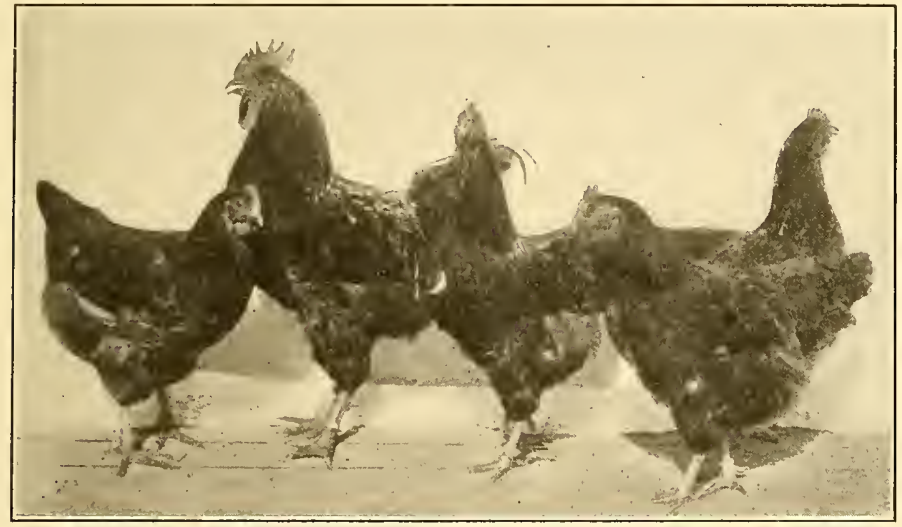

Single Comb Rhode Island Reds (American). (Courtesy of Kansas Experiment Station.)

In America the Barred Plymouth Rock and its grades are in evidence on more farms than any other breed. This is particularly true in the central states.

The original Wyandotte, the Silver, was the result of an attempt to secure an improved Cochin Bantam by crossing a Sebright Bantam with a Cochin hen. After further crossing, in which the Asiatic and Hamburg classes were used, the Silver Wyandottes were introduced in the late seventies. "The Goldens followed in the early eighties.

- ${ }^{1}$ Brown, Races of Domestic Poultry. 
The Whites were admitted to The Standard in 1888 and the Buffs and Partridge varieties in 1894."' ${ }^{\prime}$ The Silver Pencilled, Black, and Columbian varieties were later additions.

The Rhode Island Reds came nearer to being originated as a farmer's breed than perhaps any other. According to Brown, " "This breed was the result of crossing by farmers living on the shores of Narragansett Bay in New England, who had no idea of producing a new breed, but of securing strong, vigorous, and profitable fowls." The foundation of this breed was laid sixty years ago, when some Red Cochins and Malays were brought to Westport, Mass., and Little Compton, R. I., by sailors. These were crossed with the native stock, and the resulting offspring seemed particularly suited to the prevailing conditions.

Later other crosses were made, which probably included the Rose Comb Brown Leghorn and the Wyandotte.

While fowls were exhibited under the name of Rhode Island Reds as early as 1879 or 1880 , a standard was not adopted for them until 1901. There are but two varieties, the Single Comb and the Rose Comb.

All American breeds lay a brown egg that is neither so dark nor so uniform in color as the egg of the Asiatics.

These breeds have for the most part been singularly free from injurious fads, though the present breed standards are laying too much stress on non-economic points. The Plymouth Rock and Rhode Island Red bid fair to be victims of too much emphasis on absolute color requirements; while the Wyandottes, as a breed, have probably already suffered from the extreme short body and that roundness that calls rather loose and heavy feathering to its aid.

Mairs ${ }^{3}$ found, in slaughter tests, that birds of the American class gave a better dressing percentage than either the Asiatic or Mediterranean.

The English Class.-The English class consists of five breeds, Dorking, Red Cap, Orpington, Cornish, and Sussex. Of these, the Orpingtons alone have obtained a position of

\footnotetext{
1 Brown, Races of Domestic Poultry.

${ }^{2}$ Loc. cit.

${ }^{3}$ Pennsylvania Bulletin No. 87.
} 
productive importance in America. Four varieties are recognized in this country: Buff, Black, White, and Blue. All have single combs.

The Blacks were the original Orpingtons, being introduced by Mr. William Cook, of Orpington, Kent, in 1886. He also introduced the Buff's in 1894. According to Mr. Cook, the Blacks were secured by judicious crossing of Black

FIG. 28

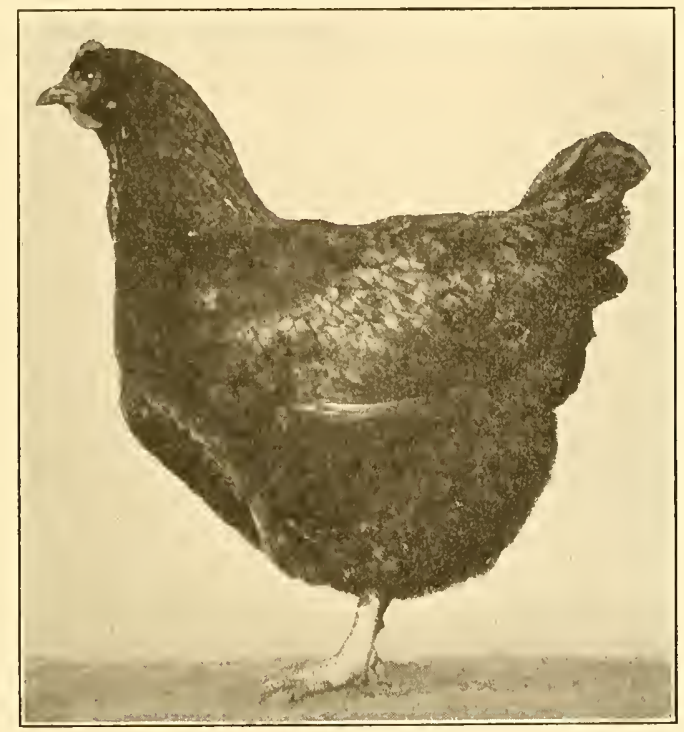

Black Orpington, female (English).

Minorca, Black Plymouth Rock, and clean-legged Black Langshan blood, followed by careful and rigorous selection. The Buff's were the result of the crossing of Golden Spangled Hamburgs, Buff Cochins, and Dark Dorkings. As will be easily seen, there is no common or even similar ancestry with these two varieties of the Orpington breed.

The Whites appeared later and were probably a "sport" from the Blacks. The Blues have only recently been recog- 
nized in this country. The Buffs and Whites are by far the most popular in America.

Aside from their averaging a pound heavier in weight, and carrying the white skin and shanks so characteristic of English breeds, they are quite similar in economic qualities to our American breeds. In fact, they have been termed "the English edition of the Plymouth Rock."

Choosing a Breed.-So far as the production of meat and eggs is concerned, it makes very little difference what shaped comb birds carry, or even what the variety color or breed type is. The real choice is not between breeds but between classes. If eggs are the product of prime interest a Mediterranean breed will naturally be chosen. They are great rustlers, capable of keeping out of the way of chicken-eating hogs. They are somewhat difficult of control under general farm conditions, however, and do not furnish as attractive and sizable a carcass as some of the other classes.

If in addition to securing a good number of eggs a convenient and attractive source of fresh meat for home use is sought, one of the American or English breeds should probably be chosen. The particular breed and variety chosen should depend upon the producer's preference. He will do best with the fowls he likes best.

Table Xili.-Showing the Comparison of Production of the Pullets and Yearling Females of the American Breeds and White Leghorns at the Vineland (New Jersey) Laying Contest Expressed in Per Cent of Perfect Production.

\begin{tabular}{|c|c|c|c|c|c|}
\hline \multirow[b]{2}{*}{ Month. } & & \multicolumn{2}{|c|}{$\begin{array}{l}\text { 1916-1917. } \\
\text { Pullet Production }\end{array}$} & \multicolumn{2}{|c|}{$\begin{array}{c}\text { 1917-1918. } \\
\text { Yearling Production }\end{array}$} \\
\hline & & $\begin{array}{l}\text { American } \\
\text { breeds } \\
\text { per cent }\end{array}$ & $\begin{array}{l}\text { Leghorns, } \\
\text { per cent }\end{array}$ & $\begin{array}{l}\text { American } \\
\text { breeds } \\
\text { per cent }\end{array}$ & $\begin{array}{l}\text { Leghorns } \\
\text { per cent }\end{array}$ \\
\hline November & . & 20.6 & 34.0 & 19.6 & 6.4 \\
\hline December & . & 26.7 & 33.8 & 14.0 & 4.3 \\
\hline January & . & . $\quad 35.1$ & 32.2 & 16.9 & 14.4 \\
\hline February & . & 43.5 & 43.2 & 30.0 & 36.5 \\
\hline March & . & 62.4 & 645 & 55.9 & 59.7 \\
\hline April . & . & 63.7 & 69.6 & 55.7 & 69.7 \\
\hline May. & . & 56.2 & 67.4 & 42.0 & 60.7 \\
\hline June & . & 48.9 & 66.3 & 39.4 & 54.1 \\
\hline July & . & 40.8 & 60.0 & 34.8 & 47.6 \\
\hline August & . & 33.8 & 48.0 & 27.2 & 35.8 \\
\hline September & & 26.9 & 22.3 & 26.8 & 24.3 \\
\hline October & & 28.5 & 14.4 & 13.6 & 8.2 \\
\hline Av. for the & rear & 40.5 & 46.3 & 31.3 & 35.1 \\
\hline Av. eggs pe & bird & $150 \mathrm{eg}$ & $169 \mathrm{eggs}$ & $117 \mathrm{eggs}$ & $137 \mathrm{eggs}$ \\
\hline
\end{tabular}


An indication of the average differences in egg production between the American breeds on the one hand and the White Leghorn on the other is given by Lewis, Hannas and Wene's ${ }^{1}$ report on the Iineland laying contest as shown in Table XIII.

The popularity of the Asiatic breeds for farm production seems to be waning. This appears to be largely due to their low laying, late maturity and persistent broodiness.

1 New Jersey Bulletin, No. 339 . 


\section{THE BREEDING OF CHICKENS.}

Definition of Breeding.- Poultry breeding is comprised of those operations which deal directly with reproducing and improving domestic poultry. It includes selection, mating, and incubation. For convenjence and because artificial incubation has been so highly developed as to need treatment in a separate chapter, only those phases which have to do with selection and mating are discussed here.

Physical Basis of Reproduction in the Female.-The organs of reproduction in the female fowl are the left ovary and the left oviduct. The right ovary and oviduct are formed at the same time as the organs on the left side, but degenerate during embryonic life, and persist, if at all, only as functionless rudiments. Lillie ${ }^{1}$ suggests that this fact would appear to be correlated with the large size of the egg and the delicate nature of the shell, as there is not room for two eggs side by side in the lower part of the body cavity.

The functioning ovary appears as a cluster of many spheres which vary in size from that of the normal egg-yolk down to the point where they are barely visible to the unaided eye. Each sphere is a more or less developed ovum or yolk and is joined to the main stalk of the ovary by a stalk of its own called a follicle.

A continuation of this follicle completely surrounds the ovum as long as it remains connected with the ovary. It is the rupture of the follicle along a preformed line or band, called the stigma, and which marks the extremities of its vascular system, that allows the ripe ovum or fully grown yolk to escape into the oviduct. In counts of the total number of ova and ruptured follicles visible to the unaided eye

I Development of the Chick. 
in the ovaries of thirteen hens made by Curtis, ${ }^{1}$ it was found that they varied in number from 914 to 3605. There did not appear to be any correlation between this total number of ova and ruptured follicles and the fowl's previous trap nest record. The ovary is situated to the left of the median line of the body just back of the lungs and below the anterior extremity of the left kidney.

Fig. 29

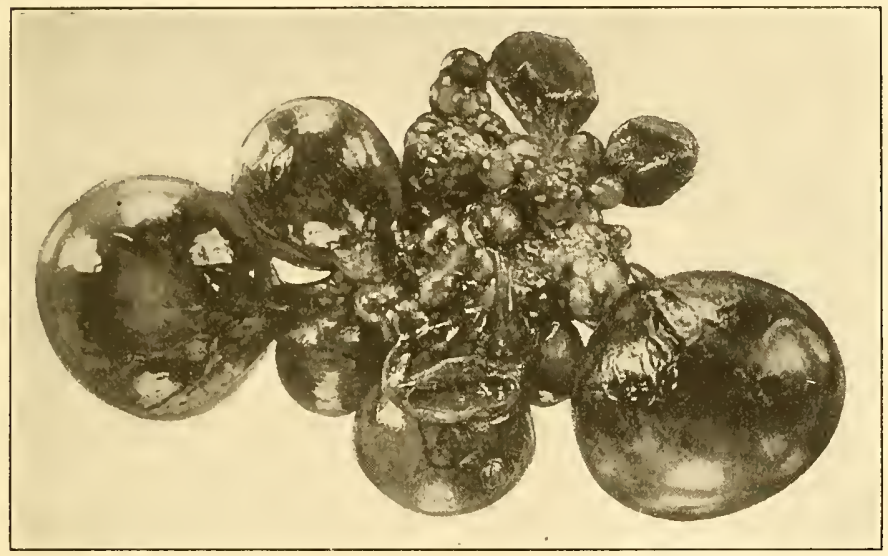

The ovary of a hen in full laying. (Courtesy of Raymond Pearl.)

Curtis $^{2}$ has described the oviduct of the laying hen as being "a large, much coiled tube filling a large part of the left half of the abdominal cavity. It is suspended from the dorsal body wall and lies dorsal to the abdominal air sac. Its anterior end is expanded into a large funnel which is spread out beneath the ovary in such a way that the mouth of the tube faces the ovary. The mutual relations of the abdominal viscera are such as to virtually form a pocket in which the ovary lies. This walling off of the ovary is of such a character as to tend mechanically to direct detached ova to the mouth of the oviduct." There is no organic

1 Maine Bulletin No. 205.

2 Ibid., No. 176. 
connection between the oviduct and the ovary, and Lillie ${ }^{1}$ adds that "The existence of double-yolked eggs renders it probable that the oviduct can pick up eggs that have escaped into the body cavity."

FI(r. 30

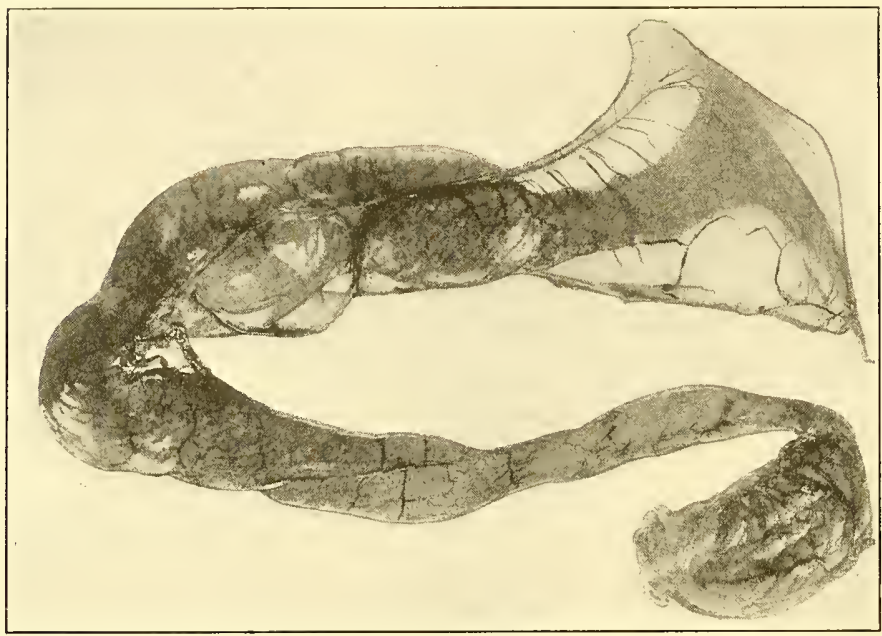

The oviduct of a hen in full laying, showing the funnel at the upper part of the photograph. (Courtesy of Raymond Pearl.)

According to Surface $^{2}$ the oviduct is divided into five more or less clearly defined regions. Beginning at the end nearest the ovary, these are: (1) the funnel; (2) the albumen secreting portion; (3) the isthmus, which secretes the shell membrane; (4) the uterus or shell gland; (5) the vagina, which leads into the cloacal opening.

Formation and Fertilization of the Egg. ${ }^{3}$ - In the formation of an egg, the yolk comes to its full size in the ovary. (See Figure 82 , page 177.) It starts as a tiny sphere not visible to the unaided eye. Its nucleus, which marks the point of the development of the embryo chick after fertilization, is in

1 Development of the Chick.

${ }^{2}$ Maine Bulletin No. 206.

${ }^{3}$ Lillie's description in "The Development of the Chick" is followed. 
approximately a central position. While the nucleus is still at the center a deposit of extremely fine granules of yolk is formed around it and gradually extends toward the cell wall. This deposit is what is later recognized as the latebra of the flask-shaped mass of white yolk.

When the ovum has reached a size approximating 0.66 $\mathrm{mm}$., the nucleus migrates to a position at the end of the flaskshaped formation and just under the vitelline membrane.

Successive layers of yellow yolk are deposited around the central mass of white yolk by the activity of the peripheral layer of protoplasm. These layers are somewhat correlated with the periodic daily physiologic rhythm of the vitality of the hen.

When the yolk comes to full size, it escapes from the ovary by the rupture of the follicle along the stigma, into the funnel of the oviduct, which, as Lillie states, "swallows it, so to speak, and it passes on by peristaltic contraction of the oviduct. The escape of the ovum from the follicle is known as the process of ovulation."

"The stimuli which initiate the peristaltic action of the oviduct and attract the funnel to the mature follicle are among the unsolved problems of physiology. The yolk is already oriented in the follicle before the funnel encloses it." 2 "Internal pressure due to continued yolk formation is probably the most important factor in the normal rupture of the follicle, since closing the funnel or removing the duct apparently does not greatly delay ovulation."'3

Fertilization takes place almost immediately after ovulation, the spermatozoa having made their way through the entire length of the oviduct. Lillie ${ }^{4}$ states that "The ovum is surrounded immediately after ovulation . . . by a fluid containing spermatozoa in suspension. The entrance of several spermatozoa (into the ovum) seems to be characteristic of vertebrates with large ova."

Only one of these (spermatozoa) serves as a functional sperm nucleus: the remainder or supernumerary sperm

1 Oppos. cit.

${ }^{2}$ Curtis, Maine Bulletin No. 228.

a Pearl and Curtis, Journal Experimental Zoölogy, vol. vii, No. 3.

${ }^{4}$ Oppos. cit. 
nuclei migrate as though repelled from the center toward the margin.

"After entering the infundibulum (funnel) the yolk remains in the so-called albumen portion of the oviduct about three hours and in this time acquires only about 40 to 50 per cent by weight of its total albumen. During its sojourn in the albumen portion of the duct the egg acquires the chalazæ and chalaziferous layer, the dense albumen layer, and (if such a layer exists as a distinct entity, about which there is some doubt) the inner fluid layer of albumen."'

This albumen has a decided bactericidal property which is highly important. "Without this defensive agency the oviduct and therefore the eggs would be very liable to infection from microörganisms by way of the cloaca. Such an infection would be very likely to greatly decrease the hatching power of the eggs." 2

"The contents of normal fresh eggs are as a rule sterile. It is quite probable that an egg yolk may become invaded before it leaves the ovary; but this is apparently an uncommon occurrence, except when the ovary is infected with the organism of bacillary white diarrhea. Little if any infection takes place in the oviduct while the white and shell are being deposited.'"3

By the peristaltic contractions of the oviduct just back of it, the egg is forced through the remaining sections of the oviduct. "Upon entering the isthmus, in passing through which portion of the duct something under an hour's time is occupied instead of three hours, as has been previously maintained, the egg receives its shell membranes by a process of discrete deposition. At the same time, and during the sojourn of the egg in the uterus, it receives its outer layer of fluid or thin albumen, which is by weight 50 to 60 per cent of the total albumen. This thin albumen is taken by osmosis through the shell membranes already formed. When it enters the egg in this way it is much more fluid than the thin albumen of the laid egg. The fluid albumen added in this

${ }^{1}$ Pearl and Curtis, Journal Experimental Zoölogy, vol. xii, No. 1.

${ }^{2}$ Lillie. The Development of the Chick.

${ }^{3}$ Rettger, Storrs Bulletin No. 75 . 
way dissolves some of the denser albumen already present, and so brings about the dilution of the latter in some degree. At the same time by this process of diffusion, the fluid layer is rendered more dense, coming finally to the consistency of the thin layer of the laid egg. The thim albumen layer, however, does not owe its existence in any sense to this dilution factor, but to a definite secretion of a thin albumen by the glands of the isthmus and uterus. The addition of albumen to the egg is completed only after it has been in the uterus from five to seven hours.

"Before the acquisition of albumen by the egg is completed a fairly considerable amount of shell substance has been deposited on the shell membranes. For the completion of the shell and the laying of the egg from twelve to sixteen, or exceptionally even more, hours are required."'

It is while the egg is in the uterus that it is possible to locate it by touch. At the Utah Station ${ }^{2}$ this fact has been made use of in keeping egg records except during the breeding season when pedigreeing is being done. It was found that the whole flock could be handled early each morning and the individual hens which would lay that day, determined with accuracy.

Curtis $^{3}$ has shown that the larger an egg, the greater is the mechanical stimulation upon the uterus and the heavier is the shell.

Infertile Eggs.- The discharging of the yolk or ovum from the ovary of the hen is analogous to ovulation in other farm animals.

With the larger animals, if ovulation is not followed by mating, there is no further development. With birds, however, whether the ovum is fertilized in the funnel of the oviduct by union with the male element or not, its further history within the hen's body is the same and an apparently normal egg is laid. If the hen has not been previously mated and there are no spermatozoa in the oviduct to unite with the ovum, the egg is called infertile and will not start to

1 Pearl and Curtis, Journal Experimental Zoölogy, vol. xii, No. 1

${ }^{2}$ Jour. Am. Assn. Inst. and Invest. in Poul. Husb., vol. iii, No. 9.

${ }^{3}$ Maine Bulletin No. 228. 
develop when placed in an incubating temperature. Such an egg is the equal of a fertile egg for food purposes, and very much superior for preserving, shipping, or storage purposes.

Freak Eggs.--There are various kinds of abnormal eggs which appear in flocks of any size with more or less frequency. The most common is the double-yolked egg, which is caused in two ways: two yolks may develop in one follicle, and escape, and be taken up by the oviduct at the same time and wrapped in the same albumen, shell membranes, and shell. A second way is by the premature rupture of a follicle, which allows the yolk to escape into the body cavity. This yolk is sought out and taken up by the oviduct, often just before or after another yolk is received from the ovary. These two yolks then travel down the oviduct together, as in the first case. In either case one or both of the yolks may be fertile and develop chicks, though these rarely hatch.

The so-called soft-shelled egg is usually one that has no shell. This may be caused by the shell gland failing to function or by the peristaltic constrictions becoming so violent as to hurry the egg to exclusion, without allowing time for the secretion and deposition of the shell.

When the shell material is first applied to the egg it is plastic and the oviduct on the outside and the egg on the inside together constitute a mould which determines the shape of the egg. For some reason that part of the oviduct which immediately surrounds the egg sometimes becomes constricted, taking on what is termed an hour-glass form. The result is that as the shell material hardens it takes the same form, becoming what is called, for want of a better name, a "dumb-bell" egg.

Of quite common occurrence are the very tiny eggs which have no yolk. These are caused by some foreign substance, as a clot of blood or a piece of detached membrane, finding its way into the oviduct and travelling down in the same way that an egg does. As it comes to the albumen secreting portion, the gland is stimulated and secretion occurs, much as though a yolk were present. After being surrounded by albumen the substance has the same history as a normal egg.

It sometimes occurs that what appears to be a double- 
yolked egg is found upon being opened to contain another egg in every way normal, instead of the expected two yolks. For some reason, after the egg is completed and is ready for laying, the constrictions that usually take place behind it, forcing it toward exclusion, become reversed and take place in front of the egg, forcing it back into the albumin secreting portion again. This causes a new secretion of albumin which surrounds the shell, and, normal action restored, the egg again travels down the oviduct, is surrounded by a second pair of membranes and another shell.

The so-called "liver spots" or "blood spots" in eggs are due to the rupture of bloodvessels in the follicle or walls of the oviduct or by the sloughing off of tiny pieces of membrane. The clot simply becomes surrounded along with the yolk. The membrane is usually suspended in the albumen.

Further Functions of the Sex Glands. - The primary function of the sex glands (ovary and testis) is the production of ova and spermatozoa. They have however, certain very important secondary functions. The removal of the testes from the male known as caponizing, which has been practiced commercially for centuries, increases the size of the bird by growth and the laying on of fat, and causes the flesh to remain tender as in a young bird, largely through the failure to develop as much connective tissue as is normal in a mature male. The neck, saddle, and tail feathers usually grow noticeably longer than in the normal male. The comb and wattles fail to develop, remaining in an infantile condition.

By way of summary, it may be said that the presence of the testes limits body size, the laying on of fat and feather length, while stimulating the development of the comb. While the body size and the feather development in some sections of the male are greater than in the female, they are not so great as in the castrated male.

Goodale ${ }^{1}$ has shown in a careful series of investigations that the difference in the length and shape of plumage between the male and female is largely due to the influence

1 Carnegie Institute of Washington, Pub. 243. 
of the ovary. When the ovary is cntirely removed the pullet grows the plumage of a cockerel (or more accurately, of a capon) with a typical hackle and saddle, and a long tail with sickle feathers. He has also shown that after successful ovarectomy the demurely colored Rouen duck takes on the brilliant colors of the male following the next molt.

Cole and Lippincott ${ }^{1}$ have shown that a hen whose ovary is destroved by a tumor grows plumage which in shape is

FIG. 31

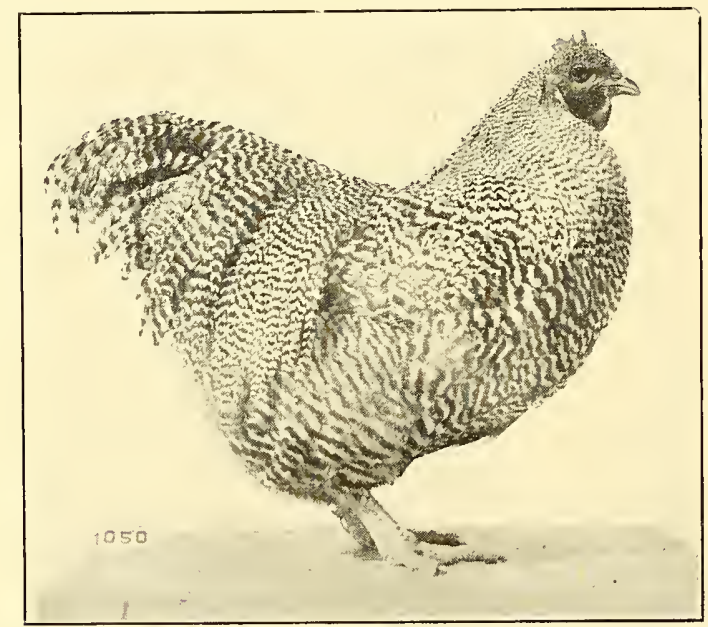

A Barred Plymouth Rock hen which developed saddle, sickle and hackle feathers typical of a male or capon, as the result of the ovary being destroyed by a tumor. (After Cole and Lippincott.)

quite typical of a male or capon (see Figures 31 and 32). They showed further that by introducing into the body cavity pieces of ovary from another female, feathers typical of a normal female could later be grown on the same bird.

Goodale $^{2}$ went even further and quite completely feminized cockerels so far as appearance is concerned, by castrating them and engrafting ovaries. 'The ovary also seems to inhibit

1 Biological Bulletin, vol. xxxvi, No. 3.

2 Genetics, vol. iii, No. 3. 
growth somewhat and to stimulate comb development, though to a less extent than the testis.

It appears from the evidence of Boring and Pearl ${ }^{1}$ coupled with that of Morgan, ${ }^{2}$ and Boring and Morgan, ${ }^{3}$ that the presence of the groups of yellow cells found in the ovaries of domestic birds (each known as a corpus luteum), may be

FIG. 32

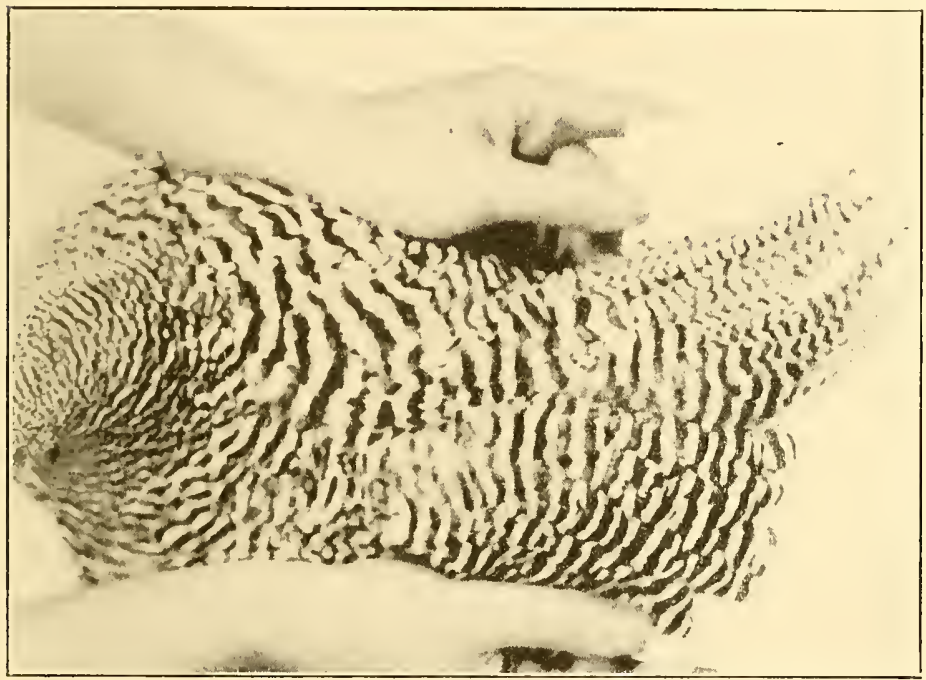

The saddle section of the female shown in Figure 31 after pieces of ovary from another individual had been engrafted. The old "male-shaped" feathers are shown at the left. On the right are seen the "hen-shaped" feathers which grew after the ovary was introduced, the old feathers having been pulled out. (After Cole and Lippincott.)

responsible for the suppression of male plumage in the female.

It is a matter of common knowledge among poultrymen that Sebright Bantam males do not have ordinary hackle or

1 Ameriean Journal of Anatomy, vol. xxiii, No. 1, and Journal of Experimental Zoölogy, vol. xxy, No. 1.

2 Proceedings of the Society of Experimental Biology and Medicine vol. $\mathrm{xr}$, pp. 3-4.

3 Journal of General Physiology, rol. i, No. 1. 
saddle feathers or long tails with sickle feathers. Their plumage is so closely similar to that of the female that they are referred to as hen feathered males. Morgan has shown that if Sebright males are castrated, they grow the long hackle, saddle and tail feathers which are typical of capons of breeds in wh ch the male is not hen feathered. Boring and Morgan ${ }^{1}$ have shown that the testes of Sebright males carry lutear cells which are identical with those found in the corpus luteum of the ovary of the hen by Boring and Pearl. It appears probable that the agent of suppression is a secretion from these lutear cells.

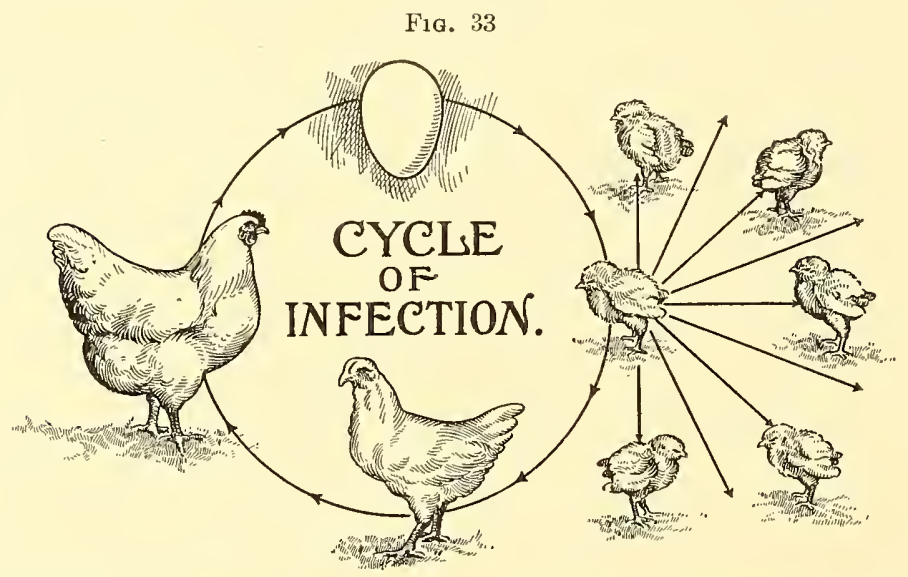

Showing how bacillary white diarrhea perpetuates itself in the breeding stock.

Inheritance of Disease.-While the statement that infectious poultry diseases are heritable is technically incorrect, practically it has a substantial basis in fact. The most conspicuous example is found in the life history of the organism causing contagious white diarrhea. When a female chick is infected with the disease and makes a recovery it becomes a bacillus carrier. According to Rettger, Kirkpatrick, and Jones, ${ }^{2}$

\footnotetext{
I Journal of General Physiology, vol, i, No. 1.

2 Storr's Bulletin No. 77.
} 
the organisms may never be entirely eliminated from the pullet's body, and as she develops, some of them migrate to her ovary. They may also reach the ovary from the alimentary tract when they are taken in with food through the mouth. They there enter the developing yolks and remain until the yolks are discharged from the ovary, fertilized, and laid. If such eggs are incubated and hatched the organisms are very likely to find their way into the alimentary tract of the chick during embryonic life and multiply to such an extent that the chick will have contracted the disease before exclusion from the shell. Such a condition corresponds somewhat to intra-uterine infection in mammals. It might perhaps be properly termed intra-ovarian infection. The point is, however, that while technically the young creature contracts the disease by infection from the mother, practically the disease is transmitted from mother to the food-supply of the potential offspring before laying or even ovulation occurs. These same investigators found that "more than 25 per cent of the pullets that were artificially infected as chicks became permanent bacillus carriers."

The same condition might be found in the case of any infectious disease that involves the ovary or oviduct. Thus if a hen with a tubercular oviduct should lay, the likelihood is that chicks hatched from her eggs would be tubercular. This does not often occur, because a bird with a diseased oviduct seldom lays.

The Male Generative Organs and Caponizing.- The essential generative organs of the male bird are the testicle, the tube leading from it to the cloaca, and the small papilla placed near the margin of the cloacal opening and serving as an organ of copulation. Each of the three organs is paired. The exact location of the testicles is of interest in connection with the reproductive apparatus of the male, because of their importance with reference to castrating or caponizing. They are placed on either side of the median line of the body just back of the lungs and below the anterior extremity of the kidneys. They are oval in shape, and at the time most favorable for caponizing are the size of a small pea. Ultimately they become so large as to inhibit their removal 
between the ribs. They are reached in caponizing by an incision between the last two ribs.

The object of castration in chickens is much the same as in other animals. Bessides the effects already noted it renders them more tractable in disposition, they are easier keepers and make more economical gains. Where it is not desirable to market the surplus cockerels as broilers, caponizing admits of rearing the males with the pullets without danger of injury to the latter, and the constant annoyance which greatly retards their development.

FIG. 34

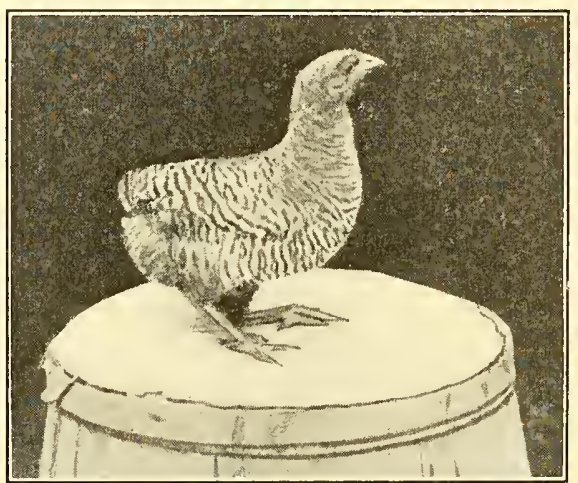

The right size for caponizing. (Courtesy of Mr. George Beuoy.)

Making Capons. ${ }^{1-}$ "Caponizing is a simple operation. Any careful person can soon learn to do it successfully. The fact that a bird's testicles are hidden away inside the body has caused most people to suppose that the operation of removing them is at once difficult and dangerous. While the percentage of loss is somewhat larger than results from the castration of the larger animals, it need not run much, if any, above 5 per cent for the beginner. One of the reasons why the number is as large as it is, may be that the bird.

${ }^{1}$ Lippincott, Kansas Circular No. 27. 
must be older, comparatively, than other farm animals before the operation can be undertaken. The birds that are killed die a quick and painless death by bleeding. They are not a total loss, as they are perfectly wholesome for food.

"It is difficult to state the exact size or age at which a cockerel may be most successfully operated upon, as different birds develop differently. As a starting-point, howerer,

FIG. 35

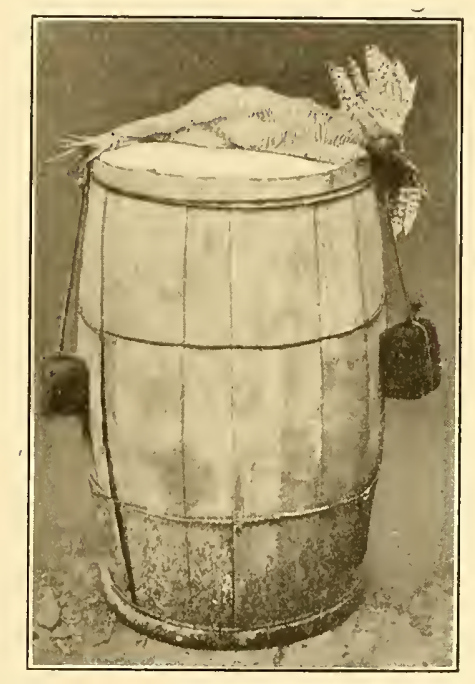

A home-made caponizing table. (Courtesy of Mr. George Beuoy.)

the beginner will be safe in using birds weighing between one and a half and two pounds if they are of the Plymouth Rock, Rhode Island Red, Wyandotte, or Orpington breeds. Leghorns weighing a pound may be used also. Later, as one becomes more familiar with the matter, the birds will be selected by their 'look' rather than by weight or age. The cockerel shown in Figure 34 is just ready. The proper time is just before he begins to make comb, when the organs are about the size of a small navy bean. 
"The tools needed are four in number, and may be purchased from any poultry supply house or veterinary instrument company at from $\$ 3$ to $\$ 6$ per set. A sharp knife is necessary for making the incision. A pocket-knife will do if it is sharp. A spreader is needed to keep the incision open

FIG. 36

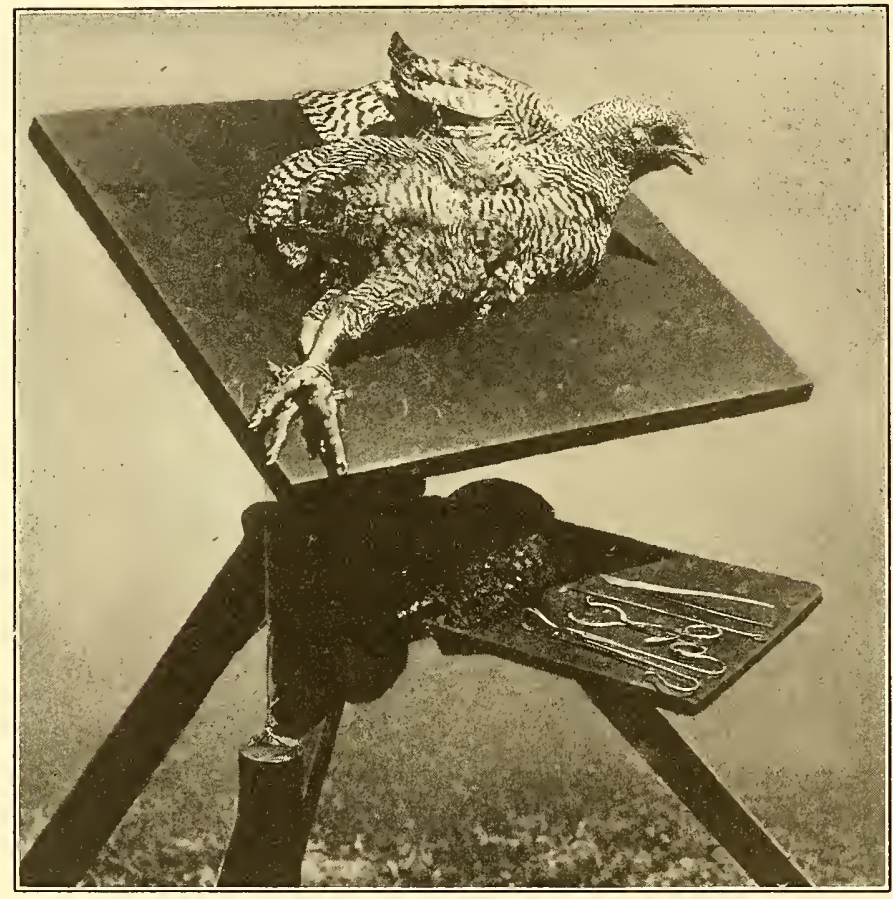

Cockerel in place on caponizing table. (Courtesy of Kansas Agricultural Experiment Station.)

while working. A probe that is blunt at one end and has a sharp bent point at the other is used in pushing the intestines aside to expose the organs and in tearing the thin membranes that surround the body cavity. And finally, there must be an instrument for removing the testicles. There are several different instruments made for this purpose, 
and it is largely a matter of preference which is used. The ones used in these illustrations are called the spoon forceps.

FIG. 37

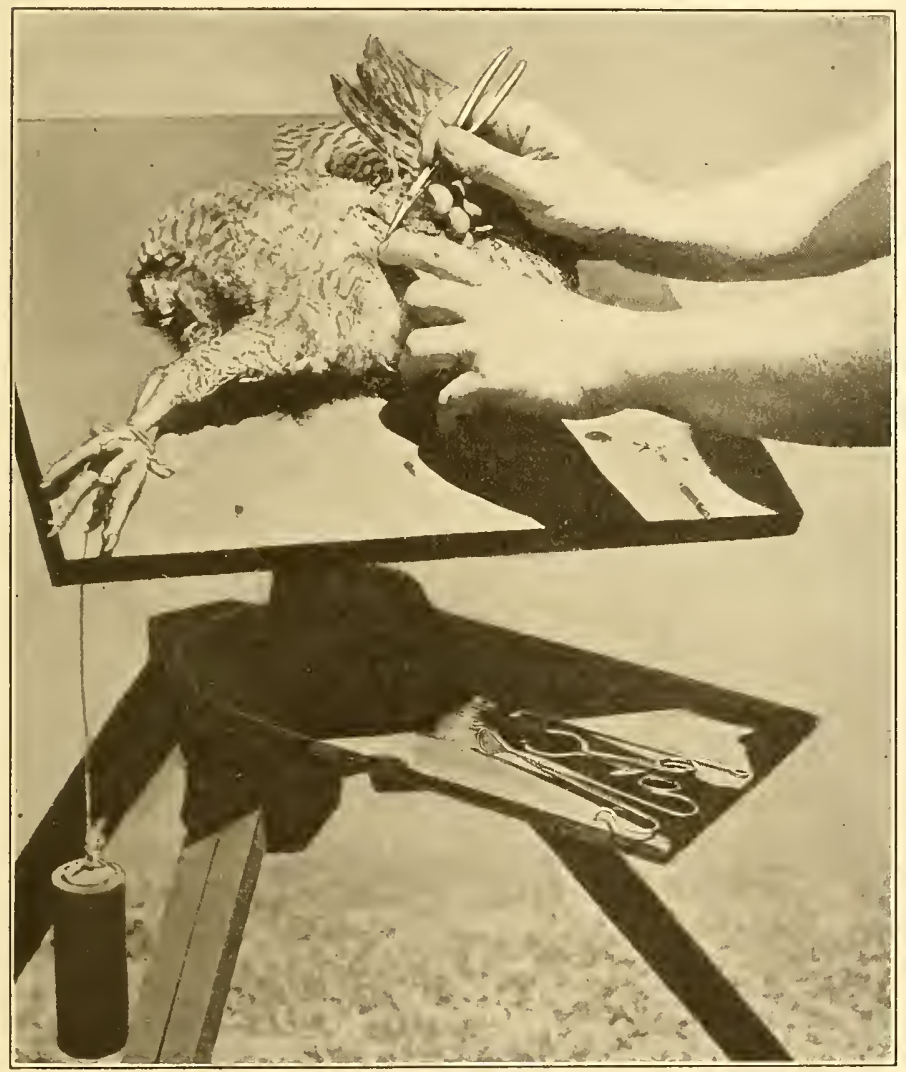

Locating the last two ribs and making the incision. (Courtesy of Kansas Agricultural Experiment Station.)

"Where one is making a business of operating it is a good thing to have a special table that can be tipped toward the light, as in Figures 36 and 37 . For home use a barrel will do nearly as well, as shown in Figure 35. In either case, what is 
wanted is something that will hold the bird firmly and well stretched out, at a convenient height. The bird is usually

FIG. 38

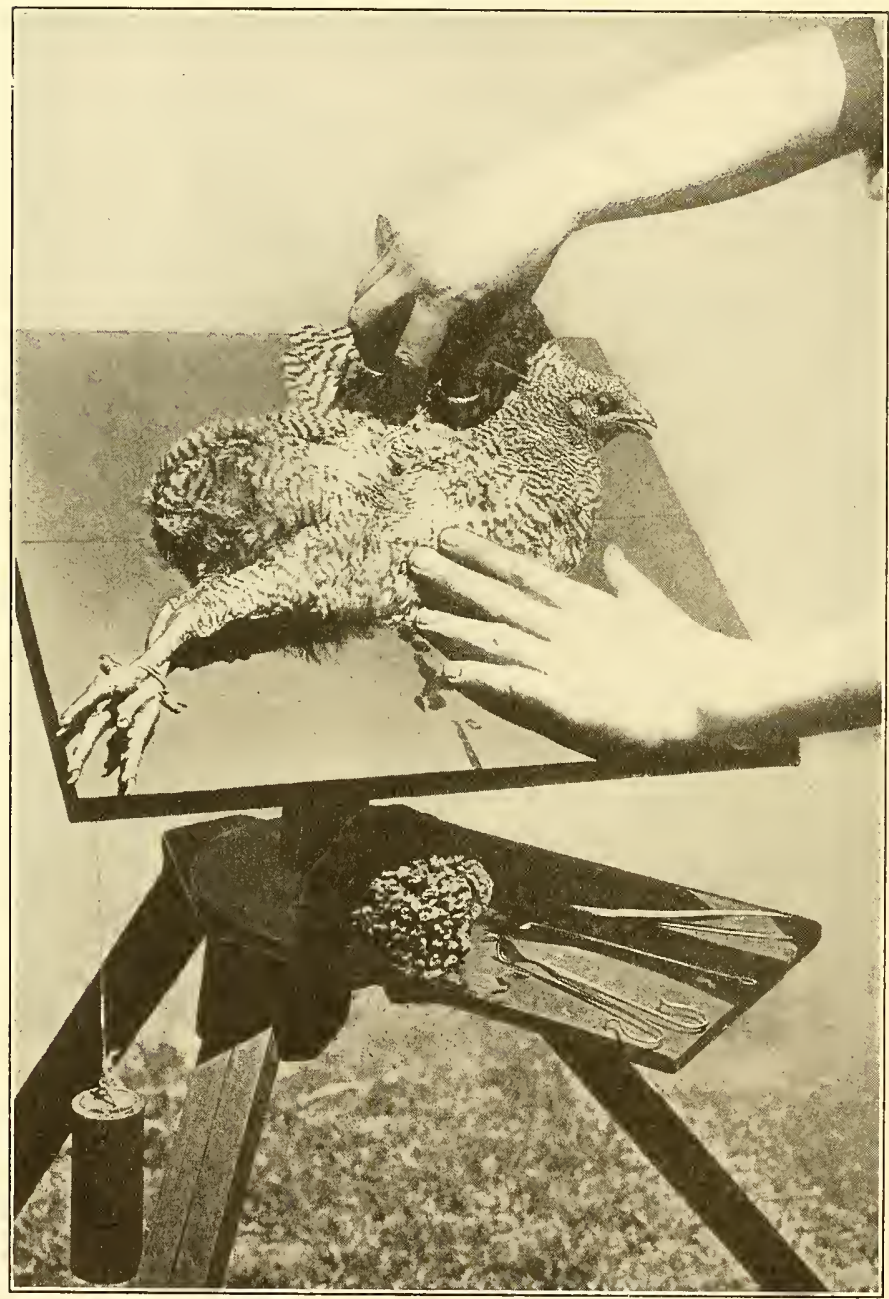

Inserting the spreaders. (Courtesy of Kansas Agricultural Experiment Station.) 
pinioned by looping weighted cords over the legs and wings, as shown in the illustrations. Previous to the operation the only preparation necessary is to keep the bird from food and water for thirty-six hours. This will allow the intestines to empty and subside, making the operation much easier and less dangerous. There will be less bleeding if water is also withheld. This must not be overlooked.

FIg. 39

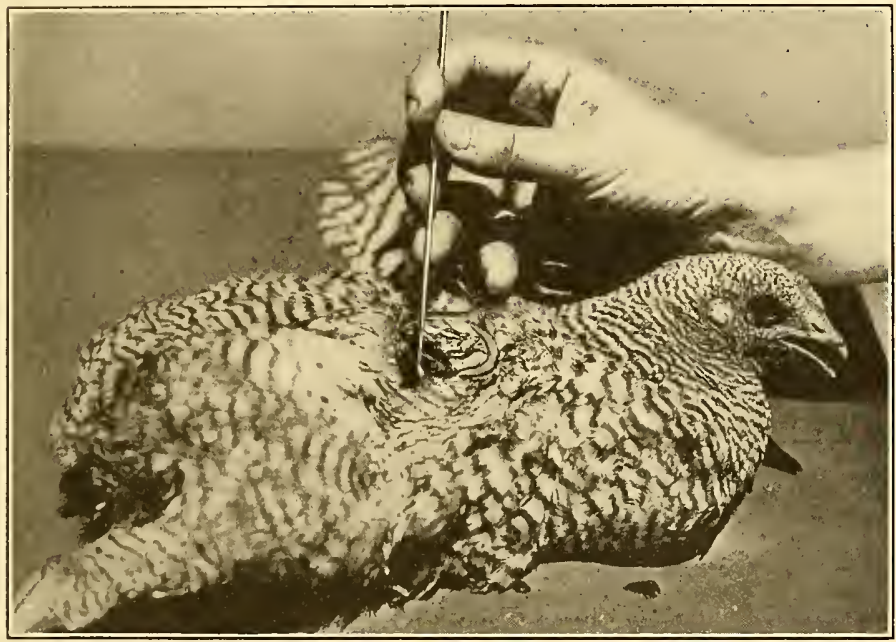

Tearing away the membranes. (Courtesy of Kansas Agricultural Experiment Station.)

"The operation may be performed from either side. A few feathers should be plucked just in front of the thigh, thus laying bare a small space just over the last rib. The surrounding feathers should be moistened to make them lie down and not interfere during the operation. The last two ribs should now be located by the forefinger of the left hand, as shown in Figure 37. Having located the ribs, pull the skin as far toward the thigh or hip as possible. (This is done so that when the operation is orer the incision in the skin will not be over the incision in the flesh, as shown in 
Figure 42.) Then pinch the skin with the thumb and forefinger to drive out as much blood as possible. Now make the incision, being careful to follow the space between the ribs. If the bird has been properly starved, there will be no danger of cutting the intestines. The first incision need not be over a hali-inch long. Then take the spreaders and insert as is being done in Figure 38. Be sure to see that each hook of the spreader is against a rib. Spread the incision as far as possible

FIG. 40

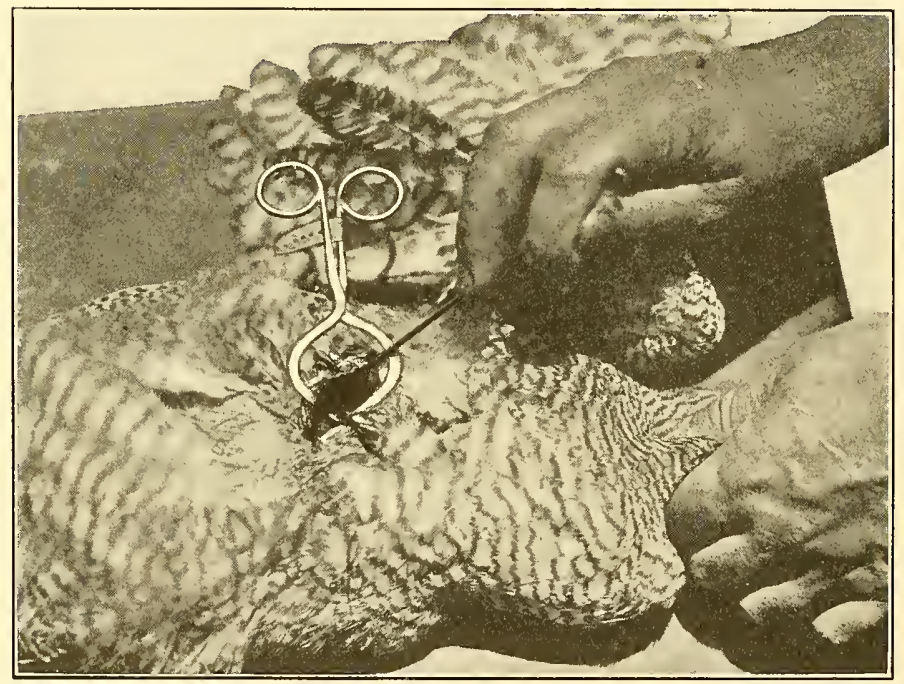

Testicle shown in place between jaws of the spreader. (Courtesy of Kansas Agricultural Experiment Station.)

without tearing the flesh. Then follow up between the ribs with the knife, lengthening the incision until the spreaders may be opened to their limit, as shown in Figure 39. Then with the hooked end of the probe tear away the thin, papery membranes that cover the intestines, as shown in Figure 39.

"When this has been done and the intestines pushed aside, the testicle will be in plain sight. In a bird of the proper age it will be a rich creamy yellow and about the size and shape of a small bean. In very young chicks whose sex can just 
FIG. 41

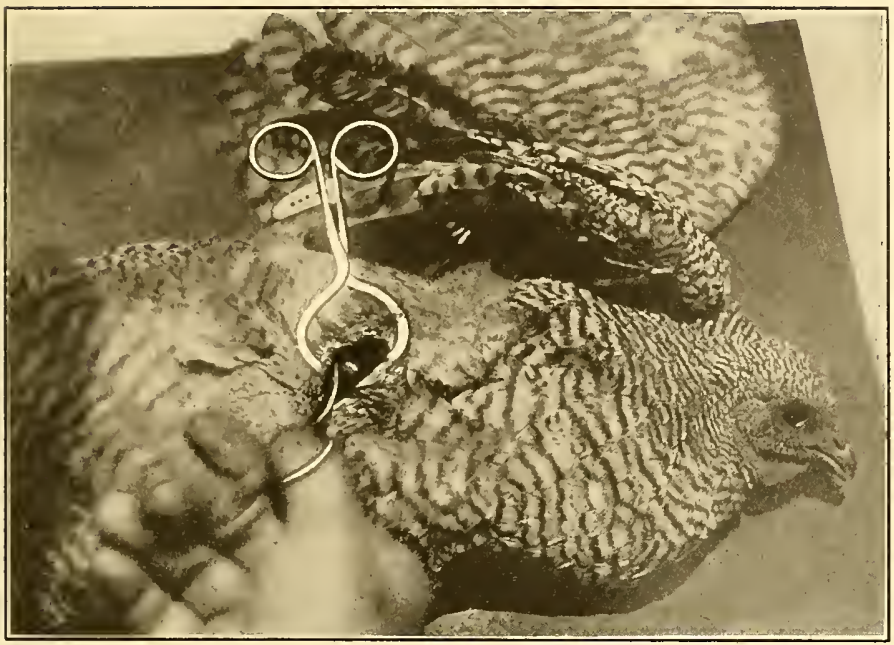

Removing the testicle. (Courtesy of Kansas Agricultural Experiment Station.)

FIg. 42

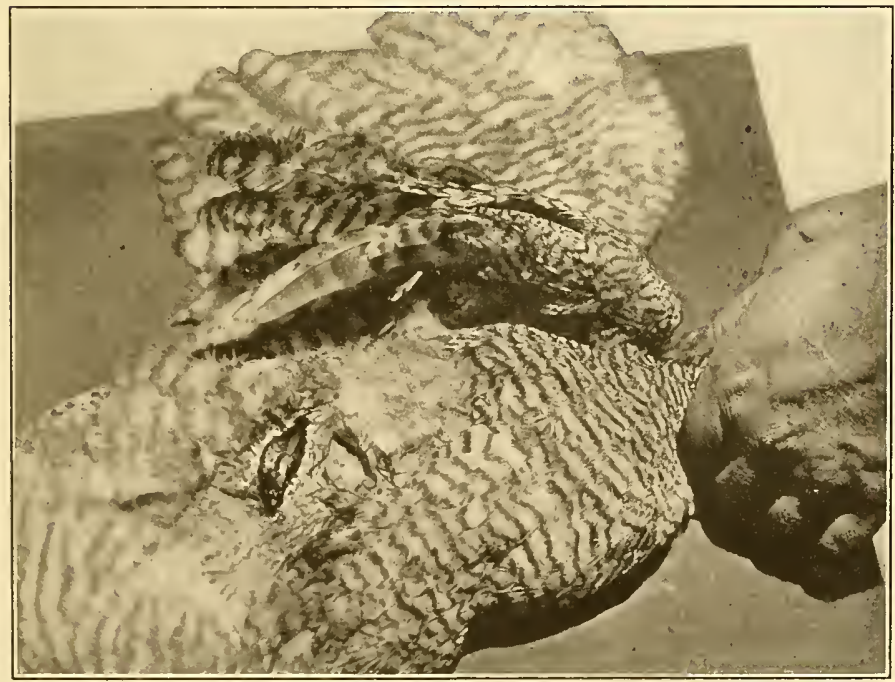

After the operation. (Courtesy of Kansas Agricultural Experiment Station.) 
be told it is scarcely larger than a grain of wheat. The testicle may be seen in position in Figure 40. It is almost between the jaws of the spreader and is glistening in the sunlight.

"Just above it the kidneys are located, but cannot be seen in the picture. Passing over the kidneys is a large bloodvessel, which constitutes practically the only source of danger during the operation. If this vessel is ruptured the bird will bleed to death almost before it ean be taken from the table.

FIG. 43

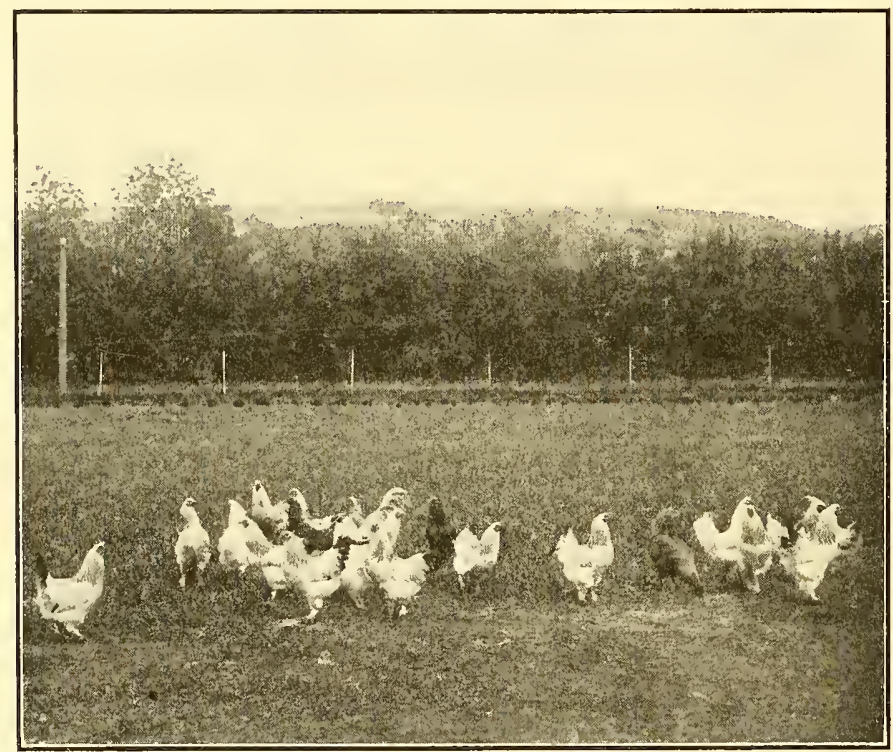

A flock of young capons. (Courtesy of Kansas Agricultural Experiment Station.)

"In Figure 41 the spoon forceps are grasping the testicle, which is still in place. The care with which the operator grasps the organ without also grasping the bloodvessel, or the tissues surrounding it, constitutes the whole trick of the operation. Having grasped the testicle, twist the forceps around a couple of times and pull them out quickly. Remove the spreaders and allow the skin to cover the opening between 
the ribs, as in lïgure 42. In ten days there will be nothing left but a shiny scar.

"It is customary to remove both testicles from one side. In that case it is better to remove the lower one first. Sometimes there is a little bleeding which would hide the lower one if the upper one was removed first. Beginners, however, will do well to make two incisions, one on each side, operating at first on a dead bird. After doing this successfully several times, one may tear away the membranes enough to see the second testicle and remove both testicles through the same incision. In fact, one may become so proficient that he can grasp both organs at once and remove them together.

FIG. 44

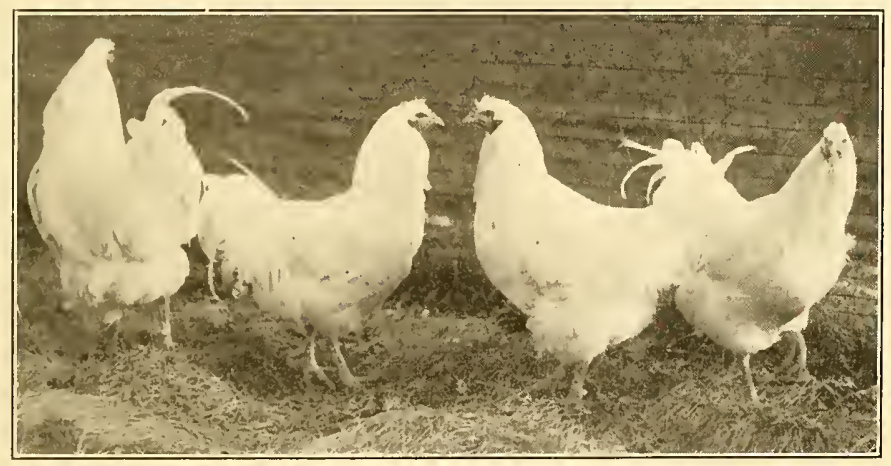

White Plymouth Rock capons. (Courtesy of Purdue Agricultural Experiment Station.)

"After the operation, the birds should be placed in a yard by themselves and fed on soft food for three or four days. After that time give them their regular rations. At the end of a week they may be turned in with the other chickens. A few of them will bloat during the first week. This is not serious, and is remedied by pricking the skin with a coarse needle or with the little blade of a pocket-knife."

Spaying of Pullets.-The spaying of pullets is not practised for two reasons: they are more profitable as egg producers than as meat producers, and there would be no economic gain in performing the operation. A further and more 
decisive reason is that because of surgical difficulties it is practically impossible to perform the operation successfully. It has been successfully accomplished a comparatively few times by trained investigators. Removing the ovary in its entirety usually results in the rupture of a large bloodvessel lying at the base of the main stock, which allows sufficient hemorrhage to cause death. If the organ is not removed perfectly clean, it has the power to regenerate from the remaining tissue and so defeat the purpose of the operation.

Time Elapsing Between Mating and Fertility.-Pearl and Surface" make note of the fact that in "Some experiments carried out by H. J. Odam of the period elapsing between mating and fertility in one case a chick was produced from an egg laid seventy-two hours after mating."

Waite $^{2}$ found that where twenty Single Comb White Leghorn pullets were mated, 50 per cent of the eggs laid on the third day (less than fifty-four hours after mating) were fertile and 70 per cent were fertile on the fourth day.

In mating eighteen Rhode Island Red pullets and one White Plymouth Rock cockerel, he found that the four eggs laid on the seventh day were all fertile. In still another test with these same breeds, eight eggs laid on the eighth day were all fertile.

In a test with Single Comb White Leghorn hens mated to cockerels, carried out by Townsley and reported by Philips, ${ }^{3}$ the first fertile egg was gathered twenty-three hours after a single mating. The detailed data are shown in Table XIV. It will be noted that the eggs were not 100 per cent infertile until the sixteenth day after the mating occurred.

Judging from common experience in addition to the foregoing, it seems safe to state that in practice it will be found that eggs laid by vigorous hens will usually be fairly fertile in six days in the case of Mediterranean breeds, and eight to ten days in the case of the American breeds, while two weeks is necessary in the case of pullets, assuming in each case that the male is vigorous and active.

1 Maine Bulletin No. 168.

2 Maryland Bulletin No. 157.

3 Jour. Am. Assn. Inst. and Invest. in Poul. Husb., vol. iv, No. 5. 
Cessation of Fertility.-In experiments with twenty Single Comb White Leghorn hens, Waite ${ }^{1}$ found that fertility held up well for eleven days, and one egg was found to be fertile after the male bird had been removed for twenty days. Bittenbender ${ }^{2}$ reports a Barred Plymouth Rock hen that produced a fertile egg seventeen days after the removal of the male. Townsley and Philips results are shown in Table XIV.

Sherwood ${ }^{3}$ reports one Barred Plymouth Rock hen that produced one fertile egg on the twentieth day after the mating was broken up; four White Leghorn pullets that produced fertile eggs on the nineteenth day; two Leghorn hens that laid fertile eggs on the eighteenth day after the male bird was removed. He found that the fertility held up well with the Plymouth Rock hens for twelve days, while the Leghorn pullets' eggs decreased markedly in fertility on the tenth day, as did also those of the Leghorn hens.

After the end of the third week, according to Lillie, ${ }^{4}$ the vitality of the spermatozoa is reduced. Eggs laid during the fourth and fifth week after the removal of the male may exhibit an abnormal cell division, which soon ceases.

In practice a period of at least three weeks is necessary to rid the oviduct of active spermatozoa and insure a cessation of the influence of a previous mating.

Influence of Previous Impregnation.-The fact that eggs remain fertile for days and even weeks after the removal of the male, combined with other circumstances, has led to a somewhat common belief that the influence of an impregnation is often permanent. A common illustration is found in the idea that if a pure white hen is once mated with a pure black male the offspring of a subsequent mating with a pure white male, which may occur the following season or even two or three years later, are likely to show black feathers, as the result of the previous mating with the black male.

As a matter of fact, black feathers are a frequent occurrence in the offspring of pure white birds that have never

1 Maryland Bulletin No. 157.

2 Unpublished data, Iowa State College.

${ }^{3}$ Ibid., Ohio Experiment Station.

4 Development of the Chick. 
been mated with anything but pure white birds. With other animals all efforts to secure a permanent influence of any sort from a previous impregnation have uniformly failed. There is no reason to believe the results would be different with fowls.

Maternal Impressions.-In chickens the claims of prenatal influence or the registering of maternal impressions are largely confined to color. One not infrequently hears the claim that yellow-painted buildings about the premises where the fowls spend much of their time tends to induce creaminess or brassiness in the feathers.

Experimentally, it has beer imposible to produce such effects. Brassiness seems to appear only when fowls are allowed to be in the sun. It is posibibly a sort of sumburn. Creaminess is usually the result of tril in the feathers and may be increased by feeding yellow com or green feed freely.

In this connection it should clearly understood that while maternal impressions do not appear in the offspring in kind, both the maternal and paternal vigor and physical thrift have very much to do "with thrifty offspring.

\section{BREEDING IETHODS.}

In general, breeding is carried on in the hope of securing improvement in one of three ways: (1) by transferring the valuable characteristics of an improved breed to common stock; (2) by impressing the excellencies of superior individuals on other families within the breed, so as to produce a higher average excellence in them than on the average is possessed by the breed itself; (3) by securing a new association of characteristics, that is, producing a new breed. The first is the way of the producer and the method is grading. The second is that of the breeder and the method is "line breeding." With the third, the method is cross-breeding.

Grading.-By grading is meant the practice of mating standard-bred males with mongrel or relatively unimproved females. 'Technically speaking, the reciprocal cross is also grading, but, practically, it need not be considered.

Grading is the method of the producer because it lends itself most readily to his purpose of securing "as many off- 
spring as possible, as good as possible, and at the least cost." It is not only the easiest and cheapest form of breeding, but also produces the most rapid improvement. For market purposes, grades are often the equal of standard-breds. For breeding purposes, grade males are usually worthless.

The theoretical rapidity with which the characteristics of an improved breed are transmitted to progeny out of the mongrels is illustrated in Figure 45. The percentages given in each generation represent the hereditary constitu-

FIG. 45

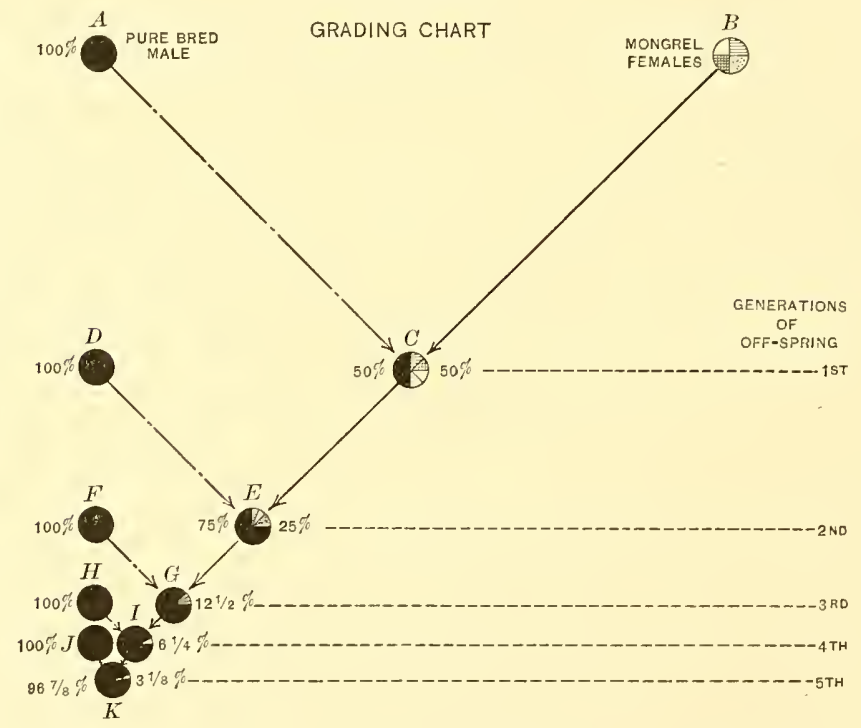

tion of that generation with reference to the "blood" of both the standard-bred bird and the mongrel. Of course, the word "blood" does not imply the real blood of the animal, but is a term used by the breeder to designate the sum total of the hereditary characteristics. The actual results are shown in Figures 46 to 49 , and in Table XV.

It should be clearly understood that only when the male is of a breed distinctly different from any represented in the females and only in the first generation of the cross, does 
the percentage given in the table directly represent anything of the hereditary constitution of the individual. After that there will be great variability in the characteristics transmitted by the females and only in the terms of averages of numerous progeny will the percentages hold true.

In Figure 45, "Standard blood" is represented by black and "mongrel blood" by a mixture of lacing, white, stippling, and barring in the various circles. Thus the circle " $\mathrm{A}$ " represents a bird that carries 100 per cent "pure blood" and the circle "B" 100 per cent "mongrel blood," or a mixture of laced, white, stippled, and barred varieties. From the nature of the case, "A" "represents a male and " $B$ " a group of females. When mated together the offspring shown at " $\mathrm{C}$ " will carry 50 per cent each of standard and of mongrel blood. If females from group " $\mathrm{C}$ " are now mated with another "standard" bred male, "D," the offspring, "E," will on the average carry 75 per cent "standard blood" and 25 per cent "mongrel blood."

By using standard-bred males as indicated in the chart, the chances of the appearance of the mongrel characteristics in the fifth generation, as shown at " $K$," would be $3 \frac{1}{8}$ out of 100 , and the chances in the following generation not indicated in the chart would be $1 \frac{9}{16}$ out of 100 . In the early history of many of the pure breeds of live stock the sixth and seventh cross, as here shown, were admitted for registry.

\section{LEGENDS FOP FIGURES 46, 47, 48 AND 49.}

Fig. 46.-Mongrel hens, mothers of pullets shown in Figure 47, by a S. C. W. Leghorn sire. Egg records and lines of descent are shown in Table XV. (Courtesy of Kansas Agricultural Experiment Station.)

Fig. 47.-First generation of S. C. W. Ieghorn grades. Daughters of mongrels shown in Figure 46 by a S. C. W. Leghorn sire. Mothers of pullets shown in Figure 48 by a S. C. W. Leghorn sire. Lines of descent and egg records are shown in Table XV. (Courtesy of Kansas Agricultural Experiment Station.)

FIG. 48.- Second generation of S. C. W. Leghorn grades. Daughters of females shown in Figure 47 by a S. C. W. Leghorn sire. Mothers of pullets shown in Figure 49 by a S. C. W. Leghorn sire. Lines of descent and egg records shown in Table XV. (Courtesy of Kansas Agricultural Experiment Station.)

FIG. 49.-Third generation of S. C. W. Leghorn grades. Daughters of females shown in Figure $48 \mathrm{by}^{+}$a S. C. W. Leghorn sire. Lines of descent and egg records are shown in Table XV. (Courtesy of Kansas Agricultural Experiment Station.) 
Fig. 46
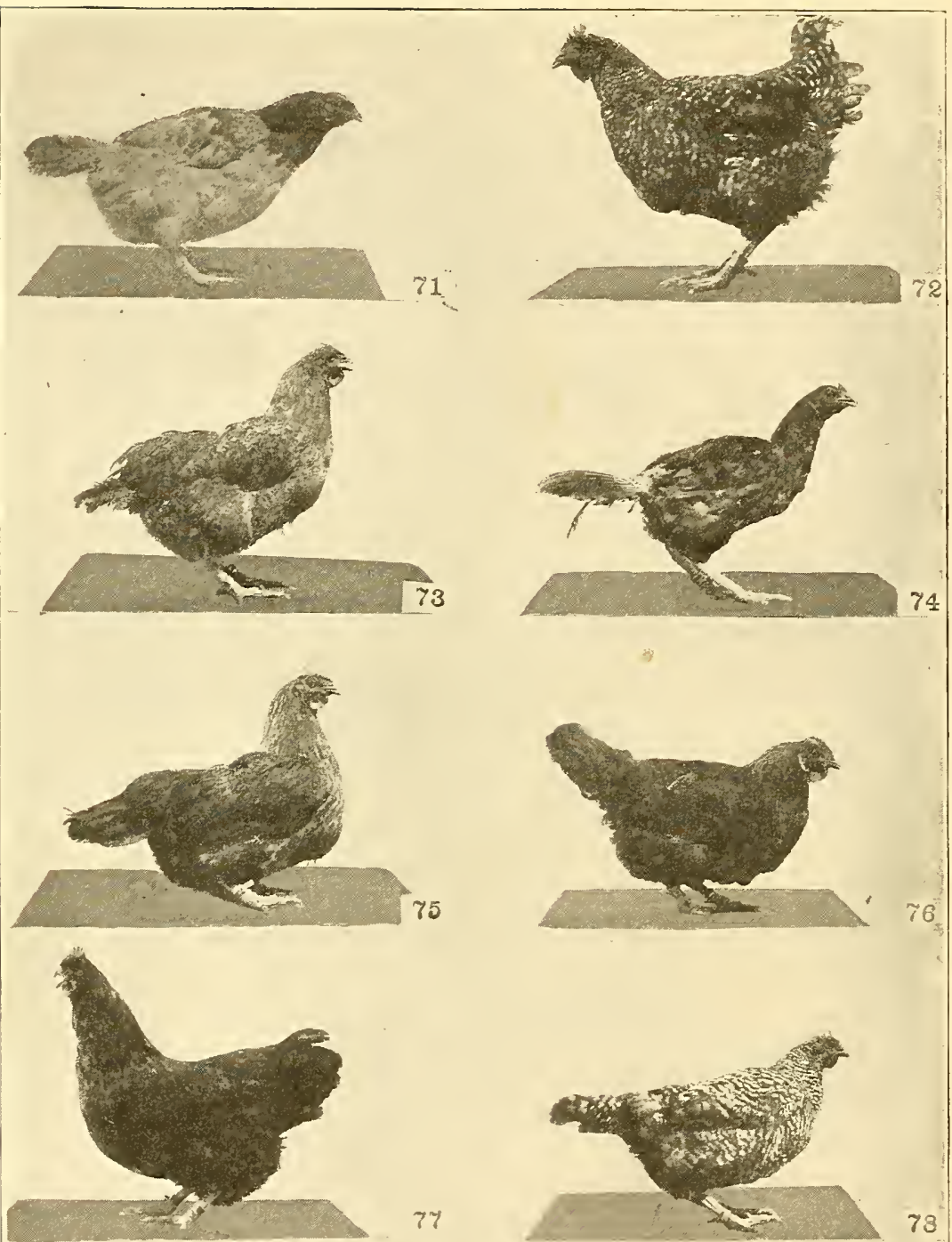

$7 \%$

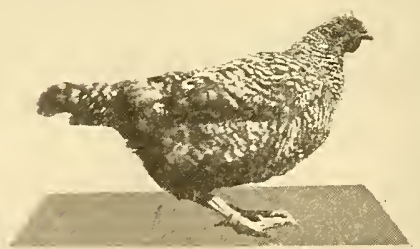

78
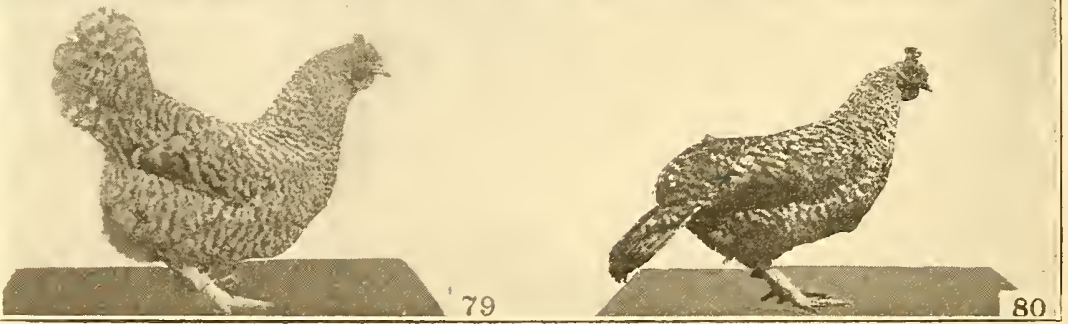
FIG. 47

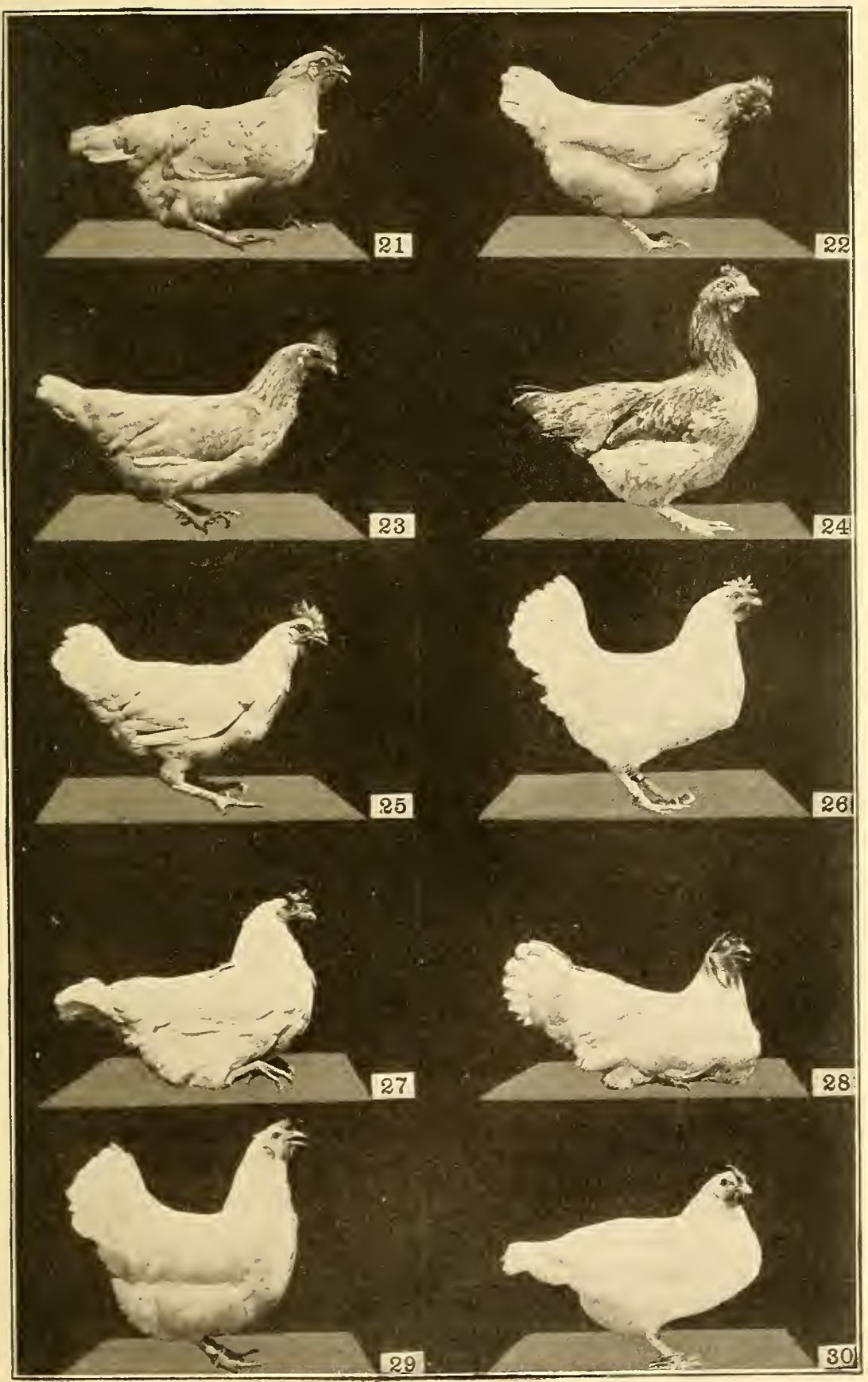


FIG. 48

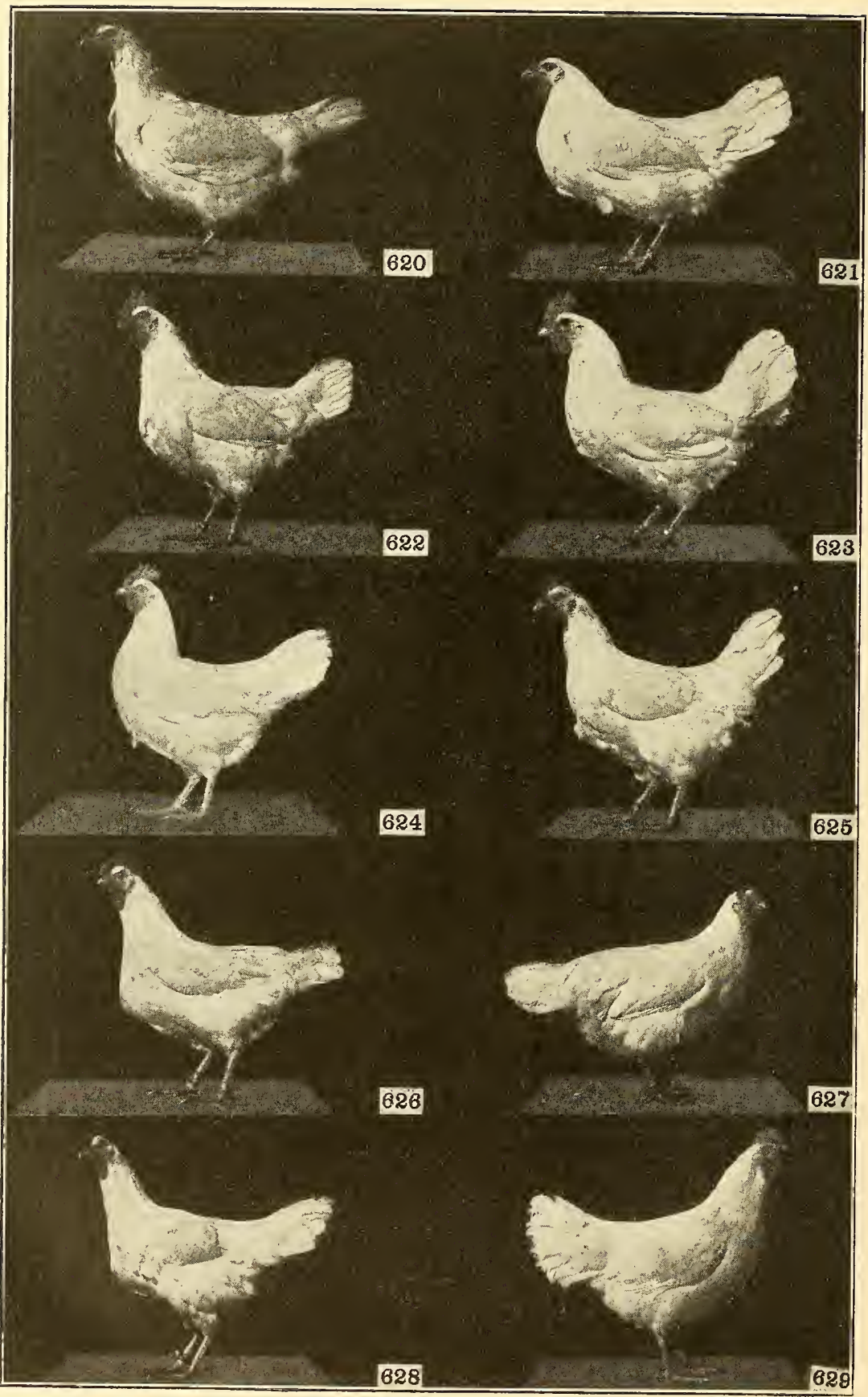




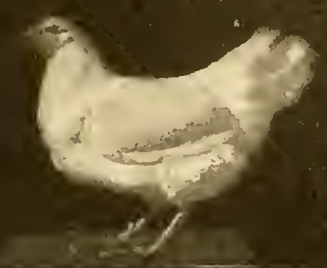

B70
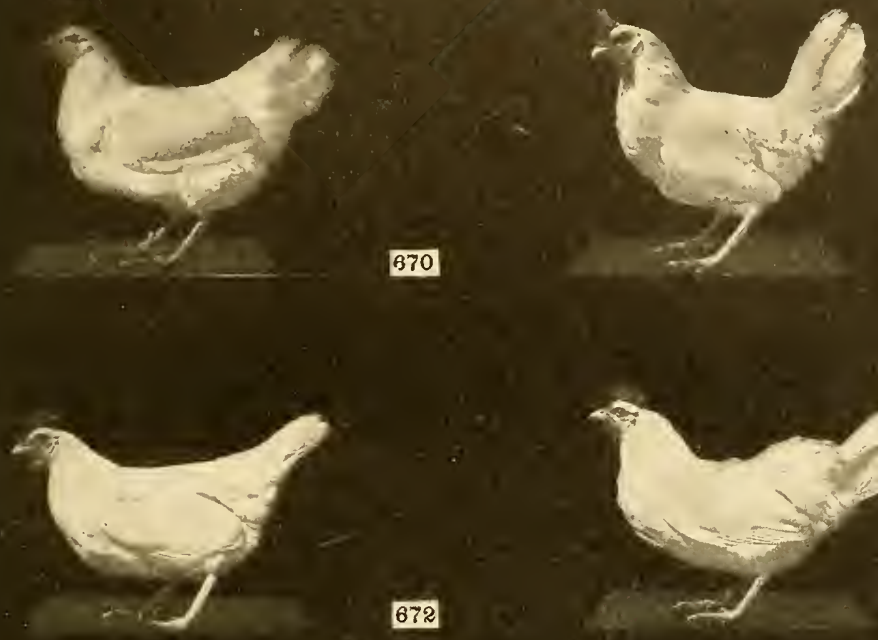

672
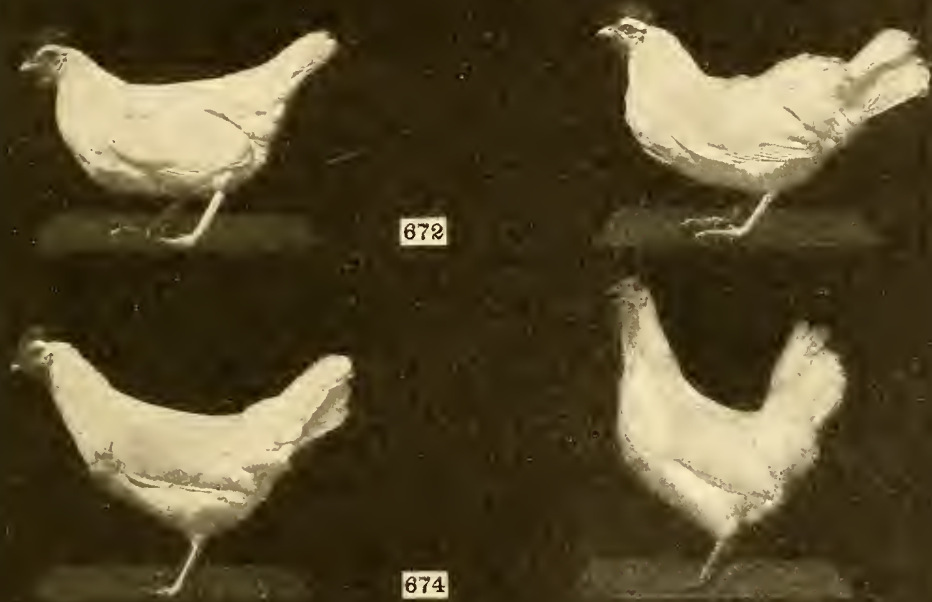

674
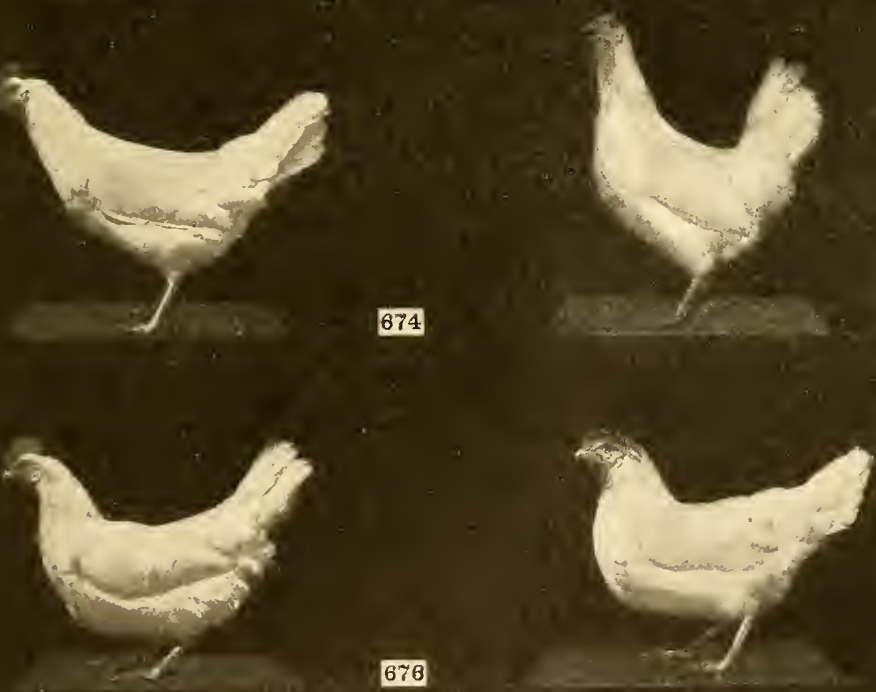

676
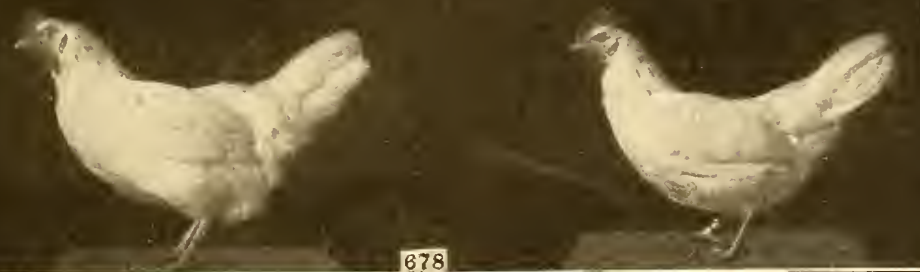


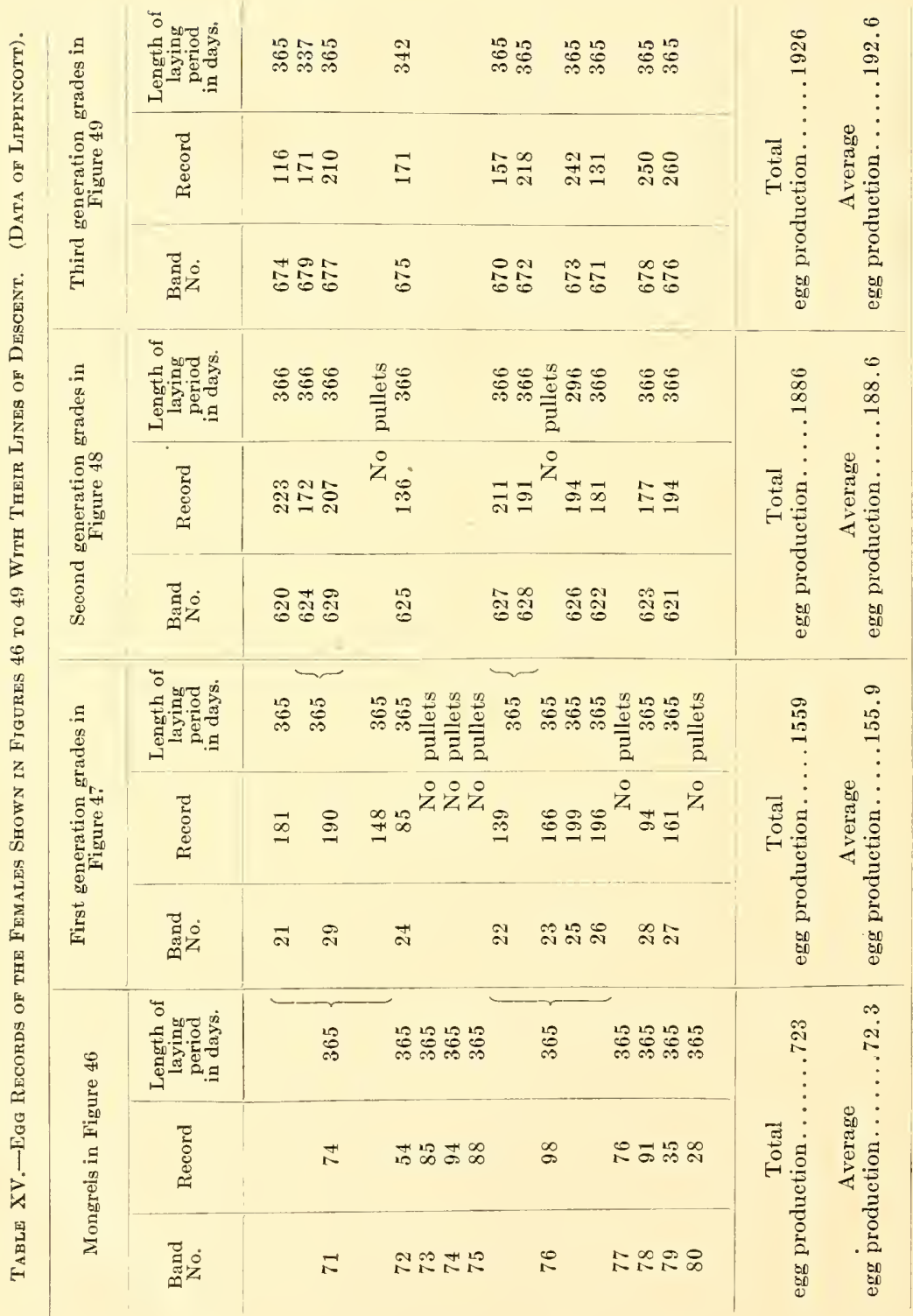


The actual improvement with regard to uniformity runs rather in advance of the percentages shown in the chart after the first cross, as shown by Lippincott ${ }^{1}$ and illustrated in Figures 46 to 49 . Furthermore, standard-bred males are prepotent over mongrel females in most characteristics. Prepotency is the breeders term for the superior power which one parent has over the other in determining the character of the offspring. It increases with (1) standard breeding, (2) line breeding, and (3) long-continued breeding, because each of these tend automatically to produce purity in a given character.

FIG. 50

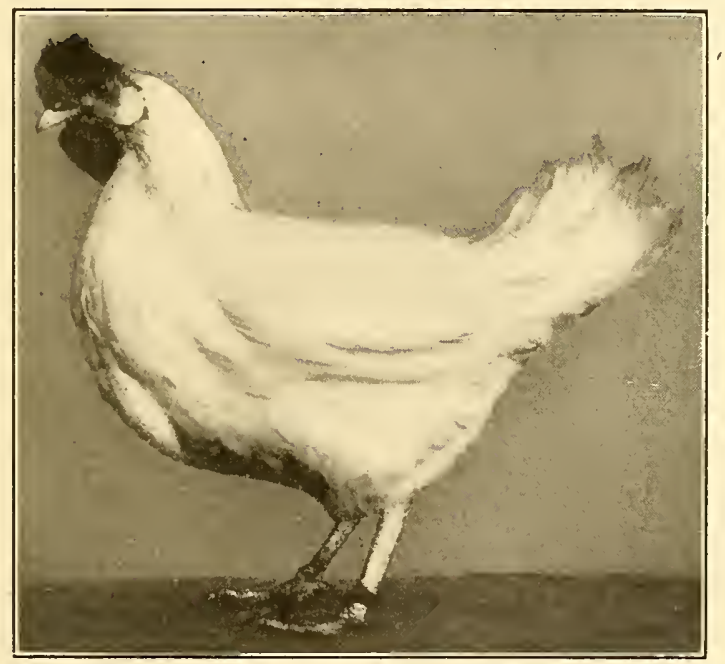

A hen carrying seven-eighths Single Comb White Leghorn blood whose egg record is 303 in twelve months and 505 for twenty-four months. (Courtesy of Oregon Agricultural Experiment Station.)

If only individuals of the highest constitutional vigor are used, improvement will be found still more satisfactory if the pure-bred males used from year to year are members of the same family as well as members of the same breed. The reasons for this are discussed under "line breeding." 
Danger of Grading.-The weakness of grading as a practice lies in its success as a method. Because in the second or third generation males are produced that very closely approach standard, line-bred birds in appearance, the temptation is to use them for breeding purposes rather than to purchase, first cost considered, a relatively expensive standard-bred bird. When this is done improvement usually stops and the ground gained will be at least partially lost.

Thus, if in Figure 45 the offspring of $C$ and $D$ appear to be fairly uniform, the breeder may yield to the temptation to use a fine-looking cockerel from group $E$. The offspring on the average carry 25 per cent mongrel blood instead of 12.5 per cent, as indicated at $G$ and is therefore no improvement over $E$. In fact, in appearance many of them will not be as good, because the offspring $E$ has the benefit of the characteristics transmitted by a standard-bred sire. A grade sire is no more prepotent than the grade females he is mated with. The result is that instead of tending to become more uniform the offspring will be less so.

Inbreeding and Line Breeding.-Authorities differ on the distinction between these terms. In a recent exhaustive study of inbreeding Pear ${ }^{1}$ suggests that most definitions of inbreeding have been based on practical expediency rather than on careful analysis of the problem. He defines inbreeding as the reduction of the number of possible different ancestors in any generation or generations. This is, of course accomplished through the mating of individuals more or less closely related.

Line breeding is a special form of inbreeding in which the number of possible different ancestors of a given bird is reduced in such a way as to increase the number of appearances of a certain ancestor in its pedigree.

The difference between line breeding and inbreeding is shown in Figures 51 and 52 .

In the third ancestral generation, as shown in Figure 51, birds $A, B, C, D$, each appear twice and the number of ancestors of $K$ is thereby reduced one-half. That is to say, $K$ has only four different individuals as grandparents 
instead of the supposedly normal number, eight. This is the mating of relatives and is, therefore, inbreeding. Because no one of these birds appears in the pedigree of $K$ oftener than any other of the same generation, no line breeding has been done.

Fig. 51

$$
K\left\{\begin{array}{l}
I\left\{\begin{array}{c}
E\left\{\begin{array}{l}
A \\
B
\end{array}\right. \\
F\left\{\begin{array}{l}
A \\
D
\end{array}\right.
\end{array}\right. \\
J\left\{\begin{array}{l}
G\left\{\begin{array}{l}
C \\
B
\end{array}\right. \\
H\left\{\begin{array}{l}
C \\
D
\end{array}\right.
\end{array}\right.
\end{array}\right.
$$

Illustrating inbreeding that is not line breeding.

In Figure 52 the number of ancestors is also reduced by half and the intensity of the inbreeding of $L$ is exactly the same as that of $K$ in Figure 51. A notable difference, however, arises in the fact that each blood line of $L$ runs back to $A$ as a sire in Figure 52. $L$ is therefore said to be line bred with reference to $A$.

$$
\text { LIG. } 52\left\{\begin{array}{c}
\text { F }\left\{\begin{array}{c}
A \\
B
\end{array}\right. \\
\text { G }\left\{\begin{array}{l}
A \\
C
\end{array}\right. \\
K\left\{\begin{array}{l}
H\left\{\begin{array}{l}
A \\
D
\end{array}\right. \\
I\left\{\begin{array}{l}
A \\
B
\end{array}\right.
\end{array}\right.
\end{array}\right.
$$

Illustrating inbreeding that is line breeding.

Line breeding is as near as the poultry breeder can come to securing the benefits of asexual reproduction, which the horticulturist secures through cuttings. If an unusually fine tree makes its appearance among seedlings it is preserved and multiplied by asexual means, and thus "the blood" is transmitted to the next generation in perfect purity. This 
cannot be done in the case of a correspondingly unusual bird. The nearest that the poultry breeder can approach this is by mating such a bird to its own progeny and founding a family whose blood lines carry a preponderance of its influence.

The purpose of line breeding is to purify and render permanent in the breed some highly desirable quality or qualities of an individual or family.

In somewhat the same way that the continued use of standard-bred males raises the average quality of a flock of mixed breeding by fixing standard-bred qualities, the continued mating of an unusually excellent breeder with offspring of his or her own get, or even a more indirect introduction of that individual's blood, tends to raise the quality of further offspring to as high grade of excellence as either of the original parents, by fixing the characters of the parent whose blood is most desired.

Felch's Breeding System.-A well-known practice in poultry breeding is that represented in the very excellent chart adapted by Pierce from one worked out by Felch, a veteran Light Brahma breeder, and shown in Figure 53.

In this chart the breeding operations are represented as beginning with a pair of unrelated birds which are indicated by the circles " $A$ " and " $B$." Throughout the diagram, solid black indicates the average proportion of blood of the original male $A$. In the same manner, white always indicates the average proportion of blood from the original female $B$.

Thus the members of group $C$, which are offspring of the original pair, will on the average receive half of their inheritance from each parent. If a pullet from group $C$ is now mated with her sire $A$, the resultant offspring represented at $D$ will, on the average, carry 75 per cent of the characteristics of the original male. If now a pullet from group $D$ is mated with the original sire $A$, the progeny represented at $F$ will, on the average, carry 87.5 per cent of the characteristics of the original male and but 12.5 per cent of those of the original female.

In exactly the same way males from groups $C$ and $E$ may be mated back to the original female $B$ with corresponding results. 
While Felch's system is commonly spoken of as line breeding, it is only with reference to the individuals shown in the outside lines of Figure 53 that true line breeding takes place.

\section{Fig. 53}

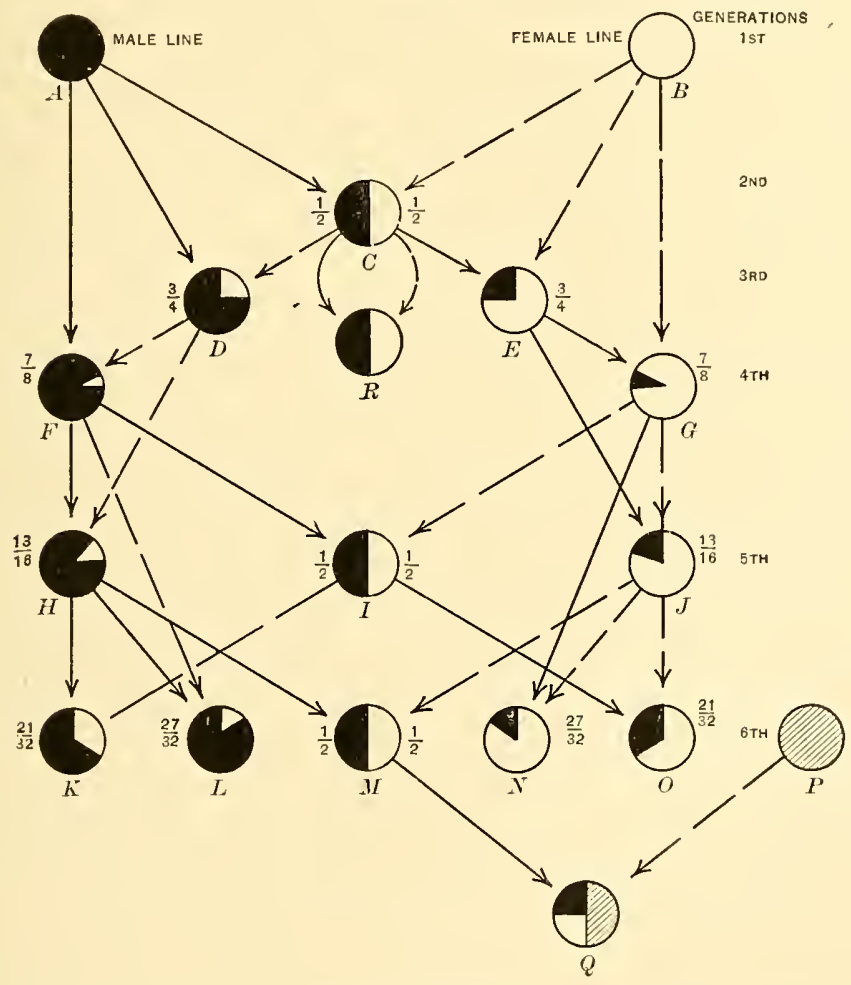

Breeding chart, after Felch and Pierce. (Courtesy of Breeders' Gazette, Chicago.)

The mating of the two extreme lines to produce the groups at $I$ and $M$ averaging half the blood of the sire $A$ and half the blood of the dam $B$ simply represents other methods of getting the results of the first cross, or of a brother and sister 
mating from group $C$ shown at $R$ without, however, having them directly connected genetically.

Danger of Line Breeding.-As in grading, danger lies in the temptation to use as a breeder a grade male that "looks good", so in line breeding the danger lies in trusting in the efficacy of line breeding, in and of itself, and in continuing to mate relatives after they have ceased to "look good." Inbreeding in any form offers opportunity for the segregation of characters, thereby not infrequently disclosing recessive poor qualities as well as tending to render pure, dominant desirable qualities. This increases directly with the closeness of inbreeding, the closest possible being that of a brother and sister mating as shown at $C$ and $R$ in Figure 53.

Few fowls are fully fertile and fewer still are both fertile and vigorous. Selecting relatives both of which approach perfection in physique is difficult. Many weaknesses are hidden, only to be discovered by disappointing experience. It is easy to mate individuals of a greater or less relationship where an unsuspected mutual tendency toward infertility will be disclosed. It is all too common to mate fowls with a more or less common ancestry, which already show the warning earmarks of a weakened constitution. The result can hardly be other than a progeny that is weaker than either parent.

Cole and Halpin ${ }^{1}$ began inbreeding Rhode Island Reds in 1913 making some matings as close as brother and sister. The selection practiced was for color and birds of wonderful color were produced. The per cent of fertile eggs hatched, however, decreased rapidly as shown by the following figures. In 1913,67 per cent of the fertile eggs hatched. In 1914 the per cent was 49 . In 1915 it was 41 per cent and in 1916 18 per cent. In 1917 not a chick could be hatched.

In 1918 a new phase of the experiment was initiated. Close inbreeding was maintained as before, but the selection was for vigor. This phase has been in progress but two years. There is so far no indication of a rapid decrease in fertility 
but the color is already going to pieces. Presumably if there were large enough numbers and selection were made for both color and vigor, both might be maintained.

It appears that the difficulty in such cases is not in line breeding as a practice, but in the skill and judgment in selection. As Marshall" puts it, "We may say of the cases (of line breeding) that have resulted unfavorably, that we should look not to the kinship of blood but the kinship of defect" for the difficulty. Thus we may also say of the successes of line breeding that they are attributable "not to the kinship of

FIG. 54

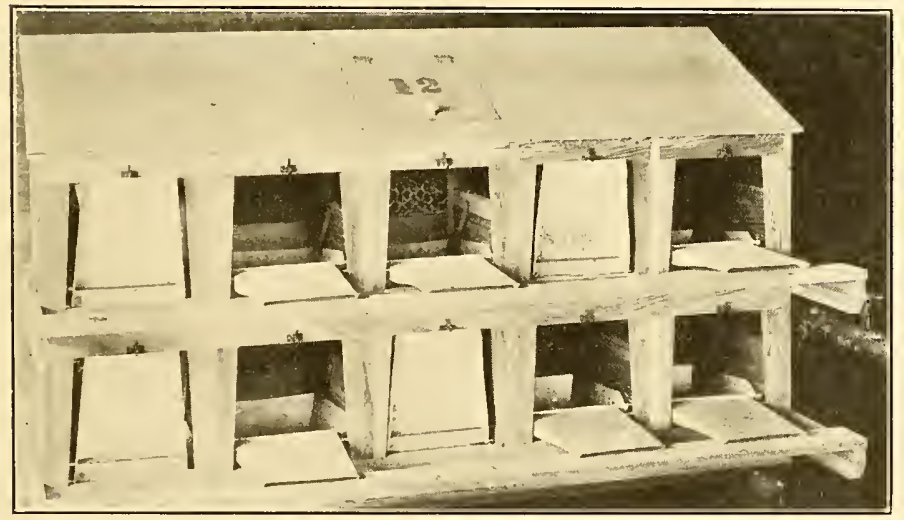

Trap-nests. Modeled on the plan of the Purdue nest. Door in top opens into wire receptacle for keeping eggs until collected for the day. (Courtesy of Kansas Agricultural Experiment Station.)

blood but the kinship of superiority. . . . Success or failure with inbreeding is clearly dependent upon selection." When vigor and hatching power are the first basis of selection, less will be heard of the evils of line breeding.

Pedigreeing.-By pedigreeing is meant keeping a complete breeding record. It involves the recording by leg-band number (or other accurate means of identification) of the male and female mated together, the recording on each egg

1 Breeding Farm Animals. 
with the aid of the trap nest, of the number of the hen laying it, of so arranging the eggs in the incubator by means of pedigree trays, small covered wire baskets, or sacks of mos-

FIG. 55

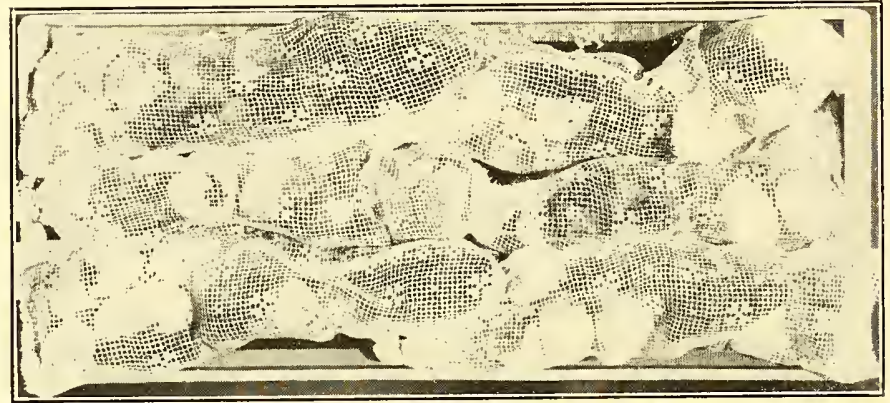

Incubator tray of pedigree sacks full of chicks. (Courtesy of Kansas Agricultural Experiment Station.)

quito-barring or curtain netting, that each chick as it hatches will be enclosed with a label identifying it with its dam,

FIG. 56

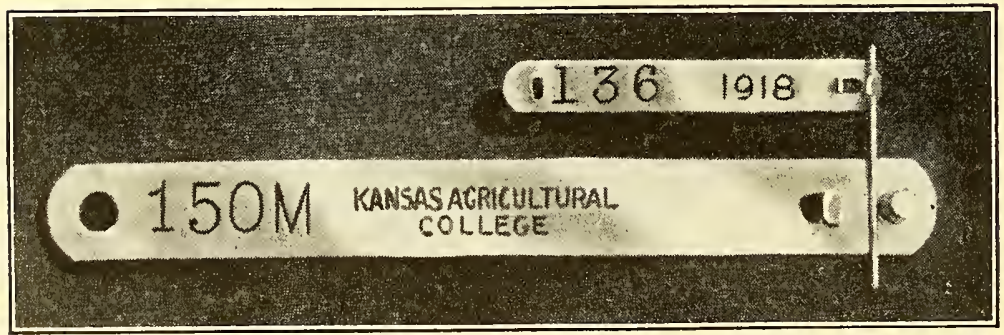

Wingband and legband used as markers for identifying individual birds. The legbands placed on males always have the letter $M$ following the numeral.

numbering each chick by means of a wingband and recording it in a chick index. Later an adult band is placed on the leg, the latter also being recorded in the chick index. Besides 
this, there must be a flock breeding record, corresponding to the herd book of the larger farm animals, by means of which pedigrees may be traced. Such a program is within the reach

FIG. 57

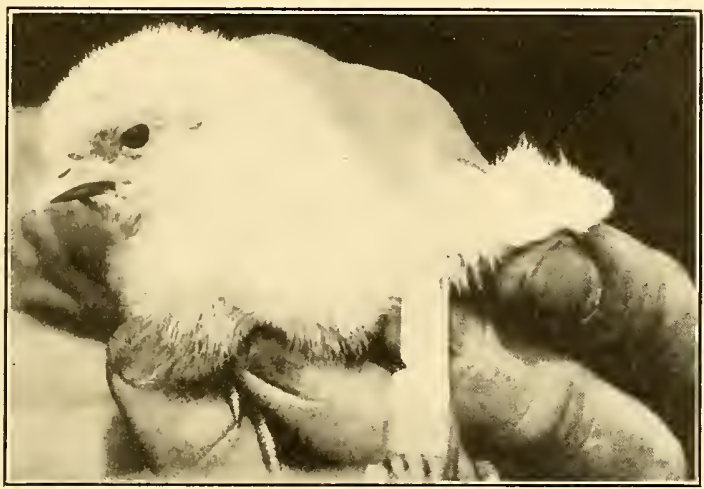

Making the incision for the wing band in the web of the wing of a newly hatched chick. (Courtesy of Kansas Agricultural Experiment Station.)

Fig. 58

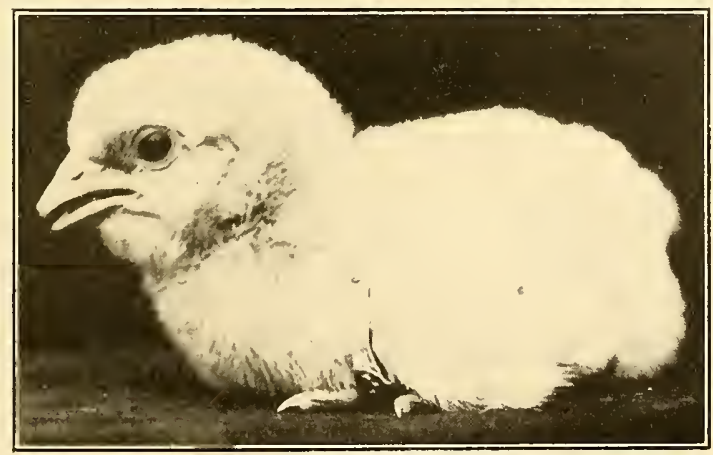

The wing band in place on a newly hatched chick. (Courtesy of Kansas Agrieultural Experiment Station.)

of the breeder who, compared with the producer, deals with fewer numbers and makes a relatively larger profit on each bird. 
The breeder's goal is not so much "how many" as "how good." Pedigree breeding is a necessity in selecting for fecundity or hatching power. There cannot be the best progress along production lines without it.

FIG. 59

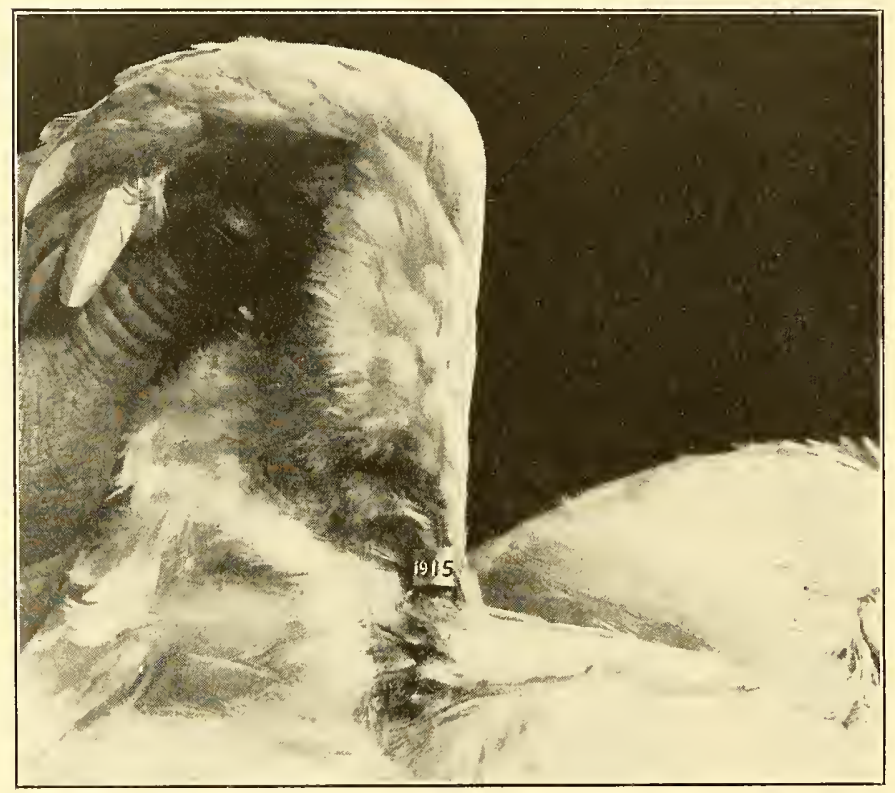

Winguand as it appears in the wing of the adult fowl. It bears the year date of hatching as well as the chick's number. As it remains in place throughout life, the age of the bird can always be told. (Courtesy of Kansas Agricultural Experiment Station.)

The general producer, however, desires numbers and sells on a comparatively narrow margin, hence the time element involved is too great to make pedigreeing practical. He must look to the production breeder to do this for him.

Breeding Record Blanks. - An individual's breeding record is started when it is hatched. As soon as it is well dried off it is wingbanded or legbanded. The number on this band 


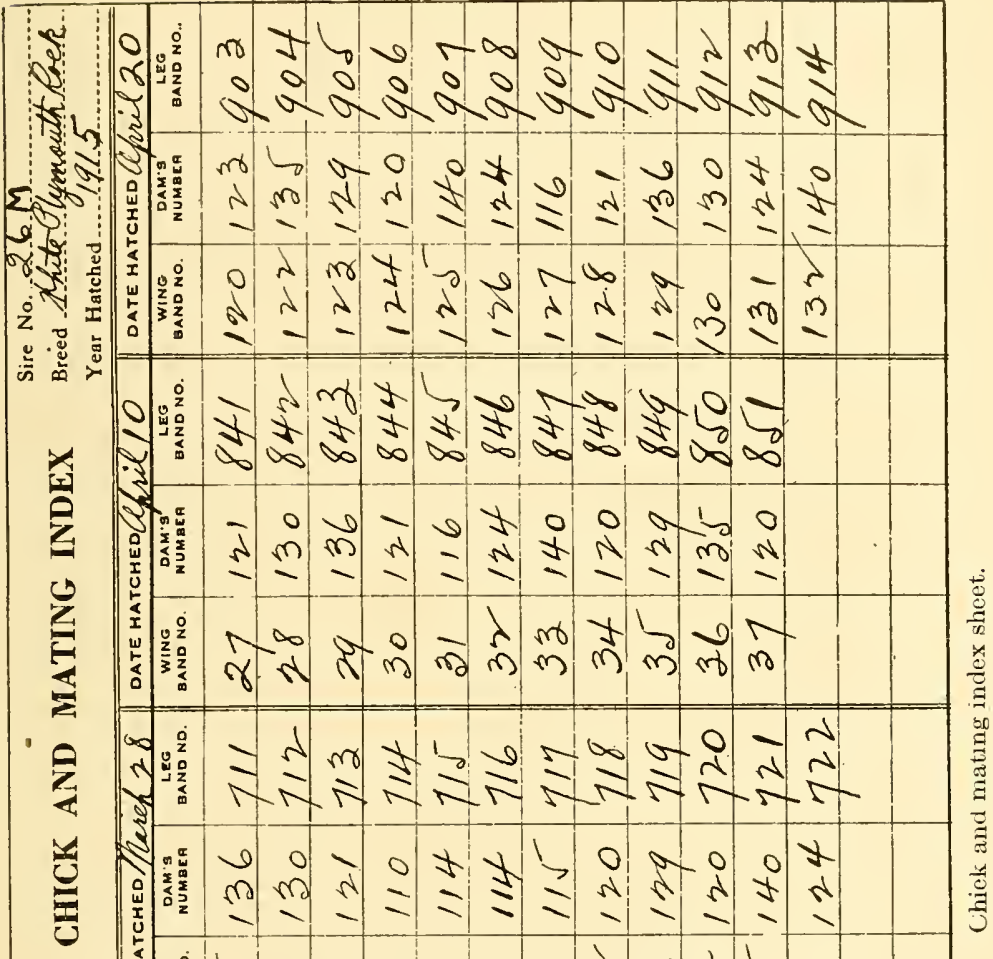


and the numbers of the chick's sire and dam must be recorded. For this purpose a printed form as illustrated in Figure 60 is most useful.

At the upper right hand corner of each sheet of this "Chick and Mating Index" is entered the legband number of the sire of all the chicks recorded on that sheet. The legband number of the dam of each chick is recorded on the same line with the chicks wingband number. These sheets therefore serve not only as a record of the parentage of the chick, but of the females mated with any given sire, which produced offspring. They also give the exact date of hatching.

When the chicks are mature enough to go into the laying house or breeding pen, they are legbanded. While the wingband remains in place throughout life, it is covered by the long feathers of a mature bird. The legband is resorted to and should be put on upside down so that it may be easily read in handling the bird without having to turn the latter upside down. The legband number should be recorded on the same line as the wingband number. The numbers on the wing and legbands are not necessarily the same.

While the Chick and Mating Index gives all the facts necessary for tracing a given birds ancestry, it does not give them in easily accessible form. For this purpose it is desirable to have a second blank called the Flock Breeding Record, as shown in Figures 61 and 62 . In the columns headed "Legband Number" are entered in serial order the legband numbers of all birds reaching maturity whether the individuals are retained as layers or breeders, or sold for breeding purposes. These numbers may run from 1 to 3000 , or 10,000 and even higher, depending upon the extent of the breeding operations carried on. On the line with each legband number and in the column headed "Mating Number" is given the mating number of the individual represented.

This mating number is made by combining the legband numbers of the sire and dam as given in the Chick and Mating Index. For example, if it is found that the sire of 716 (wingband 20, Figure 60) is 26M (upper righthand corner) while her dam is 114 , the mating number of 716 is $26 \mathrm{M} 114$. In the same way the mating number of 506 (Figure 61) is 


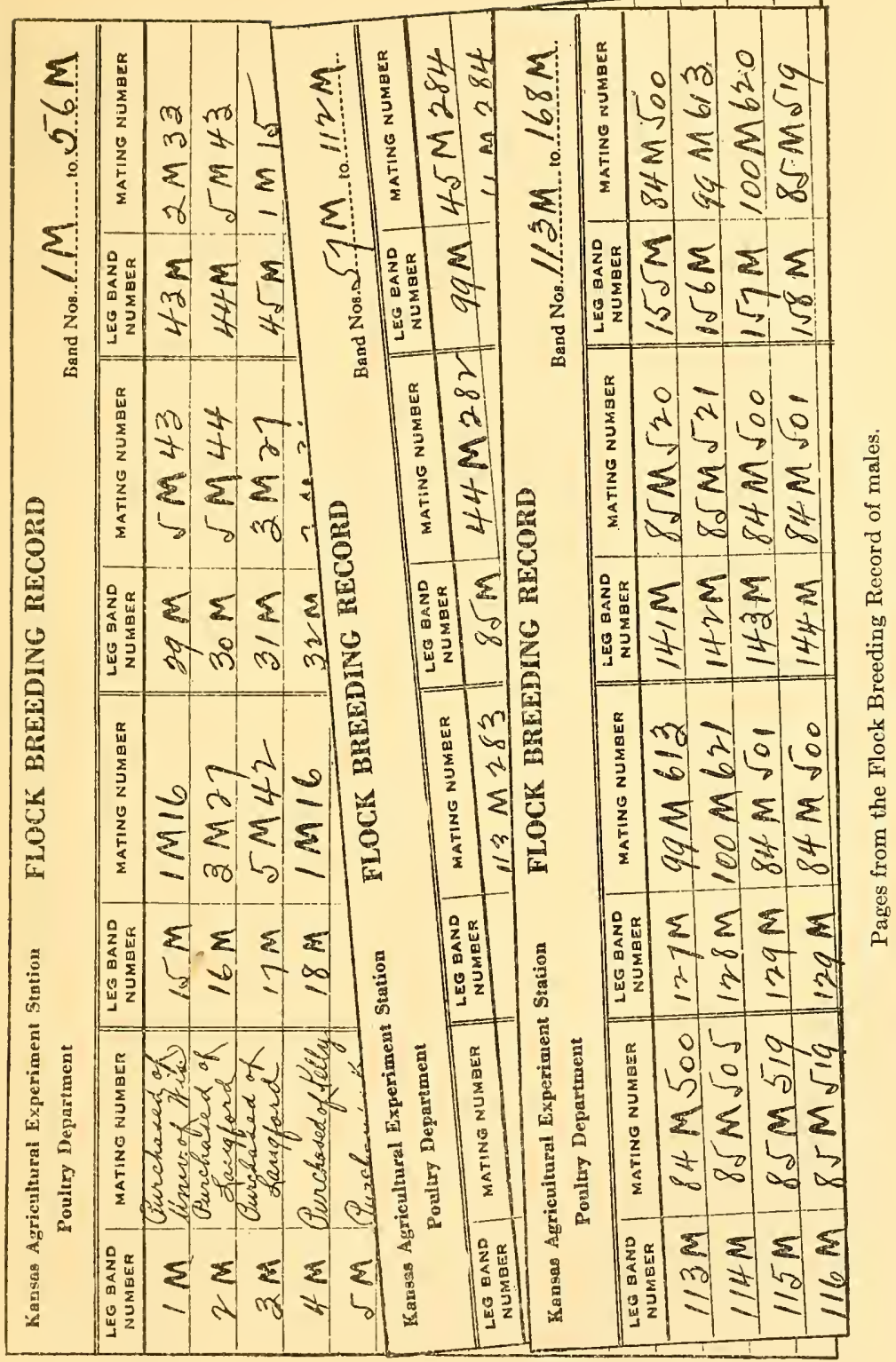





given as $17 \mathrm{M} 207$ because the sire is $17 \mathrm{M}$ and the dam is 207 , this information having been transferred to the Flock Breeding Record from a sheet of the Chick and Mating Index not shown in the accompanying figures. If the numbers ran higher and it was found that the mating number of 10,012 was 115M2006 (Figure (i1 lower left hand corner) the fact would be clear that the sire of 10,012 was $115 \mathrm{M}$ and the dam was 2006.

The Flock Breeding Record bears the same relation to the flock of the individual breeder that the herdbook does to an entire breed of cattle. It enables the breeder to readily trace the ancestry of any individual in his flock back to the parents of the individuals with which the record was first started.

Thus, when it has been found that the sire of 10,012 is $115 \mathrm{M}$ and that the dam is 2006, it may be easily determined by looking up $115 \mathrm{M}$ in the Flock Breeding Record (Figure 62) that its sire and dam are 85M and 519 respectively. In the same way it may be discovered that the parents of 2006 are $85 \mathrm{M}$ and 505 . She is therefore a half sister of her mate. The further ancestry may be traced back to the first birds recorded as shown in Figure 63.

When individual egg records (see Figure 64) are kept for all females used as breeders the mating members of the females may be written on the egg record sheets. When this is done it will be nesessary to keep a flock breeding record for the males only.

A pedigree blank as shown in Figure 63 is highly desirable for assembling the information gained from the Flock Breeding Record. Below the spaces intended for the female ancestors are spaces for the yearly egg records completed by each one.

Official Records.-As previously indicated (see page 57) there are no official breeding records for poultry, though the question of the registration of poultry is being agitated. The production records made at the laying contests conducted by several states are recognized as authentic and those records of two hundred eggs or higher made at contests are recorded as official by the American Record of Performance Council. This Council is authorized and organized by the American 


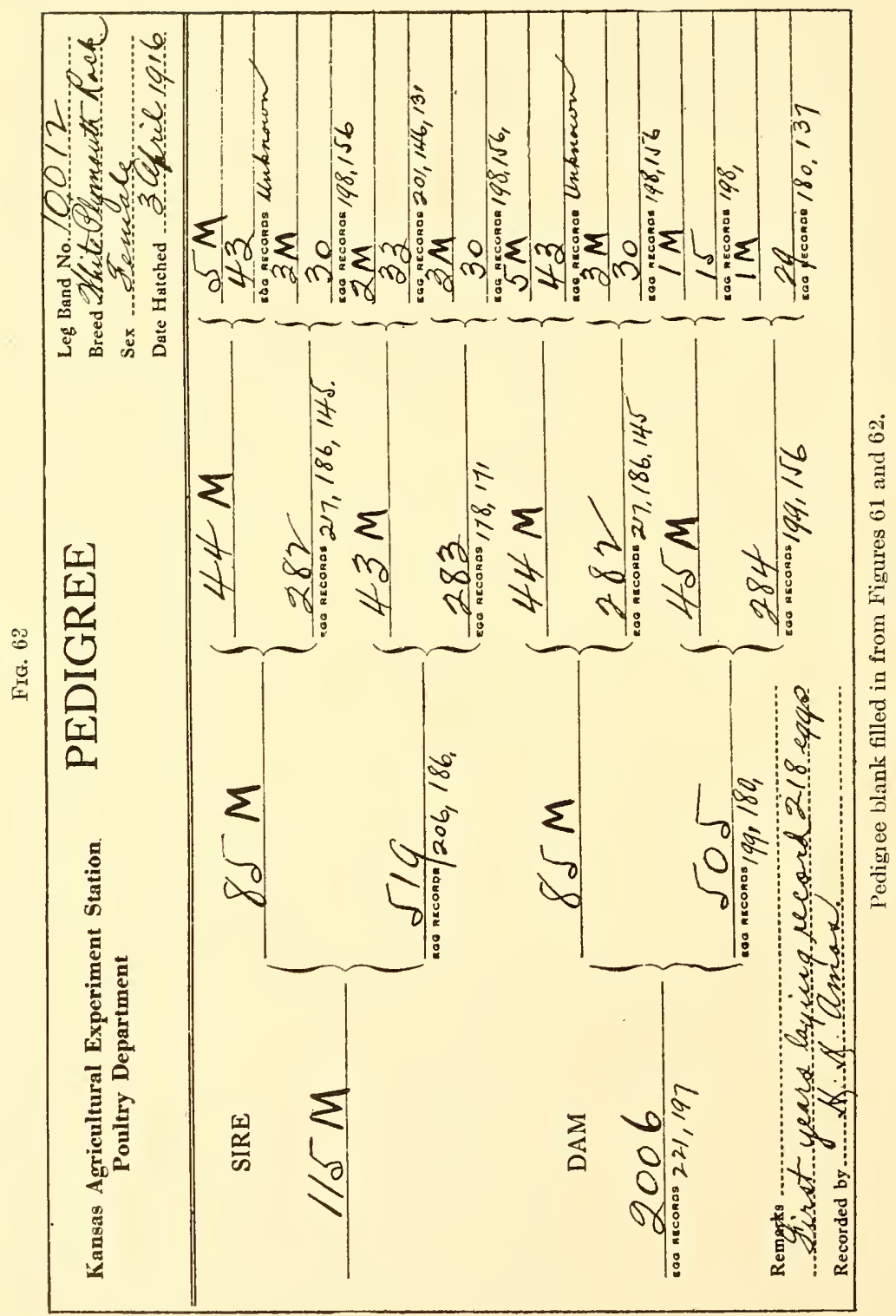


Association of Instructors and Investigators in Poultry Husbandry with offices at the New Jersey Agricultural Experiment Station, New Brunswick, New Jersey.

In New York'state a system of certifying flocks which come up to a recognized standard regarding production is administered by the New York Statc College of Agriculture at Cornell University.

FIG. 65

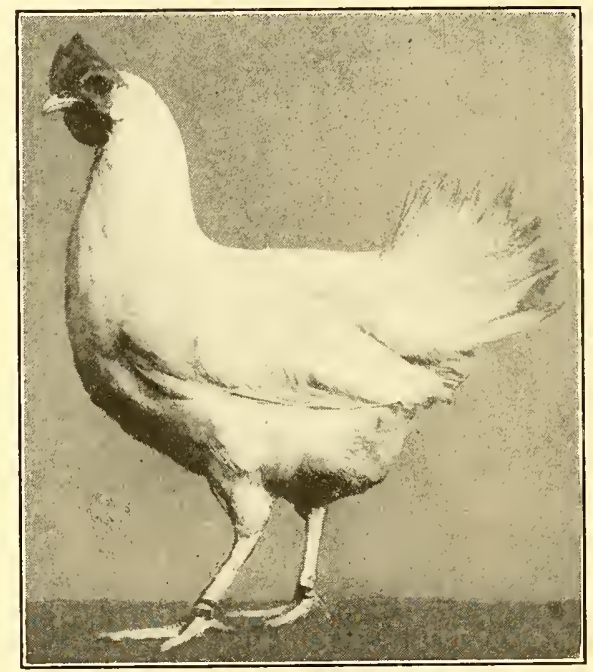

A cross-bred hen carrying three-eighths Barred Plymouth Rock blood and five-eighths Single Comb White Leghorn. Egg record, 291 in twelve months. (Courtesy of Oregon Agricultural Experiment Station.)

Cross-breeding.- Two kinds of cross-breeding are practised. With the first, which is used in endeavoring to find a new combination of characters or qualities and thus form a new breed, individuals of different breeds whose blended characters it is hoped will approach the combination sought, are mated and selected progeny of the cross are used as breeders for further operations. An illustration of this is found in the formation of the American breeds.

With the second the two breeds are kept in their purity, 
and the progeny, which always represent a first cross, are never used for breeding purposes. 'Thus it is said that for producing Philadelphia capons a cross much employed is that of the Light Brahma and White Plymouth Rock. The offspring always carry half their blood from each breed. For producing market ducks a cross much used is that of the Pekin and Aylesbury. In such breeding it should always be considered which is the better of the two reciprocal crosses.

Such a practice as this is sometimes erroneously referred to as line breeding, because both lines of stock are bred pure and only the first cross used.

\section{PURPOSE OF SELECTION.}

The purpose of selection is to prevent the birth of individuals not suited for production. In pursuance of this purpose the points to be selected for in the order of their importance are (1) constitutional vigor and capacity, (2) hatching power, (3) egg production, (4) longevity, (5) early maturity, and (6) breed and varietal characteristics.

With the producer, from the nature of the case, selection is confined to the first and the last three points. In most cases it will be confined to the first and the last. For the second and third he must depend upon the breeder. If grading is carried on, selection so far as the producer's own flock is concerned is further limited to females.

Constitutional Vigor and Capacity.-The appearance and manifestation of maximum vigor and vitality can only be present when all organs $0:$ the borly that have to do with digestion, circulation, respiration, and the nervous system which controls all, continuously perform their full work. This maximum efficiency of all organs makes up constitution.

That constitutional vigor is the foundation of good production cannot be overemphasized. The best inheritance conceivable, with regard to all other points of selection, is useless unless there is physical stamina as a foundation. Without it, inheritance is as helpless as a dynamo that has no conducting cable to connect it with its motors. It is the 
conductor that makes possible in production the possibilities generated in breeding.

There must be physical thrift to withstand the exhaustion of an inherited heavy production. Reproduction in the hen is normal only when there is an excess of vitality, as well as of feed, bevond that needed for the hen herself. In the case of persistent and continuous reproduction there must be a very large excess.

In order to realize on an inherited tendency to quick growth and early maturity, there must be good digestive power to prepare for assimilation large amounts of materials,

Fig. 66

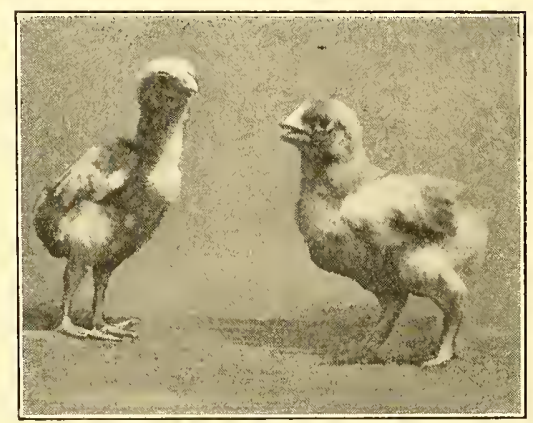

Showing the difference in the offspring of strong and weak hens. These chicks had the same sire. (Courtesy of Kansas Agricultural Experiment Station.)

out of which growth is manufactured. This can only be had when every organ of digestion and assimilation and of reproduction is large and active. Such organs can exist only in a capacious body and capacity is a first requisite of vigor.

Beyond this it is a law of universal application that low vitality means weak defensive agencies throughout the body and a greater susceptibility to disease. This extends not only to the individual, but to the offspring by way of inheritance and by lessening the bactericidal properties of the secretions of the oviduct during the manufacture of the egg.

A good constitution is as much a heritable character as are 
color and comb. Proper housing, feeding, incubating, and general care help to conserve the health of the flock, but the very best management cannot obviate the necessity of a vigorous fowl to begin with. It is "bred in the bone," and handed down to offspring from both parents.

Influence of Vigor of Dam upon Offspring.-Aside from the question of the inheritance of vigor lies the fact that only the complete health and nourishment of the body is likely to insure the highest vitality and, in the case of the males, activity in the reproductive cells. Furthermore, the vigor of the dam has an effect upon the food supply of the embryo chick, comprising the yolk and albumen of the egg.

Fig. 67

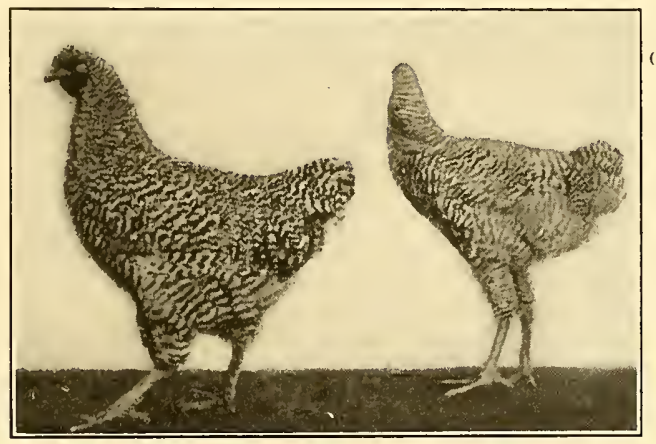

Cockerels showing strong and weak constitutions. (Courtesy of Cornell Agricultural Experiment Station.)

While technically this has no more to do with the inheritance of the chick than the amount and quality of milk drank has to do with the inheritance of the calf, practically it is of great importance in bringing out strong chicks. As a result of observations, incidental to his studies of the inheritance of egg production, Pearl ${ }^{1}$ makes the following statement: "It is certain, from observations of both egg and chick, that the same kind and quality of food is not furnished to the embryo by the egg manufactured in the body of a 
strong fowl as is furnished in the egg manufactured in the body of a weak fowl.

"Furnished with a qualitatively inadequate ford-supply, the embryo either dies before hatching or hatches into a weak, debilitated chick. 'This badly nourished, weak chick grows into an adult fowl which is weak in constitution and usually weaker and to a greater degree lacking in vitality than the

FIG. 68

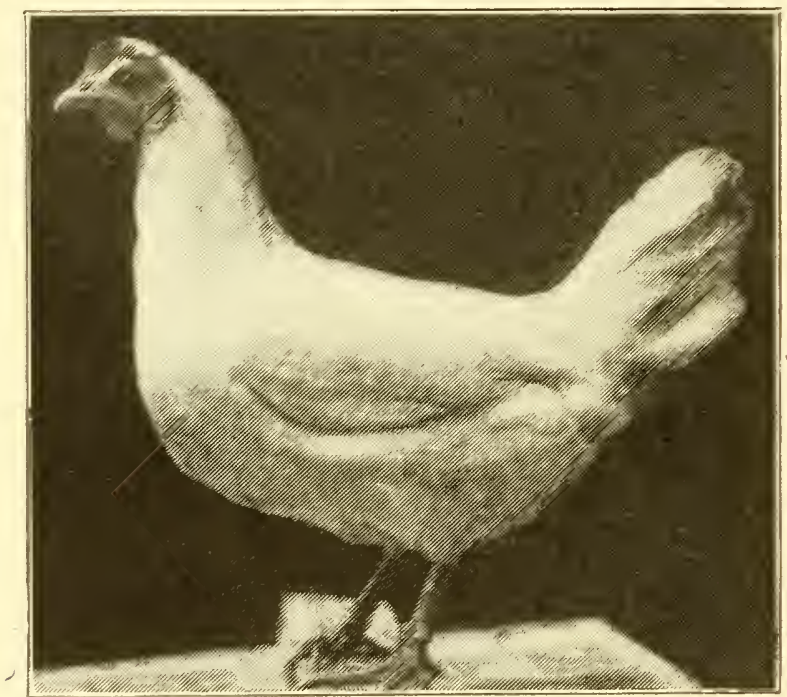

Single Comb White Leghrorn laying 295 eggs in first laying year. Note body capacity. (Courtesy of D. Tancred, Kent, Wash.)

parent. 'This offspring may thus be expected to produce a still less normal supply of nutriment in its eggs than did its mother, since it is less vigorous and normal than she was. Thus the weakress is passed on from generation to generation, tending all the time to become greater."

The Vigorons 'Type.-'There are certain characteristics which are correlated with that maximum efficiency of all organs termed constitution. These characteristics are rela- 
tive rather than absolute. While a longe, straight, narrow beak is undesirable on ans breed, the beak of a lachororn cannost be expereted to be as short, stout and of the same curvature as that of a Brahma or aven a lPyonouth looek. lioreal characteristies must be given due enosideration and the comparison of these chameteristies should be between inemhers of the same breet.

The head should be of fair size because of its breadth and depth rather than its length; show a pair of keen, alert, and rather prominest eyes, which are directed nearly at right angles to the long axis of the head and are free from puffy or oserlanging eyebrows; carry at comb that is well developed and ficery red, and a beak that is comparatively short, stout, and well corved. "The so-ralled "coross-eyed" hen is to be asoirlerl.

A head tliat carries a choronically congested comb, a long, straight beak, or is itself long and narrow, or sunken, will usually be associated with functional weakness throughout the body.

The body trunk must furnish ample room for the vital orgars and particularly these organs which are associated directly with the digestion and assimilation of feed and the rnamufacture of eggs. 'There seems to be a decirled correlation between a capacious body and digestive and reproductive organs of good size and vigor. For a tirue it was held that the rear half of the fowl's body should be deep in proprortion to the front half. This was largely based on the fact that the ovary and oviduct and the girzard and intestines extend from about the middle of the body (from front to back) to its posterior extremity. From continued oluservation, however, it appears that while the great asset is capacity and all great producers have it, the form of body with regard to its relative fore-and after-depth varies greatly.

The heavy producers that are able to jersist in their high, production for a number of yoars without becoming ruptured or, as poultrymen term it, "breaking down behoind," usually

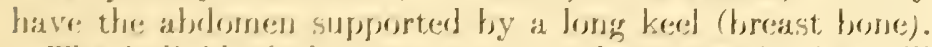

The individual that prossesses a robust constitution will have the rapacious bedy supporterl by stronge, parallet, ol 
in males slightly base-wide, legs on which the nails of the scratching toes are well worn, denoting activity. It is the highly active hen that is the last to roost at night and the first about in the morning, that the trap nest usually points to as the high producer.

Aside from the characteristics that go to make up the general conformation of a vigorous bird, there must be a good general appearance that is made up of the style and carriage that is closely associated with disposition, on the one hand,

FIG. 69

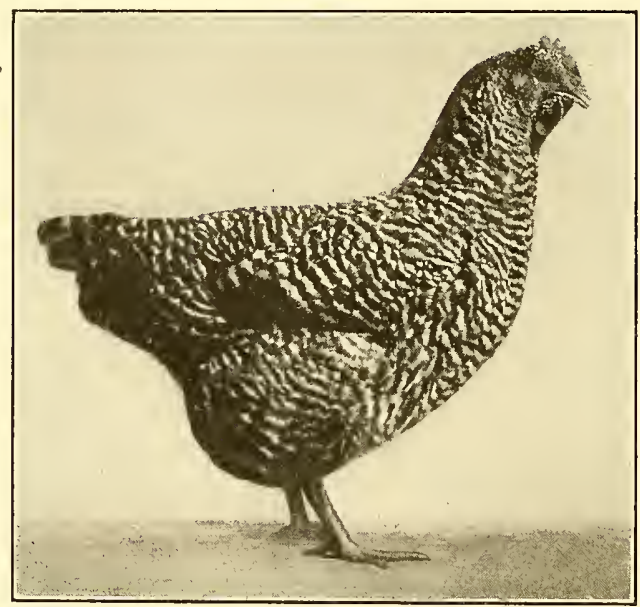

Barred Plymouth Rock, female. Record 62 eggs. Notice lack of femininity and trimness. (Courtesy of J. W. Parks.)

and that balanced development of all parts called symmetry on the other. The physically strong and, in the case of males particularly, the sexually strong bird has a well-developed oil sac, and spends considerable time oiling and preening its feathers. The well-kept glossy coat and general neatness and trimness of appearance that indicate pride in plumage are assets not to be ignored. Allowance must be made on this point for frayed and faded females at the end of a season of heavy laying. 
To these characteristics of vigor must be added the high development of those appearances associated with sex. Poultrymen often speak of the "sweet" appearance of a pullet or the "matronliness" of a hen as being desirable characteristics. This is simply one way of expressing the desirability of a decidedly feminine appearance which is likely to be most heavily marked in those hens which lay most heavily.

Evidences of strong masculinity on the part of the males is equally desirable. Great gallantry, fearlessness in fighting, a persistence in the crowing challenge, and the sidling strut before the hens, taken together, denote sexual strength. The cock-crowing contests in Belgium are not so far wrong as a basis for the selection of breeding males. As already shown, the secondary sexual characters by which we distinguish the sexes, are directly dependent upon the sex glands. Any lack of development in these characters very probably points to more or less undeveloped ovaries or testes as the case may be.

The Meat Type.-It would seem, perhaps, that with meat an important by-product some attention should be given the deepness of muscling over the breast or the thickness of flesh over the thighs. As a matter of fact, the bird that enjoys the robustness of perfect health, or that is a good performer at the nest, will nearly always be found to be well meated.

With meat practically a by-product, and the whole carcass the retail market unit, the question of a meat type is not so important as in the case of beef cattle. There, meat is the principal product, and there is a great range of value between the various cuts. These cuts are sold separately, and are, in point of fact, the retail market units. The proportion between the more and the less expensive ones in the carcass makes considerable difference in its value. Different portions of the poultry carcass are not given different market values. It is the general condition of the whole carcass that governs its desirability.

Hatching Power.-If constitutional vigor is the conductor which connects the generator with its motors, hatching power is the switch that closes the circuit. Without it production 
ceases. With the average period of profitable production but two years, the necessity for the ability to renew the flock each year with a fair degree of certainty is obvious.

Assuming good vigor, actual infertility, by which is meant the lack of a vital union between the sperm and the ovum, is usually caused by sterility, or aversion on the part of the sire, barrenness on the part of the dam, or by physiologic selection. It is not to be assumed that because a particular hen gives few or no fertile eggs she is worthless as a breeder. It often appears that males have favorites in a flock with which they mate frequently while there are others that are never served. It happens less often that two individuals, which produce healthy chicks when mated with other individuals, produce no fertility when mated together. Such a condition is referred to as one of physiologic selection. The remedy in each case is the making of a new mating or, where feasible, alternating males in the pen from day to day. If upon mating with another male a female still returns no fertility she may be assumed to be barren and useless.

In the case of partial or total sterility on the part of a male the low fertility of the eggs from all the hens mated with him will necessitate his being discarded in self-defense.

It would seem from the evidence at hand that infertility in females of itself is not to be feared from the stand-point of inheritance. It is rather an individual idiosyncrasy, highly disappointing in present, but not serious in regard to future effects upon offspring. In records furnished by Pearl and Surface 1 it is shown that "There is no evidence that the character 'fertility' of eggs (measured by per cent of eggs infertile) is in any degree or manner inherited." Very much more serious from the standpoint of progeny is the frequent occurrence of "dead in the shell," by which is meant that while the egg is fertile it fails to hatch. Pearl and Surface ${ }^{2}$ found that "The character hatching quality of eggs (measured by the per cent of fertile eggs hatched) is definitely inherited in the female line and probably also in the male line." 
Selection for this point depends upon trap-nesting. The time involved in visiting the nests several times a day and recording the number of the hen laying each individual egg is out of proportion to the price received for the products and would fail to find a place in most schemes of management of the general farm. For improvement in this quality, great as is its importance, the ordinary producer must depend upon the breeder, seeking it through the medium of improved breeding males.

Constitutional Vigor and IIatching Power.-Williams ${ }^{1}$ found that in choosing four Black Langshan hens for their strong vitality, and comparing them with four others of the same breed that were lacking in vitality, 62.95 per cent of all cggs laid by the rigorous birds that were incubated hatched. On the other hand, only 29.27 per cent of the eggs incubated from those laid by the hens that were noticeably weak hatched.

In tests involving over three thousand eggs from White Leghorns and over one thousand from Barred Plymouth Rocks, Rice and Rogers ${ }^{2}$ found that the average fertility of the eggs from flocks selected for their good vitality was 7.5 per cent greater and the actual hatching power was 7.6 per cent greater than in the case of eggs from flocks of birds that at some time had exhibited signs of weakness.

Heavy Production and Hatching Power.--The question of whether high fecundity tends to lessen hatching power, is one upon which opinion varies and upon which there is comparatively little evidence. Rogers ${ }^{3}$ reports on work with eighty-two hens in which all the eggs incubated during the second season were used. He found that taking the two years' production as a basis of comparison the hatching power was higher with average producers than with those individuals whose production was exceptionally high or exceptionally low.

The hen that lays large numbers of eggs appears to slight them somewhat from the physiologic stand-point. Beyond

1 Bachelor's Thesis, Oklahoma Agricultural College, 1913.

2 Cornell Bulletin No. 318.

${ }^{3}$ Cornell Countryman, vol. ix, No. 3 . 
a certain limit, increased egg production is obtained only at the expense of hatching power.

On the other hand, with the hen that produces an unusually small number of eggs, lack of vitality is likely to be the limiting factor which affects the hatching power as well as the production.

Bearing on this same point, Pearl and Surface ${ }^{1}$ reached the conclusion that "there is a distinct correlation between winter (November to March) egg production and the percentage of fertile eggs hatched during the subsequent breeding season. This correlation is of such sort as to indicate that in general the higher the winter egg production of a particular bird the lower will the percentage of that bird's fertile eggs hatched probably be, and vice versa."

Rate of Production and Hatching Power.-There seems also to be a relation between the rate of egg production during the incubating season and hatching power. As shown by Table XVI, hens laying 11 eggs or less during the same period that other hens were laying 19 or more, were credited with a 17.3 per cent greater hatch, considering all eggs that were set.

\begin{tabular}{|c|c|c|c|c|c|c|}
\hline \multirow[b]{2}{*}{$\begin{array}{l}\text { Eggs laid during period } \\
\text { of accumulating } \\
\text { for incubation. }\end{array}$} & & \multicolumn{3}{|c|}{ TABLE XVI. $^{2}$} & \multirow[b]{2}{*}{$\begin{array}{l}\text { Per cent } \\
\text { fertile. }\end{array}$} & \multirow[b]{2}{*}{$\begin{array}{l}\text { Per cent } \\
\text { chicks to } \\
\text { eggs set. }\end{array}$} \\
\hline & & $=$ & $\begin{array}{l}\text { Number } \\
\text { of hens. }\end{array}$ & $\begin{array}{c}\text { Eggs } \\
\text { incubated. }\end{array}$ & & \\
\hline 11 or less & - & . & 14 & 117 & 99.2 & 73.5 \\
\hline 12 or 15 . & . & . & 22 & 313 & 95.4 & 61.7 \\
\hline 16 or 18 . & . & . & 25 & 421 & 94.8 & 60.3 \\
\hline 19 or more & - & . & 21 & 424 & 90.1 & 55.8 \\
\hline Summary . & • & • & - 82 & 1,275 & 93.8 & 61.2 \\
\hline
\end{tabular}

High Egg Production.-High egg production, the supreme object of productive breeding for which vigor and hatching power are the foundation, is the point of selection which is the least understood. Egg production is an exceedingly complex character, easily affected by such environmental conditions as the date of hatching, feeding, housing, hygiene,

1 Maine Bulletin No. 168.

${ }^{2}$ Rogers, Cornell Countryman, vol. ix, No. 3 . 
the weather, fright and many others. The complexity of the character itself has been clearly set forth by Goodale ${ }^{1}$ who has shown that egg production depends upon several more or less independent internal factors. In order to arrive at definite conclusions concerning the inheritance of egg production, each of these factors must be investigated separately. The factors pointed out are, date of laying of first egg, age at laying of first egg, earliness of maturity, rythm and rate of production, broodiness, molt and the persistance of production in the fall.

Goodale $^{2}$ shows that for Rhode Island Reds the date of the laying of the first egg, aside from the date of hatching, depends upon the rate of growth and the earliness of sexual maturity. On the average, pullets that lay at six or seven months of age, lay more eggs than those which begin laying at eight or nine months or older.

Bearing on this same point, Rice ${ }^{3}$ offers the records of 169 Single Comb White Leghorn hens, as shown in Table XXVI which indicate very marked correlation between early laying and high production. The four hens which began to lay at an age between one hundred and fifty-one and one hundred and eighty days gave the largest average first year production of any of the other groups and also gave the highest average total production for a period of three years. The groups that began to lay at ages between one hundred and eighty-one and two hundred and and ten days and between two hundred and eleven and two hundred and forty days gave the second and third largest average production respectively, for the first year and for the three year period.

Goodale ${ }^{4}$ and others have shown that some pullets lay nearly continuousy for long periods of time while others which lay relatively rapidly lay in cycles with periods of rest in between. He has also shown that broodiness tends to reduce production very materially. The appearance of a molt usually accompanies a break in production, while

1 American Naturalist, vol. lii, Nos. 614-618.

3 Cornell Countryman, vol. xii, No. 7.

2 Loc. cit.

${ }^{4}$ Op. cit. 
those individuals which molt late in the fall also lay late and usually lay more eggs during the year than the early molters. It is of course the female which combines the most of the favorable factors mentioned above which makes the greatest layer, other things being equal.

In spite of the great complexity of the problem, as the result of studies involving thirteen generations and several thousand individuals of the Barred Plymouth Rock breed, Pearl ${ }^{1}$ was able to reach rather definite conclusions concerning the result of selecting for egg production.

\section{FIg. 70}

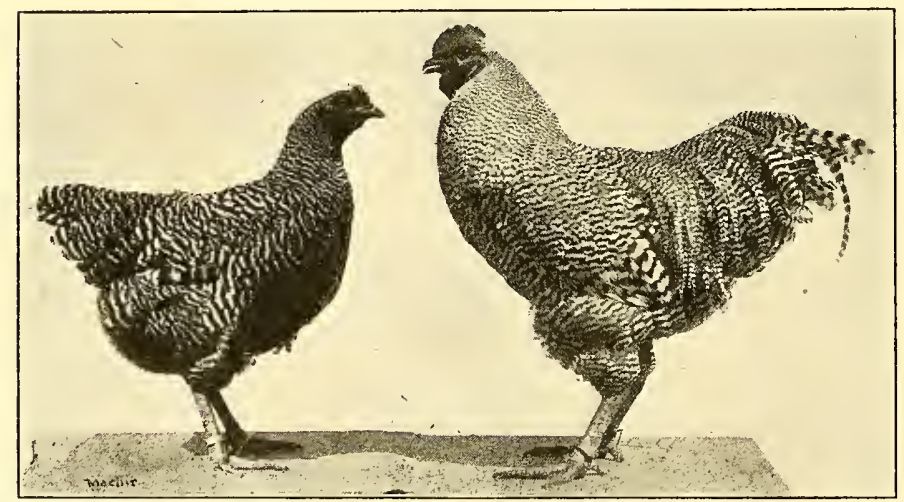

Showing the difference in barring of Plymouth Rocks that are full brother and sister. (Courtesy of Kansas Agricultural Experiment Station.)

He proved first of all that high egg production is just as much a heritable character as the type of the comb or the color of the feathers. His results were of such a nature however, that he was forced to conclude that in the Barred Plymouth Rock breed a pullet can inherit the powers of high production from her sire only, a type of inheritance referred to as sex-linked.

The most familiar example of this type of inheritance in poultry and one which may aid in understanding the way in 
which the inheritance of fecundity is limited, is found in the color of the Barred Plymouth Rock. It is a matter of common observation that the Plymouth Rock males are always of a lighter shade than the females. This comes about through the fact that the females inherit the light bars from their sires only and never from their dams, whereas the males always inherit light barring from both sire and dam, thereby receiving a double dose of the light barring.

The reason for this appears to lie in the fact that hens produce two kinds of eggs, one of which when fertilized, always produces males, while the other produces females. The male produces only one kind of sperm so far as sex is concerned, and these all carry the factor for barring. The female-producing eggs never carry the barring factôr, while the male-producing eggs always do. The only result possible is that the male inherits light barring from both his sire and dam, while the female inherits it only from her sire.

A summary of Pearl's conclusions ${ }^{1}$ are as follows:

1. "The record of fecundity of a hen taken by and of itself alone gives no definite reliable indication from which the probable egg production of her daughters may be predicted. Furthermore, mass selection on the basis of fecundity records of females alone, even though long continued and stringent in character, failed completely to produce any steady change in type in the direction of selection.

2. "High fecundity may be inherited by daughters from their sire independent of the dam. This is proved by the numerous cases . . . where the same proportion of daughters of high fecundity are produced by the same sire, whether he is mated with dams of low ${ }^{2}$ or high fecundity.

3. "High fecundity is not inherited by daughters from their dam. This is proved by a number of distinct and independent lines of evidence, of which the most important are $(a)$ con-

${ }^{1}$ Maine Bulletin No. 205.

2 "Low fecundity" as used by Dr. Pearl refers to a winter production of below 30 eggs. This term has been widely misunderstood by practical poultrymen. It represents the result of the presence of the $L_{1}$ factor and might possibly have been better described as "mediocre fecundity," allowing "low fecundity" to describe, as it seems to have done in the popular mind, the really poor layer that gives no winter production at all. 
tinued selection of highly fecund dams does not alter in any way the mean egg production of the daughters; $(b)$ the proportion of highly fecund daughters is the same whether the dam is of high or low fecundity, provided both are mated to the same male; $(c)$ the daughters of a highly fecund dam may show either high fecundity or low fecundity, depending upon their sire; $(d)$ the proportion of daughters of low fecundity is the same whether the dam is of low or high fecundity, provided both are mated to the same male."

Goodale, ${ }^{1}$ who worked with Rhode Island Reds, secured results which do not appear to agree with Pearl's, in that he found quite a marked correlation between the production of pullets and the production of their dams. The daughters of high producing hens were, on the average, better producers than the daughters of low producing hens mated to the same male. It may be that egg production, or certain factors which affect egg production markedly, are inherited differently in the Rhode Island Red breed than in the Barred Plymouth Rock.

From the standpoint of the practical producer, it might prove fortunate if the transmission of high productive powers were confined to the male. Selection for high production, further than is made possible through culling, is out of the reach of the mass of producers because it involves pedigree breeding, which, as pointed out elsewhere, is not practicable on the general farm. The purchase of cockerels from high producing families, however, is practicable. Whatever the exact mode of transmission of high production may finally prove to be, it may be introduced into a flock of poor layers through the use of males from high laying families of the Barred Plymouth Rock and Single Comb White Leghorn breeds, as shown by Lippincott. ${ }^{2}$

As shown by Goodale, ${ }^{3}$ it is not possible on the basis of present knowledge to devise a set of detailed instructions that could be followed by a poultryman of ordinary intelligence which would enable him to proceed step by step in the

\footnotetext{
1 Jour. Am. Assn. Inst. and Invest. in Poul. Husb., vol. v, No. 10.

${ }^{2}$ Kansas Bulletin No. 223.

${ }^{3}$ Loc. cit.
} 
development of a race of ligh producers with the same certainty that a set of instructions could be devised for comparatively simple characters as comb type, feather color, silky plumage, etc. It is possible, however, through the culling out of the poorer producers in the flock so that only the thrifty, better laying hens are saved, and the mating with them of pedigreed cockerels with at least four generations of high producing female ancestors on both the sires and dams sides back of them, to improve a flock of poor producers or to maintain a flock of good producers. Sight should never be lost of the fact that the male is at least half of any breeding flock so far as the offspring is concerned, and there is evidence that he is more than half with regard to high egg production in at least some of the breeds.

Average Production. - Taking their data from 150 commercial flocks which included about 120,000 head, mostly Leghorns, about a third of which were hens and two thirds pullets, App, Waller and Lewis ${ }^{1}$ found that the average annual production per bird was 110 eggs. This represents approximately a 30 per cent production for the year distributed by months as shown in Table XVII. This in all probability exceeds the average production of general farm flocks by at least three dozen eggs.

Table XVil. The Average Per Cent of Perfect Production Shown During the Different Months of the Year by One Hundred and Fifty Commercial Flocks in New Jersey. (Data of App, Waller AND LEWIS.)

\begin{tabular}{l}
\multicolumn{1}{c}{ Nlonth } \\
November \\
December \\
January \\
February \\
March \\
April . \\
May \\
June \\
July \\
August \\
September \\
October
\end{tabular}

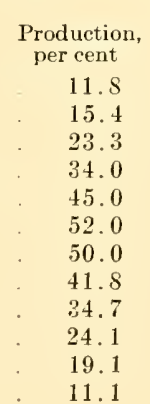
Average number of eggs per
bird calculated from App, Waller and Lewis' data.
3.54
4.77
7.22
9.52
13.95
15. 60
15.50
12.54
10.75
7. 47
5. 73
3.44 
Lewis $^{1}$ has also calculated the average per cent egg production for each month from the records of all the laying contests in American during the years 1912 to 1919, inclusive. The result of his calculation is shown in Table XVIII.

Table XVili.-The Average Per Cent of Perfect Production During the Different Months of the Years 1912 to 1918 Inclusive for All of the Laying Contests in America. (First Laying Year Only.)

\begin{tabular}{|c|c|c|c|c|c|}
\hline Month & & $\begin{array}{c}\text { Production } \\
\text { of American } \\
\text { Breeds, } \\
\text { per cent }\end{array}$ & $\begin{array}{l}\text { Calculated } \\
\text { number of } \\
\text { eggs, per bird. }\end{array}$ & $\begin{array}{c}\text { Production } \\
\text { of the Leg- } \\
\text { horns, } \\
\text { per cent }\end{array}$ & $\begin{array}{l}\text { Calculated } \\
\text { number of } \\
\text { eggs, per bird }\end{array}$ \\
\hline November & & 19.1 & 5.73 & 24.8 & 7.44 \\
\hline December . & . & 27.7 & 8.58 & 24.2 & 7.50 \\
\hline January & . & 34.5 & 10.69 & 25.1 & 7.78 \\
\hline February & . & 48.0 & 13.44 & 41.0 & 11.48 \\
\hline March. & . & . $\quad 61.8$ & 19.15 & 61.7 & 19.12 \\
\hline April & . & . $\quad 63.1$ & 18.93 & 68.7 & 20.61 \\
\hline May & . & . $\quad 59.3$ & 18.38 & 69.3 & 21.48 \\
\hline June & . & . 53.0 & 15.90 & 67.4 & 20.22 \\
\hline July & . & . $\quad 46.9$ & 14.53 & 60.6 & 18.78 \\
\hline August & . & . 44.1 & 13.67 & 54.2 & 16.80 \\
\hline September & & . $\quad 38.9$ & 11.67 & 33.1 & 9.93 \\
\hline October & 政 & . 28.7 & 8.89 & 12.8 & 3.96 \\
\hline
\end{tabular}

Indications of Laying. ${ }^{2}$ - In order to lay well a hen must first of all be sound and vigorous. The characteristics of a vigorous fowl have already been described. There are, however, further indications of laying not necessarily associated with vigor. These are pigmentation, body changes, molting and temperament.

Pigmentation.- - In those varieties showing yellow pigment in the subcutaneous fat, shanks, and earlobes (in those varieties having the so-called white earlobe), the pigment tends to disappear as laying progresses. Palmer ${ }^{3}$ has shown that the presence or absence of this pigment in the fowl or its eggs is directly correlated with the presence or absence in the feed of a carotinoid pigment called xanthophyll. For this reason a hen fed on a ration devoid of feeds which carry it in

1 Jour. Am. Assn. Inst. and Invest. in Poul. Husb., vol. v, No. 5.

2 This account is adapted and slightly amplified from the one adopted at the judging school held at Cornell University July, 1918, and approved by the American Association of Instructors and Investigators in Poultry Husbandry and published in its journal, vol. v, No. 1.

3 Journal of Biological Chemistry, vol. xxiii, No. 1. 
considerablc amounts, such as yellow corn and green feed, might have the appearance of laying so far as pigment is concerned though she had never produced an egg. 'The character of the feed the hen has been receiving should therefore always be considered in relation to her condition with reference to pigment.

When hens have feeds carrying an abundance of pigment, and the skin, shanks and beak are not normally pale as in the English breeds, Palmer and Kempster ${ }^{1}$ have shown that the beginning of laying diverts all the pigment received in the feed from other parts of the body to the ovary where it finds its way into the developing yolks. The pigment of the external parts gradually disappears as a result of the natural physiological change in the structure of the skin. It is not replaced according to these investigators, as long as the individual continues to lay.

The vent loses its pigment very quickly so that a white or pink vent in a yellow skinned variety usually indicates that the bird is laying, while a yellow vent indicates that she is not laying.

The eye-ring formed by the inner edges of the eye-lids loses its pigment a trifle slower than the vent. The earlobes of the Mediterranean breeds bleach out somewhat more slowly than the eye-ring so that in these breeds a white earlobe on a vigorous bird usually means that laying has been in progress longer than does a bleached vent or eyelid.

The color disappears from the beak begimning at the base and remaining longest at the tip. The lower beak bleaches more rapidly than the upper one. With the average yellow skinned bird a bleached beak means that laying has been in progress for from four to six weeks.

The shanks are the last to lose their color. Bleached shanks therefore indicate a much longer period of production than does the bleaching of the other parts. The pigment disappears from the front of the shank first and finally from the back. A bleached shank usually indicates a continued egg production for at least fifteen to twenty weeks. 
When laying stops, the pigment reappears in the several regions in the same order in which it disappeared. The relative rapidity of loss and regain in the various parts is probably correlated with the thickness of the skin, the pigment change being slowest where the epidermal covering is thickest. The fact that a given hen stopped laying two to three weeks back may sometimes be determined by the fact that the tip of the beak is colorless while the base is yellow.

Table XIX.-Showing the Mean Annual Production of Groups of White Leghorn Hens Selected on the Basis of Vent, Beak and Shank Color. (Data of Card.)

\begin{tabular}{|c|c|c|c|c|c|c|}
\hline \multirow{3}{*}{$\begin{array}{l}\text { Color } \\
\text { class. }\end{array}$} & \multicolumn{6}{|c|}{ Number of Birds and Mean Annual Production. } \\
\hline & \multicolumn{2}{|c|}{ Vent. } & \multicolumn{2}{|c|}{ Beak. } & \multicolumn{2}{|c|}{ Shanks. } \\
\hline & Birds. & Production. & Birds. & Production. & Birds. & Production. \\
\hline Pale & 101 & 189.5 & 114 & 184.3 & 141 & 178.6 \\
\hline Medium . & 91 & 152.2 & 80 & 163.3 & 104 & 160.5 \\
\hline Yellow & 183 & 136.3 & 181 & 131.8 & 130 & 123.4 \\
\hline Entire flock & 375 & 154.5 & 375 & 154.5 & 375 & 154.5 \\
\hline
\end{tabular}

Body Changes.-When laying, a hen has a large, moist vent, showing a dilated pliable condition as compared to the puckered hardness of the vent of the non-laying hen. The abdominal region is enlarged in the layer, as compared with the non-layer. The pelvic bones move apart and become comparatively elastic and pliable. In an individual that is not laying, these bones almost come together just below the vent. The same individual when in full laying may show a distance of three or even four finger widths between them. The distance from the pelvic bones to the point of the keel (breast bone) is increased at the same time. These changes provide room for the passage of the egg, the enormous increase in the size of the ovary with its several rapidly growing ova and for the distention of the alimentary tract to accommodate large amounts of feed.

The heaviness of production is indicated in a measure by the relative softness and pliability of the skin and the thinness 
and elasticity of the pelvic bones. The subcutaneous fat of the abdomen is used up by laying, so that the abdominal skin of the heavy producer becomes velvety and the whole abdomen soft and flexible. The pelvic bones are also thin, tapering and elastic. In the non-layer they are likely to be thick, blunt and stiff, while the whole abdomen is surrounded under the skin with a layer of hard fat if the bird is on full feed. The great layer is slab-sided and deep, rather than round.

FIG. 71

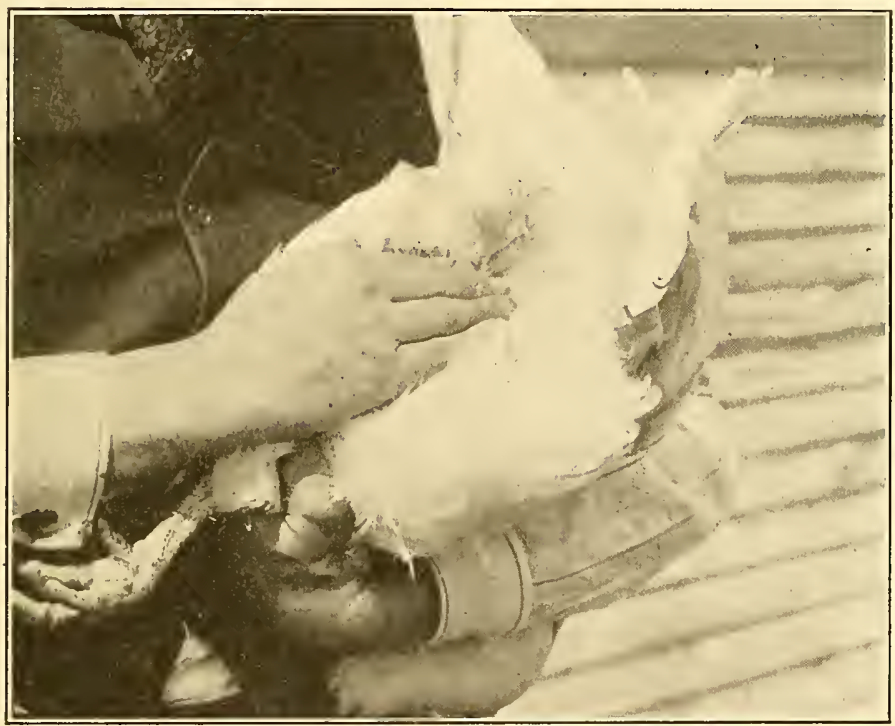

Proper way to hold a hen for finding the distance between the pelvic bones. (Courtesy of T. S. Townsley, University of Missouri.)

Among the most valuable indications of the heavy layer are the refinement of the head and the closeness and dryness of feathering. The wattles and earlobes fit close to the beak and are not loose and flabby. 'The face is clean cut and rather thin Puffiness in the face indicates meat rather than eggs. The eye is full, round and prominent as viewed across the tip of the beak. The high layer is trimmer in feathering than the poor layer, but after prolonged heavy production the oil 
does not keep the plumage so sleek and glossy. It becomes worn and frayed.

There is a close correlation between the relative size of the comb and wattles and ovarian activity. If they are comparatively large, full, smooth, hard and waxy, the hen is probably laying heavily; if the comb is limp but warm, the birds may be laying slowly; but if it is dried, shrunken and cold, she is not laying at all. When the comb warms up it is an indication that the bird is coming back into production.

FIG. 72

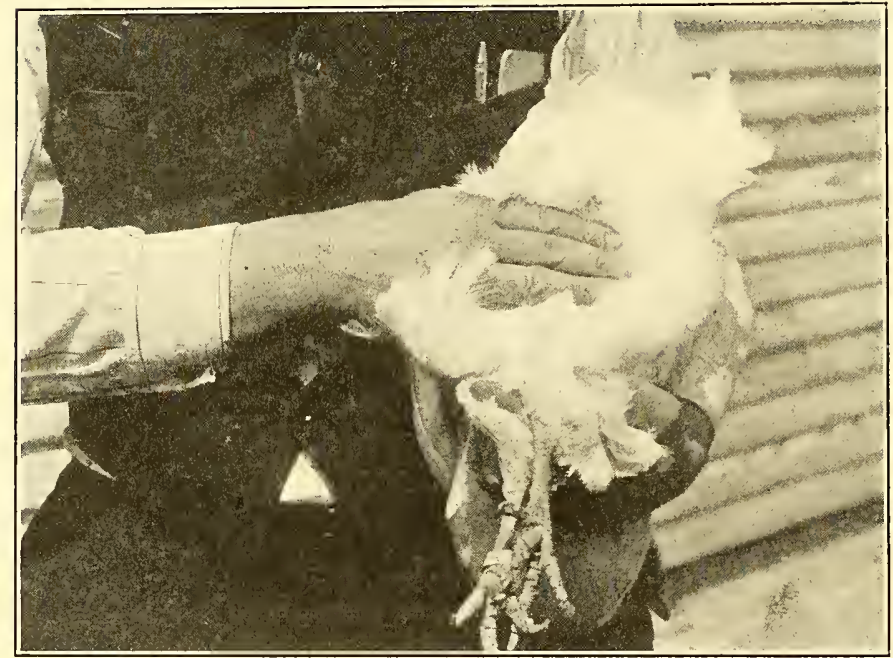

Showing the way to find the distance from the pelvic bones to the keel. Courtesy of T. S. Townsley, University of Missouri.)

Molting. - When a hen molts in the summer she almost always stops laying. The great producer is usually a late molter. The length of time a hen has been molting and hence not laying is indicated by the progress of the molt. It takes about six weeks to completely renew the primaries next to the axial feathers and an additional two weeks to renew each of the remaining primaries. 


\begin{tabular}{|c|c|c|c|c|}
\hline 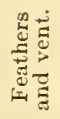 & 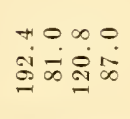 & מㅇำ & $\begin{array}{l}0.00 \\
0 \\
0 \\
0 \\
-1 \\
\end{array}$ & 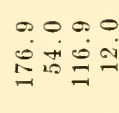 \\
\hline 趈 & 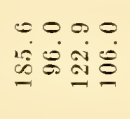 & $\begin{array}{l}20+0 \\
\text { is } 000 \\
0\end{array}$ & $\begin{array}{l}-0=0 \\
-000= \\
-000\end{array}$ & 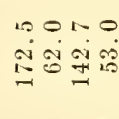 \\
\hline 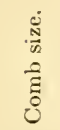 & $\begin{array}{l}000 \\
0000 \\
0=-10\end{array}$ & 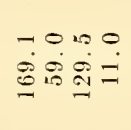 & $\begin{array}{l}19000 \\
10020 \\
0+1=0 \\
=00\end{array}$ & $\begin{array}{l}\infty 0100 \\
+0050 \\
0 \infty 00\end{array}$ \\
\hline $\begin{array}{l}\dot{0} \\
\stackrel{0}{0} \\
\dot{\Xi} \\
\ddot{\tilde{\Xi}}\end{array}$ & $\begin{array}{l}00+0 \\
0000 \\
000\end{array}$ & 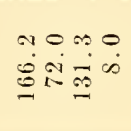 & $\begin{array}{l}\text { yon } \\
\text { is } \\
0.00 \\
0\end{array}$ & $\begin{array}{l}+0-0 \\
20 \\
0\end{array}$ \\
\hline 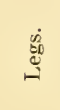 & $\begin{array}{l}00+0 \\
\infty \\
\infty \\
\infty\end{array}$ & 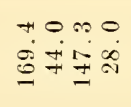 & $\begin{array}{l}+000 \\
090 \\
0\end{array}$ & $\begin{array}{l}0 \infty 0 \\
0 \infty \\
0 \\
0\end{array}$ \\
\hline 宛 & $\begin{array}{l}-0 \infty 0 \\
\dot{0}=-\infty\end{array}$ & 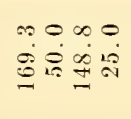 & $\begin{array}{l}10-0 \\
0=00 \\
1\end{array}$ & $\begin{array}{l}\theta 0 \infty 0 \\
\dot{0} \dot{0} 0 \\
\dot{0}\end{array}$ \\
\hline$\stackrel{\vec{E}}{\underline{\Xi}}$ & 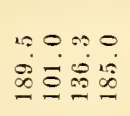 & 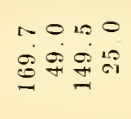 & 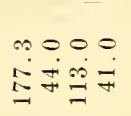 & 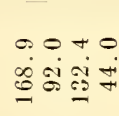 \\
\hline
\end{tabular}

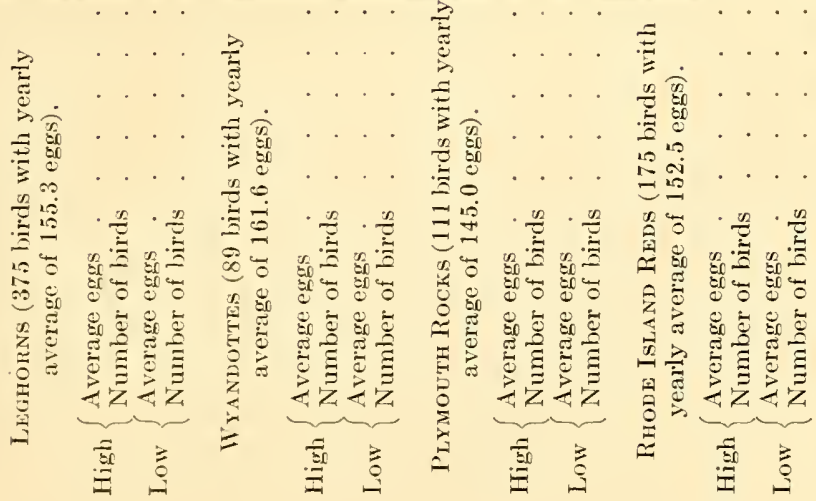


Temperament-A good layer is more active, nervous and alert, yet at the same time more easily handled than the poor layer. She is among the first off the perch in the morning and among the last on it at night. When not on the nest she is busy and business-like, scratching or ranging in an eager search for feed. The great layer is a bird of a never satisfied appetite.

Change in Weight of Eggs.-Hadley' has found that the innate producing ability of a hen is also shown by the degree of increase or decrease in the mean weight of her eggs, when this increase or decrease, calculated as per cent increase or decrease in those periods of laying characterized by the markedly increased production of the flock (particularly the spring). On this basis, groups of hens characterized by higher production may be differentiated as accurately as by any other means. 'The impulse to lay is manifested not only by numbers of eggs but by an increase in their weight.

Culling. - There is but one accurate means of determining the egg production of an individual hen or pullet, the trapnest. As has been pointed out in other comnections, the practice of trap-nesting is not practicable on most general farms. Fortunately, however, through the observation of the presence or absence of the indications of egg producing ability in individual hens, the better and poorer layers in a given flock may be separated with a fair degree of accuracy. The practice of making this separation and discarding the poor producers is referred to as culling.

In practising culling it is much easier to judge a hen's past performance than to predict her future production. Because it has proved most satisfactory, the usual season for culling is the late summer and early fall. During the summer the hens that go into a molt and display pigmented shanksmay be sent to market without reducing the flock production. Such a practice does reduce the feed bill. During the fall the culling should be more cautious but should be continued until the flock of hens is reduced to the size desired for carrying over winter for laying in addition to the pullets, and for 
FIG. 73

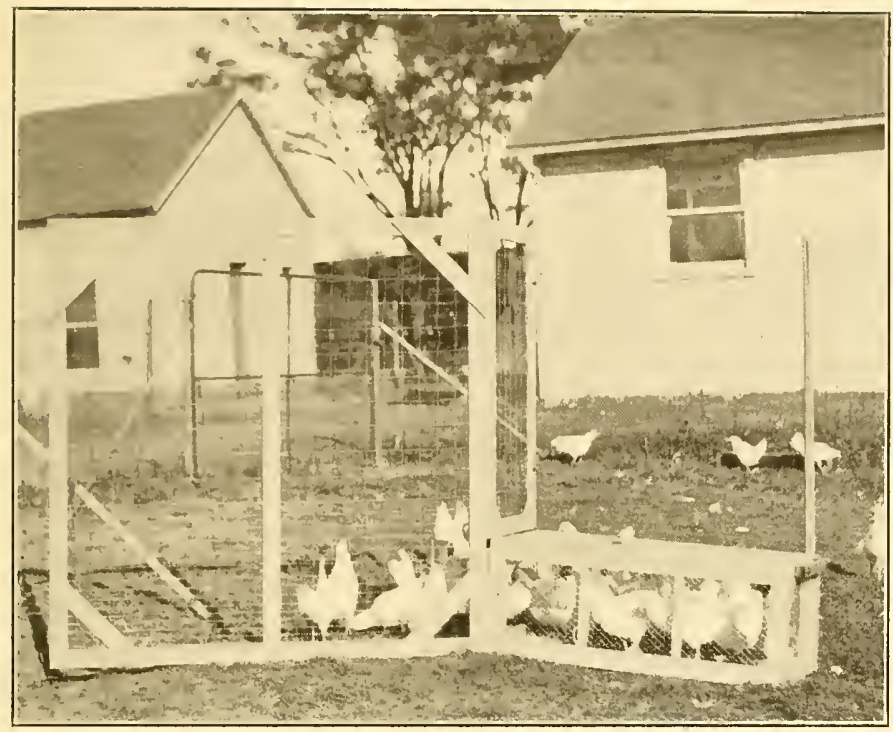

Portable wing and coop for catching chickens. A great convenience at culling time. (Courtesy of Kansas Agricultural Experiment Station.)

FIG. 74

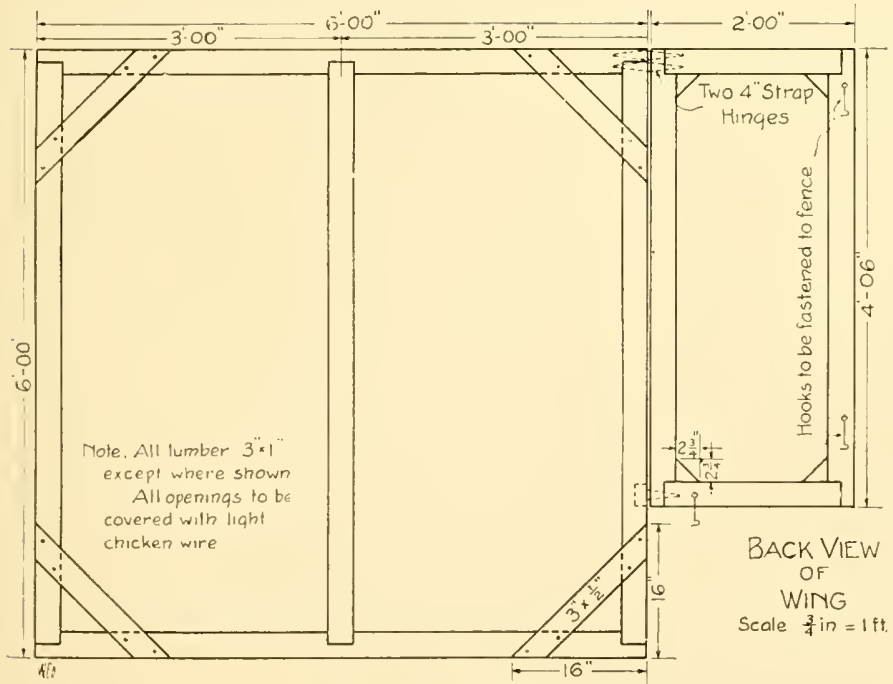

Plan of portable catching-wing shown in Figure 73. (Courtesy of Kansas Agricultural Experiment Station.) 

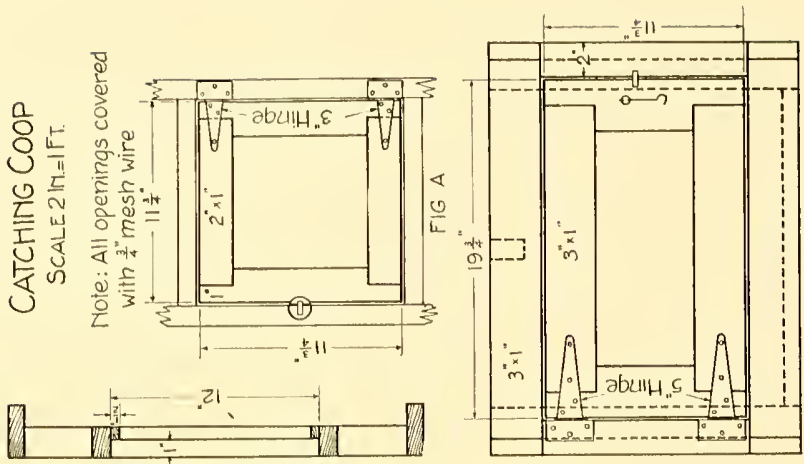

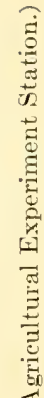
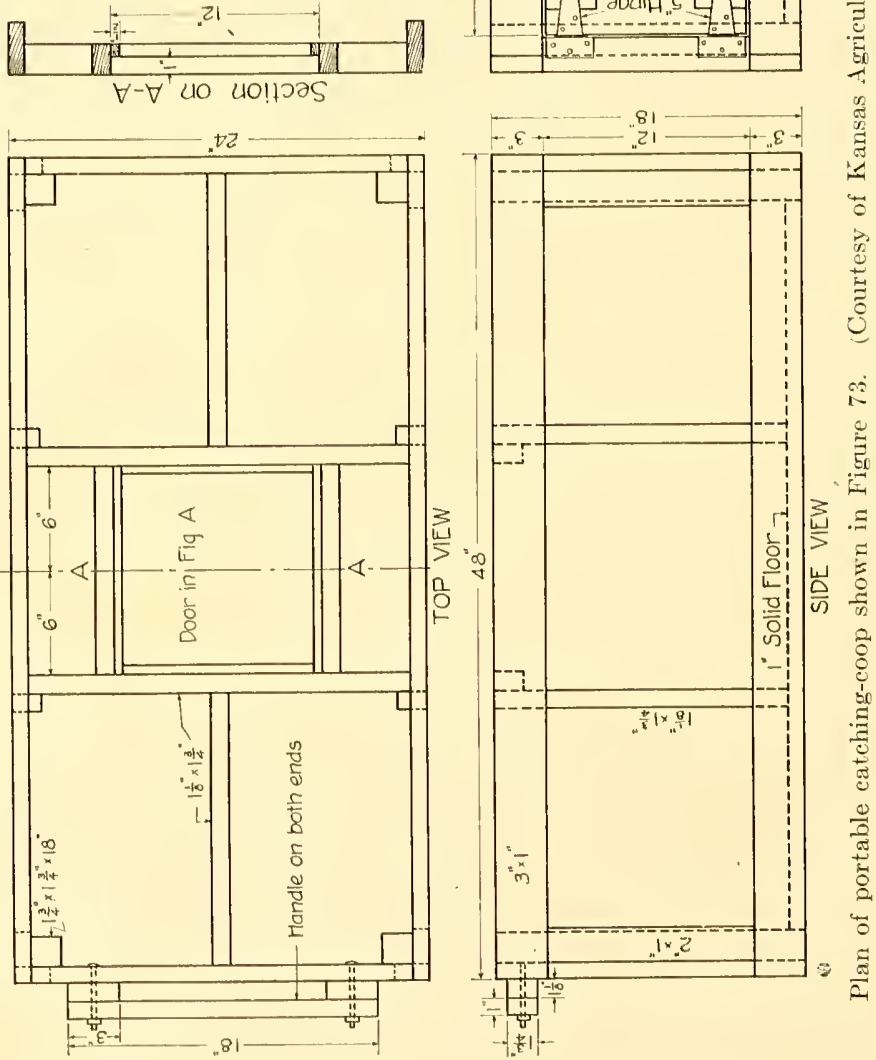
brecding the following spring. 'The late molting, pale shanked slab-sided hens of eapacity and refinement are those which should be the mothers of the next year's pullets.

Fis. 76

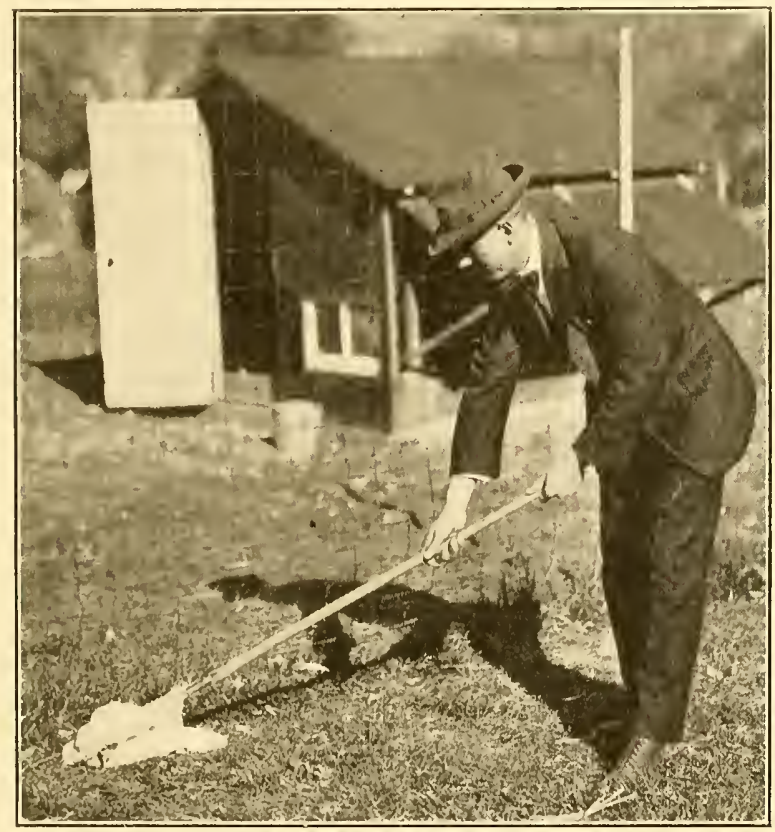

A common dip net is very convenient for catching single birds. (Courtesy of Kansas Agricultural Experiment Station.)

Comfort and Egg Production.-There is a very direct connection between the functioning of the reproductive apparatus and the comfort of the hen. 'This is to be expected, for it is the law of the field and of the breeding pen that organisms reproduce themselves most of ten when the conditions are most favorable for the race. Egg production is reproduction. The happy hen is the laying hen. Fright; improper food; damp, cold, or excessively hot weather; the irritation of vermin; too close confinement; or any other 
discomfort will radically affect the reproductive organs, with the very practical result of quickly cutting down egg production. These conditions also tend to lower vitality in both parent and offspring.

Productive Type.-It is impossible, in our present state of knowledge concerning the correlation between form and function, to formulate a definite and detailed description of the productive type, at all comparable with that of the dairy type in cattle, beyond that suggested by the indications of vigor and egg production, in connection with the breed types as given in The Standard. The present search for a fowl that will produce white eggs of good size in large numbers, carry a light pin-feather, and be as easily restrained and controlled as the present American breeds, gives a concrete example of what some of the very practical, though perhaps fundamentally superficial, items that make up the productive type will be. The dark pin-feather is coming into disfavor from a market stand-point because of its unattractive appearance upon the dressed carcass. Some packers make a difference of two cents a pound in the price paid for poultry of the same quality with the exception of the color of the pinfeathers. This puts a handicap upon the dark-feathered breeds, which will be much more apparent in the next few years than it is now. The demand for a white egg for table purposes is somewhat less insistent, and is slowly gaining in some sections while losing in others.

Longevity.-The desirability of longevity as a point of selection has not received the emphasis it should. Its lack is one of the fundamental weaknesses of the business of poultry breeding. It is one of the causes at the bottom of the generally recognized instability of poultry production as a separate and specialized industry.

In common with other live stock, there are three tests by which a breeding bird may be judged. These are, in the order of their efficiency, (1) the character of its progeny, (2) its own individuality, and (3) its ancestry.

The actual breeding test as shown by the character of the progeny is worth far more than both the other tests combined. This is increasingly true in the light of the recent 
revelations concerning the inheritance of fecundity. As a stallion bred in a speed-producing line, but not himself a great performer, can only be discovered to be a sire of great speed by the performance of his get, so the actual breeding ability of a male bird, with reference to fecundity, can be discovered only through the performance of his daughters at the nest. Under present practice, it is probably safe to assert that in nine cases out of ten, by the time the records

Fig. 77

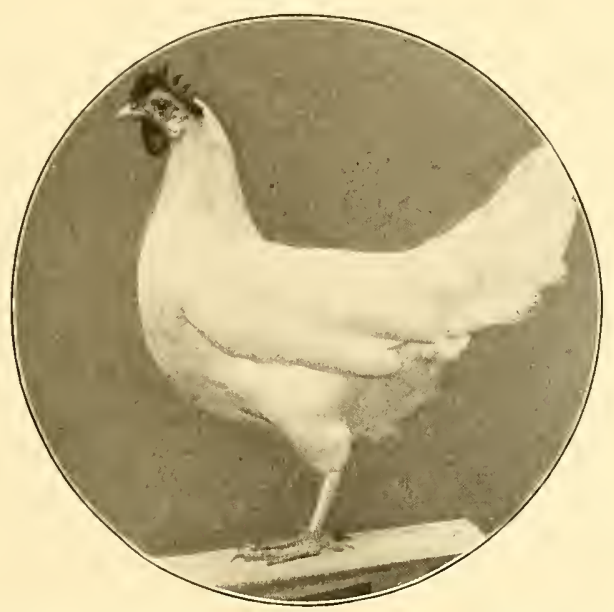

S. C. W. Leghorn, Oregona, with a five-year record of 987 eggs. She rounded out her 1000 eggs early in her sixth year. (Courtesy of Oregon Agricultural Experiment Station.)

of the daughters of an unusual breeder are available and it is discovered that he has a whole bevy of high-producing daughters, he is discarded and lost track of, if not actually destroyed. As long as the sire of prepotent sons and highproducing daughters can beget a few dozen chicks a year, he is a profitable investment to any breeder and of great value to his breed. To hope for stability in breeding for production there must be time to judge a male's breeding powers by the performance of his offspring, so that he may 
be used to his limit after his real value is discovered. The practice should be to use both males and females for breeding purposes so long as they will produce a reasonable number of vigorous chicks. There appears to be no good reason why the average breeding life of both males and females should not be at least five years.

Longevity is of as great importance to the producer as to the breeder. The profitable productive life of a hen is generally considered to be limited to two years. This neces-

FiG. 78

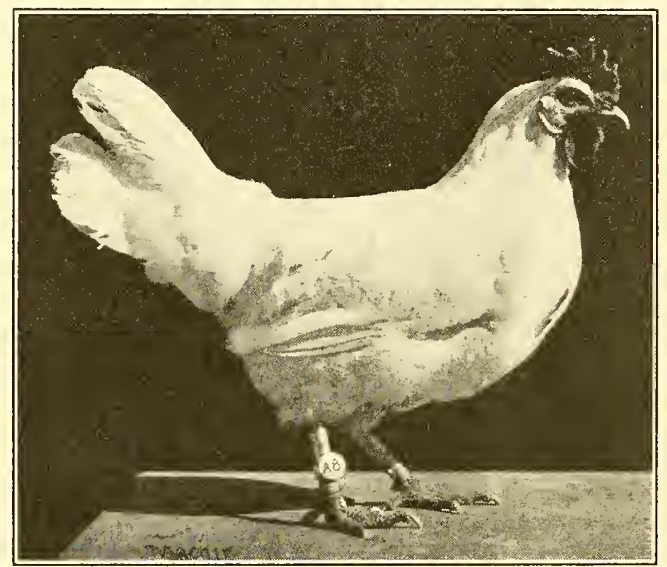

S. C. W. Leghorn, Kansas A8, with a fourth-year laying record of 226 eggs. Note button leg band whose number can be seen for some distance. (Courtesy of Kansas Agricultural Experiment Station.)

sitates the renewal of at least one-half the producing flock each year: an item of uncertainty with present methods and one of great expense.

As one step in developing a long-lived race of persistent producers, no breeding females should be used which have not lived at least two years and maintained the best of health. This engages the aid of the great law of "the survival of the fittest" in the selection of the breeders. The producer is then sure that his breeders at least have vitality enough 
to live and lay through the second summer. And those that stand this test and give strong indications of good production should be kept in service so long as they enjoy good health and remain active.

Pullets and Cockerels as Breeders. - The foregoing raises the question of the desirability of pullets and cockerels as breeders. Regarding the pullets the evidence is somewhat contradictory. In making a study of the comparative efficiency of pullets and hens as breeders, Stewart and Atwood ${ }^{2}$ made eight separate tests of Single Comb White Leghorn hens and pullets which are summarized in 'Table XXI. The hens were two and three years old.

Fig. 79

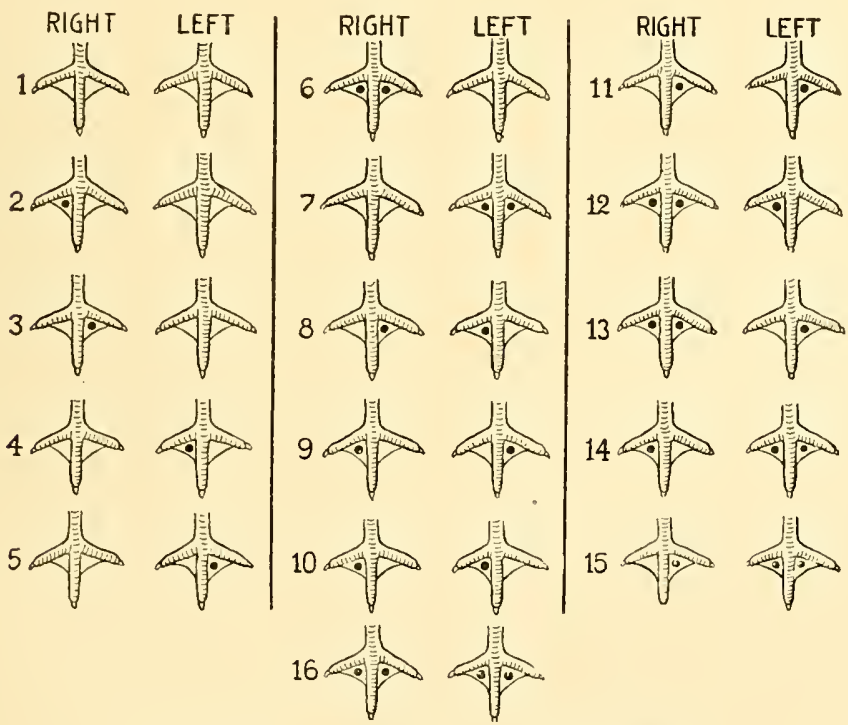

Showing sixteen ways of toe-marking chicks.

From Table XXI it will be readily seen that "the eggs from the pullets were smaller than the eggs from hens, and 
the chicks were smaller when they were hatched, grew more slowly, and more of them died from chick diseases than was the case with chicks hatched from eggs laid by the mature fowls."

\section{TABLE XXI.1}

Total number of eggs incubated

less those cracked in turning 1094.00

Average weight of eggs per hundred

Total number of chicks . . .

Per cent hatched of eggs incubated

12.96 pounds

840.00

76.7

Pullets.

Average weight of chicks per hundred when removed from incubator

Average weight of chicks at second weighing, per hundred

Hens.

871.00

11.19 pounds 591.00

67.8

Total number of recorded deaths

Per cent. of chicks which djed. .

\subsection{8 pounds}

29.56 pounds

42.00

5.00

\subsection{2 pounds}

23.07 pounds

85.00

14.5

FIG. 80

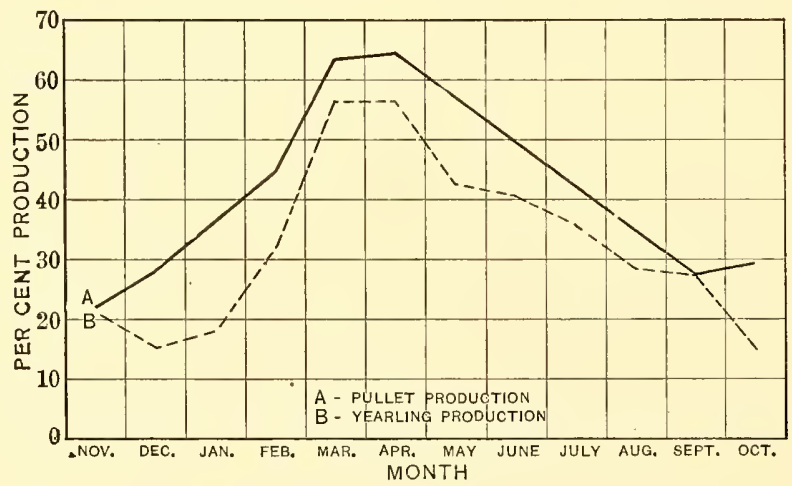

Comparison of pullet and yearling production of American breeds at the Vineland International Egglaying and Breeding Contest during the years 1616-1918.

Pearl $^{2}$ on the other hand, working with Barred Plymouth Rocks, found that the first breeding year was the best for both males and females. In his very careful study he made

1 West Virginia Bulletin, No. 124.

2 Genetics, vol. ii, No. 5. 
use of what he termed the Reproductive Index, which he proposed as a measure of the net reproductive ability of

Fig. 81

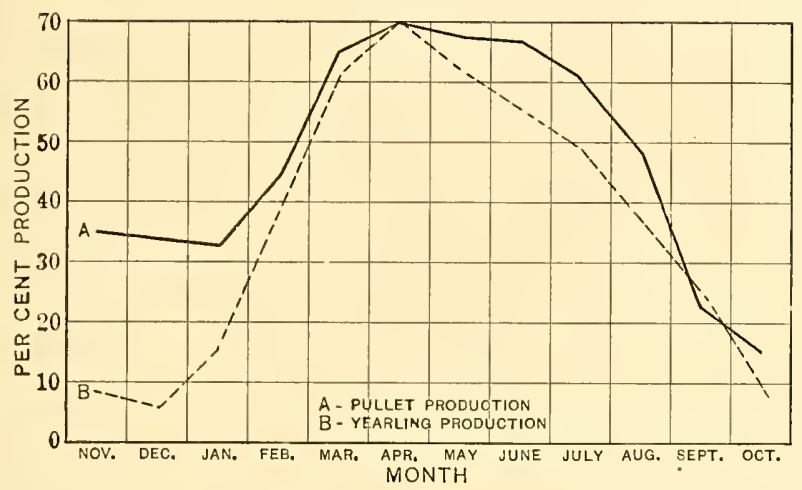

Comparison of pullet and yearling production of Leghorns at the Vineland International Egglaying and Breeding Contest during the years 19161918.

various matings. This Reproductive Index (RI) is as follows:

$$
\mathrm{RI}=\frac{\text { Number of chicks alive at end of the third week after hatching } \times 100}{\begin{array}{c}
\text { Total number of days from the day when this mating began to the } \\
\text { day when the last egg from this mating began its incubation. }
\end{array}}
$$

It is not altogether clear just what is meant by "the day when this mating began." Obviously the mating must have been made some days before the first eggs were saved in order that fertility might be established. "The day the first egg saved was laid" would possibly be a clearer statement.

The results of his studies based on the records of 1114 matings, shown in Tables XXII and XXIII, clearly indicate that for the stock he was breeding, the first was the best breeding year for both cockerels and pullets. It indicates further that the decline in reproductive ability with advancing age was more rapid for males than for females.

Pearl specifically states that only well-matured young 
birds were used, never less than ten months of age and from that up to fourteen months. Stewart and Atwood, on the other hand, refer to their pullets as early hatched. The three-year-old hens, they state, were selected on the basis of vigor. It is quite evident that there is need for more extensive records from all the breeds than is now available.

Table XXII.-Weighted Mean Reproductive Indices for Males of Specified Ages Mated with Females of all Ages. (Pearl's Data.)

Ages.

Male $=1$ mated with $q q$ of all ages

Male $=2$ mated with $q \uparrow$ of all ages

Male $=3$ mated with $q$ ㅇ of all ages
Weighted mean RT.

12.868

10.214

9.625

Table XXIII.-Weighted Mean Reproductive Indices for Females of Specified Ages Mated with Malfs of all Ages. (Pfarl's Data.)

Ages.

Female $=1$ mated with $\delta \delta^{\circ}$ of all ages

Female $=2$ mared with $\delta$ of all ages

Female $=3$ mated with $8 \delta^{\circ}$ of all ages
Weighted mean RI.

$$
\begin{aligned}
& 12.765 \\
& 11.660 \\
& 11.455
\end{aligned}
$$

Table XXIV.--Weighted Mean Reproductive Indices for Matings of Individuals of the Specified Combined Ages. (Pearl's Data.)

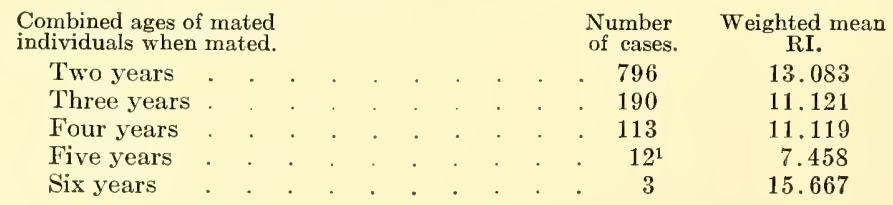

A record of the age of a fowl may easily be indicated by toe-marking each generation as it comes along in cases where pedigree records are not kept. By punching a different combination of holes in the webs of the feet each year a convenient and permanent means of establishing the age of any individual in the flock is furnished.

Individual Variation in Annual Production.-Opperman ${ }^{2}$ reports the individual yearly records of production given in

1 The cases are too few to give reliable results after a combined age of four years.

${ }^{2}$ Maryland Bulletin No. 157. 
Table XXV. The birds were March and April hatched Single Comb White Leghorns.

Table XXV.

\begin{tabular}{|c|c|c|c|c|c|c|c|}
\hline $\begin{array}{l}\text { Hen } \\
\text { No. }\end{array}$ & $\begin{array}{l}\text { First } \\
\text { year. }\end{array}$ & $\begin{array}{l}\text { Second } \\
\text { year. }\end{array}$ & $\begin{array}{l}\text { Third } \\
\text { year. }\end{array}$ & $\begin{array}{l}\text { Hen } \\
\text { No. }\end{array}$ & $\begin{array}{l}\text { First } \\
\text { year. }\end{array}$ & $\begin{array}{l}\text { Second } \\
\text { year. }\end{array}$ & $\begin{array}{l}\text { Third } \\
\text { year. }\end{array}$ \\
\hline 51 & 169 & 162 & 144 & 78 & 186 & 126 & 115 \\
\hline 54 & 168 & 192 & 146 & 86 & 207 & 172 & 174 \\
\hline 60 & 164 & 178 & 158 & 172 & 166 & 157 & 86 \\
\hline 62 & 162 & 120 & 102 & 178 & 156 & 144 & 122 \\
\hline 73 & 190 & 142 & 81 & 189 & 196 & 112 & 97 \\
\hline 76 & 152 & 119 & 136 & 190 & 185 & 186 & 171 \\
\hline 78 & 158 & 93 & 92 & 191 & 188 & 146 & 100 \\
\hline 82 & 165 & 140 & 108 & 195 & 217 & 161 & 132 \\
\hline 83 & 149 & 124 & 102 & 199 & 161 & 59 & 25 \\
\hline 84 & 146 & 104 & 107 & 208 & 156 & 140 & 102 \\
\hline 95 & 180 & 126 & 102 & 211 & 239 & 183 & 148 \\
\hline 97 & 173 & 151 & 156 & 215 & 144 & 110 & 111 \\
\hline 98 & 189 & 187 & 10 & 217 & 158 & 163 & 154 \\
\hline 110 & 191 & 142 & 111 & 218 & 169 & 210 & 159 \\
\hline 118 & 181 & 135 & 80 & 221 & 205 & 170 & 171 \\
\hline 121 & 164 & 96 & 102 & 223 & 158 & 113 & 82 \\
\hline 124 & 187 & 147 & 83 & 224 & 165 & 133 & 108 \\
\hline 125 & 164 & 212 & 163 & 236 & 182 & 107 & 82 \\
\hline 126 & 176 & 135 & 131 & 238 & 142 & 178 & 101 \\
\hline 127 & 216 & 199 & 167 & 239 & 143 & 221 & 111 \\
\hline 131 & 155 & 165 & 123 & 253 & 169 & 202 & 101 \\
\hline 132 & 166 & 147 & 180 & 256 & 178 & 152 & 91 \\
\hline 139 & 175 & 165 & 128 & 257 & 179 & 159 & 113 \\
\hline 147 & 179 & 142 & 111 & 260 & 147 & 114 & 90 \\
\hline 149 & 187 & 161 & 121 & 264 & 188 & 115 & 113 \\
\hline 156 & 179 & 175 & 134 & 265 & 162 & 153 & 131 \\
\hline 159 & 166 & 145 & 99 & 270 & 161 & 177 & 122 \\
\hline 165 & 157 & 152 & 25 & 272 & 11 & 155 & 101 \\
\hline 166 & 169 & 177 & 148 & 276 & 145 & 140 & 117 \\
\hline 170 & 153 & 112 & 97 & 290 & 147 & 140 & 130 \\
\hline Total & 5,130 & 4,445 & 3,447 & Total & $\begin{array}{l}5,150 \\
5,130\end{array}$ & $\begin{array}{l}4,498 \\
4,445\end{array}$ & $\begin{array}{l}3,460 \\
3,447\end{array}$ \\
\hline $\begin{array}{l}\text { Grand } \\
\text { Averag }\end{array}$ & duct & n per & . & & $\begin{array}{l}10,280 \\
171.3\end{array}$ & $\begin{array}{r}8,943 \\
149.05\end{array}$ & $\begin{array}{r}6,907 \\
115.1\end{array}$ \\
\hline
\end{tabular}

It will be noticed that while the first year's production is usually the best, there are numerous cases in which the 
second year gives the greater production, as with hens Nos. $54,125,239$, and 253 .

In the grand totals, however, the second year's production shows a decrease as compared with that of the first year of 13 per cent. And the third year shows a shrinkage of 32.2 per cent. as compared with the production of the first year, or a decrease of 56.2 eggs per hen.

Card ${ }^{1}$ found in a study of 106 White Leghorns at the Storrs Station that the correlation between the first and second year production was quite marked $(.688 \pm .035)$. This probably represents the average condition more nearly than the results of Ball, Alder and Egbert ${ }^{2}$ at the Utah Station which lead them to make the statement that for the family of birds with which they were working "individuals making an exceedingly high record one year very rarely hold their place the second or third year."

Early Maturity.-Quick growth means a less cost of production of both meat and eggs. The cost per pound of the slow-growing sorts is very much greater than with those that mature early. Quickly made gains are usually economical gains. With the rapid maturing bird, egg production comes earlier and is likely to be more persistent. As already stated in another connection, Rice $^{3}$ found from a study of the trap-nest egg records, covering several years' work at Cornell University, that it was the general rule that the early layers were the heavy layers in point of annual production. Evidence obtained at the Maine Station indicates that in all probability a close correlation exists between the rate of growth of a pullet during the first six weeks after hatching and her subsequent performance as a layer.

At the same time the point may well be raised, whether early maturity and longevity are not characters that are in more or less mutual opposition. The completion of records at the various experiment stations throwing light upon the question whether the precocious bird, so far as maturity is concerned, does not tend to be a short-lived bird will be

1 Jour. Am. Assn. Inst. and Invest. in Poul. Husb., No. 5, vol. iii.

2 Utah Bulletin, No. 148.

${ }^{3}$ Cornell Countryman, March, 1913. 
awaited with interest. Pearl ${ }^{1}$ remarks in discussing the inheritance of fecundity in domestic fowl that "after two years the fecundity of Plymouth Rocks, in all cases which have been observed at the Maine Experiment Station, becomes greatly reduced."

Table XXVi.--Reration of Early Laying to High Production.

(DAta of Rice.)

\begin{tabular}{|c|c|c|c|c|c|c|c|}
\hline $\begin{array}{l}\text { Grouped } \\
\text { according to } \\
\text { age first egg } \\
\text { was laid. }\end{array}$ & $\begin{array}{l}\text { Num- } \\
\text { ber of } \\
\text { hens. }\end{array}$ & $\begin{array}{l}\text { Per cent. } \\
\text { of total } \\
\text { hens. }\end{array}$ & $\begin{array}{c}\text { Average } \\
\text { age when } \\
\text { first egg } \\
\text { was laid. }\end{array}$ & $\begin{array}{l}\text { Average } \\
\text { product } \\
\text { first year. }\end{array}$ & $\begin{array}{l}\text { Average } \\
\text { product } \\
\text { second } \\
\text { year. }\end{array}$ & $\begin{array}{l}\text { Average } \\
\text { product } \\
\text { third } \\
\text { year. }\end{array}$ & $\begin{array}{l}\text { Average } \\
\text { total pro- } \\
\text { duct for } \\
\text { first three } \\
\text { years. }\end{array}$ \\
\hline $\begin{array}{l}151-180 \\
181-210 \\
211-240\end{array}$ & $\begin{array}{r}4 \\
71 \\
52\end{array}$ & $\begin{array}{r}2.37 \\
42.01 \\
30.77\end{array}$ & $\begin{array}{l}176.25 \\
199.77 \\
222.46\end{array}$ & $\begin{array}{l}173.25 \\
157.01 \\
140.10\end{array}$ & $\begin{array}{l}135.75 \\
133.63 \\
121.37\end{array}$ & $\begin{array}{l}126.50 \\
116.41 \\
106.19\end{array}$ & $\begin{array}{l}435.50 \\
407.05 \\
367.66\end{array}$ \\
\hline $151-240$ & 127 & 75.15 & 208.32 & 150.60 & 128.67 & 112.54 & 391.81 \\
\hline $\begin{array}{r}241-270 \\
271-300 \\
301-330 \\
331-360 \\
476 \\
1110\end{array}$ & $\begin{array}{r}22 \\
11 \\
6 \\
1 \\
1 \\
1\end{array}$ & $\begin{array}{r}13.02 \\
6.51 \\
3.55 \\
.59 \\
.59 \\
.59\end{array}$ & $\begin{array}{r}255.50 \\
285.09 \\
315.50 \\
359.00 \\
476.00 \\
1110.00\end{array}$ & $\begin{array}{r}108.10 \\
93.91 \\
88.33 \\
45.00 \\
27.00 \\
0.00\end{array}$ & $\begin{array}{r}121.05 \\
93.56 \\
129.00 \\
75.00 \\
155.00 \\
0.00\end{array}$ & $\begin{array}{r}108.50 \\
84.27 \\
107.67 \\
69.00 \\
126.00 \\
3.00\end{array}$ & $\begin{array}{r}337.65 \\
271.74 \\
325.00 \\
189.00 \\
308.00 \\
3.00\end{array}$ \\
\hline $241-1110$ & 42 & 24.85 & 299.88 & 95.55 & 111.81 & 99.00 & 306.36 \\
\hline Total & 169 & 100.00 & 231.08 & 136.92 & 124.48 & 109.18 & 370.57 \\
\hline
\end{tabular}

Breed and Varietal Characteristics.-Breed and varietal characteristics do a very real service in aiding in the selection of breeders. As pointed out in another connection, strong breed characteristics are generally considered to indicate close and careful breeding and to be a mark of prepotency. Other things being equal, the bird that shows most strongly the breed type and color markings is the bird to choose. Without them there could be no uniformity, which is so vastly important from the standpoints of both feeding and marketing.

Official Breeding Tests.-There is an urgent need of permanent breeding records of high-producing lines of stock

1 Maine Bulletin No 205. 
somewhat comparable to the records of the advanced registry for dairy cattle. The enormous numbers involved, the comparatively small economic value of the individual fowl, combined with the difficulty of accurately checking a system of reports, seem to inhibit any comprehensive plan for securing official production records. It is not unreasonable to hope, however, that a scheme for testing breeding males by making an actual trial of their breeding powers under certain specified conditions and later furnishing an official record of the winter production of their daughters may be worked out. Thus a March hatched male could be tested the following March and the winter production of his daughters known early in the following breeding season.

It would seem that at present the experiment stations of the several states furnish the logical place for such tests to be made.

\section{MANAGEMENT OF BREEDERS.}

The aim in the management of breeding stock is to secure a maximum of thrifty chicks. It involves the feeding, housing, incubating, and rearing of the stock intended for breeding purposes as well as the questions of exercise, the number of hens to be mated with one male, care of the breeding male, and the forcing of breeding hens for egg production. The more general questions of feeding, housing, incubating, and brooding are applicable to laying stock as well, and are treated in chapters bearing these headings respectively. These further questions concerning breeders specifically are important and should be given due consideration.

Exercise.-The relation between the activity of a bird and his or her breeding power is very marked. This is witnessed by the fact that in the breeds that are naturally very active, more females may be mated with a single male with good results than in the less active breeds. Those breeds that are not naturally rustlers must be encouraged to exercise freely. The free range offers the ideal opportunity, of which vigorous birds of any but the heaviest and most phlegmatic breeds will not be slow to take advantage. If free range is not available, the birds must be compelled to exercise 
freely the year round by scratching for grain in a deep straw litter. In extremely hot weather judgment must, of course, be used, and the enforced activity confined to early morning and the cool of the evening.

Number of Hens to be Mated with One Male.-Just what the maximum number of hens is that is proper to mate with any particular male is a matter of judgment which must be left to the individual breeder. It depends upon the present condition and previous treatment of the male himself and of the hens to be mated with him, and upon the conditions under which they are mated as well as upon breed and family characteristics.

In a general way it may be said that in confinement the number will run from 8 to 12 for the heavy breeds, from 10 to 15 for the breeds of medium weight, and 15 to 25 for the light, nervous, active breeds, supposing all have good vitality. Where the stock is ranging freely the numbers may be very much larger. The author once had occasion to hatch several hundred eggs from a flock of 250 Single Comb White Leghorn hens and four cockerels which were running on range, and secured above 90 per cent fertility.

In practice it is always better to err on the side of having too few hens than too many. The results will be very much more satisfactory from every standpoint. App, Waller and Lewis ${ }^{1}$ found that on 150 commercial poultry farms in New Jersey the proportion of males to females varied from one to fifteen up to as high as one to twenty-five with one to eighteen or twenty as the usual number. The stock on these farms was 94.3 per cent Leghorns.

Care of the Breeding Male.-The male bird during the breeding season should receive careful attention, as at this time he is truly "half the flock." Care should be taken that he receives sufficient food, as many males are so attentive in looking to the welfare of the hens that they will not eat enough food to maintain themselves in a vigorous and prepotent condition. It is well to feed the male apart from the hens. By a little care the male may be taught to jump up 
on the dropping board, where he may be fed, or come and eat from a dish held in the hand.

Attention should be paid to the claws and spurs, to see that they are blunt on sides and points in order to avoid torn backs in the hens. This is specially important in males of the heavy breeds. The feet should be examined to see that he is not suffering from bumble foot or any other trouble that would prevent satisfactory service. Not infrequently in loose feathered breeds it will be found necessary to clip the feathers about the vent before satisfactory service can be secured. This may apply to the females as well. The male should be kept free from lice by frequent applications of a good louse powder, as lice may be rapidly spread throughout an entire flock by an infested male.

He should be watched to see that he renders service completely and satisfactorily. He should be attentive but not clumsy and rough. At the end of ten days after a male has been placed with a flock which has not been running with a male previously, and at the end of two weeks when changing males, eggs should be incubated and tested for fertility at the end of five days, in order to be sure that the male is fertile.

Alternating Males.-Two practices resorted to for the purpose of securing good fertility with as few males as possible are the alternating of males and stud-breeding. With the former, twice the number of hens that would ordinarily be mated with one bird are confined in a single pen. With these two males are used, but on alternate days. One is allowed to run with the hens for twenty-four hours while the other is confined to a coop. The following day an exchange is made and the second male is given the freedom of the flock, while the first one is confined.

The theory of this practice is based on the supposition of favoritism on the part of males. It is generally believed that there are certain hens in most breeding flocks that are slighted by the male. By alternating males it is hoped that if favoritism is shown it will not be to the same hens.

This question of favoritism on the part of males is one upon which there is little definite information and upon which 
further investigation is needed. Philips ${ }^{1}$ has made a limited number of observations upon the mating habits of Leghorns, Plymouth Rocks, Rhode Island Reds and Langshans and and finds that mating or failure to mate is a matter largely controlled by the individual hen. The sex reaction appears to be much more markerl in some than in others. The former respond to the advances of the male and the mating act is accomplished. The latter fail to respond and no mating takes place. Should these observations be further substantiated it would appear that the alternating of males is unnecessary. It is impracticable where pedigreeing is practised because the paternal ancestry of the offspring is always in doubt.

Stud-breeding. - With the larger animals it is considered necessary to limit the number of services of a sire very strictly, for the purpose of conserving his strength and potency.

Assuming that the same principle holds with fowls and that the mating of a male with a female more than once within a given period of time is a waste of his powers, certain breeders have adopted the plan of controlling the number of times a male and a given female mate. Such a practice has been termed "stud-breeding." It is accomplished by keeping the males and hens in separate pens. The hens are one by one dropped in with the male. As soon as mating occurs, they are removed to their own pen.

Just what practical advantage there is in such a practice has not been determined. It would seem to be worth while only in case of extremely valuable birds.

Artificial Insemination. - It has been demonstrated at the Oklahoma Station, by Payne ${ }^{2}$ that hens may be successfully inseminated by artificial means, and eggs fertilized and hatched. It is possible that in the future such a practice may be resorted to in an effort to conserve the power of an exceptional male but at present no practical use is made of it.

Double Mating.-Double mating refers to the practice of using separate groups of breeders to produce exhibition birds

1 Jour. Am. Assn. Inst. and Invest, in Poul. Husb., vol. v, No. 4.

2 Oklahoma Circular, No. 30. 
of the two sexes. It is resorted to by breeders for the purpose of overcoming sex limitations in color.

The most familiar example of this practice is found among the breeders of Barred Plymouth Rocks. As previously explained, the males of this variety are always lighter in shade than their sisters (see Figure 70, page 144). According to the Barred Plymouth Rock "Standard," both males and females should be nearly the same shade for exhibition purposes. In order to secure them so, it is necessary to mate different groups of birds. A group dark enough to produce cockerels of the proper shade is referred to as a cockerel mating. The pullets from such a mating will generally of necessity be discarded for show purposes because they are too dark.

In the same way, a mating light enough in color to produce pullets of the proper shade is spoken of as a pullet mating. The cockerels from such a mating will usually be unfit for showing. A standard which requires double mating is an artificial one, and, from the standpoint of production, a ridiculous one. It results practically in breeding two subvarieties, from one of which exhibition males are selected, while exhibition females are selected from the other.

Surplus Cockerels.-All the cockerels on the producer's farm are surplus cockerels. They are a necessary by-product of pullet production, useless as breeders, unless the entire flock is pure bred, and to be disposed of in the easiest and most profitable way possible.

There are two alternatives open. One is to market them as broilers or fryers before they develop sexually and begin to tread the hens and worry the pullets. The price paid for early broilers usually is high enough so that at the age of a few weeks they bring in as much cash per bird as later when they weigh several pounds, but are staggy.

The second alternative is to caponize them and feed them out. In the sections where there is a ready market for capons, this may be done more profitably and the birds grown with the laying flock without inconvenience.

The Farm Breeding Flock.-The circumstances surrounding the producer are usually such that his laying flock and his 
breeding flock are the same. This necessitates the production of fertile eggs by all the layers, using eggs for hatching purposes from pullets as well as hens, and furnishing males enough to mate with the entire flock. Altogether this is an expensive proposition entailing loss in the market quality of the eggs, lower hatching power and weaker chicks from the eggs laid by pullets, and more males to feed.

Under general farm conditions, there is no reason why any distinction between breeders and layers should be made nine months in the year. All should have the free run of the farm. During the breeding season, however, a group of selected hens, should be confined in a chicken-tight, roomy pasture, with the males selected for the season's breeding. Only males out of standard-bred high-laying dams should be used as breeders. It must be clearly understood, however, that only a portion of such males will transmit high production to any large proportion of their daughters. 'This will remain true until line breeding with reference to high production has been carried on for a very much longer time than it has at present.

If one is so located that there is no danger of males from neighboring farms mixing with the breeding flock, a better practice would be to confine the laying flock and let the breeders range. At the end of the breeding season the males should be confined or sold. They should not be allowed to mingle further with the hens and pullets.

Community Breeding. - What is likely to be an increasingly important phase of poultry improvement work is community breeding. This refers to the uniting upon a single breed and variety of the majority of farmers in a given community, to the exclusion of other breeds. The advantages of this from the standpoints of feeding, marketing and general management are numerous as will appear in later sections of this book.

The Petaluma district of of California, the Little Compton section of Rhode Island and the Vineland district of New Jersey are famous the country over for particular breeds.

Effort directed toward bringing about similar conditions in other parts of the country is rather recent. Kentucky 
is taking a leading place in work of this kind. In that state twenty-four counties are endeavoring to breed Single Comb Rhode Island Reds, eight counties have chosen the White Wyandottes, twenty-seven counties are working toward making the White Piymouth Rock the predominating breed, and ten counties have chosen the Barred Plymouth Rock.

In Canada the province of Ontario is fast getting rid of everything but Barred Plymouth Rocks, which are being bred in a high state of excellence and breeding stock distributed by the Ontario Agricultura! College. 


\section{CHAPTER IV.}

\section{THE INCUBA'TION OF HENS' EGGS.}

The Egg and its Structure.-The analogy between the egg and the grains is in many ways closer than between the egg and any animal product commonly found on farms. Each represents an analogous stage in the reproductive cycle. Each contains, besides the living part, which develops into a new organism, enough food material to nourish that organism until it can seek nourishment for itself. With such grains as corn and wheat, where the food material is stored in an endosperm which is merely connected with the embryo, rather than in cotyledons which are a part of it, the analogy may be pressed still closer, because the food material in the egg is merely connected with the living part.

There are, however, certain interesting differences. The food material stored in the grain consists of starch, oil, and protein, while that of the eggs is fat and protein. The grain does not contain enough moisture for development, and must increase its moisture content about 200 per cent before it can germinate. 'The egg contains sufficient moisture for its own development, and though it is sometimes necessary to retard the evaporation of egg moisture, the egg does not, so far as is known, ever increase its moisture from outside sources. Grains germinate over a range of temperature running from nearly freezing, in the case of wheat, to about $103^{\circ} \mathrm{F}$. While eggs will start to develop at a much lower temperature than is popularly supposed $\left(68^{\circ} \mathrm{F}\right.$.), the range for eggs is not nearly so great as it is for seeds. The optimum germinating temperature for most seeds is around $86^{\circ} \mathrm{F}$., while the optimum incubating temperature is close to $103^{\circ}$ F., with an upward limit which Kellicott ${ }^{1}$ states is $41^{\circ} \mathrm{C}$. $\left(105.8^{\circ} \mathrm{F}\right.$.).

1 Chordate Development. 
The principal divisions of the egg, and their weights in per cent of the total weight of the egg are (1) the yolk, 32.75 per cent; (2) the white, 57.01 per cent; (3) the shell membranes, 0.25 per cent, and (4) the shell, 9.99 per cent.

The yolk and its "germ spot," known as the blastoderm, are inclosed in a delicate transparent membrane called the vitelline membrane. This membrane is responsible for the yolk maintaining a spherical shape. The material making up the body of the yolk is a highly nutritious food which is gradually digested and absorbed by the growing embryo. It has a rather definite structure, being divided into yellow and white yolk. As shown in Figure 82, the yellow yolk makes up the bulk of yolk material. 'The most of the white yolk is found in the flask-shaped mass situated at the center of the yolk sphere, with the neck extending toward and flaring out just beneath the blastoderm and entirely surrounding the yolk just inside the vitelline membrane. There are said to be several thin concentric layers of white yolk throughout the yolk mass (Figure 82 ), but these are sometimes difficult of demonstration.

In an egg that has not been moved for some time the yolk will be found to be floating on the white near that portion of the shell which is then uppermost and with the blastoderm uppermost. If the egg is turned the yolk will gradually return to the same relative position. This is caused by the lower specific gravity of the yolk as compared with the albumen, and of the hemisphere of the yolk supporting the blastoderm as compared with the opposite one.

It has been suggested that nature's purpose in this arrangement is to bring the blastoderm as close to the source of heat during natural incubation as possible.

According to Lillie, " "Both kinds of yolk are made up of innumerable spheres, which are, however, quite different in each. Those of the yellow yolk are on the whole larger than those of the white yolk, with extremely fine granular contents."

Immediately surrounding the yolk and adhering closely'

1 Development of the Chick. 
to the vitelline nembrane is a layer of very dense white which is prolonged toward the large and the small ends of the exg, respectively, in two whitish, convoluted strands (alled chalaze (Figure S2). The two chalaza are twisted in opposite directions. The line describing the long axis of the egg will pass through the bases of the two chalaza and be at right angles to the axis of the yolk passing through the center of the blastoderm.

Surrounding and continuing this dense white is a spiral layer of somewhat less dense white which is in turn

Fig. 82

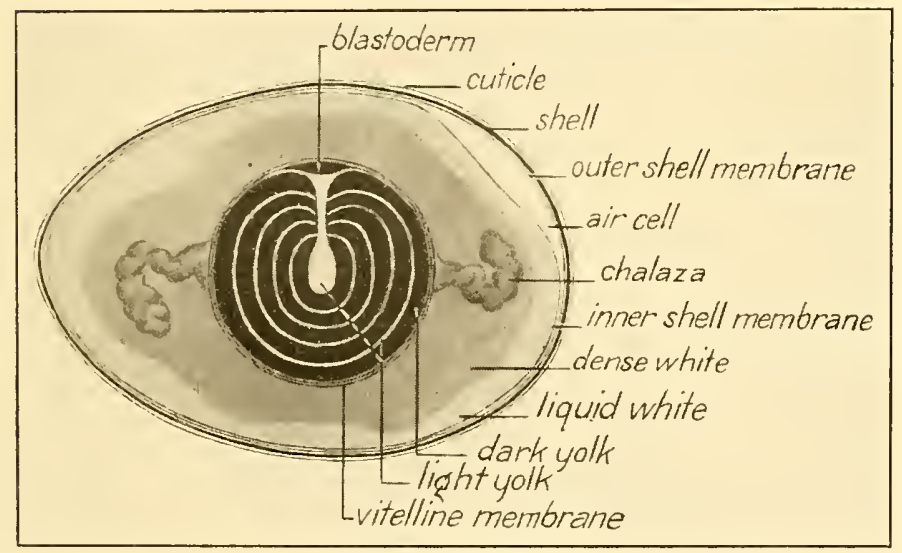

Parts of an egg.

surrounded by a thin, watery white. The difference between the dense and thin white is easily noted when a new-laid egg is broken into a saucer. ${ }^{1}$ The spiral formation of the white may be noted by carefully dissecting a hard-boiled egg. One of the functions of the white is to prevent microorganisms from reaching the germ spot. To this end it has marked bactericidal properties. Once in the yolk, bacteria are safe, for the yolk has no defensive properties. The shell membrane consists of two layers, a thick outer layer next to 
the she'l and a thinner one next the white. Both are composed of matted organic fibers (more delicate in the inner than

FIG. 83

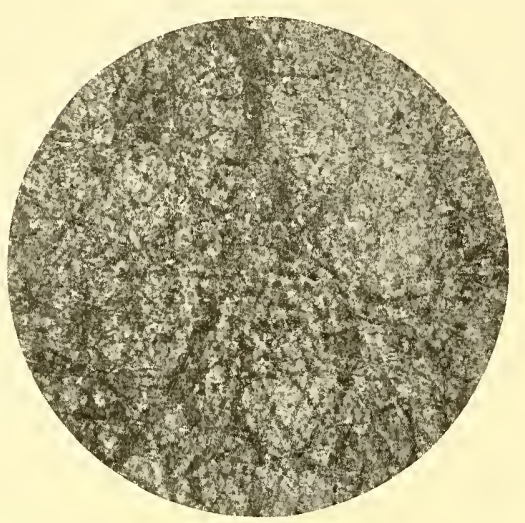

Outer shell membrane (magnified). (Courtesy of Bureau of Chemistry.)

FIG. 84

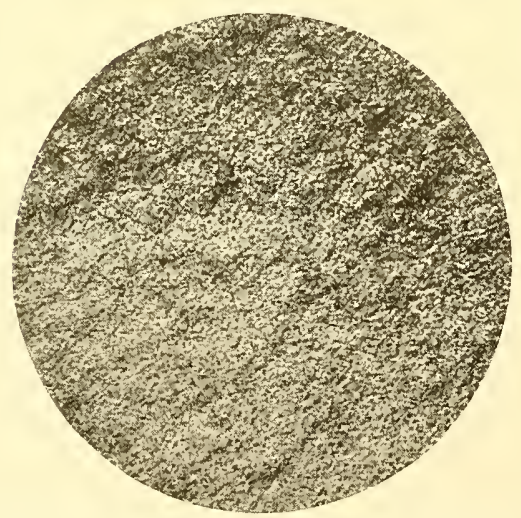

Inner shell membrane (magnified). (Courtesy of Bureau of Chemistry.)

in the outer layer), crossing one another in all directions. At the blunt end of the egg the two layers are separated and form an air chamber after the egg is laid. 
"The shell is composed of three layers: (1) the inner or mammillary layer, (2) the intermediate spongy layer, and (3) the surface cuticle.

"The mammillary layer consists of minute calcareous particles welded together, with conical faces impinging on the shell membrane; the minute air spaces between the conical inner ends of the mammillæ communicate with the meshes of the spongy layer, which is several times as thick, and which is bounded externally by the extremely delicate shell cuticle, spoken of on commercial eggs as the "bloom." The spongy layer consists of matted calcareous strands. The shell cuticle is porous, but apparently quite structureless otherwise. The cuticular pores communicate with the meshwork of the spongy layer; thus the entire shell is permeable to gases and permits embryonic respiration and evaporation of water."

"Under normal conditions the shell is bacterium proof. Moisture lessens its impervious character, however, and, when combined with dirt or filth, makes it possible for microorganisms to enter and bring about decay."'2

Size of Eggs.-The eggs of the different breeds of chickens vary somewhat in size. The average hen's egg is 2.27 inches long and 1.72 inches in diameter, where the circumference is greatest, and weighs about two ounces. This brings the weight of eight eggs of good size to a pound and the weight of a dozen eggs to a pound and a half. In some of the eastern states, where egg production has become a specialty, the average weight of hens' eggs is somewhat above two ounces. In most of the heavy-producing western states the average is somewhat below two aunces. The state of Iowa has a legal weight of one and a half pounds to the dozen, but the law is not enforced as the law concerning the moisture content of butter is enforced in many states.

Eggs laid by pullets are nearly always smaller than the eggs laid by the same individuals a year later. It was found by Atwood, ${ }^{3}$ at the West Virginia Experiment Station, that

\footnotetext{
1 Lillie's "Development of the Chick."

${ }^{2}$ Rettger, Storrs' Bulletin No. 75.

3 West Virginia Bulletin No. 124.
} 
this difference for hens and pullets of the same strain and under identical conditions was 1.77 pounds per hundred eggs.

Curtis ${ }^{1}$ found that eggs increase in weight continuously up to the end of the second laying season, but at a slower and steadily decreasing rate.

Development of the Chick.-The growth of the chick in the egg occupies the incubation period, which is analogous to the gestation period in mammals. It begins with the fertilization of the ovum and continues until hatching or birth, unless checked by some unfavorable condition.

Fig. 85

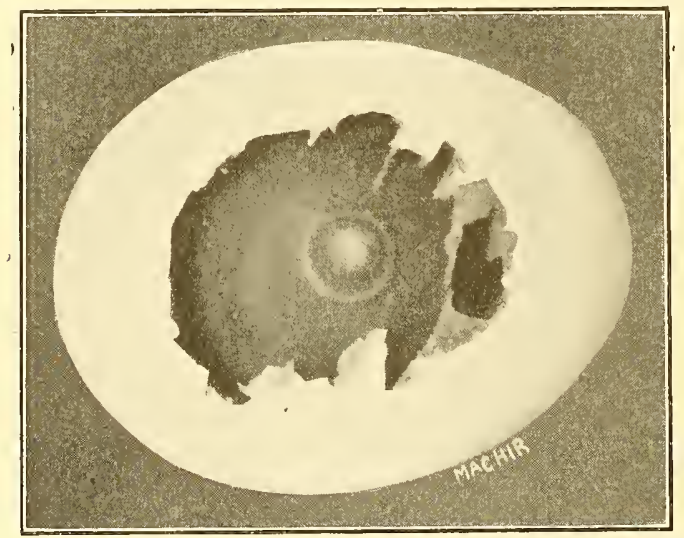

Appearance of a chick embryo after twelve hours in an incubator. (Courtesy of Kansas Agricultural Experiment Station.)

Development begins by simple cell division in the living portion of the egg, which is called the blastoderm, or, more commonly, the germ spot. The first development is a clear area called the area pellucida, and surrounded by a denser ring of cells called the area opaca. The growth of the embryo takes place in the area pellucida. In this area the so-called primitive streak develops, which is the first sign of the chick's body. This point in development is reached at about

1 Maine Bulletin No. 228. 
sixteen hours after fertilization, which usnally finds the egg still within the body of the hen (Figure S6).

" The position of the main embryonic axis is farry uniform, though not completely fixed. It lies approximately at right angles to the long axis of the whole egg, the anterior end of the embryo directerl to the left when the sharp end of the egg is held pointing away from the observer."'

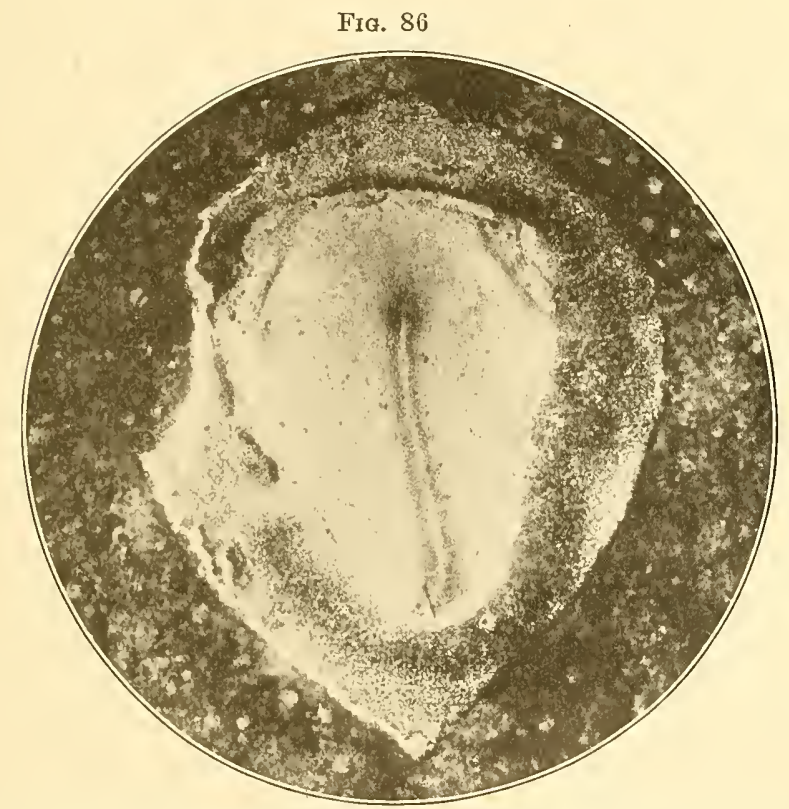

Embryo chick, sixteen hours old. Magnified. (Courtesy of Iowa Agricultural Experiment Station.)

If, after laying, the temperature of a fertile egg is allowed to fall below a temperature of $68^{\circ} \mathrm{F}$., all growth ceases, and the egg remains in a dormant condition until its temperature is again raised to incubating temperatures. While development takes place at all degrees of temperature between $68^{\circ} \mathrm{F}$. and that which is sufficiently high to destroy the life

1 Kellicott, Chordate Development. 
of the egg, normal development only takes place at normal temperatures. Pennington and Pierce $^{1}$ note that at $86^{\circ} \mathrm{F}$. to $91^{\circ} \mathrm{F}$. seven or eight days are required to equal three days at the normal heat of incubation. 'The reverse, however, is true also. If the temperature is somewhat above $103^{\circ} \mathrm{F}$., germination proceeds more rapidly. For instance, twentyfour hours at $104^{\circ} \mathrm{F}$. to $106^{\circ} \mathrm{F}$. gives a chick which is equal in development to one incubated for three days at $103^{\circ} \mathrm{F}$. In this commection the observations of Alsop on seventy-twohour embryos developed at high and low temperatures are of great interest. (See page 208.)

\section{FIG. 87}

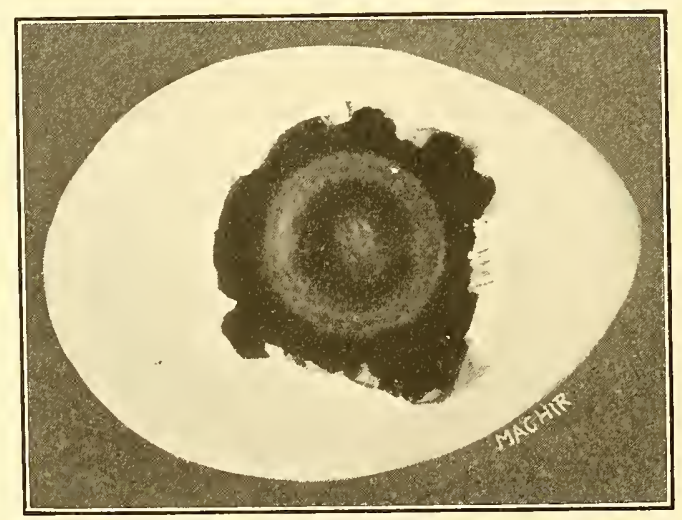

Appearance of a chick embryo after twenty-four hours in an incubator.

(Courtesy of Kansas Agricultural Experiment Station.)

As soon after laying as the egg is placed at a normal incubating temperature, cell division proceeds rapidly, and the cells form themselves into three layers which, from without to within, are referred to as the ectoderm, mesoderm, and endoderm. These three layers are the beginnings of three distinct divisions of the body.

From the ectoderm, the skin, feathers, beak, claws, nervous system, lens, and retina of the eye and linings of the

${ }^{1}$ Year-book, United States Department of Agriculture, 1910. 
mouth and rent are formed. The bones, muscles, blood, reproductive and excretory organs develop from the mesoderm, while the endoderm produces the linings of the digestive tract and the respiratory and secretory organs.

FIG. 88

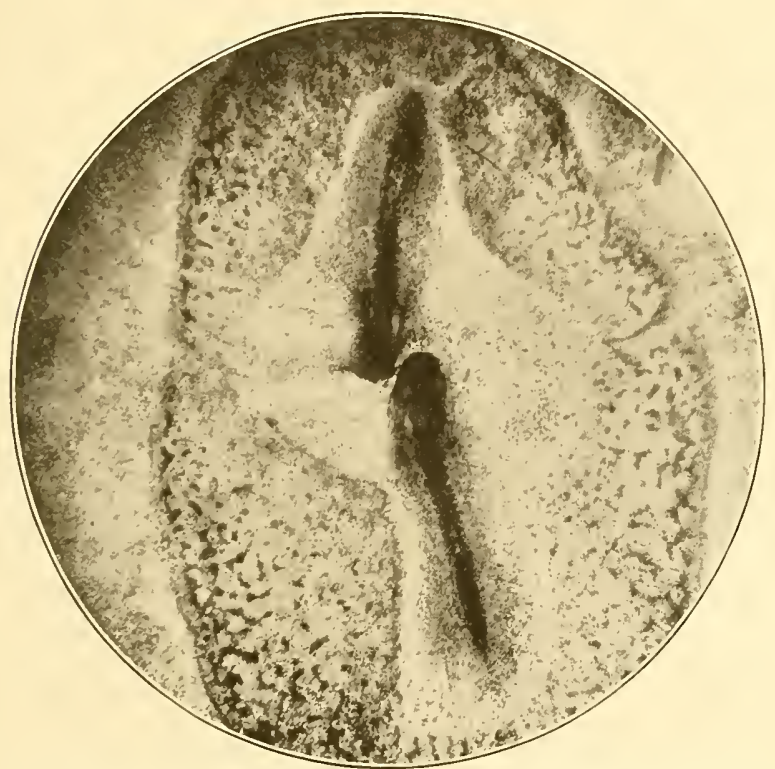

Two embryos (twins) developing on one yolk, thirty-two hours old. Magnified. (Courtesy of Iowa Agricultural Experiment Station.)

At about the twenty-fourth hour of incubation a membrane called the amnion develops and gradually surrounds the growing embryo. This amnion is filled with a colorless fluid called the amniotic fluid, which serves as a protection from shock and allows the embryo to move about freely. The growth of the amnion constricts the connection of the yolk with the embryo to a narrow stem called the yolk stalk. This stalk corresponds to the umbilical cord in mammals. At about the thirtieth hour the heart of the chick has developed far enough to be observed to beat. 
Near the middle of the second day a blind sac begins to push out from the posterior end of the alimentary tract, which grows rapidly until it completely covers the embryo at about the ninth day and has come in close contact with the shell membrane. It is abundantly supplied with bloodvessels and, although it is outside the body of the embryo, serves as the organ of both respiration and excretion until the chick commences to pip the shell and the lungs and kidneys of the chick commence to function.

It is the veins of this allantois which are seen radiating from the embryo at the first testing, about the seventh day

FIG. 89

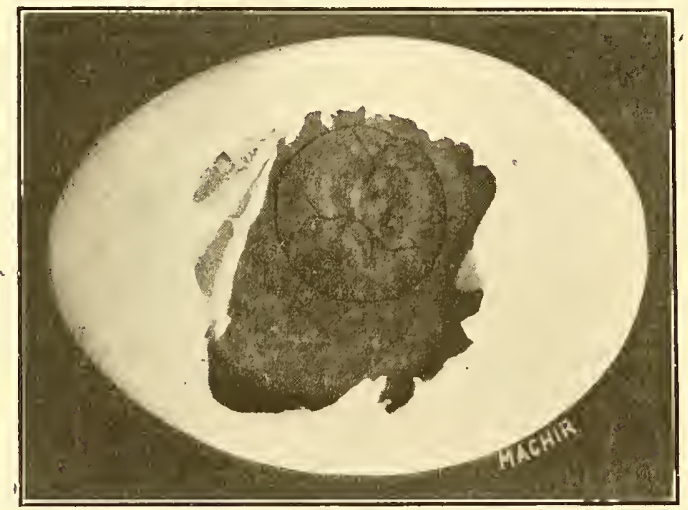

Appearance of a chick embryo after thirty-six hours in an incubator.

(Courtesy of Kansas Agricultural Experiment Station.)

of incubation, and which may be noted plainly at the second testing, about the fourteenth day. As soon as the chick pips the shell, pulmonary circulation starts and the allantois ceases to function, begins to degenerate, and is left behind in the shell at hatching.

Up to the sixth or seventh day there is nothing about the chick embryo that would help one to distinguish it from the embryo of any other animal. At this time the legs and wings begin to take a recognizable form. The body, which has been very small in proportion to the head, begins to develop 
more rapidly and to assume a more proportionate size. About the tenth day the little sacs containing the feathers begin to protrude, particularly along the back of the embryo. At this time there is a chalky deposit about the mouth opening, which is the beginning of the horny beak. Upon breaking an egg, what appears to be voluntary movement may be noticed as early as the sixth day.

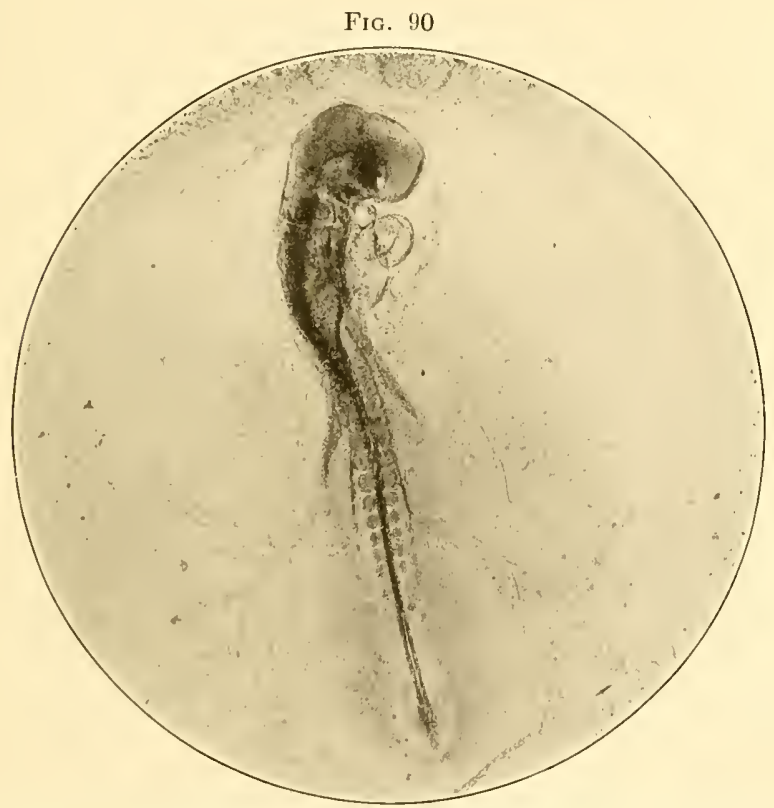

Embryo chick, forty-eight hours old, with the heart located outside the body. Magnified. (Courtesy of Iowa Agricultural Experiment Station.)

By the thirteenth day the feathers are distributed over the body. Their color may be seen through the thin walls of the sacs, which inclose them until the nineteenth day. On the thirteenth day the scales and nails appear, and by the sixteenth day are found to be quite firm and horny, as is also the beak. By the sixteenth day the white of the egg has disappeared, and the embryo subsists thereafter wholly 
upon the yolk. On the n neteenth day what remains of the yolk is drawn into the body cavity. This appears to be the most critical day of the incubation period, for as Payne ${ }^{1}$ has shown, 20 per cent of the mortality occurring during the twenty-one days of the incubation period occur on the nineteenth day, and 48 per cent of the total prehatching mortality occur on the eighteenth, nineteenth, twentieth and twenty-first days. The respiratory system changes completely on the twentieth day. Until that time the allantois functions as the chief respiratory organ, and, in fact, as the excretory organ as well. With the pipping of the shell pulmonary breathing begins.

Fig. 91

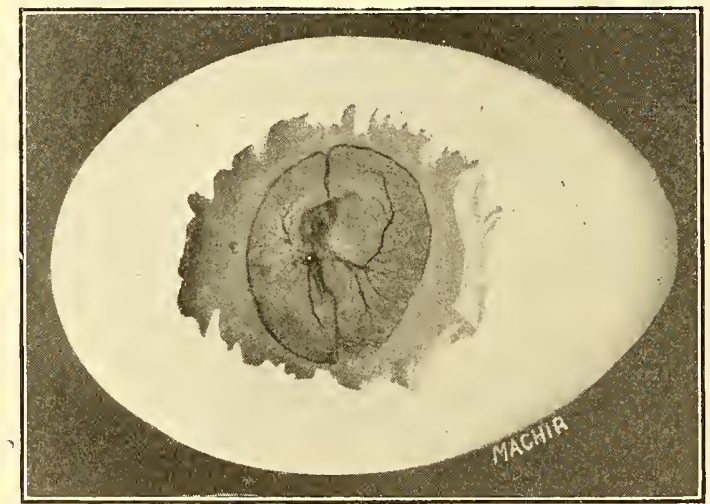

Appearance of a chick embryo after forty-eight hours in an incubator (Courtesy of Kansas Agricultural Experiment Station.)

When formed the chick is placed in the egg with its head bent forward beneath the right wing and the legs brought up toward the head. The end of the upper mandible of the beak is equipped with a horny cap which bears a sharp point, and by means of this, while slowly revolving in the shell, the chick is able to press against the shell, chipping it in a circular path around the large end of the egg, at the same time

1 Jour. Am. Assn. Inst. and Invest. in Poul. Husb., vol. vi, No. 2. 
cutting the membranes within. According to Pohlman ${ }^{1}$ "the active muscular agent in breaking the shell comes about

FIG. 92

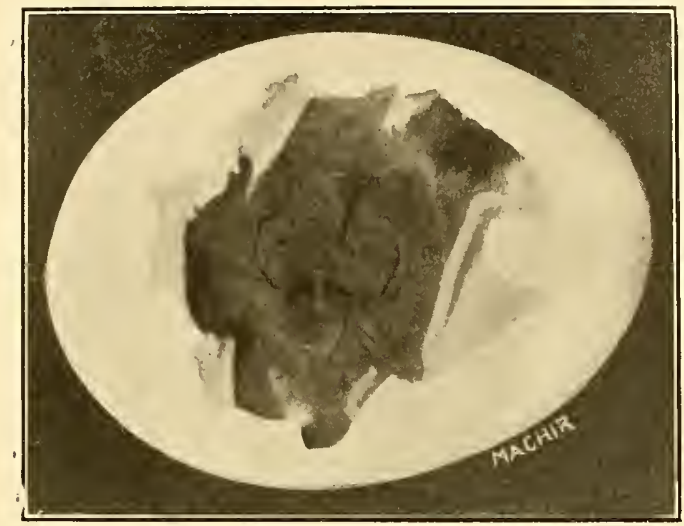

Appearance of a chick embryo after sixty hours in an incubator.

(Courtesy of Kansas Agricultural Experiment Station.)

FIG. 93

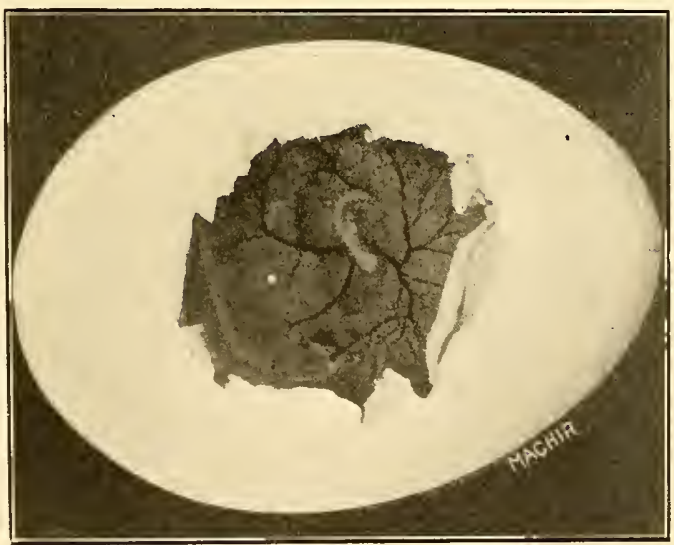

Appearance of a chick embryo after seventy-two hours in an incubator. (Courtesy of Kansas Agricultural Experiment Station.)

1 Anatomical Record, vol. xrii, No. 2. 
through a change in posture of the head and upper cervical vertebræ, chicfly dependent on the musculus biventer and musculus spinalis. The reflex mechanism which touches oft this muscle system is probably a respiratory reflex, not dependent on demand for oxygen, but dependent on distention of the abdomen . . . brought about through injection of the yolk sac (into the body cavity)." When the shell is nearly cut around a final convulsion by the chick finishes the break, and the chick can emerge.

FIG. 94

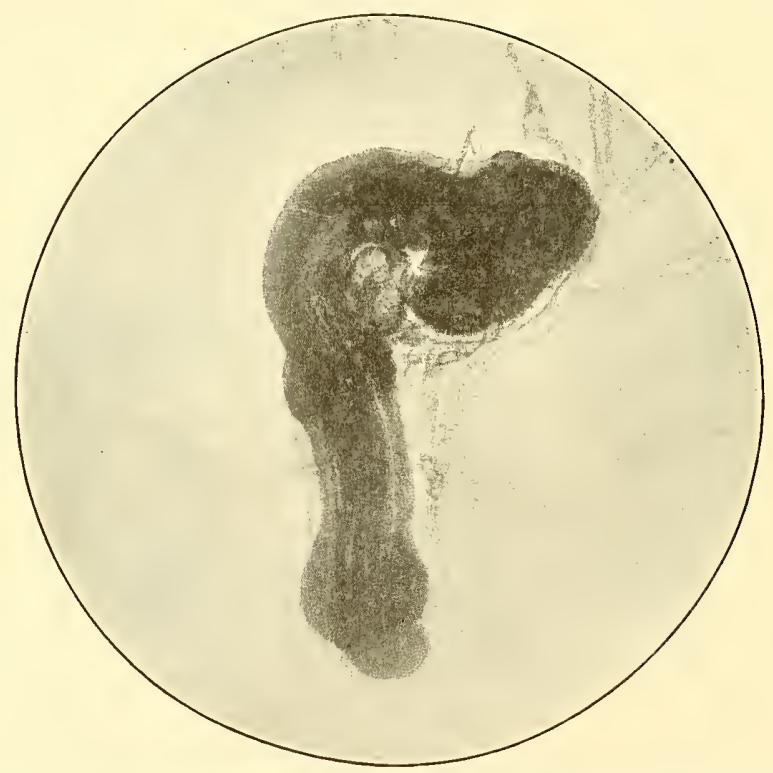

Embryo chick, ninety-six hours old, the wing and leg buds and the tail fold showing plainly. The heart is still located outside the body. (Courtesy of Iowa Agricultural Experiment Station.)

Selecting Eggs for Hatching.-In selecting eggs for hatching purposes, by far the most important consideration is the health and vigor of the parent stock. The reason why this is so vastly important is fully discussed elsewhere. Suffice 


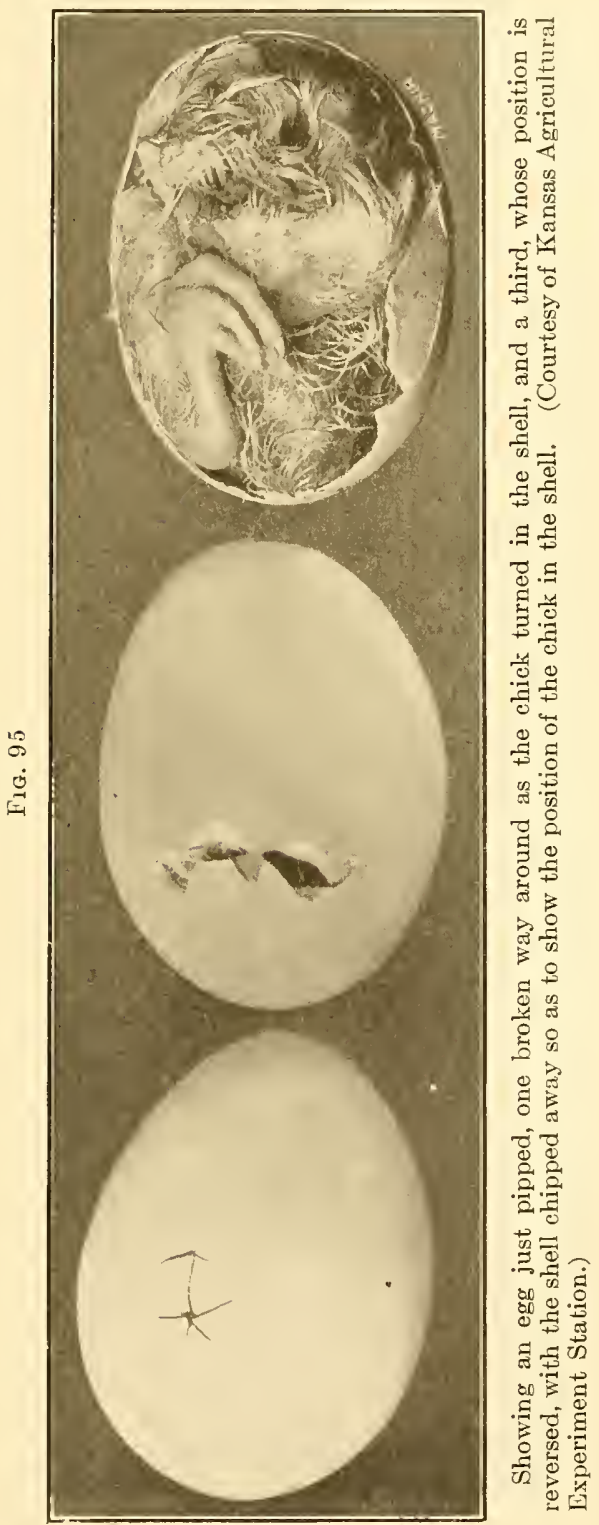


it to say that the fundamental selection is that of the parents. It far outweighs every other consideration.

Beyond this it is well that the eggs from desirable breeders should be normal in every observable characteristic, and of the size and color most demanded by the market catered to. It should be noted in this connection that Philips ${ }^{1}$ and Atwood ${ }^{2}$ have independently come to the conclusion that brown eggs are more difficult to hatch than white ones. No eggs should be incubated which weigh less than two ounces. The twenty-four-ounce dozen and the case of thirty dozen weighing forty-five pounds net are the generally accepted standards, below which eggs are not considered first class.

They should be uniform in size, shape, and color; free from ridges, excrescences, or weak shells. The practice of hatching abnormal eggs tends to increase the lack of that uniformity which is so desirable from every stand-point, because pullets hatched from small or odd-shaped eggs are likely to produce abnormal eggs in turn.

Philips $^{3}$ found as a result of four seasons work during which several thousand chicks were hatched, that on the average it took 1.83 eggs to hatch one Leghorn chick, and 4.57 eggs to produce a twenty-four weeks old Leghorn pullet. With the heavier breeds under average management conditions it will be safe to allow at least seven or eight eggs for each mature pullet desired.

Predetermining Fertility and Sex.-The manifest advantage of being able to ascertain whether an egg is fertile and if hatched what the sex of the chick will be, by an external examination, is so great that it has led to much speculation. Out of this speculation have grown "sure methods" of accomplishing it. Needless to say these "methods" are unsupported by experimental evidence, and are practically worthless. The one which is given widest credence is that the shape of the shell is an indication of the sex of chick that will result if the egg is hatched. It has long since been found that the long, narrow eggs popularly credited with hatching only

1 Jour. Am. Assn. Inst. and Invest. in Poul. Husb., vol. iii, No. 9.

2 West Virginia Circular, No. 25. 3 Purdue Bulletin, No. 196. 
males in the long run give about 50 per cent females, and that the short, round eggs supposed to produce a preponderance of females, when hatched in large numbers produce a little above or below 50 per cent of males.

The position of the air cell during incubation, though not so widely preached, is equally unreliable as a means of prejudging sex. It has been maintained that when the air cell develops so that the long axis of the egg passes through the approximate center of the air space the sex of the developing embryo is male. When the long axis is very much eccentric and the cell extends down the side of the egg the sex of the embryo is said to be female. The author had occasion to examine several hundred eggs for the purpose of observing the relative numbers of each sex hatched from eggs containing each type of air cell. Unfortunately the detailed data have not been preserved, but the sex of the resulting chicks in each case was represented in nearly equal numbers.

The only means of predetermining the fertility of an egg that has had any very general acceptance has been by determining the relative specific gravity of eggs.

The claim is made that the eggs showing a great specific gravity are fertile, while those whose specific gravity is much less are infertile. As a matter of fact, these differences between the eggs of certain hens may be observed whether the hens have been mated with males and are laying eggs that are presumably fertile, or whether they have been separated from male birds for several weeks. While there does appear to be a correlation between the specific gravity of an egg and the vigor of the hen laying it on the one hand, and the chick hatching from it on the other, there is no noticeable correlation between the fact of a great specific gravity and the fact of fertilization.

Care of Hatching Eggs. - At the time the fertile egg is laid it is usually in a fairly advanced stage of development from an embryological stand-point, having been incubated within the body of the hen for approximately twenty-four hours. It would seem that the ideal method of caring for hatching eggs would be to allow development to proceed without checking, by incubating the eggs at once without ever 
allowing them to become completely cool. Poultry keepers, however, are under the necessity of holding hatching eggs for a longer or shorter time, and are confronted with the very practical question of how to handle them during the period of suspended development with the least possible damage to their vitality and hatching power. They should be collected several times a day during February and March to prevent chilling.

Table XXVil.-Relation of Time of Holding Hatching Eggs to Their Hatching Power. Summary of 189 Incubator Records1914 то 1919. (DATA OF WAITE.)

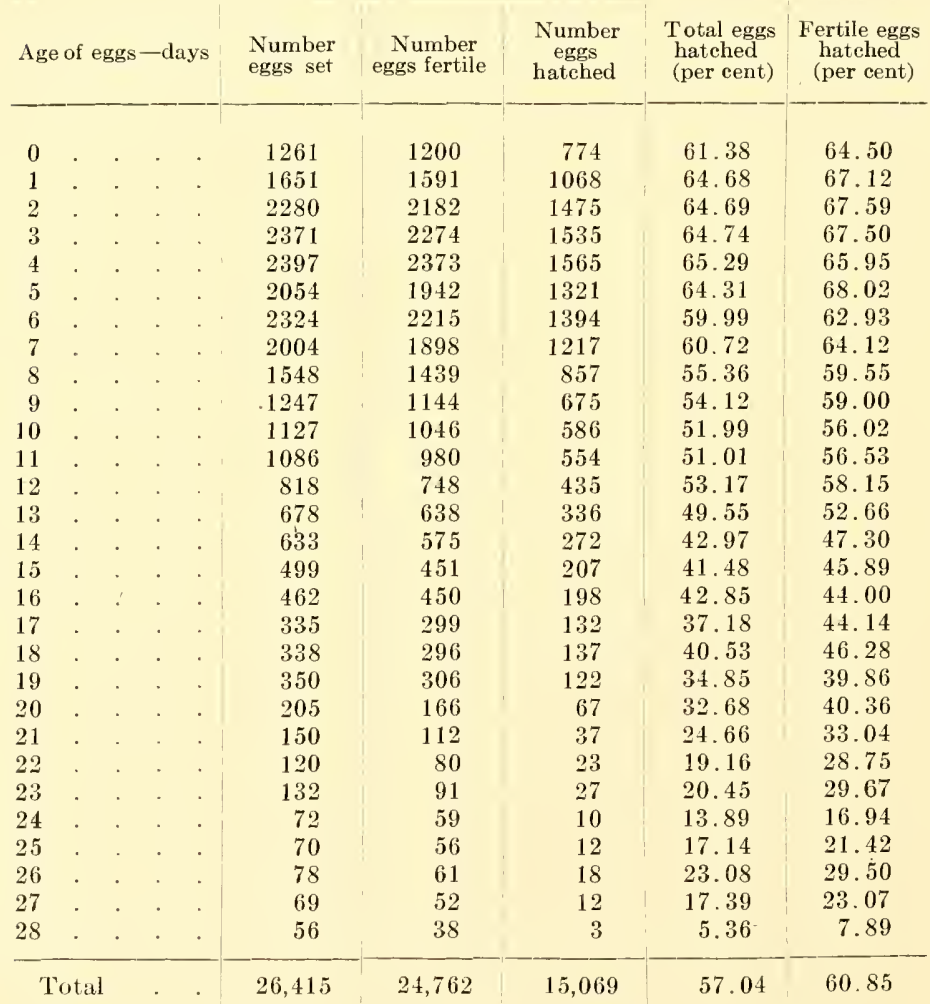


Time of Holding Hatching Eggs.-Holding eggs for incubating purposes is a necessary evil to be practised as little as possible. Two weeks is generally considered as the outside limit of holding eggs under the very best conditions that will give satisfactory hatching results. Waite ${ }^{1}$ found, as shown in Table XYVII, that the percentage of eggs not hatching showed a fairly consistent increase for all periods longer than one week.

FIG. 96

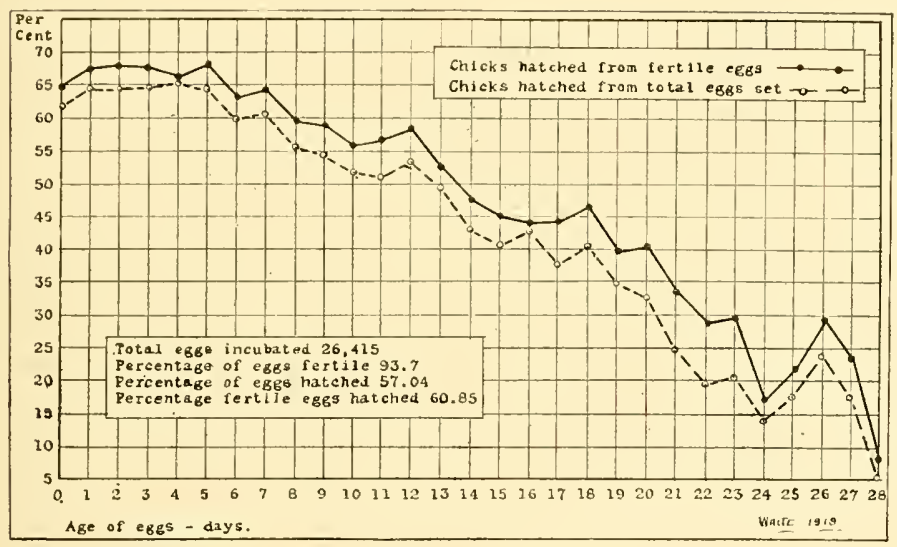

A graphic presentation of Table XXVIr. (After Waite)

Temperature for Holding Hatching Eggs.-The belief that the earlier the development that is under way at the time of laying is checked, the better are the chances of holding eggs successfully for hatching, has led to the general practice among poultrymen of gathering the eggs often during the incubating season and putting them in a cool place.

Edwards, ${ }^{2}$ as the result of a series of comprehensive experiments, has fixed the physiologic zero of the hen's egg at a temperature lying between $20^{\circ}$ and $21^{\circ} \mathrm{C}$. This is the practical equivalent of saying that an egg will start to incubate at a temperature lying between $68^{\circ}$ and $70^{\circ} \mathrm{F}$, and that to

1 Miryland Bulletin, No. 233.

2 American Journal of Physiology, vol. vi, No. 35. 
insure the complete checking of development, eggs must be kept in a temperature below $68^{\circ} \mathrm{F}$. Practical experience seems to indicate that eggs held in a temperature that is even as possible, lying between the limits of $55^{\circ}$ and $65^{\circ} \mathrm{F}$., give best results. Just what the temperature is at which eggs begin to show the effects of chilling has not been determined so far as the author is aware. The place most likely to furnish the best holding condition is a cool, well-ventilated cellar.

Turning Hatching Eggs.-As already pointed out, the yolk, with the germ spot uppermost, tends to float on the albumen. It is prevented from coming in actual contact with the shell membrane by the dense layer of albumen which surrounds it. When left in the same position for a considerable time a constant though gentle tendency upward parts the coat of dense albumen and allows the germinal disc to come in contact with the shell membrane. With evaporation constantly taking place the tiny embryo becomes adhered to the membrane and is destroyed. When the eggs are not allowed to remain in the same position, but are turned fairly frequently, a new point of contact is given, and more albumen brought between the germ and the shell membrane.

Jackson $^{1}$ reports, as the result of experiment, that after the first two weeks there was a distinct advantage in keeping eggs on their side and turning daily over, keeping them in any other position or without turning. It is considered good practice to turn all eggs daily during the whole time they are held.

Washing Hatching Eggs.-Eggs that are stained or dirty are frequently washed with the hope of increasing their hatching power. As a protection against disease, hatching eggs are often washed in alcohol or other disinfectant.

Washing eggs destroys their protective coating, called the cuticle or bloom, and allows more rapid evaporation. As shown elsewhere, when artificial incubation is practised, evaporation is likely to be abnormally rapid, and any practice which increases evaporation should be looked upon with 
suspicion. Jackson ${ }^{1}$ found in a test where 440 eggs were incubated in several groups, and half of each group were washed and half unwashed, that the unwashed eggs hatched 12.5 per cent more vigorous chicks, than the washed eggs.

Where eggs are broken in a nest and their contents smeared over other eggs in the nest, it is very likely to prevent the latter from hatching. In this case, washing appears to be the lesser of two evils.

In cases where it seems advisable to disinfect hatching eggs, they should be dipped, instead of sponged or washed, and allowed to dry without being rubbed.

Resting Shipped Eggs.-Persons shipping eggs any distance for hatching, frequently furnish instructions to the effect that the eggs are to be unpacked, placed in a normal position on their sides, and rested twenty-four hours before setting, for the purpose of allowing the germ to resume its normal position at the uppermost point of the yolk. Such resting does no harm beyond increasing the holding period by so long, but it remains to be proved that the eggs cannot rest just as successfully in an incubator or under a hen as in any other place.

Apparently the only data on this point are those given by Gowell ${ }^{2}$ who shipped two similar lots of eggs a distance of 514 miles. From the lot of 65 eggs which were rested twentyfour hours, 15 chicks were secured, while from the other lot put immediately into the incubator 22 chicks were obtained. The numbers are too small to be conclusive but there appeared to be no marked advantage at least, in resting the eggs.

Warming Hatching Eggs.--Under natural conditions all eggs but the one laid last are of necessity held for hatching for a longer or shorter time. Jackson ${ }^{3}$ observed that very often the oldest egg in a clutch was frequently the first to hatch. He further noted the fact that in laying, the average time spent on the nest was approximately sixty minutes. As a result of two years' work, he found that by placing eggs, being held for hatching for a considerable time, under

1 Pennsylvania Bulletin No. 120.

2 Maine Station Report, 1902.

3 Ibid, 
hens for sixty minutes daily during the holding period, he increased the number of vigorous chicks by 10 per cent.

He states that he "noticed further in handling eggs in incubators both years, that the embryos of the warmed eggs, after being placed in the incubator, presented a distinctly different appearance from those eggs not warmed, being more clear cut, larger in size at the same period of incubation, more active, and giving every appearance of being stronger and more vigorous.

"Considering both tests, it seems apparent that there is no particular gain to be secured from warming eggs that are to be held for a period of not more than ten or twelve days, although this requires further investigation. Apparently the vitality of the embryo suffers when held for a longer period."

Jackson suggests no practical method of warming eggs held for hatching purposes, and no good method has been devised.

A possible partial explanation of the above may be had in the findings of Bushnell and Maurer, ${ }^{1}$ who report that bacteria found in normal eggs do not develop readily at blood (or incubating) temperatures, but do develop at ordinary room temperatures. As they suggest, when eggs are kept for hatching at ordinary temperatures, enough development of the organisms may take place during the time intervening between the laying of the eggs and their incubation, to bring about decomposition enough to injure the delicate embryo chick by vitiating its food-supply. Infertile eggs presumably frequently infected do not decompose when kept at incubator temperatures for three weeks.

Disinfecting Purchased Eggs.-Because of the prevalence of certain chick diseases, and the fact that their germs are found adhering to the shells, some poultrymen are disinfecting their eggs by dipping them in 92 per cent alcohol or in a 2 to 3 per cent solution of a standard stock dip. This is a safe precaution in all cases where eggs are secured from flocks with whose history one is not perfectly familiar. It is unnecessary in cases where the eggs come from stock that

${ }^{1}$ Unpublished data of Kansas Agricultural Experiment Station. 
has been strong and vigorous for years and without serious outbreak of disease of any kind. It should be recognized as simply a precautionary measure to eliminate any disease germs that may be on the outside of the egg, and not in any measure a sure preventive of chick diseases.

Incubation Periods. - The number of days necessary for the incubation of the eggs of the various species of poultry are as follows: chickens, varying from 19 for light breeds to 21 for heary breeds; turkey 28 , varying from 26 to 30 ; all ducks except the Muscovy 28, varying from 26 to 32 ; Muscovy ducks 33 to 35 ; goose 30 , varying from 27 to 33 ; guinea, varying from 26 to 30 , and pigeon 17 from the day the second egg is laid, but varying at times from 16 to 20 days.

Relative Hatching Efficiency of Hens and Incubators. - The time has passed when the question of the desirability of having an incubator on a farm where upward of one hundred and fifty chickens are raised annually is any more debatable than the desirability of having a cream separator, seed tester, or any similar piece of modern farm equipment. Hens are uncertain hatchers. Broodiness depends very much upon the season and the condition of the hens. A late spring means late laying, late setting, ${ }^{1}$ and hatching. 'The time of hatching determines quite largely whether pullets are in laying condition by the following winter. And further, it is usually difficult to secure enough broody hens at one time to handle a very large number of eggs.

Concerning the efficiency of incubators as hatchers, Pearl $^{2}$ makes the following statement, which would be concurred in spirit by the majority of practical poultrymen and investigators.

"In the experience of this station, with proper management during and subsequent to incubation, the chicks so produced are fully the equal in constitutional vigor, average duration of life, and productivity, of hen-hatched chicks.

1 The author takes the position with reference to the use of the terms "sit" and "set," or their derivatives, as describing the act of a broody hen in incubating eggs, that good use, rather than any rule of technical grammarians, should be the test applied. The terms "set," "setters," and "setting" are used throughout this work.

2 Poultry Management at Maine Station, 1913. 
"For more than ten years past all chicks in the Maine Experiment Station's poultry plant have been hatched in incubators. There has yet to appear any reason for going back to the old system of hatching with hens."

Payne, ${ }^{1}$ on the other hand, found in contrasting natural and artificial incubation that several interesting differences occur. The incubator according to his data appears to be more efficient than the hen during the first week of incubation, judged by the number of embryos dying, but is conspicuously inferior during the last week.

Natural Incubation.-The principles involved in natural and artificial hatching are the same. While the effort in artificial hatching is to furnish the conditions found in nature, it should be recognized that nature rarely furnishes optimum degrees of all conditions at the same time. Recognizing the proper conditions of successful hatching, one may assist nature in combining all conditions at their best.

Kind of Hen to Set.-The best hens for setting are those of medium weight, such as are found among the American and English breeds. They are fairly persistent setters, but are not so heavy as to be clumsy, nor so heavily feathered as to make the eradication of vermin difficult. The Asiatic breeds are very persistent setters, but are so heavy and clumsy that the loss of eggs from breakage is considerable. Their long, heavy feathers furnish a safe harbor for lice.

The Mediterranean breeds seldom become broody. Such individuals as do take to the nest are unreliable and likely to leave it permanently with little or no provocation.

The Hatching Nest.-The nest for hatching should be roomy and secluded, and placed where it is cool and the ventilation good. It should be at least sixteen inches square by six inches deep, and placed where the hen will not need to fly or jump into it. If placed on the floor there is little danger of broken eggs if the nest is made right.

The nesting material should be of such consistency that it will neither pack, as does dirt, sawdust, or planer shavings, nor become tangled with the hen's feet so that she is likely to

1 Jour. Am. Inst. Assn. and Invest. in Poul. Husb., vol. vi, No. 2. 
wreck the nest upon leaving it to eat, as in the case of excelsior, rags, or long shavings. At the same time it should not be given to knotting or balling up, but soft and pliable enough to conform more or less closely to the body of the hen. Oat straw is probably the most satisfactory nesting material, with wheat straw or hay as second choice.

In placing the straw in the nest, care should be taken to round the nest out so that the eggs will roll apart readily when the hen steps among them, but not to leave it so flat that the eggs will not roll together of their own accord.

The nesting material should be renewed for every hatch or when eggs are broken, and the nest carefully disinfected. A vigilant lookout must be kept for mites about the nest box during the setting period, and prompt and thorough measures for eradication taken upon their appearance. During the warm weather, these pests multiply so rapidly as to greatly deplete a setting hen's vitality, even causing them to die on the nest.

It is good practice to place a teaspoonful of a good coal tar dip in the bottom of the nest before putting in the straw. Many successful poultrymen follow the practice of putting a damp sod beneath the straw for the purpose of furnishing moisture where it is not possible to make the nest on the ground.

Management of Setting Hens.-When more than one hell is setting at the same time and place, it is a safe plan to confine them to the nest and allow them to come off once daily at a regular time to feed and dust. If all are set at the same time it makes little difference whether they return to the same nests or not. The material used for confining them should allow a free circulation of air, such as poultry netting.

Clean, cool water and plenty of whole grain, grit, and charcoal should be available for the hen when she leaves the nest. Nothing in the nature of sloppy food, which tends toward bowel looseness, should be fed.

If possible a setting hen should be rendered absolutely louse-free before being placed on the hatching nest, as lice form one of the commonest and greatest sources of danger to hen-hatched chicks. She should be thoroughly dusted 
with good insect or louse powder before being placed on the eggs, and the process repeated at the end of the first and second weeks of the incubating period. It is unsafe to dust the hens just before hatching because some of the commercial powders are of such strength that they will kill chicks under a week old.

Care should be taken to be particularly thorough in working the powder well into the feathers, under the wings, and the fluff around the vent. These are the regions which usually show the heaviest infestation.

It is always a safe precaution to grease the heads of henhatched chicks with lard, in order to preclude the possibility of head lice.

Number of Eggs per Hen.-The number of eggs that should be given to one hen is determined by the size of the hen and the season of the year. The usual number constituting a setting is fifteen. In cold weather, however, eleven to thirteen is all that one hen of medium size can cover successfully. When the weather is warm, fifteen, or if it is very warm, seventeen eggs may be placed under a hen with safety.

Breaking up Broody Hens.-When hens that are not desired for setting become broody, and it is desired to leep them from the nests of the layers and to induce them to lay again as soon as possible, they should be confined in a coop that offers no opportunity for nesting. The broody coop shown in Figure 155, having a slatted bottom, is useful for this purpose.

During the time that the birds are confined they should be well fed and cared for, so that they will soon be in laying trim. For all but the heaviest breeds a few days of confinement on a bare floor with no nesting material will be sufficient to overcome the desire for setting. The starvation and other mistreatments sometimes recommended are not only inhuman, but are also bad practice from the standpoint of production.

History of Artificial Incubation.-The hatching of chicks by artificial means has been practised by the Chinese and Egyptians since centuries before Christ. In Egypt, tradition credits the invention to the ancient priests of the Temple of 
Isis. The methods used from the earliest times are still in use.

The first account of these methods is given in The Voiage and Tracaile of Sir John Maundeville, Kt., written before 1356 A.D. A Frenchman, Reaumur, in a treatise on The Art of IIatching and Bringing up Domestic Fowls, published in 1750, gives a detailed description of the Egyptian incubatory, which tallies quite closely with that of the Lnited States Consul-General Cardwell, of Cairo, made in 1890.

Fig. 97

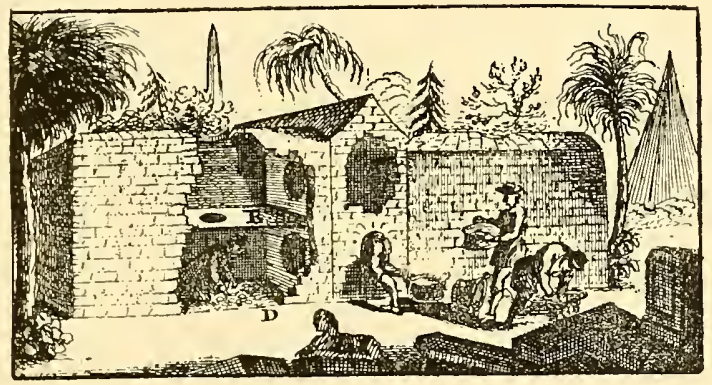

Ancient Egyptian hatchery.

The general plan of the Egrptian hatcheries is shown by Figures 97 and 98 , taken from Reaumur. 'The one described by Cardwell was " constructed of sun-dried brick, mortar, and earth." It "was a structure seventy feet long, sixty feet wide, and sixteen feet high. It was provided with twelve compartments, or incubators, each capable of holding 7500 eggs, making a total capacity of 90,000 eggs undergoing incubation at one time." Heat is furnished by fires in grates built in the rooms where the eggs are hatched. The proper temperature is judged by the attendant by his sense of heat and cold, and regulated by means of ventilators in the walis. The eggs are tested for fertility on the tenth day with the palm of the hand, or by placing against the face. Those noticeably cold are regarded as infertile, and discarded. The Egyptian ovens are public institutions and run on a toll 
basis. From the fact that two chicks are usually expected from three eggs, this method is evidently fairly satisfactory.
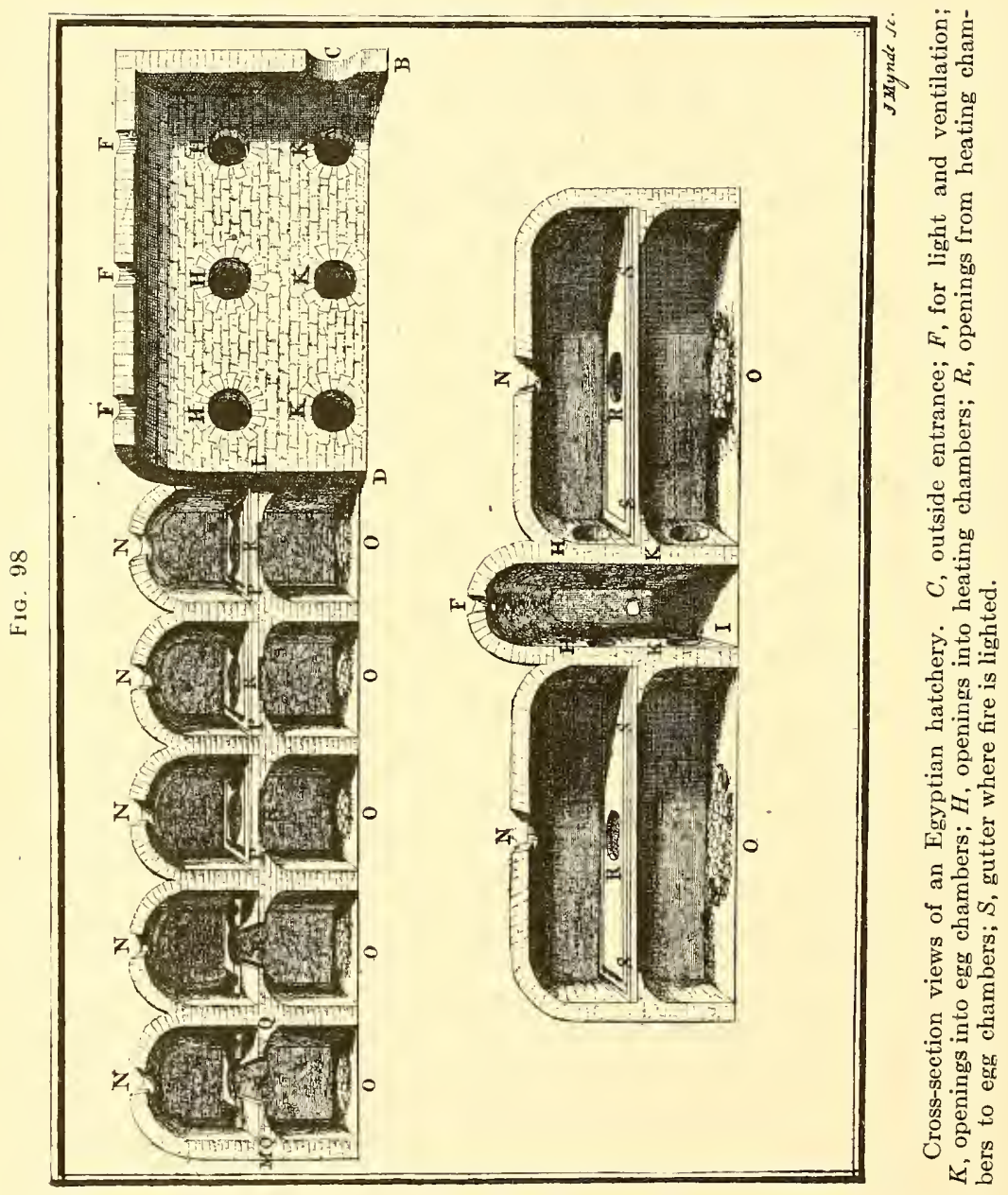

The theory has been advanced that because of continued artificial incubation the fowls of Egypt have developed 
the non-setting traits found in the Mediterranean breeds today.

The Chinese method, still in vogue, is equally primitive. The ovens are much smaller, and made of wickerwork plastered with mud. They are heated by fires in the same compartment with the eggs.

Various attempts have been made to perfect artificial means of incubation during the last three or four centuries. In 1750 , Reaumur hatched chicks successfully by surrounding a cask containing eggs with heating horse manure.

In 1770 John Champion, of Berwick-upon-Tweed, England, hatched eggs by passing flues carrying hot air through the room in which the eggs were. In 1777 Bonneman, a French physician, established hatching ovens in Nauterre, whereby the heat was conducted from a fire to the eggs by the circulation of hot water.

The first American incubator was invented in 1844 and patented in England under the title of Cantelo's Patent Incubator. This was also a hot-water-heated machine, the water being heated by a charcoal fire. The following year a regulating device, whereby the temperature of the egg chamber could be controlled, was invented by M. Vallee, a poultryman, near Paris. It was not until about 1870 , however, that incubators began to engage serious attention in this country, when a patent was awarded to one Jacob Graves for an incubator and artificial mother, which was followed by James Rankin, of southeastern Massachusetts, with a machine that was guaranteed to hatch as many chicks as could be done with hens. From that time the increase in patents, ideas, and improvements have been enormous, but it is only within the last twenty years that incubators have been perfected in this country to such an extent as to be practical successes.

Value of the Incubator.-Generally speaking the most profitable branch of poultry is the production of winter eggs, which is very largely dependent upon maturing the pullets so that they will come into full laying before cold weather sets in. To do this the time of hatching must not be dependent upon seasonal conditions but under perfect control. The incubator is always in working order. 
The labor of caring for one hundred eggs in an incubator is considerably less than caring for the same number under hens. By the use of a properly disinfected incubator it is possible to start chicks out absolutely free from vermin, and, if brooders are used, to keep them so until nearly grown.

Types of Incubators.-Incubators are usually classified according to the medium used in transmitting the heat from the heater to the egg chamber into "hot-air" and "hotwater" machines.

In actual efficiency there appeares to be no difference between the two types. Hot-air machines are more quickly but not more accurately regulated. While the hot-water type is less sensitive to outside changes of temperature, once affected it is much slower in regaining the proper temperature.

|FIG. 99

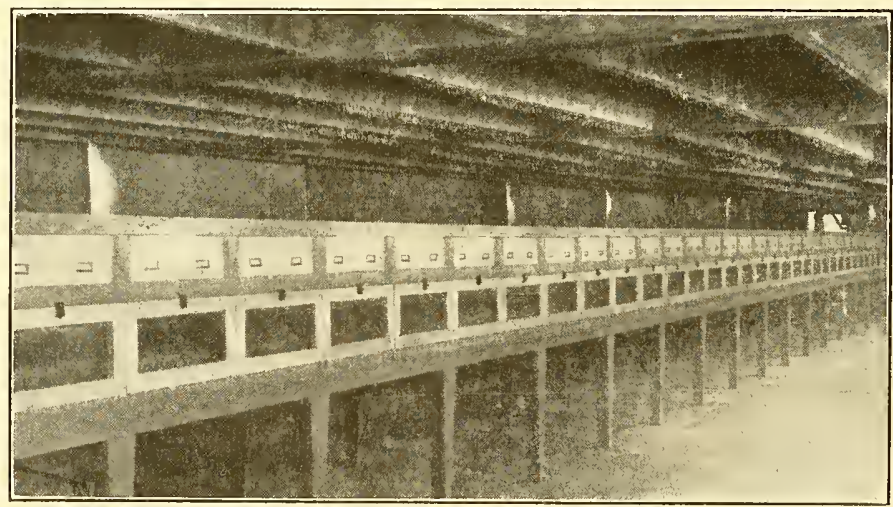

Mammoth incubator. (Courtesy of Kansas Agricultural Experiment Station.)

Incubator Sizes.-Most farm incubators range in capacity from fifty eggs to four hundred and fifty. The sizes ranging between one hundred and fifty and two hundred egg capacity have trays that may be conveniently handled and are not so large as to have great differences in temperature between opposite sides or corners of the egg chamber.

Where the capacity runs much above three hundred there 
is likely to be a difference in temperature of several degrees between opposite corners, and the trays are heavy and awkward for the ordinary person to handle, when they are full of eggs.

The so-called mammoth incubators, with egg capacities running into the thousands, are made up of a larger or smaller number of ordinary sized incubator units built together. Aside from the fact that there is a central heating system, each unit is independent of every other unit, having its own regulator, nursery, and trays. It is entirely possible to be bringing off a hatch in one compartment and just starting another one in the next one.

Principles of Operation.-So far as present knowledge indicates, successful incubation depends primarily upon four conditions. These are (1) temperature, (2) moisture, (3) ventilation, and (4) position. The principles involved in the operation of incubators have to do with making these conditions favorable.

Place of Operation.-The place of operation has much to do with furnishing proper incubating conditions. It is highly desirable (1) that it shall not be subject to frequent or sudden changes in temperature; (2) that an abundance of fresh air may be admitted, while the heavy gases near the floor and the light gases near the ceiling have means of escape; (3) that the relative humidity be rather high; (4) that it be impossible for the sunlight to strike the incubator at any time of day.

A cellar, and particularly a cave cellar, having a grade entrance and a top ventilator, will come about as near meeting these conditions as any room found on the farm. Outside changes do not quickly affect it, it is likely to be reasonably damp, does not admit the sunlight, allows the light gases to escape above and the heavy ones that have settled to the floor to flush out every time the door is opened.

Temperature.-The temperature at which eggs are incubated naturally depends primarily upon the temperature of the setting hen. As will be seen in Table XXVIII, this temperature is quite variable between different hens on the same day and for the same hen on different days. This 
table was made by Eycleshymer ${ }^{1}$ from observations made by placing thermometers in nests, so that they would come in contact with the body of the setting hens. The Roman numerals designate the hens, while the arabic numerals indicate the days of incubation.

TABLE XXVIII.

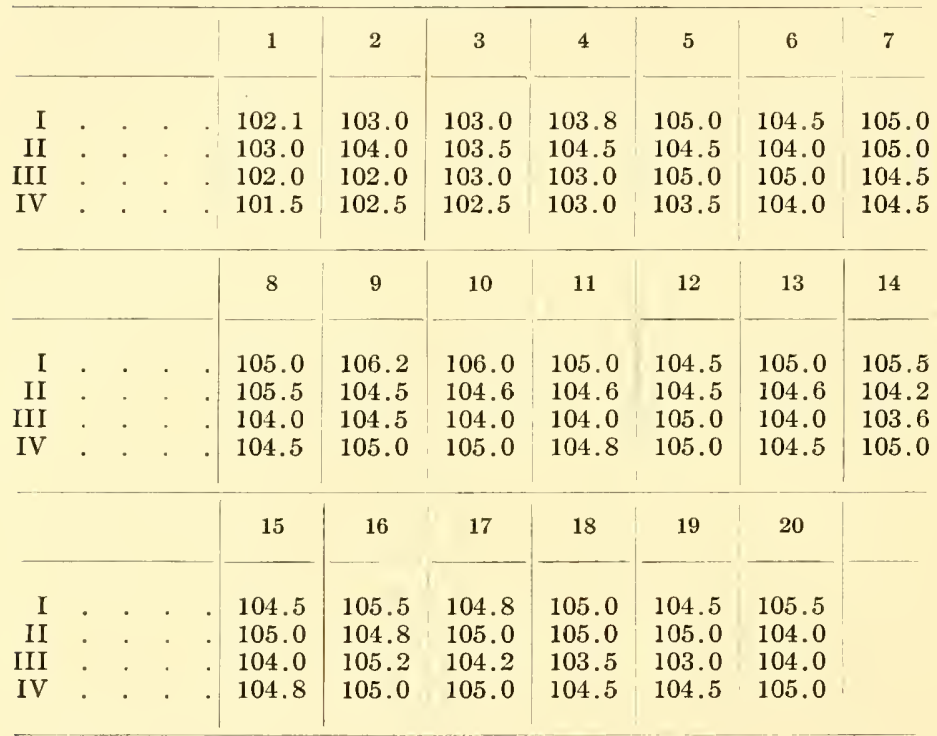

Eycleshymer $^{2}$ also made observations of eggs in relation to the temperature of the setting hen. The temperature of the hen was secured as before, and that of the eggs by breaking the shell immediately over the embryo and inserting the bulb of the thermometer. The results are tabulated in Table XXIX. It will be noted that the temperature of the egg is influenced throughout by the temperature of the fowl, and that while there is an average difference of over $3^{\circ}$ the first four days of the incubation period, there is an average difference of $1 \frac{3}{4}^{\circ}$ the last four days of the period. This

1 Biological Bulletin, May, 1907.

2 Ibid. 
difference is doubtless due to the increasing animal heat generated by the growing embryo.

It should be recognized that this is but a single test, which should be supplemented by many further tests before drawing too definite a conclusion. It leads the way, however, to an understanding of the principle of governing the temperature of the incubator. That principle is to carry such a temperature in the egg chamber that the egg will be as nearly as possible the same temperature as when under a hen.

TABLE XX1X.

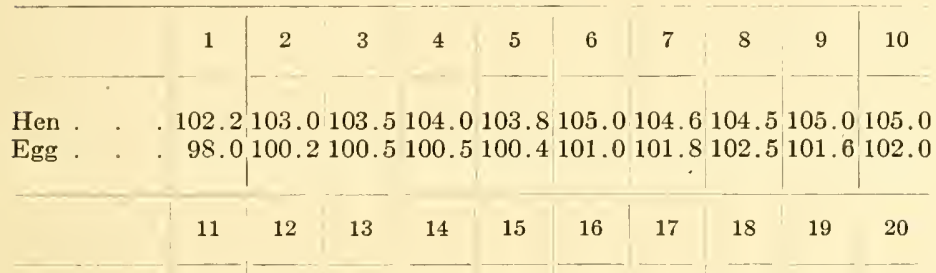

Hen . . $\quad 104.8105 .2104 .5105 .0105 .2105 .0104 .6104 .8104 .5104 .5$

Egg . . 101.8102 .2102 .0102 .5102 .0103 .0102 .4 .103 .0103 .0103 .0

In carrying the egg chamber temperature at $102^{\circ}$ to $103^{\circ}$ the first half and $103^{\circ}$ to $104.5^{\circ}$ the remainder of the period, Eycleshymer ${ }^{1}$ observed the temperatures shown in Table XXX.

TABLE XXX.

\begin{tabular}{|c|c|c|c|c|c|c|c|c|c|c|c|}
\hline & & 1 & 2 & 3 & 4 & 5 & 6 & 7 & 8 & 9 & 10 \\
\hline \multirow[t]{2}{*}{$\begin{array}{l}\text { Inc'b } \\
\text { Egg . }\end{array}$} & . & $\begin{array}{r}102.0 \\
. \quad 99.5\end{array}$ & $\begin{array}{l}102.0 \\
100.0\end{array}$ & $\begin{array}{l}103.0 \\
101.0\end{array}$ & $\begin{array}{l}102.0 \\
100.5\end{array}$ & $\begin{array}{l}102.5 \\
100.5\end{array}$ & $\begin{array}{l}103.0 \\
101.0\end{array}$ & $\begin{array}{l}102.5 \\
100.0\end{array}$ & $\begin{array}{l}102.0 \\
100.0\end{array}$ & $\begin{array}{l}103.0 \\
101.0\end{array}$ & $\begin{array}{l}103.5 \\
101.5\end{array}$ \\
\hline & & 11 & 12 & 13 & 14 & 15 & 16 & 17 & 18 & 19 & 20 \\
\hline Inc'b & . & 103.0 & 103.5 & 104.0 & 103.5 & 104.0 & 104.5 & 104.0 & 103.5 & 104.0 & 104.5 \\
\hline Egg . & . & 101.5 & 101.8 & 102.0 & 102.5 & 103.0 & 103.0 & 103.0 & 102.5 & 5102.5 & 103.5 \\
\hline
\end{tabular}

1 Biological Bulletin, May, 1907. 
In this trial, 85 per cent of the fertile eggs set hatched. Eggs destroyed for the purpose of taking temperatures were not counted.

As the result of careful and rather extended experiment Philips ${ }^{1}$ recommends temperatures of $101^{\circ}$ to $102^{\circ}$ and $103^{\circ}$ $F$. for the first, second and third weeks of incubation respectively, using a standing thermometer with the bulb on a level with the top of the eggs but not touching them. It is quite possible that the temperature requirement varies with the vigor of the breeding stock and one must not necessarily be guided by rule. The chicks should be brought out promptly. As Lamson and Kirkpatrick ${ }^{2}$ remark "one chick hatched on the twentieth day is worth two hatched on the twentysecond."

Regarding the precise effects of high and low temperatures upon the developing embryo there is little information. Alsop $^{3}$ found that temperatures between $103^{\circ} \mathrm{F}$. and $108^{\circ} \mathrm{F}$. produced 90 per cent of the embryos with abnormal nervous systems by the seventy-second hour of incubation or earlier. Of these abnormalities 46 per cent were in the head region and 54 per cent were in the neural tube. In those eggs incubated at $94^{\circ} \mathrm{F}$. to $101^{\circ} \mathrm{F} .67$ per cent of the embryos had abnormal nervous systems by the seventy-second hour. Seventeen per cent of these were in the head region and $\$ 3$ per cent were in the neural tube. Eggs from the same hens incubated at usual temperatures produced $6 \frac{1}{2}$ per cent abnormalities by the seventy-second hour or earlier. These abnormalities apparently differed from those noted above.

It would be interesting to carry eggs incubated at abnormal temperatures for the first seventy-two hours, through the rest of the incubation period at normal temperatures to determine what proportion, if any, of these abnormalities were subsequently overcome.

Cooling Eggs.-The custom of cooling eggs during the period of incubation has arisen from a desire to imitate

1 Jour. Am. Assn. Inst. and Invest. in Fowl Husb., vol. iv, No. 9.

2 Storr's (Conn.) Bulletin, No. 95.

3 The Anatomical Record, vol. xv, No. 5. 
Nature. During the time that a setting hen is away from her nest for the purpose of feeding the eggs become more or less cool. Because this happens in Nature it is assumed that better hatches will result if the eggs are cooled when artificially incubated.

There are two reasons given why cooling strengthens the hatching power of eggs. It is argued that just as persons, even in cold weather, seek relief from the constant heat of internal combustion by drinking cold water, so the embryo needs relief from the continued high temperature of incubation.

What would seem to be more reasonable is the suggestion that by cooling, the contents of the egg contracts somewhat, thus drawing fresh air through the pores of the shell for the ever-increasing demands of the embryo.

Atwood" suggests that "as chick embryos behave like coldblooded animals, reducing the temperature of the egg decreases the vital activity and it is difficult to conceive any ralid reason for slowing down this activity."

Lamson $^{2}$ compared cooling and not cooling, keeping keeping records on between six and seven thousand eggs. "The cooling method was to begin cooling on the third day and cool each night and morning for five minutes, then the following day the time was increased one minute and so on until the eighteenth day."

Sixty-seven per cent of the fertile eggs hatched in the incubators which were cooled and 70 per cent of the fertile eggs hatched where they were not cooled.

Five hundred chicks, half of which had been cooled during incubation, and half not cooled, were watched for the first four weeks during which $3 \pm$ chicks died. Twenty were from the cooled eggs and 14 from the uncooled.

He further found that eggs from strong stock would stand from four to five hours at $50^{\circ} \mathrm{F}$. after the first twenty-four hours of incubation. From this point on the time could be increased up to fifteen hours on the tenth to twelfth days.

1 West Virginia Circular, No. 25.

2 Jour. Am. Assn. Inst. and Invest. Poul. Husb., vol. iv, No. 5. 
After the seventeenth day continued exposure at $50^{\circ} \mathrm{F}$. caused the death of the embryos before hatching.

Moisture.-As the temperature maintained in the incubator is determined by the temperature of the eggs when incubated naturally, so the proper relative humidity of the egg chamber would appear to be that which limits the evaporation of the eggs to a normal rate. It should be recognized, however, that even with natural incubation the rate of evaporation will be different under different conditions. Just what the optimum rate of evaporation or the normal relative humidity is has not been definitely determined.

Normal Moisture Loss.-Atwood ${ }^{1}$ computed, from observations made upon eggs incubated under hens, that the normal loss of each of the first nineteen days for 100 eggs that hatched was as follows:

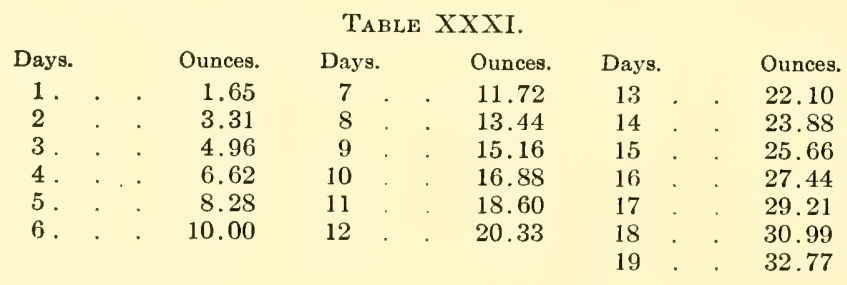

The difference in moisture loss between fertile and infertile eggs is shown graphically in Figure 100.

Assuming that these eggs averaged two ounces each, the loss for the nineteen days is 16.3 per cent. This work was done in West Virginia.

Dryden $^{2}$ found that in Utah, where the atmosphere is very much less humid, the loss of weight in eggs under hens was 14.87 per cent.

Eycleshymer ${ }^{3}$ found that the normal loss of an egg during natural incubation was 13 per cent, but that healthy chicks could be hatched when the evaporation was reduced to 9 per cent by the introduction of moisture or increased 20

I West Virginia Bulletin Nos. 73 and 98

${ }^{2}$ Oregon Bulletin No. $100 . \quad{ }^{3}$ Biological Bulletin, May, 1907. 
per cent by reducing the relative humidity of the egg chamber.

Such evidence seems to indicate that there are certain fairly narrow limits between which the rate or amount of evaporation may be considered normal. Before these limits are definitely determined it will be necessary to have many more observations. At present it appears that the limit lies between 13 and 16.3 per cent for the incubation period.

FIG. 100

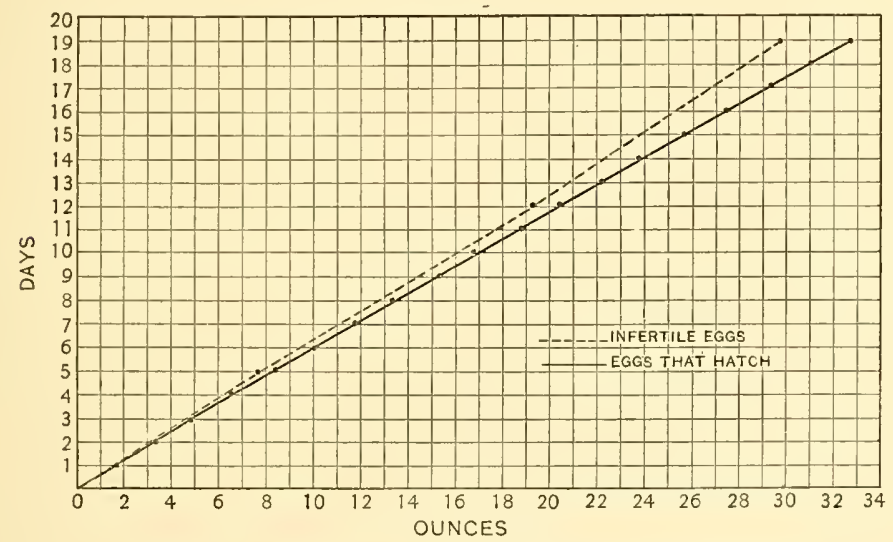

Showing relative evaporation in fertile and infertile eggs.

Artificial Supply of Moisture.-The desirability of introducing moisture into the egg chamber during incubation is a question upon which incubator manufacturers, successful operators, and experimental data are in mutual disagreement. It appears from all evidence at hand that the question is one of local management, with due regard to climatic condition.

In West Virginia Atwood ${ }^{1}$ obtained the results as shown in Table XXXII.

It will be noted that more chicks were hatched when no moisture was used, that the percentage mortality was the 
same in both cases, while the advantage in weight of the moisture chicks was so slight as to be practically negligible.

It should also be noted that in the case of the moisture chicks, evaporation was much restricted as compared with the calculated normal loss. (Calculations from 'Table XXXI.)

Table XXXiI.--Result of Incubating with and without Moisture

Number of eggs incubated

Number of ehicks hatched

Total loss of weight in eggs

Normal loss as calculated

Departure from normal loss of weight

Average weight of chicks per 100 when removed from incubator

Average weight of chicks per 100 at second weighing

Total deaths from all causes.

Per cent. died of all hatched .
No moisture

used.

2860

2012

44.49 pounds

46.77

2.28

8.44

35.70

415.00

20.60
Moisture
used.

2860

1943

29.41 pounds

46.77

17.36

8. 79

36.20

402.00

20.60

Lewis ${ }^{1}$ found that under Massachusetts conditions in a cellar showing an average relative humidity of 60 per cent, increasing the moisture content of the air in the incubator by means of sand trays increased the percentage hatch, produced chicks which weighed more at hatching and were more vigorous, and brought about a greater uniformity in hatching. Unfortunately neither the evaporation nor the relative humidity were recorded.

Graham $^{2}$ reports that under Ontario conditions, of all eggs set, 11.2 per cent more were hatched when moisture was supplied than when it was not, and further that on an average, for every one hundred eggs set there were 16.6 per cent more chicks living at the age of four weeks that were hatched in moisture machines than in the case of those hatched in non-moisture machines. Here again there is no indication of the per cent. of relative humidity.

In Oregon ${ }^{3}$ Dryden secured the results shown in Table XXXIII.

1 New Jersey Experiment Station Report, 1911.

${ }^{2}$ Ontario Bulletin No. $163 . \quad{ }^{3}$ Oregon Bulletin No. 100. 
Table XXXili.-Effect of no Moisture, Medium MoIsture, and Maximum Moisture.

Number of eggs hatched

No moisture.

. 330.0

47.1

Percentage of fertile eggs hatched

69.1

Medium
moisture.
701.0
424.0
60.5
82.1

Maximum moisture. 712.0 420.0

59.0

77.3

In this case the relative humidity averaged 48.7 per cent in the non-moisture machines, 55.3 per cent in the medium moisture, and 64.7 per cent in the machines having the maximum supply of moisture. The corresponding wet-bulb temperatures were $84.5^{\circ}, 87.6^{\circ}$, and $91^{\circ}$. At the same time the relative humidity of the room where the incubators were operated ranged from 66 per cent to 83.1 per cent, with an average of 73.4 per cent.

In other observations made in Utah, where it was much drier and the relative humidity of the room where the incubators were operated was only 45.5 per cent on the average, Dryden ${ }^{1}$ found that the maximum moisture machines had a relative humidity of but 55.5 per cent and gave the best results.

Referring to the Oregon results, Dryden says: "In comparing the weighings of incubator and hen eggs, the eggs in the non-moisture incubators lost 12 per cent more weight than the eggs under hens, but the moisture machine showed less loss. The results show that the dry machines "dry down" the eggs too much, while the maximum moisture machines show too little evaporation. Between the medium moisture machines and the hens there is considerable difference. It is a question, however, if less evaporation of the eggs under the hens would not be desirable. It has never been demonstrated, to the writer's knowledge, whether it is better to set the hens on the ground than on dry nests. On the whole the result of the weighings agrees with the results of the hatching in showing the necessity of supplying a certain amount of moisture to the incubator."

Hannas ${ }^{2}$ found from a large number of measurements that

1 Oregon Bulletin No. 100.

2 Jour. Am. Assn. Inst. and Invest. in Poul. Husb. rol. v, No. 10. 
on a normal egg, the proper depth of the air cell on the eight day of incubation was $\frac{23}{32}$ of an inch. On the fourteenth day it was about $\frac{2}{3} \frac{6}{2}$ of an inch, and on the nineteenth day it was $\frac{31}{3} \frac{1}{2}$ of an inch. This means approximately a little less than a third of the contents of the egg is taken up by the air cell on the eighth day, a little over one-third on the fourteenth and about two-fifths on the nineteenth day.

Best Means of Supplying Moisture.-Dryden ${ }^{1}$ found that a tray of moist sand placed in the bottom of the nursery was more efficient in limiting the evaporation of eggs during incubation than was a tray of the same size and location filled with water.

The average loss of weight by evaporation was 16.13 per cent when no sand was used and but 12.28 per cent when it was used. This seems to indicate that the sand furnishes a more efficient evaporating surface for moisture than does the unbroken surface of the water.

Pearl ${ }^{2}$ reports that "The most satisfactory way to supply this extra moisture where sand trays are not an integral part of the incubator, has been found to be by sprinkling the eggs with warm water twice a day. The water is warmed to a temperature of from $104^{\circ}$ to $108^{\circ} \mathrm{F}$. . . . The application of moisture is begun as soon as the eggs go into the machine, and is continued until the eighteenth day. Since adopting this procedure a very considerable reduction in the mortality of chicks in the shell has been effected."

Dryden $^{3}$ has shown that when water is present it dissolves carbon dioxide which is normally present in an incubator. This tends to weaken the shells of the eggs making the exclusion of the chick easier, the calcium of the shell being soluble in water containing carbon dioxide. This may be a factor in Pearl's results.

Ventilation.-The question of what constitutes proper ventilation for an incubator is one upon which there is little satisfactory experimental evidence. Yet restricting or aug-

1 Utah Bulletin No. 102.

${ }^{2}$ Poultry Management at the Main Station, 1913.

${ }^{3}$ Utah Bulletin, No. 92. 
menting ventilation has a profound effect upon the developing embryos. Dareste (as quoted by Eycleshymer) ${ }^{1}$ found that when "all apertures of the incubator were closed during incubation . . . nearly all the embryos died. It was further found that there had developed in the albumen a microscopic organism resembling the ordinary yeast plant."

Gerloch (as quoted by Eycleshymer) ${ }^{2}$ found that by diminishing the quantity of air during incubation he could cause dwarfing of the embryo. On the other hand, when shells were scraped very thin so that the supply of oxygen to the egg was increased the embryos "developed at a remarkably rapid rate, nearly twice as fast as in normal growth."

Eycleshymer ${ }^{3}$ took two incubators having similar ventilating systems, which were believed to be inadequate. One was left as it was. The other was provided with two one-inch intake pipes which extended outside the building, and were so arranged that there was a continuous current of fresh air passing into the egg chamber. Eggs from the same hens were placed in each machine. The former hatched 44.3 per cent of fertile eggs while the latter hatched 85.7 per cent.

While the foregoing shows unmistakably that there is a ventilation problem it does not solve it. Common experience rather than experimental evidence must be depended on in formulating our practice in ventilation. This is done in the suggested routine of management (see page 225).

Position of the Egg.-It is generally understood among poultrymen that the position of the egg during the period of incubation has a profound influence upon the development of the chick. It is a matter of common knowledge that the head of the chick normally develops at the large end of the egg. As a usual thing, both in the nest and in the incubator, the large end of the egg is uppermost. This is due to the shape of the egg itself and possibly by the lessening of the specific gravity of the large end as incubation proceeds, due to the increasing size of the air cell. 
Occasionally, however, chicks develop with the head directed toward the small end. The cause of this, it is asserted, is allowing the egg to rest in the nest or incubator with the small end uppermost. Definite information on this point is scarce. Eycleshymer, ${ }^{1}$ after conducting experiments which did not involve as large numbers as we could wish, came to the conclusion that the "position of the egg is a factor of little or no importance in natural incubation." He further concluded "that when the supply of good fresh air is inadequate the oblique position of the egg, thereby bringing the embryo in closer contact with the air chamber, is decidedly advantageous. Where there is an abundant supply of fresh air, there is but little to be gained through placing eggs obliquely." Where plenty of tray room is allowed, most of the eggs will be found to assume a position that is slightly oblique.

In making a study of the effect of crowding eggs into the trays for the purpose of increasing the capacity of the incubator, Jackson ${ }^{2}$ reached the conclusion that in the case of white eggs, which could be tested for fertility after three days of incubation, crowding so that the eggs stand on end until the first test results in no serious disadvantage.

Turning Eggs.- The hen turns the eggs she is incubating in two ways. The first is by peculiar lateral movements of the body with which she settles on the nest after feeding, and which she continues from time to time throughout the day and probably throughout the night. The purpose of these lateral movements is presumably to seek a more comfortable position. The practical results are to bring the body in closer contact with the egg and so closer to the developing germ, and also to turn the egg. The second way is by what is incorrectly called "billing," in which the hen reaches under her body and rearranges the eggs with her beak. Payne's ${ }^{3}$ recent observations of setting hens in glass nests have shown that the eggs were turned at least every

1 Biological Bulletin, May, 1907.

${ }^{2}$ Pennsylvania Bulletin No. 120.

3 Paper read before Thirteenth Annual Convention of American Association of Instructors and Investigators on Poultry Husbandry, 1920. 
hour both day and night, and that they were completely rotated as many as ten times in two hours.

Such observations as have been reported show that in artificial incubation fairly frequent turnings increase the hatching power of eggs. Eycleshymer ${ }^{1}$ found that where eggs were unmoved during the incubation period but 15 per cent of fertile eggs hatched. A very large proportion of the fertile eggs that failed to hatch did so because in the early stages the embryo, or in the later stages the allantois, had adhered to the shell. It is assumed that this could have been largely overcome by turning.

Eggs from the same hens that were turned at 6 A.M. and 6 P.M. gave a hatch of 58 per cent of fertile eggs. In this same connection, Jackson ${ }^{2}$ kept a record of 1350 eggs, half of which were turned twice daily during the incubation period, while the remainder were unturned. These eggs were distributed in equal lots through several different incubators. Although the group of eggs that were turned twice daily contained six more infertile eggs than the other group, 66 per cent of all eggs set that were turned twice hatched, while but 59.8 per cent of the unturned eggs gave living chicks.

Payne $^{3}$ found that eggs turned four to six times daily during incubation in March and April hatched from 4 to 22 per cent better than eggs tumed twice daily, with an average of about 10 per cent. Eggs handled in the same manner in May and Jume showed no adrantage in the extra turnings. Ile also found that the per cent of deformed chicks was reduced during March and April by the extra turning, but not in May and June.

In practice the eggs should be turned as frequently as possible. In most cases this will be three times dailymorning, noon, and night.

Date of Hatching. - The proper date for hatching chicks depends upon local climatic conditions and the breed being hatched. The Mediterranean breeds may be hatched

${ }^{1}$ Biological Bulletin, May, 1907. $\quad{ }^{2}$ Pennsylvania Bulletin No. 120.

${ }^{3}$ Paper read before Thirteen Annual Convention of American Association of Instructors and Inrestigators in Poultry Husbandry, 1920. 
thirty to forty-five days later than the American and English breeds, and still mature early enough to begin laying by fall.

For the north central states, American pullets that are expected to lay the following winter should be ont between the first of March and the middle of April. Goodale found that in Massatchusetts, March hatehed Rhode Island Red pullets gave a mean winter egg production of 42.65 eggs. April hateded pullets gave a mean winter production of 35.40 , while Mary pullets gave an average winter production of 20.50 cogess.

The Mediterineans should be hatehed late in April or carly in May. Sehwartze eime to the conchusion as the result of a set of observations on White Leghorn pullets, that the month of hateh had eomparatively litte influence on the molt. 'The Astaties should be hatehed as early ats possible. Indging from the results in production at the laving competition conducted by the Comectiont Agricultural College, Card concluded that for that state late April or early May was the proper hatehing time for Leghorus. Pullets hatehed during this period usually showed an advantage over both Malde and Jume hatehed pullets. Lewist has since reported that in New Jersey, February hatehed lewhorn pullets eould be arried thromgh the bollowing fall withont molting by means of the feeding methods mate possible by illmumated houses.

lawis, in companing the rate of growth of Leghom chicks hatehed April 1 and June 1, found, as shown in Table XXXIV, that the April-hatehed ehicks averaged 1.70 pounds heavier in November than the Inme-hatehed chicks, althongh there was an average dillerence in weight at July 1 of but 1.17 pounds. The younger chicks were not able to make proper gains until the cool weather of the fall eame. At three and a half months the late-hatehed ehicks did not weigh as much as the early-hatched ones did at three months.

1 American Nituralist, vol. lii, No. 611.

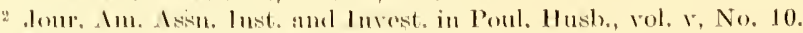

"Stores (Comm.) Bulletin, No. 9).

4 Now Jorsey Experiment Station Anmual Report. 


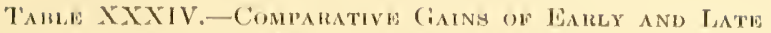

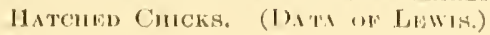

\begin{tabular}{|c|c|c|c|c|c|c|c|c|c|c|}
\hline \multirow{2}{*}{\multicolumn{2}{|c|}{ 1) ato }} & & \multicolumn{4}{|c|}{$\begin{array}{c}\text { Lot (A). } \\
\text { April liatelicel. }\end{array}$} & \multicolumn{4}{|c|}{$\begin{array}{l}\text { Lot (13). } \\
\text { Juno hatchod. }\end{array}$} \\
\hline & & & 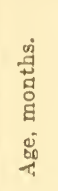 & $\begin{array}{l}\text { 岕 } \\
\text { 咅 } \\
\text { 劣 }\end{array}$ & 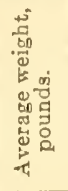 & 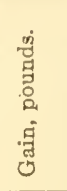 & 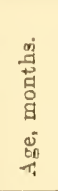 & 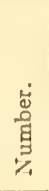 & 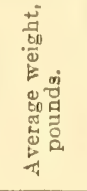 & 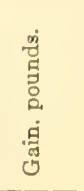 \\
\hline July & 11 & . & 3.0 & 50 & 1. 47 & & 1.0 & 50 & 0.300 & \\
\hline July & 15 & $v^{\circ}$ & 3.5 & 50 & 1.81 & 0.34 & 1.5 & 45 & 0.402 & 0.102 \\
\hline Aug. & 15 & & 4.5 & 48 & 2.50 & 0.69 & 2. & 44 & 0.870 & 0.468 \\
\hline Sept. & 15 & . & 5.5 & 48 & 3.30 & 0.80 & 3. & 44 & 1.210 & 0.340 \\
\hline Oct. & 15 & & 6.5 & 48 & 4.05 & 0.75 & 4.5 & 42 & 2.100 & 0.890 \\
\hline Nov. & 15 & . & 7.5 & 47 & 4.70 & 0.65 & 6.6 & 42 & 3.000 & 0.900 \\
\hline
\end{tabular}

Mairs also found that early-hatehed chicks grew faster than late-hatched ones, and suggested April 1 as a suitable hatching date for Penusylvania without making any difference for different classes of chickens.

Where the falls are quite late, judginent must be used in selecting the date of hatching. It is entirely possible to hatch out pullets so early that they will go through a general molt in the fall, precisely as do the hens, and quit laying until along toward spring.

Distribution of Incubator Mortality.--II a very caleful and interesting study of the time distrilution of the mortality of embryos, Payne fomel that (i9.4 per cent of all the mortality oceured during seven days, mamely; the fourth fifth and sixth and the eighteenth to twenty-first inclusive. The mortality was 16.2 per cont during the third to fifth mul 45.7 per cent during the eighteenth to twenty-first. Many of the embryos dying during the latter period were deformed. A eraphice presentation of the distribution of embryo mortality is shown in Figne 101.

1 Pennsylvania Bulletin No. 87

2 Jour. Am. Assn. Insl. and luvest. in l'oul. Husb., vol. vi, No. 2. 
In hatches averaging about 50 per cent of total eggs set, approximately 40 per cent of the deaths occur during the first thirteen days of incubation and about 60 per cent die between the fourteenth and twenty-first days inclusive.

Fig. 101

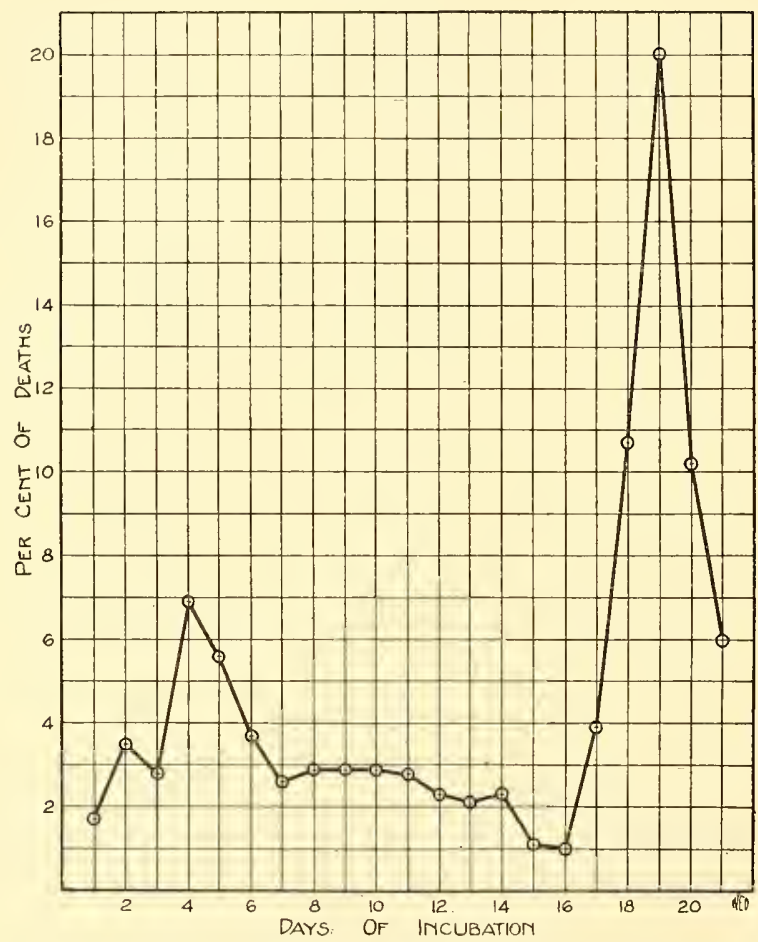

Graphic presentation of the distribution of incubator mortality. (From data of Payne.)

This gives an approximate basis for calculating on the fourteenth day the probable number of chicks which will hatch in the event of a normal run by the incubator.

Routine of Management. - The practical application of the principles of incubation will vary under different conditions 
and in different locations. The routine of management suggested hereafter has been found satisfactory in three west-central states lying in the heart of the heavy poultry producing section.

Levelling the Machine.-The incubator should be made level so that there will be no high, hot corners. This may be accomplished by the use of a carpenter's level, taking care to see that it is level from front to back as well as from side to side.

Disinfection.-If the incubator has been used before, during the same or previous season, the egg chamber and nursery should be very thoroughly disinfected, including the trays, thermometer, and moisture pans. Disease that has done no special harm among chicks of a previous hatch may assume the proportions of an epidemic in a subsequent one. A 3 per cent solution of any of the standard coal-tar stock dips will be found satisfactory for this purpose. It is not necessary for the machine to be dried out before putting in the eggs, provided the proper temperature has been reached.

Preparing the Lamp. - The lamp should not be filled above a point a half-inch from the top. In a lamp that is too full the oil is likely to work out on the outside of the bowl and up on the burner, causing fumes, and possibly a deposit of soot, and smoking.

It is an excellent practice to pin two wicks together in starting the hatch as a precaution against the oil being low and the wick getting short and putting out the lamp toward the end of the hatch.

Care should be taken in the beginning as throughout the run to see that the flame is round, as in Figure 102, and has no points or corners, as in Figure 103. This may be accomplished in the beginning by cutting off the corners of the wick, as shown in Figure 102, and by wiping or scraping off the charring thereafter rather than cutting it off with the scissors. Corners or points on the side of a flame tend to deposit soot on the side of the heater flue. If this continues unnoticed the accumulations soon become sufficient to choke the draft and cause a bad "smoke up" and even a fire.

The burner and lamp must be kept absolutely free of oil 
and clean of accumulations of any kind. The best lamps will smoke and be dangerous if choked with charrings.

FIG. 102
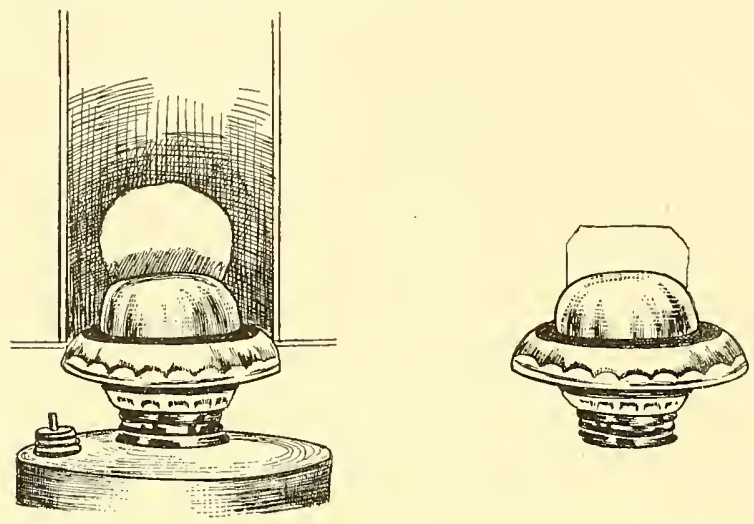

Showing how to trim a wick to produce a round flame.

Fig. 103
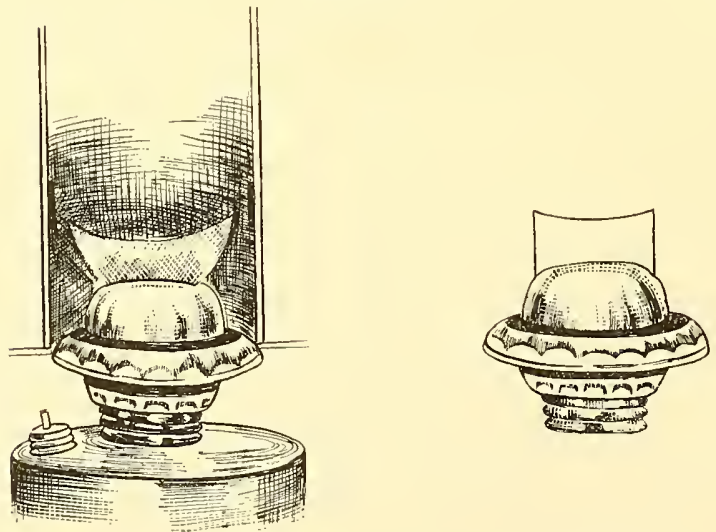

Showing a wick trimmed so as to produce a flame with corners which will cause the deposit of soot on the side of the direct heat flue, ultimately causing a smoking heater. 
Because of the tendency for a flame to "run up," as the lamp and heater become warm, it is best to make a practice of filling and cleaning the lamp in the morning so that if the flame needs further attention it will be noticed during the day and be in good working order by night. It is also a good plan to do all handling of the eggs before caring for the lamp, so that there will be no kerosene on the hands to be brought in contact with the eggs.

Starting the Incubator.-In starting a new incubator, or one with which the operator is unfamiliar, a medium to low flame should be maintained and a half-inch play given on the connecting rod by loosening the thumb-nut. This will allow considerable expansion at the thermostat without raising the damper disk. A high flame or too much play on the connecting rod is likely to allow the temperature to run high enough to ruin the thermometer. It is a safe precaution to use an ordinary high registering thermometer until the proper temperature has been reached, and so avoid this difficulty. Care should also be taken at the beginning of each season to see that the thermometer is registering accurately. It shou'd be carefully compared with a physicians clinical thermometer by moving the bulbs of both back and forth in water that is $103^{\circ}$ to $105^{\circ} \mathrm{F}$. in temperature. Because a thermometer works perfectly one season is no criterion that it will do so the next.

When the play has been taken up and the damper raised, the thumb-nut should be cautiously loosened, the amount being governed by the rise in temperature necessary to bring it to $101^{\circ} \mathrm{F}$. on a level with the top of the eggs. When this temperature is reached the flame should be so adjusted that the temperature will be maintained with the damper disk hanging an eighth of an inch above the heater. This allows a reserve of heat for the regulator to make use of in case of a drop in the incubator-room temperature. This condition should be maintained for at least twenty-four hours before putting in the eggs, in order to make sure that everything is in good running order. The eggs should then be put in and the incubator left closed for two days. 
Temperature.-The temperature should be held at $101^{\circ}$ to $102^{\circ} \mathrm{F}$. during the first week, $102^{\circ}$ the second week, $103^{\circ}$ the third week until the eggs began to pip, when it may be allowed to go to $104^{\circ}$. Inder no circumstances should it be allowed to run above $105^{\circ}$ and $104^{\circ}$ is a safer upward limit.

Moisture.-At the same time that the eggs are put in, moisture should be supplied. The amount depends upon local climatic conditions. In dry sections or during a drouth, a shallow pan, the size of the floor of the nursery, filled with sand and puddled with water, should be used. Such an arrangement is usually referred to as a sand tray.

Where there is a fair amount of moisture in the air a sand tray half as large may be used, and in damp sections, or during a wet season, the sand may be left out and only water put in. In any case the water should never be warmed more than is barely necessary to take off the chill.

The common means of gauging the amount of moisture to be supplied as the period advances is the size of the air cell. A more reliable means is weighing the eggs, as suggested by Atwood, ${ }^{1}$ and comparing the evaporation loss with the calculated normal loss for the same number of fertile eggs. The ordinary person usually does not judge the relative size of the air cell very accurately. It is an excellent plan to use a hygrometer or wet-bulb thermometer in connection with the weighing. Where their relationship in a given locality is once established the weighing may be dispensed with and the wet-bulb temperature used as a guide.

Turning.-After the second day the eggs should be turned three to five times daily. 'Turning may easily be accomplished by shuffling the eggs gently with the hands. It is a good practice to remove about two rows of eggs from the front of the egg tray, roll all the eggs forward, and place those removed in the back. This, in combination with turning the tray a quarter of the way around each time it is removed, tends to equalize any differences in temperature there may be between different sides or corners of the egg chamber. In 
the case of a two-tray incubator the trays may be turned end for end one time and shifted from side to side the next.

While turning the eggs the incubator door should be closed to conserve both the temperature and moisture. All drafts or any means of sudden chilling must be avoided. Turning should be discontinued after the eighteenth day.

Ventilating.-Different styles of incubators vary so in their styles of ventilation that it is difficult to make any general suggestions that will apply in all cases. It is usually well to follow the manufacturer's instructions. If, however, poor results that cannot be ascribed to any other cause are had, means for admitting more air should be devised. Few if any incubators are overventilated.

While the hatch is coming off, ventilation should be restricted for the purpose of conserving the moisture left in the machine after the removal of the sand trays. As soon as the hatch is over the ventilators should be opened fully.

Testing.--It is customary to test the eggs at the end of the first weck in order that all eggs that are not developing may be removed. This is desirable in order to avoid breaking eggs having dead germs in turning, and that the developing eggs may have the added room. In the case of poor fertility the eggs from two or more machines may be combined. White-shelled eggs may be tested as early as the third day, with very dark-shelled ones the germ often cannot be seen until the eighth or ninth day.

The two classes of eggs tested out are "infertiles" and "dead germs." Technically the term "infertile" refers to the fact that an egg has never been fertilized, while practically it includes those which have started to develop but have died before progressing far enough to be distinguished before the tester. The dead germ refers to one that is fertile in which the germ has died after developing far enough to be seen before the tester.

The so-called infertile egg appears to be clear save for a floating shadow, which is easily distinguished as the yolk.

The live germ is spider-like in appearance, the body of the embryo representing the body of the spider and the radiating 
bloodvessels its legs. The live germ floats about freely in the contents of the egg when the egg is rotated before the tester.

The dead germ may be recognized by the absence of the bloodvessels, its adhering to the shell, or by the quite typical pink ring surrounding it which is called the blood ring.

The second test is commonly made at the end of the second week. If the first has been accurately done there will be

FIG. 104

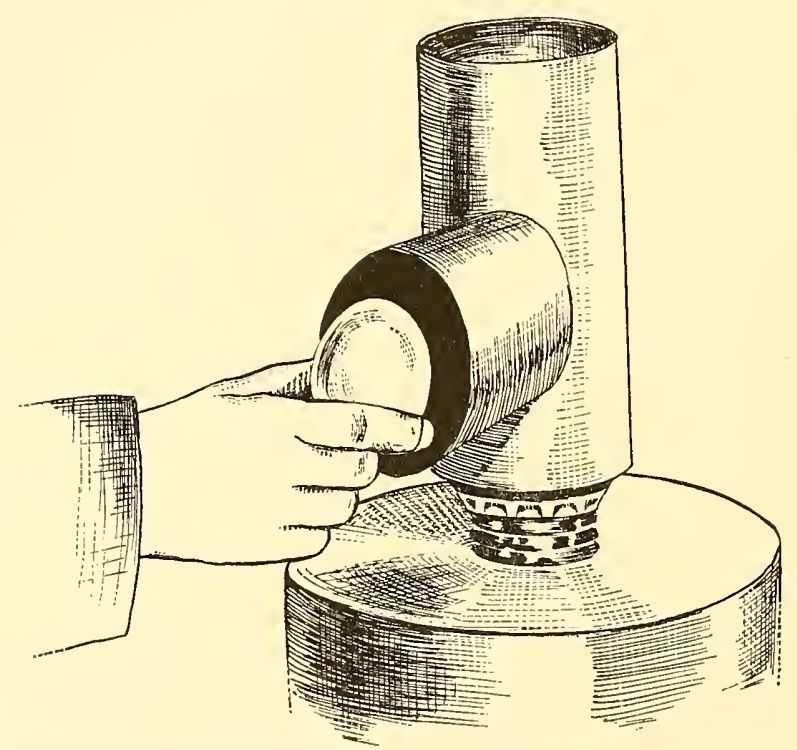

A lamp tester. There are many styles of testers but all work on the principle of shutting off all light from the eye except that which passes through the egg, thereby showing whether there is a live embryo or not.

only dead germs to test out. The live embryo at this time appears to nearly fill the egg. In the one or two light spaces which are usually present, bloodvessels will be noticed and the embryo chick will frequently be seen to move when the egg is rotated.

The dead germs may vary in appearance from typical blood rings to embryo chicks of nearly normal size. The 
latter will usually be readily recognized by the absence of bloodvessels and a general indefiniteness of outline.

FIg. 105

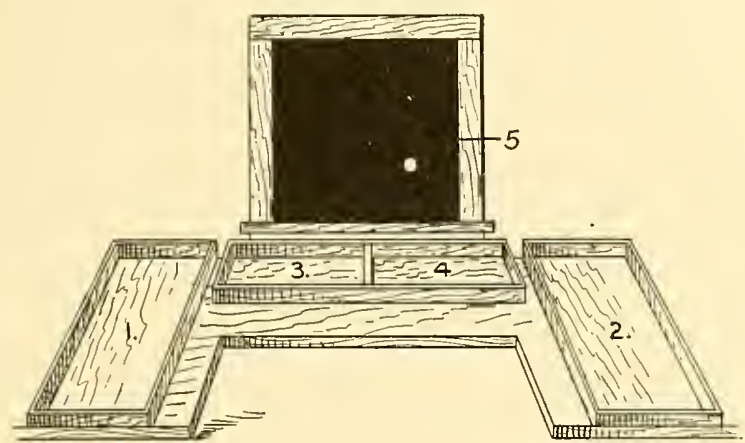

A convenient arrangement for sunlight testing. 1, tray for untested eggs; 2 , tray for fertile eggs; 3 and 4, trays for unfertiles and dead germs; 5 , prepared roofing with egg opening placed over window. (Courtesy of Cornell Reading Courses.)

FIG. 106

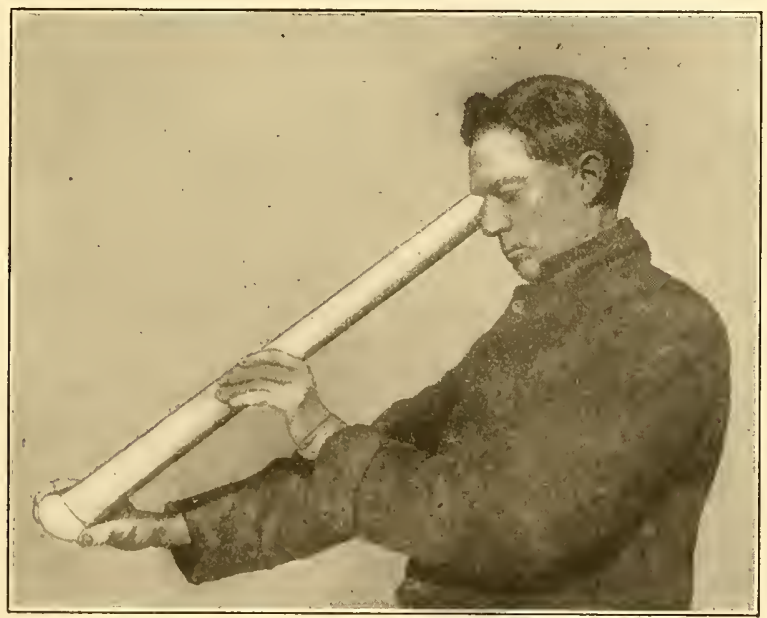

Testing eggs in the sunlight. 
Taking off the Hatch.-As soon as the chicks begin to pip the moisture pans should be removed (unless they are so protected by a wire screen that the chicks cannot get into them), and the aperture through which the chicks drop down into the nursery, opened. 'The incubator should then be closed and left closed until the hatch is well over. The temperature should be carefully watched at this time, because the heat generated by the struggling chicks is often sufficient to raise the temperature beyond the limit of the regulator's ability to act. It should not be allowed to rum above $105^{\circ} \mathrm{F}$.

FIG. 107

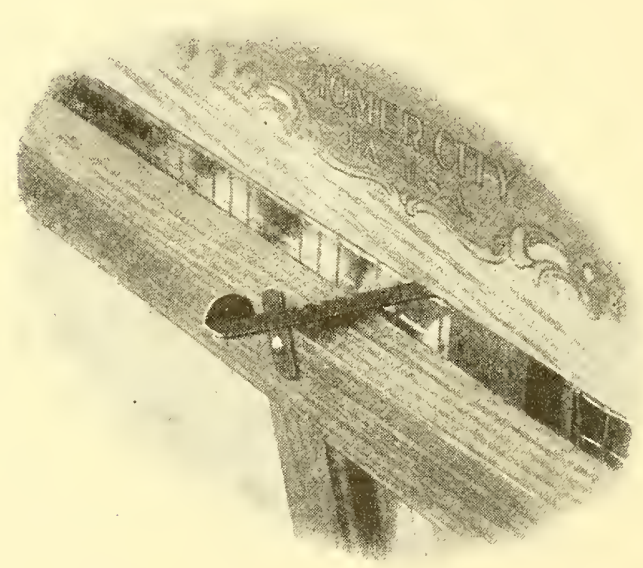

A handy arrangement for hardening the chickens. (Courtesy of Prairie State Incubator.)

After a normal run the hatch will be well over by the end of the twentieth day in the case of eggs from Mediterranean breeds, and the twenty-first day in the case of the American breeds. With the Asiatics it frequently takes eight to twelve hours longer. If the temperature runs low the hatch will be delayed, and if it runs high it will be hastened. When the hatch is well over, the egg trays should be removed and the shells and unhatched eggs burned. 
The chicks should be left in the incubator without feeding for at least thirty-six hours after hatching, and as much longer as is necessary to compel a lusty demonstration of the fact that they are hungry. As soon as they are dried off and fluffed out, the temperature on a level with the chicks should be reduced to $93^{\circ}$ or $95^{\circ} \mathrm{F}$. by opening the door enough to admit a little fresh air without cooling the machine down suddenly. Reducing the temperature and admitting fresh air is referred to as "hardening the chicks." During this time darken the egg chamber by hanging a dark cloth in front of the door. This prevents the chicks from picking at the droppings or developing the vice of toe-picking. The reason for delaying the removal of the chicks is to secure as complete yolk absorption as possible. The yolk that remains unused just prior to hatching is taken into the chick's body through the navel, and acts as a food supply for a number of hours. This fact is at the bottom of the successful shipping of newly hatched chicks. Giving a new supply of food before the old supply is exhausted seems to lead to digestive complications.

As soon after the thirty-six-hour period as the chicks give evidence of real hunger they may be removed to the brooder: For this purpose a flannel-lined, hooded basket should be used, which will fully protect them from the cold. A cold wind striking them at this time is likely to prove disastrous. If possible the transfer should be made at dusk so that the chicks will have no tendency to wander from the warm compartment of the brooder until they have it permanently located.

Insurance Restrictions.-A matter of practical importance that should not be overlooked is that of fire-insurance restrictions relative to the operating of incubators in dwellings. One's policy should be carefully scrutinized in this regard. Some policies have no restrictions. Others have specifications to which the incubator must conform, while still others become void if an incubator of any type is operated without special permission. 


\section{CHAPTER V. \\ THE BROODING OF CHICKS.}

Natural Brooding. - The essentials of natural brooding are comparatively few. They consist of a quiet, motherly, broody

FIG. 108

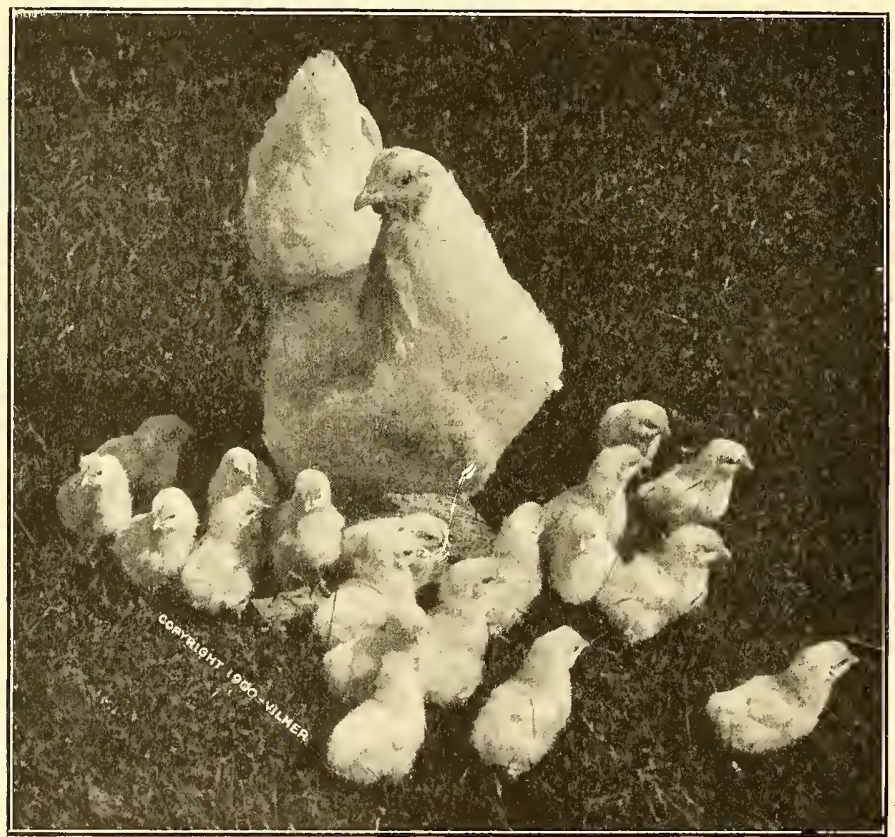

Hen and chicks. (Courtesy of Vilmer, Crown Point, Indiana.)

hen or capon, some sort of coop that will protect the mother and chicks from the weather and from enemies, and a fairsized, grassy, shady range. (230) 
'Those hens which are best for setting will usually be found to make the best mothers. The coop may be of almost any size and shape. The "A" shaped coops with a small protected run shown in Figure 109 will be found convenient, serviceable, and inexpensive.

Capons are sometimes used as mothers, but are more of a curiosity than a success. In inducing them to take the chicks, confine them in a roomy nest box with a low roof and place the chicks under them at dusk. If on examination in the morning it is found that the capon has not accepted the chicks, they should be taken away and kept warm throughout the day and placed under

FIG. 112

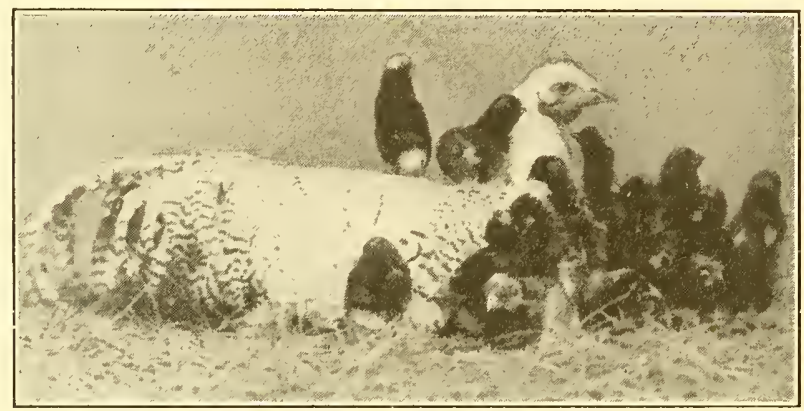

Capon brooding chicks. (Courtesy of George Beuoy.)

the capon again at dusk, he having been confined to the nest throughout the day. He will frequently accept the chicks the first night and rarely refuses them on the second. Some breeders who use capons extensively for brooding, wait until the chicks are two weeks old before trusting them to the capons.

Natural versus Artificial Brooding.-Artificial brooding is a more or less necessary accompaniment of the use of incubators. Its advantages and disadvantages are quite comparable with those of artificial incubation. The natural method is the proper one where only a few chicks are raised. With any numbers, however, the use of brooders is to be 
advised. It concentrates the many small flocks into a few larger ones, thereby reducing the care. The great advantage of artificial brooding is the possibility of raising chicks past weaning, absolutely louse-free.

Principles of Artificial Brooding.-The principles of brooding are essentially those of housing, with the addition of a temperature requirement. A complete brooder is simply a special form of house designed for the purpose of keeping chicks comfortable. The most recent developments in commercial brooders are the portable hover and the large colony brooder. The portable hover is a small compartment containing its own heater, in which the temperature may be

FIG. 111

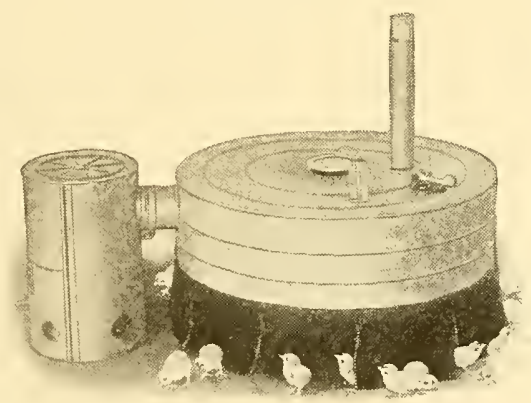

A portable hover. (Courtesy of Prairie State Incubator Company.)

controlled and which may be placed in any ordinary poultry house, thereby rendering it habitable for chicks. The large colony brooder is usually heated by a stove burning either coal or oil.

The conditions necessary for successful brooding are (1) a compartment in which the temperature is under control and which has (2) a constant supply of fresh air and is (3) dark; (4) dryness; (5) adequate space; (6) the admission of sunlight; (7) ease of disinfection; (S) protection against chick enemies; (9) safety from fire.

Temperature.-There is no general agreement among poultrymen as to what constitutes exactly the proper hover 
FrG. 112

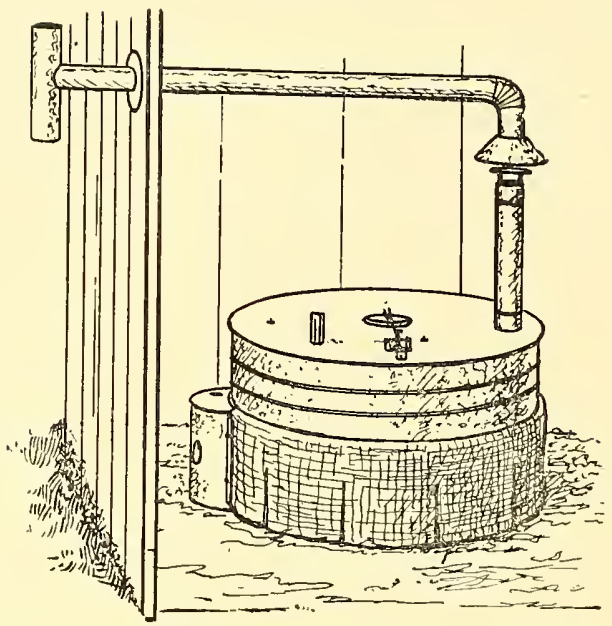

Showing method of conducting fumes out-of-doors from a portable hover, (Courtesy of Cyphers Incubator Company.)

FIG. 113

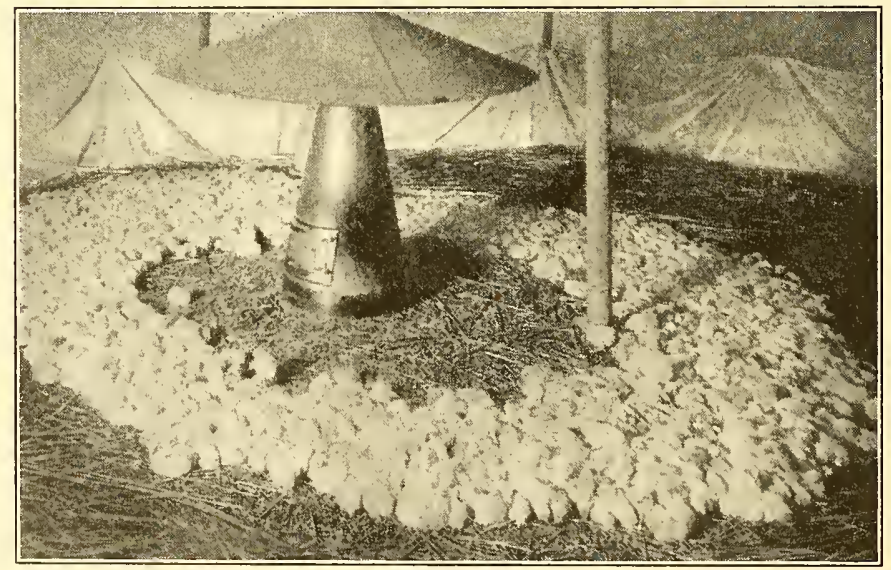

Large colony brooder, oil heated. (Courtesy of H. F. Arenberg. Petaluma, Cal.) 
temperature for chicks just out of the incubator or at succeeding ages. There is no cumulative experimental evidence determining definitely what these temperatures should be. General experience, however, agrees with the results of a

F1G. 114

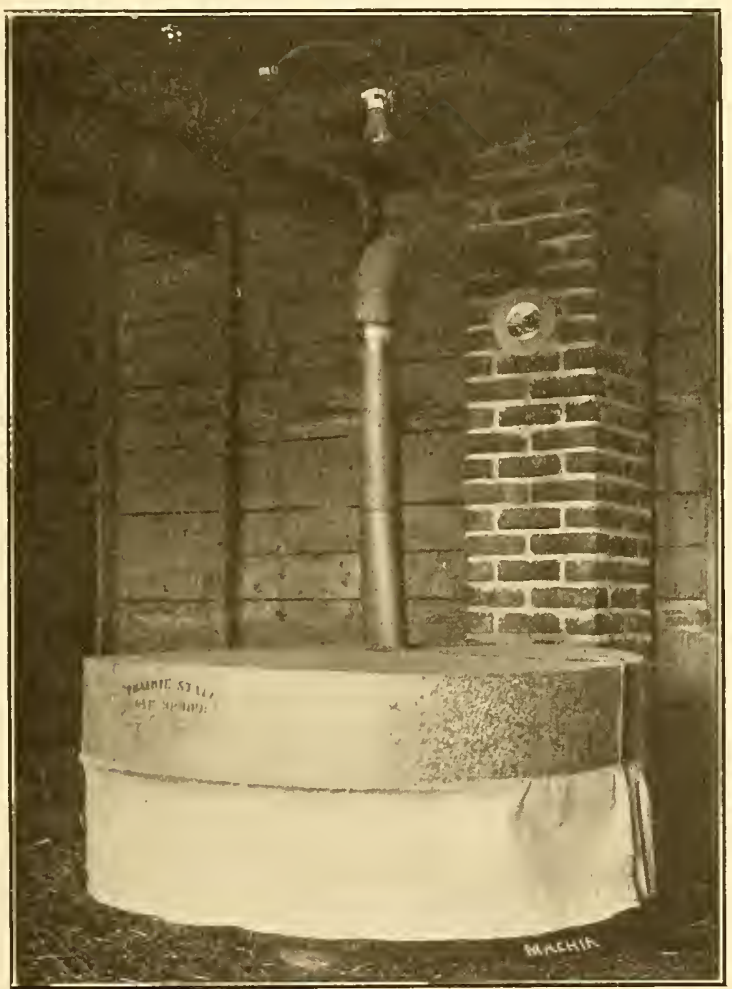

Large colony brooder, coal heated. Capacity 500 chicks. (Courtesy of Kansas Agricultural Experiment Station.)

single experiment reported by Lewis ${ }^{1}$, in which he brooded four groups of fifty chicks each in brooders where all conditions were exactly alike, except that of temperature.

1 Thirty-second Annual Report, New Jersey Agricultural Experiment Station. 
The first brooder was kept very warm, having an average hover temperature of $112^{\circ}$ for the first twenty-eight days. The mortality was 42 per cent. The second brooder was cooler, having an average temperature of $104^{\circ}$, but the

FIG. 115

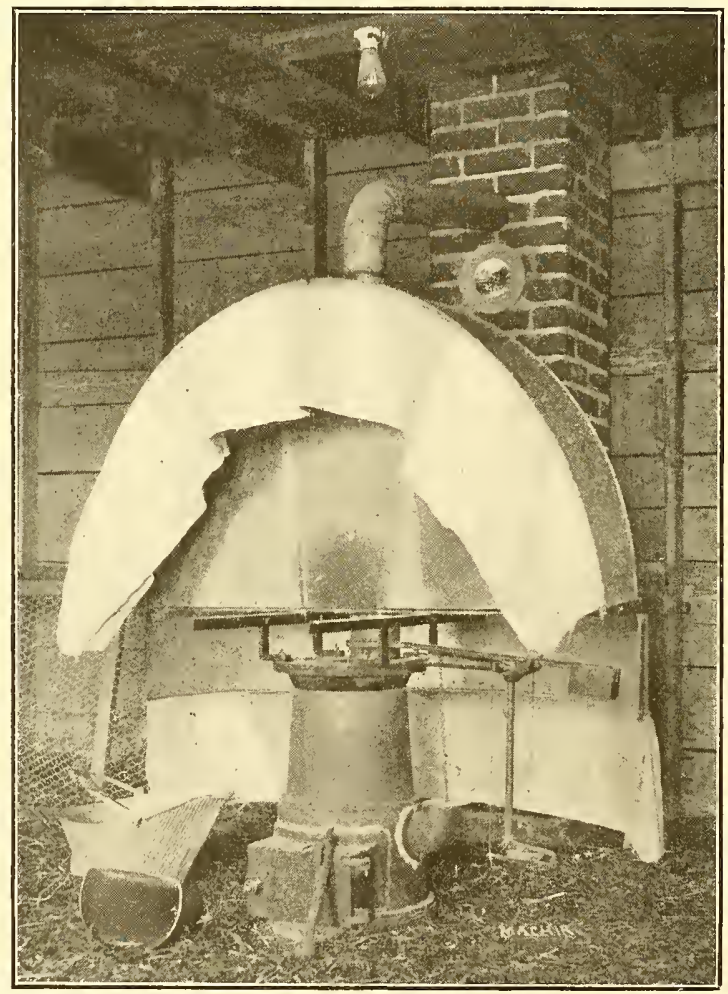

Large colony brooder with hover raised. (Courtesy of Kansas Agricultural Experiment Station.)

variations in temperature were extreme, varying from $86^{\circ}$ to $120^{\circ}$. In this brooder the percentage of mortality was 68 . The third brooder was started at $100^{\circ}$ and gradually reduced to a temperature of $85^{\circ}$ at the end of twenty-eight 
days, the average temperature being $94^{\circ}$. The mortality was 10 per cent. The fourth brooder had an initial hover temperature of $90^{\circ}$, which was gradually reduced to $74^{\circ}$ at the end of the period. The average temperature was $85^{\circ}$ and the mortality was 24 per cent.

FIG. 116

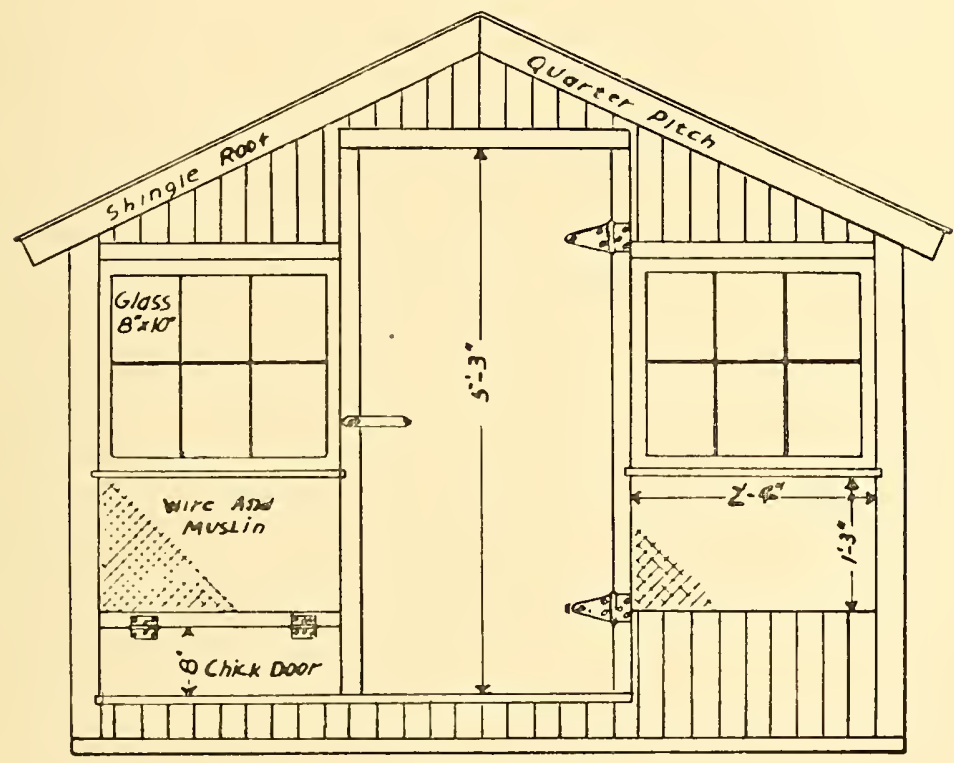

Front view

Plan of colony brooder house. (Courtesy of Missouri Agricultural Experiment Station.)

As the result of this experiment, Lewis suggests $100^{\circ}$ as a suitable temperature for the first week, $96^{\circ}$ for the second, $92^{\circ}$ for the third, and $S 8^{\circ}$ for the fourth, where the chicks are Leghorns.

It is unsafe to lay down absolute rules for all breeds and conditions. First and always the chicks must be comfortable. In quite cold weather it is likely to take a higher temperature to accomplish this than in more moderate weather. Less heat 
is required for snappy, vigorous stock than for birds of less vitality. The temperature should in all cases be reduced as rapidly, as the chicks grow older, as is compatible with their comfort, and artificial heat taken away altogether as soon as they are well feathered out.

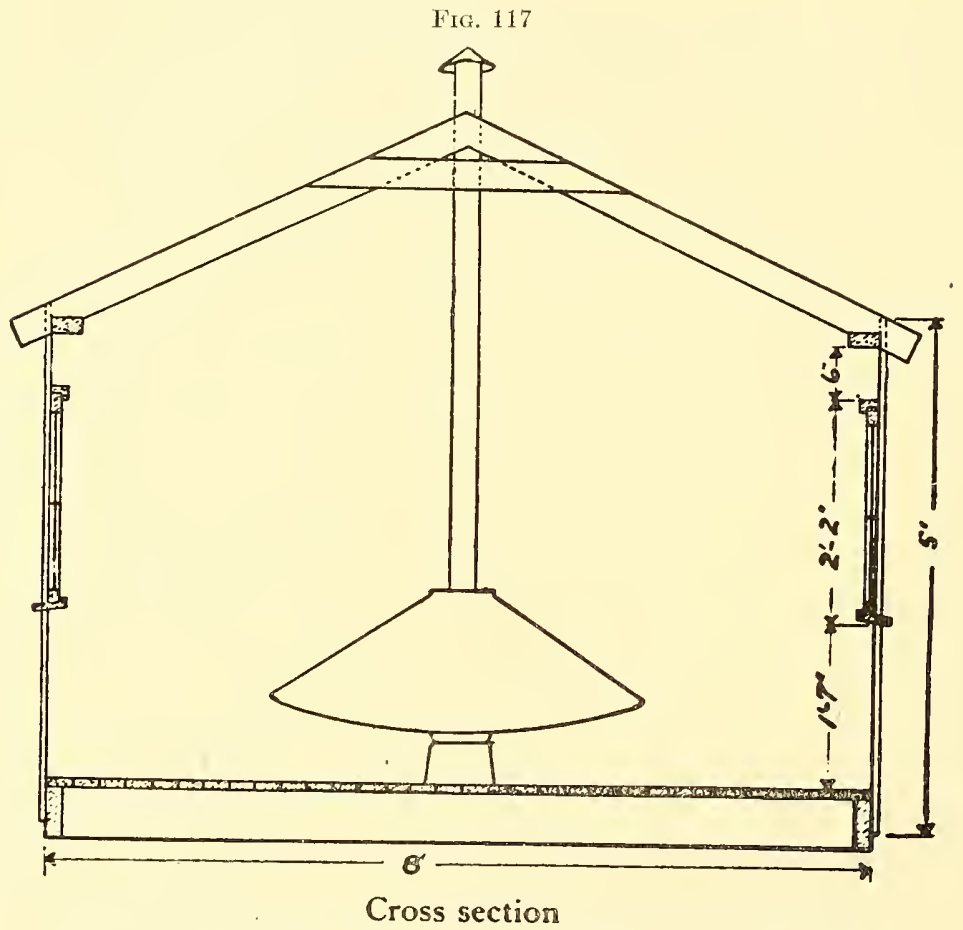

Plan of colony brooder house. (Courtesy of Missouri Agricultural Experiment Station.)

While it is exceedingly desirable to get the chicks on a self-sustaining basis with regard to the maintenance of body temperature, it is always best to err on the side of too much heat than too little. This is particularly true in cold weather, when a high hover temperature is necessary to warm chicks up quickly when they get cold. It does not hurt chicks to 
run out in quite cold weather, provided they can get warm quickly whenever they desire. Even after all artificial heat

FIG. 118

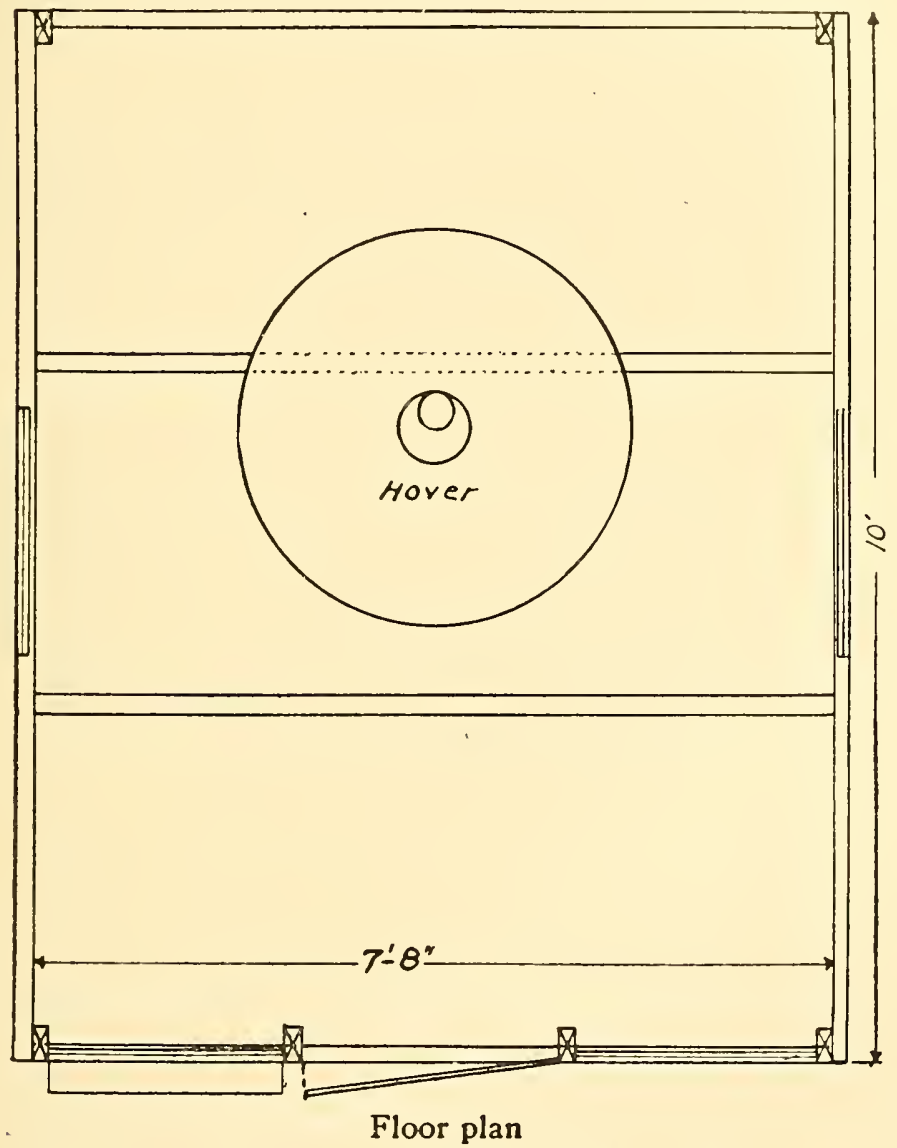

Plan of colony brooder house. (Courtesy of Missouri Agricultural Experiment Station.)

has been done away with, and the chicks well feathered, the brooding apparatus should be held in readiness against 
unusually cool nights, which are likely to produce crowding if a little extra heat is not supplied.

The thermometers used should be carefully tested at the beginning of each season, if they are to be relied upon, just as in the case of incubators.

FIG. 119

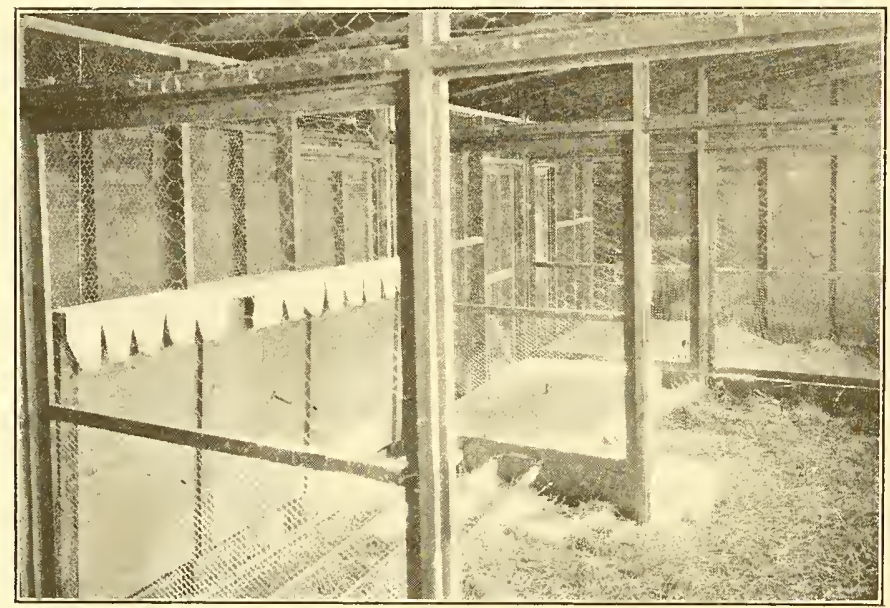

Continuous hot water pipe brooder. Hover in foreground raised. (Courtesy of Kansas Agricultural Experiment Station.)

Effect of Chilling.-A little chick compelled to remain in the cold after he begins to feel chilly, soon becomes helpless. This is apparently caused by the paralysis of the breathing apparatus. The lungs are located on either side of the median line of the back at the circumference of the body cavity. Lobes of the lungs extend between the ribs and are protected from the outside temperature only by a thin membrane, the skin, and a coat of down. It is not surprising that when the chick is chilled the lungs are quickly affected, breathing power restricted, and a general enfeeblement of the powers of movement ensues.

In natural brooding, the back and lungs are the best protected portions of the body. When a chick becomes 
uncomfortably cold under conditions of artificial brooding, and is unable to locate heat enough to warm him quickly, he obeys that instinct which tells him to get his back up against the mother hen. The result is that he tries to crawl under the other chicks. This, taken up by the other chicks in turn, results in bunching and crowding with the accompanying evils of smothered chicks and a diminution of thrift on the part of the entire flock.

Where the temperature is not sufficiently low to actually chill the chicks, but fails to make them comfortable, they quickly show the effect by ruffled feathers, "winginess," and

FIG. 120

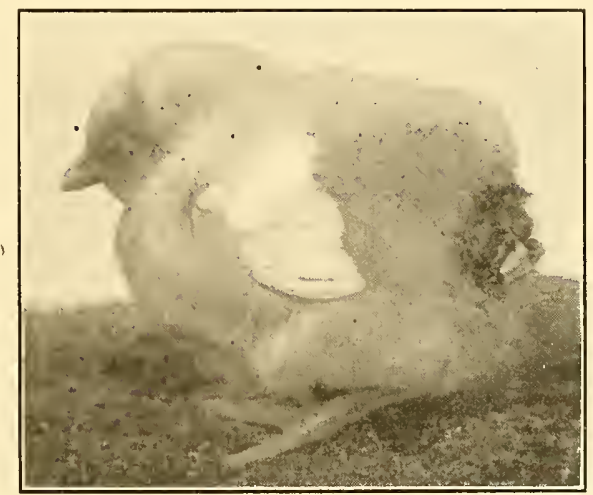

Showing the result of chilling. (Courtesy of Purdue Agricultural Experiment Station.)

a general appearance of unthrift, which is frequently accompanied by digestive disorders quite similar to contagious diarrhea in symptoms and results.

Fresh Air.- Not only should there be a well-ventilated exercising pen and outdoor rum, but the brooder-hover must be so arranged that there will be a constantly changing supply of the air. In the small oil-heated portable hovers of the best type, the heater is. so constructed that it both radiates heat from a drum and heats air which is poured under the hover, displacing and forcing out the old air. With the coal- 
stove brooders in which the hover acts largely as a deflector, there is usually a good circulation of air. With those having a long fringe or curtain, the latter should not be allowed to reach the floor by at least three inches if the air underneath is to be kept sweet.

Darkness. - "For the very best results the hover should be at least partially darkened. The reason for this is evident. Not only does the chick normally seem to enjoy seclusion, but when anything occurs to frighten him the first thing he wants to do is to get out of sight. In natural brooding he

FIG. 121

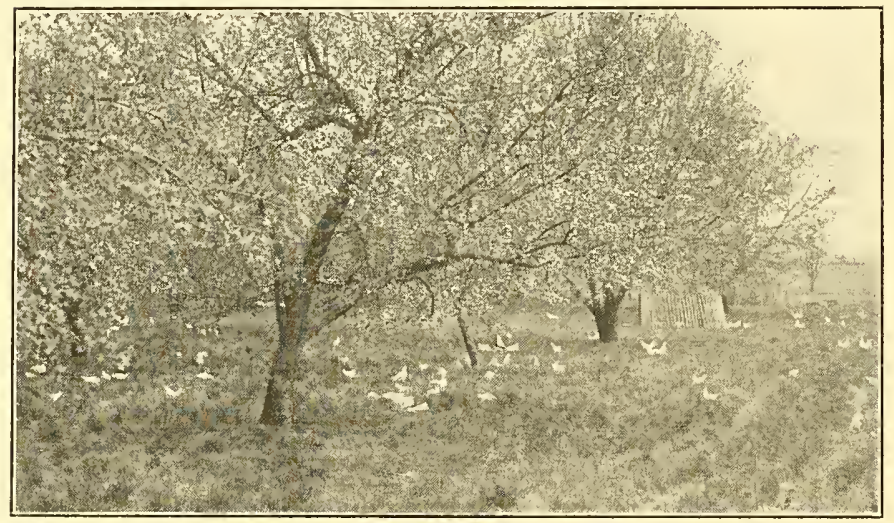

An orchard is a great place for the chicks. (Courtesy of Purdue Agricultural Experiment Station.)

ducks under the mother hen. As soon as he get out of sight or where he cannot see the thing that frightened him, he feels safe. This is a case where it pays in dollars and cents to humor the chicks."' Fright interferes with proper growth and comfort aids it.

Dryness.-Chicks cannot thrive in damp quarters. While heat is supplied the floor of the hover is likely to be dry. This should be true of the whole room or pen in which the brooder is located. Dampness makes filth out of litter and

1 Card and Kirkpatrick: Storrs (Conn.) Bulletin, No. 96. 
droppings, which harbors disease. Thrifty chicks may be cxpected only when their quarters are dry and clean.

Sunlight.-Sunlight and cheerfulness are synonymous in the brooder house. Sunlight is a powerful disinfectant and aids in keeping the quarters dry. It adds materially to the health and comfort of the chicks and aids in securing a profitable growth.

Number of Chicks to a Hover.-Commercial brooders are usually overrated as to their capacity. While many of the small hovers on the market rated at 100 chicks are capable of brooding 100 chicks at the beginning, it is only when the entire hover space is left free for the occupancy of the chicks. In some hovers nearly half the floor space under the hover is occupied by the heater. No hover, however, which is not over $2 \frac{1}{2}$ feet in diameter is capable of properly rearing to weaning more than 50 chicks.

While large coal stove hovers are capable of keeping 1500 to 2000 chicks warm, the advice of Card and Kirkpatrick, ${ }^{1}$ that not more than 500 chicks be started in one lot is based on sound practice. They advise 1 square foot of floor space for each 4 chicks. On this basis a house or pen 10 by 12 feet is needed for each coal brooder.

Ease of Disinfection.-The mutual arrangements of the brooder and the room in which it is housed must be such that every crack and crevice may be easily reached and thoroughly soaked by disinfectant from a spray pump.

Safety from Fire.- While the brooder of today is much safer from fire than its forerunners, this point should be carefully considered in making a purchase and kept constantly in mind after the purchase. There is always a considerable fire hazard where colony brooders are being operated.

Place of Operation.-Brooders should be located only in buildings which meet the requirements of a good poultry house. These requirements, already covered in part, are fully discussed in Chapter VI. They are (1) dryness, (2) good ventilation without drafts, (3) plenty of sunlight, (4)

1 Storrs (Conn.) Bulletin, No. 96. 
ease of cleaning and disinfection, (5) plenty of scratching room for the chicks, and (6) protection against their enemies. To this should be addled that abundant shade is a necessity as soon as the chicks are out of doors.

Preparing for the Chicks.-A brooder which has ever, at any time, been used, should be carefully cleaned and thoroughly disinfected in every part, including the thermometer, drinking fountains, and feed troughs, before attempting to brood a new group of chicks. The house in which it is located (in the case of an indoor brooder) should receive the same treatment.

It should then be leveled and the heater started. A new machine, or one with which the operator is not familiar, should be required to hold a fairly uniform temperature of $100^{\circ}$ for at least two days before trusting chicks to it.

The floor beneath and surrounding the hover should be covered with a fine litter of some such digestible material as fine-cut alfalfa or clover. Where indigestible material is used, such as chaff, cut straw, sand, and the like, there is always danger of the chicks filling themselves on this material, thereby causing impaction and a resulting high death rate. This may be replaced by a less expensive litter after the chicks are three or four days old.

Some such arrangement as is shown in Figures 122 or 123 should be made, which will prevent the chicks from wandering too far from the hover at first. They are particularly prone to being attracted by "sun spots" (i.e., the bright places where the sun strikes the floor), and, feeling the warmth of the sun, to camp there. When the spot moves on or disappears, the chicks will remain and become chilled.

As soon as they all learn to go under the hover at night without assistance, the arrangement may be removed.

The drinking fountain should always be located some little distance from the hover so that any water that is spilled will not render it necessary for the chicks to sleep in damp quarters. A device for avoiding a spill is shown in Figure 124.

Daily IManagement.-Brooding routine consists in regular and scrupulous care of the lamp, frequent and thorough. 
FIG. 122

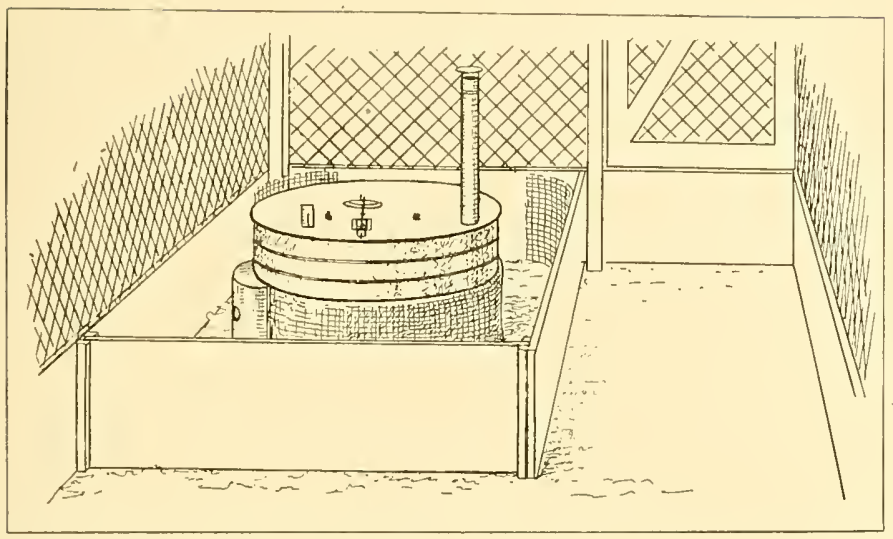

Showing square chick guard with corners protected. (Courtesy of Cyphers Incubator Company.)

FIG. 123

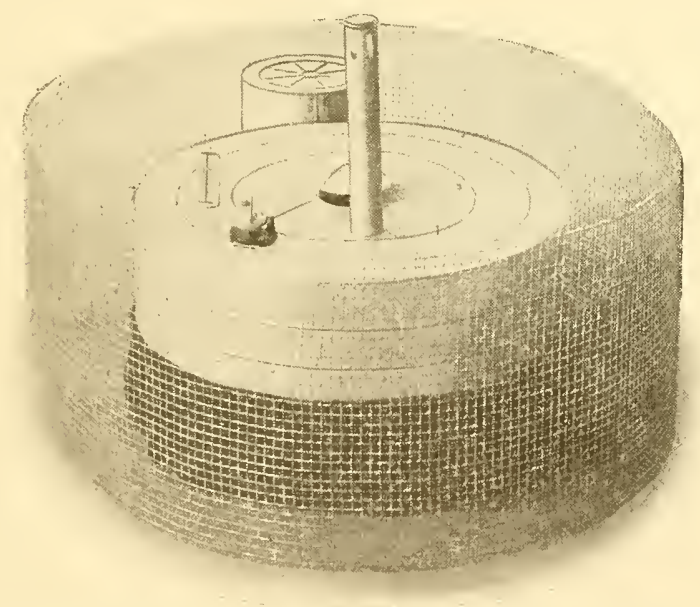

Half-inch mesh hardware cloth circular chick guard,an excellent arrangement for confining the newly hatched chicks for the first few days. The circle may be enlarged as the chicks get older. A very good substitute is a light wood frame covered with burlap or light cotton cloth. (Courtesy of Prairie State Incubator Company.) 
cleaning and disinfecting of the hover and its surroundings, and a constant watch over the comfort of the chicks.

The lamp should be filled, cleaned, and the wick trimmed every day with the same scrupulous care as with an incubator. The fact that the lamp bowl contains enough oil to last forty-eight hours should be made use of only on such terrifically windy days that there is danger of being unable to relight the lamp if it is put out. 'The time of filling and cleaning should be that which proves, in the case of the particular brooder being operated, to give the steadiest and most dependable flame throughout the night.

Fig. 124

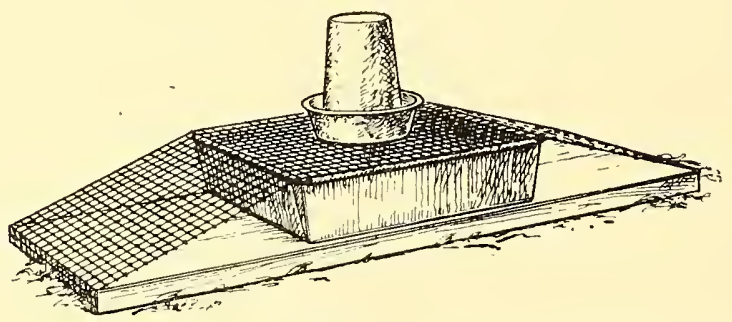

Device for catching spill. (Courtesy of Cyphers Incubator Company.)

The first four weeks of a chick's life is the most critical period. Usually when chicks are safely past this time, one may be reasonably sure of rearing them. During this time, however, they are highly susceptible to numerous chick diseases and should be guarded against them in every way possible. This means that the hover should be kept clean, the litter frequently changed, and in case of the appearance of disease, or of death under or about the hover for any cause except injury, the brooder and its immediate surroundings should be painstakingly disinfected. A whisk broom will be found a convenience in spraying a small brooder.

Where several groups of chicks are being brooded, it pays to have a cleaned and disinfected hover in reserve, which may be used to replace one that needs special attention. 
The necessity for constant watching during the early weeks is fortunately made possible by the frequent feeding, which is an essential of good feeding practice for little chicks.

It is considered good practice to get the chicks out onto the ground just as soon as possible. This may be done as soon as they have the hover sufficiently well located so that they may be allowed some distance away from it with reasonable assurance that they will come back to it when they feel cool. It will be sooner with some bunches than with others.

FIG. 125

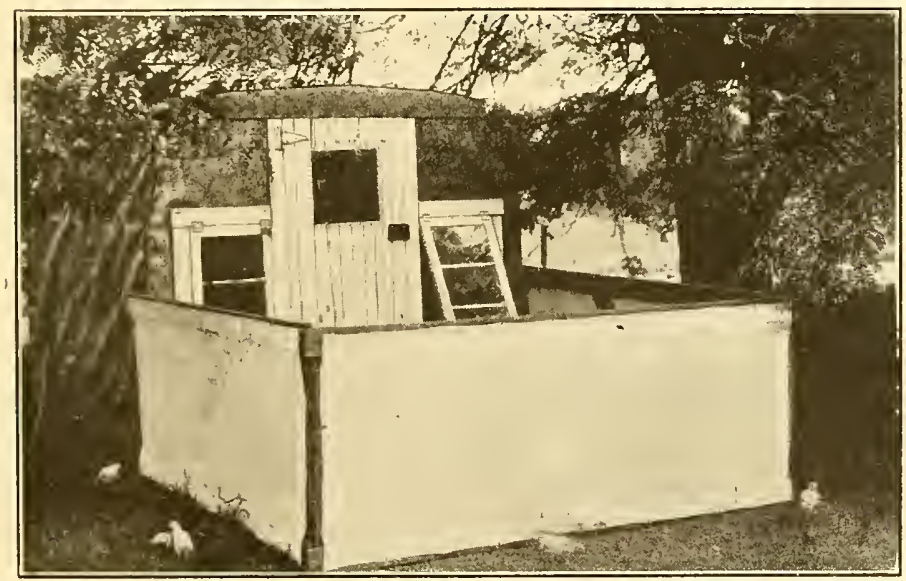

A muslin windbreak for littie chicks. (Courtesy of Kansas Agricultural Experiment Station.)

This should be done even with early chicks in quite cool weather. If it is inclined to be a bit brisk, the chicks may be protected by a cloth-frame enclosure, as in Figure 125. An easy approach to the house or brooder should always be provided. If it is at all steep it should be fitted with cleats or have poultry netting tacked down for the chicks to hold to with their toes.

Chicks should always be grouped by hatches when put in the brooders. It is a great mistake to put a newly hatched bunch in with a group a week or more old. Later on, the few outstanding individuals which make a thriftier growth than 
the rest, should be moved to an older group, after having been marked as possible breeders. The stragglers, however, should not be moved to younger groups, but disposed of as unfit to' survive. 'The skilled breeder begins his work of selection in the brooder.

For best results the sexes should be separated as soon as they are certainly distinguishable. It is the only method by which normal growth and satisfactory development of the pullets can be secured.

Early roosting should always be encouraged. Perches should be placed near the hover when the chicks are four or five weeks old. A few will start to roost before the heat is discontinued in the hover. "Early roosting helps materially in carrying the chicks over the critical period between artificial heat and full feather, when they are most likely to crowd at night and become heated or smothered.'1

Brooder Vices. - The most common brooder vices, aside from crowding, are "toe-picking," and the development of a "depraved appetite."

Toe-picking with the youngsters appears to develop for much the same reasons as feather-pulling with old stock. It is likely to develop when the quarters are crowded or when there is insufficient animal feed in the ration. The constant picking at the toes finally causes blood to flow, This, proving palatable, leads to cannibalism, which is difficult to check, and which may cause quite serious loss.

When toe-picking is discovered, roomier quarters or more animal feed or both should be provided. 'The chicks with bleeding toes should be removed and kept separate until they are well healed.

The depraved appetite is frequently difficult to assign a cause or cure for. It may consist in eating the felt fringe curtains of the hover, filling up on sand or earth, or other unnutritious materials. The cause usually ascribed is the lack of some necessary ingredient in the ration.

Unless impaction occurs the vice usually does the chick little harm. If the object of their interest is the hover curtain, it may be necessary to substitute oilcloth for the felt or flannel.

1 Card and Kirkpatrick, Storrs (Conn.) Bulletin, No. 96. 


\section{CHAPTER VI. \\ HOUSING AND HYGIENE.}

Housing is Unnatural.-When the hen is confined in a building she is placed under a highly artificial condition. In her wild state she does not ordinarily seek protection or seclusion in caves or burrows as do certain other birds. The ancestors of the domestic white-egged varieties were jungle dwellers, and sought safety and rest on the high limb of a tree or the seclusion of the underbrush. While the ancestors of at least a part of the feather-footed varieties probably had somewhat different habits, nevertheless, they never left the open.

Housing is Necessary. - The housing of poultry is necessary, however, for, as Brown ${ }^{1}$ points out, there has been a "general enfeeblement (of the races of poultry), which is the penalty we have to pay for breeding under unnatural conditions, for inbreeding to fix defined characters, and for using as stock birds those specimens which, in respect to vigor of body, are the least fit, even though they show the racial type to the highest degree." Artificial protection is necessary to offset this general enfeeblement.

It is also necessary in order that as much as possible of the energy derived from feed may be used for productive purposes, rather than in withstanding heat or cold winds and dampness. The tree-roosting hen is usually vigorous, but she is not a great producer except in very favorable weather.

Comfort the Prime Essential.-Other things being equal, production of meat or eggs is in direct proportion to the comfort of the hens. So far as the hens are concerned, egg production is essentially reproduction. The balance of the process of bringing a new creature into the world may be accomplished without the aid of the hen. The conditions

${ }^{1}$ Races of Domestic Poultry. 
FIG. 126

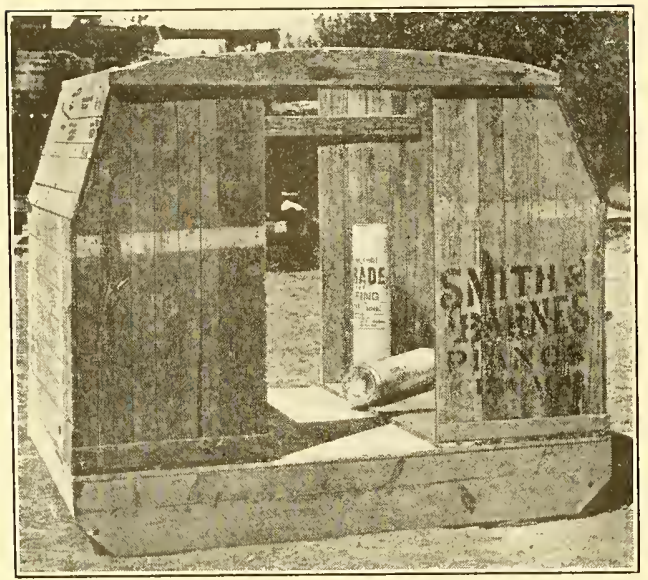

A simple and serviceable house may be made from piano boxes. (Courtesy of Kansas Agricultural Experiment Station.)

FIG. 127

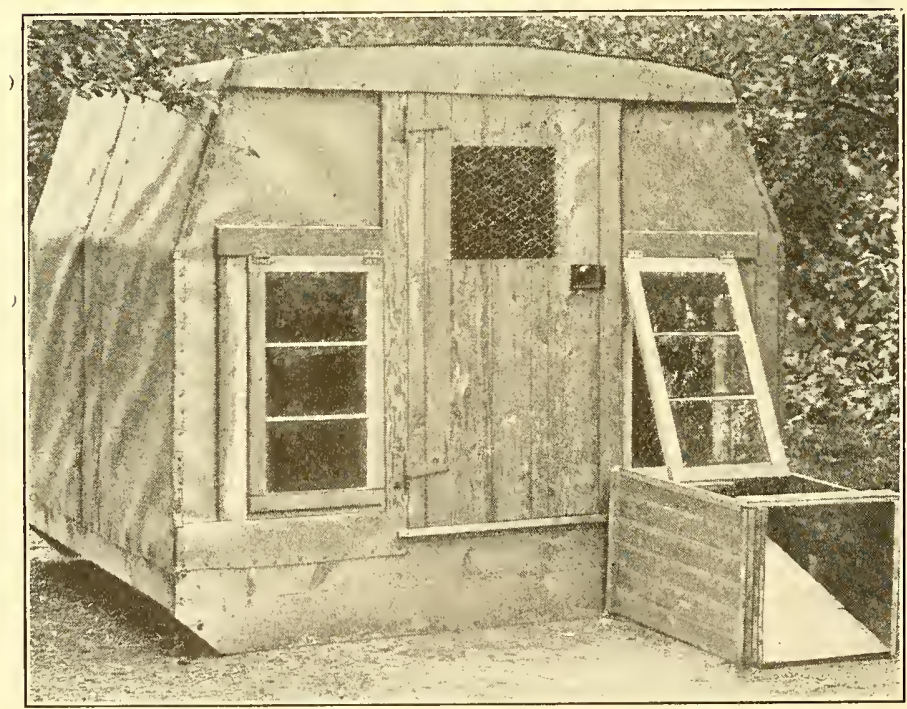

The piano-box house complete. (Courtesy of Kansas Agricultural Experiment Station.) 
which lead to rapid reproduction are those which tend toward comfort. The natural laying and breeding season is in the spring, because conditions are those which furnish comfort. The successful hen-house will furnish its occupants with permanent protection from dampness, drafts, wind, filth, vermin, or other causes of discomfort and disease, and from their larger enemies. At the same time it will give free access to the sunlight and fresh air. It furnishes all the protective advantages of the tree limb or hedge row without furnishing their discomforts or adding others, and insofar as possible duplicates spring conditions the year round.

Location.-Comfort in the poultry-house is as much a matter of location as it is of construction, and the location of the building has very much to do with its success. In a general way the house fixes the center of the circle which marks the limits of the birds' range. This is increasingly true under modern methods of feeding, where each flock of fowls is always fed in or near its own house, whether it be fed by hopper or out of hand.

The house marks the spot where they spend much of their time in the winter, which is the season that most taxes the producer's skill. The well-located house will be so situated that its occupants spend a maximum of time out of doors. This is desirable because it adds to the fowl's health and lessens the relative cost of the house. The greater the proportion of time that the fowls remain outside, the larger is the number of fowls the house will accommodate.

Shade and Shelter.-Extremes of temperature lessen production, and should be modified insofar as it is practicable. Although the ancestors of many of our common varieties of chickens are believed to have come from a warm country, the domestic fowl does not seem to be very well equipped to withstand high temperatures. There are no sweat glands, as in the horse, to aid in keeping the body cool. The molt comes as a preparation for winter rather than for the purpose of keeping the hen cool, as does the shedding of other animals. About the only means for reducing her body temperature when it is too high that has been furnished the hen is panting, and panting steals productive energy. 
The jungle-dwelling fowl of the hot country is kept cool by the shade of the thicket, and the domestic hen should be protected in the same way. In addition to trees, there

FIG. 128

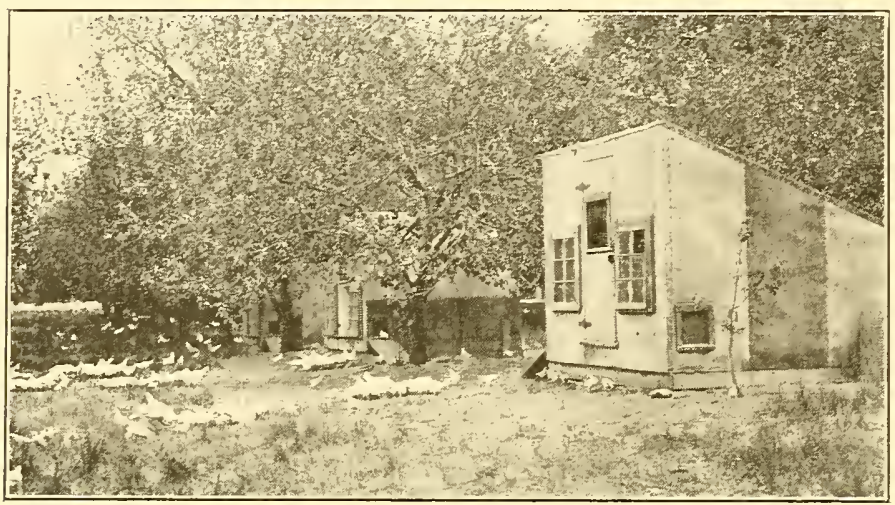

Growing chickens need shade. (Courtesy of Purdue Agricultural Experiment Station.)

FIG. 129

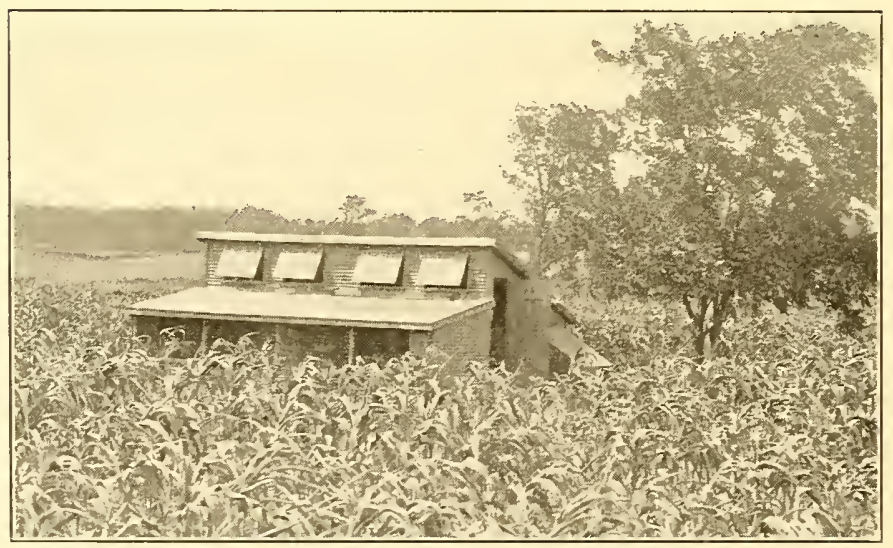

A chicken house near a corn field is good for the corn and good for the chickens. (Courtesy of Purdue Agricultural Experiment Station.) 
should be some low shrubbery under which the hens love to hide and which serves as a protection from hawks and crows in the case of young stock, as well.

The same trees that furnish shade will keep out the wind. It is not enough to locate the poultry-house in the lee of some larger farm building. Such shelter is valuable if it is the best to be had, but the large building will not always be to windward, and hot winds are often quite as blighting as cold ones.

FIG. 130

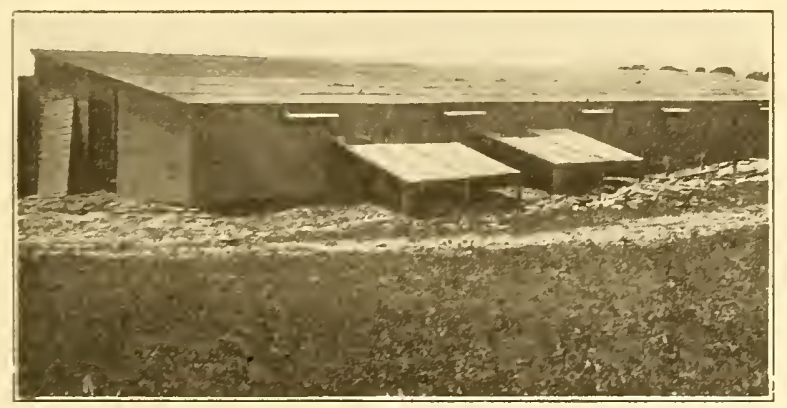

When it is necessary to build where there are no trees, shade must be provided for the stock. (Courtesy of Kansas Agricultural Experiment Station.)

Sudden changes in temperature always lessen egg production and generally lessen hatching power. The house that is completely surrounded by trees will not be subject to such sudden and severe changes as the house that is in the full sweep of the wind. These trees may at the same time comprise the farm orchard or be the means of supplying fence posts. A hillside may be of great assistance in protecting a house from prevailing winds, but it should be supplemented by trees.

Soil and Drainage.-The ideal soil for the location of the hen-house is one that is open enough to allow water to drain out and warm air to get in quickly, and at the same time is fertile enough to support a vigorous vegetable growth. The sandy or gravelly loam furnishes these conditions. The clay and gumbo soils are usually undesirable, because 
moisture passes through them with difficulty. Where there is moisture there is evaporation. Evaporation is a cooling process, and damp soils are always cold. Cold and dampness are limiting factors in egg production.

Such a soil, unless thoroughly drained by tiling, is a source of positive danger to the health of the flock. Moisture furnishes one of the essentials of the survival and development of disease-producing bacteria. A damp soil harbors disease. When the movement of the soil water is slow, unless the ground surrounding the house is so steep that it is selfcleaning every time it rains, it becomes coated with filth and contaminated with accumulations of droppings. Muddy yards are unsatisfactory to feed on, and soon make the feeding floor of the houses dirty. Unlike ducks, chickens are highly sensitive to filth in their feed.

Aside from its hygienic aspects, the fact must not be lost sight of that muddy yards mean that mud will be carried into the pens and nests and dirty eggs will result. Dirty eggs' bring less on any market where quality is considered.

Exposure.-There are periods when despite the efforts of the poultryman the birds are driven indoors. These periods are shortened when the house is placed on a south slope, well sheltered, that offers good air and water drainage. The south slope is advantageous for poultry for the opposite reason that a north slope is sought for fruits. The early arrival of spring conditions is as desirable for poultry, as the retarding of those conditions until all danger of frost has passed is for fruit. The soil on a south slope will be several degrees warmer than the same type of soil on any other slope or on the level. Because it is warmer it is dryer. The snow melts more quickly, and there is less discomfort for the birds. Spring conditions arrive earlier and tarry later on a south slope than on any other exposure, and spring is the season of the greatest and most economical production. Next to the southern exposure the east is the most desirable, because if they cannot have both, chickens, in common with flowers, prefer the morning to the afternoon sun. The west slope is the next most desirable, and the north exposure is the least desirable of all. 
Air Drainage.-Poultry houses are sometimes placed on low ground because of the shelter afforded by the higher ground, or for reasons of convenience. Cold, damp air settles in low places and frosts appear there earlier in the fall and later in the spring than on the surrounding higher ground. If there is no lower ground beyond, on to which the cold air may drain, such a situation is bad. Because damp, chilly air is uncomfortable it is not conducive to good production. The shelter of high ground is desirable only when there is enough ground lower than that upon which the house is situated, so that the cool air that settles about the house may quickly drain away.

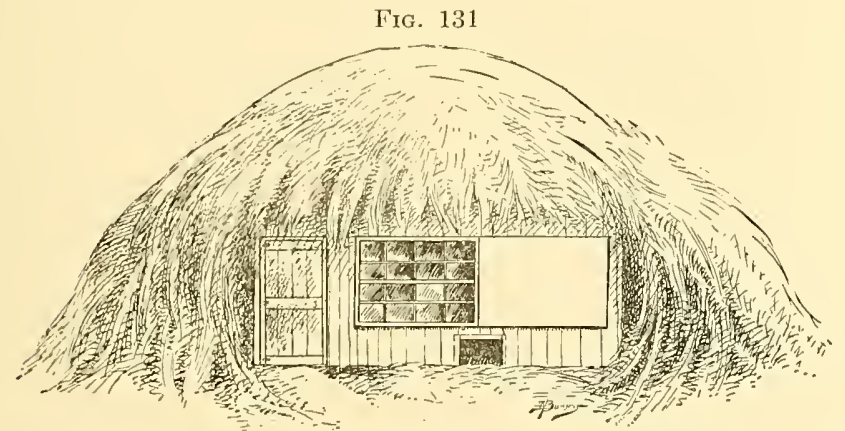

A comfortable house with a board, glass, and muslin front, covered with straw. (Courtesy of Reliable Poultry Journal.)

The Hen-house and other Buildings.-In locating a permanent poultry-house the fact that it must fit into the general routine of farm work and bear certain relations to other farm buildings must not be lost sight of. It is highly undesirable to build very near granaries, cribs, or barns, where the poultry is a nuisance, and which harbor rats and other vermin that prey on poultry and destroy eggs. The hen-house that is properly cared for may be located considerably nearer the dwelling than the stables for other stock. This is of ten a convenience for several reasons, among which is the fact that it is likely to be near the water supply.

It sometimes happens that the physical characteristics 
of a location near the dwelling-house are bad. 'The soil may be of a poor texture or the orchard and woodlot at some distance. In general, however, if the building site for the dwelling has been well chosen it will furnish good conditions for the hen-house.

Dryness. - Of those conditions which help to make a henlouse comfortable, drymess is of the utmost importance. It is a condition dependent upon proper location, good construetion, thorough rentilation, ame an abundance of sunshine. There is no condition under which poultry is kept, unless it is a state of starvation, that is more surely and quickly fatal to profitable production than dampness in the roosting and scratehing quarters. It makes the birds meomfortable and renders them susceptible to disease.

'The chicken is of necessity a rapid breather. Its temperature is high (average $106^{\circ} \mathrm{F}$.) and the oxidation within the body is enormously rapid. Fowls live at a high rate of speed, and, as with a highly geared machine, clogging spells disaster.

Damp air compels fowls to increase their already rapid respiration. It is not uncommon to see chickens confined in a damp house panting on a day that is rather cold. 'This extra work of faster breathing uses up energy that should be employed in the production processes.

A reason for the increased rapid breathing lies in the fact that with the fowl a much larger proportion of the body moisture is eliminated by way of the respiratory system than in the case of other farm animals. While fowls do not drink as much water in proportion to their weight as do other animals, there is no elimination by means of sweat glands, and the amount of moisture in the feces is comparatively small. There is no urine passed. In the light of the fowl's high temperature, as well as the foregoing, it seems reasonable to assume that a larger percentage of the water drank by fowls is gotten rid of by means of the breathing apparatus than is the ease with other farm animals.

The elaborateness of the apparatus itself would also suggest this probability. Besides a well-developed pair of lungs, there are comnected with them four pairs of air saes of considerable proportions placed on either side of the body, 
and ranging in position from the neck to the abdomen, with a single median sac located in the cavity of the thorax. Besides opening into the lungs, these sacs communieate directly with the eavities of most of the bones of the body, with the exception of those of the forearm and hand of the wing and those below the hock-joint of the leg.

Hix. 132

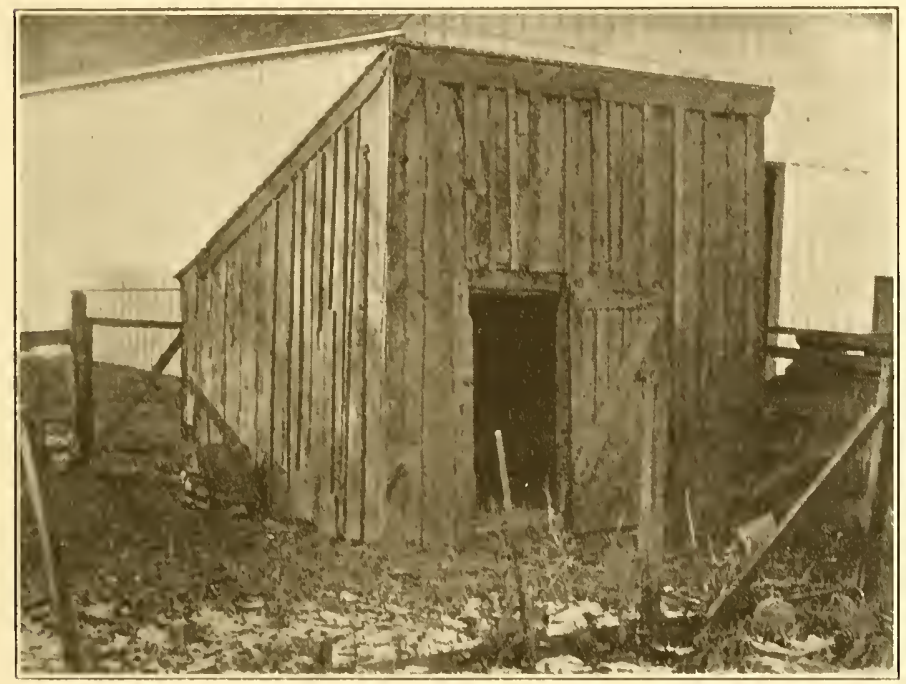

A farm poultry-house: no light, no ventilation. (Courtesy of Purdue Ixriculural Experiment station.)

This elaborate system for gathering moisture from every part of the body trunk is working at a distinct disadvantage when the air which must be depended upon to take up the moisture vapor is already laden with it.

Such a condition is debilitating to the system as well as fatal to production. It is a law of universal application that a debilitated condition always means weakened defensive powers and a greater susceptibility to disease.

Moisture is one of the essentials of the development of disease germs in common with all other bacteria. The 
more moisture there is in a building the more opportunity there is for disease-bearing organisms to be present in large numbers.

With the moisture of the body being constantly given off by means of respiration and feces the air of the poultry-house is bound to become laden unless it is as constantly replaced with new air.

FIG. 133

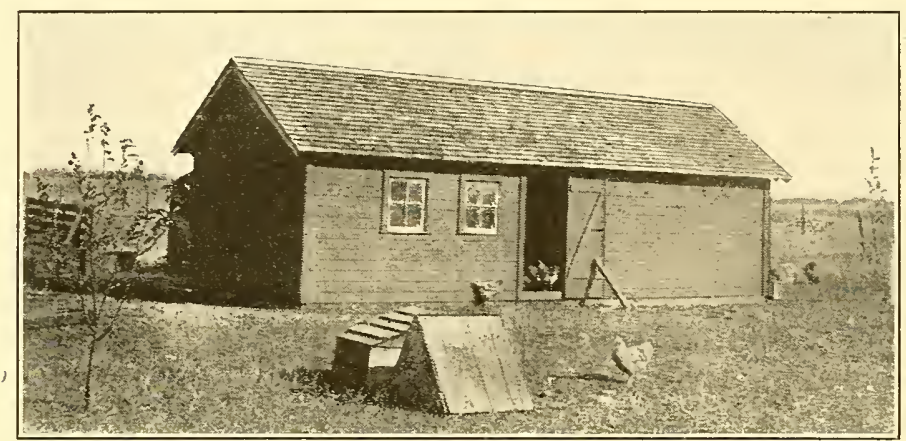

A farm poultry-house having no ventilation. (Courtesy of Purdue Agricultural Experiment Station.)

Ventilation.- Ventilation is of profound importance, however, not only because of the relation to the elimination of moisture. With the moisture of the expired air, gases are also given off, the principal one of which is carbon dioxide. Among these gases are certain ones that are actually poisonous if rebreathed. They are far more poisonous when breathed by another individual than when breathed by the individual giving them off. There is no reason to suppose that the striking result reported by King, ${ }^{1}$ where a mouse confined in a pint fruit-jar until it was nearly suffocated lived longer than a perfectly fresh mouse did that was put into the jar at that point, is not holding true in the hen-house continually. Every bird in the flock of fifty or a hundred is compelled to breathe the poisons given off by all the other

1 Physics of Agriculture. 
individuals in the flock unless there is constant and positive displacement of the expired air by fresh air.

F1G. 134

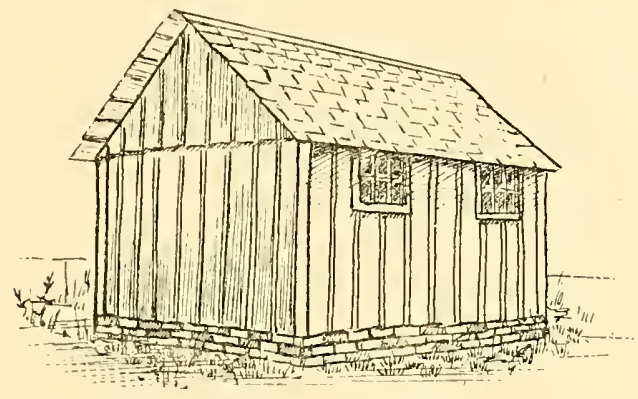

A poor poultry house; no ventilation.

F1G. 135

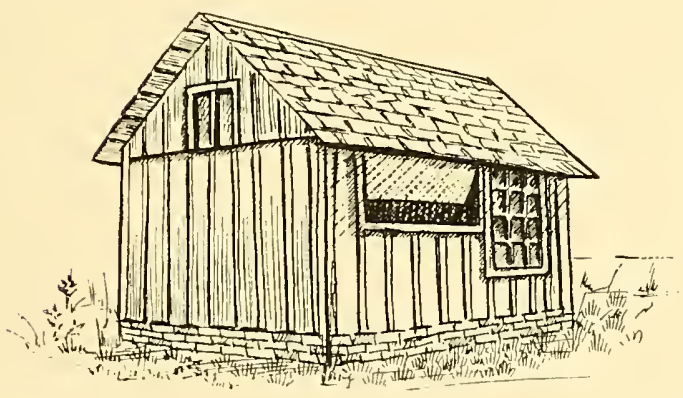

Making a good poultry house out of a poor one (Figure 134) by providing ventilation by means of a cloth-curtain window and a straw loft.

The need of ventilation is further emphasized by King, ${ }^{1}$ who quotes Calin as giving the cubic feet of air breathed by certain animals per thousand pounds of live weight as follows:

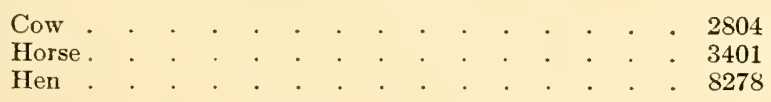

1 Physics of Agriculture. 
Pearl and Surface ${ }^{1}$ have to say, in reference to certain breeding experiments: "Conditions of housing have a marked and definite influence on the mean or average fertility and hatching quality of eggs." In the experiments discussed it was found that both fertility and the hatching quality of eggs were very much better when the breeding was done in a curtain-front house, which furnished an abundance of fresh, pure air, than when it was done.in what was formerly considered to be a highly desirable type of heated house without curtain front, but with a supposedly adequate system of indirect ventilation.

Ventilation and Drafts.-It is difficult to so house fowls that they will have as full advantage of fresh air as they have in the tree and at the same time be protected from drafts. While a fowl can roost all night in a tree when it is blowing a gale and not take cold or suffer any other noticeable ill effects, it will take cold very quickly if compelled to be in a draft inside of a house. Colds frequently form the beginning of epidemics of roup, diphtheria, catarrh and other kindred ills. While ventilation should be ample it must be without drafts.

Artificial Warmth versus Fresh Air.-A moderate temperature is one of the conditions of spring which is conducive to high production. The question arises whether it will be profitable in the broad sense to furnish artificial heat even at the expense of ventilation. There is not nearly as much evidence on this point as there should be, but such as we have seems to point decidedly to the conclusion that to have air fresh is of far greater importance than to have it warm.

Sunlight.-An essential of the best success of a chickenhouse is plenty of sunshine. Nothing helps more in the effort to reproduce spring conditions in the hen-house than flooding it with sunshine. The hens like it, and it helps to moderate low temperature and to keep the house dry. It helps to prevent disease as well. It is one of the most effective germicides that can be made use of. Other things being equal the house that admits the most sunshine in the 
winter time will be the one out of which comes the greatest production. As Dryden dryly remarks, "Sunshine is a germ destroyer and a better egg producer than red pepper or other condimental foods."

F1G. 136

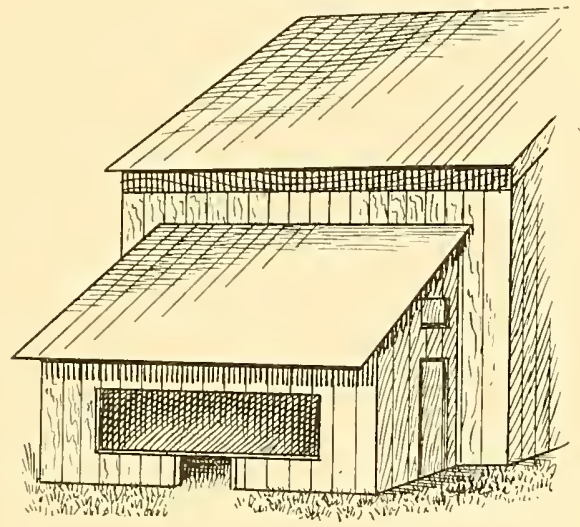

A "lean-to" that was converted into a most satisfactory poultry-house. Poles were placed inside to form a ceiling and the loft thus made was filled with straw to add to the warmth of the house. (Courtesy of Reliable Poultry Journal.)

FIG. 137

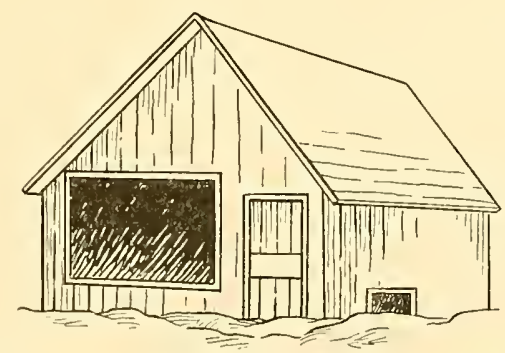

A shed with the end toward the south that was converted into a satisfactory poultry-house by cutting a large opening. (Courtesy of Reliable Poultry Journal.)

Artificial Light.-A comparatively recent development in poultry husbandry is the use of artificial lighting in the chicken house to prolong the feeding day. The lighting 
problem is proving to be largely a feeding problem and will be discussed in that connection in a later chapter.

For the present purpose it may be said that proper lighting accompanied by proper feeding markedly increases the winter egg production of pullets, and under certain circumstances, probably of yearling hens.

While rather early to pass final judgment, it now appears probable that where electric current is available and eggs are produced as a source of moncy income rather than to supply the home table, lights should form a part of the equipment of the poultry house.

Fig. 138

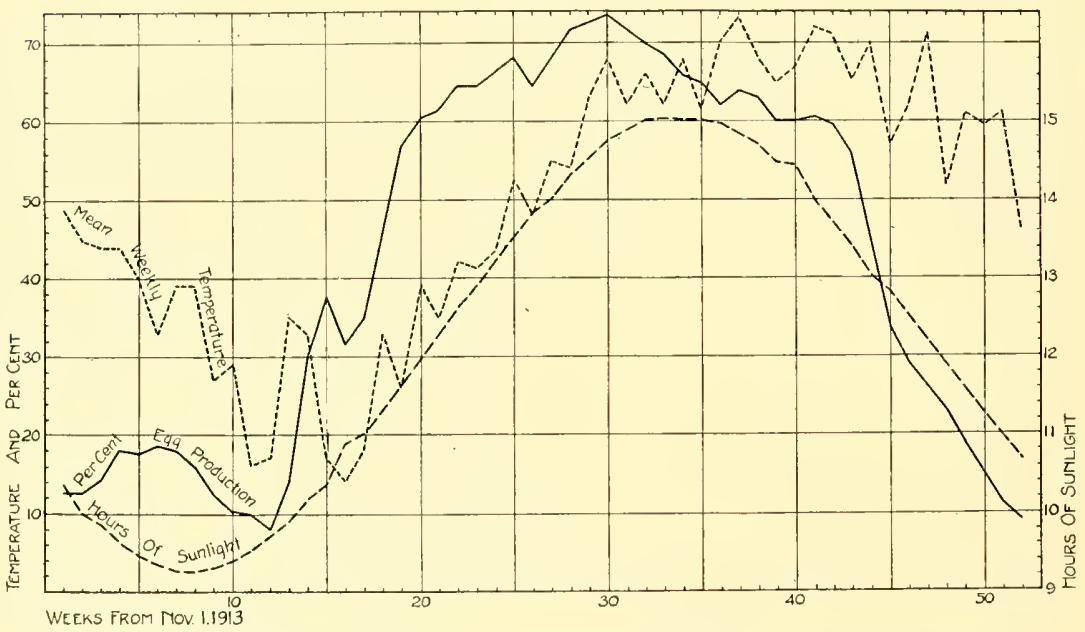

Showing graphically the relation between the per cent (of perfect) egg production, temperature and hours of sunlight. (Temperature and egg production per cents from the data of Card, Storrs (Conn.) Bulletin, No. 91.)

Rice $^{1}$ advises the use of lights which allow one watt to 6 to $S$ square feet of floor space, assuming the walls are white and reflectors are used. Lewis ${ }^{2}$ has shown that two comparatively small lights are preferable to a single large one

1 Cornell Poultry Department, Stencil No. 1661.

${ }_{2}$ Paper read before Thirteenth Annual Convention of American Association of Instructors and Investigators of Poultry Husbandry. 
because shadows are thus largely avoided if wide angle reflectors are used. 'The lights must be bright enough to show fine grains in the straw. Lanterns and gasoline lamps have so far not proved highly satisfactory.

Ease of Disinfection.-Because of the small size and corresponding small economic value of the individual hen, not much time can be spent in doctoring her if she becomes sick, even if the knowledge of how to treat her is at one's disposal. Yet many poultry diseases are highly contagious. If they once gain entrance to the flock, nearly every bird is likely to be affected. The only satisfactory way to deal with such epidemics is by taking every precaution for prevention.

An essential of a good poultry-house, therefore, is ease of cleaning and disinfection. All fixtures and appliances should be movable, so that they may be easily cleaned and sprayed. The general construction should be as tight as possible, so that there will be a minimum of cracks and crevices. It is in the cracks that the mites breed. They attack the hens when on the nest or the perch and hide in any crack they can find during the day. Such cracks as are unavoidable must be easily reached.

Size of the House.-The size of the chicken-house is determined by the number of birds to be sheltered, the amount of time they will be compelled to stay in the house by unfavorable outside conditions, and by its portability or permanence. The portable house will necessarily be of such size that it can be hauled from one part of the farm to another with the motive power available. The topography of the farm will influence the size of the portable house somewhat, as a very much larger house can be handled by a team where the ground is level than where it is rough and broken.

With regard to the amount of floor space required per bird, Dryden ${ }^{1}$ estimates that "Where there is little or no snow, or where chickens can be out of doors every day in the year, about two square feet of floor space will be sufficient. This would apply to flocks of twenty or more. For smaller flocks a more liberal allowance of space should be made. Where the 
climate is such that the fowls will seek shelter part of the year rather than go outdoors in the yards and fields, more space should be provided, say four to five square feet per fowl. Halpin ${ }^{1}$ says that a flock of fifty hens should usually be allowed about five square feet of floor space per hen. $\mathrm{He}$ further calls attention to the fact that "One hundred hens will thrive in a pen $20 \times 20$ feet, that is, four square feet of floor space per hen, but one hen will not thrive in a pen two by two feet. As the number of the flock becomes less the

FIG. 139

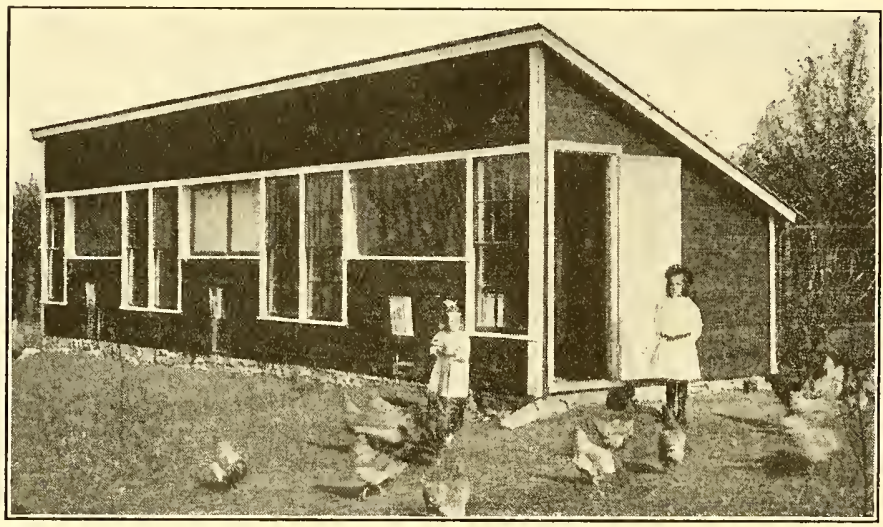

A good farm poultry-house. (Courtesy of Kansas Agricultural Experiment Station.)

amount of floor space per hen must increase, and anyone keeping eight or ten hens should allow at least ten square feet of floor space per bird unless he is prepared to give special attention to cleaning and bedding the house. Rice and Rogers ${ }^{2}$ add that "The lighter breeds, because they are more active and restless, require nearly as much room as larger breeds." App, Waller and Lewis ${ }^{3}$ report that the average floor-space per mature bird allowed by commercial poultrymen in New Jersey was 3.9 square feet, based on a survey of 150 farms.

1 Wisconsin Bulletin No. 215.

3 New Jersey Bulletin, No. 329.

${ }^{2}$ Cornell Bulletin No. 274. 
Evils of Overcrowding.-When hens are too closely penned or are not allowed enough floor and yard space they are naturally discontented. Following the laws of nature, that both plants and animals shall reproduce themselves most abundantly when the conditions surrounding them come nearest to fulfilling their wants, egg production is likely to suffer under close confinement.

Besides this, certain vices generally appear in the flock of considerable size that is closely confined or whose quarters are too small. One of the first to appear is feather-pulling. Starting at first as a manifestation of nervous impatience by a few birds, it is likely to be imitated by most of the flock, with the result that many fowls in the flock are kept rather destitute of feathers. If it so happens that the feathers are green and a little blood appears, cannibalism is likely to develop, and at times is the cause of serious loss. At best, protein that might otherwise be used toward the manufacture of eggs must be used in constantly growing new feathers.

Egg-eating is very much more likely to develop in a crowded pen, largely due, perhaps, to the fact that eggs are more often broken under such conditions. Nevertheless the loss from such cause may be large.

A further evil of crowding that must not be overlooked is the curtailment of the production of the weaker individuals of the flock. Where generous space is allowed each fowl the less vigorous ones have more opportunity and are likely to respond with a stronger production. A fowl that is being continually pecked around, as the least vigorous ones are in crowded quarters, cannot be expected to be a profitable producer.

Size of the Pen.-The small flock is usually housed in a building containing a single room or pen. Large flocks are generally divided in groups even when kept in the same house and each group given a separate pen.

The question of just what constitutes a flock of the proper size is a question upon which practical poultrymen differ and upon which there is little experimental evidence. The natural covey of the wild ancestors of at least a part of our domestic hens is five or six. With an unskilled poultryman 
the individual egg production of hens kept in comparatively small groups is higher. On the other hand the more groups there are the greater is the labor of caring for them.

Combining two small flocks in one larger one lessens the time necessary for their care by nearly half. Just where the increased labor of caring for small flocks begins to offset the increased production is impossible to state. For general farm practice, where poultry is not a specialty, the maximum group is probably about one hundred. This would require a pen $20 \times 20$ feet.

Foundations. - A good foundation will be solid enough to support the building and keep the cold winds from blowing under the house, deep enough to prevent heaving by frost, and high enough above grade to keep out surface water. In most sections it will be found advisable to build foundations twenty inches deep to prevent heaving and twelve inches above grade to keep out surface water. In order to leave room for the opening and shutting of doors where a deep litter is used the top of the foundation must be at least six inches above the floor level. This brings the tops of the door sills eight or more inches above the floor. If for some reason it is necessary to locate the house where the texture of the ground is such that it tends to hold moisture a tile placed even with the bottom and just at the outside of the foundation, and furnished with a suitable outlet is a necessary precaution if the house is to be dry.

Floors.-The hen-house floor must be moisture-proof, free from cracks, and easily cleaned. It should be rat-proof and durable. The board floor, if properly laid, is free from cracks and is easily cleaned and disinfected. It is usually a dry floor, because the air space below it stops capillary attraction.. It is not a durable floor when compared with cement, and it is not rat-proof unless raised well off the ground as in Figure 142.

The dirt floor is popular because of the supposed economy and its being "nearer nature." Unless certain rather expensive precautions are taken the dirt floor is likely to be damp. If it is not damp it is dusty. Either condition threatens the health of the birds. To keep out the capillary 
moisture it will be necessary in most locations to excavate the floor and put in an eight-inch course of coarse-crushed rock. Over this may be laid a course of gravel or cinders, and finally the dirt. This will keep out the moisture, but will not keep down the dust, which is very irritating to the air passages, often producing a cold-like condition that develops into roup. Unless fairly frequently replaced the

FIG. 140

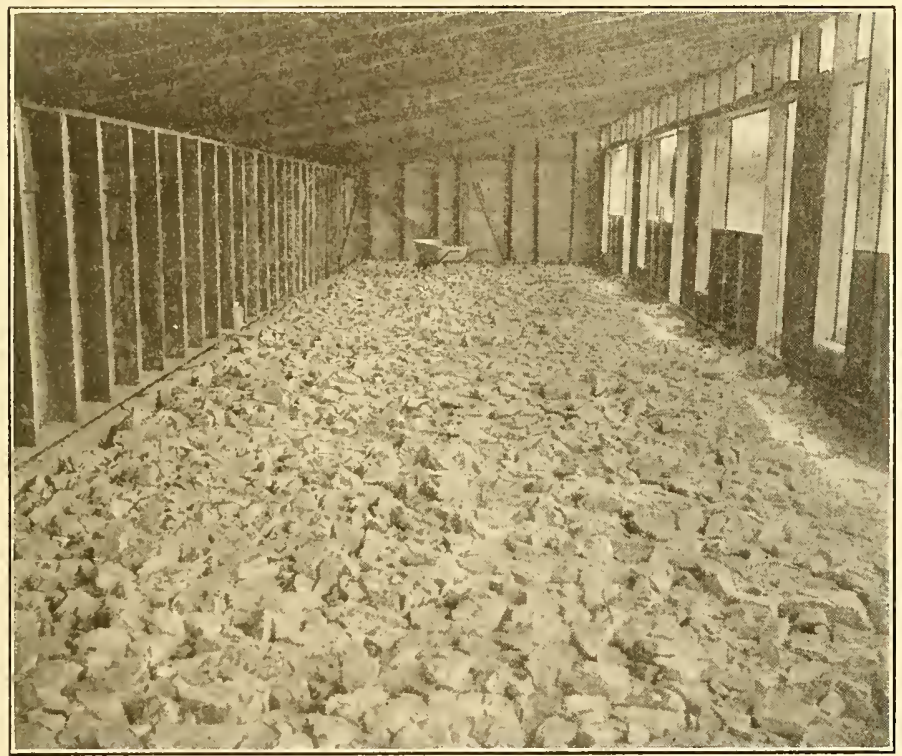

A six- or eight-inch course of coarse crushed rock or hollow building-tile laid flat should be the floor foundation. (Courtesy of Kansas Agricultural Experiment Station.)

dirt becomes contaminated with filth and is a source of danger.

The cement floor is dry, if properly constructed, and is sanitary, durable, and rat-proof. It is not a cold floor when properly bedded with a straw litter. In order to insure a cement floor being dry it is necessary to take a precaution similar to the one mentioned in the case of the dirt floor. 
The capillary moisture must be stopped. A six- or eight-inch course of coarse-crushed rock or hollow building tile laid flat, should be the floor's foundation. Over this may be placed a layer of gravel and finally the finishing coat, which should be smooth to insure easy cleaning. It is an additional safeguard against moisture with both dirt and concrete floors to make the floor level six inches above the level of the ground outside.

Fig. 141

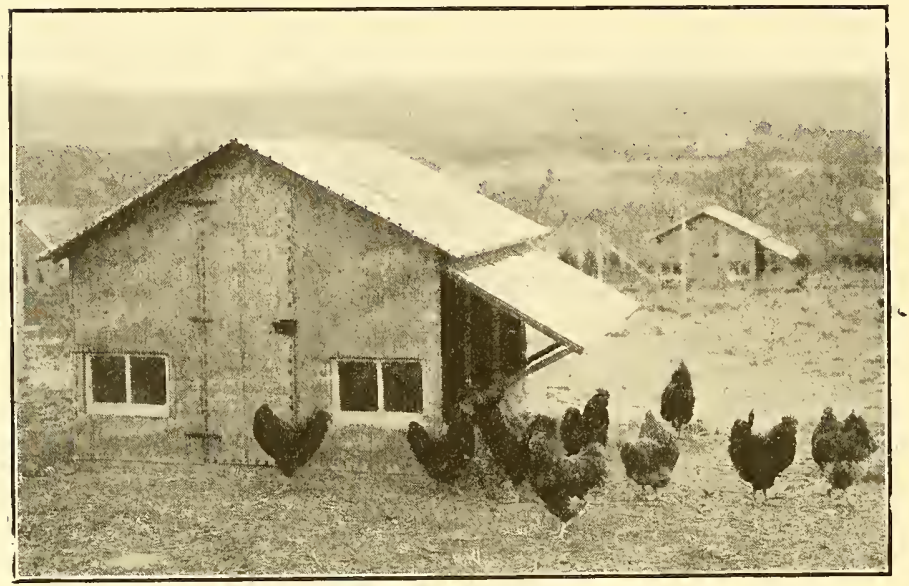

The Kansas colony house. (Courtesy of Kansas Agricultural Experiment Station.)

What seems to be proving a very satisfactory floor is made by laying hollow clay building blocks on their flat side in a bed of well-settled gravel and plastering the whole with cement plaster. This floor is durable, rat-proof, and dry. It has the advantage of an air space below it, the same as does the board floor.

Windows.-It is necessary to have windows in a chickenhouse for both light and ventilation. The window intended primarily to furnish light is of glass. The window for furnishing fresh air is only protected by a light cloth curtain, by open slats, or in some cases not at all. 
Because of the desirability of admitting as much sunlight as possible into the back part of the house it is customary to place the glass windows as high as the construction of the

FIG. 142

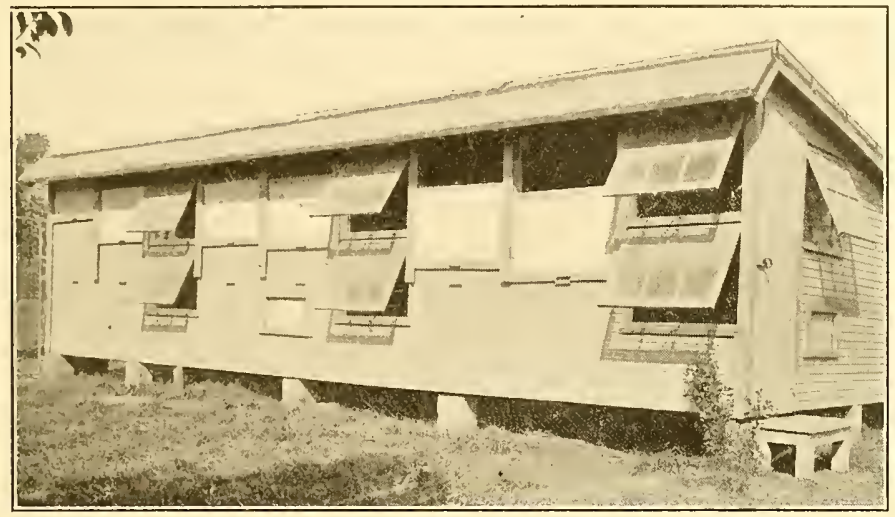

A board-floor house set on cement blocks. The cloth curtains are arranged to slide up and down instead of being swung on hinges. (Courtesy of Purdue Agricultural Experiment Station.)

FIG. 143

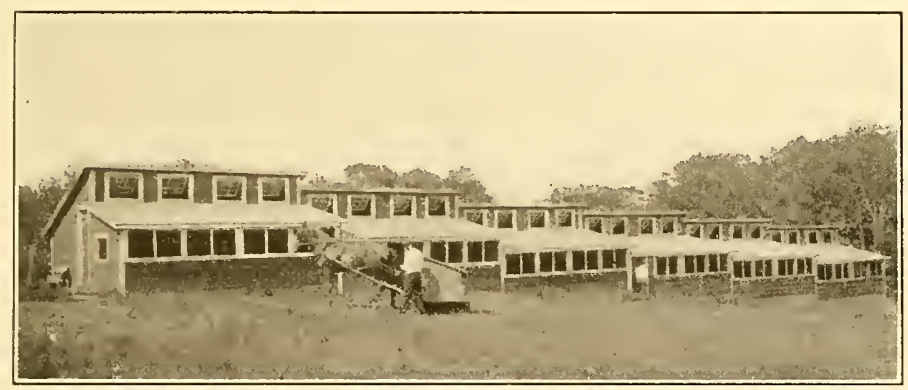

A row of half-monitor roof fresh-air houses. (Courtesy of F. L. Sewell.)

house will allow, and to have their length run vertically so that as much as possible of the floor will be swept by the sunlight. 
The custom often differs in the placing of the open window. It is usually placed high enough so that the wind will not strike the fowls, as in Figure 139, or clear at the floor, as in the case of the Tolman house in Figure 162, and the Woods house in Figure 143. Either way is satisfactory. The main function of this open window is to allow the free admission of fresh air without creating drafts. In extreme cold or stormy weather these windows should be protected by frames covered with light mushin, heavy cheese-cloth, or by a slatted frame as shown in Figure 148.

In the shed roof and combination roof types of houses it is usual to have all the openings on the south side, as in Figures 139 and 147. For very warm weather it is often desirable, however, to have extra ventilation, as is given in the house shown in Figure 151. In the combination-roof houses of the type shown in Figure 162 the open window is placed at the south and the glass window and door on the east and west sides. In houses having openings on more than one side, care must be taken to see that the fowls are so protected that they are out of the line of any drafts.

Ventilation Systems.-Most of the ventilating systems used in stables depend upon a considerable difference between inside and outside temperatures for successful operation. Owing to the facts that chickens require a much greater amount of floor space per hundred pounds of live weight than do the larger animals, and that the roof must be high enough to furnish head room for the feeder, there is too much cubic space in a hen-house for the hens to heat it sufficiently to make such systems work. Up to the present time, openfront, curtain-front, and slatted-front houses seem to furnish the best means of ventilation. Where the summers are extremely hot, such ventilation may be supplemented by ventilators at the back of the house, as shown in Figure 144. This is so arranged that the fowls are never in a direct draft.

Walls and Partitions.-The walls and partitions must be solid enough to support the roof and withstand heavy winds. They must be draft-proof, dry, and easy to clean and disinfect. Matched boards free from knots, well painted, and 
lined with building paper, or covered with prepared roofing, will usually be draft-proof. If the boards are dressed on the

FIG. 141
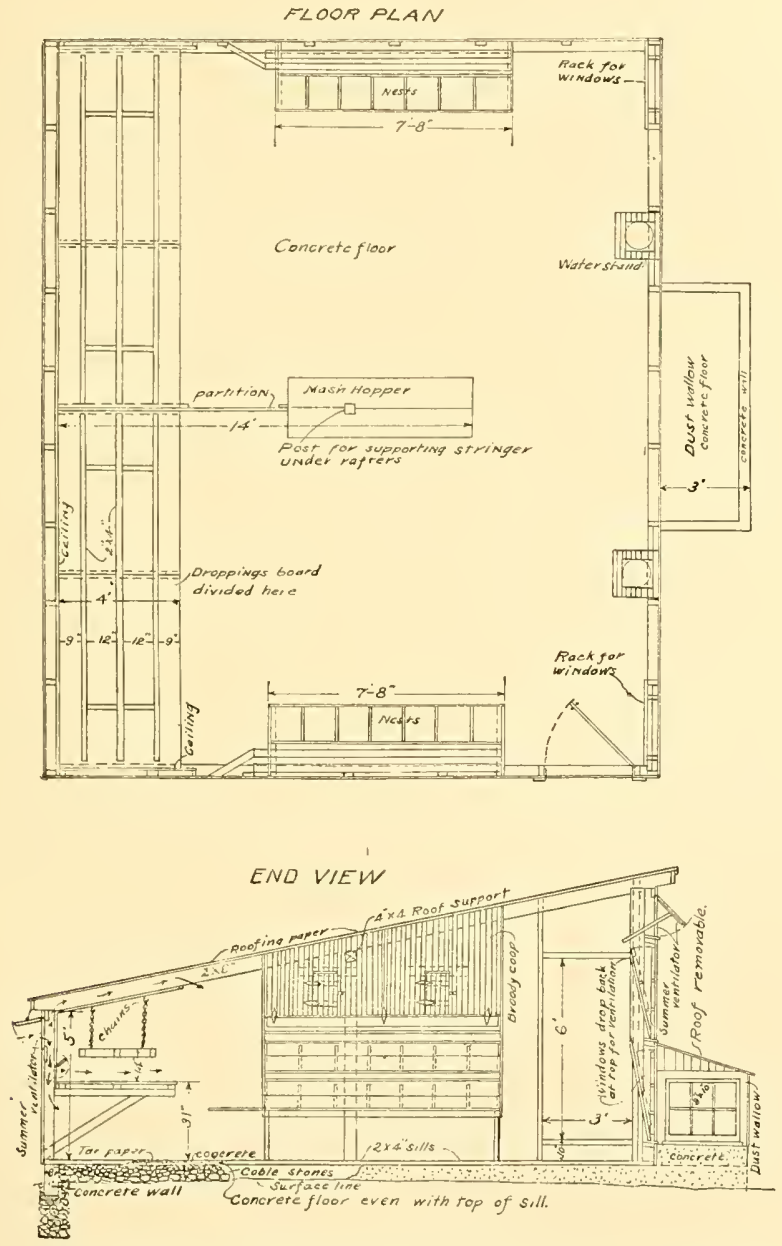

End view and floor plan of Cornell laying house. (Courtesy of Cornell Countryman.) 
inside, as they should be, they will be easy to clean. By having the siding run vertically instead of horizontally the

FIG. 145
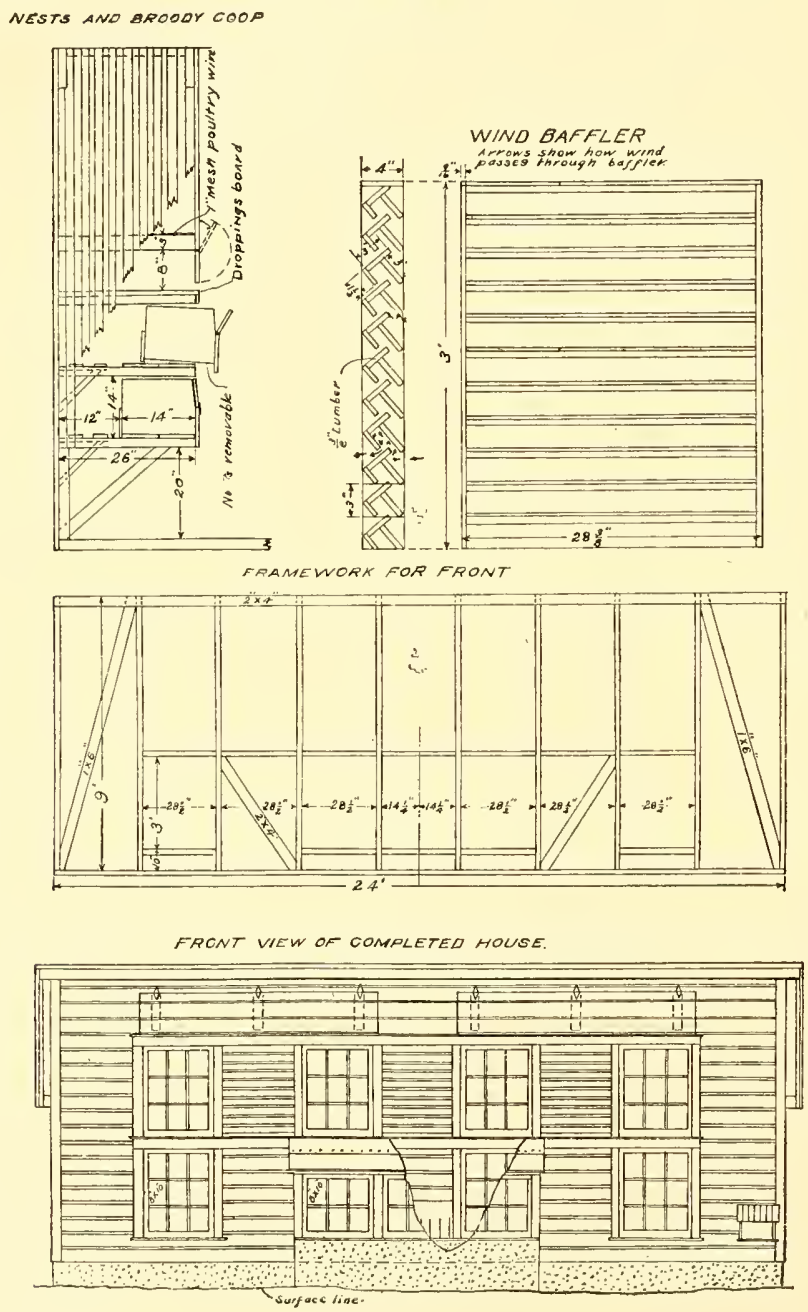

Front view and framing plan of Cornell laying house. (Courtesy of Cornell Countryman.) 
disinfectant used in spraying will penetrate the cracks much better and render it an easier matter to get rid of mites should they gain access to the house.

FIG 146
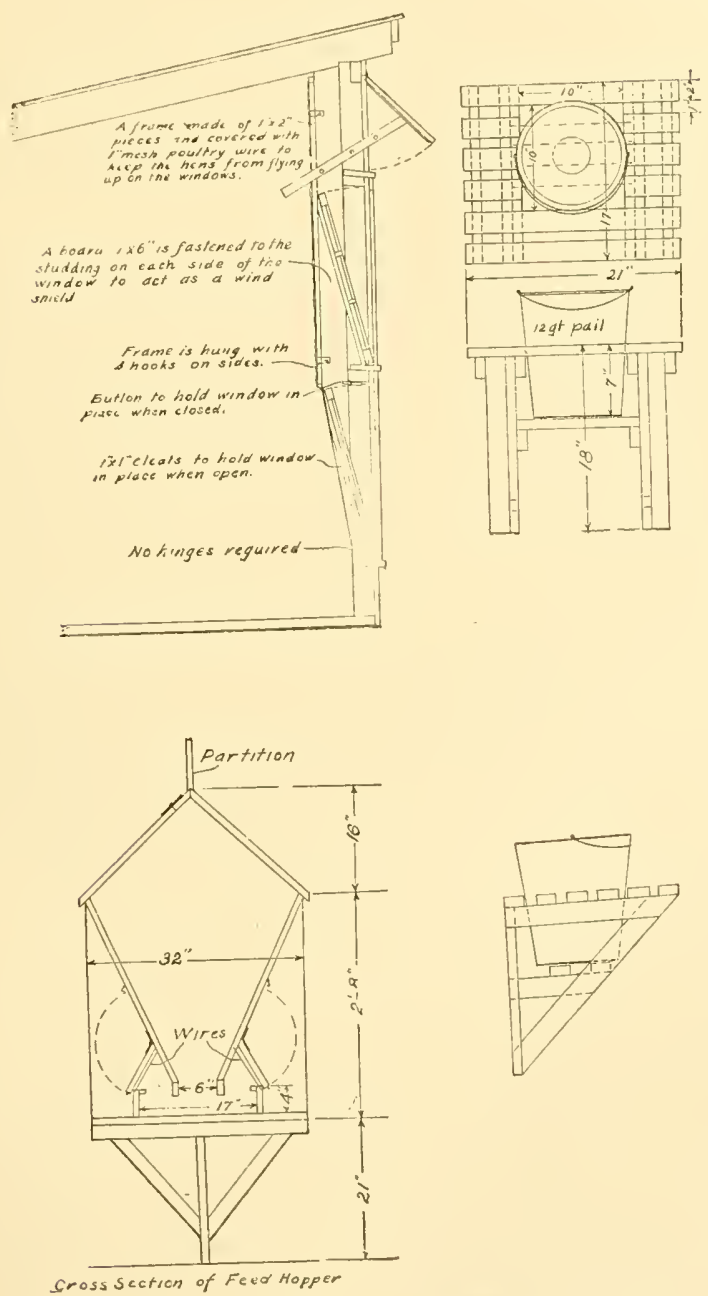

Details in Cornell laying house. (Courtesy of Cornell Countryman.) 18 
FIQ. 147
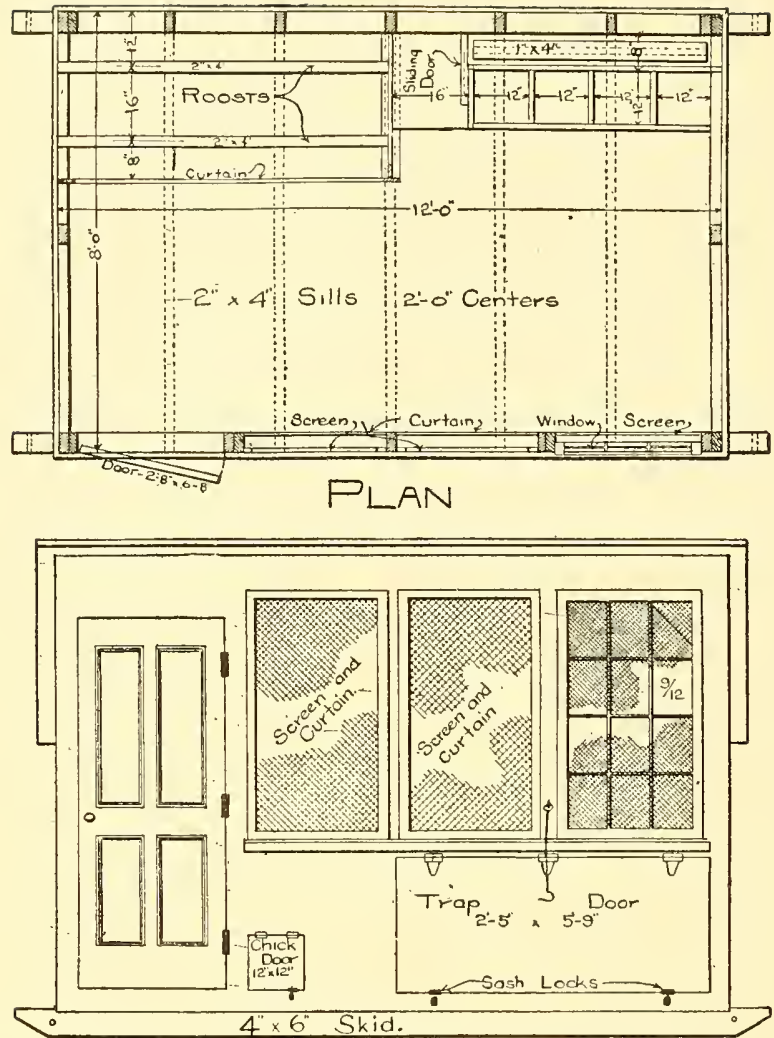

FRONT ELEVATION.

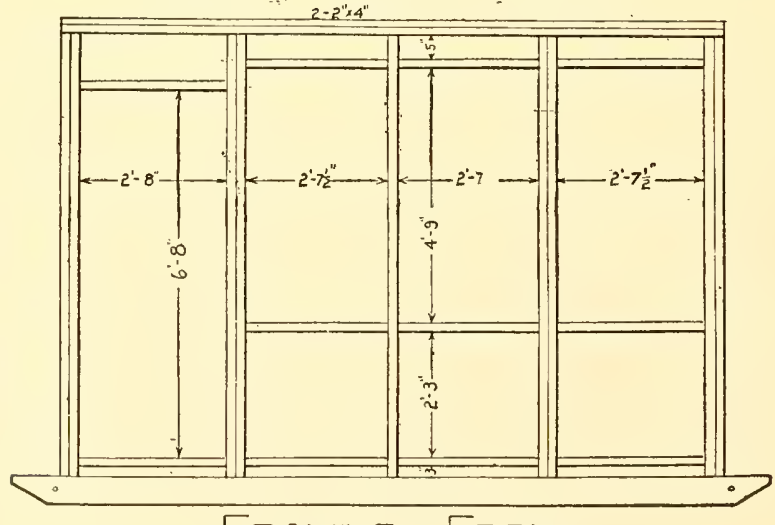

FrAMING of FrONT

Showing front elevation and framing of the "Iowa Colony House" (portable). (Iowa Bulletin No, 132.) 
Such a wall as this will meet the requirements of most climates and will be dry. The greatest difficulty from moisture gathering on the walls usually comes from dead air spaces in the walls that are double boarded. During the night the air between the boards becomes cool. In the morning when the sun pours into the pen it warms it faster than it does the air shut in between the boards. The result is that the wall on the north side in particular will be cooler than the air of the pen and will condense the moisture from it.

FIg. 148

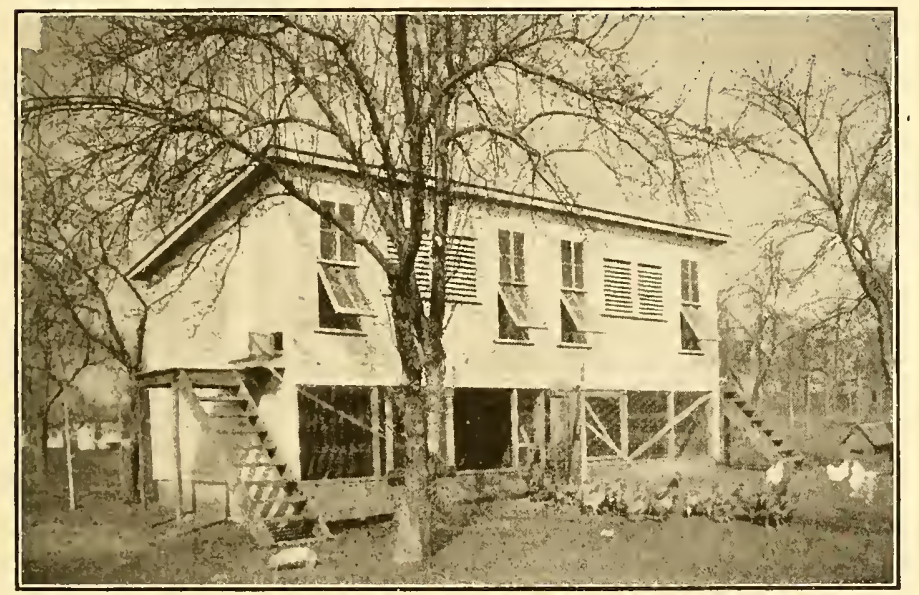

A permanent farm poultry house, with slatted front and scratching basement.

(Courtesy of Missouri State Poultry Experiment Station.)

Roofing Materials.--The so-called "prepared roofing" is the material most widely used for poultry house roofs. It has the advantages of being reasonable in price, and draftproof, as well as moisture-proof. It has the disadvantages of drawing heat badly when placed on a south slope, unless it is painted white, and of ripping in severe wind storms, unless cleated down with wooden strips.

The Straw Loft.-One means of helping to keep the poultryhouse dry is the straw loft. A loft is built just under the roof, 
the floor of which is made of rough boards placed one to two inches apart. On this floor is placed a layer of straw about

Frg. 149

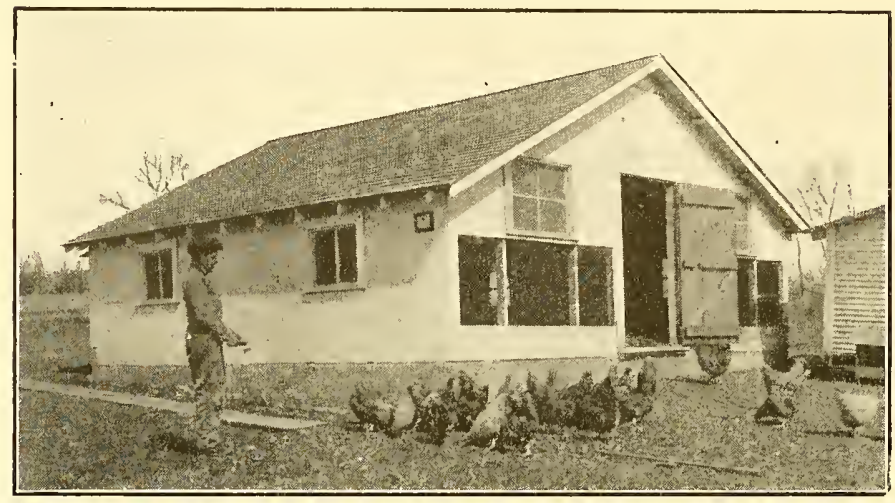

A good farm poultry house with straw loft. (Courtesy of University of Missouri.)

Fig. 150

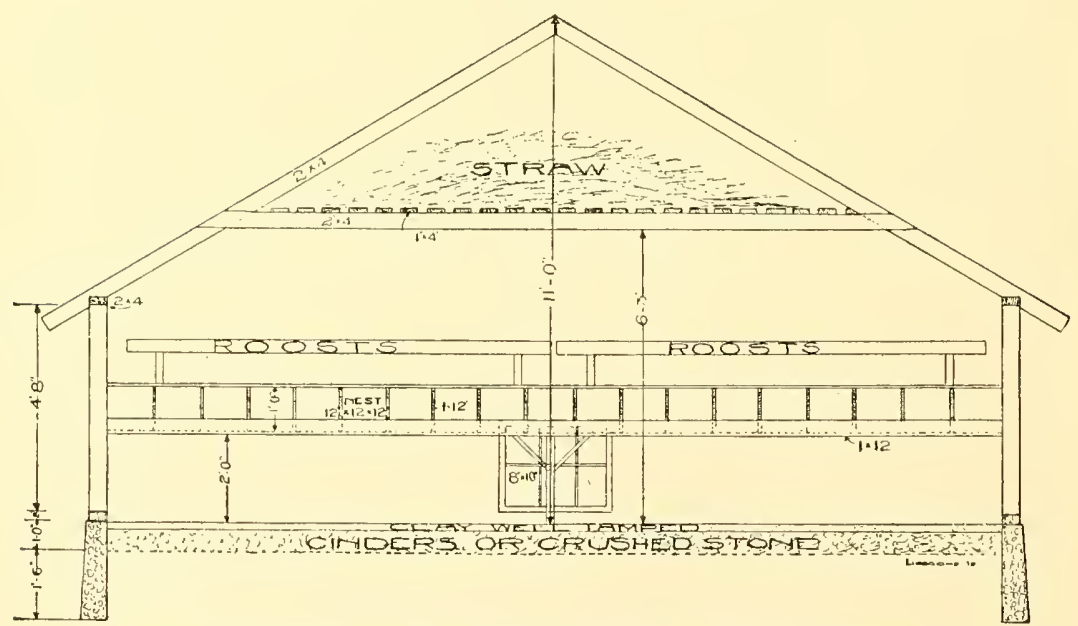

Sectional view of house shown in Figure 149, showing arrangement of straw loft. (Courtesy of University of Missouri.) 
two feet deep. Doors or windows open into the loft so that there may be a good circulation of air above without creating a draft in the pen below. The straw absorbs any dampness there may be in the air below through the openings between the boards. On clear days the doors or windows in the loft are opened and the current of air passing through dries out the straw.

The straw loft also tends to make the house warmer in winter and cooler in summer. It acts as an insulator between

FiG. 151

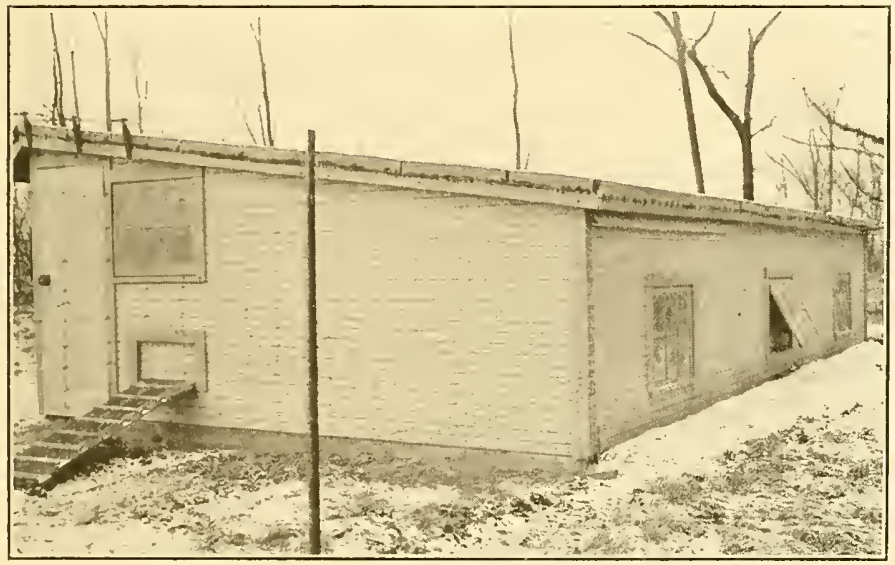

Showing ventilator door under eaves and windows for lighting the floor under the dropping boards. (Courtesy of Purdue Agricultural Experiment Station.)

the roof and the pen below. It is also likely to be a harbor for rats and mice, and mites once established in it are difficult to get rid of. So far as the efficiency of the loft is concerned the straw may be left from year to year.

The straw loft is best adapted to the gable-roof houses, as shown in Figure 149. It may be used with less conrenience in cither a shed roof or combination roof house.

Fixtures.-Those pieces of equipment which are built as a part of the house should be simple, few in number, placed high enough not to use up floor space, and removable. They 
will generally consist of nests, perches, a broody coop, and a shelf for the watering device and feed hoppers. A dropping board beneath the perches is desirable, where bedding is expensive or the manure is to be saved for gardening purposes. It is essential if the nests are located below the perches.

Nests.- The desirable qualities of a nest are that it be roomy, easily cleaned and sprayed, dark, conveniently located, and capable of being closed. For the common farm breeds a nest fourteen inches square and six inches deep is a good size. At least fifteen inches of head room for the hens should be provided. There should be one nest for every eight hens in farm flocks of ordinary size and production. In high producing flocks there should be one nest for every four or five hens. Enough of the parts should be removable so that cleaning and thorough spraying are possible. The whole battery of nests should be so arranged that they can be taken out of the house for cleaning, spraying, and sumning when it appears desirable.

Dark nests are highly desirable because the hen loves seclusion for laying. If her whims are satisfied in this particular she is very much less likely to steal her nest in undesirable places. If the nests are dark, fowls are far less likely to get to scratching in the nest, break an egg, and contract the vice of egg-eating. Arranging it so the fowls may be easily shut out, precludes their roosting in the nests and fouling them. This they are prone to do, particularly at molting time, in order to escape being crowded by other birds on the perch. While the new feathers are coming through they are sensitive to being touched by other birds.

For convenience the nests should be placed at such a height that the person gathering the eggs, who presumably has a basket or bucket in one hand, may pick up the eggs with the other without bending over.

Probably the commonest location for the nests is underneath the perches, though it is not necessarily the best. Nests and perches are the two commonest locations for infestations by mites. It would seem that the chance of discovering and eradicating them before they have infested both the perches and the nests, and so drain the vitality of the laying hens both 


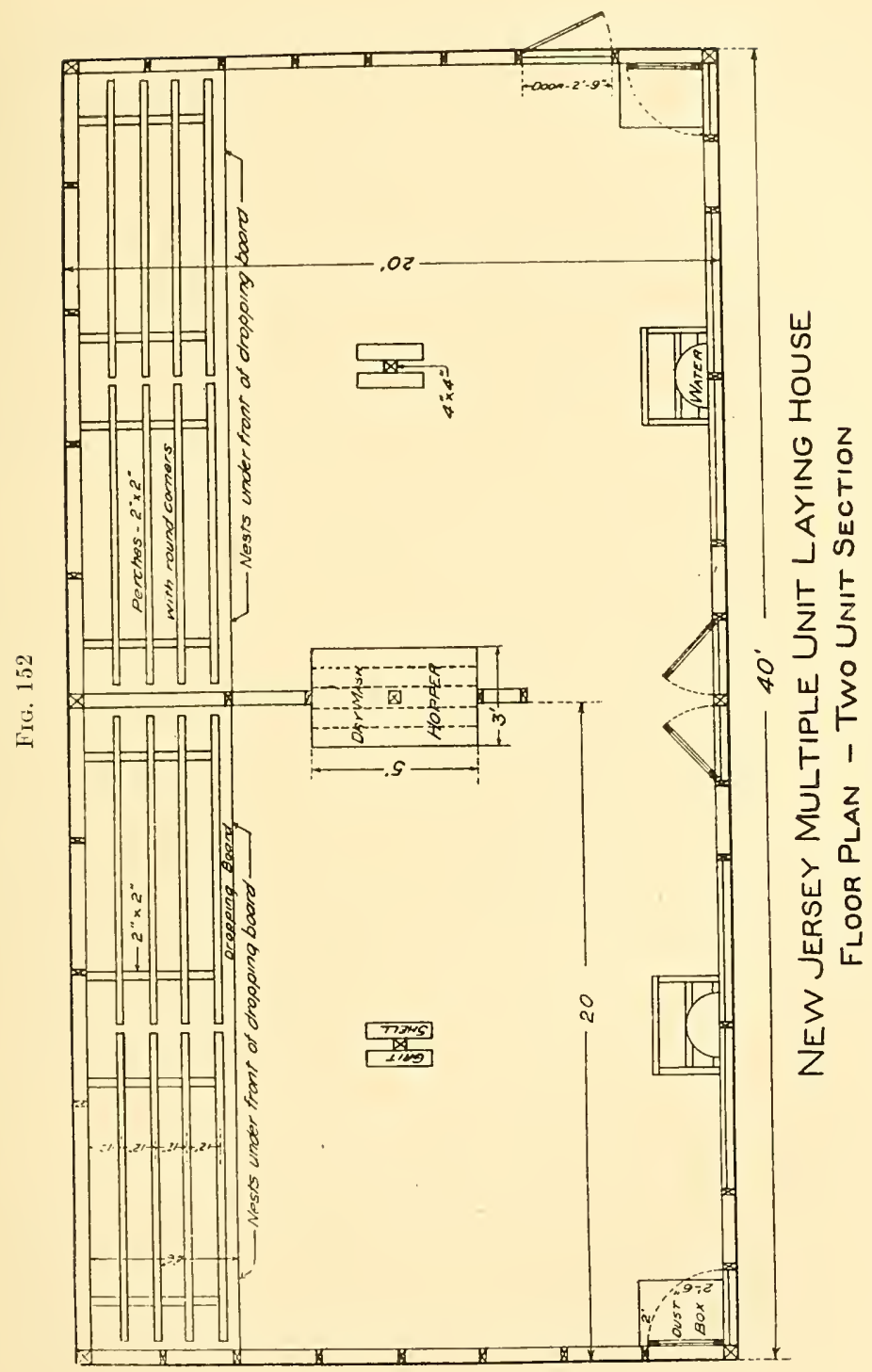



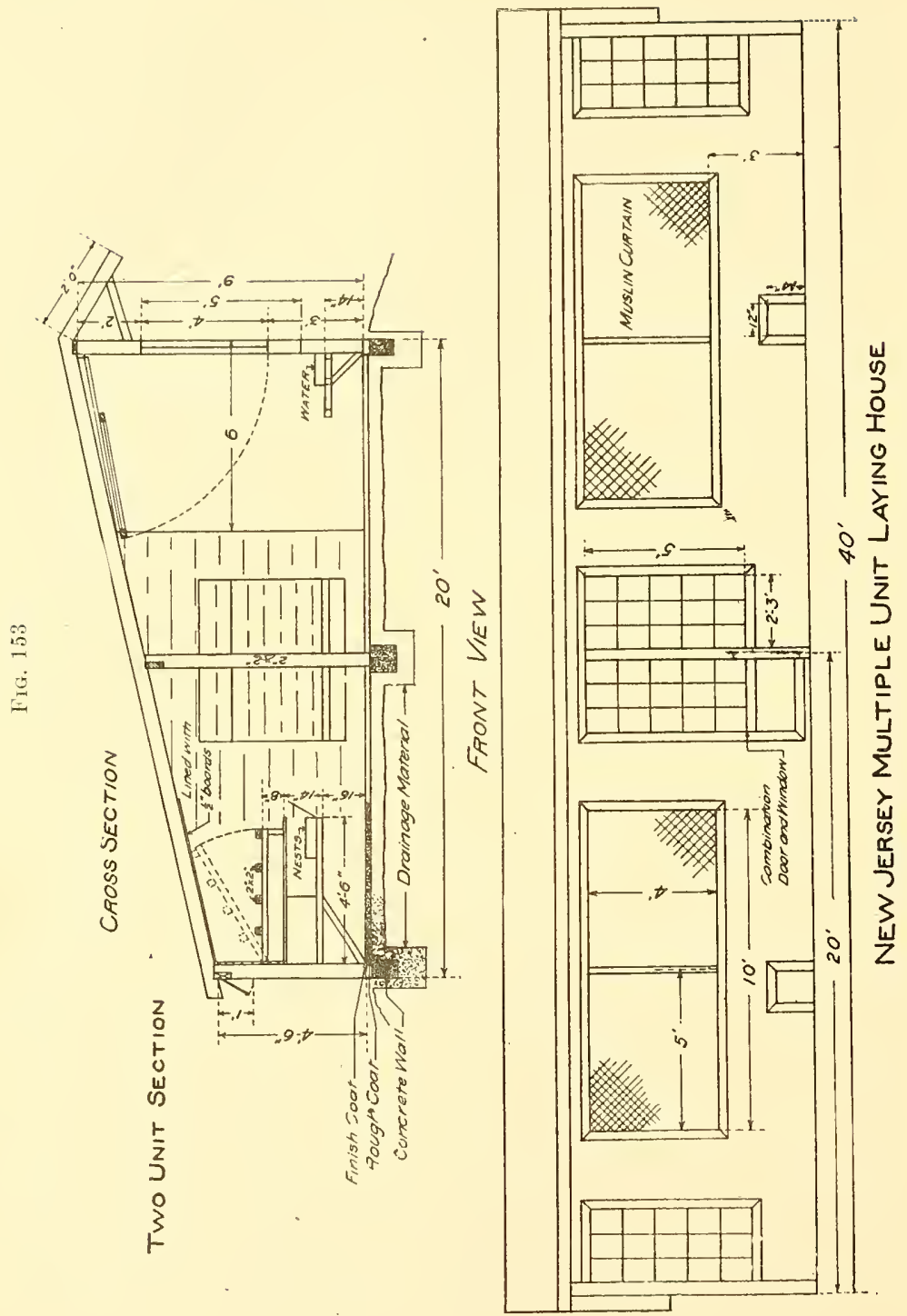
by night and by day, is better if these two fixtures were somewhat separated. When the nests are placed under the perches a dropping board is necessitated and the nests must either be too low for the convenience of the caretaker or the perches too high for the hens in heavy laying. If the perches are not more than three feet high the bottoms of the nests will perforce be so low as to make it difficult to clean out below them and so dark that the floor is of little use for feeding, and the hens are likely to lay there rather than in the nests.

FIG. 154

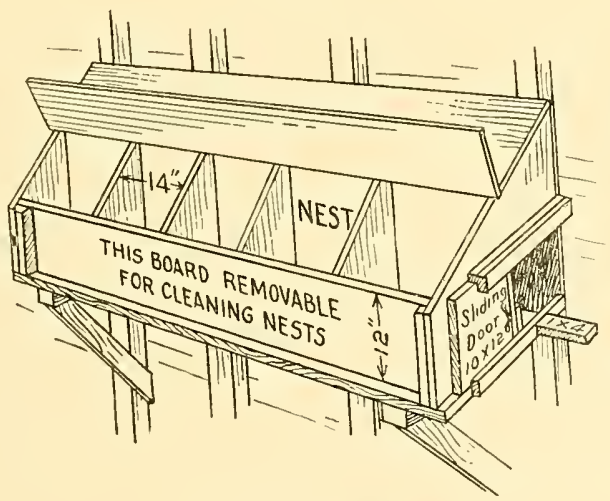

A good type of wall nest.

The perches should be the most frequently disinfected of any part of the house. With the nests below the perches they are very likely to catch some of the drippings from the spray and the eggs be tainted.

In bedding the nests the same care should be taken as is suggested for the hatching nest (see page 198).

Nests for ducks should always be on the floor. In fact there is no need of nests where the floor of the house is kept well bedded with straw.

Perches.-Perches are necessary for chickens, but not for waterfowl. The droppings of the former adhere to the feathers if the birds are not on an elevated perch. With waterfowl the voidings are semifluid and the feathers so arranged 
that soiling does not occur. The perches should be removable, free from cracks, located where there is no possibility of drafts, and comfortable. The roosting quarters are likely to be the part of the house most often infested with mites. Unless the perch is free from cracks and can be removed so as to expose the ends, it is very difficult to reach the mites and their eggs. Unless the eggs are reached and killed, spraying only gives temporary relief. In order to avoid drafts the perches will be located as far away from the windows or doors as possible. In an open-front pen this will usually be the back side.

Fia. 155

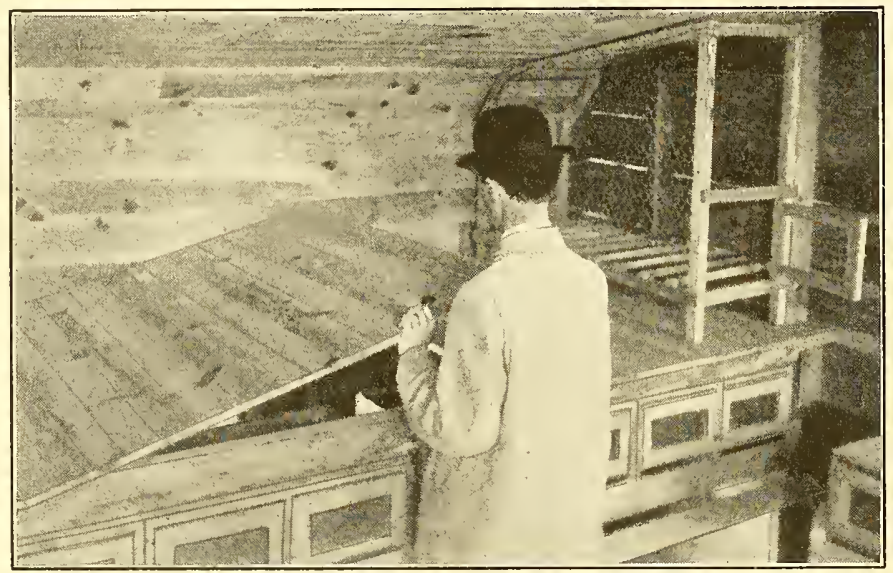

The dropping board should be removable for spraying. Good type of broody coop. (Courtesy of Missouri State Poultry Experiment Station.)

In order to insure comfort the perches provided should allow from seven to nine inches of room for each bird and be fifteen inches apart, even more room is desirable for the Asiatics. All perches should be on the same level to avoid the crowding that results from the effort of all to sleep on the topmost perch. Good rest is as essential to chickens as to any other class of live stock. The most common material used for perches is $2 \times 4$ lumber. This may be laid on the side or placed on edge. In the latter case it is well to round the upper edges to avoid bruising the feet. 
If a dropping board is used in connection with the perches it should be of the very best of matched material and tightly made so that there will be no cracks for mites to find their way into. It should be removable so that the ends may be easily accessible when spraying. The dropping board should be far enough below the perches to permit its being cleaned without removing them.

Dust Wallow.-The advisability of furnishing hens with a dust bath is a question upon which poultrymen differ. The great arguments in its favor are that the hens like it and it helps to keep down the lice. However, even where a covered wallow is furnished, it makes the house dirty and fills the air with dust particles. Almost invariably the hens will come outside the inclosure before shaking themselves. If it lessens the labor of fighting lice it increases the necessity of the rather frequent cleaning of the house.

Broody Coop.-The broody coop is a great convenience for breaking up broody hens, isolating injured fowls, or for keeping extra male birds where one is alternating males. For its main purpose of breaking up broody hens it should be constructed with a slatted bottom. It is often convenient to locate the broody coop at the end of the dropping board, but it may be fastened to the wall or suspended from the roof.

Feeding Shelf.-It is necessary to have a place where the watering device and feed hoppers can be kept so that the hens cannot scratch the litter into them. For this a shelf, as shown in Figure 15\%, is convenient. It should be placed high enough so that the hens will not be tempted to lay under it and it will not be an obstruction in cleaning out the litter. It is well to place it near the door for the convenience of the caretaker and toward the front of the house. Hens are likely to face the light as they scratch and the litter flies toward the back of the house more often than any other direction.

Types of Houses.-Houses are usually classified according to the number of rooms or pens they contain, their portability or permanence, or their style of roof.

The term "continuous house" implies that several pens have been incorporated in one building and several separate groups of birds may be housed under one roof. 
F1G. 156

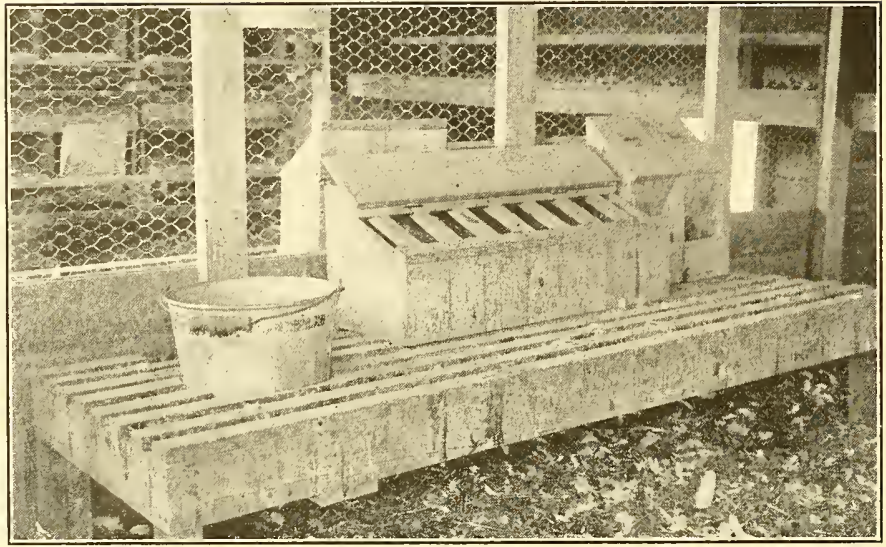

A slatted feeding shelf. (Courtesy of Purdue Agricultural Experiment Station.)

FIG. 157

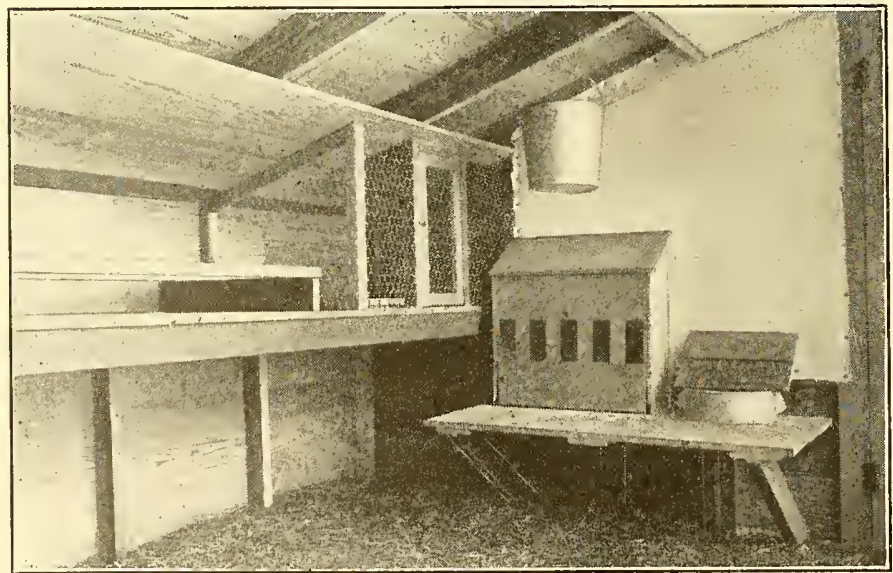

Interior of poultry-house, showing feeding shelf, dry mash hopper, protected watering device, broody coop, perches, and dropping board. (Courtesy of Purdue Agricultural Experiment Station.) 
The term "colony house" usually indicates that only one group is housed under one roof and usually at a considerable distance from other groups. Portable colony houses are comparatively small, so that a team can haul them from one part of the farm to another. Permanent colony houses of sufficient size to house a colony of a thousand birds are being used successfully on specialized poultry farms. In a few cases large-sized colonies of chickens are divided into two groups, each having its own pen.

FIG. $15 \mathrm{~s}$

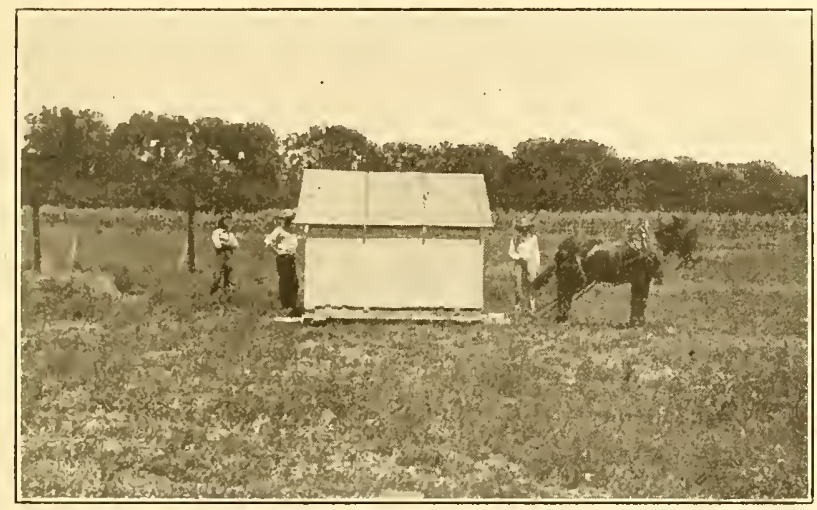

There should be at least one portable colony house on every farm where chickens are kept. (Courtesy of Kansas Agricultural Experiment Station.)

The continuous house, containing several pens, is somewhat less expensive to construct than colony houses containing the same amount of floor space as the respective pens. Its pens are better protected in extremely cold weather and the labor of caring for the several groups is concentrated. The contamination of the ground and the loss of fertility will be somewhat greater than with a permanent colony house, and a great deal worse than with a portable colony house that is moved from place to place. The danger of epidemics travelling from flock to flock is very much greater in the continuous house. 


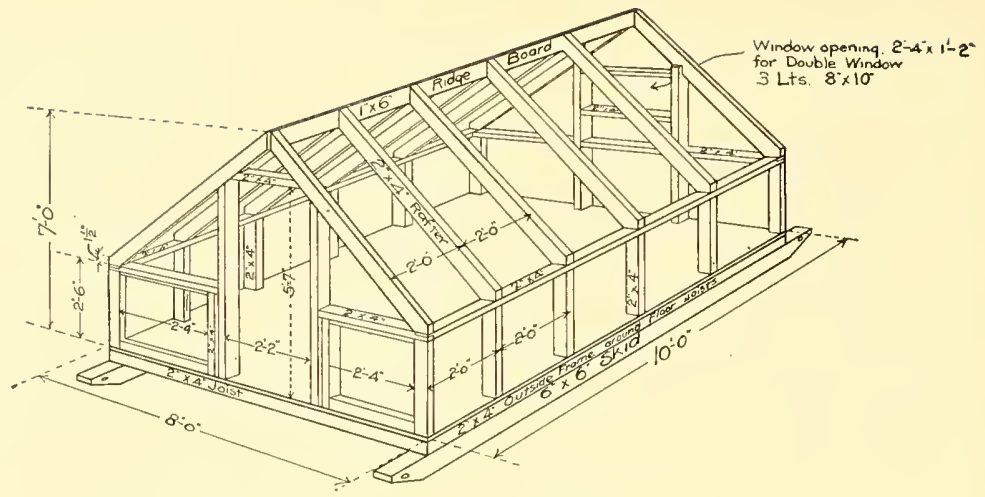

\section{PERSPECTIVE oF FRAMING}
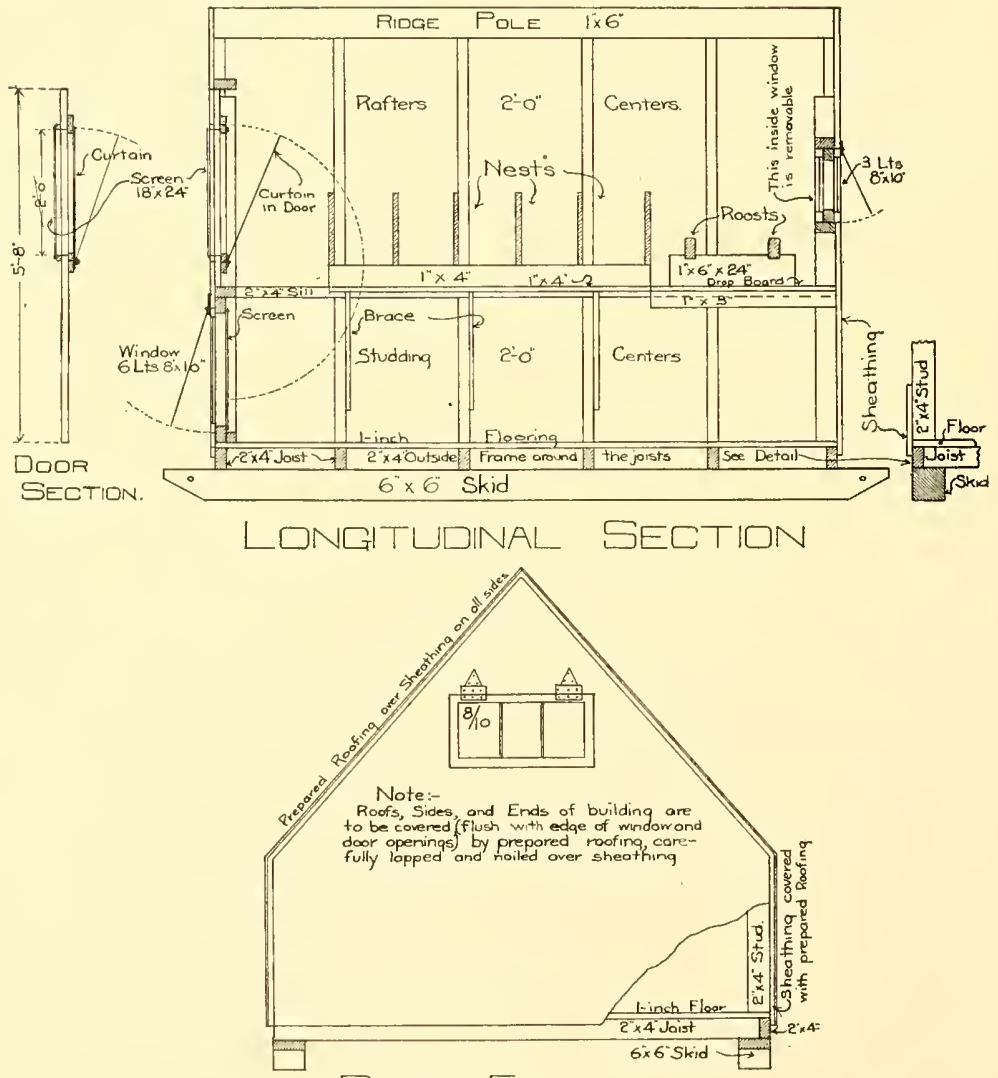

REAR ELEVATION

Showing the details of construction of an " $A$ " shaped portable colony house suitable for hauling about in an orchard. (Iowa Bulletin No. 132.) 
The portable house differs from the permanent house in that instead of being anchored on a foundation it rests on runner sills and may be drawn from one location to another. This is highly advantageous in that it is possible to have the fowls frequently on fresh ground; it allows the chickens to be fitted into a rotation of crops, picking up the waste grain and insects in the field after harvest, and dropping fertility on the field where it can be used. Dryden makes a statement that the droppings of fifty fowls will keep an acre of ground in a high state of fertility, and Purvis ${ }^{1}$ estimates that one hundred fowls running at large on an acre should in the summer season of six months have added to its fertility the equivalent of at least 200 pounds of sulphate of ammonia, 100 pounds high-grade acid phosphate, and 60 pounds of kainit.

In those western States where grasshopper outbreaks occur, a portable house, full of young chickens drawn to the edge of a field in the spring, and moved from time to time, will do very much toward preventing damage in case of an outbreak. If the house is moved at night with the chickens in it, there will be little if any trouble about their returning there to roost.

For most farms it will pay to have at least one portable house to be used for the rearing of young stock and later for the housing of pullets. Pullets develop much more satisfactorily when range raised, and lay better when they are kept by themselves. When they are turned in with the old stock, they are so abused that their production is cut down very appreciably.

In the winter time the portable house can be drawn up close to the dwelling. If there are several of them they can be drawn up close together and joined together as shown in Figure 160. A furnace pipe furnishes a covered passageway and the birds can roost in one house and lay and scratch in the rest of them.

The styles of roofs commonly used in poultry-house construction are the shed or single pitch (Figure 161), the gable 
or double pitch (Figure 160), the combination (Figure 162), and the half monitor (Figure 143).

FIG. 160

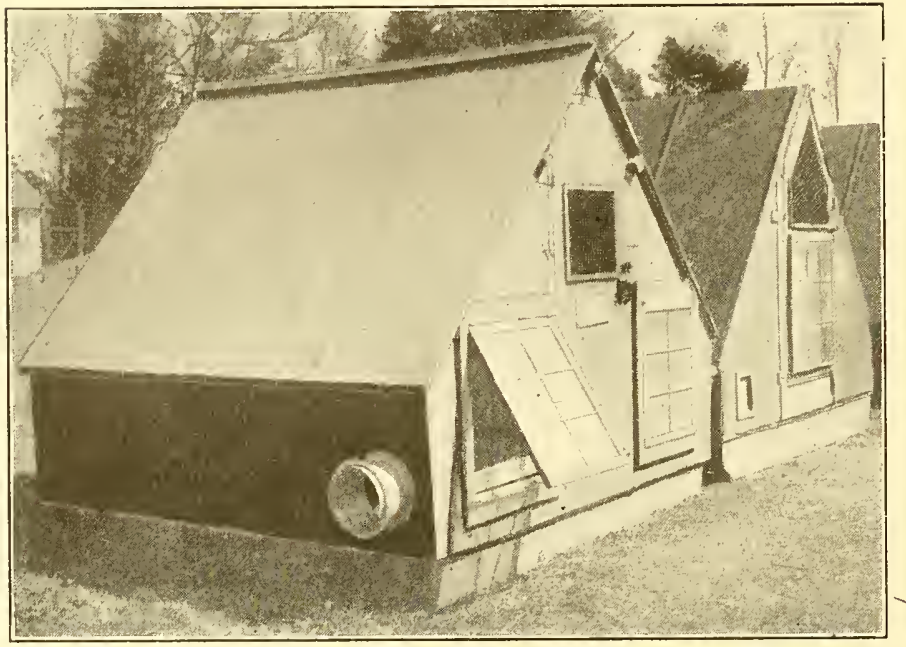

Showing method of uniting colony houses. (Courtesy of Cornell Agricultural Experiment Station.)

Fig. 161

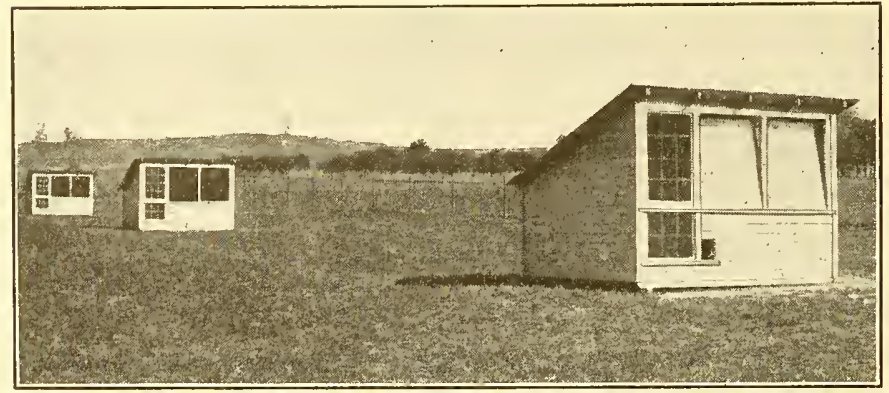

Large portable colony houses, having window for a dust bath. (Courtesy of Kansas Agricultural Experiment Station.

The full monitor is sometimes used where prevailing winds make it desirable to build a continuous house, running north 
and south, rather than east and west. The monitor allows the morning sun to find its way into the west side of the building and the afternoon sun to reach the east side.

Aside from the special case just noted the particular style of roof does not have much to do with efficiency. The shed roof is the simplest to build, throws all the rain-water to the back, allowing the windows to be placed high, and does not expose the roof to the direct rays of the sun. Where prepared roofing is used, it lasts much longer on a north than on a

FIG. 162

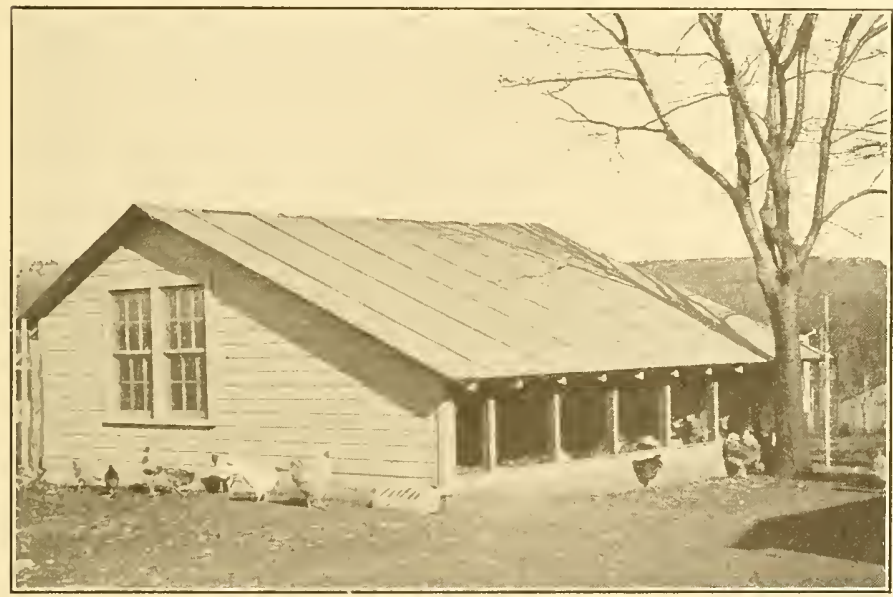

A combination roof house known as the Tolman house. (Courtesy of Kansas Agricultural Experiment Station.)

south slope and does not draw heat so badly, thereby rendering the house cooler.

The combination roof is desirable for portable houses that are hauled up and down orchard rows, as it will not catch the tree limbs so badly as a shed roof. It gives good height to the windows where the short slope is toward the front, and gives good protection for houses with the open front running clear to the ground where the long slope is toward the front. The gable roof has the same advantage on a portable 19 
house used among trees that a combination roof has. For a permanent house it is well adapted for having windows on all sides, and for the straw-loft method of ventilation, as shown in Figure 164.

The half monitor roof, as shown in Figure 143, allows a low open front, and at the same time admits the sunlight from above to the back of the pen, where the roosting quarters are.

F1G. 163

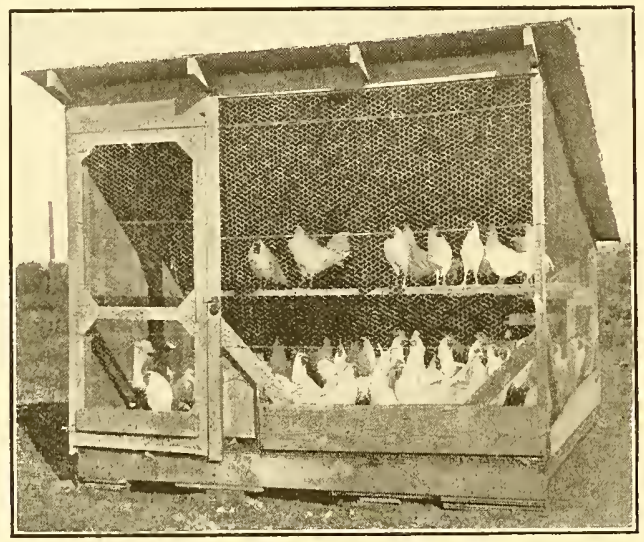

A cheap and serviceable house for capons and cockerels that are to be marketed before extreme weather sets in. (Courtesy of Kansas Agricultural Experiment Station.)

Two-story Houses. - A rather infrequent style of house, used with marked success in a few cases, but not fitting in with ordinary general farm conditions very well, is the two-story house. It has some advantage in the cost of construction as compared with one-story houses for the same number of hens. It offers the same evils of congestion that the continuous house does. If advantage of this style of house is taken to house a considerable number of birds under one roof it requires that greater attention be given the flocks than is generally possible under general farm conditions.

A successful two-story house sheltering one thousand birds is shown in Figure 164. This house runs from northeast to southwest, so that at some time during clear days the sun 
shines in every window. The attention necessary to properly ventilate a house with windows on every side, so that the birds will not be the victims of drafts, is more than can be given on the farm where poultry is a side line. In this house the birds are fed and have their scratching quarters on the lower floor and the roosting quarters are above.

FIG. 104

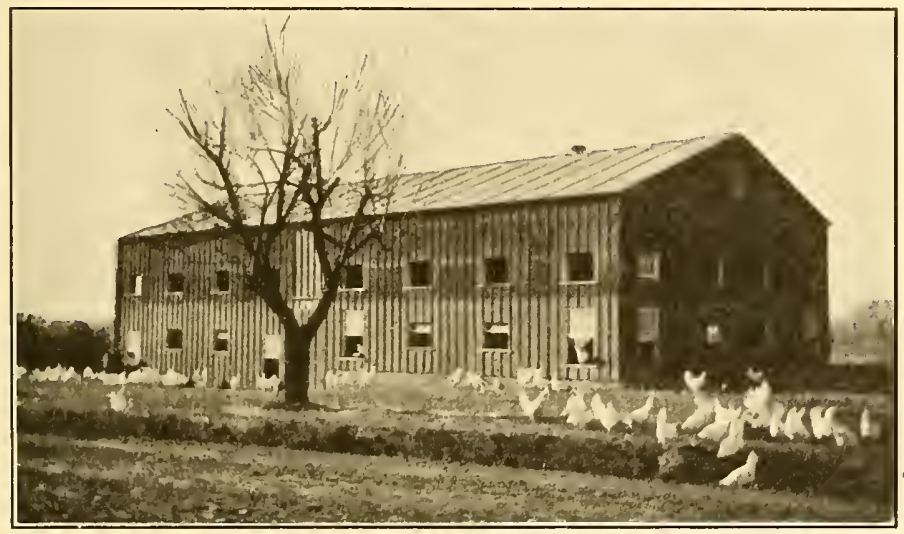

Two-story house. (Courtesy of Yesterlaid Egg Farms Company.)

Yards and Fences.-For profitable farm poultry production there should be a minimum of yards. Insofar as is practicable, poultry should be fenced out rather than in. There will be far better thrift if the hens are fenced out of the garden and the door yard and allowed the range of the farm.

Stewart and Atwood ${ }^{1}$ found that when all other conditions were as equal as it was possible to make them, eggs from Leghorn hens on free range gave a fertility of 91.5 per cent, while eggs from those confined in yards 15 by 100 feet gave a fertility of 75.6 per cent. At the same time, 83 per cent of the fertile eggs from hens on free range hatched, while but 67.5 per cent of the fertile eggs from the yarded hens hatched. Bushnell and Maurer ${ }^{2}$ found that range, as com-

1 West Virginia Bulletin.

2 Unpublished data, Kansas Experiment Station. 
pared with close confinement, makes a decided difference in the bacterial content of the eggs laid, even when the rations fed are the same. Whether the difference was due to the increase in exercise or the green feed and insects it was impossible to determine, but when hens were given free range on April 20 there was a marked falling off in the bacterial content of the eggs. This change was not due to seasonal variation, as summer eggs usually showed more than 10 per cent greater infection than spring eggs.

FIG. 165

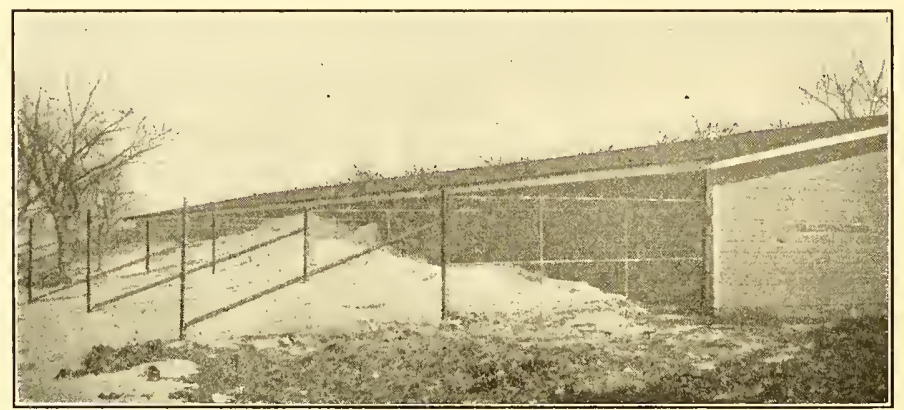

North yards are frequently piled high with snow while the birds are dusting themselves to the south of the house.

When circumstances make it necessary to yard the stock the yards should be as large as possible and provision made for double yarding. By double yarding, reference is made to the practice of keeping the stock in one yard while a crop is grown on the other. In this way, by alternating the yards from season to season, the ground is freshened, there is pasture for the fowls, and the fertility dropped by the fowls is made use of.

It is practically impossible to yard hens at the rate of more than four hundred fowls to the acre and maintain a sod. Yards that are crowded so as to be kept bare of greenness, unless given considerable attention in the way of turning the ground over, or by applying lime, or by cropping from time to time, are a source of danger. 
The efficiency of a poultry fence depends as much upon having an invisible top as upon the height. 'The height of the fence will need to be in inverse proportion to the size of the yard it surrounds. Any but the Asiatic breed will fly very high if they can see a place to alight, and it is necessary to have the tops of the gates invisible as well as the fence.

Care of the House.-The poultry-house should be well bedded with straw at all times when it is available at reasonable cost. When not available, shavings, cotton-seed hulls or other similar material may be substituted. The straw should be renewed whenever it becomes badly broken up, damp, or so full of droppings that grains fed out of the hand are not quickly lost from sight, compelling the fowls to scratch to find them. Where birds spend most of their time out of doors and the house is so dry that the droppings dry out soon after being voided, they need be removed only at rather infrequent intervals. If they tend to remain moist for some time, however, they should be frequently removed, as their presence is likely to cause dirty eggs by being carried to the nest on the feet of the hens, and in a moist condition they serve as a harbor for germs.

As a precautionary measure the poultry-house and all its fixtures should be thoroughly cleaned and then soaked in every part with a good strong disinfectant at least once a year, preferably before the beginning of the breeding and growing season. This should be repeated promptly upon the appearance of any ailment that shows the least sign of being communicated from one individual to another. In cold weather, low-grade kerosene with enough crude carbolic acid to give it a distinct odor is preferable to the use of such sprays as are administered in water solutions.

The most frequent cause for spraying is the appearance of the chicken mite. It is usually first noticed on the under side of the perches or in the corners of the nests. This tiny, spider-like bloodsucker does not live on the body of the hen as does the less troublesome louse, but at some place where it can make its way onto the fowl's body for the purpose of feeding with fair regularity. Unless promptly checked, they multiply with enormous rapidity, particularly in warm 


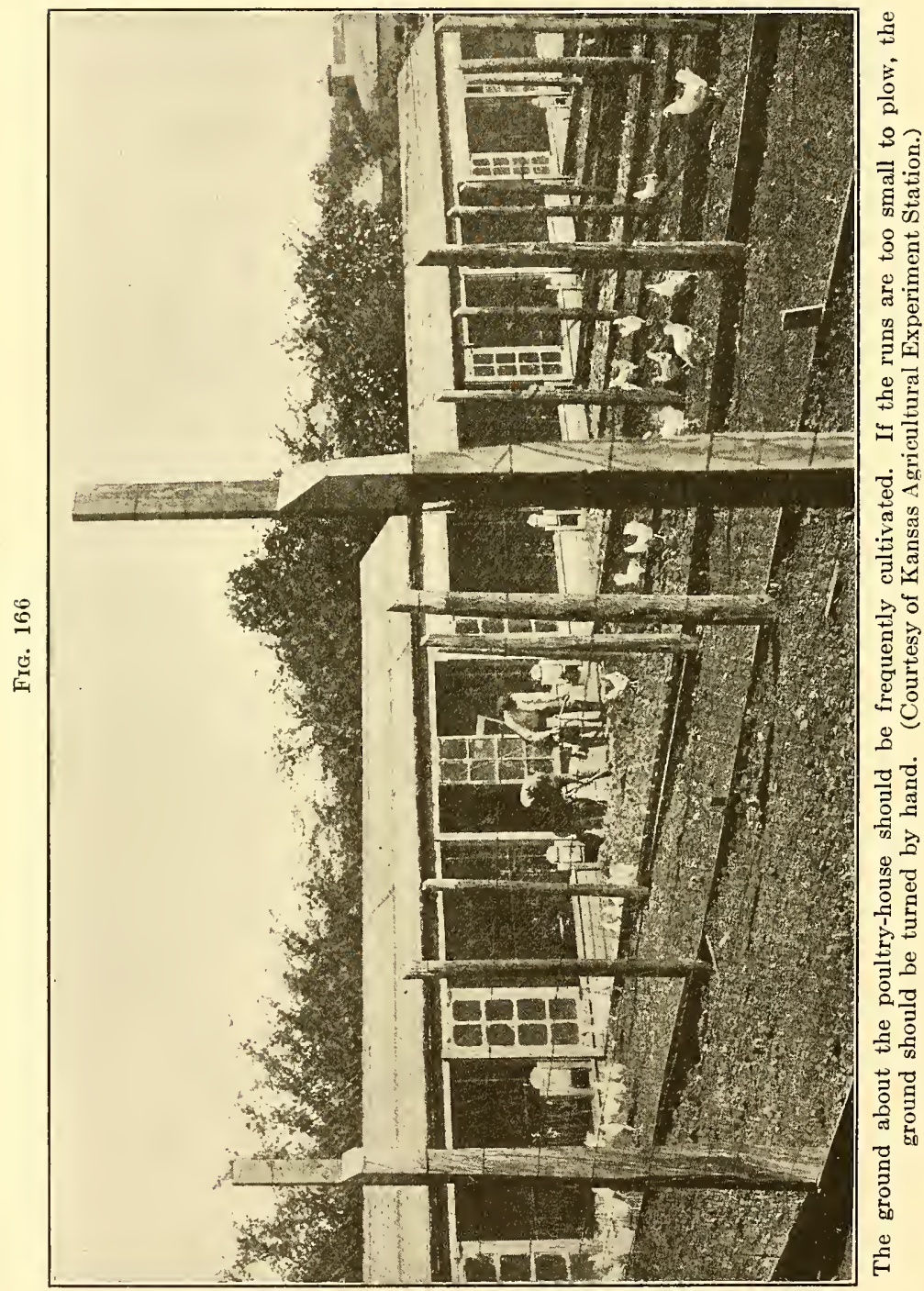


weather, and quickly sap the vitality of the stock and often cause death. In order to eradicate them it is always necessary to spray twice and often three times.

Most of the commercial coal-tar dips kill the mites, but it is difficult to make them penetrate far enough into the cracks between the boards to reach and destroy the eggs. The result is that a new generation soon appears. It is necessary to spray again in order to destroy these. The period between sprayings is governed by the prevailing temperature. If it is very warm the second spraying should follow the first in five to seven days. If it is rather cool, ten days will be about right.

Fig. 167

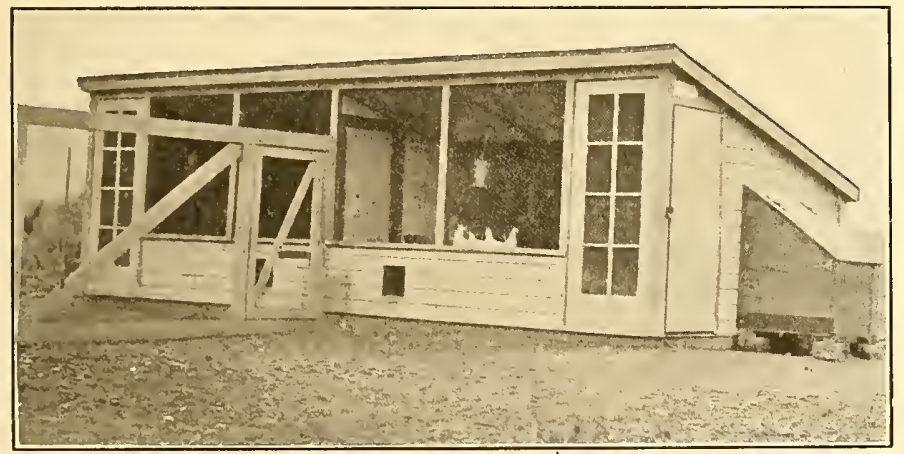

An excellent type of permanent poultry-house. Note the box for saving the droppings at the right end of the building. (Courtesy of Purdue Agricultural Experiment Station.)

Value and Preservation of Poultry Manure.-With reference to conserving the value of the fertility in the droppings, Purvis $^{1}$ quotes the New Hampshire Experiment Station as saying: "As is well known, when poultry droppings accumulate under the roosts and when they are left in barrels there is a strong odor of ammonia noticeable. The development of such an odor is a sure sign that gaseous ammonia is escaping into the air, to be lost for the present." Several

1 Poultry Breeding. 
chemicals of more or less fertilizing value in themselves, may be added to the droppings from time to time with good effect, both in stopping the waste and in making the air of the hen-house more wholesome. The best materials for this purpose are gypsum or land plaster, acid phosphate, and kainit, a cheap potash salt. Each of the compounds has the power of forming new compounds with the ammonia as fast as it is set free from the original combination. Wood ashes or slaked lime should never be used, because neither combines with ammonia, but forces it out of the compounds and takes its place. W. P. Wheeler ${ }^{1}$ states that over 40 per cent of the nitrogen in poultry manure is normally lost in drying. Philips $^{2}$ reports that Leghorn pullets produce about 21 pounds of manure a year while on the perch.

Hoskins and Walker ${ }^{3}$ report the average analysis of poultry manure as showing 1.44 per cent nitrogen, 0.39 per cent potash, and 0.99 per cent phosphoric acid. At current prices for fertilizers the value of a ton of fresh poultry manure is $\$ 6.28$. On the basis of the average night droppings from the medium breeds, reported by the Massachusetts Experiment Station, ${ }^{4}$ the droppings per fowl amount to eighty pounds annually.

${ }_{1}^{1}$ Twenty-sixth Annual Report, New York Experiment Station.

${ }^{2}$ Purdue Bulletin, 82.

3 Massachusetts Circular No. 35.

Ibid. 


\section{THE NUTRIENTS AND NUTRITION.}

The Objects of Feeding.-The purpose of feeding is the transformation of vegetable, animal, and mineral matter, in forms not edible by man, into food in the form of eggs and meat.

This manufacturing process is accomplished through the agency of three physiological processes carried on within the body of the fowl. These processes are (1) growth, (2) reproduction, and (3) the storing of fat. Each process is made up of a number of lesser ones which are in turn dependent upon the proper functioning of many organs and tissues.

The objects of feeding are to furnish the proper kinds and amounts of materials necessary: first, for the maintenance, in perfect adjustment, of the organs and tissues concerned in these tributory processes, and, second, to furnish the raw materials out of which eggs, bone, muscle, and fat may be manufactured.

The Maintenance of Life.-The first use of all feed is to support life. Unless life is maintained it is obvious that neither growth, reproduction, nor the increasing of flesh may occur. The maintenance of life depends upon (1) the provision of heat, (2) the renewal of tissues, (3) a supply of muscular energy, (4) the elaboration of secretions, and (5) the proper activity of the organs and tissues.

Heat is necessary in order that various functions of the body, such as digestion, fertilization, and incubation, may be performed, and which are at their best when that degree of heat which is recognized as the normal temperature of an individual is maintained. The normal temperature of the common fowl is generally recognized to be $106^{\circ} \mathrm{F}$. This is considerably higher than the temperatures maintained by the human race or by the common farm animals, and is the result of the fowl's tremendously rapid metabolism. It is probable 
that only in the severest weather is feed used directly as a source of heat.

A considerable amount of muscular work must be done if the bird is to live. It must at least make the motions necessary for eating, and most individuals find it necessary to move about in the search of feed. 'This is done by the fowl's own volition, and such movements are termed voluntary. At the same time there is considerable muscular activity within the body of the fowl over which it has no control, and which is termed involuntary. Such motion is found in the contraction of the gizzard and intestines in preparing and digesting the feed. Energy must be furnished for both voluntary and involuntary motion.

All the tissues of the body, whether active or at rest, are continually breaking down and must be replaced. Material for replacement must be furnished.

In order that the joints and muscles may move with little friction and that the egg may slip down the oviduct to a successful exclusion there must be lubricating material. And in order that feed may be digested there must be digestive juices. All these call for the elaboration of secretions of various sorts for which there must be material.

It is a recent discovery that for the proper performance of the various organ systems of the body, even for maintenance, certain substances called vitamins, the chemical composition and precise function of which are not understood, are necessary.

The source of the supply of energy, the material for new tissues and secretions and of the vitamins, can only be the feed. A certain part of the feed, therefore, must always be used for fuel, repairs, and lubricants; that is to say, for the maintenance of life. With hens in full laying it takes amounts varying from a little less than three-quarters to about four-fifths of the feed supplied to meet the needs of maintenance alone. ${ }^{1}$

Growth.-In reaching a normal size a chick is sajd to grow. Growth, which is primarily an increase in bone and protein 
tissue, is a necessity of production. Bone furnishes the framework for the support of the reproductive and vital organs and the attachment of the muscles. The protein tissue furnishes the material out of which the muscles and bodily organs are very largely fashioned. Muscle, which is termed lean meat when used for food, is one of the ultimate objects of poultry production, and in the case of turkeys and most waterfowl is the primary object. 'The development of the vital organs is necessary to the maintenance of life itself, while the reproductive organs are responsible, not only for the perpetuation of the race, but, in the case of the hen, for the manufacture of the primary product.

Growth is possible only when there is some source of supply from which bone and protein tissue, as well as certain growth promoting substances (vitamins) may be drawn. 'This source can only be the feed that is fed in excess of that needed for the bare maintenance of life.

Reproduction.-When growth is complete, or is nearing completion, reproduction usually occurs. 'This is a necessary process of production, not only from the stand-point of the perpetuation of the race, as in all species, but, in the case of the hen, because the egg, representing one stage in the reproductive cycle, is so highly prized for human food as to have a great commercial value. The whole philosophy of egg production is bound up in the effort to induce abundant reproduction.

Just as growth is possible when the material out of which growth is made is furnished in excess of that necessary to merely maintain life, so reproduction can only occur when an excess of feed is furnished. While generous reproduction depends on several conditions, it cannot be accomplished at all without material out of which to form the potential new creature, and which is furnished only in the form of feed.

Fattening. - In all birds, and especially in those that have ceased to grow or reproduce, some of the feed consumed above that necessary for maintenance is stored up in the body as a reserve in case the regular supply of feed fails. This surplus is stored in the form of fat, and increases not only the quantity but the quality of poultry flesh. 


\section{THE NUTRIENTS.}

Every constituent of the feed that can yield heat or energy or can serve for the production of body tissue is called a nutrient. All poultry feedstuffs are composed of one or more of the following groups of nutrients: (1) water, (2) ash, (3) proteins, (4) carbohydrates, and (5) fats. For convenience, these nutrients may be classed as follows:

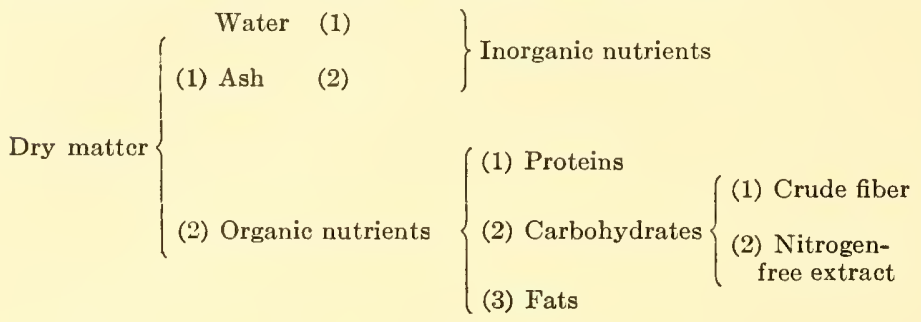

Of these, water alone is a definite chemical compound. Ash, protein, carbohydrate, and fats, which collectively form the dry matter, are classes or groups of compounds having certain distinctive characteristics.

Relation of the Nutrients to Production.-Both the fowl's body and the egg are composed of the same five groups of compounds. These compounds are not in most cases transferred directly as such from the feed to the tissues, but are split up in the digestive tract, absorbed and rebuilt into the body.

There is, however, a close relation between the nutrient composition of the feed and its use in building tissue. The ash in the body or in the egg can only come from the ash in the feed. The protein of the body can be built up and the protein of the egg elaborated only when protein of the proper kinds is furnished in the feed. While, as is shown elsewhere, fat may be manufactured from protein, it is normally made over from fats in the feed or built up from carbohydrate from the same source. The very small amount of carbohydrate in the fowl's body and the still smaller amount in the egg usually have the carbohydrate of the feed as their original source. 
Water.- Water plays a highly important part in the processes which collectively result in production. (1) It serves to soften the feed in the crop, preparing it for maceration in the gizzard. (2) It is a constituent part of the body of the fowl and of the contents of the egg, comprising over 55 per cent of the former and more than 65 per cent of the latter. A dozen eggs of good size contain a pint of water. (3) It serves as a carrier, transporting the end products of digestion from the digestive tract to all parts of the body and carrying the waste products from all parts of the body to the points of elimination. (4) It serves to cool the body by evaporation through the air sacs and lungs and keep its various parts at the same temperature. (5) It aids in the process of digestion and absorption, by dissolving the end products of digestion that are too concentrated to penetrate the walls of the intestine. (6) It acts as a lubricant for the joints and muscles.

Water usually forms from $\delta$ to 12 per cent of the air-dry weight of the common grains which generally make up the bulk of the poultry ration. This fact points to the necessity of a liberal supply beyond that furnished in the food.

The lack of water retards most of the processes of the body. It hinders digestion and limits excretion. A continued lack of water thickens the blood and raises the body temperature. Growing chicks are easily stunted in their development by a lack or an irregular supply of water. Starving is better withstood by fowls than a complete absence of water in warm weather.

Ash.-Ash is a term used to designate collectively the mineral compounds found in feedstuffs, the fowl's body, and the egg. It varies from 1.1 per cent (gluten feed) to 17.6 per cent (meat scraps) of the weight of the common poultry feeds, averaging 4.66 per cent. It forms 3.4 per cent of the live weight of a laying hen and 12.2 per cent of the weight of whole raw egg. While the common feeds would usually supply sufficient ash to meet the necessities of the hen's body, they fall very short of supplying the needs of the laying hen or growing chick.

As far back as 1844, von Bibra, as reported by Emmerich 
and Loew, ${ }^{1}$ found that feeding hens with potato and barley alone caused the shell of the egg to disappear. After about three weeks laying stopped, apparently due to the ash deficiency in the ration.

The principal ash elements required in poultry feeding, aside from oxygen, are calcium, phosphorus, sodium, potassium, silicon, sulphur and iron. Calcium and sodium salts are essential for muscular contraction. Calcium as a carbonate forms nearly the entire shell, or 11.4 per cent of the new-laid egg. In combination with phosphorus, calcium is an important constituent of bone. Phosphorus is found in the eggs, where it forms 0.27 per cent of the edible portion. Sulphur and iron, which are essential constituents of the proteins of the body, are also found in the egg. Silicon is found largely in the feathers.

In the ordinary farm feeds, enough of all the ash elements will ordinarily be furnished with the exception of calcium and phosphorus, which should be furnished in the form of calcium carbonate (oyster shell) for laying hens and calcium phosphate (granulated bone) for growing stock. Lewis ${ }^{2}$ found that an organic source of phosphoric acid such as animal bone was much more efficient than an inorganic one such as phosphate rock.

Protein.-The term protein, or more properly crude protein, designates the group of compounds found, both in the feedstuff's and the fowl's body and egg, which contain nitrogen. These compounds are often referred to as nitrogenous substances, because the constant presence of nitrogen is their most distinguishing characteristic.

There are thousands of different proteins all of which may be decomposed into eighteen or twenty amino-acids. Among these are glycocoll, lysin, argenine, histidin, cystin and tryptophan. Certain amino-acids can be built up by the body while others cannot. Glycocoll, an essential constituent of feathers may be built up by the body while tryptophan, cystin and lysin cannot. Milk casein carries but a trace of cystin, which is a sulphur-bearing amino-acid.

1 Deutsche Revue, July, 1912.

${ }^{2}$ New Jersey Bulletin, No. 265. 
Commercial meat scrap, on the other hand, is well supplied with cystin. Experiments in progress at the Kansas Station indicate that possibly the lack of cystin in casein is a limiting factor, when casein is used as the main source of protein in the laying ration.

It is because of the fact that nitrogen is an absolute essential to animal life that the nitrogenous compounds are called "protein," a term adapted from the Greek word meaning "to be first." Besides nitrogen, protein compounds always contain carbon, hydrogen, and oxygen, and sometimes contain sulphur, phosphorus, and iron.

As will be seen by referring to Table XXXV, over 21 per cent of the entire body of a Leghorn hen is protein, while it constitutes 48.9 per cent or nearly half of the total dry matter. While it forms but 12.83 per cent of the new-laid egg because of the large amount of water and ash, it will be noticed that it constitutes 49.8 per cent of the dry matter of the contents of the egg.

In the fowl's body the muscles, skin, feathers, tendons, brain, blood, and internal organs are composed mainly of protein. The dry matter of the white of the egg is nearly 94 per cent. protein, while that of the yolk is over 34 per cent protein.

Lewis ${ }^{1}$ found that laying hens fed a ration deficient in protein not only gave a low production but that the eggs produced were undersized.

Egg white shows very nicely some of the characteristics of protein compounds. In analysis it approaches very closely the average analysis of proteins as given by Sherman:2

$\begin{array}{lrcrrr} & \begin{array}{c}\text { Carbon, } \\ \text { per cent }\end{array} & \begin{array}{c}\text { Hydrogen, } \\ \text { per cent }\end{array} & \begin{array}{c}\text { Oxygen, } \\ \text { per cent }\end{array} & \begin{array}{c}\text { Nitrogen, } \\ \text { per cent }\end{array} & \begin{array}{c}\text { Sulphur, } \\ \text { per cent }\end{array} \\ \text { Average analysis of proteins } & 53.00 & 7.00 & 23.000 & 16.00 & 1.000 \\ \text { Analysis of egg white . } & 52.75 & 7.10 & 23.024 & 15.51 & 1.616\end{array}$

When dry it forms a horny substance which decomposes in the flame, forming a black mass. At the same time fumes are given off, which smell like burning hair or feathers. When

1 New Jersey Bulletin, No. 265.

${ }^{2}$ Chemistry of Food and Nutrition. 
in solution proteins display a mucilaginous character which is made use of in the commercial glues and mucilages.

The most familiar example of a mixture of vegetable proteins is the gluten of wheat. The protein content of wheat averages a little less than 12 per cent and of corn a little over 10 per cent. Most of the common whole grains depart very little from these figures. While some of the grain by-products such as wheat middlings (17.8 per cent) and gluten feed (25.4 per cent) have a considerably higher percentage, they are usually fed in rather limited quantities.

Table XXXV.-Composition of Fowl and Egg. ${ }^{1}$

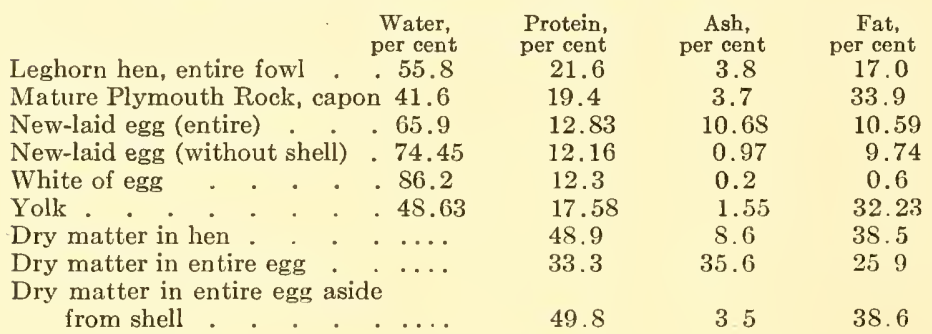

Carbohydrates.-Carbohydrates are compounds of carbon, hydrogen, and oxygen, in which the hydrogen and oxygen are almost always in the same mutual proportion as in water $\left(\mathrm{H}_{2} \mathrm{O}\right)$. They are plentiful in plants, appearing usually in the form of sugar, starch, or cellulose. As protein predominates in the fowl's body, so carbohydrates predominate in the structure of the plant.

The sugars are soluble in the juices of the plant and constitute the common portable carbohydrate building material of plants. Starch is the form in which most plants store their reserve. It serves much the same function for plants as does fat for animals. The starch stored in the kernel of corn and the potato tuber are familiar examples. It is with this form of carbohydrate that the feeder of poultry has most to do, forming as it does from 50 to 75 per cent of the feed of vegetable origin.

Cellulose is that substance which constitutes the greater

${ }^{1}$ The analyses recorded in this table are from several different sources and are not always in exact agreement. 
part of the slieleton or framework of plants. In connection with poultry feeding it is usually referred to as crude fiber which is largely cellulose, and will be throughout this work. It constitutes from 2 to 5 per cent of seeds and grains. All of the other carbohydrates of nutritive value are found $n$ the nitrogen-free extract.

Carbohydrates, which are so plentiful in plants, are scarcely found in the fowl's body or the egg. Glycogen, an animal starch, is stored in the liver, which converts it into a sugar called glucose, and gives it out to the circulation, from whence it helps to supply energy to the muscles.

According to Atwater, ${ }^{1}$ carbohydrates form 2.4 per cent of the total weight of the liver of the young chicken. Langworthy ${ }^{2}$ reports that 0.67 per cent of the egg is carbohydrate, one-third of which occurs in the yolk and two-thirds in the albumen.

Fats. - Fat contains the same elements as do the carbohydrates, but in very different proportions. Perhaps the most characteristic difference is in the proportion of oxygen, which is very much lower in the case of fat. The carbohydrates are oxidized fats. The comparison between the percentage composition of starch and stearin, a fat found in both the fowl's body and the egg, is as follows:

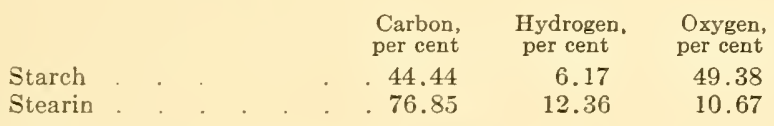

Fats (lipins) are present in nearly all grains, but in very small proportions as compared with the body of the fowl or even the egg. While they form 5 per cent 0 ? the air-dry weight of corn and oats and 2.1 per cent of wheat, they constitute 17 per cent of the live weight of a nervous, active Leghorn hen and $3 S$ per cent of the dry-matter weight. Fat comprises 8.9 per cent of the weight of the new-laid egg, all but a trace being located in the yolk, of which it forms

1 U. S. Farmers' Bulletin No. 182. 
33.3 per cent. The fats in both the eggs and the carcass are chiefly palmitin, stearin, and olein.

Fat stores energy and acts as a non-conductor of heat, the subcutaneous deposits being a very efficient protection against cold.

Nature's Provision of the Nutrients. ${ }^{1}$ - The source of the various nutrients in the rations of wild and domestic birds is as follows:

NATURE PROVIDES

Worms, grubs, and Protein.

insects.

Seeds.

Sprouts and grasses.

Gravel.

Water.
THEY SUPPLY

Carbohydrate (protein and fat).

Succulence $^{3}$ (water, carbohydrate, protein, fat and vitamins).

Ash and grit.

Water.
Producer feeds

Meat scrap, milk, oil meal, gluten-feed.

The grains and their byproducts.

Sprouted oats, pasture, etc.

Commercial grit, oyster shell, granulated bone, etc.

Water.

Mutual Relations of the Nutrients.-The elements, carbon, hydrogen, and oxygen, are always present in all three of the nutrients. These alone are found in the carbohydrates and fats, and the practical difference between the two classes is the greatly increased proportion of carbon in the case of the fat. It has been found by careful experiment that fat has a fuel and energy value about 2.25 times as great as does the carbohydrate, principally because of this greater proportional amount of carbon. That is to say, a pound of fat will generate over twice as much heat as a pound of carbohydrates, or will furnish the power for more than twice as much muscular effort. It may therefore be said to have a feeding value 2.25 times as great.

It was shown by Voit and Lehmann (as reported by Lusk $^{3}$ ), in experiments where rice was fed to geese, that almost one-third of the carbon was retained in the bodies of the

1 Adapted from a statement of Jaffa, California Bulletin No. 164.

2 Succulence is a form of feed containing a large amount of water. Green succulence is most desirable because of its vitamin content.

3 Science of Nutrition. 
geese in the form of fat, and that this fat must have been built up out of the carbohydrate (starch).

The great difference between the foregoing and protein is the presence of nitrogen in the latter. While fat and carbohydrate are mutually interchangeable in feeding practice to a considerable extent, neither of them can be fed in the place of protein. Protein, on the other hand, may to a limited extent replace either or both of the other two. This is because of the fact that it contains all the elements to be found in them (carbon, hydrogen, and oxygen), and by wasting the nitrogen may be made by the body into energy, or fat.

FIG, 168

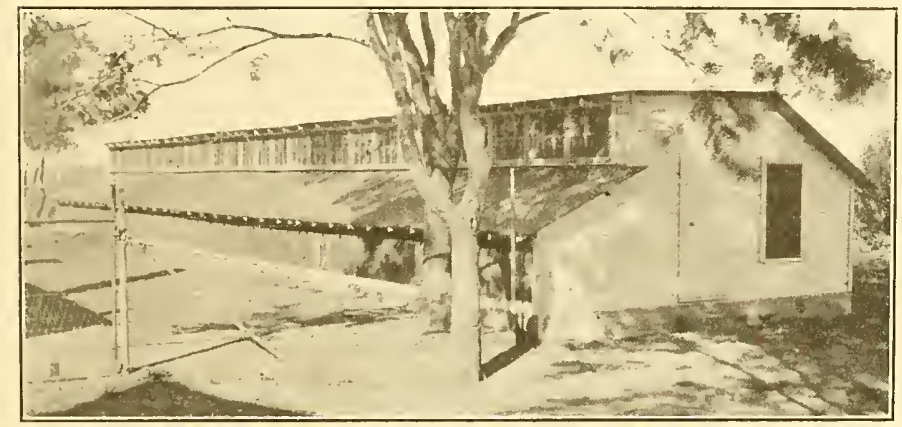

Laboratory deroted to the study of nutrition of chickens at Kansas State Agricultural College.

This was demonstrated by Wolffberg and confirmed by Kulz (as quoted by Lusk-1), who showed in feeding fowls chopped meat that part of the carbon of the protein was retained in the body as glycogen (a carbohydrate of the liver). While this is of interest it is not of great practical value, owing to the fact that protein is the most expensive of the five food nutrient groups and the tendency with most poultry feeders is to slight the protein portion of the ration.

Further Functions of the Nutrients.-Besides furnishing material out of which the parts of the body and egg of the

I Science of Nutrition. 
same class are manufactured, as is also the case with ash and water, the organic nutrients (protein, carbohydrates, and fats) of the feed perform other services to the body. The carbohydrates and fats are largely responsible for furnishing the energy with which both voluntary and involuntary work is performed. The waste tissue is repaired with protein and the reproductive elements are largely protein.

A summary of the uses of the nutrients is given below, with the less important class placed in parentheses: ${ }^{1}$

Service Rendered.

Furnishing energy.

Repairing waste tissue.

Furnishing material for growth.

Reproduction.

Fattening.

\section{Classes.}

Carbohydrate and fat (protein).

Protein.

Protein and ash.

Protein (carbohydrate and fat).

Carbohydrate and fat (protein).

\section{THE VITAMINS.}

In the past the feed has been regarded chiefiy as the source of the material necessary for the constructive processes going on in the body and of the energy required to support its various activities. This aspect of the matter has been prominent in the preceding paragraphs.

Recent investigations, however, are bringing into prominence another class of influences exerted by the feed upon the organism. The study of the vitamins is rendering it increasingly evident that quite aside from its value as a supply of structural material and of energy, the nature of the feed may profoundly influence the results of feeding.

It is clear that the vitamins influence the nutritive value of a feeding stuff in an essentially different way than does the quantity of ash, protein and energy which it supplies. The latter limits the amount of production which the feeding stuff can support; the former may determine how much of the nutrients supplied may actually be used. A mixture of pure nutrients may be prepared upon which young animals fail to grow, while the addition to such a mixture of minute 
amounts of substances associated with certain fats enables the ration to support normal growth.

In some ways the vitamins might crudely be compared with the lubricants of a machine which of themselves furnish neither power nor material, but which enable power derived from the consumption of the fuel to be more efficiently used. ${ }^{1}$

The vitamins so far discovered and entering largely into the nutrition of chicks are called "fat soluble A" and "water soluble B." At least one other vitamin referred to as the "antiscorbutic ritamin" is known but just what relation it bears to the nutrition of birds is not understood.

FIg. 169

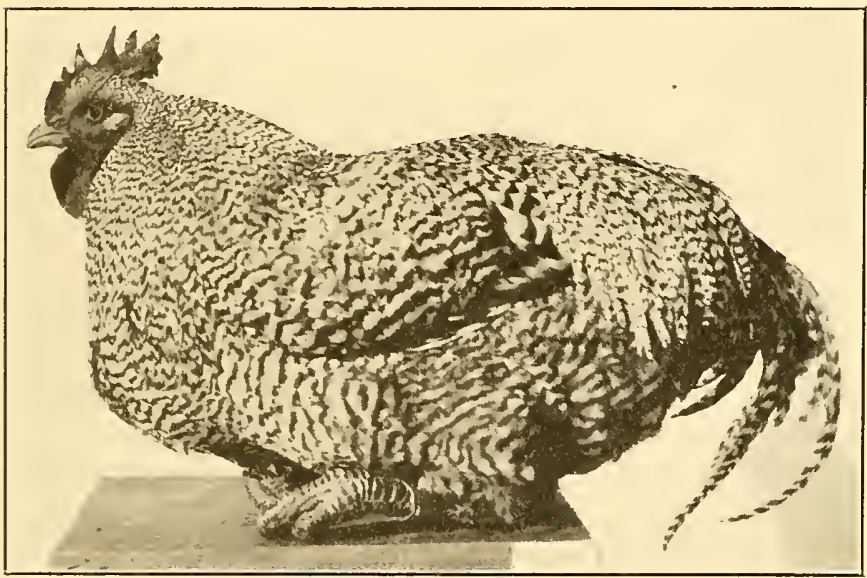

A Barred Plymouth Rock male, down on his legs because of a defieiency water soluble B in his ration. (Unpublished photograph kindly furnished by Hughes and Fox, Kansas Agrieultural Experiment Station.)

As previously stated the chemical compositions of these substances are not known. They have not so far been isolated as separate substances and are known only by their nutritional effects. It is known that certain feeding stuffs contain both, or lack one and contain the other. It has been

1 The foregoing was somewhat modified from a statement by Armsby in his "The Nutrition of Farm Animals." 
possible in some cases to measure comparatively the amounts certain feeding stuffs contain through the agency of feeding trials. It is indeed possible to state with confidence that one or the other is found in abundance in one part of a given grain while almost totally absent from another part As compared with the nutrients, however, the knowledge of them is so far very meager.

Water soluble B, found in abundance in the grains and in the fresh green leaves of plants, is necessary for growth, and for the proper functioning of the nervous system in adult

FIG. 170

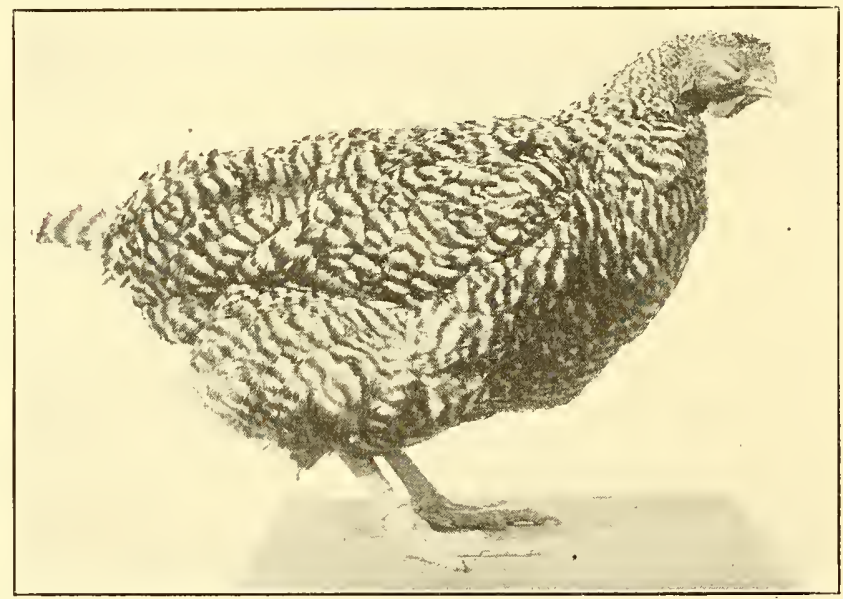

A Barred Plymouth Rock hen which had been fed on a ration deficient in fat soluble A. Notice the sore eye. (Unpublished photograph kindly furnished by Hughes and Fox, Kansas Agricultural Experiment Station.)

fowls. Its absence from the ration prevents or limits growth in young stock and brings on nervous disorders in both young and mature individuals, particularly the paralysis of the peripheral nerves. The latter condition is usually referred to as polyneuritis. In growing stock the lack of the water soluble causes the atrophy, or at least prevents the development of the internal organs of secretion, including the testis and probably the ovary. 
Fat soluble $\mathrm{A}$ is found in abundance in the fresh green leaves of plants and in butter fat. Its lack in a ration brings on a general unthrift and in particular a characteristic pathological condition of the eyes.

Both vitamins are more or less easily destroyed, the water soluble being more sensitive to adverse conditions than the fat soluble. The drying of the legumes to make hay reduces their vitamin content and may totally destroy it. Heating to high temperatures is also likely to destroy or at least reduce the amounts of these substances.

\section{DIGESTION.}

Definition of Digestion.-Digestion is the process, accomplished by the crop, glandular stomach, gizzard, pancreas, liver, and intestine, of so dissolving and chemically changing the material taken into the alimentary tract that it can be absorbed by the blood and used by the body.

The Digestive Tract.- "The structure of the alimentary canal of the bird suggests that the digestive process is rapid and that it partakes of features associated with both the carnivora and herbivora. Thus the relative shortness in length is a carnivorous characteristic, while the character of the diet and the thorough comminution of the food in the gizzard are features more akin to the herbivorous type."'s

Mouth Parts. ${ }^{2}$ - The distinctive character of the mouth of birds is the absence of lips and teeth, these parts being replaced by a horny mandible on each jaw and forming the beak of the land fowl and the bill of the water fowl. With land fowl the beak is short, pointed, thick and strong, the upper mandible curving over the lower. In water fowl the bill is longer, less firm, flatter, widened at its outer end, and supplied along the edges of each mandible and within the mouth with a series of thin and sharp transverse laminæ, whose purpose is to cut soft herbage.

${ }^{1}$ Brown, Bureau of Animal Industry, Bulletin No. 56.

2 This account of the digestive tract is gleaned from various sources, principally McNair, New York State Veterinary College Laboratory Bulletin No. 3, Chaveauxs' Comparative Anatomy of Domesticated Animals, and F. Smith's Manual of Veterinary Physiology. 
The tongue in fowls and turkeys is shaped like the barbed head of an arrow with the point directed forward. 'The

\section{FIG. 171}

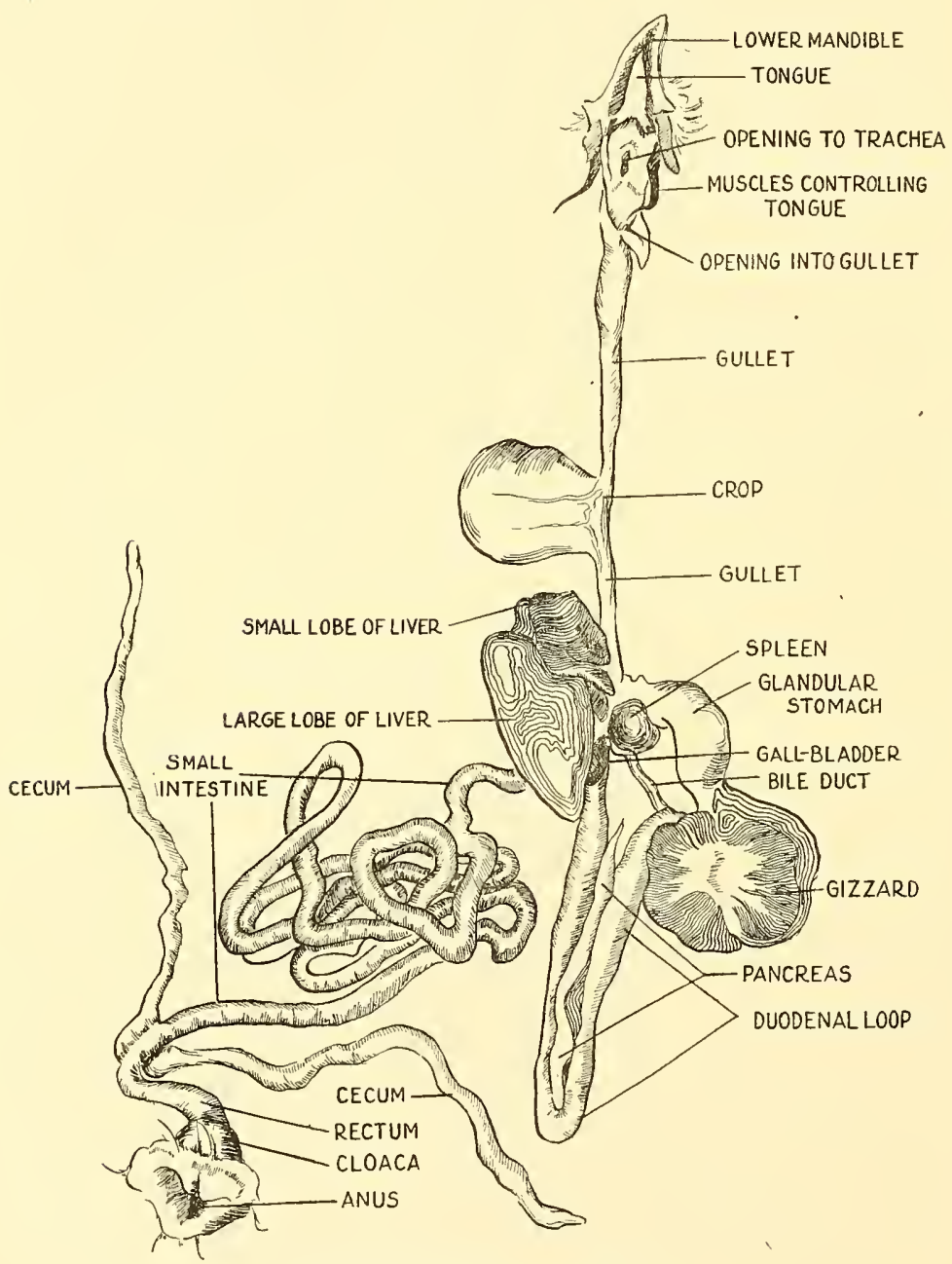

The digestive tract of the fowl. 
barb-like projections at the back of the tongue serve the purpose of forcing the grain toward the entrance to the gullet when the tongue is moved from front to back. In water fowl, the tongue is wider, softer, and more flexible.

The salivary glands are present in the mouth of the common sorts of domestic birds, but are imperfectly developed. Shaw ${ }^{1}$ recently showed that ptyalin, a starch-digesting enzyme, is present in the saliva of a chick soon after hatching.- The presence of abundant saliva is made unnecessary by the fact that the feed is swallowed whole, or in quite large pieces, and there is little opportunity for its action.

Gullet and Crop.-Upon leaving the mouth the feed is forced into the gullet by the tongue. The gullet (esophageal canal) is distinguished by its enormous expansibility. Immediately before entering the body cavity the gullet enlarges to form a pouch called the crop (ingluvies), which acts as a storage for the food eaten much as does the paunch of ruminants. It is into this pouch that the feed finds its way. Here it becomes softened and takes on an acid reaction. Although a comparatively profuse secretion is poured into the pouch, it contains no ferments. Its function, if other than storing and softening, is not yet understood.

Glandular Stomach.-Beyond the crop the gullet contracts until well within the body cavity, when it expands somewhat to form the glandular stomach (proventriculus), from which it passes immediately into the gizzard (ventriculus bulbosus), an involuntary sphincter muscle separating them.

The glandular stomach, which is little more than a thickening of the gullet wall, does not appreciably detain the feed, but surrounds it with an acid gastric juice which passes with it into the gizzard. It is supplied with but one type of complex cells, which secrete pepsin and acid. The pepsin reduces the proteid to peptones, which are further reduced by the pancreatic juice. Besides furnishing the proper medium for the action of the gastric juice, the acid acts as a solvent for such mineral matter as is not in assimilable form, thereby making its absorption possible.

${ }^{1}$ American Journal of Physiology, 1913, vol. xxxi, No. 7. 
The Gizzard.-The gizzard is oval in form, having two openings on its upper side, one communicating with the proventriculus and the other with the small intestine. It is depressed on each side, being situated behind the liver and partly covered by the lateral lobes of that gland. It is composed of two thick, red, powerful muscles covered internally with a thick, horny epithelium.

The gizzard is a very efficient crusher. It has been stated that iron tubes capable of supporting a weight of 535 pounds have been completely flattened out by passing through the gizzard of a turkey. This crushing process is absolutely necessary for the digestion of grains, and is most efficient only when aided by the presence of grit and gravel taken in through the mouth and always present in a normal bird. The gastric juice is incapable of digesting the cellulose walls of the grains and does not act until the grains are reduced by the gizzard to a more or less homogeneous pulp. The constant action of the gizzard may be noticed by holding a little chick that has been supplied with grit to the ear. "The gizzard does not possess digestive glands."

From the gizzard, the partially digested material passes into the small intestine. Up to this point there has been no digestion of fats, a limited digestion of carbohydrates and protein, and a dissolving of mineral elements.

Pancreas.-Immediately after its attachment to the gizzard the intestine is folded in a long loop called the duodenum, the sides of which are parallel and inclose the pancreas. The pancreas, though it does not come in contact with the food material, plays a very important part in the work of digestion, and is relatively longer in birds than in animals. It secretes a fluid known as the pancreatic juice, which contains "proteolytic, amylolytic, and lipolytic ferments," which help prepare protein, starch, and fat respectively for digestion, acting in a slightly alkaline medium. This juice emptied into the duodenum by one duct at each end.

In 1856 Bernard, as reported by Brown,, "first pointed

${ }_{1}$ Shaw, Jour. Am. Assn. Inst. and Invest. in Poul. Husb., vol. i, No. 2.

2 Shaw, American Journal of Physiology, vol. xx, No. 7.

${ }^{3}$ Bureau of Animal Industry, Bulletin No. 56. 
out the great vital significance of the pancreas in birds. He removed the organ, and observed that while the subjects endured the operation well, starch passed through the gastrointestinal tract undigested, and death resulted in from ten to twelve days."

Liver.-At practically the same time that the pancreatic juice enters the intestine the bile from the liver is also poured in. The function of the bile is to aid in the digestion of fat by furnishing the alkali with which it may unite to take on a soluble form. It also aids in neutralizing the acid of the gastric juice received from the gizzard, so that the pancreatic juice may have the proper medium for activity. The liver of the chick contains glycogen on the twentieth day of incubation. ${ }^{1}$

Besides secreting the bile, an eminently necessary contribution to digestion, the liver of the goose has been demonstrated by Minkowski (as quoted by Brown²) to be the seat of much of the synthesis of the uric acid that escapes in the urine. It is also the seat of the manufacture of glycogen, a carbohydrate whose function is to furnish energy to the muscles throughout the body.

Intestine.--The walls of that portion of the intestine which forms the duodenal loop probably secrete no digestive fluids. Further on it secretes a fluid (succus entericus) which contains erepsin and the invertases. Erepsin is an enzyme which carries to a conclusion the work of digesting the protein. The invertases are enzymes which have the power of converting more or less complex sugars into simple ones, capable of absorption.

It will be noticed that there has been no provision for the digestion of crude fiber. So far as the all too few digestion trials show, crude fiber is almost entirely undigested by chickens and geese. In the first three compartments of the stomach of ruminants and in the cecum of the horse, bacteria have an opportunity to act on crude fiber.

With fowls, however, bacteria have little opportunity for action. As soon as the hard-coated grains become moist

\footnotetext{
1 Shaw, American Journal of Physiology, vol. xxxi, No. 7.

${ }^{2}$ Bureau of Animal Industry, Bulletin No. 56.
} 
and soft enough for bacterial action, the material passes down the gullet to the proventriculus, where the acid reaction checks bacterial action. Immediately after passing from the gizzard to the intestine the reaction becomes so alkaline as possibly to inhibit their development. The time spent in the short rectum, which corresponds to the large intestine in larger animals, is so limited and the uric acid from the kidneys so plentiful that bacterial growth is again inhibited.

Besides its digestive function, the small intestine also acts as an organ of absorption, as does also the rectum to a certain degree, taking in the soluble nutrients and inorganic salts.

Ceca.-At the juncture of the intestine and the rectum are two blind pouches, given off from either side, called ceca. These are usually four to six inches in length, and more or less completely filled with fecal matter. Their function, if other than absorption, is not understood.

Rectum.-The rectum terminates the digestive canal, being a short and somewhat enlarged continuation of the intestine. It is terminated by the cloaca, a chamber common to the digestive and genito-urinary passages, and which opens externally at the anus. One marked function of the rectum is the absorption of water from the urine, as it is delivered from the kidneys by the ureters. The urine appears with the feces normally as a white paste. It leaves the kidneys in a highly liquid state. The only possible conclusion from this and other evidence seems to be that the water is reabsorbed by the rectum, to be used further in the economy of the body, travelling as it were in a sort of vicious circle. Weiner, as quoted by Sharpe, ${ }^{1}$ noted that when an artificial anus was provided so that there was no chance for water to be absorbed by the rectum, hens drank abnormally large amounts of water. Pohlman ${ }^{2}$ notes that until pulmonary breathing starts the muscles of the chick embryo contain a very large amount of water. This decreases rapidly after hatching which he interprets'as meaning that most of the water in birds is excreted by the lungs.

1 Sharpe, American Journal of Physiology, vol. xxxi, No. 11.

2 Anatomical Record, vol. xvii, No. 2. 
Bacteria and Digestion. - It is probable that bacterial action is responsible for a part of the digestive process, though studies of the bacterial flora of the digestive tract have not proceeded far enough to give a great deal of accurate information on the subject. While there is no opportunity for microörganisms to break down crude fiber and make it available, as is done in the rumen (paunch) of the ruminants, the work of Schottelius (as reported by H. J. Wheeler ${ }^{1}$ ) seems to show that they enter very markedly into the digestive processes. He hatched chickens from eggs which were free from foreign organisms, in germ-free air, and fed them on sterilized food, only to have them die in two to three weeks. If hatched in the same manner and fed unsterilized or normal food the chickens lived. Other chickens fed like the first until near death were saved by feeding normal chicken feces or unsterilized feed. This work was done before anything was known concerning the vitamins and it is possible that these may have been a factor in the result.

Disposition.-In comparing fowls with other farm animals, besides the anatomical differences, there is a decided difference in disposition. Birds are more active, have a higher temperature, and more rapid digestion. As a rule, six months represents the age of maturity and four or five years the life period.

With these things in mind it is easy to see that all of the body processes must be extremely rapid. The relation between feed and these productive processes, while no closer in point of composition than is the case of other domestic animals, in point of time is very much closer.

The result of wrong feeding is more quickly disastrous than with any other class of stock, and for the same reason that breakage is likely to be more serious in a high-geared as compared with a low-geared machine, the disaster caused by wrong feeding, particularly during the growing period, is more likely to be so serious as to be permanent. With slower-growing animals there is more opportunity for recovery and repair. 
Physiological Efficiency of the Laying Hen.-In the amount of edible food solids manufactured as compared with the weight of the dry matter in her body the hen leads all farm animals. As shown in Table XXXVI, a three and a half pound Leghorn hen, laying two hundred eggs in a year, produces five and three-quarter pounds of edible-food solids, or 3.8 times the amount of dry matter in her body. The cow is the only farm animal which is at all comparable with the hen in this particular.

A Jersey cow weighing 1000 pounds, giving 7000 pounds of milk containing 14 per cent solids, would rank as high, if not higher, among dairy cattle than the hen mentioned would rank among high-producing hens. Such a cow would produce 2.9 times her own dry-matter weight in solid food.

\section{Table XXXVI.-A Comparison of the Hen and the Dairy Cow in Physiological Efficiency.}

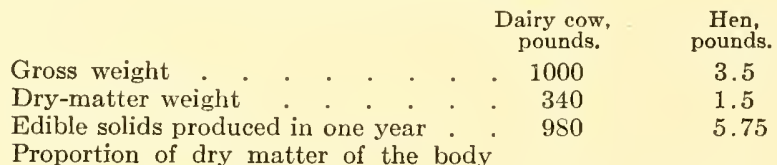

to edible solids produced . . . . 1 to $2.88 \quad 1$ to 3.83

Digestibility of Feeds. - The mere chemical composition of a feedstuff is of little value in poultry feeding unless it is known how much of each nutrient is digestible and available for the fowls. It is not enough, for instance, to know that oats contain 11.8 per cent protein, 59.7 per cent carbohydrates and 5 per cent fat. In order to have an intelligent basis for feeding, it must also be known what proportions of these nutrients are digestible for poultry.

Ash is usually absorbed by the intestine without change in composition, and cannot be said to undergo digestion in the ordinary sense of the term. Insoluble ash compounds may be rendered soluble by the hydrochloric acid of the glandular stomach.

Ordinarily no nutrient is completely digested and assimilated by fowls. The undigested portion passes through the body without change, and has manurial value only. That 
percentage of a nutrient which is digested is called the digestive coefficient of that nutrient. The digestive coefficients vary for each nutrient and are determined by direct experiment.

These experiments, which are usually referred to as digestion trials, are made as follows: A fowl is fed a given amount of feed, the exact composition of which has been determined by analysis. All the intestinal voidings produced during the period are carefully collected, weighed, and analyzed, the excreta from the kidneys having been diverted. The undigested portions of the nutrients appear in the roidings, and the difference between the amount fed and that excreted, reduced to a percentage basis, represents the digestion coefficient. It is never exactly accurate, however, since some waste material is given off from the intestines.

Digestion trials are very much more difficult with poultry than with other farm animals, owing to the fact that the urine is not temporarily stored in the bladder and eliminated through a separate genito-urinary opening, as in mammals, but is conveyed directly from the kidneys through the ureters to the cloaca, where it is constantly mixed with the fecal matter from the intestines. "The fact that the urine and feces are excreted together has formed the chief obstacle to progress in the performance of digestion experiments with poultry."' This is because the so-called urine contains the broken-down tissue from the body, which cannot be distinguished from the lindigested portions of the food by present analytical methods.

The white, pasty material appearing in the droppings of birds is uric acid, excreted by the kidneys. This increases in amount as the ration becomes more nitrogenous. The droppings of wild birds living almost entirely upon worms and insects are quite white.

No satisfactory method of separating the urine from the feces has been generally adopted. Some successful work has been done by means of a surgical operation, whereby a false urinary aperture has been made. In very few cases, 
however, do the birds operated upon return to apparently normal health so that the results of the trials are trustworthy. The digestive coefficients of the three organic nutrients for those feeds upon which trustworthy work has been done is given in Table XXXVII.

\section{Table XXXVII.-Average Digestion Coefficients of the} Nutrients with Chickens. ${ }^{1}$

\begin{tabular}{|c|c|c|c|c|c|c|c|}
\hline & & & $\begin{array}{l}\text { No. of } \\
\text { trials. }\end{array}$ & $\begin{array}{l}\text { Organic } \\
\text { matter. }\end{array}$ & Protein. & $\begin{array}{l}\text { Nitrogen-free } \\
\text { extract. }\end{array}$ & Fat. \\
\hline Bran (wheat) & - & . & 3 & 46.70 & 71.70 & 46.00 & 37.00 \\
\hline Beef scrap & . & . & 2 & 80.20 & & $\ldots$ & 95.00 \\
\hline Beef (lean meat) & 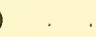 & & 2 & 87.65 & 90.20 & & 86.30 \\
\hline Barley . & 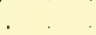 & , & 3 & 77.17 & 77.32 & 85.09 & 67.86 \\
\hline Buckwheat & . & . & 2 & 69. & & 80 & 89.22 \\
\hline Corn (whole) & 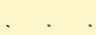 & . & 16 & 8 & & 2 & 88.11 \\
\hline Corn (cracked) & . & & 2 & 8 & 20 & 0 & 87.60 \\
\hline Corn-meal & & . & 2 & 83.10 & 74.60 & 86.00 & 87.60 \\
\hline eal and & clover & (equa & & & & & \\
\hline & 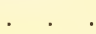 & . & 3 & & & & 66.90 \\
\hline Clov & . & . & 3 & 27 & & 30 & 35.50 \\
\hline wheat & . & . & 3 & 72.70 & & 40 & 83.80 \\
\hline Mil & . & & 2 & & & 39 & 85.71 \\
\hline hole) & . & & 13 & 62.69 & & 90.10 & 87.89 \\
\hline Oats (rolled) & . & & 4 & & & 94.30 & 92.20 \\
\hline Peas. & . & . & 3 & 77.07 & & 84.80 & 80.01 \\
\hline Wheat & 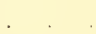 & 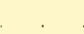 & 10 & 82.26 & & & 53.00 \\
\hline Rye & 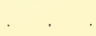 & & 2 & 79.20 & 66.90 & 86.70 & 22.60 \\
\hline Potatoes. & . & . & 6 & 78.33 & 46.94 & 84.46 & \\
\hline
\end{tabular}

Digestive Powers of Chickens.-The different structure of the alimentary tract of chickens as compared with other farm animals would lead one to suspect a different digestive capacity and different digestive coefficients. In comparison with other animals, fowls show digestive powers most nearly comparable with swine, except that in the digestion of fat they correspond most closely to the ruminants. Unlike ruminants, they digest very little crude fiber.

While they consume over twice as much feed as is required by the same weight in cattle, they cannot make use of the coarser kinds of feed, such as hay and fodder. They must be fed a concentrated ration made up quite largely of grains and their by-products.

\footnotetext{
'Rearranged from Bartlett, Maine Bulletin No, 184, who secured the data from various sources.
} 
While the different nutrients have differing coefficients in different feedstuffs and under different conditions, as a rule the nutrients rank in the following order of digestibility for poultry: Nitrogen-free extract, protein, fat, and crude fiber.

Variations in Digestibility and Their Cause.-It would seem that it should be a comparatively easy matter to determine the digestive coefficients of a nutrient aside from the physiological and chemical difficulties already described. As a matter of fact there are many causes of variation in the digestion of foods which make accurate determinations that may have general application difficult. A knowledge of the more important known and probable causes should be had by a practical feeder as well as by the investigator. These are (1) the mechanical condition of the feed; (2) the combination of feeds; (3) amounts of feed consumed; (4) the source of the feed, whether vegetable or animal; (5) the concentration of the feed; (6) its palatability; (7) cooking and wetting the feed; (8) age and exposure of the grain or grass when cured, and (9) age, species, and individuality of the bird fed.

Mechanical Condition of Feed.-While for some of the larger animals grinding certain of the grains increases their digestibility, this does not hold true for poultry. Fields and Ford ${ }^{1}$ found that chickens digested kafir and corn more completely when the grain was fed whole than when it was ground into meal. It will be noted in Table XXXVII that over 3 per cent more organic matter from whole corn was digested than when the corn was cracked or ground into meal. The increased digestibility brought about by grinding for larger animals is usually because hard grains are not well masticated. With poultry the grinding of the feed is involuntary and, unless grit is not available, consistently thorough.

Because of the fact that corn or any other grain is less digestible for poultry when ground it must not be assumed that it is less profitable and therefore bad practice to feed a part of the ration in ground form. (For further discussion see page 336. .) 
Combinations of Feeds.- Some feeds are more digestible when combined with certain other feeds than when fed alone. Thus Bartlett ${ }^{1}$ found by combining 7 per cent bone meal with a ration made up of 200 pounds bran, 50 pounds corn meal, 50 pounds linseed meal, and 100 pounds gluten feed the organic matter was rendered 4.6 per cent more digestible.

Sometimes combining certain feeds adds to the palatability, thereby inducing a greater consumption of feed, but not actually rendering the feed consumed more digestible. This is very possibly the case in adding salt to the ration.

Kalugine (as reported by H. J. Wheeler ${ }^{2}$ ) is authority for the statement that fine gravel, when fed in combination with a ration, increases the coefficient of digestibility of the nutrients.

Amount and Frequency of Feeding.-There is no direct experimental evidence bearing on these points. There is no reason to believe, however, that, even taking into account the involuntary grinding on the part of the fowl, poultry are an exception to the rule for other animals, that when large amounts of food are consumed the work of the digestive tract is not so thorough and the coefficients of digestion of at least some of the nutrients will be smaller. With other animals this difference is noted with all food constituents except fat. ${ }^{3}$

There appears to be small probability that the frequency of feeding affects digestibility appreciably.

Nutrients from Vegetable and Animal Sources.-As will be seen by reference to the table of digestion coefficients for poultry, protein in all cases, and fat in most cases, is more digestible when supplied from animal sources than from vegetable sources. These coefficients are borne out by practical experience and by feeding experiments generally. With particular reference to protein Hartwell and Kirkpatrick $^{4}$ found that beef scraps and milk albumin showed a marked superiority over cottonseed meal, linseed meal,

1 Maine Bulletin No. 184.

${ }^{2}$ Rhode Island Bulletin No. 84 .

${ }^{3}$ Kellner, The Scientific Feeding of Animals.

${ }^{4}$ Rhode Island Bulletin No. 45. 
and gluten feed as a source of protein for growing winter chickens, where the same amount of protein was added to the same basal ration in each case, and an abundance of ash supplied.

W. P. Wheeler ${ }^{1}$ found that with 10 lots of chicks, 6 lots of immature pullets, 2 lots of yoing hens, and 2 lots of old hens, fed contrasted rations which were as nearly alike as possible, except that all the protein was of vegetable origin in one case and 40 to 50 per cent of animal origin in the other, with every two lots contrasted, the results were markedly more satisfactory where the animal feed was the source of protein. The chicks having the animal feed ration consumed 12 to 34 per cent more feed and made 22 to 100 per cent faster gains.

The pullets fed the animal-feed ration consumed 13 per cent more feed and laid 30 per cent more eggs than those restricted to protein of vegetable sources, while the old hens having the animal protein consumed 15 per cent more food and laid 36 per cent more eggs.

Kempster ${ }^{2}$ reports that he could find no evidence that regetable proteins alone or in combination with feed of animal origin increased egg production. Lewis ${ }^{3}$ found that protein from a vegetable source, even when supplemented by feeds rich in available phosphoric acid was not efficient for growing chicks or laying hens.

There is much further evidence bearing out the above from numerous sources.

A possible partial explanation of this may be in the fact that the protein in the plant is surrounded by cellulose, while in animal products it is surrounded by the more easily digested fat.

Concentrated Feeds.--Poultry are able to digest little of the bulky feeds, such as the cured hays and fodders. The concentrates, such as grains and their by-products, they digest with a fair efficiency. It is possible, however, to secure a feed of so great a concentration that the digestive tract will

1 New York Experiment Station, Twenty-sixth Annual Report

2 Missouri Bulletin, No. 155.

3 New Jersey Bulletin, No, 265. 
become disarranged and fail to carry on the work of digestion properly, in which case the digestive coefficient would undoubtedly be lowered.

Cochel and Jackson ${ }^{1}$ found that rations carrying 3.5 per cent of total weight in crude fiber seemed to give better results for laying hens than those with a higher or lower per cent, and it is reasonable to suppose that at least a part of the value of the fiber is to be found in its opening up the ration so that the digestive juices may act more readily and thoroughly.

Palatability.-Experimental evidence showing that palatability in and of itself increases the digestive coefficient of feeds is lacking. It is popularly supposed to be the case, however, and the supposition does no harm. As Brown ${ }^{2}$ points out in discussing the comparative digestibility of oats and corn, palatability and good digestibility are likely to go together. Bartlett ${ }^{3}$ calls attention to the fact that of two mixtures he was feeding in digestion trials, the mixture which was the least palatable was also the lowest in digestibility.

The relative palatability of different feedstuffs is somewhat dependent upon the individual idiosyncrasies of the stock. Kempster allowed 15 hens to choose their own ration. Eight consumed more wheat than any other feed-stuff. Five consumed more kafir, 1 more middlings and 1 more cornmeal. The relative digestibility of the nutrients of these feedstuffs was not given.

Cooking and Wetting Feed.-The cooking and wetting of feeds have little if any effect upon their digestibility, directly, though either may increase the palatability of a ration.

Rice $^{4}$ found as a result of a year's test with forty Single Comb White Leghorn pullets, to twenty of which the ground or mash portion of the ration was fed wet and to twenty it was hopper fed dry, that the dry mash gave better results in gain in weight, production of eggs, gain in weight of eggs, hatching power of eggs, days lost in molting, mortality

1 Pennsylvania Bulletin No. 120.

2 Bureau of Animal Industry, Bulletin No. 56.

${ }^{3}$ Maine Bulletin No. 184.

${ }^{4}$ Cornell Bulletin No. 249. 
and profit per hen. Atwood ${ }^{1}$ concluded, from experiments with White Leghorn pullets, "that there was no benefit from the cxtra labor involved in moistening mash as compared witl hopper feeding if dry." Mairs ${ }^{2}$ found that "the loss among chicks fed on wet mash was much greater than those on dry feed." While none of these experiments included digestion trials, the results were not such as to point to the probability that moistening the feed made it more digestible.

Age and Curing of Feedstuffs.-The younger a plant is the less crude fiber it contains. Unless, as in the case of young rye, it contains a laxative property which brings about its voidance before digestion is complete, the younger a plant is the more completely will it be digested. For this reason young clover is more desirable for poultry feeding than fully matured clover, whether it is fed in the green or matured state since young plants are richer in the vitamins. Exposure of alfalfa, clover, oats, etc., to rain during curing will also lower the digestive coefficient by bleaching out the soluble constituents which are likely to be highly digestible and leaving the less soluble and less digestible ones.

Age, Species, and Individuality of the Bird Fed.- It is probable that, as in the case of other farm animals, the age of poultry does not influence their digestion of the food and that different breeds of the same species possess an equal digestive power.

There is considerable variation between individuals of the same breed which may be due to some slight physical weakness. Bartlett, ${ }^{3}$ for instance, reports a Plymouth Rock capon that digested 81.6 per cent of the organic matter of a given ration, while another capon of the same breed digested 94.1 per cent of the organic matter of the same ration.

It is not likely that different species of poultry have an average digestion coefficient that is the same, any more than do horses and cattle. St. Weiser and Zaitschek, as reported by Brown, ${ }^{4}$ found that the digestive coefficient for the starch of millet was 65.80 for ducks and 91.80 for geese. There

1 West Virginia Bulletin No. 130.

2 Pennsylvania Bulletin No. 87.

${ }^{4}$ Bureau of Animal Industry, Bulletin No. 56.

3 Maine Bulletin No. 184. 
has been very little work done with any species of poultry besides the chicken, however, and it is not possible to draw general conclusions on the meager data available.

Nutritive Ratio.-In order to quickly and conveniently see the relation between the protein that is digestible for poultry and the digestible carbohydrate and fat, what is termed the "nutritive ratio" is made use of. The nutritive ratio is an arithmetical proportion stating the amount of digestible carbohydrate and fat (estimated as carbohydrate) that fall to one part or one pound of digestible protein.

It will be seen by referring to Table LIII, that 100 pounds of corn contains 8.4 pounds of protein that can be digested by chickens, 64.29 pounds of carbohydrate and 4.4 pounds of fat. As previously noted, fat has a feeding value 2.25 times that of carbohydrates. It is possible to estimate the fat as carbohydrate by multiplying its weight by the factor 2.25. For the purpose of securing a simple proportion, the equivalent of the fat in carbohydrates may be added to the amount of carbohydrate found in the corn, giving the proportion of 8.4 pounds of protein to 74.19 pounds of carbohydrate In order to simplify this proportion and make it comparable with all other similar proportions, both amounts are divided by the amount of protein, giving the porportion of one to eight and eight-tenths, and expressed thus: 1:8.8. This is called the nutritive ratio of corn for chickens. Expressed arithmetically, the process is as follows:

Digest. fat Digest. car bohydrate

$$
\left(4.4 \times \frac{2.25)+64.29}{8.4}=8.8 \begin{array}{l}
\text { Second factor of } \\
\text { nutritive ratio. }
\end{array}\right.
$$

Digestible protein

The nutritive ratio of corn for ruminants is $1: 9.7$.

In calculating the nutritive ratio, care should be taken to distinguish between the amounts of the nutrients consumed and the amounts digested. Brown ${ }^{1}$ found 100 pounds of hens fed on the exclusive diet of corn consumed 4.83 pounds of organic matter daily, but they digested only 4.19 pounds. The nutritive ratio for corn, as may be seen from Table 
XXXVIII, was 1 to 8.6 on the basis of the nutrients consumed, but was 1 to 9 on the basis of the nutrients digested. It is the latter ratio in which the feeder is interested:

Table XXXVIII.-A Comparison of the Nutrients Consumed on an Exclusive Diet of Corn, and the Nutrients Digested Per Hen for Birds Weighing Between Three and Four Pounds, on the Basis of One Hundred Pounds Live Weight.

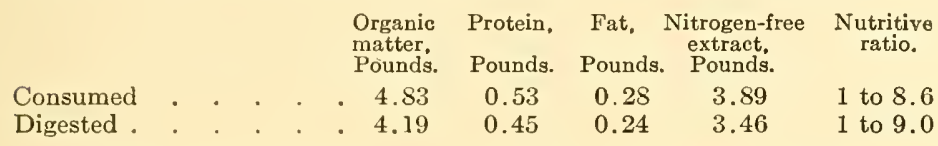

Nutritive ratios are referred to as wide, medium, or narrow, when the difference between the first and second factors of the ratio is great, medium, or slight, respectively.

Just what the exact limits of a wide or narrow ration are is not fixed with definiteness. For convenience in this work, any ratio less than 1 to 5 will be referred to as narrow and any ratio having a greater proportion of protein than 1 to 7 will be called wide. A ratio lying between 1 to 5 and 1 to 7 will be called medium.

An illustration of the relation which may exist between a proper nutritive ratio and production is given by W. P. Wheeler, ${ }^{1}$ who reports that a nutritive ratio of 1 to 4.3 gave 21 per cent more eggs during the more productive months, with the heavier breeds, then did a ratio of 1 to 5.8. Hens of the lighter breeds gave 26 per cent more eggs where the latter ratio was used.

The nutritive ratio in and of itself, however, is not so much emphasized as a guide in feeding practice as in times past. This is for two reasons. The first is that various proteins vary so widely in their nutritive desirability, that a proper nutritive ratio from the standpoint of some proteins might be a very improper one with others. Thus the most efficient nutritive ratio for a ration whose chief source of protein supply was meat scrap, might very well differ from that where the chief source of protein was powdered milk.

1 Twenty-sixth Annual Report, New York Experiment Station. 
In order to determine such matters much careful experimental work is sorely needed.

A further reason lies in the fact the nutritive ratio of a feed or ration gives no information concerning its vitamin content, the importance of which is increasingly apparent. It would be easily possible to prepare a ration in which the relative proportion of proteins to carbohydrates and fats was highly satisfactory, yet fowls fed on it would die for lack of one or both of the vitamins. 


\section{CHAP'TER VIII.}

\section{THE FEEDS.}

\section{CLASSIFICATION OF FEEDING STUFFS.}

For convenience, poultry feedstuffs may be classified according to the five divisions of a ration, which are grain, green feed, mash, mineral feed, and drink, into grains, succulence, mash constituents, mineral constituents and liquids.

The Grains.-While chickens are omnivorous feeders they are primarily granivorous, or grain eaters. As Jaffa ${ }^{1}$ points out, rations for chickens are properly built up by selecting such grains as are available and reasonable in price, and supplementing them with the mash, mineral ingredients, succulence and liquids necessary to the needs of the fowl.

In experiments carried on at the Petaluma (California) Poultry Station with barley, wheat, and corn, it was found that as far as egg production alone was concerned, one grain was just as valuable as another, provided it was properly supplemented. This allows a choice between grains on the basis of their price.

Grains and their products, which make up the majority of poultry feeds, are classed among the concentrates for the larger animals. They are usually sufficiently bulky to supply the needs of poultry in this particular, and roughage, save when it is fed as succulence in its green form, has small place in the poultry ration.

Grains in general are very deficient in fat soluble $A$. It is more abundant in the germ than in other parts of the grain. Those grains having a comparatively large endosperm are particularly deficient. All grains appear to have an abundance of water soluble B which is largely localized in the outer coating. 
Barley.-This grain contains less fat, fiber, and ash than oats, but more protein and carbohydrates. It does not rank as high as wheat in digestible protein and contains more fiber. It is not as palatable a feed as corn, wheat, or oats, but is a good one to add to a ration by way of variety.

The amounts of digestible nutrients found in 100 pounds of whole barley as determined by digestion experiments with chickens are 9.3 pounds of protein, 1.2 pounds of fat, and 58.4 pounds of nitrogen-free extract. It contains 2.5 pounds of ash and has a nutritive ratio of 1 to 6.6 for chickens. The crude fiber content is 4.2 pounds.

Buckwheat.-Owing to its large proportion of crude fiber, this grain has a lower per cent. of digestible organic matter than any of the grains except oats. Fowls do not eat it readily because of its dark, unattractive appearance. It has a tendency to cause light-colored yolks. The amounts of digestible nutrients found in 100 pounds of buckwheat as determined by digestion experiments with chickens are 6.4 pounds of protein, 2.1 pounds of fat, and 51.9 pounds of nitrogen-free extract. It contains 2 pounds of ash and has a nutritive ratio of 1 to 8.8 for chickens. The crude fiber content is 11.7 pounds.

Corn.-As the result of digestion experiments, Bartlett ${ }^{1}$ is led to remark that his results, "like those of Brown and others, show that corn is a most valuable grain for poultry. Its palatability and high digestibility has brought it into much favor with all poultrymen. It cannot, of course, be fed alone, as it is too concentrated a feed and is also deficient in protein, but when combined with feeds rich in protein and some bulky material, as cut clover, it makes a most desirable ration."

The Cornell Experiment Station ${ }^{2}$ records the fact that chickens fed an exclusive corn diet failed to develop satisfactorily. This was especially true of the feathers, which are largely protein. An exclusive corn diet induced sluggishness and caused the laying on of masses of internal fat. 
Hughes ${ }^{1}$ has, however, shown that corn alone is an adequate diet for adult pigeons for maintenance for at least one year. The protein deficiency in corn seems to be due to the poor quality rather than to the quantity. For corn which usually contains about 9 per cent protein will produce a very slight growth even when all the other necessary dietary factors are present in sufficient amounts. A diet containing this amount of protein in the form of milk albumen as shown by Osborne and Mende ${ }^{2}$ will produce a maximum growth. This protein deficiency in corn is undoubtedly due to the high per cent of zein, a protein which contains neither lysin nor tryptophan, and which is incapable of supporting life.

FIG. 172

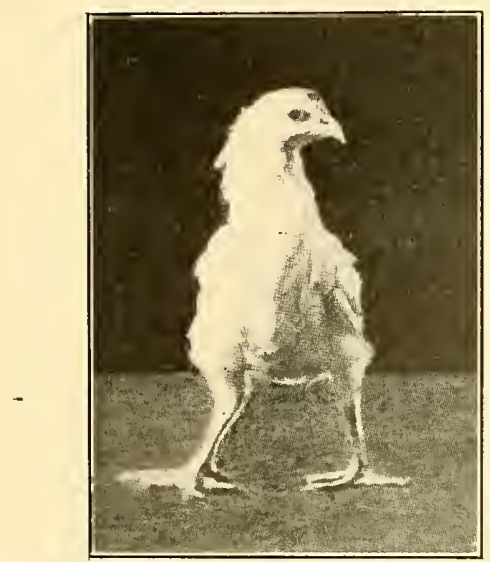

White Leghorn cockerel at eight months' of age which had been fed only corn and salt mixture. (After Hughes.)

Corn is the best liked grain that is fed to poultry in the Middle West. Yellow corn imparts a deeper color to the yolk of eggs than wheat or oats and produces yellow flesh as a fattening ration. It carries more of fat soluble $\mathrm{A}$ than the white corn. It also tends to make white birds creamy in color.

1 Kansas Technical Bulletin, No. 5.

2 Journal of Biological Chemistry, vol. xxiv. 
There is little, if any, advantage in feeding corn cracked to fowls that can consume whole grains. Because of its cheapness, attractiveness, palatability, and, in the case of yellow corn, its effect on the yolk of the egg, it should form a large proportion of the ration.

The amounts of digestible nutrients found in 100 pounds of corn as determined by digestion experiments with chickens are 8.4 pounds of protein, 4.4 pounds of fat, and 64.29 pounds of nitrogen-free extract. It contains 1.5 pounds of ash and has a nutritive ratio of 1 to S.S for chickens. The crude fiber content is 2.2 pounds. It contains an abundance of water soluble B but not enough fat soluble $A$ to produce normal growth.

Cow Peas.-Peas, as well as other leguminous seeds, contain a large amount of protein. They are little used as a poultry feed because of their scarcity and high price. Manufacturers of prepared scratch feeds often include them in the ration to narrow it and add to its attractiveness.

The amounts of digestible nutrients found in 100 pounds of peas as determined by digestion experiments with chickens are 17.8 pounds of protein, 1.2 pounds of fat, and 47.7 pounds of nitrogen-free extract. 'They contain 3.2 pounds of ash and have a nutritive ratio of 1 to 2.5 for chickens. The crude fiber content is 3.9 pounds.

Kafir-The only data to be found concerning the availabilty of the nutrients in kafir for chickens ${ }^{1}$ has been somewhat criticised and declared untrustworthy by certain investigators. While they perhaps cannot be trusted in certain details, it appears that in the matter of the comparison of the total digestible matter with that of corn, the data may be tentatively relied upon. At least, they are the best we have.

According to this data, kafir and kafir meal yielded about 2 per cent. less total digestible matter than corn and corn meal. Judging from its feeding value for swine, it is nearly as valuable as corn as a chicken feed.

The average amounts of the nutrients found in 100

1 Fields and Ford, Oklahoma Bulletin No. 46. 
pounds of kafir are 11.S pounds of water, 1.7 pounds of ash, 11.1 pounds of crude protein, 70.1 pounds of carbohydrates, of which 2.3 pounds are crude fiber and 3 pounds of fat. The proportions digestible for poultry have not been definitely determined.

- Millet.-Millet is similar in composition to oats and is used extensively as a chick feed, but it contains too much fiber to be a very economical feed. It is supposed to have a beneficial action upon the kidneys. Probably because it glistens it is one of the first grains that a newly hatched chick will pick up.

The amounts of digestible nutrients found in 100 pounds of millet as determined by digestion experiments with chickens are $6 . S$ pounds of protein, 3 pounds of fat, and 61.59 pounds of nitrogen-free extract. It contains 2.8 pounds of ash and has a nutritive ratio of 1 to 10 for chickens. The crude fiber content is 8.1 pounds. Having a comparatively large germ it carries enough fat soluble A to support nearly normal growth.

Oats.-The general nutritive value of whole oats for poultry appears to be less than that for ruminants and horses. This is because the crude fiber seems to be of insignificant feeding value for domestic birds. Oats, including the hulls, possess the largest amount of fiber and nearly the highest of ash of all the cereals, while the percentage of fat runs nearly as high as in corn. Hulled oats are similar to wheat in composition, except that the fat content is higher.

The relative amount of hull and kernel governs their desirability for poultry feeding. Light oats have a poor feeding value because of large per cent. of hull, which is about as digestible as straw. Heavy, clean oats are relished by chickens and add variety to the ration.

Hulled oats seem to be especially adapted for growing chicks because of their oil content and their stimulating effect on the nervous system.

The amounts of digestible nutrients found in 100 pounds of whole oats as determined by digestion experiments with chickens are 8.1 pounds of protein, 4.2 pounds of fat, and 53.5 pounds of nitrogen-free extract. It contains 3.2 pounds 
of ash and has a nutritive ratio of 1 to 7.7 for chickens. The crude fiber content is 10.8 pounds.

Rice.-While rice is classed as a fattening feed because of its large proportion of carbohydrate, nevertheless it is considered an excellent feed for little chicks because of its regulating effect on the bowels. It is usually fed in the grain portion of the ration. In the case of a tendency toward bowel trouble, however, it is frequently boiled. The boiled rice is fed as a wet mash, and the water drained off and given the chicks to drink after being cooled.

The average amounts of the nutrients found in 100 pounds of polished rice are 12.3 pounds of water, 0.5 pound of ash, 7.4 pounds of crude protein, 79.4 pounds of carbohydrates, of which 0.4 pound is crude fiber, and 0.4 pound is fat. The amounts digestible for chickens are not known. Hughes ${ }^{1}$ found that pigeons fed on polished rice only, developed polyneuritis in twenty to twenty-eight days. These birds could be cured by feeding the polishings, which goes to show that there is little water soluble B in polished rice, but an abundance in the outer coating, taken off in the polishing process.

Rye.-This grain, although quite similar to wheat in composition, is not suited for poultry feeding. It seems to contain some ingredient which renders it unpalatable to the fowl though this is possibly due to low per cent of fat. When fowls are compelled to eat it, it has a tendency to cause digestive disorders and affect the flavor of the egg.

The amounts of digestible nutrients found in 100 pounds of rye as determined by digestion experiments with chickens are 7.5 pounds of protein, 0.48 pounds of fat, and 64.6 pounds of nitrogen-free extract. It contains 2.1 pounds of ash and has a nutritive ratio of 1 to 8.7 for chickens. The crude fiber content is 1.5 pounds.

Sunflower Seeds.-The high fat content (21 per cent) of sunflower seeds, makes them highly prized for feeding birds intended for exhibition. The oil produces a desirable gloss that is much sought. Their high fiber content (nearly 30 per cent) and the prevailing high prices render them unprofitable for feeding except for the purpose noted above.

\section{Kansas Technical Bulletin, No, 5 .}


Wheat. - Wheat is usually spoken of as the best of the grains for poultry feeding. This is probably because it contains more protein and ash than corn or kafir and less fiber than oats.

As shown by Brown ${ }^{1}$ the amount of protein available for chickens found in 100 pounds of wheat is 9.69 pounds, while the amount found in 100 pounds of corn is 9.27 , or but 0.42 pounds less. At the same time, wheat contains less than one-third as much digestible fat as corn and slightly less nitrogen-free extract.

Brown further reports digestive disturbances when fowls were fed on a pure wheat diet, accompanied by loss of appetite and bodily depression. Changing to a diet of oats and corn stopped the trouble.

These facts, coupled with its high cost, due to its demand for flour-making, indicate that too much emphasis has been laid upon wheat as the most important single grain for poultry feeding. It is, however, a very valuable addition to any ration by; way of variety and because of its palatability.

The plump, soft wheats are more palatable for fowls than the hard wheats, but the comparative feeding value has not been determined.

Shrunken wheat, caused by frost or drouth, contains a larger proportion of protein than plump wheat because the starch, which is the last material stored in the grain, failed to reach it before growth ceased. As such wheat is unfit for flour-making, it may usually be purchased at a less price than fully matured wheat, while it is more valuable for feeding purposes.

The amounts of digestible nutrients found in 100 pounds of wheat as determined by digestion experiments with chickens are 8.9 pounds of protein, 1.1 pounds of fat, and 62.6 pounds of nitrogen-free extract. It contains 1.8 pounds of ash and has a nutritive ratio for chickens of 1 to 7.3. The crude fiber content is 1.8 pounds.

Shrunken wheat has been found to carry 4 per cent more digestible protein than plump wheat on the basis of 
digestion experiments with other animals. On this basis its nutritive ratio was 1 to 4.6 .

Wheat Screenings.-Screenings are the refuse of the better grades of wheat. They usually contain weed seeds, broken and shrunken kernels, and often much trash in the form of chaff, straw, and dirt. 'The feeding value depends upon the quality. Musty, smutty, heated, or burnt wheat should never be fed, because of the bad effect upon the digestive organs of the fowl.

Mash Constituents.-As previously noted, it is considered good feeding practice to furnish about one-third of the ration in a finely ground form comprising what is termed a mash. The mash furnishes an opportunity of supplementing the whole grains which are normally deficient in protein and saves the energy that would be used up by the gizzard in grinding the whole ration. The mash constituents, which are frequently grain or animal by-products, usually furnish digestible protein at less cost than do the whole grains.

The further fact should not be lost sight of, that in marketing nearly every farm product except butter, considerable nitrogen, the characteristic element in protein, is being carried off the farm. It is excellent farm practice to replace this nitrogen by the purchase of the concentrated by-products used as the mash constituents of a ration.

Care should be taken to see that the constituents of the mash are evenly ground. Any coarse particles are likely to be picked out by the birds, while the remainder of the mash is wasted.

Alfalfa Meal.-During the last few years finely ground alfalfa hay has appeared on the market as alfalfa meal, and if of good quality is a good substitute for wheat bran, as it is high in protein, ash, and fat. In buying this feed, however, the guaranteed analysis should be carefully considered and an examination made as to the crude fiber content. A large proportion of fiber would indicate that the meal was ground chiefly from stalks, which are of little feeding value, rather than the leaves, which contain most of the nutrients and the vitamins. The efficiency of alfalfa meal as a source of the latter depends upon the relative proportion of leaves and 
stems and also upon the way it is dried, though conditions governing the latter are not well understood.

Other alfalfa feeds, known as chopped and shredded alfalfa, are more easily examined and less liable to be of a poor grade because of their coarser condition than alfalfa meal. Although alfalfa feed contains a large percentage of nitrogen compounds, it must be remembered that they are made from alfalfa hay and not concentrates, and therefore should not be fed to excess because of their high crude fiber content and low availability. They may be used with good results up to 20 per cent of the mash portion of the ration, provided no bran is used. The total amount of bran or alfalfa meal should not exceed 25 per cent of the mash at any time.

Alfalfa meal has the same composition as does the best quality of alfalfa hay. In protein content it is ahead of that reported for bran or middlings, but the total food value of the latter is greater because they contain comparatively little fiber (average 5 per cent) as compared with alfalfa meal (over 26 per cent).

The average amounts of the nutrients found in 100 pounds of alfalfa meal are 8.8 pounds of water, 9 pounds of ash, 14.3 pounds of crude protein, 65.9 pounds of carbohydrates, of which 30.1 pounds are crude fiber, and 2 pounds are fat. The amounts digestible for chickens are not known. Under certain not well-understood conditions it may serve as a source of both the ritamins.

Barley (Ground).- "Barley meal, or ground barley, is an excellent material to use in a mash, but great care must be taken in preparing it. It is necessary either to have the entire grain evenly ground or sift it before using, or the hulls cause trouble in the chicken's crop, especially when dry mash is used. Care must be exercised in the sifting or a considerable part of the nutritious bran will be discarded with the hulls, causing unnecessary waste." 1 Where barley meal can be purchased at a reasonable price it is an excellent addition to a fattening ration as well as to a mash. 
Brewers' Grains.-Brewers' grains are a barley refuse from the brewing of alcoholic beverages and are sold on the market both wet and dry. Wet brewers' grains can be purchased only in the vicinity of breweries, where they may be hauled directly to the farm, because of their high water content and the ease with which fermentation takes place. Wet grains make an excellent food, as they are succulent, palatable, and nutritious. Care should be taken, however, that they be fresh and unfermented, as, if strong or musty, they will affect the flavor of the egg.

Dried brewers' grains are the wet grains with the moisture driven off. In this state they have good keeping qualities and are light in weight, thus enabling them to be shipped to distant markets. Because of their high protein and fat content, together with their light, chaffy nature, they make a valuable addition to the mash portion of the ration and form a good supplementary food to corn meal and wheat middlings.

The average amounts of the nutrients found in 100 pounds of dried brewers' grains are 7.5 pounds of water, 3.5 pounds of ash, 26.5 pounds of crude protein, 55.6 pounds of carbohydrates, of which 14.6 pounds are crude fiber, and 6.9 pounds are fat. The amounts digestible for chickens are not known.

Buckwheat Bran and Middlings.-In the preparation of buckwheat flour the outer layers of the kernel are separated into the hulls and middlings. The hulls, which have but very little feeding value, are sometimes mixed with a varying proportion of the middlings and sold as buckwheat bran. This feed is a better cattle than poultry feed, however, as poultry do not require the hulls to add bulk to the ration.

Buckwheat middlings are high in protein and fat, and are oftentimes used in fattening rations to produce white flesh. When buckwheat feeds of any kind, either whole grain or ground, are fed, they have a tendency to lighten the color of the yolks of the eggs.

The average amounts of nutrients found in 100 pounds of buckwheat middlings are 12 pounds of water, 4.8 pounds of ash, 28.3 pounds of crude protein, 47.5 pounds of carbo- 
hydrates, of which 4.8 pounds are fiber, and 7.4 pounds are fat. The amounts digestible for chickens are unknown.

Condiments. - The advisability of feeding stimulating foods like pepper and mustard is a point upon which opinion is divided. The belief that such feeds will sometimes stimulate egg production appears to be well founded. It is also true that there is always a reaction in the animal body when it has been artificially stimulated. In practice it is safe to use condiments only with great moderation, not more than is necessary to season the mash fairly well.

Corn Meal.-For use in mashes, corn meal possesses the same desirable qualities as it does in the whole grain for the grain portion of the ration. It is also very valuable for fattening rations. The bolted corn meal, which has much of the bran and germ removed, differs somewhat from corn in the amounts of digestible nutrients it contains. These two parts contain the vitamins, ash and the best of the proteins. On the basis of 100 pounds, it contains 6.9 pounds of protein, 3.3 pounds of fat, 59.1 pounds of nitrogen-free extract, and 1.4 pounds of ash. The nutritive ratio for chickens is 1 to 9.8. The crude fiber content is 1.9 pounds. Meal made from new corn is quite likely to heat in the bin, or even in the sack. Heated meal is undesirable for old stock and absolutely unfit for chicks.

Cottonseed Meal.- The evidence relative to the value of cottonseed meal as a source of protein for poultry is somewhat contradictory. Morrison" found "that cottonseed meal used as a chief source of protein is palatable to fowls" and further, "that as far as can be determined (after a six months' trial) the general condition of the cottonseed-meal-fed fowls seems just as good as the condition of those on beef scrap." Bittenbender and Lippincott ${ }^{2}$ found in crate-fattening trials that cottonseed meal could be successfully substituted for meat scrap, that it produced flesh of fine flavor and texture, and was more palatable when added to a basal ration of ground oat meal than oil meal, meat scrap, mutton tallow,

${ }^{2}$ Unpublished data, Iowa State College. 
beef fat, barley meal, or molasses. It was excelled in this particular only by corn meal.

Hartwell and Lichtenthaeler, ${ }^{1}$ as the result of a rather extensive comparison of cottonseed meal and meat scrap, concluded that "If the constituents of bone are'supplied, there appears to be no reason why cottonseed meal may not be used to furnish a considerable portion of the protein required by chicks, especially if a moderate consumption of food is satisfactory to the feeder. If the most rapid growth is desired, regardless of the amount of feed consumed, beef scrap will be found more satisfactory, since the chicks consumed more of the beef-scrap ration when allowed to have all they would eat, and made a more rapid growth in consequence. When limited to the same amount of nitrogen, however, the gains were not very different whether cottonseed meal or beef scrap formed a prominent part of the rations."

Jeffrey, ${ }^{2}$ however, reports that in experiments including Barred and Buff Plymouth Rock and Buff Orpington pullets, cottonseed meal was not relished and the birds ate sparingly of mash containing it. The pullets were slower in developing and coming into laying when the main source of protein was cottonseed meal than when it was meat meal. Philips ${ }^{3}$ reports that Leghorn pullets fed cottonseed meal as the chief protein concentrate, derived practically no benefit from it, laying no better than birds fed no protein concentrate of any kind. Pullets receiving their protein mainly from cottonseed meal gave an average annual production of $55.69 \mathrm{eggs}$, while pullets fed on a ration in which 5.3 pounds of cottonseed meal was replaced by 50 pounds of buttermilk, gave an average annual production of 166.87 eggs. There is further evidence bearing out Jeffrey's results, and the general opinion among poultry feeders is that cottonseed is not a desirable feed, Until a greater preponderance of decisive data is secured for or against its use, it should be avoided, or at least used with extreme caution.

1 Rhode Island Bulletin No. 156.

2 North Carolina Bulletin No. 211.

${ }_{3}$ Purdue Bulletin, No. 227. 
The average amounts of the nutrients found in 100 pounds of cottonseed meal are 7.5 pounds of water, 6.2 pounds of ash, 44.1 pounds of crude protein, 33.1 pounds of carbohydrates, of which 8.1 pounds are fiber, and 9.1 pounds are fat. The amounts of these digestible for chickens are not known. The vitamin content is small.

Cut Clover.--Young clover hay cut fine is a valuable feed for poultry, though it is not so generally used as alfalfa meal. Bartlett ${ }^{1}$ found that equal parts of early, fine-cut clover and corn meal made a more digestible feed than wheat bran. Steamed cut clover, like steamed cut alfalfa, makes a good temporary substitute for succulence, but it should be recognized that such a substitute is only temporary.

The amounts of digestible nutrients found in 100 pounds of early cut clover hay based on digestion experiments with chickens are 8.68 pounds of protein, 2.77 pounds of fat, and 31.77 pounds of nitrogen-free extract. It contains 6.2 pounds of ash and has a nutritive ratio of 1 to 4.4 for chickens. The crude fiber content is 24.8 pounds. It is similar to alfalfa in its vitamin content.

Dried Blood.-Dried blood is not palatable for chickens. Wheeler found that even when supplemented by bone meal, dried blood gave a much slower growth when fed to ducklings than did one containing meat scraps or another containing milk albumin supplemented with bone meal. Lack of palatability appeared to be a cause, though blood is known to be an inefficient protein, lacking certain of the amino-acids.

Fish Scrap.-Dougherty2 found "that a good grade of fish scrap gave as good results as commercial meat scrap, and when properly fed did not in any way taint the eggs laid." Philips $^{3}$ found that when the feeding value of meat scrap was $\$ 23.92$ per hundred pounds and of skim milk was $\$ 2.04$ per hundred pounds, fish scrap had a feeding value of $\$ 27.65$ per hundred pounds. While all these values have been criticised for being high, there appears no reason for doubting them from a comparative standpoint.

1 Maine Bulletin No. 184.

${ }^{2}$ California Experiment Station Report, 1914-1915.

${ }^{3}$ Purdue Bulletin No. 182. 
The average amounts of the nutrients found in 100 pounds of fish scrap are 12.8 pounds of water, 32.6 pounds of ash, 52.4 pounds of crude protein, and 2.2 pounds of fat. The amounts of these digestible for chickens are not known.

Gluten Feed.-In the manufacture of glucose and corn starch, the kernels of corn are soaked and separated into germ, hull, gluten, and starch. The gluten is dried and ground and was formerly sold as gluten meal, containing about 35 per cent protein and 3 per cent fat. Because of its high concentration it has so frequently produced a bad effect on animals when used by inexperienced feeders, and also to provide a market for corn bran, it is now mixed with corn bran and marketed as gluten feed.

The bran increases the bulk, reduces the fat and protein content and increases the proportionate amount of the water soluble. The proportion of meal to bran is about 55 per cent to 45 per cent. 'The protein content of gluten feed varies so much that it should always be purchased on a guaranteed analysis.

Gluten feed is a valuable source of protein, as it appears to be readily digested and palatable. It should never be used to entirely displace protein feeds from animal sources and should be accompanied by bone meal.

The average amounts of the nutrients found in 100 pounds of gluten feed are 8.7 pounds of water, 2.1 pounds of ash, 25.4 pounds of crude protein, 60 pounds of carbohydrates, of which 7.1 pounds are fiber, and 3.8 pounds are fat. The amounts of these digestible for chickens are not known.

Hominy Feed.-This consists of the hull, germ, and part of the starch cells of the corn kernel which are separated out in the process of making hulled corn or hominy. This feed runs about the same as the whole grain in protein and carbohydrates, but is higher in ash and fat. It is an excellent poultry feed, but is not used extensively because of the limited supply.

The average amounts of the nutrients found in 100 pounds of hominy feed are 10.1 pounds of water, 2.6 pounds of ash, 10.6 pounds of crude protein, 68.7 pounds of carbohydrates, of which 4.4 pounds are fiber, and 8.0 pounds of fat. The amounts of these digestible for chickens are not known. 
Meat (Fresh).-Fresh meat is undoubtedly the most palatable feed of animal origin except that furnished in nature in the form of insects and worms. It may be ground fine and mixed with a wet mash or it may be fed separately. An idea of its feeding value may be gathered from the discussion of meat scrap.

Kionka, as reported by Brown, ${ }^{1}$ found that an exclusive diet of meat increased the uric acid output of chickens 550 per cent, as compared with an exclusive diet of barley. Each fowl receiving large quantities of beef (150 grams daily) developed symptoms similar to gout in man, and autopsies revealed uric acid in certain of the joints and tissues. This same result would probably prevail in the case of overfeeding meat scraps and possibly any protein of animal origin.

Meat Scrap.-Meat scrap, quite commonly called beef scrap, is composed of the meat trimmings, including some bone, from various animals slaughtered at the packing-houses. These are cooked to extract some of the fat or tallow, and then ground to varying degrees of fineness and sacked. Being cooked dry and fairly free from fat, it will keep for a long period if stored in a dry place.

Meat scrap "should not contain any appreciable quantity of hoof, horn, or hair, as these materials have practically no food value for the growing chick or laying hen. A preliminary examination of such food preparations may be made by placing a small sample on a piece of white paper and noting carefully the particles which have more or less the appearance of a 'dark-brown glass.' These represent the hoof and horn, are very rich in nitrogen, but not of the form that is adapted to the nutrition of fowls. Another method of testing beef scrap is to treat a small quantity with boiling water. If there is a putrid odor, indicating decomposition, the scraps should not be used."'

In the buying of this feed, attention should also be paid to the guaranteed analysis, as it varies widely, sometimes running as low as 20 per cent protein, and as high as 80 per cent.

1 Bureau of Animal Industry, Bulletin No. 56.

2 Jaffa, California Bulletin No. 164. ${ }^{3}$ West Virginia Bulletin No. 83. 
Meat scrap is the most generally used source of animal protein there is, though it is being somewhat displaced in some sections by the use of milk and milk by-products.

Stewart and Atwood report that when the same amount of protein was furnished by beef scrap, milk albumin, and fresh meat scrap, respectively, to three pens of twenty White Leghorns each, ten of which were pullets and ten hens, the hens receiving beef scrap laid 386 eggs in 120 days; the ones receiving milk albumin laid 228 eggs during the same period, while the hens receiving the fresh meat and ground bone laid 279 eggs.

This test began November 1 , and at the end of 120 days the pens were shifted so that the beef-scrap pen received the fresh meat, the milk-albumin pen received beef scrap, and the fresh-meat pen received milk albumin. During the 120day period following, the pen receiving fresh meat laid 947 eggs, the one receiving beef scrap 987 eggs, while the one receiving milk albumin laid 935 eggs.

Philips $^{1}$ reports results in which three pens of Leghorns were fed corn, wheat, oats, bran, and shorts in the same proportion. To the ration of pen No. 1 was added 10 per cent meat scraps. To pen No. 2 was added enough skim milk to equalize the amount of protein contained in the meat scrap of pen No. 1. He makes note of the fact that this was about all the milk the chickens would drink. In pen No. 3 no animal feed of any kind was given. As the result of two years' work, the following average egg production was secured:

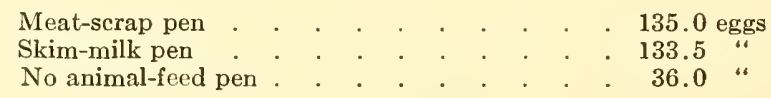

He further found ${ }^{2}$ that meat scrap at $\$ 2.50$ a hundred pounds was slightly cheaper than skim milk at 30 cents a hundred pounds when fed to Leghorns.

In later experiments ${ }^{3}$ with White Leghorns which were

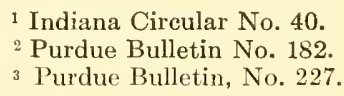


of better breeding as regards egg production, he found that when pullets were fed the same ration except that one contained 10 per cent meat scrap while the other contained no animal feed, the meat scrap fed pullets gave an average production of 179 eggs while the no animal feed birds gave an average production of 59.35 eggs.

It is sometimes claimed that liberal feeding of meat scrap injures the fertility of eggs, but so far no definite data on the matter has found its way into experimental reports.

The amounts of digestible nutrients found in 100 pounds of meat scrap of good quality, as determined by digestion experiments with chickens, are 65.9 pounds of protein, 13.01 pounds of fat, and 0 pounds of nitrogen-free extract. It contains 4.1 pounds of ash, and has a nutritive ratio of 1 to 0.44 for chickens. It contains no crude fiber.

Middlings (Wheat). - Wheat middlings are more finely ground than either bran or shorts, and run lower in crude fiber, ash, and protein, but higher in carbohydrates and fats. They are frequently only a good grade of shorts, but should more nearly approach low-grade flour. They will usually contain more gluten than most of the grain by-products, and because of their finely ground, heavy character, should be mixed with bulkier feeds.

The average amounts of the nutrients found in 100 pounds of wheat middlings are 10.7 pounds of water, 3.7 pounds of ash, 17.8 pounds of crude protein, 62.8 pounds of carbohydrates, of which 4.7 pounds are crude fiber, and 5 pounds are fat. The proportions of these digestible for chickens have not been determined. They contain less of the water soluble than bran.

Molasses.-Bittenbender and Lippincott ${ }^{1}$ found that when enough molasses was added to a basal ration of oat flour to form 10 per cent. of the solid portion of a milk-fattening ration, it increased the average gains slightly, though a little less feed was consumed. It did not appear to increase the palatability of the ration. The flavor of the fowls fattened on molasses was excellent (see Sugar, p. 347).

${ }^{1}$ Unpublished data, Iowa State College. 
Oil Meal (Linseed).- - In the extraction of linseed oil from flaxseed, the residue or cake that is left is ground and placed on the market as a stock food of considerable worth. There are two methods commonly used in extracting the oil, called the old and new processes, respectively.

In the old process the flaxseed is crushed, heated, placed in sacks, and the oil expressed by hydraulic pressure. In the new process the oil is extracted by washing the crushed and heated seed with naphtha, thus dissolving out the oil. The naphtha is then driven out by steam, the seeds dried, ground, and sold.

Old process (O. P.) meal is more valuable as a food because it contains a much larger percentage of fat than new process meal, and is also rich in protein. It makes a good feed for moulting hens, as its oil, being readily assimilated, assists in the formation of new feathers. It also has a beneficial physiological effect upon the digestive system and seems to aid in the assimilation of concentrated rations. Because of its laxative tendencies, however, it should not form over 10 per cent of the ration. It is undesirable for use in wet mashes because it tends to gum up the mash, making it difficult for the fowls to eat.

The average amounts of the nutrients found in 100 pounds of old process (O.P.) oil meal are 9.1 (9.6) pounds of water, 5.4 (5.6) pounds of ash, 33.9 (36.9) pounds of crude protein, 44.1 (45) pounds of carbohydrates, of which 8.4 (8.7) pounds are fiber, and 7.5 (2.9) pounds are fat. The figures in parentheses represent the amounts in the new process meal. Its vitamin content depends somewhat on the process of manufacture.

Red Dog Flour.-This is similar to middlings, but more nearly approaches the patent grades of flour. It is richer in gluten and has a wider nutritive ratio. It is a valuable feed when it can be secured at a reasonable price. Like middlings, it should be lightened up with some more bulky feed.

Shorts (Wheat).- Shorts are composed chiefly of the outer portions of the wheat kernel which lie nearer the starch than those which go to make up bran. It is practically fine bran mixed with low-grade flour. Shorts usually contain less 
fiber, protein, and ash and more carbohydrate and fat than bran. Very many markets do not distinguish between shorts and middlings.

The average amounts of the nutrients found in 100 pounds of wheat shorts are 10.5 pounds of water, 4.4 pounds of ash, 17.4 pounds of crude protein, 62.8 pounds of carbohydrates, of which 6 pounds are fiber, and 4.9 pounds are fat. The proportions of these digestible for chickens have not been determined. It contains less vitamin than bran.

Tankage.-Philips ${ }^{1}$ used common "digester" tankage in comparison with commercial meat serap in feeding White Leghorn pullets with excellent results. He replaced the meat scrap in the following ration with 3 pounds of tankage and secured an equally good egg production.

Grain.

10 pounds of corn

10 pounds of wheat

5 pounds of oats
MASH.

5 pounds of bran

5 pounds of shorts

4.5 pounds of meat serap

In practice the precise amount of tankage which should replace a given amount of meat serap will depend upon the protein content of each. In the work quoted the protein content of neither was given. It took about 5.4 pounds of feed to produce a dozen eggs when tankage was fed.

The average amounts of nutrients found in 100 pounds of tankage varies, but is on the average 7.5 pounds of water, 19.7 pounds of ash, 51.7 pounds of erude protein, 7.2 pounds of carbohydrates and 14.0 pound of fat.

Sugar.-Hartwell and Kirkpatrick ${ }^{2}$ found that the addition of sugar at rates varying from 20 to 100 grams for each quart of milk added to a mash made up of 5 parts corn meal, 1 part wheat bran, and $\frac{1}{2}$ part whole milk, and fed to Rhode Island Red chicks weighing 1.1 lbs., for two and three weeks, for the purpose of finishing them off as broilers, did not bring increased gains, nor an increased palatability, as shown by the amount of feed consumed. 
Wheat Bran.- Wheat bran is a by-product of flour manufacture and consists of the outer layer of the wheat kernel. It is one of the most popular means of adding bulk to the mash. Its chaffy character has seemed to make it particularly well suited for mixing with some of the heavier concentrates, as corn meal, oil meal, middlings, and gluten feed. It is also said to have a cooling effect upon the digestive tract and be slightly laxative in character due to the presence of phytic acid. It frequently forms 50 per cent of the constituents of a mash intended for mature stock and is just as frequently kept constantly before very young chicks without addition of other feedstuffs.

The only data as to its digestibility available represent three experiments by Bartlett ${ }^{1}$ which uniformly show a decidedly low digestibility of the organic matter. He further found that a mixture of equal parts of fine-cut clover and corn meal was sufficiently bulky to feed with concentrates and was more digestible and, for the East at least, a more economical feed than bran.

It may be that bran, like succulence, will continue to be fed for its physiological effect rather than its feed value. There is need of further light upon its exact value as a constituent for mashes.

The amounts of digestible nutrients found in 100 pounds of wheat bran as determined by digestion experiments with chickens are 11 pounds of protein, 1.48 pounds of fat, and 24.79 pounds of nitrogen-free extract. It contains 5.8 pounds of ash and has a nutritive ratio of 1 to 2.5 for chickens. The crude fiber content is 9.5 pounds. It is high in the water soluble but low in the fat soluble.

Succulence.-Regarding green feed, Jaffa ${ }^{2}$ remarks that it " must be considered from the stand-point of its medicinal or hygienic value rather than from the stand-point of nutrition. Some green stuff, like alfalfa and the legumes in general, possesses a much higher food value, but the more tender and succulent the green, the more it is enjoyed. Some green stuff should always be given as a separate feed where it is possible

1 Maine Bulletin No. 184.

${ }^{2}$ California Bulletin No. 164. 
to do so. Alfalfa meal, fed in the mash, does not take the place of a succulent feed. At the same time, it must be remembered that kale, cabbage, lettuce, etc., if fed beyond the amount necessary for hygienic or physiological purposes, become an expensive form of nourishment." Besides having a desirable effect on the digestive tract, it serves as an appetizer, adds variety to the ration, and tends to give a good color to the yolk, owing, according to Palmer and Kempster, ${ }^{1}$ to the xanthophyl the green feeds contain.

It now appears probable one of the reasons for its great desirability in the rations of both growing stock and layers, is that the green leaves of plants are a splendid source of fat soluble $\mathrm{A}$ which is deficient in the grains.

During the spring and summer months, fowls that run at large will find an abundance of succulence, and the problem of its supply arises only during the winter. A supply of succulence is distinctly a spring condition.

Alfalfa (Green).--It is frequently claimed by commercial egg men that green feed, and particularly alfalfa, is responsible for an undesirable condition in eggs which appears in the spring, known as "green whites," or "grass eggs." W. P. Wheeler ${ }^{2}$ states that, while the orange-yellow color of the yolk varied in intensity in direct proportion to the amount of clover hay and green alfalfa in the ration, the greenish color of the white also varied, but not so regularly.

At the Kansas Experiment Station, Maurer and Harris kept six Barred Plymouth Rock hens in an alfalfa field for several weeks. The eggs from half the hens were subjected to careful qualitative bacterial analysis. Although infection was frequent, no pigment-producing organisms could be isolated. Alternate eggs from the rest of the hens were kept for four weeks at room temperature and blood temperature respectively. They were then broken into a white porcelain dish and carefully examined for greenish discoloration. No grass eggs were found. Until further data on the subject is accumulated, no statement on the point is possible. ${ }^{3}$

${ }^{1}$ Journal of Biological Chemistry, vol. xxxix, No. 2.

2 Jordan's Feeding of Animals.

${ }^{3}$ A pigment-forming organism has recently been isolated from green whites by the Bureau of Chemistry. 
Alfalfa and clover are generally considered to furnish the very finest pasturage for fowls. Both are an excellent source of the vitamins. Cut alfalfa hay that is cured green furnishes an excellent temporary substitute for succulence when steamed.

Beets (Mangel Wurtzels).-Mangel wurtzel beets are among the most convenient forms of succulence for winter feeding, all things considered. They are easily and cheaply raised and are good keepers. They should not be fed in large quantities in the early fall, as they have a tendency to cause scours. In the winter they may be fed raw at about the rate of 25 pounds per 100 hens per day. A good way to feed them is to split them in halves lengthwise and stick on nails driven in the walls of the pen, about 18 inches from the floor, allowing the hens to pick at them. As mangels are practically 90 per cent water, they have a low feeding value except as a succulence. Their dry matter, however, contains a large percentage of ash. They are low in vitamins.

Cabbage.-Cabbage forms an excellent early green feed, but is more difficult to raise, keep, and has a lower feeding value than either beets or turnips. It is rich in water soluble B but deficient in the fat soluble.

Clover.--Simply as succulence, green clover is probably just as desirable as alfalfa, though it does not have quite as great feeding value. The need of supplying succulence usually arises in the winter, when green clover and alfalfa are not available. While they are highly desirable for pasture or for birds that are confined in bare yards, they cannot be considered among the forms of succulence for winter feeding as can cabbage, sprouted oats, and mangel beets.

Lettuce.-Lettuce is used chiefly to furnish succulence for brooder chicks in early spring, before other greenness is arailable, and is among the best plants for this purpose. It is a good source of the vitamins.

Onions.-Onions and onion tops are relished by both chicks and mature stock, and if fed occasionally give a welcome variety to the diet and are said to have a beneficial effect on the digestive system. Sliced onion is particularly valuable in "cheering up" a bunch of brooder chicks that 
have become listless and dumpish. When they once become acquainted with it, chicks will scrap and tussle over pieces of onion about as quickly and freely as over worms.

Care must be exercised, in feeding onion to laying stock, not to overdo the matter. If fed to excess to laying hens onions will impart their flavor to the eggs.

Pumpkins.-Pumpkins form a good feed for fall and early winter, but keep poorly.

Rape.-Rape can be planted in drills and, if not cut below the crown, may be gathered several times during the summer. It furnishes an excellent source of succulence for birds confined on bare lots.

Rye Pasture.-Because of its early greenness in the spring, rye is often planted in the fall. It is liable to cause scours if the fowls are allowed to eat too large quantities at first, but, if fed with caution, makes an excellent early source of succulence.

Silage.-Little is known concerning the value of silage in poultry feeding. Apparently, the fowls relish it and it seems to have no bad effects, unless it has been frozen or partially spoiled.

Sprouted Oats.-One of the increasingly common means of supplying succulence during the winter is sprouted oats. It should be recognized that sprouting only changes the form of the feed and does not increase the nutriment.

There are several ways of sprouting oats. The necessary conditions are warmth and moisture. They may be placed in a bucket or tub which is filled with water as warm as the hand can bear, and left over night. They may then be drained off and placed in racks as shown in Figure 173, being spread out until they are about an inch deep. If there is a good, warm furnace cellar with a cement floor available, they may be spread out on the floor. In either case they should be sprinkled with warm water daily.

In order to prevent mould, Rice and Rogers ${ }^{1}$ recommend that the oats be treated with formalin. "One pint of formalin should be added to thirty bushels of oats. The liquid should 
be sprinkled over the grain and thoroughly mixed with it. Success will depend largely upon the thoroughness of mixing. The pile of wet grain should be covered with blankets and

\section{FIG. 173}

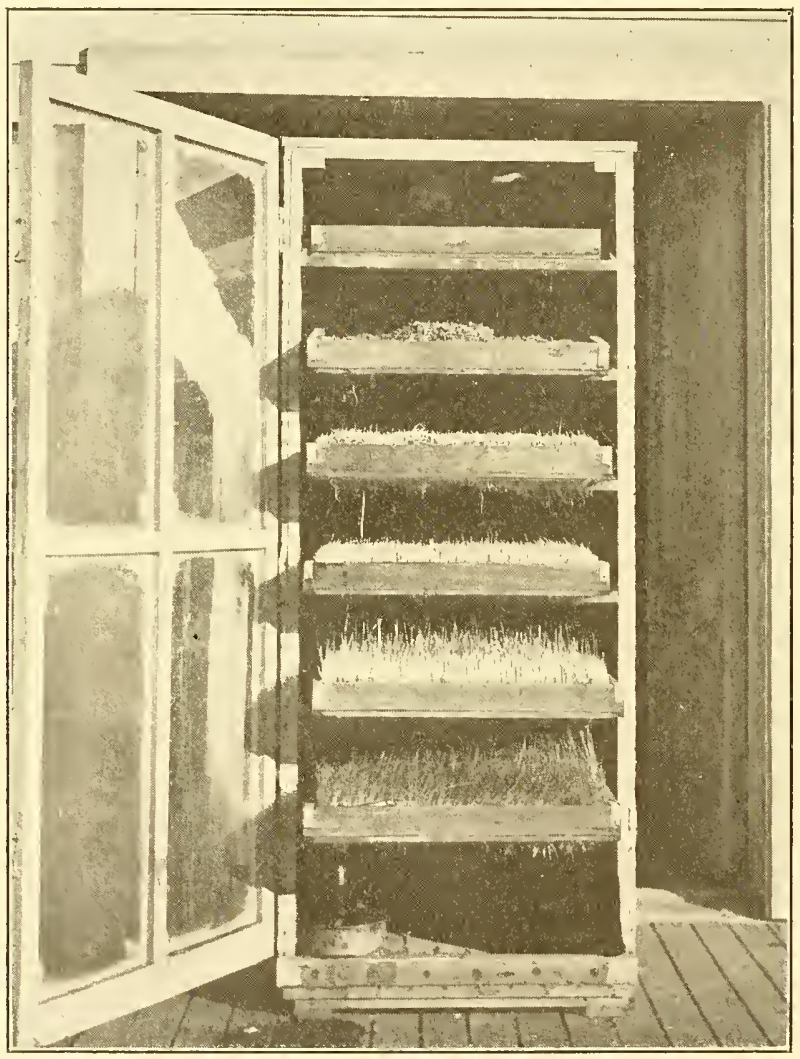

A homemade oat sprouter. (Courtesy of Kansas Agricultural Experiment Station.)

allowed to remain for twelve hours. The blankets should then be removed and the grain stirred twice a day until dry, requiring usually about two days. It should then be bagged 
in sacks which have been sprayed thoroughly with the formalin mixture each time they are used."

When the top sprouts are two or three inches long, the root sprouts will be found to have become closely interwoven so that the whole tray of oats may be picked up like a rug and thrown over the shoulder. Tear off as much for the birds as they will entirely clean up in twenty minutes to half an hour. Bartlett" states that "sprouted oats at the proper stage to feed will carry about 77 per cent of water, 2.8 per cent protein, 3 per cent crude fiber, 1.3 per cent fat, and 16 per cent nitrogen-free extract. There is an actual loss of dry matter in sprouting oats and the only advantage of the process is to produce a succulent green food at times when grass or other green foods are not available." It should be added that green sprouted oats undoubtedly supply both the fat and water solubles.

Turnips and Rutabagas.-While these are a good feed, they are not as good a source of succulence as mangels, because they do not yield so highly per acre, are poorer keepers, and if fed in excess may give a strong taste to the eggs. Also, cooking is necessary to make them palatable. They are useful, however, to feed in the fall, if enough mangels are not obtainable to last the entire winter.

Mineral Constituents.-Eight and six-tenths per cent of the dry matter of the fowl and 35.6 per cent of the dry matter of the whole egg are ash, or mineral matter. It can therefore be readily seen that it is necessary to supply mineral matter in a form that may be assimilated by the fowl, for the rapid upbuilding of the bones in the growing chick and the formation of shell on eggs. It is also necessary that mineral matter in a hard form not easily assimilable be furnished for the purpose of crushing and grinding the feed in the gizzard so that digestive juices may act upon it with ease.

Bone (Granulated).-The phosphate of lime is as desirable for the formation of bone in growing chicks as the carbonate of lime is in the ration of the laying hen for the formation of the egg shell. 
The customary form for furnishing it is granulated bone. This is a by-product of the packing-house and consists of animal bones, from which all the gristle and grease have been removed, ground to a suitable size varying from powder to the size of a grain of corn.

Rock phosphate (floats) has sometimes been urged as a more desirable source of phosphate than bone. H. J. Wheeler, ${ }^{1}$ and Hartwell and Kirkpatrick, ${ }^{2}$ both found that ground bone was a better source than the rock phosphate.

Bartlett ${ }^{3}$ found that the addition of 7 per cent bone ash to a ration consisting wholly of vegetable matter gave a slightly higher digestion coefficient than when the mixture was fed without it. Bolte ${ }^{4}$ reports that the addition of bone ash to a ration whose main source of protein was granulated milk markedly increased the efficiency of the ration.

Fine ground bone contains: ${ }^{5}$

Phosphoric acid

Lime .

Protein

20.22 per cent.
28.00 "“ ".
26.47 "

Bone (Green Cut).-Fresh bone trimmed from meats in butcher shops are run through a green bone cutter and used for feeding poultry. This is a palatable and nutritious food, containing a high percentage of ash in the bone and easily digestible proteids in the meat which clings to the bone, and is especially good for egg production. This food cannot be shipped or kept for any length of time before it spoils. Therefore it is usually prepared directly on the farm, or in the market for a local trade. Although fowls are more fond of meat in this form than any other, care should be taken not to feed an excess or any that is tainted in the least. When fed at the rate of one ounce per fowl every other day, no harm results and it is decidedly palatable. Too high a price should not be paid for this feed, however, as it contains but about 18 per cent protein and should be purchased on the protein basis, using first quality beef scrap as a standard. The Massachusetts Experiment Station ${ }^{6}$ report bowel

${ }^{1}$ New York Bulletin No. 242.

${ }^{3}$ Maine Bulletin No. 184.

${ }^{5}$ North Carolina Bulletin No. 211
${ }^{2}$ Rhode Island Bulletin No. 145.

4 Rhode Island Bulletin No. 126.

${ }^{6}$ Bulletin No. 122. 
trouble "among fowls receiving cut bone . . . . apparently due to the fact that in spite of the precaution taken to distribute it evenly some fowls occasionally secured more than their proper share."

Charcoal.-This is fed for its effect, and probably does not enter directly into the nutrition of the fowl. It is an intestinal corrective and should be kept before the fowls in a readily obtainable form at all times. It is sold commercially as granulated charcoal.

Grit.-The chief functions of grit are to prevent impaction in the gizzard and aid it in crushing food, although some of it may perhaps be assimilated. Its most desirable quality is hardness. If there is not an abundance of gravel where the birds may pick up pebbles, grit should be constantly supplied. Fowls prefer shiny particles of sparkling grit to that which is dull. Commercially, grit appears on the market under many names, but is made chiefly from crushed quartz, feldspar, phosphate rock, and granite. Oyster shell, which is very valuable as a source of ash, is not hard enough to serve as grit.

The size of grit must of necessity be regulated by the size of the stock fed. Commercially, it is usually offered as chick size, medium, and large size grit.

W. P. Wheeler ${ }^{1}$ found that mixing sand with the food of newly hatched chicks resulted in better health for the chicks and a more efficient use of food. He also found that ground oyster shell could not take the place of sand.

Salt.-Salt in some quantity is considered necessary to all farm animals. It adds palatability to the ration and is generally supposed to aid digestion. It should be fed with caution. Wheeler ${ }^{2}$ reports experiments in the feeding of salt in which he found no bad results until he reached a proportion of 6.3 ounces per 100 hens. At that point diarrhea appeared. This disappeared when the amount of salt was reduced one-third. He recommended salt at the rate of 5 ounces per 100 pounds of feed for mature stock, and that no salt be fed young stock until after they are two months old.

1 New York Bulletin No. 242.

${ }_{2}^{2}$ Twenty-sixth Annual Report, New York Experiment Station. 
Payne, ${ }^{1}$ however, notes that when salt was used interchangeably in four different mashes it did not appear to influence their palatability as indicated by the relative amounts consumed.

Shell (Oyster).-The necessity of a supply of lime or calcium for the formation of egg shells is shown by Wieke (as reported by H. J. Wheeler ${ }^{2}$ ) in the following analysis of egg shells:

Carbonate of lime .

Per cent.

Carbonate of magnesia

93.71

Phosphate of lime

1.39

Organic substance .

0.76

4.24

W. P. Wheeler ${ }^{3}$ found that where oyster shell was the only mineral feed given hens, aside from that contained in the grains, in one case 84 per cent, and in another over 88 per cent of the lime of the egg shell was unaccounted for by any feed given aside from the oyster shell. When broken glass was substituted for the oyster shell, fewer eggs were laid and the shells were thinner.

Card ${ }^{4}$ has shown that the correlation between the number of eggs laid and the amount of oyster shell consumed is very high $(.8724 \pm .0079)$. That is to say, the consumption of shell increased or decreased directly as egg production increased or decreased.

Oyster shell contains 95 per cent carbonate of lime. One pound of oyster shell contains lime enough for the shells of seven to eight dozen eggs. Like grit, shell should be fed in sizes to suit the size of the stock. Clam shell is not so highly esteemed by poultrymen as oyster shell. Hart and Halpin ${ }^{5}$ found that when the exact calcium equivalent was furnished from oyster shell and clam shell the former was considerably more efficient for egg production, and both were superior to lime rock, calcium carbonate and bone.

I Jour. Am. Assn. Inst. and Invest. in Poul. Husb., vol. iii, No. 3.

${ }^{2}$ Rhode Island Bulletin No. 84.

${ }^{3}$ Twenty-sixth Annual Report, New York Experiment Station.

${ }^{4}$ Jour. Am. Assn. Inst. and Invest. in Poul. Husb., vol. ii, No. 6.

5 Wisconsin Bulletin No. 319. 
The Liquids. - One of the marks of recent progress in feeding practice has been the increasing attention given to supplying all classes of stock with abundant and suitable drink.

Developments in connection with feeding under artificial lights have emphasized the necessity of having drink always a vailable, winter as well as summer, whenever the birds are off the perehes. The growing knowledge concerning the vitamins has given a further impetus to the use of milk as a regular feature of rations for growing, laying and breeding stock, as well as for fattening stock.

Mill. (Butter).-Buttermilk is similar to skim milk, but has a still higher feeding value. The amounts of digestible nutrients found in 100 ) pounds of buttermilk, as estimated from digestion experiments with skim milk with swine, are $3 . S 4$ pounds of protein, 1.05 pounds of fat, and 3.92 pounds of nitrogen-free extract. It contains 0.7 pounds of ash and has a nutritive ratio of 1 to 1.6 . It contains no crude fiber and an abundance of both vitamins. Dried and semi-dried buttermilk are finding their way into the market but their value for egg production has not been determined The semi-solid milk is used in large quantities at packing houses in milk fattening. What effect the process of manufacture has on the ritamin content has not been determined.

Milk (Skim).-Skim milk is being increasingly recognized as a valuable poultry feed. Philips ${ }^{1}$ reports that Leghorn pullets consumed an average of about 93 pounds of skim milk a year. This amounts to nearly 5 tons or 1171 gallons for each 100 hens. He further found that when all the milk the pullets would drink was added to a ration consisting entirely of grains, it was at 30 cents per hundred, slightly more expensive to feed than meat seraps at $\$ 2.50$ per hundred pounds.

In later experiments with White Plymouth Rock pullets he found the feeding value of skim milk to be $\$ 1.60$ per hundred pounds as compared with a meat serap value of $\$ 20.03$ per hundred pounds. Pullets fed on a standard 
ration with the animal protein supplied by skim milk gave an average production of 140.2 eggs, while pullets fed the same ration except that 50 pounds of milk was replaced by 3.5 pounds of meat scrap gave an average production of 135.9 eggs.

Anderson $^{1}$ found that the addition of skim milk to a ration increased the consumption of other feed. Nixon ${ }^{2}$ found that during the first eight weeks Leghorn chicks grew faster when sour skim milk was used for moistening the mash than when the mash was fed without milk. Sour skim milk was found to have no harmful effect on the chicks, even when fed from the first meal.

Milk may be fed either sweet or sour, but is to be preferred sour. Shaw ${ }^{3}$ reports that milk-sugar cannot be digested by young chicks, but that when this sugar is converted into lactic acid by the souring process it is digestible. "Our experiments show that not only is lactose not digested (by the chick), but it acts as an irritant to the gastro-intestinal tract." According to Rettger, Kirkpatrick, and Jones, ${ }^{4}$ "sour milk has a most favorable influence on growth and vigor" and "is an important agent in the reduction of mortality from all causes."

Thompson ${ }^{5}$ found that when two one-hundred bird lots of February hatched White Leghorn pullets were both fed a standard ration, but one pen had access to sour skim milk at all times, while the other did not, the sour milk lot laid 3661 more eggs in a year than did the no milk lot.

Kempster ${ }^{6}$ found that 100 pounds of sour skim milk took the place of 5.4 pounds of meat scrap in the ration, though unfortunately he does not mention the per cent of protein the meat scrap contained.

Milk may be used to moisten mashes, or given the fowls to drink. In the latter case particular care must be taken of the drinking vessels in warm weather. Unless the precaution of

${ }^{1}$ Indiana Bulletin No. 71.

${ }^{2}$ Cornell Bulletin No. 327.

${ }^{3}$ American Journal of Physiology, vol. xxx, No. 7.

${ }^{4}$ Storrs Bulletin No. 77.

b Jour. Am. Assn. Inst. and Invest. in Poul. Husb., vol. iii, No. 2.

${ }^{6}$ Missouri Bulletin, No. 155. 
frequent scalding is taken there will be an accumulation of solids which will putrify and are likely to cause such nervous troubles as limberneck, so-called, and the like.

The average amounts of the nutrients found in 100 pounds of skim milk are 90.1 pounds of water, 0.7 pound of ash, 3.8 pounds of crude protein, 5.2 pounds of carbohydrates and 0.2 pound of fat. The proportions of these which are digested by chickens have not been determined. It contains both of the vitamins, though not nearly so much of the fat soluble as does the whole milk.

Milk (Whey).-Whey is low in protein content because of the loss of the casein in the making of cheese. It is good for moistening mashes or as a drink. Its sugar content furnishes nourishment and its acidity aids digestion. Practically all the water soluble of milk is found in the whey.

Water.-This highly important part of all poultry rations has been discussed as a nutrient (see page 301). It must be further emphasized, that a suitable and constant supply of clean, cool water is essential to the best feeding practice. To provide water that is always clean and cool is a summer problem that must be met by the feeder's ingenuity if he is not so fortunate as to have running water available (see Figure 176).

In the northern and central states a constantly available supply of water during the winter also presents its problems. The recognition of its importance, however, is bringing into use water heaters of various styles so designed as to involve slight fire hazard and heat the water sufficiently to prevent its freezing in the coldest weather. 


\section{CHAPTER IX.}

\section{THE COMPOUNDING OF RATIONS.}

Definition of a Ration.-Technically, a ration is the feed consumed by a given number of birds in a specified time. The formula of a ration should include a statement of the kinds, proportions, and amounts of feeds included, the time being assumed to be twenty-four hours unless otherwise stated. In poultry feeding practice, the amount is so largely governed from day to day by the judgment of the feeder, based on the changing requirements of the birds themselves, that it is not customary to specify the amount to be fed in a given time, and a statement of the kinds and proportions of constituents fed, without regard to the amount, is referred to as a ration.

A Balanced Ration.-A balanced ration is a combination of feeds furnishing the vitamins, and the several mutrients in such proportion, amount, and form as will, withont exeess of any mutrient, properly nourish a given group of hirds for a specific time. ${ }^{1}$

\section{FEEDING STANDARDS.}

A feeding standard is a statement of the exact quantities and proportions of all the digestible mutrients necessary for a ration that is to serve a particular purpose. It differs from a balanced ration in that it does not specify the amount or kinds of feed from which the nutrients shall be secured and thus takes no arecount of the vitamins. IIaring a feeding standard as a basis from which to work and a knowledge of the feedstuffs available, inchuding not only the amounts of the digestible mutrients contained but their mutritive effect

1 Adapted from Henry and Morrison, Feeds and Feeding. ( 360$)$ 
as well, the feeder may compute a balanced ration, making due allowance for the vitamins.

There are two methods of calculating a feeding standard. One is by means of digestion trials and the other by dietary trials. Theoretically, the proper method is by means of digestion experiments. While this is possible for maintenance standards, it is not practicable for a standard for hens in full laying or for growing young stock. This is because the necessary technique employed in carrying on digestion experiments would greatly interfere with egg production or growth and so would defeat their purpose.

The method using dietary trials is the one to which poultry feeders must look for the present. By this method the efficiency of different rations for a given purpose is compared and the amounts and proportions of the digestible nutrients in the most efficient rations may then be taken as a standard.

The most complete standards to be had at present are those compiled by W. P. Wheeler at the New York Experiment Station. Unfortunately in the absence of specific data for poultry his calculations were of necessity based on coefficients of digestibility observed for other animals. These are therefore only approximations to a true standard. It will remain impossible to compile a true standard until very much more work has been done upon the establishing of the digestion coefficients of all the common poultry feeds, than has been done up to the present time. In the meantime the Wheeler standards will continue to be of great service in pointing toward the rational feeding of poultry.

Maintenance Standard.-A maintenance ration is one that furnishes a sufficiency of each and all of the several nutrients, but no more than is required to maintain a given bird that is not laying and is as nearly at rest as possible, so that it will not gain or lose in weight.

Because of the pronounced vitality, the very rapid breathing, the high body temperature, and the fact that the smaller the animal the greater is the surface area relative to bulk, and the greater the relative heat production, it might be expected that poultry would demand a relatively high consumption of carbohydrate. As a matter of fact, while 
fully nine-tenths of a maintenance ration of the larger farm animals may consist of carbohydrate, a somewhat less proportion prevails in the maintenance ration of chickens.

The fact that poultry "requires a much higher proportion of nutrients per unit body weight, presupposes their adaptability to concentrated feedstuffs, like the grains." 1

Table XXXIX.-Digestible Nutrients Required per Day for Each 100 Pounds Live Weight for Maintenance.

\begin{tabular}{|c|c|c|c|c|c|c|}
\hline & $\begin{array}{l}\text { Total dry } \\
\text { matter. }\end{array}$ & Ash. & Protein. & $\begin{array}{l}\text { Carbohy- } \\
\text { drates. }\end{array}$ & Fat. & $\begin{array}{l}\text { Nutritive } \\
\text { ratio. }\end{array}$ \\
\hline $\begin{array}{c}\text { Capons of } 9 \text { to } 12 \text { pounds } \\
\text { weight }\end{array}$ & 2.30 & .06 & .30 & 1.74 & .20 & 1 to 7.5 \\
\hline $\begin{array}{l}\text { Hens of } 5 \text { to } 7 \text { pounds } \\
\text { weight } \\
\text { Hens of } 3 \text { to } 5 \text { pounds }\end{array}$ & 2.70 & .10 & .40 & 2.00 & .20 & 1 to 6.2 \\
\hline weight.$\cdot$. & 3.90 & .15 & .50 & 2.95 & .30 & 1 to 7.4 \\
\hline
\end{tabular}

From feeding trials not covering any moulting period and during a time when egg production was suspended, W. P. Wheeler ${ }^{2}$ deduced the standards given in Table XXXIX and the tables following.

This data was taken from a total of 52 capons averaging by different lots from 9 to 12 pounds in weight and fed for 158 days, and from 69 hens ranging from 3 to 7 pounds and fed for 150 days.

"A ration which corresponds to the standard given for maintenance for hens of the larger size could be composed of 1 pound of cracked corn, 1 pound of corn meal, $\frac{1}{2}$ pound each of ground oats, wheat middlings and clover hay, $\frac{1}{4}$ pound fresh bone, and 10 ounces of beef scraps."'3

Standard for Growing Chicks.-As is to be expected, the proportions of protein and ash in a growing ration for chicks is even greater than that for a hen in full laying, because growth means the building of tissues, the development of vital organs, and the growth of feathers ${ }^{4}$ that are largely

${ }^{1}$ Brown, Bureau of Animal Industry, Bulletin No. 56.

2 W. P. Wheeler in Jordan's Feeding of Animals.

${ }^{3}$ Ibid.

4 Rice, Rogers and Nixon (Cornell Bulletin No. 258) found that growing chicks experienced at least four moults by the time they were old enough to lay. 
protein, and of bone, which is largely ash. Both are so important from the stand-point of growth that they are frequently referred to as "the growing nutrients."

As will be noted in Table XXXV, of the dry matter of the hen's body, about one-half is protein and 8 per cent is ash. As W. P. Wheeler suggests: "This of itself would suggest that a slow growth must follow the use of feeds containing small amounts of nitrogenous and mineral matter." The proper development of the bony skeleton of the chick is dependent upon an adequate supply of ash. If this supply is stinted, the chicks quickly show signs of stunting, which can never be entirely overcome.

Wheeler finds that the "requirements of rapidly growing young fowls are so constantly changing that a satisfactory average ration for any extended period cannot be formulated. In the following statement of rations for chicks they are averaged for periods of two weeks at different ages during the time of most rapid growth. The ration for the last period will suffice for several weeks longer, although the amount required per 100 pounds live weight will gradually diminish up to maturity."

Table XL.-Digestible Nutrients Required per Day for Each 100 Pounds Live Weight of Growing Chicks.

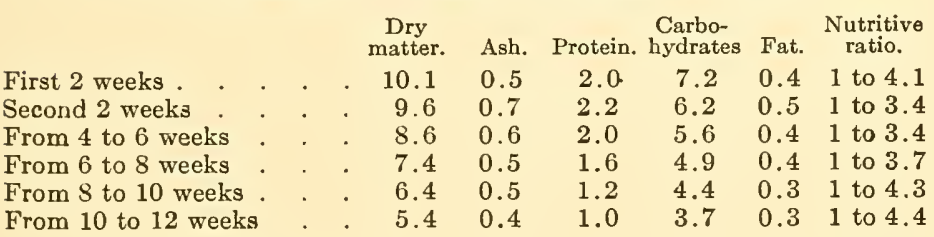

"As an example of a day's ration which would correspond to the requirements of the standard given for young chicks during the second week, the following is stated: Four pounds of cracked wheat, 2 pounds of granulated oat meal, 3 pounds of corn meal, $\frac{1}{2}$ pound each of wheat middlings, buckwheat middlings, ground oats and old-process linseed meal, $2 \frac{1}{4}$ pounds of animal meal, and $2 \frac{3}{4}$ pounds of young green alfalfa. 
This would feed from eight hundred to a thousand chicks of this age."

In practice it is not always practicable to vary the ration from week to week with the exactitude pointed out in the standard. The needs of the chick govern its appetite very largely, and if offered a variety of feeds it may be depended on to balance its own ration with fair accuracy.

Laying Standard.- "It is a physiological axiom that protein is a cell stimulant." It is to be expected therefore that growing. chicks and laying hens need considerably more digestible protein than the minimum that will barely maintain them. Because of the large amount of ash required for the manufacture of egg shell, the proportion of ash is also noticeably increased. The amounts and proportions of the nutrients for hens in full laying as computed by W. P. Wheeler ${ }^{2}$ are given in Table XLI:

Table Xli.-Digestible Nutrients Required per Day for Each 100 Pounds Live Weight of Hens in Full Laying.

$\begin{array}{lll}\text { Total dry } & & \text { Carbohy- } \\ \text { matter. } & \text { Ash. } & \text { Protein. } \\ \text { drates. } & \text { Fat. Nutritive } \\ \text { Pounds. Pounds. Pounds. Pounds. Pounds. ratio. }\end{array}$

Hens of 5 to 8 pounds

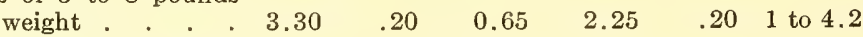

Hens of 3 to 5 pounds

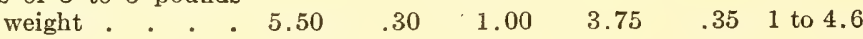

W. P. Wheeler ${ }^{3}$ has to say concerning these standards: "These standards are not absolute and inflexible rules, for such would not be justified by a thousand times the number of available data. They supply a starting point and do not bbviate the use of judgment. Because it is found convenient on account of different requirements and capabilities to divide hens into two groups, it should not be presumed that a hen just under five pounds in weight must always have one ration, or a hen just over five pounds must always have the other."

The following stated ration is given as an illustration of one which would supply the nutrients called for in the

${ }^{1}$ Henry and Morrison, Feeds and Feeding.

2 Jordan's Feeding of Animals.

3 Ibid. 
standard for laying hens of the larger size: One pound of cracked corn, $\frac{3}{4}$ pound of wheat, $\frac{3}{4}$ pound of corn meal, $\frac{1}{2}$ pound each of wheat middlings, buckwheat middlings, and animal meal, $\frac{2}{3}$ pound of fresh bone, and $\frac{3}{4}$ pound of young green alfalfa.

Computing Rations.-Rations are computed by trial, taking the standard feedstuffs as basal and balancing them with such feeds as will supply the deficiency of nutrients. By referring to Table XLI, it is found that hens in full laving and weighing between 3 and 5 pounds should be furnished with 0.3 pound ash, 1 pound of digestible protein, 3.75 pounds of digestible carbohydrates, and 0.35 pound of digestible fat for every 100 pounds of live weight. This has a nutritive ratio of 1 to 4.6 .

In an effort to formulate a ration giving the nutrients in proper proportions and amounts, as a trial ration, 3 pounds cracked corn, 1 pound wheat, 1 pound cornmeal, 1 pound oatmeal, 1 pound bran, and $\frac{1}{2}$ pound meat scrap may be taken. Upon reference to the proper Table LIII, it is found that this ration supplies the following amounts and proportions of the nutrients: Protein, 0.967 pound; carbohydrates, 4.03 pounds; fat, 0.321 pound, and ash, 0.175 pound, making the total dry matter 5.49 pounds. The nutritive ratio is found upon calculation to be 1 to 5.1 pounds.

Upon comparing this with the standard it will be noticed that there is a negligible deficiency in total dry matter and that the nutritive ratio is a little wide. In order to narrow the ration, the amount of meat scrap may be increased to 0.7 pound. It will then be found that the ration supplies the nutrients in approximately proper amounts and proportions, save for a deficiency in ash which may be made up by hopperfeeding, oyster shell or granulated bone. The vitamins may be supplied by an abundance of green feed.

\section{REQUIREMENTS OF A RATION.}

In the feeding of poultry we may regard the fowl as a physiological machine which manufactures eggs and meat. The ration is the raw material from which the desired product 
must be obtained. It must be prepared in accordance with the requirements of the desired product and the process of manufacture. If best results are to be obtained, other factors beside feeding, such as kindness, cleanliness, and the general comfort of the fowls must be considered and may be referred to as the care of the machine.

The requirements of a ration with the view of obtaining the greatest efficiency in production will be discussed under the following topics: (1) amount of feed, (2) feeding conditions, (3) size of ingredients, (4) palatability and attractiveness, (5) nutritive effect, (6) composition, (7) digestibility, (8) variety, (9) adaptation to purpose, (10) effect on product and (11) cost.

Amount of Feed.-It is readily understood that the amount of a ration may easily govern not only the amount of eggs produced or flesh put on, but may have an effect upon the general health of the bird. Eggs are formed and flesh produced from the feed fed in excess of that required for the mere maintenance of the body. If the amount of feed fed is sufficient for maintenance only, no products can be secured. If it is less than enough for maintenance, the bird will lose flesh and perhaps eventually die of starvation.

There are, on the other hand, dangers from overfeeding. If the ration is extremely palatable, a fowl may eat such an amount as to overtax the digestive organs. This may cause both a waste of nutrients and those ailments grouped under the head of indigestion.

While the high art of poultry feeding is to so encourage and stimulate the appetite of a flock that it will consume large amounts of feed, overfeeding is to be avoided with care. Of the two feeding errors, overfeeding or underfeeding, a little overfeeding is by far the most serious. It tends to make the fowls "go stale," depressing the appetite, and checking their activity.

No rule can or should be given as to the exact amount of feed to be given any certain class of poultry during a specified time. The amount offered should be that which the fowls will work industriously to secure until the last bit is gone. This applies to growing, laying or fattening stock. The 
proper amount is always just a little less than the fowls would like to consume. The ability to judge just what this amount is, comes from a study of the flock, and marks the skilful feeder.

It may appear that hopper feeding young stock on range or leaving dry mash available for laying stock, forms an exception to this rule. It must be noted that in each case the supply of the most palatable kinds of feed is limited. On range, the bugs and worms are so eagerly sought and at such an expenditure of exercise, that there is little danger of the chicks overeating of the hopper-fed grains, from the stand-points of amount and proportion. Only enough will be sought to satisfy the craving that is developed from the necessity of balancing up the ration of insects and worms, and furnishing energy for abundant exercise.

In hopper feeding dry mash to laying fowls, the same condition prevails. The hens prefer the whole or cracked grains to the finely ground mash, and usually eat only as much as is necessary to piece out the ration of whole grain, or to satisfy the craving for some ingredient of the mash, as meat scrap or salt.

Feeding Conditions.-Rettger, Kirkpatrick and Jones ${ }^{1}$ call attention to the fact that "with early hatched chicks that are confined in small quarters without an opportunity for an abundance of green food, fresh air and particularly exercise, . . one-half or less (of the regular proportion) of the protein concentrate should be incorporated in the ration when the chicks are supplied with all the milk they care to consume. In short, chicks grown in small quarters instead of on range, and on a 15 or 20 per cent meat ration in combination with an abundance of milk are likely to be literally grown off their feet, or, in other words, suffer with rickets or what is ordinarily called weak legs." Hart, Halpin and Steenbock, ${ }^{2}$ however, have since shown that certain forms of leg-weakness may very possibly be due to a deficiency of crude fiber in the ration (see page 370 ).

1 Storrs Bulletin No. 77

2 Journal of Biological Chemistry, vol, xliii, No. 2. 
Size of Ingredients. - The size of each particle of the ration must be such that it may be readily eaten by the fowl. Poultry generally seem to prefer the larger grains. It has been unquestionably proved by experiment and experience, however, that a hen will consume more feed and lay more eggs if a part of her ration is ground for her. This is perhaps owing to the fact that the alimentary tract can digest and assimilate more feed than the gizzard can grind.

It is owing to this, and the fact that protein may usually. be purchased more cheaply in the ground by-products of the grains than in the whole grains, that the custom of feeding mashes has grown up. It is possible to overdo the matter of giving ground grain, thereby failing to compel enough work of the gizzard to keep the digestive tract in good tone. The consensus of opinion at present seems to be that the proportion of two pounds of the whole and cracked grain to one of the ground is proper. The amount of mash eaten may be controlled by the amount of the more palatable whole and cracked grain given.

It is also customary to use cracked corn in the scratching feed for the purpose of making the birds scratch and hunt for more particles. Gowell ${ }^{1}$ found, however, in a test with 1000 pullets, lasting from November to April, during which half of them received cracked corn and half whole corn, that there was very little difference in actual results, the balance being slightly in favor of the birds receiving the whole corn.

Palatability and Attractiveness.-Palatability and high digestibility usually go together, as is noted by Brown, ${ }^{2}$ who holds that it "should be emphasized that in incorporating grains into poultry rations, the relative palatability should be correlated with the digestion coefficients." The amount of feed consumed depends quite largely upon its palatability. It is a safe rule to use very little or leave out of the ration entirely any ingredients that are not palatable where fed singly. Rye, cottonseed meal and blood meal are examples of unpalatable feeds. Jeffre ${ }^{3}$ found that pullets ate sparingly

1 Maine Bulletin No. 144.

2 Bureau of Animal Industry, Bulletin No. 56.

${ }^{3}$ North Carolina Bulletin No. 211. 
of a mash containing cottonseed meal and as a result were slower in developing and coming into laying, where it furnished the main source of protein, than when the protein was furnished by the more palatable meat scraps.

Grits are selected by fowls according to their attractiveness, those which shine and sparkle most being the ones chosen.

Nutritive Effect.-The nutritive effect of a feed or ration must be considered as well as the amount of the various digestive nutrients it contains. Linseed meal is a valuable source of vegetable protein, but if fed in a greater proportion than 10 per cent of the ration it is likely to be very laxative in its effect, or to impart an undesirable greenish cast to the color of the egg yolks. Winter rye offers a convenient source of early spring greenness, but it must be fed with caution at first, as it frequently causes digestive disorders.

Musty grain or tainted meat is likely to cause difficulty in the alimentary tract, which in young stock may be so serious as to cause heavy mortality.

Certain materials, as grit and charcoal, are not properly feeds, as they are not fed for the purpose of furnishing any of the nutrients. They are spoken of as feeds, however, because they are commonly fed to bring about certain nutritive effects. The function of the grit is to grind the feed, thereby increasing its digestion coefficient, while charcoal acts as an absorbent and as a corrective of intestinal disorders.

One of the most important feed constituents in this connection is crude fiber. While it has a very limited digestibility, a certain proportion is necessary in the ration. Its function is to dilute and open up the ration in the crop, gizzard, and intestines so that the secretions in these respective organs may have an opportunity to act. It serves to keep the intestine properly distended and aids in preventing constipation. If it was possible to feed fowls a ration that was wholly digestible, they would very probably die of acute constipation.

Hart. Halpin and Steenbock ${ }^{-1}$ have secured very suggestive results in feeding growing chicks in confinement on a synthetic

1 Journal of Biological Chemistry, vol. xliii, No. 2. 
diet which indicate that there may be a close relation between the crude fiber content of the ration and a chick malady called leg-тreakness (see page 511). The chicks in the several lots fed on various diets exhibited this trouble to a greater or lesser extent except the lot which was fed a ration containing 10 per cent of crude fiber in the form of finely ground paper. Just what relation this result bears to practical chick feeding it is too early to state. The lots fed were small and the number of lots was not large. Further work mill be awaited with interest.

Too much crude fiber in a ration is also disastrous. Gowell ${ }^{1}$ reports that hens that had been bedded with oat straw, and giving a 60 per cent egg yield, were suddenly reduced to a yield of less than 10 per cent by bedding the house down with oat hay cured green. The hens ate freely of the finer parts, which immediately caused acute digestive disorders. The hay was removed at once, but it was twenty days before the birds regained their normal production.

Cochel and Jackson ${ }^{2}$ found that rations carrying 3.5 per cent of the total weight in crude fiber gave better results for laying hens than those with lower or higher percentages. Fowls were kept in fairly good condition on a ration carrying 5 per cent of crude fiber, but showed a decreased egg yield. Serious intestinal disorders occurred when a ration carrying over 5 per cent was fed.

They further found that fowls did not seem to make any appreciable use of coarse floor litter to supply a deficiency in the fiber content of a ration; that the amount of succulence consumed was governed to some extent by the proportion of crude fiber in a ration, and that fowls with unlimited alfalfa or bran will make up rations carrying approximately 3.5 per cent of crude fiber.

Composition.- If the best results are to be obtained from feeding, the ration must be complete and properly balanced. If the ration is improperly balanced with regard to the proportions of the nutrients, the fowl is compelled to consume a larger amount of one nutrient to secure the necessary 
amount of others. So, in an extremely wide ration, a fowl is compelled to consume more carbohydrates than its body requires in order that it may obtain the vital amounts of protein.

Securing the proper composition not only refers to the proper nutritive ratio, regarding the nitrogenous and nonnitrogenous nutrients, but also the completeness and proper balance between grain, animal food, succulence, ash, grit, charcoal, bone or any other material that may be fed. A ration is balanced when it contains all the nutrients in right proportions. It is complete when it contains, in addition to the nutrients, every material that may produce a desirable nutritive effect.

Digestibility. - The digestibility of feeds has been fully treated elsewhere in another connection. In feeding practice it is necessary to fully appreciate its importance in relation to cost, the need of guarding against too much bulk on the one hand and too great concentration on the other. A ration composed wholly of mangel beets (90 per cent water) and chopped oat straw might have a nutritive ratio that was approximately correct, but it would be so bulky and so lacking in available nutrients that enough energy could not be secured from it to carry on the work of digestion.

On the other hand, a ration composed entirely of corn and meat scraps would contain so small an amount of bulky material that the intestines would not be sufficiently distended to allow for thorough digestion and prevent constipation.

Between two feeds having the same composition and costing the same, the one having the highest digestion coefficient is the more profitable to feed. While the exact situation is not met in actual practice, the principle involved is met and must constantly be considered.

Variety.-Variety is one of the spring conditions responsible for the increased production of that season. There is not only grain, animal feed, and green feed in abundance, but there are very many kinds of each. Aside from the cultivated grains, there are many seeds from the weeds and grasses, there are hundreds of kinds of insects and worms and nearly as many different kinds of tender greenness. 
In formulating the ration, not one, but several kinds of both whole and ground grains and as many sorts of animal food and greenness should be furnished as possible. Variety stimulates the appetite and offers an opportunity for the fowl to exercise some choice in the selection of the ration. It also makes likely a supply of the vitamins so far recognized and perhaps others not yet discovered.

Philips ${ }^{1}$ reports observations upon the feeding habits of hens, wherein he found in feeding a grain ration containing corn, oats, and wheat, that certain hens preferred corn to the exclusion of the other grains, others preferred wheat, while still others showed a marked preference for oats. If any one of the grains had been fed to the exclusion of the others, even though properly balanced with a mash, the birds would not have been quite satisfied and production would probably have been lessened.

Adaptation to Purpose.-There is usually one of four productive purposes in view in feeding. These are (1) laying, (2) fattening, (3) growing, and (4) breeding. In addition to these, there are the factors of age, class, and species to consider. The most characteristic differences between rations formulated for these respective purposes are as follows: An egg ration is composed, in addition to grit, shell, charcoal, bone and water, which are before the fowls at all times for all purposes except fattening, of whole or cracked grains and mash mixtures. A laying ration should have a nutritive ratio between 1 to 4 and 1 to 5 , the lighter hens requiring a proportion coming nearer to the latter and heavier hens coming nearer to the former ratio.

A fattening ration is usually composed entirely of finely ground grains or grain by-products, mixed with buttermilk or skim milk to a consistency of a porridge. Wheeler ${ }^{2}$ suggests a nutritive ratio of 1 to 8 as proper for a fattening ration for mature fowls. Bittenbender and Lippincott ${ }^{3}$ found a ratio of 1 to 6.3 gave better gains than any narrower ratio, while Lee $^{4}$ reports that in commercial establishments and packing

1 Kansas Bulletin No. 164.

2 Jordan's Feeding of Animals.

${ }^{3}$ Unpublished data, Iowa State College.

${ }^{4}$ Bureau of Animal Industry, Bulletin No. 146. 
plants where fattening is carried on on a large scale, rations having a nutritive ratio of 1 to 6.2 gave the best results. In both cases, however, the birds were young and still growing.

The fattening ration is made up entirely of ground grains and milk, because it is desirable that the ration be of condition consistency and palatability to be consumed, digested, and assimilated rapidly and in large quantities. This is because the fattening period rarely lasts over three weeks, and usually not over two.

A growing ration for young chicks is similar to a laying ration, save that the ingredients are smaller and the proportion of both ash and protein is greater.

The breeding ration is frequently exactly the same as the laying ration. Many poultrymen, however, hold the view that the fertility of eggs and the vitality of offspring are injured by encouraging the laying of large numbers of eggs by feeding a narrow ration, and prefer to widen it somewhat for feeding breeding birds. This view appears to be borne out by experimental evidence. Others feed only whole grain, so that the birds will be kept in good trim by plenty of internal exercise in grinding the grains, as well as by the usual exercise in scratching for them.

Effect on Product.-Certain feeds have an undesirable effect on the flavor of the eggs and flesh of fowls, that are at the same time nutritious, palatable, and healthful. Onions, rape, turnips and fish scrap, if fed in excess, impart a strong taste to eggs, but otherwise are excellent feed.

Green feed and yellow corn help to give the rich goldenyellow color which is so desirable in the yolk, while excessive amounts of linseed meal impart a green color to the yolks. Beets give the yolks a pale color. Waite ${ }^{1}$ found that yellow corn, when composing three-sevenths of a ration, gave a very deep yellow to the yolk of the resulting eggs. When it formed three-elevenths of the ration, it gave a noticeable yellow tint, but not as rich a yellow as is desired.

Wheat, when forming the same proportions as above, gave no yellow color to the egg yolks, and white corn gave no 
better results. The balance of the ration was in each case the same.

In fattening experiments, Bittenbender and Lippincott ${ }^{\prime}$ found that when meat scraps formed 25 per cent of the finely ground portion of a fattening ration, it imparted a distinctly strong flavor to the flesh of the fowls, as compared with birds fattened on oat flour and gluten feed.

It is because of the effect of their food that wild ducks have the characteristic "gamey" flavor that is conspicuously absent in the same species when domesticated.

Bushnell and Maurer ${ }^{2}$ found that there was a marked increase in the bacterial infection of eggs laid by hens when fed a wet mash, as compared with a dry mash.

FIG. 174

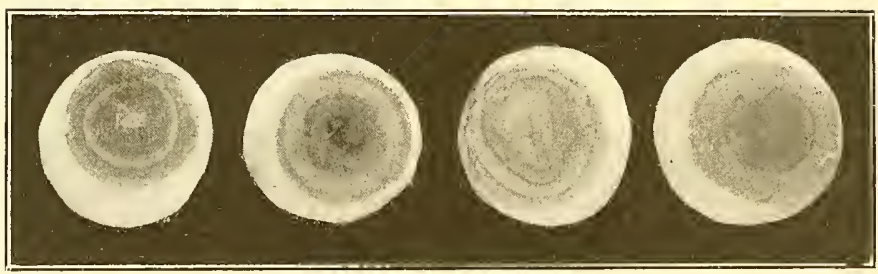

Showing effect on the egg yolk of feeding a fat stain (Sudan III) to laying hens.

Cost.-A very important factor in any ration is its cost. The best ration, all things considered, is the one which gives the greatest economic returns. This does not mean either the greatest returns or the cheapest ration. The greatest returns might be obtained only from a ration that cost more than the product is worth, and the cheapest ration might result in such limited production that it would be as unprofitable as the most expensive ration. To find the most profitable means between these two unprofitable extremes is the nice problem which confronts every practical feeder.

It is customary to rate feeds on the basis of their digestible protein content, because protein is an essential nutrient for

I Unpublished data, Iowa State College.

2 Unpublished data, Kansas Agricultural Experiment Station. 
Table Xlit.-Feed Cost of a Dozen Eggs at Varying Prices OF FEEDS.

Price per
pound of

fecd.

$\$ 0.010$

0.015

0.020

0.025

0.030

0.035

0.040 .

0.045 .

0.050 .

0.055 .

0.060
Pounds of feed consumed per dozen eggs produeed.

$\left\{\begin{array}{l}6.0^{1} \\ 7.5^{2} \\ 9.0^{3}\end{array}\right.$

60

7.5

9.0

6.0

7.5

9.0

6.0

7.5

9.0

6.0

7. 5

9.0

6.0

7.5

9.0

6.0

7. 5

9.0

6.0

7.5

9.0

6.0

$\{7.5$

9.0

6.0

7.5

9.0

6.0

7. 5

9.0
Cost per

dozen

eggs.

$\$ 0.06$

0.075

0.09

0.09

0.1125

0.135

0.12

0.15

0.18

0.15

0.1875

0.225

0.18

0.225

0.27

0.21

0.2625

0.315

0.24

0.30

0.36

0. 27

0.3375

0.405

0.30

0.375

0.45

0.33

0. 4125

0.495

0.36

0.45

0.54

1 The amount of feed necessary to produce one dozen eggs by Leghorns whose average normal production was $155.5 \mathrm{eggs}$.

2 The amount of feed necessary to produce one dozen eggs by American breeds whose average production was about 142 eggs.

3 The amount of feed necessary to produce one dozen eggs on commercial farms whose stock was about 94 per cent Leghorns and whose average production was 109 eggs. 
all rations and is the most expensive. This classification holds only to a limited extent on the market. The feeds containing the most digestible protein are ordinarily comparatively high in price, but the prices are not always in exact proportion to the protein content. Therefore protein may be cheaper from one source than from another.

It frequently becomes advisable in practice to vary the nutritive ratio of a ration in order to use larger amounts of a cheap feed. While this may be done without serious results, care should be taken that too great a deviation is not made from the accepted ratio, and a return to the correct ratio should be made as soon as the prices of feeds will permit.

The feed cost of a dozen eggs with feed at varying prices is shown in Table XLII, page 375. This table was calculated from the data of Kirkpatrick and $\mathrm{Card}^{1}$ and of App, Waller and Lewis'2 (see page 380).

1 Storrs Bulletin, No. 82.

2 New Jersey Bulletin, No. 329. 


\section{CHAPTER X. \\ FEEDING PRACTICES AND APPLIANCES.}

\section{FEEDING PRACTICE.}

Basis of Feeding Practice.-There is no other class of live stock that surpasses poultry in the difficulty of successful feeding. With the larger animals, and particularly the dairy cow, with which the laying hen is most nearly comparable, the individual may be dealt with, and individual tastes and peculiarities catered to.

FIG. 175

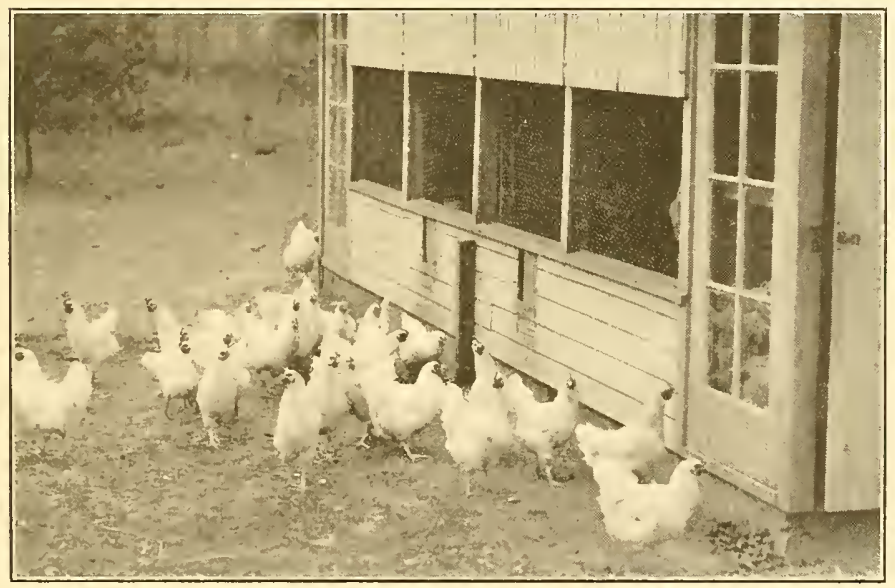

The foundation of an efficient feeding practice is a uniform flock. (Courtesy of Purdue Agricultural Experiment Station.)

With poultry, the value of the product of a single individual is not sufficient to warrant individual care and attention. The best that can be done is to build up feeding practices that meet the requirements of the average hen. 
In order to make such practices really efficient, however, it is necessary to have every hen in the flock approximate fairly closely the average hen. It means little to feed the average hen intelligently if the extremes on either side of the average vary from the Mediterranean to the Asiatic type, as is frequently the case in mongrel flocks. The first step toward making a rational and efficient feeding practice possible is building the foundation for a uniform flock $b_{y}$ grading or by establishing a pure-bred flock.

The Feeding Problem.- "Skill in feeding is the art of stimulating the appetite." The factors which enter into the problem of inciting the fowls to a large consumption of feed include (1) variety, and (2) palatability which have received a full discussion elsewhere. The further factors which have to do directly with feeding practice are (3) regularity, (4) compelling of exercise, and (5) gauging the amount to be fed.

Regularity.-Fowls of all sorts are highly responsive to regularity in feeding. Where regular feeding hours are kept the birds will usually congregate at the place of feeding shortly before feeding time and wait quietly for the appearance of the feeder. In the event of his non-appearance at the usual time the birds begin to become irritated and fretful. Such a condition long continued or occurring with frequency, in common with all sources of discomfort, causes a more or less noticeable lessening in the consumption of feed and a corresponding loss in production.

Exercise-Good feeding practice requires the encouragement of a generous amount of vigorous exercise as an accompaniment of the ration for all purposes save maintenance and fattening. As feeding for a bare maintenance is seldom desirable in practice it may be said that the compelling of exercise is a part of the feeding routine with all classes of stock except that which is being fattened.

Stock on range during the spring and summer will need little encouragement in this line. The eager desire for insects, worms, and tender greenness will keep any but the heaviest and most inactive breeds hunting and scratching quite constantly. 
During the winter, or with stock that is somewhat closely confined it is usually necessary to compel exercise by forcing the fowls to scratch for all whole or cracked grain in a deep litter of straw or some similar material. Plenty of exercise is distinctly a spring condition and should be required in abundance save in hot weather, if the digestive and reproductive organs are to be kept in good tone.

The Amount of Feed.-While ability to so stimulate the appetite that birds of all classes will consume large amounts of feed with relish is the feeder's greatesst virtue, overfeeding is his greatest failing. Nothing will more quickly defeat the very purpose of feeding, in contrast to allowing the fowls to feed themselves, than habitually offering more feed than the fowls are keen to consume. The difference between "just enough" and "a little too much" is a cloyed appetite and a listlessness that foretells a limited performance at the nest or small gains in the crate.

The amount of feed offered to any class of birds, for whatever purpose, must be governed by the judgment of the feeder, based on the size and disposition of the fowls and the amount of feed they are picking up about the farm.

The fact should not be overlooked that the crop capacity of the hen is insufficient to supply through the long winter nights the feed necessary for heavy egg production. It is perfectly possible to overfeed during the day and underfeed during the night. Both practices limit production. The derelopment of the use of lights to lengthen the feeding day and shorten the night is overcoming the latter difficulty but the former must still depend upon the skill and judgment of the feeder.

As a basis for estimating production costs or for purchasing feeds the following records will be found useful.

Gowell reports that the amount of feed consumed per hen in twelve months by a flock of Barred Plymouth Rocks averaging 144 eggs each was:

Grain and mash

Oyster shell

90.0 pounds

Dry cracked bone

4.0 " "

Grit .

Charcoal

2,4 "

2.0 “"

2.4 “

Clover

10.0 " 
He further reports that 2000 pullets of the same breed were raised to laying age with an average consumption of:

$\begin{array}{rll}28 & \text { pounds of grain and mash } \\ \frac{3}{4} & \text { “" } & \text { granulated bone } \\ 2 \frac{1}{2} & \text { " } & \text { oyster shell } \\ 2 \frac{1}{4} & \text { " } & \text { grit } \\ \frac{1}{2} & & \text { charcoal }\end{array}$

At the third annual international egg-laying contest Kirkpatrick and Card ${ }^{1}$ found that the average feed consumption of 380 Plymouth Rock, Rhode Island Red, and Wyandotte females for one year, when the average egg production was a trifle under 142 eggs, was 88.34 pounds of grain and mash. On this basis it took 7.5 pounds of feed to produce a dozen eggs. During the same period the average consumption of 330 Leghorn females whose average production was 155.5 eggs, was 76.8 pounds of grain and mash, the amount of feed per dozen eggs being approximately 6 pounds.

App, Waller and Lewis ${ }^{2}$ found that on commercial poultry farms in New Jersey, where Leghorns composed 94.3 per cent of the stock and the average annual production was 109 eggs, the average ammual feed consumption, not including green feed, was $\$ 2.97$ pounds per head. This approximates 9 pounds of feed for each dozen eggs produced. The amount of feed necessary for the production of a dozen eggs varies with the class of stock and the rate of production.

Wet and Dry Feeding.-The relative merits of wetting all or a part of the feed and of feeding it all dry are points upon which skilled poultrymen are not agreed. The experimental evidence at hand leans rather favorably toward dry feeding (see page 324) with regard to both results and labor, except under conditions hereinafter mentioned.

Hopper-feeding Dry Mash.-One of the great advantages of dry mash is that it may be hopper fed. Aside from the lessening of labor there is a great advantage in the avoidance of mobbing which always occurs when a wet mash is fed in a tray or trough. The weaker and more timid hens are likely

${ }^{1}$ Storrs Bulletin No. 82

${ }^{2}$ New Jersey Bulletin, No, 329 
to be abused or crowded out so that they fail to get their share and frequently go hungry, while the more vigorous fowls gorge themselves. Where the mash is hopper fed there is opportunity for all birds to eat all they desire. At the same time there is not the same likelihood of overeating on the part of some individuals, found with wet-mash feeding, because of the fact that the fowls prefer the whole grain of the seratching ration and will eat only as much of the dry mash as they need to satisfy their appetite. This affords a basis of control of the amount of dry mash consumed that is fully as effective as the daily measuring out of the portion of the wet mash to be offered.

Wet-mash Feeding.-Many poultrymen prefer moistening the mash with water to feeding it dry. This practice is not to be recommended except under circumstances that warrant a considerable increase in labor for small and doubtful increase in production. Apparently the only advantage in wetting mash comes by inereasing its palatability. 'The resulting increase in production is not ordinarily commensurate with the labor involved in wetting up the feed at each feeding, spreading it upon the feeding trays, and cleaning the trays from time to time in warm weather.

As pointed out previously (see page 374), wet mash increases the number of infected eggs when fed to laying hens, and is generally supposed to predispose the stock to bowel trouble somewhat.

Mairs ${ }^{1}$ found that chicks under one pound in weight seemed to grow faster on a wet mash, while those weighing a pound and a half or more made faster growth on dry feed. The loss of chicks, however, was much greater among those fed wet mash than among those receiving only dry feed, even when weighing less than one pound.

Lewis $^{2}$ found that for little chicks a wet-mash system of feeding produced a greater gain in weight than a ration that was wholly dry. This gain, however, was more than offiset by the increased mortality of the chicks fed the wet mash.

Where wet mash is fed for any purpose except fattening,

1 l'ennsylvania Bulletin No. 87.

${ }^{2}$ New Jersey Experiment Station, Thirty-second Anmual Report. 
it should be moistened only enough to render it erumbly. Sloppiness should be consistently avoided.

Feeding Little Chicks. - Chicks should not be fed for from thirty-six to forty-eight lours after hatehing. 'The exact time will be determined by the ehicks ealling so lustily as to leave no uncertainty about their being hungry.

It has been found that when feeding is somewhat delayed the yolk material which is taken into the borly just prior to hatehing is more quickly and satisfactorily absorbed. It is the linet that the yolk furnishes an ample supply of feed for two to three days after hatching that makes possible the practice of shipping baby chicks. 'Tongl (as reported by lask') found that "4S per (ent of the original energy in the egre is largely found in the abdomen of the chick" and is absorbed by the intestine during the early days of life. Before griving any grains the chicks should be provided with dean fresh water that is not too cold, hone meal, and clean sand or very fine grit. Grit, bone, and charcoal should be before them at all times thereafter.

When regular feeding begins, frequeney of lecding is an essential of good practice. 'This is particularly true in tie ('ase of artificially brooled chicks which do not have the hen to hunt: up their feed for them bit by bit and keep them interested. Little and often should be the rule, with periods of not longer than three hours elapsing between feeds.

Successful poultrymen difler as to the advisability of feeding moistened feed to chicks, as well as to laying hens, thongh the number that prefer the dry leeds seems to be increasing.

"A solt feed of" dried bread-crumbs soaked in milk is very nomishing and supplies all the elements essential to growth, but is open to the eriticism of being solter than the food supplied by mature. A mixture of hard-boiled egrg chopped tine, shell and all, and mixed with four to six times its bulk of dricel erumbs or rolled oats (one cog to 100 chicks) secms a little nearer to the natural diet of bugs and seeds. 
This ean be supplemented by milk to drink by those: who aul obtain it at at suitable mice."

As soon as possible the rhicks shomld be gotten to scrateding for eracked grains, and exereise eneomraged in every possible way. At times when they appene a little listless they should be interested and livened mply smpplying something that they like very much and will sorap over, Angle: worms are the best thing for this purpose, hot are not always casily available. Lang pieces of onion made by slic-

liai. $171 i$

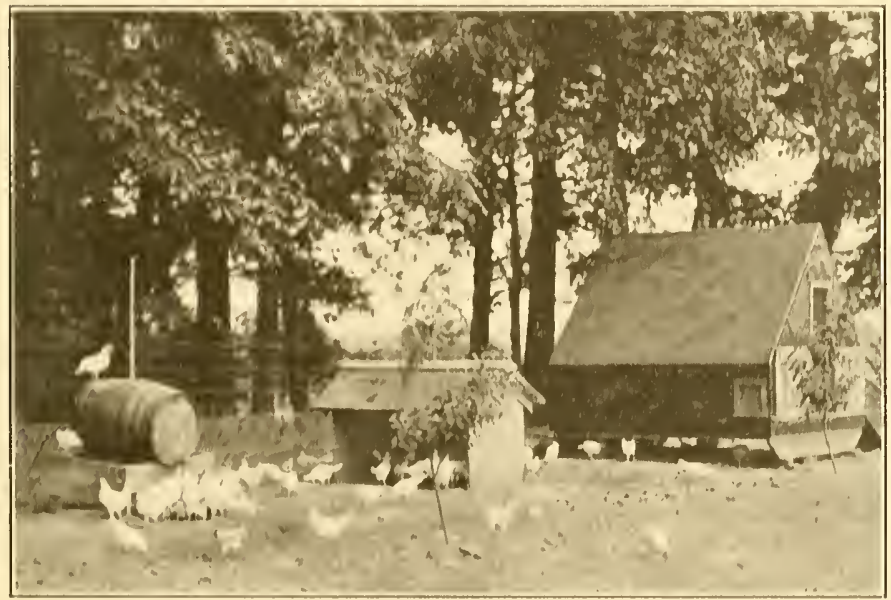

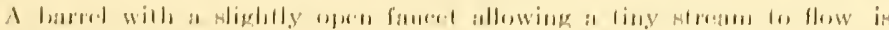

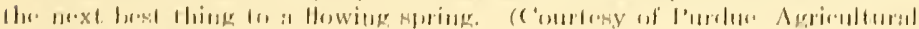
lix]mrinant Silation.)

ing the onions, separating and cutting the rings, will serve: nearly as well after the chicks becomes acerustomed to it. The skilled feeder is one who so foeds lis rhicks that they are constantly active and husy. Overleceling or infrequent leeding is likely to result in listlessmess or dumpishuess on the part of the entire flock, which should be resognized at once as a danger signal and some means of livenimg them up resorted to.

\footnotetext{
1 Jaffil, ('ulifornia liallerlin Nis. Itid.
} 
Chick Feeds Must be Sweet.-In feeding little chicks it is absolutely essential that the grains be perfectly free from mould or must and the meat scraps from taint. So important is this in newly hatched chicks that poultrymen frequently go to the expense of purchasing kiln-dried grain in order that they may be sure that it has not heated or moulded. A feeder should always take the precaution to bury the nose in a double handful of any grain intended for newly hatched youngsters in an effort to detect the slightest suggestion of sourness or mustiness. Meat scraps should also be carefully scrutinized for taint (see page 343). Only those feeds which are perfectly sweet may be fed without grave danger of a high death rate.

Chick Rations.-Philips ${ }^{1}$ reports excellent results from the ollowing ration for chicks:

\section{Grain.}

6 pounds eracked corn (sifted)

4 pounds cracked wheat

2 pounds "steel cut" oats
Mash.

2 pounds bran

2 pounds shorts

$\frac{1}{2}$ pound charcoal

All of the sour milk or buttermilk the chicks will drink.

All the green feed the chicks will consume. Grit and granulated bone before them all the time.

If milk is not available, $2 \frac{1}{2}$ pounds of fine meat scrap must be added to the mash. The milk, however, is very much preferred.

For chicks, as for old stock of whatever class, the drinking water should be plentiful, kept fresh and always contain enough permanganate of potassium to give it a rich wine color. The reason for doing the latter with all classes of stock is that it helps to keep in check intestinal parasites of various sorts, and is an excellent means of preventing the spread of such diseases as effect the nasal cavities, mouth and intestinal tract, through the drinking water.

The grain is fed in a litter from the first and the mash supplied in a suitable hopper when the birds are five to seven days old. If it is desirable to force the chicks rapidly, the proportion of mash may be increased. 
Jaffa ${ }^{1}$ recommends as a chick feed a mixture made up of the following material cracked or crushed until it is the size of a millet:

20 parts wheat

15 parts oats

5 parts millet

2 parts rice
6 parts corn

10 parts grit

5 parts charcoal

5 parts bone meal

FIG. 177

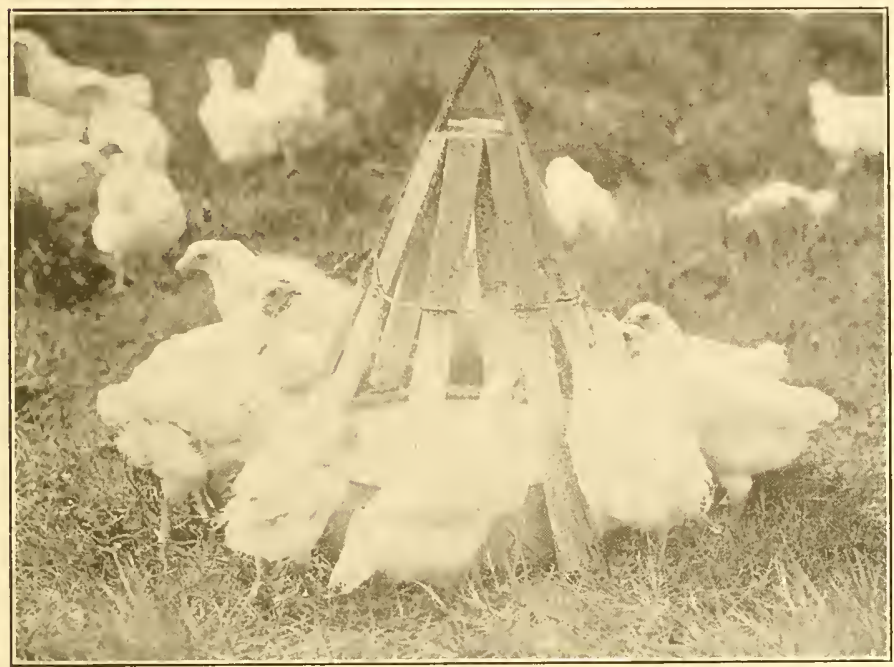

Chickens relish sour milk and thrive on it. (Courtesy of Purdue Agricultural Experiment Station.)

"The grit and charcoal are added to the chick feed, as the babies cannot at first be depended upon to visit the grit trough regularly, but the trough is placed in the run to teach them to acquire the habit for the future.

"Toward the end of the second week it will be well to add a little cracked wheat and steel-cut oats to the above mixture, gradually increasing the amount until it finally replaces the chick feed. Then begin gradually to add whole wheat to the cracked until at the end of the sixth or seventh week 
they are having only whole wheat and cracked corn. The steel-cut oats are too expensive for long use and the unprepared article is not safe on account of the husks.

"A mash may be used about the eighth to the tenth day. This may be fed dry or wet. By 'wet' is never meant a sloppy mass, but one which is just sufficiently moistened to make it adhere in lumps or appear crumbly. The difference of opinion in regard to the adrantages of these two mashes may be due to the fact that a careless feeder can produce bad results in his chicks by cramming them with mash that is soft and sloppr and handled with difficulty by the digestive apparatus. If moistened with skim milk the mash will be more palatable as well as more nourishing.

"The mash can be made from rarious materials, and the two presented below are offered as samples of many that may be equally good:

I.

3 parts bran
2 parts shorts
1 part coarse corn meal
1 part oat meal
3 part meat meal
3 part bone meal
3 part charcoal

3 parts bran

aparts shorts

1 part coarse corn meal

1. part oat meal

part meat mea

part bone meal

part charcoal

"One teaspoonful of salt should be added to each couple of gallons of this mixture. The meat meal and alfalfa meal should be sifted so that no coarse particles remain.

"The abore mixtures are suited to chicks that are from ten days to six weeks old. From this time to about the tenth week the meat meal should be gradually increased from one-quarter part to one-half part. From the tenth to fourteenth week another gradual increase should bring the meat meal up to one part in the above formula, which would then be the same as a formula for laving hens.

"The bone meal should also be increased. but more gradually, so that when the meat meal reaches one part the borre meal amounts to one-half part."

Card and hirkpatrick recommend the following: "On 


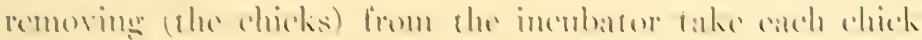

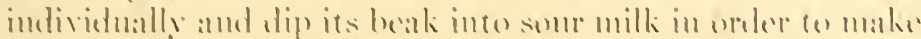
stme that milk is ghe tirst fond taken imo its ststem. be

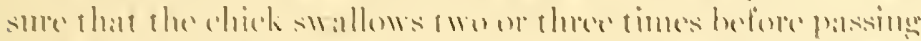

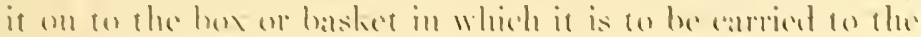
bronder.

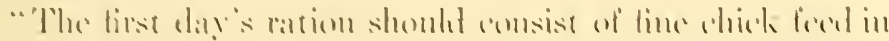

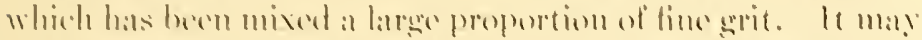

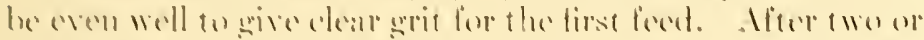

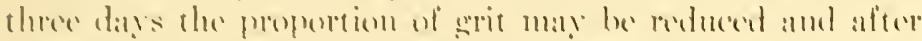
the first week it mas be heppere fod if desired.

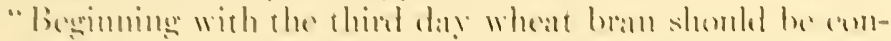

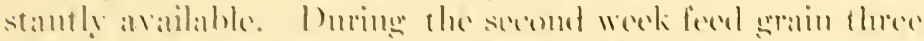

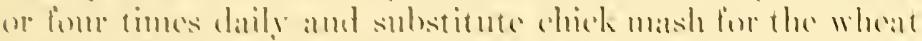

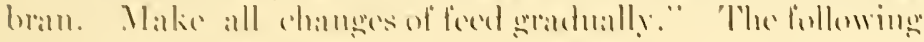
is the rittion.

\begin{tabular}{|c|c|c|c|c|}
\hline \multicolumn{2}{|l|}{ אוגוkו } & \multicolumn{3}{|l|}{ MINIII } \\
\hline ('rached whuset & lin mumuls & Whusil lorsul & $\because 11$ & (1111: \\
\hline 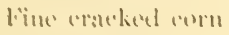 & 15 & Cirtu t11:sl & 10 & $\cdot \cdot$ \\
\hline l'inlust mals. & (1) & silfol sroumd onts. & 111 & " \\
\hline limken rices & $\ddot{3}$ & low-ersude \|lome & 10 & . \\
\hline Fise chancest & $\because$ & Mient :mel tish ser:up & 111 & $\cdot \cdot$ \\
\hline
\end{tabular}

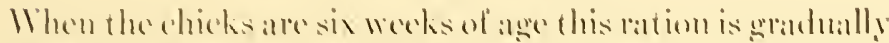

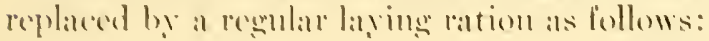

(ili)

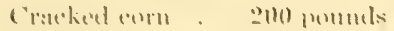

11 heil.

\begin{tabular}{|c|c|c|c|}
\hline \multicolumn{4}{|c|}{ M.1. } \\
\hline (') & & $(101)$ & muls \\
\hline 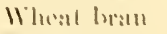 & & 1011 & $\cdots$ \\
\hline (irmutul usts & & $1(11)$ & $"$ \\
\hline Mlidulings & & 1001 & " \\
\hline Mlisil or lish & I:Ii) & 1011 & "* \\
\hline
\end{tabular}

Schoppe recommends as a first feed a mixture of "2 parts wheat bran and 1 part rolled oats fed in shallow tin pams. the bottoms of which have been sprinkled with line chick grit. 'The chicks are allowed to pick at this for abont ten minutes and then it is removed. For the first lew days they are fed fire times a day very sparingly. During the lirst week the mash is gradually chamged until it contans conal parts of bran and rolled oats.

1 Montana Agrieulural Colloge, in Poultry Life, Mrarch, 19) 13. 
On the second day a little fine-cracked grain is sprinkled into the litter. This may be made up as follows:

Parts by weight.

Fine-cracked wheat

Pinhead oats

10

Fine-screened cracked corn . . . . . . . . . 15

Fine-cracked peas . . . . . . . . . . . . 3

Broken rice . . . . . . . . . . . . 2

Chick grit (limestone) . . . . . . . . . 5

Fine charcoal (chick size) . . . . . . . . . . . 2

This grain mixture should be fed during the first three weeks, then gradually changed during the fourth week so that at the end of the week it will contain:

Parts by weight

Cracked corn

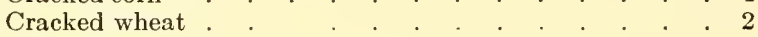

Pinhead oats . . . . . . . . . . . . . 1

The grains are cracked somewhat coarser than for the chick feed. This grain mixture is fed for the remainder of the summer.

During the second week the mash should contain a little corn meal, which is gradually increased, and later animal meal and Daisy flour are added, so that at the end of the second week it contains:

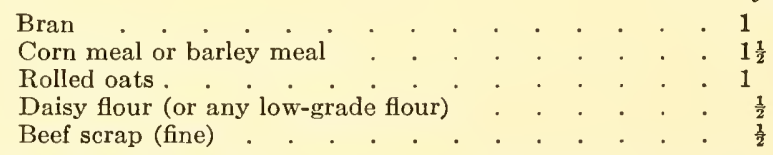

The chicks should be fed this about four times a day.

During the third week this mash is gradually changed by dropping out the rolled oats and adding gluten meal and increasing the other ingredients until it contains:

Parts by weight.

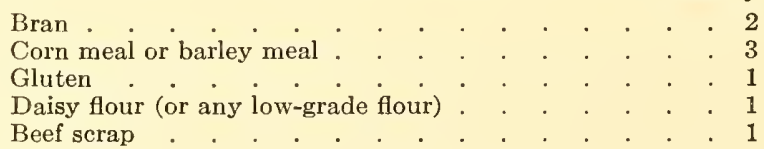

This mash is fed until the chicks are six to eight weeks old. It is kept in the hopper before the birds all the time, 
and they also have access to ground oats, fed from the hopper or flats.

After the eighth week the composition of the mash is varied to suit the needs of the birds, as indicated by their stage of development. This change is generally made by decreasing the proportion of gluten, as indicated:

Parts by weight.

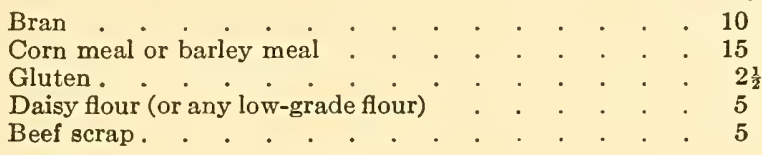

The mash is always fed dry.

During the first three weeks the tops of sprouted oats cut fine are furnished for succulence and from three weeks on rape or clover. Whenever the chicks show signs of diarrhea they are given some boiled rice at once and until the trouble disappears. As the result of somewhat extended feeding experiments Rice and Nixon ${ }^{1}$ recommend the following rations and methods of feeding:

The Ration

Mixture No. 1.

8 pounds rolled oats.

8 pounds bread-crumbs or cracker waste.

2 pounds sifted meat scrap (best grade).

1 pound bone meal.

Mixture No. 2.

3 pounds wheat (cracked). 2 pounds cracked corn (fine) 1 pound pinhead oatmeal

Mixture No. 3.

3 pounds wheat bran.

3 pounds corn meal.

3 pounds wheat middlings.

3 pounds meat scrap (best grade).

1 pound bone meal.
The Method

One to Five Days.

Mixture No. 1, moistened with sour skimmed milk, fed five times a day; Mixture No. 2 in shallow tray containing a little of No. 3 (dry) always before chicks. Shredded green food and fine grit and charcoal scattered over food.

Five Days to Two Weeks.

No. 2 in light litter twice a day; No. 3 moistened with sour skimmed milk, fed three times a day; No. 3 (dry) always available.

Two to Four Weeks.

As above, except that the moist mash is given twice a day.

${ }^{1}$ Cornell Bulletin No. 327. 
The Ration

Mixture No. 4.

3 pounds wheat (whole).

2 pounds cracked corn.

1 pound hulled oats.

Mixture No. 5.

3 pounds wheat.

3 pounds cracked corn.
The Method

Four to Six Weeks (until Chicks are on Range).

Reduce meals of moist mash to one a day; Mixture No. 4 in litter twice a day; dry mash always available.

Six Weeks to Maturity.

No. 3 and No. 5 hopper fed. One meal a day of moist mash if it is desired to hasten development.

\section{Further Directions.}

1. Provide fine grit, charcoal, shell, and bone from the start.

2. Give grass range or plenty of green food.

3. Have fresh, clean water always available.

4. Feed only sweet, wholesome foods.

5. Avoid damp and soiled litter.

6. Test all meat scrap before feeding.

7. Keep chickens active by allowing them to become hungry once daily.

8. Feed moist mash sparingly.

9. Keep dry mash always before the chicks.

Feeding Broilers.-When the young males are to be disposed of as broilers they are frequently forced a little more rapidly than the pullets or males intended for breeding purposes. The feeding of broilers may for convenience be divided into three periods: (1) growing, (2) forcing, and (3) fattening.

The growing period is generally about four weeks, its length varying somewhat with the breed, the time of hatching, and the size at which it is desirable to market them. The early-maturing breeds are usually forced somewhat earlier than the slower-growing kind.

During this growing period a regular growing ration is fed. It should be continued until the chicks have become well established physically and are well past the danger of the ordinary little chick ills.

The length of the forcing period is also variable and for the same reasons as the first period.

The forcing ration usually differs from the growing ration for chicks of the same age by carrying a larger proportion of protein which may be accomplished, as Philips suggests 
(see page 3St), by increasing the proportion of ground feed. The chicks must be watched carefully for any indication of digestive disorders which sometimes arise when the proportion of protein or of mash is made too great. If possible the increase in protein should be brought about by adding cottage cheese to the ration rather than by increasing the meat scraps. By doing this the ration may be made narrower without upsetting the digestion, than may usually be done with the aid of meat scraps.

During the fattening period the method and rations described under milk feeding may be used (see page 401). The fattening period for broilers is usually not longer than twelve days and is frequently limited to eight. The time of feeding depends somewhat upon how long the chicks "stand up" to the fattening ration without losing their appetite.

Where the broilers are not intended for private trade they should not be milk-fed but penned up and corn-fed for a period of two to three weeks. They will then be in good shape for the milk feeding at the packing house.

Developing Pullets.-It is not a wise practice to force pullets intended for egg production or breeding. In order to have them mature for winter laying they should be hatched early enough to allow them to reach their proper development normally and without forcing.

Any deviation from normal development tends to lessen vitality and reproductive powers. If a pullet is to stand up under the strain of being forced for heavy egg production after she begins to lay, or to produce vigorous offspring if she is a breeder, she should have the benefit of a normal development prior to that time. Mairs ${ }^{1}$ found that chicks forced when young did not make as rapid growth as they approached maturity as those fed a more moderate ration.

When the cockerels are taken out for forcing and finishing, the pullets should be moved to a grassy range where they can develop unmolested by male birds. The ration should be one to promote health, and calculated to produce substantial growth rather than particularly quick growth. 
It may be entirely honper fed, though most feeders will prefer to feed out of hand at least once a day in order to keep in touch with the progress of the stock.

The pullets should be left on range until they are beginning to lay, when they should be moved into their permanent laying quarters.

Developing Breeding Males.-The same principles and practices involved in developing pullets apply to breeding males. They should be kept separate from the pullets from the time they begin to show marked secondary sexual characteristics. The cockerels develop sexually earlier than the pullets do, and, unless they are separated, will worry the pullets to a degree that will seriously interfere with the proper development of the latter.

Routine in Feeding Layers Without Lights.-The details of feeding practice, like the constituents of a ration, vary with feeders and conditions. As there is no one best ration, so there is no feeding routine for chickens that is outstanding in its excellence. The following practice, which has proved successful in a large number of cases where lights were not used to lengthen the feeding day, is given as being suggestive of what a good routine may be:

Give a light feed of grain, soon after the birds leave the perch in the morning. This should be scattered in a deep litter of straw to every part of the pen so that the birds will be compelled to scratch vigorously for some hours in order to search it all out. Fresh water should be supplied in the morning.

At noon as much succulence as the birds will clean up in twenty minutes to half an hour should be supplied. Fresh water should be given and the dry mash hopper opened.

Two to three hours before the birds go to roost they should be given a full feed of grain thrown in the litter. It is essential to the best results that the birds go to roost with full crops, and this feeding should not be stinted. An examination of the crops of the birds should now and then be made after they are on the perch to ascertain whether they are well filled.

It is better to overdo the matter of evening feeding a 
little than to slight it. If a little grain is left in the litter it will be eagerly scratched out in the morning. Great care should be taken, however, to so feed that the straw is scratched absolutely free of grain at least once a day. In following this particular routine this should be the condition at noon. The really skilled feeder is the one who so handles the ration that he constantly piques the appetite of his fowls that they will consume large amounts of feed with relish, yet never gives quite all they would like to consume. As noted in other connections, of the two evils, "overfeeding" or "underfeeding" to a slight degree the latter is preferable. It limits production slightly, by not furnishing quite all the raw material that could be made over into a finished product, but it keeps the appetite keen and the body in good working order. Overfeeding, on the other hand, cloys the appetite and clogs the system, thereby limiting production even more than in the first case.

Unless the weather is quite cool, fresh water should be supplied at the time of the evening feeding. In freezing weather commercial water heaters should be used, or other means provided to keep the water from freezing. Water must be available whenever the birds can see to eat if the best production is expected.

Feeding with the Aid of Lights. - Rice ${ }^{1}$ has pointed out that for best results at the nest, the period between feeds should never be over ten to twelve hours. During the winter months the time between the night and morning feeds exceeds this by several hours. The use of lights to lengthen the feeding day appears to have been first practised by Dr. E. C. Waldorf ${ }^{2}$ in 1595 . Halpin ${ }^{3}$ secured favorable results from the experimental use of lights at Michigan Agricultural College as early as 1906 . It is only within quite recent years, however, that practical use has been made of artificial light in connection with feeding. The practice is now quite general in the coast states where commercial poultry farms abound.

1 Cornell Countryman, vol. xvi, No. 1.

2 Reliable Poultry Journal, vol. xxvii, No. 8.

3 Ibid., vol. xxri, No. 3. 
Lewis ${ }^{1}$ reports that practically all of the commercial poultry raiser's of New Jersey are making use of lights.

Just what the approved practice regarding the use of lights will finally be, cannot yet be foreseen. Among the several methods in use two appear to give the most promise. These are referred to as "morning lights" and "evening lunch."

Morning Lights.-Lewis found morning lights superior to evening lights or to a combination of morning and evening lights. The best time for starting the lights was found to be 4 A.M. running them until sun-up. In. connection with morning lights grain should be fed four times daily in a deep litter, viz., 4 and 8 A.M., 1 P.M. and just before dusk. The heaviest feedings should be given at dusk and at 4 A.M. The early morning feed may be scattered in the litter at night after the birds are on the perch.

Evening Lunch.--With the so-called evening lunch method the birds are allowed to go to perch at dusk, and come down at daylight. The lights are turned on, however, for one hour at 8 P.M. during which time the birds are given a heavy feeding of grain with plenty of fresh water available. This method reduces the cost of lighting, as compared with other metlods, gives the birds longer hours of rest and does not require the use of dimming devices as when evening lights are used; for after the first few days the birds will have all returned to their perches by nine o'clock at which time the lights are turned off.

A graphic presentation of Lewis's ${ }^{2}$ results with 600 pullets without lights, 500 pullets with morning lights and 100 pullets given an evening lunch may be seen in Figure 178. The comparative profits per bird for a period of nine months were $\$ 3.30, \$ 5.07$ and $\$ 5.4 \$$ respectively for the three groups.

Details of Lighting Practice.-Following Lewis, when lights are used it is of the greatest importance that the stock should be graded and flocked according to age, condition and laying qualities. Pullets of different ages or pullets and hens should always be kept in different flocks.

1 Hints to Poultrymen, vol. ix, No. 1.

2 Ibid. 
When pullets are kept under lights, the latter should be started November 1st and continued until April 1st, or later. Beginning with lights before November 1st brings on a heavy production in the early fall, making it almost impossible to hold the birls in high producing condition during the winter months. The few early eggs gained by the earlier starting of the lights are more than discounted by the winter production slumps which are almost sure to follow.

FIG. $17 \mathrm{~S}$

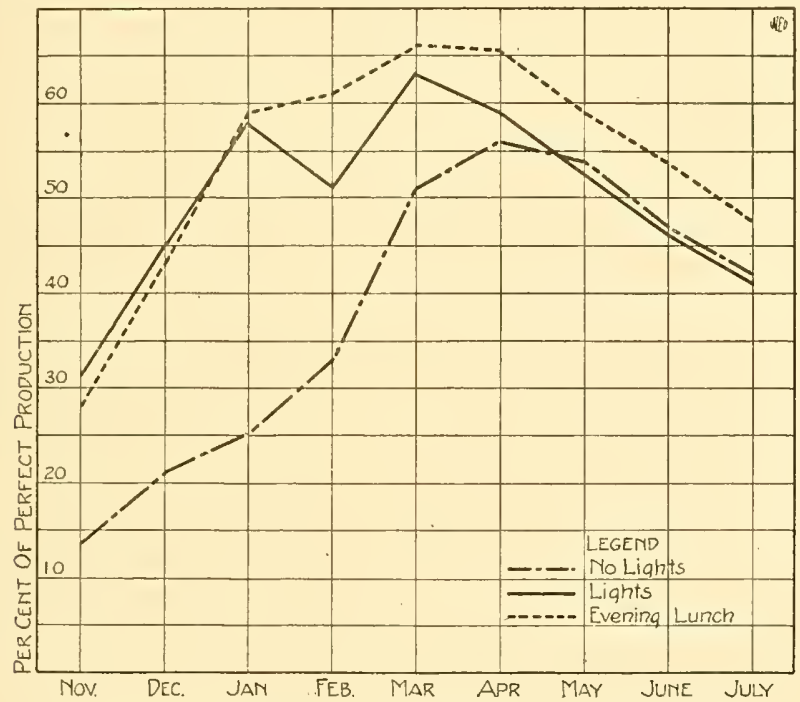

A graphic presentation of Lewis's data on the use of lights.

Lights are usually not so profitable with hens as with pullets. They should not be started before January 1st. The reason for this is that the hens must have time to finish the fall molt and regain their body weight. The regaining of the body weight is essential to satisiactory results in the breeding pen the following spring.

Tests show that layers will respond to lights in from seven to ten day's. 
All classes of birds under lights should be more heavily grained than is customary under ordinary feeding conditions. The purpose of this is the maintenance of body weight. If it is not done the birds will lose weight rapidly under the drain of heavy laying, and are likely to go to pieces in the spring, so far as production is concerned. Lewis found that for heavy producing Leghorn pullets 14 pounds of grain daily for each 100 birds was about the right amount, dry mash being available at all times.

After April 1st the shortening of the period of lighting under any method should be very gradual, a reduction of ten minutes a day being the maximum. The sudden stopping of lights is quite likely to bring on a spring molt which is disastrous to production. Irregularity will produce a like result.

Typical Laying Rations.-The Purdue Experiment Station ${ }^{2}$ has had excellent success with the following ration for laying hens in confinement:

Grain

10 pounds corn

10 pounds wheat

5 pounds oats

25 pounds
DRY MASH.

5 pounds bran

5 pounds shorts

$3 \frac{1}{2}$ pounds meat scraps

$13 \frac{1}{2}$ pounds

The grain mixture is fed in a deep litter, a light feed being given in the morning, and all the hens will consume in the evening. The dry-mash hopper is kept open all the time in the case of the lighter breeds, but is left closed until noon for the middle-weight and heavy breeds. In the winter, succulence in the form of silage, sprouted oats, cabbage, or stock beets is supplied. Professor Philips suggests the following possible variations in this ration: (1) replace the beef scrap with 50 pounds of skim milk; (2) drop out the wheat and increase the corn and oats; (3) in case fowls are following stock and can pick up an abundance of corn, the grain portion of the ration may be greatly reduced; (4) during the summer when the fowls

1 Hints to Poultrymen, vol. ix, No. 1.

${ }^{2}$ Purdue Extension Bulletin No. 10, and Purdue Bulletin No. 218. 
are allowed to range freely, the mash portion of the ration may be considerably reduced.

A laying ration originating at the Cornell Station and fed with excellent success at several of the stations is made up as follows: The scratching part of the ration consists of three parts wheat, two parts corn or kafir, and one part oats. The dry mash, fed at the rate of one pound for each two pounds of the scratching feed consumed, consists of:

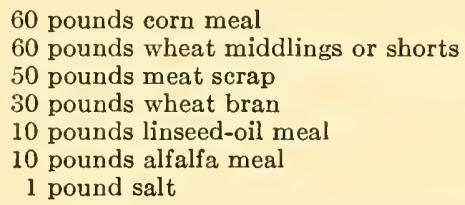

This ration is fed in accordance with the routine outlined on page 392, succulence being furnished at noon, and grit, bone, shell, and charcoal kept before the birds at all times.

A ration that has proved successful for laying hens of the Mediterranean type consisted, for the scratching part of the ration, of corn and wheat in equal parts. The dry mash was made up as follows:

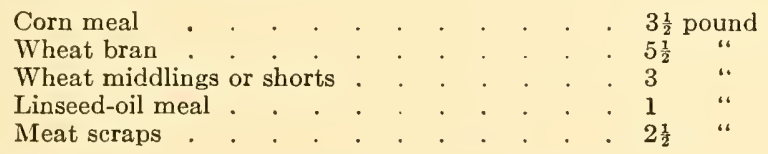

Silage was fed in place of greenness during the winter. Shell grit and charcoal were before the fowls constantly.

Gowell ${ }^{1}$ recommended the following ration and routine for American breeds, which has been widely used:

"Early in the morning for each 100 hens, 4 quarts of screened cracked corn are scattered on the litter, which is 6 or 8 inches deep on the floor. This is not mixed into the litter, for the straw is dry and light and enough of the grain is hidden; so the birds commence scratching for it almost immediately. At 10 o'clock they are fed in the same way, 
2 quarts of wheat and 2 quarts of oats. This is all of the regular feeding that is done.

"Along one side of the room is the feed hopper. In it is kept a supply of dry meals mixed together. This dry-meal mixture is composed of the following materials: 200 pounds good wheat bran, 100 pounds corn meal, 100 pounds middlings, 100 pounds gluten meal or brewers' grains, 100 pounds linseed meal, and 100 pounds beef scrap.

"Oyster shell, dry cracked bone, grit, and charcoal are kept in slatted troughs and are accessible at all times. About 5 pounds of clover hay cut into half-inch lengths is fed dry daily to each 100 birds in winter.

"For green food during winter and spring, mangels are used. They are liked by the birds, and when properly harvested and cared for remain crisp and sound until late spring. They are fed whole, by sticking them on to projecting nails about a foot and a half above the floor. Care must be exercised in feeding them, as they are laxative when used too freely. On the average about a peck per day to 100 hens can be safely used. They would eat a much greater quantity if they could get it."

Forcing Egg Production.- "Forced egg production during the season when eggs are the highest in price can sometimes be accomplished by increasing the protein, especially the animal protein, and stimulating the fowl by the use of moderate amounts of pepper, onion, etc. This must be done cautiously, however, and must not be continued too long. Green feed stimulates in a more normal manner, by refreshing the system (and furnishing an abundance of the fat soluble). Any grateful change in the feed stimulates the fowl."

Feeding During the Molt.-Poultrymen írequently force chickens, intended for winter shows, to molt early, by gradually cutting down the amount of feed fed to about one-third the normal amount during a period of about three weeks, and then during the following week increasing the ration rather rapidly until the birds receive all they will eat.

This practice results in the dropping out of the old feathers, 
and if done far enough in advance will result in the growing of a new coat of feathers in time for the early winter shows.

It is a matter of common knowledge that hens usually stop laying while going through their general molt in the fall, and do not begin again until along toward spring.

The question is frequently raised whether hens cannot be induced to begin laying in the late fall or early winter by forcing the molt so that it will be well over by that time.

In extensive experiments carried on by Rice, Rogers, and Nixon $^{1}$ they found that starved hens produced less eggs after the molt was complete and produced them at a greater cost per dozen than with hens fed normally. Mairs ${ }^{2}$ also found that the net result of forced molting was against the practice.

It is sometimes considered that as long as egg production ceases during the molt the feed may be cut down. Voit (as quoted by Lusk ${ }^{3}$ ) showed that the metabolism of a pigeon may be doubled after removing its feathers. In a late general molt when the weather is cold, it seems reasonable to suppose that this condition is somewhat approached by hens. This certainly does not call for a diminution in the heat-supplying foods. The feathers themselves are largely protein, and demand a generous supply of protein for their growth.

It is considered good practice to furnish an extra amount of oily feeds such as old-process oil meal, or sunflower seeds, and an abundance of granulated bone to furnish phosphates.

Feeding Breeding Hens.- "The hens selected for breeding should not be forced either for rapid growth or egg production. In the early weeks they are fed, just as the others are, for growth, health, and vigor. When the special feeding for rapid growth or fattening of broilers begins, and also later when the laying stock is being pushed toward egg production, the breeding stock should be allowed to develop more slowly. It is better for the vigor of the progeny that they should lay fewer eggs and these of a high degree of vitality. The:r

${ }^{1}$ Cornell Bulletin No. 258.

2 Pennsylvania Bulletin No. 87.

3 Science of Nutrition. 
mash should contain somewhat less of the concentrated protein."'1

So far as routine is concerned, it is essentially the same as for layers.

Feeding Capons.--In tests at Ohio Station, Sherwood and Buss $^{2}$ found that capons fed a ration consisting of corn, ground corn and meat scrap gave practically as good gains as a more elaborate ration containing wheat, oats and bran in addition, and gave a pound of gain a cent and a quarter cheaper at the then prevailing prices. The capons used were Barred Plymouth Rocks hatched June 6 and caponized October 6. They were fed for a period of fifty-seven days beginning December 12 and ending February 6. The birds were hopper fed in pens and allowed to balance their own ration. The average weight at the beginning of the feeding period was 4.13 pounds and at the end was 7.24 pounds, making an average gain of 47.77 per cent. The average feed consumption per bird for the period was 11.38 pounds of corn, 5.88 pounds of ground corn, 6.7 pounds of meat scrap and 0.4 pound of grit, shell and charcoal combined.

Pen Fattening.-The final finishing of fowls for slaughter is usually the work of the packer rather than the grower. It is accomplished by milk feeding in crates. Farm-fattening, when practised at all, is usually limited to penning the birds intended for market so as to limit their exercise and feeding them for a period of from one to three weeks on a somewhat wider ration than is given for growing or laying, and increasing the amount of mash, moistening it if necessary.

Because of the fact that the final finish is put on by the packer, fattening on the farm is usually unnecessary if the birds have been properly fed for laying or growth. A hen in prime laying condition usually carries a considerable amount of fat, and a rapidly growing bird will make more gain in weight by growth than will be taken on in the form of fat.

When for any reason stock has been restricted with regard to feed or because of unfavorable conditions the chickens are not in good flesh, it will be found profitable to feed mature

1 Jaffa, California Bulletin No. 164.

${ }^{2}$ Ohio Bulletin No. 262. 
stock for a limited period upon a ration consisting largely of corn and corn meal before killing or selling for food purposes. Care should be taken, while encouraging the fowls to eat a large amount of feed, not to overdo the matter. It is well to supply all the accessories of the ration, including grit, shell, and charcoal, as with other classes of stock, and to furnish succulence and animal feed by way of variety.

Milk Fattening.-Milk fattening refers to the practice of forcing the laying on of flesh with fowls by feeding a ration which consists of about two-thirds buttermilk by weight.

So far as the author can ascertain, milk fattening was first practised in this country in 1900. During that year S. Brill, a large poultry dealer from London, spent the fall months at the St. Joseph (Mo.) plant of Swift and Company and fed 1200 birds by way of demonstration. The following season he supervised the feeding of seven thousand head, since which time milk feeding has had an enormous growth.

Owing to the action of acid in the milk or the lack of calcium in the ration, or some other cause, the bones of milkfed chickens are usually very brittle and easily broken. 'This, in connection with the fact that milk-fed birds shrink very badly when shipped alive, precludes milk fattening on the farm, unless the fowls are also dressed at the farm. It is practically impossible to move fowls that have been fully finished on milk without causing the breakage of legs or wings, so bruising and scarring them that they present an unattractive dressed carcass, and having such a shrinkage that a large part of the gains are lost.

In the routine of fattening, as many birds are placed in crates (see p. 415) as can find room to stand along the front of the crate to reach out to the trough for feed. They are starved twenty-four hours before the first feeding. The feed, which usually consists of about two parts by weight of buttermilk to one of ground grain, is in the form of a porridge, which is poured into the troughs before the birds, the feeder being very careful not to supply more than the birds will consume, or, in case of an oversupply, removing what remains just before the birds have had all they desire. The development of that judgment which enables the feeder to sense when the birds 
are almost through eating and remove the feed just before they secure the last mouthful, which they desire, is the mark of the slilled fattener.

The practice as to the number of times stock is fed daily, varies. It may be either two or three times. For the beginner, three times is probably advisable.

Table XliII. - The Results of Milk Feeding Under PackingHouse Conditions.

\begin{tabular}{|c|c|c|c|c|c|c|c|c|}
\hline \multirow[b]{2}{*}{$\begin{array}{l}\text { Number } \\
\text { of head. }\end{array}$} & \multirow[b]{2}{*}{$\begin{array}{l}\text { Days } \\
\text { fed. }\end{array}$} & \multirow[b]{2}{*}{$\begin{array}{l}\text { Average } \\
\text { weight. } \\
\text { Pounds. }\end{array}$} & \multicolumn{3}{|c|}{ Per cent of gain. } & \multicolumn{3}{|c|}{ Grain per pound of gain. } \\
\hline & & & $\begin{array}{c}\text { High } \\
\text { per cent. }\end{array}$ & $\begin{array}{c}\text { Low } \\
\text { per cent. }\end{array}$ & $\begin{array}{l}\text { Average } \\
\text { per cent. }\end{array}$ & $\begin{array}{c}\text { High } \\
\text { pounds. }\end{array}$ & $\begin{array}{c}\text { Low } \\
\text { pounds. }\end{array}$ & $\begin{array}{l}\text { Average } \\
\text { pounds. }\end{array}$ \\
\hline $2,06 \mathrm{~S}$ & 10 & 2.51 & 23.5 & 11.5 & 18.5 & 5.32 & 3.01 & 4.04 \\
\hline 10,360 & 9 & 2.40 & 26.1 & 11.2 & 19.4 & 5.10 & 2.55 & 3.52 \\
\hline 11,875 & s & 2.55 & 27.1 & 10.9 & 17.2 & 4.40 & 2.17 & 3.37 \\
\hline 15,731 & 7 & 2.39 & 29.6 & 11.4 & 19.2 & 4.55 & 1.92 & 2.68 \\
\hline 3,907 & 6 & 2.18 & 1S. 6 & 8.2 & 13.1 & 5.35 & 2.14 & 2.66 \\
\hline 43,944 & . & 2.42 & 29.6 & S.2 & 18.1 & 5.35 & 1.92 & 3.26 \\
\hline
\end{tabular}

\begin{tabular}{|c|c|c|c|c|c|c|c|c|c|}
\hline \multirow[b]{2}{*}{$\begin{array}{l}\text { Number } \\
\text { of head. }\end{array}$} & \multicolumn{3}{|c|}{$\begin{array}{l}\text { Cost of labor per } \\
\text { pound of gain. }\end{array}$} & \multicolumn{3}{|c|}{$\begin{array}{l}\text { Cost of feed per } \\
\text { pound of gain. }\end{array}$} & \multicolumn{3}{|c|}{$\begin{array}{l}\text { Total cost per pound } \\
\text { of gain. }\end{array}$} \\
\hline & $\begin{array}{l}\text { High. } \\
\text { Cts. }\end{array}$ & $\begin{array}{l}\text { Low. } \\
\text { Cts. }\end{array}$ & $\begin{array}{c}\text { Aver- } \\
\text { age. } \\
\text { Cts. }\end{array}$ & $\begin{array}{l}\text { High. } \\
\text { Cts. }\end{array}$ & $\begin{array}{l}\text { Low. } \\
\text { Cts. }\end{array}$ & $\begin{array}{l}\text { Aver- } \\
\text { age. } \\
\text { Cts, }\end{array}$ & $\begin{array}{l}\text { High. } \\
\text { Cts. }\end{array}$ & $\begin{array}{l}\text { Low. } \\
\text { Cts. }\end{array}$ & $\begin{array}{c}\text { Aver- } \\
\text { age. } \\
\text { Cts. }\end{array}$ \\
\hline 2,068 & 1.95 & 1.43 & 1.67 & 10.37 & 5.81 & 7.84 & 12.32 & 7.24 & 9.51 \\
\hline 0,360 & 2.09 & 0.99 & 1.51 & 9.95 & 4.97 & $6 . \mathrm{SS}$ & 11.77 & 5.96 & 8.39 \\
\hline $11,87 \mathrm{~s}$ & 1. 86 & 0.92 & 1.39 & S. 55 & 4.23 & 6.64 & 10.12 & 5.15 & 8.03 \\
\hline 15,731 & 2.31 & $0 . S S$ & 1.17 & S.TS & 3.71 & 5.42 & 11.09 & 4.61 & 6.59 \\
\hline 13,907 & 2.81 & $0.9 \mathrm{~S}$ & 1.73 & 10.39 & 4.17 & 7.28 & 13.14 & 5.15 & 9.01 \\
\hline 43,944 & 2.51 & $\overline{0} . \mathrm{Ss}$ & 1.40 & 10.37 & 3.71 & 6.45 & 13.14 & 4.61 & 7.85 \\
\hline
\end{tabular}

As shown in Table XLIII, Lee ${ }^{2}$ found that on a ration consisting of 60 per cent corn meal and 40 per cent low-grade wheat flour, stock averaging 2.42 pounds in weight and fed for periods ranging from six to ten days, made an average

1 Bureau of Animal Industry, Bulletin No. 140.

2 Ibid. 
gain of 18 per cent at an average feed cost of 6.45 cents per pound.

These figures involved nearly 44,000 birds fed under packing-house conditions, and represent a fair average for birds of this weight. The stock used was of all sorts and conditions.

With smaller numbers and high-grade stoek the producer that sells dressed birds may seeure greater and somewhat more economical gains than are secured under packing-house conditions.

Pierce and Lippincott, ${ }^{1}$ using a ration composed of :

1 part ground corn
1 part ground oats (hulls removed)
1 part ground barley (hulls removed)
1 part meat scrap
8 parts buttermilk

which was fed to grade Barred Plymouth Rock cockerels averaging between $3 \frac{1}{4}$ and $3 \frac{1}{2}$ pounds, secured an average gain for twelve birds of over 50 per cent in a two-week feeding period at a cost of less than $4 \frac{1}{2}$ cents per pound gain in one test, and a trifle over 5 cents at the then prevailing prices in the second test. The results in detail are shown in Table XIIV.

Table Xliv? - The Results of Milk Feeding Fowls in SMall Groups.

Cost of ration per pound.

First
test.
s.

Average weight of twelve birds, beginning . . . 3.25 Second

Average weight of twelve birds, end of first week .

Average gain per bird

4.25

1.00 test.

Average weight of birds, end of second week . .

5.05

3.49

Average gain for seeond week

0.80

4.72

Total rain per bird

Per cent. gain for entire period.

1.80

Amount of ration eaten, first reek . $.55 .6 \%$

Amountiof ration eaten, second week . . . 6.44

Total amount of ration eaten

10.85

Cost of rution for twelve birds

0.9768

1.22

Cost per pound of gain

0.0441

0.68

1.90

$54.6 \%$

5.77

6.97

12.74

1. 146

0.0503

1 Unuublished data, Iowa State College.

Ibid. 
Bittenbender and Lippincott ${ }^{1}$ found that while the addition of 5 per cent mutton tallow or beef suet to a basal ration of oat flour for crate fattening slightly increased the gains and lowered the cost of gains a little, the flavor of the resulting flesh was comparatively poor. When meat scrap formed 25 per cent of the solid portion of the ration it imparted a noticeably strong taste to the flesh. When the meat scrap was replaced by corn meal the flavor of the flesh was excellent. It was also found that when green clover and charcoal were put before the birds, two or three times a week, they ate of them greedily, brightened up considerably after each feeding, and consumed more of the regular ration.

$\mathrm{Mitchell}^{2}$ tested rations containing varying proportions of corn meal, low-grade flour, oat meal, pea meal, buckwheat middlings, and wheat middlings, and found that their efficiency varied directly with the proportion of corn meal. As a result of these tests he recommended that 24 pounds of white bolted corn meal, 6 pounds of wheat middlings, and 4 pounds of pea meal or oat flour be mixed with enough buttermilk to make it the consistency of thin batter. Sour milk may be used if buttermilk may not be had, and if neither is available, add 15 per cent of beef scrap to the ration and moisten with water. This will not be nearly so satisfactory, however, as buttermilk.

Philips $^{3}$ reports excellent results from a ration composed of :

2 pounds corn meal
1 pound shorts
1 pound ground oats
8 pounds buttermilk

This mixture was allowed to stand twenty-four hours before feeding.

\section{FEEDING APPLIANCES.}

The feeding appliances found in general use are supply cans, feed hoppers, feeding troughs, and watering pans.

${ }^{1}$ Unpublished data, Iowa State College.

${ }^{2}$ Missouri State Board of Agriculture Bulletin, vol xi, No. 2.

3 Jour. Am. Assn. Inst. and Invest. in Poul. Husb., vol. ii, No. 8. 
For force-fattening, crates are a necessity, and cramming machines are infrequently used.

Supply Hopper.-A supply of the grain fed out of hand should be kept at the hen-house. Everything that can reasonably be done to encourage poultry to make the poultryhouse their headquarters when they are not ranging should be resorted to. It is bad farm practice to throw out feed for poultry around the granary. They soon learn the source of

Fig. 179

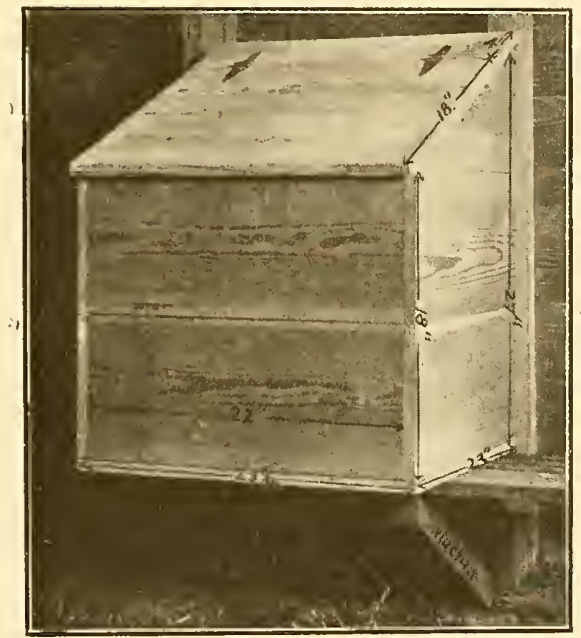

A serviceable supply hopper of proper dimensions to hold 200 pounds of grain.

(Courtesy of Kansas Agricultural Experiment Station.)

supply and will hang about the granary waiting for feeding time or watching for an opportunity to fly in. On most farms this constitutes a nuisance.

If the poultry is fed at the poultry-house, as the practice should be, at least two trips from the granary to the chickenhouse become necessary. These may be avoided by having a supply of grain at the chicken-house and at the same time will result in the hens gathering at the proper place at feeding time. 
A supply hopper, large enough to hold grain for at least a week's feeding, is a great convenience. While a metal hopper is preferable to a wooden one, because it is mouse- and ratproof, a covered box hung on the wall will serve the purpose. It should have a sloping top, so that the fowls cannot roost on it. Such a hopper, of proper size to hold 200 pounds of grain, is shown in Figure 179.

Feed Hoppers.-Hopper feeding is finding its way into all lines of feeding practice with the exception of crate fattening. In some cases it is restricted to the feeding of mineral foods. Usually it includes the feeding of the dry mash and in the case of growing stock at certain seasons of the year may be extended to include the feeding of whole ration.

A hopper should have capacity enough not to require too frequent filling, should allow the birds free access to whatever it contains, when open, without waste, and in some eases should be capable of being closed. If in addition it can be rat-proof, it is a great advantage.

The most popular type of hopper is what is called the force-feeding, or self-feeding, hopper, by which is meant that only a small part of the feed contained in the hopper can be reached by the fowls at one time. As fast as it is consumed, however, more feed slips down from the storage compartment to take its place. An outdoor hopper covered over with prepared roofing is shown in Figure 1S5. Figure 186 shows working plans of the same hopper. Figures 183 and 184 gives the plans of a home-made indoor hopper that is capable of being closed. Figure 187 shows a three-compartment and Figure $18 \mathrm{~S}$ a single-compartment hopper for grit, charcoal, granulated bone, or oyster shell

Feeding Troughs.-For those mixtures which will not serve as scratching feeds and are not suited for hopper feeding, troughs or trays of some sort are usually necessary. 'This applies to moist mashes for young and old stock and for the finely ground dry material fed little chicks before they are big enough to eat from a self-feeder.

The desirable features of such appliances are ease of cleaning where moist feeds are given and the prevention 
FIG. 180

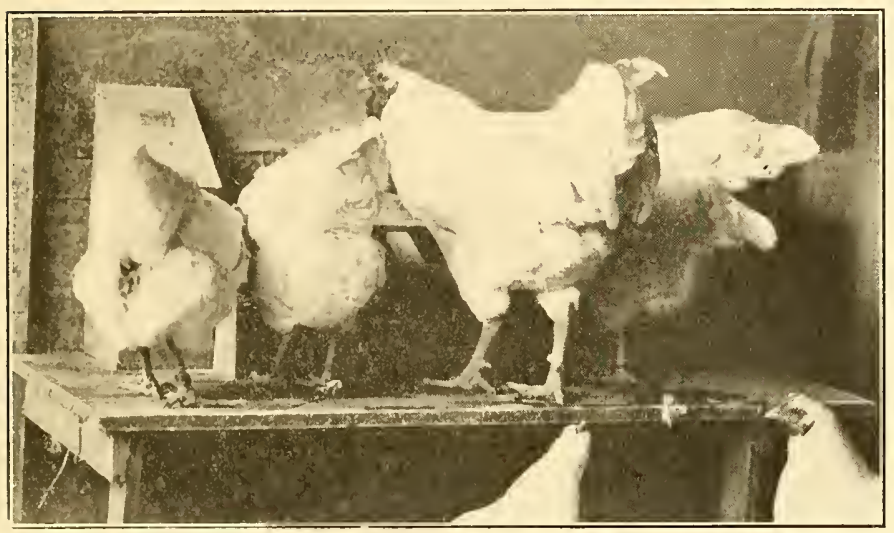

Home-made indoor hoppers. (Courtesy of Purdue Agricultural Experiment Station.)

FIG. 181

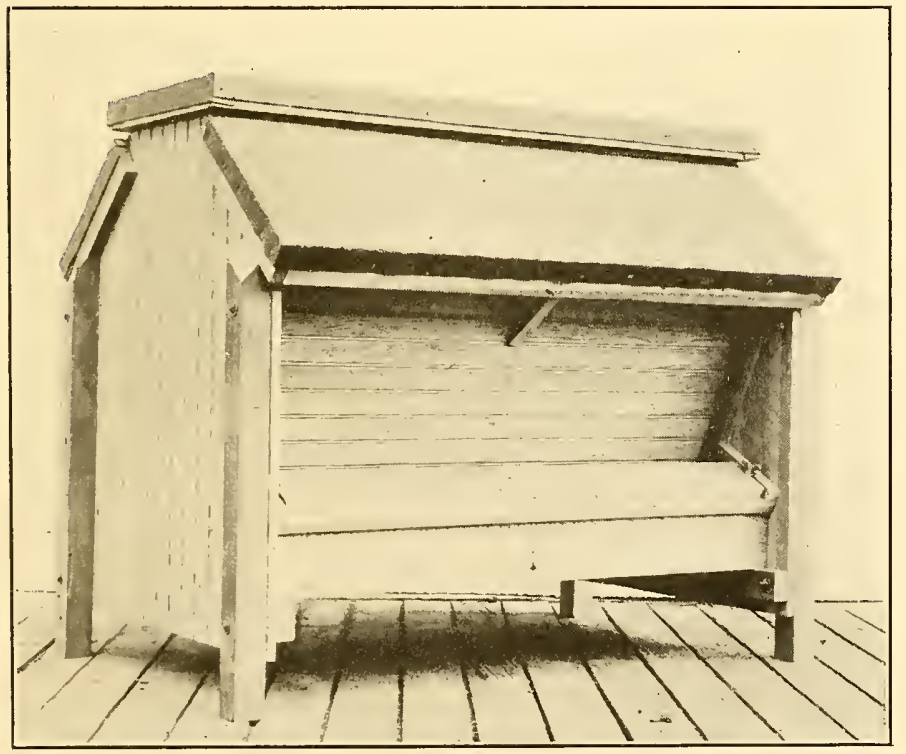

A home-made hopper for indoor or outdoor use. (Courtesy of Kansas Agricultural Experiment Station.) 


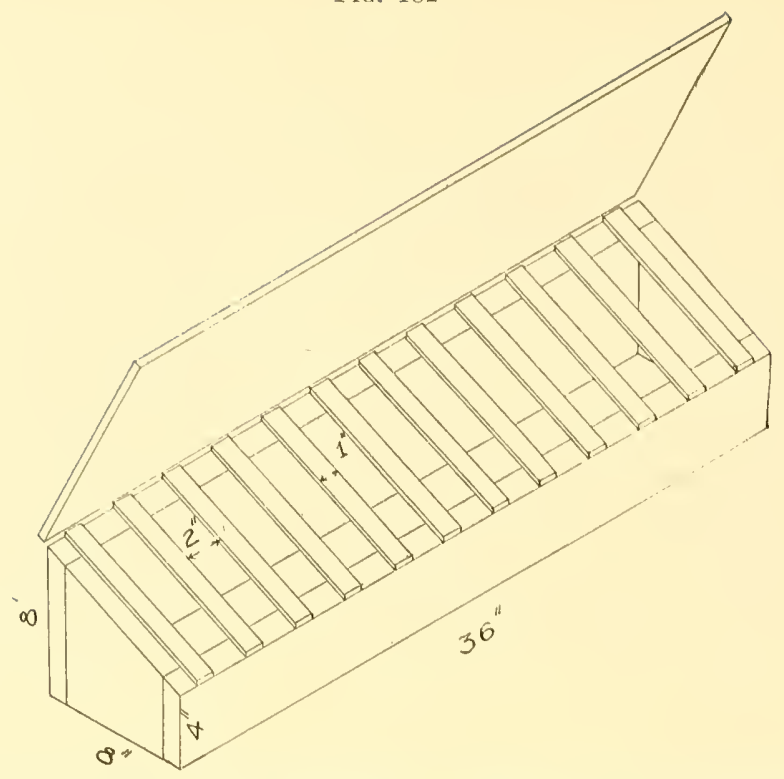

A simple home-made dry-mash hopper. (Courtesy of Kansas $\Lambda$ gricuitural Txperiment Station.)

\section{FIG 183}

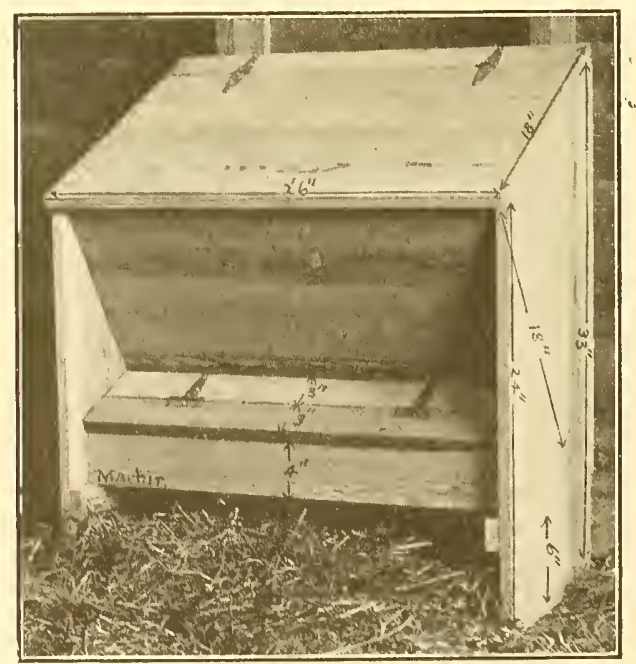

Hone-made, self-feeding mash hopper holding 100 pounds, closed. (Courtesy of Kiansas Agricultural Experiment Station.) 
Fit? 1 sh

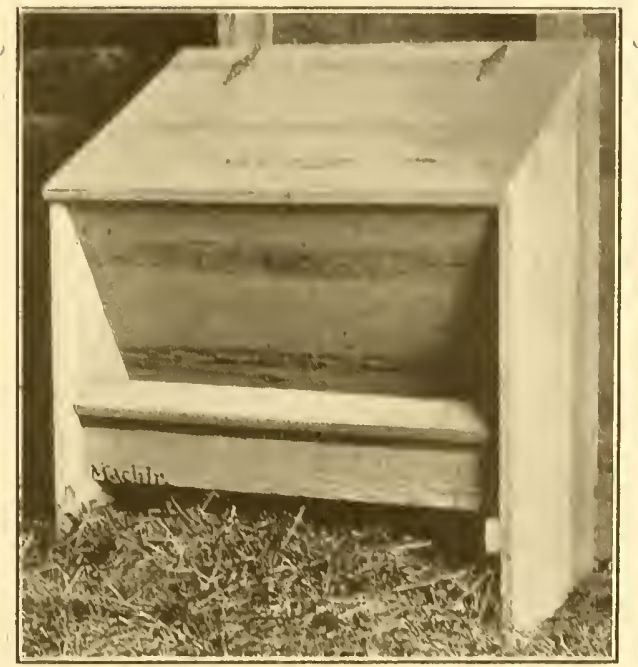

Showing the same hopuer as in ligure tsis npened for the fowls to ant.

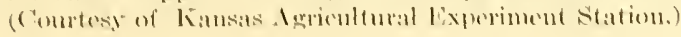

Fis. 1 sis

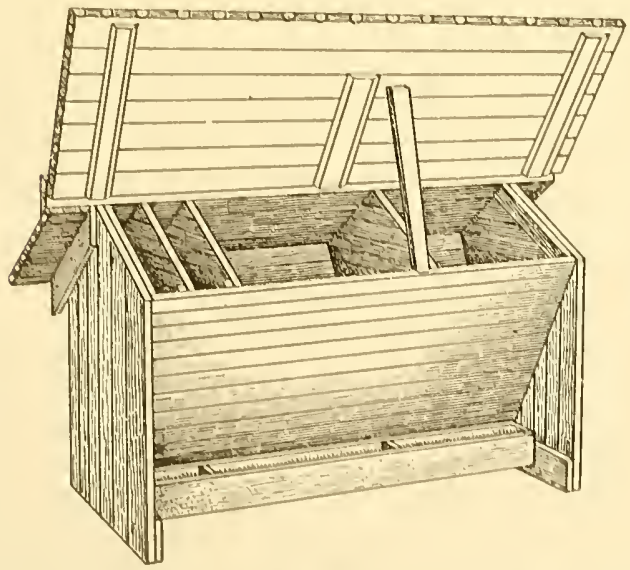

An outdoor hepper. (Courtesy of cornell University.) 
of waste with the dry. For little chicks the latter may be accomplished by putting a piece of half-inch mesh hardware cloth into the top of the tray, as shown in Figure 190. The chicks are able to eat through this, but camnot scratch out the feed and waste it.

Watering Pan.-A perfect watering device should keep the water clean and cool in warm weather, and be of such construction that it may be easily cleaned and freezing will not injure its usefulness. To keep water clear the watering arrangement should be high enough so that straw will not be scratched into it, and at the same time so situated that the fowls are not likely to perch on the edge and contaminate

FIG. 186

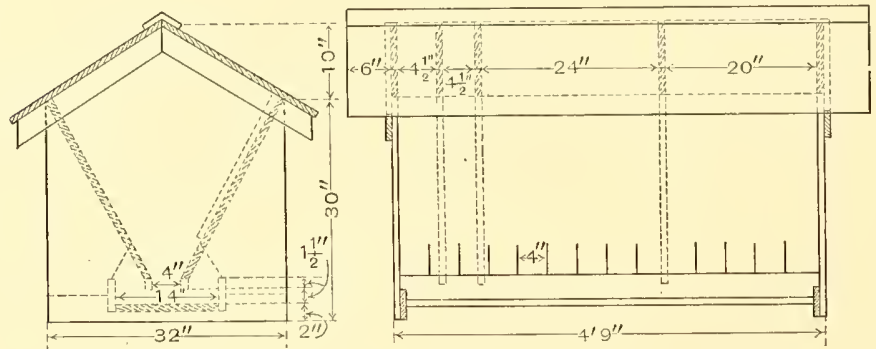

Working plans of the double outdoor hopper shown in Figure 185.

it with droppings (see Figure 191). Earthenware is probably best for keeping water cool in summer, but it will not stand freezing. Galvanized iron pans with flaring sides, as shown in Figure 191, withstand freezing well, and are among the most used watering devices for mature stock. Galvanized iron, however, is attacked by potassium permanganate, which is frequently put in the drinking-water to prevent the spread of disease by means of the water. In the course of time the permanganate will eat holes in it if used to any extent.

For small chicks, a good form of watering utensil is shown in Figure 193. These work much the same as a self-feeding hopper. The tank, $A$, is closed at the top and open at the bottom. When it is filled and in place in the pan, $B$, the 
FIG. 187

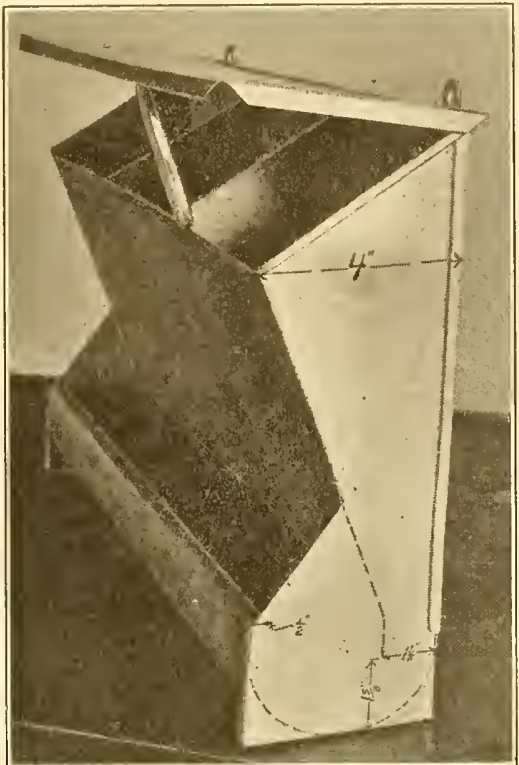

A three-compartment hopper for grit, shell, and bone. (Courtesy of Cornell A rricultural Experiment Station.)

FIG. $18 S$

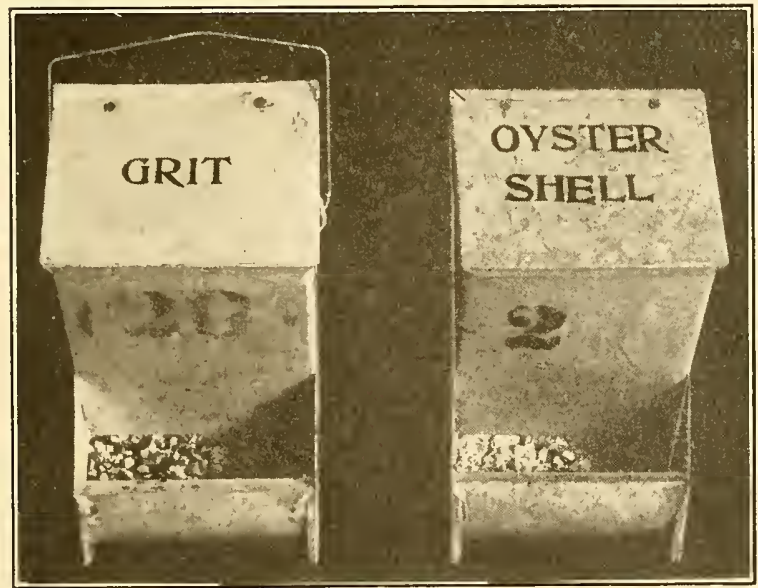

Single-compartment grit and shell hoppers. (Courtesy of Cornell Agricultural Experiment Station.) 
water is given down only as fast as air is admitted to take its place. The latter can occur only as the chicks drink

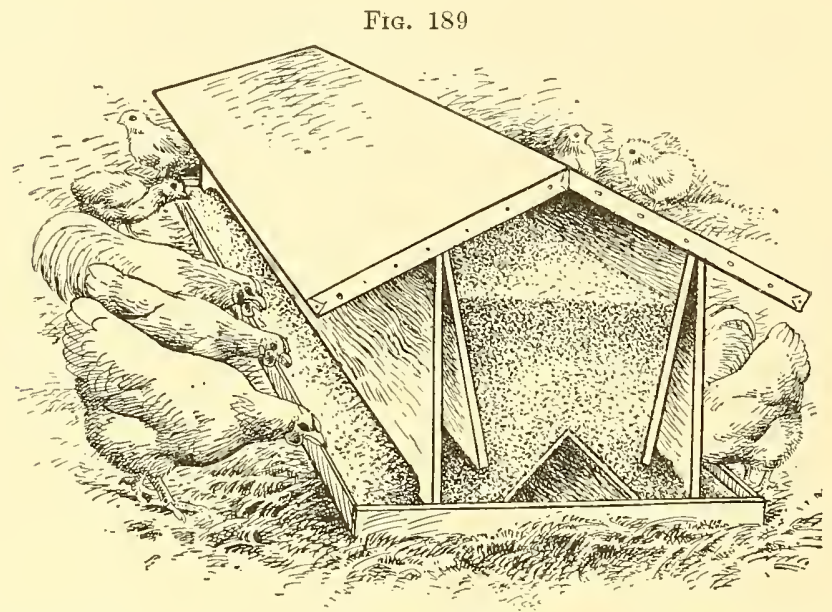

A home-made hopper to be used for free-range chicks. It can be divided so that one side holds a mash and the other coarsely cracked grains. (Courtesy of Reliable Poultry Journal.)

enough of the water in the pan surrounding the tank to lower it below a small hole near the bottom of the tank. This allows a small volume of air to be admitted and enough

FIG. 199

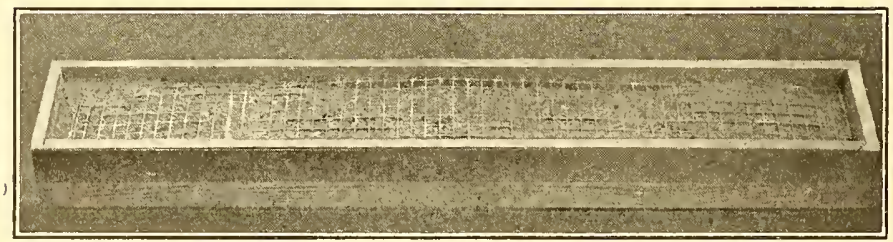

A chick feeding-trough. (Courtesy of A. G. Philips.)

water flows into the pan to bring the water level above the hole, thereby preventing any further flow of water into 
the pan. A tomato can and a pie tin will serve the same purposes.

This arrangement gives a constant supply of water and prevents the chicks from getting into the water. It does

\section{FIG. 191}

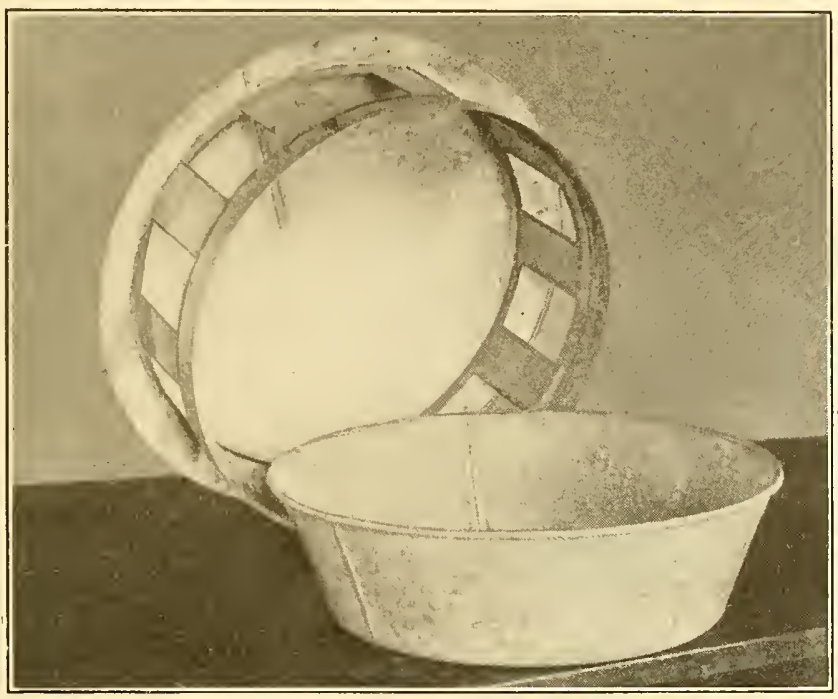

A desirable galvanized-iron watering pan with a sloping top for protection.

Fig. 192
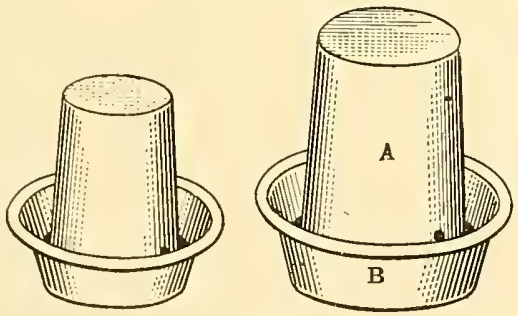

Chick drinking fountain. Used for young chicks in brooders and on range. Easy to keep clean. 
not preclude the scratching of litter and dirt into the pan or avoid some slopping and spilling. This may be accomplished, however, by the arrangement shown in Figure 124. Where sufficient care is taken to keep the pan free of dirt these devices prove very satisfactory. While they are not so shaped as to withstand freezing, they are not likely to be in use in freezing weather.

\section{FIG. 193}

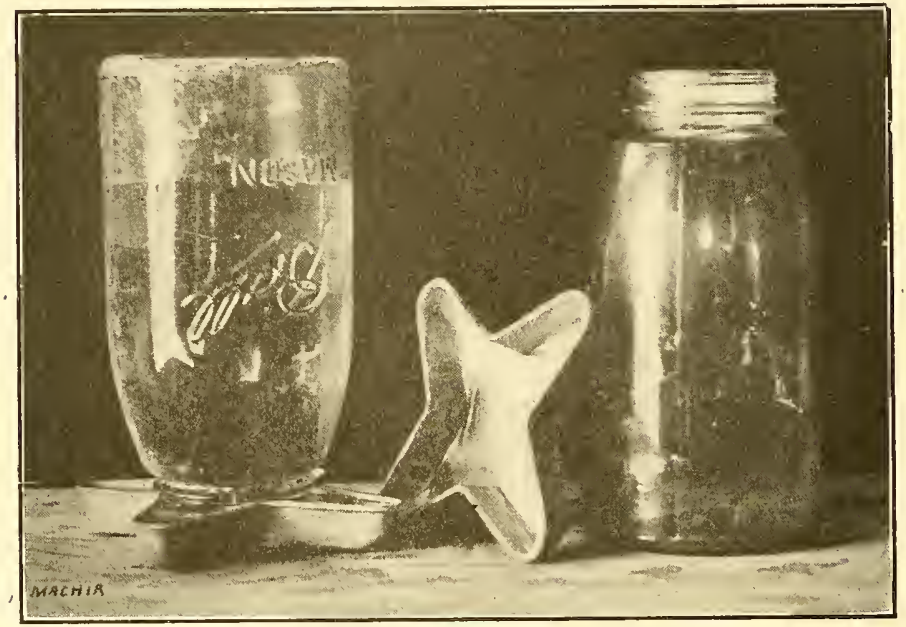

A Mason jar water fountain for chicks. (Courtesy of Kansas Agricultural Experiment Station.)

Commercial watering devices fitted with a small lamp which warms the water just enough to keep it from freezing are finding increasing favor among poultrymen.

Fattening Crates.-The purpose of the fattening crate is to so confine the birds intended for fattening that they will have little opportunity for exercise and will be grouped within a small space so that the labor of feeding is reduced as much as possible. A number of crates built together as is usually done at the feeding stations of the packing-houses is called a battery. 


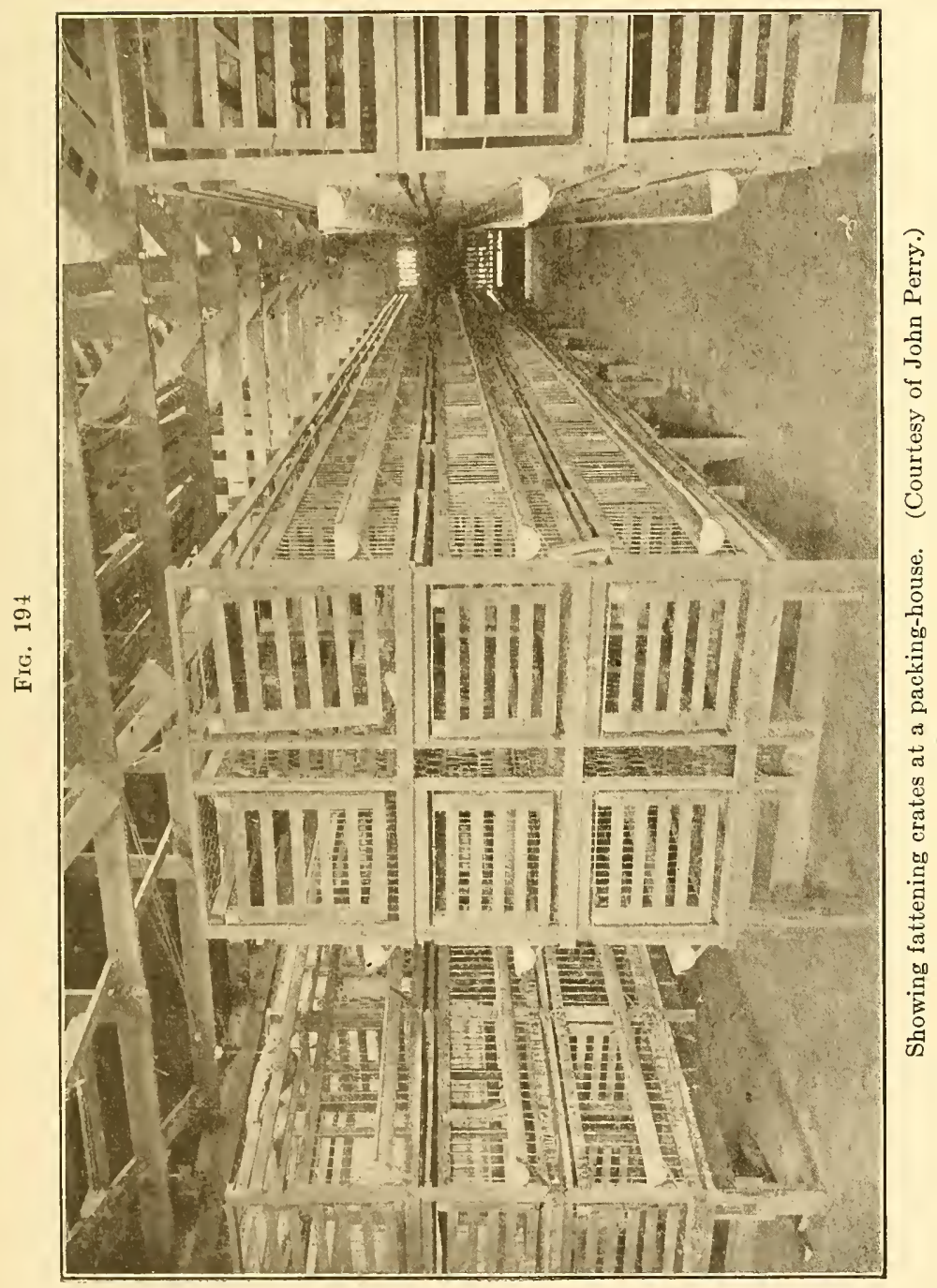


The floor of each crate is 1-inch mesh-woven wire, which allows the droppings to work down into the dropping pan below. Each crate is provided with a removable roosting board upon which the fowls may rest between feeds. The dropping pan as shown in Figure 195 may be taken out and cleaned as frequently as necessary.

F1G. 195

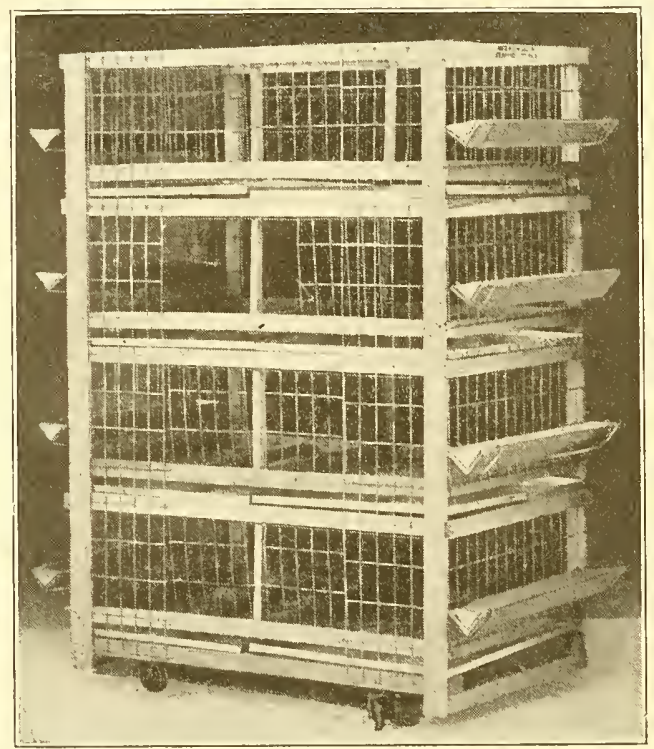

Portable battery of feeding crates. (Courtesy of J. V. Mitchell.)

For good results the crates should be located in the coolest spot possible. If this happens to be in a shed, care should be taken to provide an abundance of ventilation without direct drafts.

Cramming Machine.-In European countries, cramming or machine feeding is practised quite extensively for the same purpose as crate feeding. It consists of a container in the form of a bucket, which is connected with a force pump worked by the feeder's foot by means of a treadle. 
A tube leading from the pump is inserted into the gullet of the fowl until it reaches the crop, as shown in Figure 196, and the crop is filled by pressing the foot on the treadle. The ration used is the same as for crate fattening.

FIG. 196

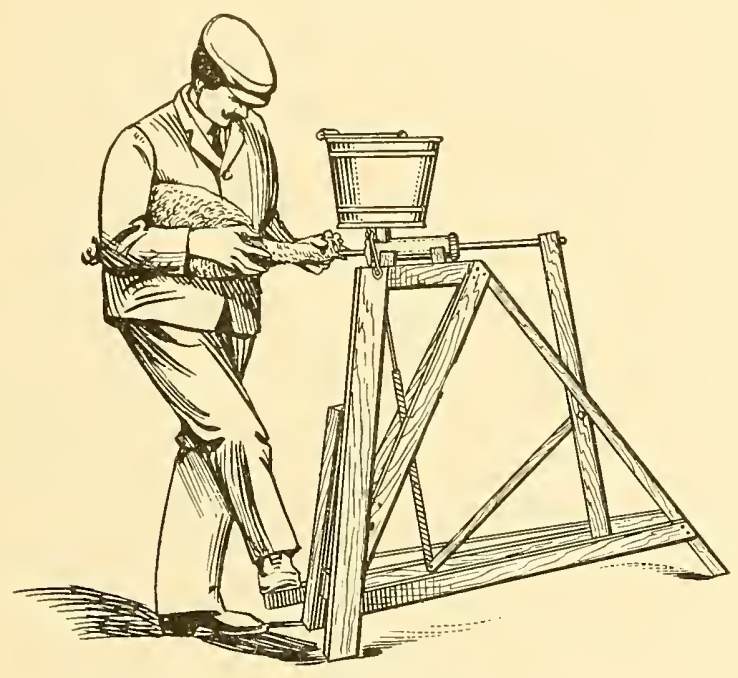

Cramming machine.

The advantage of this method over crate feeding lies in the fact that the fowl may be forced for several days after the appetite has begun to wane. The labor is considerably in excess of that necessary for crate fattening. Owing to a lack of skill, or some other unknown cause, machine feeding has not proved nearly so successful in this country as it has across the water. These two facts have prevented its general adoption in this country. 


\section{CIIAP'TER XI. \\ TLRKEYS.}

Turkers were first discovered on the American continent in 151S. They are still found wild in a few sections of North America and over wide areas in Central and South

FIG. 197

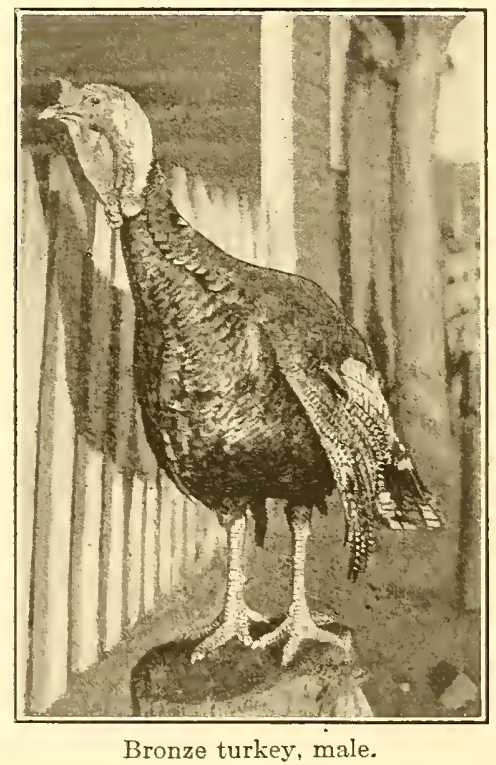

America. After their discovery they were promptly domesticated and found their way to England as soon as 1524. They spread rapidly over Europe, and by 1565 were famous as a Christmas dish both at home and abroad, though there (418) 
are records that indicate that they did not reach Germany until 1580 .

In this country the Bronze and White Holland varieties have proved by far the most popular.

FIG. 198

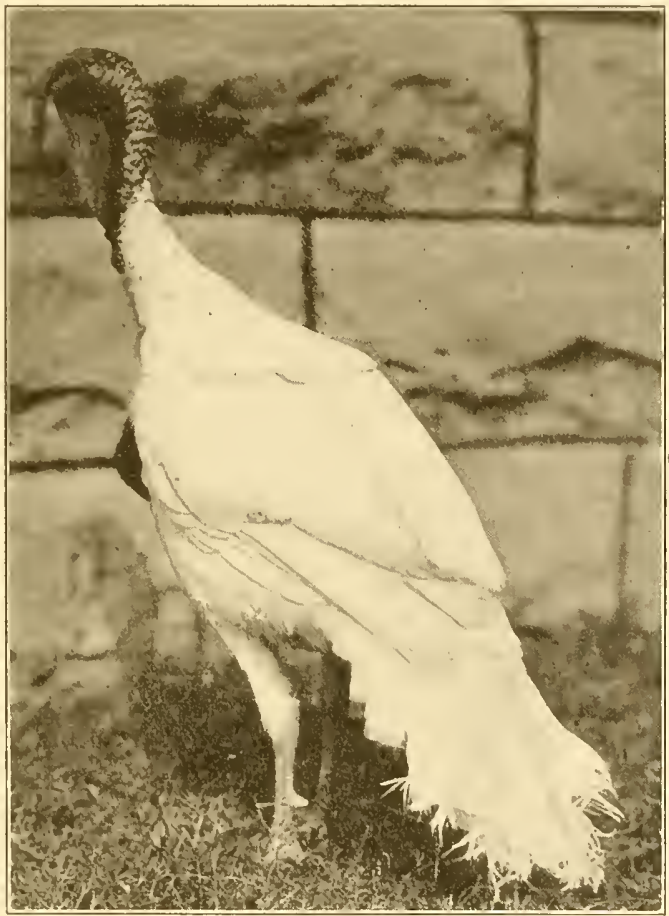

White Holland turkey, male.

Turkeys are essentially birds of the open country. For the best development, ease and economy of rearing, a wide, free range is necessary. Although they are indigenous to America and the climatic conditions are favorable, their numbers in the United States have declined very markedly in recent years, the last general census (1910), showing a loss 
of $1 t$ per cent as compared with the last census previous, and it is a serious question whether the race is not travelling toward extinction. The decrease has continued since 1910 according to poultry dealers. This loss in numbers has been due in large measure to the spread of a fatal disease populary known as "blackhead" (infectious enterohepatitis), and the reduction of suitable ranges by more intensive methods of farming.

With the hope of building up the vitality of the domestic races to a point where ther may resist this and other diseases, wild turkers have quite frequently been crossed with them. In sections where wild turkeys still prevail, the crossing has been almost as frequently without design. This, combined with the fact that turkeys have never taken as kindly to domestication as chickens, has made them restless and impatient of confinement, given to ranging and stealing their nests in out-of-the-way places.

It has been found that the blackhead disease is apparently harbored by chickens, though causing them little inconvenience. When it is communicated to the turkeys, howerer, it proves surely, and usually rather quickly, fatal. Once introduced on a farm, turkey-raising becomes difficult as long as chickens are also kept.

This condition has led to the use of the restern ranges for rearing turkers, and it appears now as though the bulk of turker-raising might erentually be found in the semiarid regions where great stretches of country are arailable. It is now frequently customary to put them out on range in droves, with a drover to look after them. A round-up of over eleren thousand turkers in a turker-raising district in Texas is shown in Figure 199.

Farm Production. - The farm rearing of turkers is extremely profitable in those sections in which blackhead has not made its appearance. and where fores and corotes are not preralent. A flock of turkers requires but little investment in the way of buildings, and practically no feed, except during the fall when they are being fattened for market, and for the breeding stock during the winter.

The turkey is a valuable aid to the farmer in keeping 


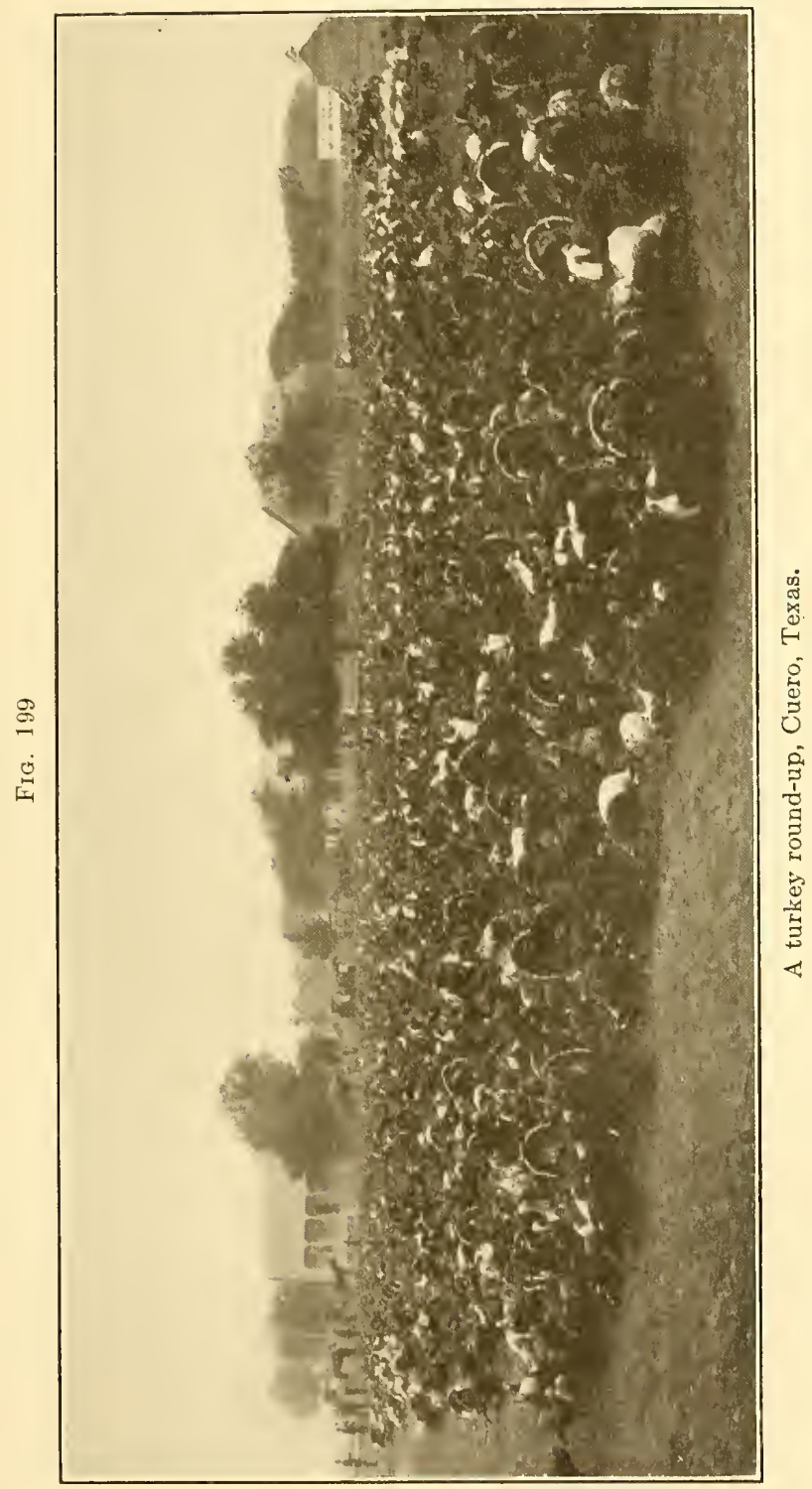


down insects and worms in the fields, and in making them over into a marketable form.

This is particularly true at the time of grasshopper outbreaks and the like. In 1911, Mr. Coffin, of Scott City, Kansas, had the second crop of 160 acres of alfalfa badly damaged by grasshoppers. After the damaged crop was removed, he turned 100 turkeys into the field. Thereafter there was very little damage done and but few grasshoppers found in the field the last week in August.

"In 1912, Mr. Maume, of McCue, Kansas, raised 140 turkeys whose range included 135 acres of alfalfa, 35 of which was left for a seed crop. The seed crop on other fields in that vicinity where no turkeys ranged was entirely destroyed, but this 35 acres set a heavy crop of seed."'

F1G. 200

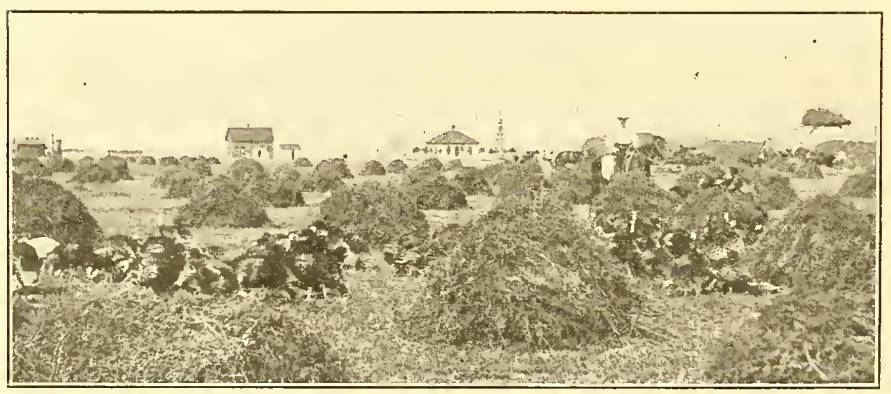

Turkeys saved this alfalfa crop. The neighboring fields were taken by grasshoppers. The owner of this field marketed the grasshoppers in the form of turkey meat. (Courtesy of Kansas Agricultural Experiment Station.)

Selection of Breeding Turkeys.-The same care and attention regarding constitutional vigor, size, trueness to breed type, and color should be observed in the selection of breeding turkeys as in fowls, particular attention being given to securing birds that show good size of bone in the shank.

Birds that are deformed in any way, such as having crooked 
backs, legs or toes, blindness or lameness, should never be used as brecders, unless the deformity is known to be the result of an accident and will not impair the breeding powers. There is a tendency among turkey breeders to breed as large in size as possible. Bronze toms have been known to weigh as much as 50 and 60 pounds. This tendency to breed large sized birds is because the large-sized birds appear best at shows and we gh most on the market.

The market for large birds for meat purposes is limited, as the popular family weight is from nine to eighteen pounds, which will be the weight of a well-grown pullet and cockerel in the fall of their first year. Besides this, large toms are hard on the hens and usually do not make successful breeders.

Number of Hens Per Tom.-One tom will serve from twelve to twenty hens, a good number being fifteen. It is well to have more than one male in each flock, as but one mating is required to fertilize a clutch of eggs, and if one hen does not mate well with one tom she may with another, thus avoiding infertility in her clutch. Most turkey breeders use early hatched, well-grown young toms (coekerels) as breeders. Care should be taken where more than one tom is used to see that they are docile and will not fight with each other. If they are quarrelsome they should be used alternately. The toes and spurs should be blunted and rounded, if necessary, before the breeding season, in order to prevent torn backs in the hens; especially is this necessary with extra heary toms. If any backs are torn the euts should be carefully washed out and the edges sewed together with a needle and thread, the hen kept in a separate pen for three or four days, and the wound bathed with a creosote disinfectant or rubbed with vaseline or lard and sulphur, to aid in rapid healing. Birds affected with torn backs may be detected in the flock by being lame and stiff in their walk, the torn skin being hidden by the surrounding feathers.

Incubation of Turkey Eggs.-Turkey eggs may be successfully hatched in incubators and the poults raised in brooders in a similar manner to chicks. It is the usual custom, however, to allow the hens to raise their own poults.

When a turkey becomes broody, as evinced by her remaining upon the nest at night and becoming angry when dis- 
turbed, she should be either allowed to set in the nest where she lays regularly or she may be moved. Moving a hen to a nest more suitably located should be done at night and two or three china or hard-boiled eggs should be placed under her as nest eggs. The nest should also be darkened during the day after removal, and the bird allowed off for food and water near night. If the moving is carefully done and the hen is thoroughly broody the change may be done without "breaking up" the hen. After she has been setting for two or three days a clutch of fifteen to twenty eggs may be placed under her, depending upon the size of the bird and the season. A large bird in warm weather may cover the larger number easily. At the time the turkey sets, from seven to nine turkey eggs should be placed under a broody common fowl, and the poults when hatched given to the turkey hen. The number allowed each hen should not exceed twenty to twenty-five.

Turkey eggs hatch in from twenty-six to thirty days, the average being about twenty-eight. At the time of hatching the first hatched poults may be removed and placed under hens, if they will own them, or kept wrapped in a flannel in a basket in a warm place, or placed in a brooder, thus encouraging the hen to remain on the nest until the last hatched poults gain strength, rather than to start off with the first hatched, leaving the weaker ones behind. The poults removed may be placed under the hen at night, when she will own them without difficulty. The hens should be dusted three times with insect powder while setting, the last time on the twenty-fourth day.

Nesting of Turkeys.- Turkeys mate the first clutch of eggs from the first of March until the first of April, and commence laying during the latter part of March or in April. These dates are subject to variation, due to climatic conditions. The breeding fowls should have been selected not later than the first of the year and only those birds held over which are to be used as breeders or sold on the holiday market. It is natural for a hen turkey to steal her nest, therefore many breeders place boxes and barrels tipped on their side and a nest made therein about the farm, in order to entice the turkeys to lay in them, where the eggs may be easily gathered. Other 
breeders yard their turkeys until about four o'clock in the afternoon, when all eggs have been laid, thus compelling the hens to lay in nests provided for the purpose. Either method is good, and better than allowing the hen to steal her own nest, where it is subject to the raids of foxes, weasels, hawks, and skunks.

A hen turkey will lay from twelve to twenty eggs in the first clutch before evincing a desire to set. If broken up at this point she may begin laying a second clutch after an interval of ten days. As soon as the hens begin to lay, the eggs should be gathered daily and kept in a cool place of even temperature and turned gently at least every two days. One egg of some kind should be left in the nest as a nest egg. More eggs will be laid when the eggs are gathered daily than when allowed to accumulate in the nest, because the large number of eggs in the nest seems to induce the hen to set sooner.

Care and Feeding of Young Poults.-The attitude of investigators toward the black-head disease (infectious enterohepatitis) in turkeys has recently undergone a marked change. Hadley, ${ }^{1}$ who is perhaps the foremost American authority on blackhead in turkeys, gives the reasons for this reversal of attitude in a recent paper. He now takes the position that the organisms causing this malady are omnipresent, and that effort to avoid them is useless. Wild turkeys are quite free from the trouble, however, while their domesticated brothers are highly susceptible. This is in spite of the fact that the wild birds probably always harbor the organisms in the digestive tract. The difference is that modern methods of domestic turkeys feeding have somehow broken down the defensive agencies of the species, whatever they may be.

The problem in feeding poults, therefore, is to so feed that the "normal antagonistic factors" can operate advantageously with regard to the disease.

Dr. Hadley tentatively suggests the following routine for feeding to avoid blackhead. He points out that "it does not make so much difference what young turkeys are fed as

${ }^{1}$ Jour. Am. Assn. Inst. and Invest. in Poul. Husb., vol. ii, No. 8. 
it does how, and how much, they are fed. Particular attention should therefore be given to his method.

"After collection from the nests, hatch the turkey eggs in incubators, in the meantime having ordinary hens set on china eggs in nest boxes or brooders on the permanent range. Remove the poults from the incubator about twentr-four hours after hatching, and distribute at night among the hens, giving from twelve to fourteen to each hen. Be sure that the hen accepts them before they are left. Give no feed before the poults are two days old. Each family may then receive two teaspoonfuls of egg chopped fine with some green food such as nettles, dandelion, onion tops or lettuce. A little cracker may be added to take up surplus moisture so that the mixture will not be pasty. This ration may be repeated for the remainder of the feedings upon this day, or bread soaked up in sweet milk may be substituted for one meal.

"During the first three or four dars of feeding, the poults receive four meals each day, at about eight o clock, eleren, two and fire; after this but three meals are given. On the second day of feeding about the same rations are given, but one of the meals may be of chick grain, and some rolled oats may be added to the chopped-egg mixture. The third day of feeding is like the second. The poults are allowed to rum in their enclosure. On the fourth or fifth day of feeding, the number of meals may be reduced to three, at eight o clock, twelve and four-thirty, respectively. The amounts are slightly increased and a little grit may be added.

"When the poults are about a week old they may be allowed to run free with the old hen on the range on pleasant dars when the grass is dry. Chopped egg in the ration is reduced and omitted by the serenth day of feeding. On the sixth day of feeding the feeding is put on a time basis. Several spoonfuls of food are put on the tray and well distributed, but the poults are not allowed to eat for more than about three minutes at any one meal. By the end of the second week, the time limit is reduced to two and one-half minutes, since the poults are now obtaining more food on the range in the form of insects.

"About the same time sour milk is introduced. It is placed, whey and curd well mixed, in shallow pans or in troughs 
scattered about the range. It is at first given each morning and night at the rate of about one quart to forty poults, and is gradually increased in amount until by the beginning of the fourth month one quart may be given for each twenty birds, each morning and night.

"During the second month, which is the critical period for the young birds, the feeding is continued about as in the latter part of the first month. But, after the age of about six weeks the number of meals per day may be reduced to two. Green food in the form of chopped carrot tops, onion tops, or lettuce should be given in abundance; it should comprise at least one-half of the ration for each meal. The time limit remains at about two and one-half minutes.

"When the poults are about six weels old the nest or brooder coops should be replaced by larger houses made. of laths and covered partly with roofing paper. Such a house may suffice until the poults are about three or four months old. These may be about three feet by five feet and three feet high at the apex. Family houses should then be given up and all the poults, with their mothers, be brought together in a single roosting shed.

"The feeding for the third month is like that of the second except that the amount of sour milk is gradually increased and that a grain mixture of equal parts of cracked corn and wheat may be gradually substituted for the chick grain.

"As the autumn months advance and the insect life disappears, the time limit may be lengthened to three or three and one-half minutes. In rainy weather the noonday meal may be added and a four-minute period allowed. Rolled oats may be omitted and the ration made to consist of the grain mixture with an occasional feed of rolled oats or bread and milk. A mash may now be added containing some beef scrap.

"Before Thanksgiving the breeders for the coming season should be selected and marked. Their feeding for the winter may consist of the following grain mixture fed at the rate of one quart for six or seven turkeys each night and morning:

Cracked corn .

3 parts

Barley .

2 "

Wheat .

2 "

Oats

1 part." 
Both hen and poults should be carefully examined for lice, and if they are found should be carefully dusted with lice powder twice a week. The lice may usually be found, if present, in the vicinity of the vent, on the head and neck and at the base of the wing feathers. The walls and roof of the roosting-house may also be sprayed with a liquid lice killer or creosote dip, but it should not be applied to the floor, as the fumes rising under the feathers of the hen will sometimes suffocate the poults. Lard in very small amounts may be rubbed on the head of the poults to kill the head lice, but care should be used not to apply too much, as it will kill the poults if applied in excess. A piece the size of a pea is sufficient for each bird.

Feeding for Market.-As soon as the supply of feed on the range fails the turkeys begin to hang around the buildings more. Unless the birds are penned up it is practically impossible to do much in the way of fattening until they quit ranging, which is hardly early enough to get them ready for Thanksgiving trade in most sections.

Bolte $^{1}$ found that while greater gains could be secured by crate-fattening than by corn-feeding on range, the increased gains were not great enough to pay for the extra labor involved.

Blanchard $^{2}$ tried feeding turkeys in darkened pens for two weeks, admitting light only at feeding time, and could secure no gains. Other birds fed the same ration and confined in roomy pens having a runway of twenty by fifty feet gained two pounds to ten and one-half pounds each in two weeks. The ration consisted of 6 parts corn meal, 2 parts wheat middlings, 2 parts meat scrap by weight, moistened with milk. No statement is made as to the cost of the gains.

Where penning is impracticable they should have all the corn they will consume and be given a liberal allowance of meat scraps. The birds that are not in condition at Thanksgiving should be fed out for the Christmas market.

1 Rhode Island Bulletin No. 126.

2 Washington Bulletin No. 96 . 


\section{CHAPTER XII. \\ 1)UCKS AND GEESE.}

\section{DUCKS.}

Ducks are the meat birds among poultry. They are hardy, easy to handle, with the exception of picking, and make the quickest gain in flesh from time of hatching of any lind of domestic poultry excepting possibly geese. A duck, to be profitable, should weigh five pounds at the end of ten weeks. It will take a chicken of the American varieties twice as long to attain that weight.

Most of the domestic breeds of ducks are Asiatic in origin, though Europe and America have each made contributions. The Pekin, which is easily the most important meat producer among the ducks, came originally from China. It was first imported into England in 1872, and reached the United States in January, 1874. The Aylesbury originated with a pair of wild white ducks, captured in England. The Rouen is descended from domesticated wild Mallards in France and takes its name from the city of Rouen. The Muscovy originated in South America where it is still found in the wild state. "The Cayuga derives its name from Cayuga County, New York, where it was probably developed about $1850 .{ }^{\prime}{ }_{1}$ It resembles the Pekin in shape, but is somewhat lighter in weight. Though a very good market duck, it has not become widely distributed, possibly because of its dark plumage.

The Runner duck was introduced into England about the middle of the last century and reached this country during the last decade of that century. It is winning a reputation as an egg producer, but their ultimate popularity

${ }^{1}$ Lee. U. S. Bulletin 697 . 
FIG. 201

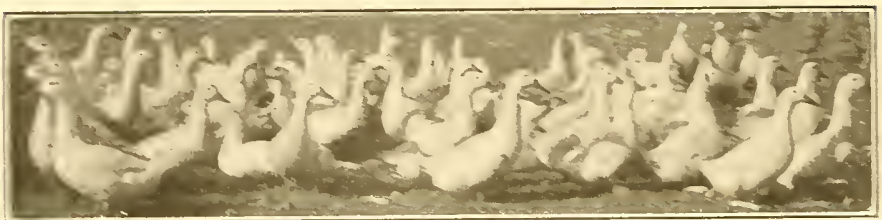

A Astm Eng of White Pejiu ducts.

EIS. 20:

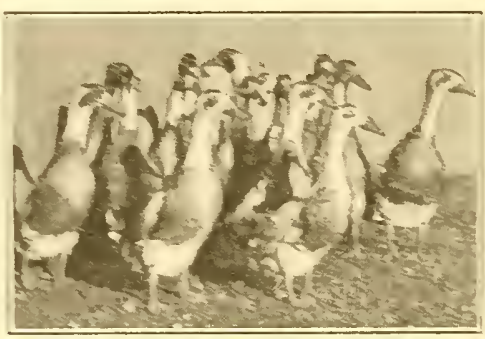

Fom and White Rumer ducts.

FIG. 908

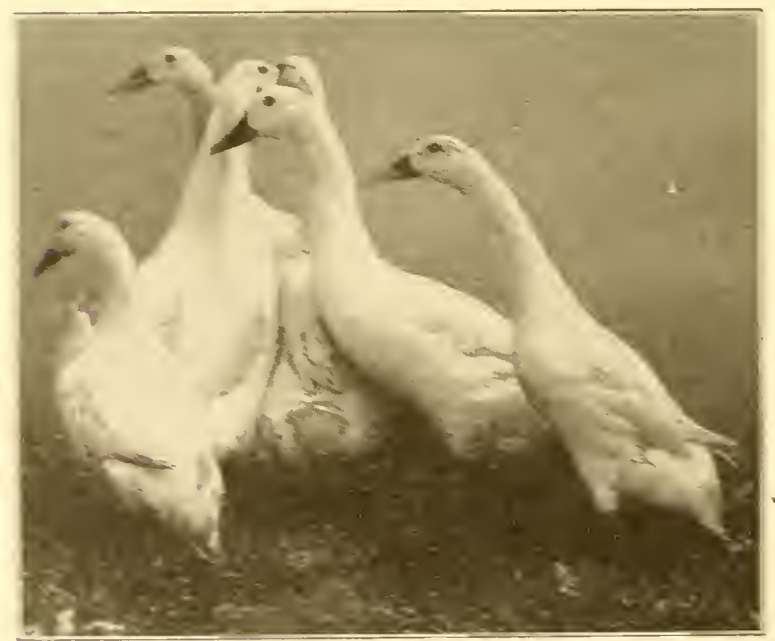

Whive Runre: Sugs 
amd motulness are not get defomined. Its plate of origin. msmally attributed on ludia, is metrtam.

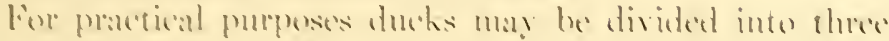

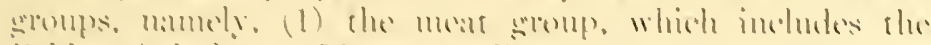

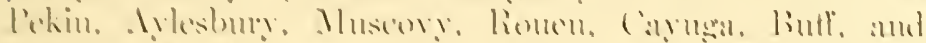

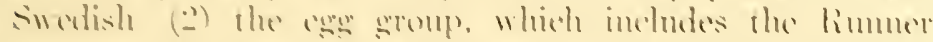

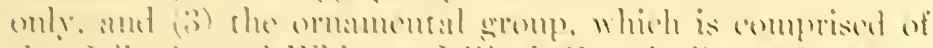

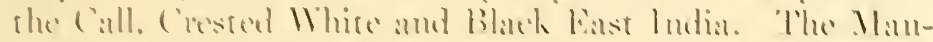

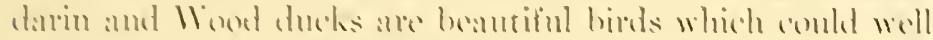
be induded in The stumbur.

Breeding Ducks.-Phe hesviest. most vigoroms. and bestshaped birds shomkd be selected. at the time of morketing

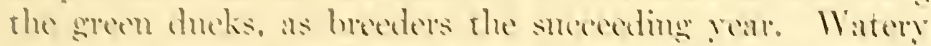

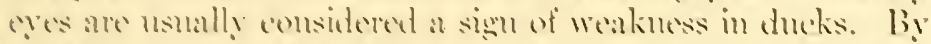

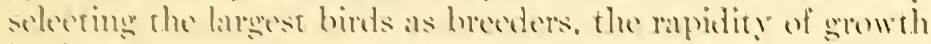

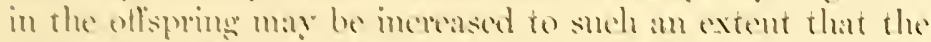

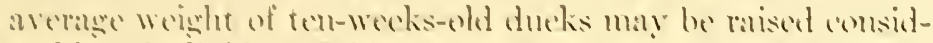
crably. Individual Pokin drakes have been known to werigh

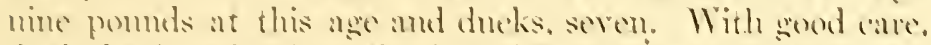

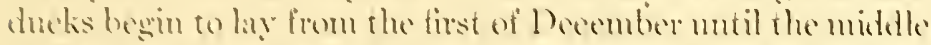
of lishruary, amd should lay from cighty to ome humbed egess ench before the midelle of tuly, when they begin to moult. Only ducks over two years old shonld be used for breding. The drake is at his best the first two seasons.

Number of Dicks per Drake.-In the early part of the bresting season five ducks should he allowed for each drake, and the number increased as the seatson progeresses. "The proportion of drakes should be decreased when they begin to worry the ducks. In Aproil right or ten females is not too mamy for me dritke.

Means of Telling Drake from Duck.-In the colored vatrieties. as the lionem, the drake may be distinguished by his brilliant coloring, but in the solid white varieties, such as the Pekin and dylesbury, the task is not so easy. The drake seldem quacks, but hisses, is wenerally heavier, and not so tine about the hesd and neck. 'lhe most pronomed diflerence. however, is that the drake has two feathers near the base of the tail. "alled " end feathers," wheh curl toward the head, while the duck's fenthers lie smooth. 
Incubation of Duck Eggs.-The desire to incubate their own eggs has been bred out of many strains of ducks, especially the Pekin. For this reason the incubator or broody hens are necessary. The eggs should be gathered daily, kept in a cool place, and turned daily. Ducks' eggs will not keep as well as hens' eggs.

In natural incubation the eggs are placed under a broody duck in a nest on the ground or floor of the house. If placed under hens, ten are about all that may be successfully covered.

When placed in incubators the care given duck eggs is similar to that given hens' eggs except that the temperature should be kept at $102^{\circ}$ F. for the first three weeks. Special duck incubators are manufactured, which have a larger egg chamber than do those used primarily for hens' eggs. More moisture is also required in the hatching of ducklings than of chicks. Ducks' eggs should be tested for fertility on the third or fourth day when developing embryo may be readily seen.

Brooding Ducks.-Ducklings take even more kindly to artificial brooding than chicks do. They are handled in the same manner as chicks except that the temperature which should be $95^{\circ} \mathrm{F}$. at the beginning will usually be reduced to between $80^{\circ}$ and $85^{\circ}$ within a week or ten days.

Housing and Yarding Ducks.-The chief factors in a house for ducks are dryness, fresh air with freedom from draughts, and cleanliness. It is not necessary to build as expensive houses as for fowls, because ducks are naturally hardier and can stand the cold and lack of sunshine better. The floor of a duck-house, which may be any tight shed or outhouse if but few are kept, should be kept well bedded with straw and cleaned out as soon as the straw becomes matted and damp. Dry feet while in the house at night seems to be a necessity for good egg production. The ducks will make their nests on the floor of the house by burrowing in the straw. The number of ducks per house should be about one for every six square feet of floor space for breeders; fattening and young ducks may be kept closer.

An eighteen-inch two-inch mesh fence will hold most ducks, 
and a two-foot fence all of those commonly raised, as most of them cannot fly.

Care should be taken not to frighten ducks by moving among them at night with a lantern, as they are liable to stampede, thereby causing a stopping of egg production, loss of flesh, if not the death of some by trampling.

Feeding Standard for Growing Ducks. - Ducks grow faster than ehickens do, and not only demand more pounds of dry matter per unit of weight, but also a greater proportion of the growing nutrients, protein and ash. The standard for growing ducklings as computed by W. P. Wheeler is given in Table XLV.

Table XlV.-Digestible Nutrients Required per Day for Each 100 Pounds Live Weight of Growing Ducklings.

\begin{tabular}{|c|c|c|c|c|c|c|}
\hline & $\begin{array}{c}\text { Dry } \\
\text { matter. }\end{array}$ & Ash. & Protein. & $\begin{array}{l}\text { Carbohy- } \\
\text { drates. }\end{array}$ & Fat. & $\begin{array}{c}\text { Nutritive } \\
\text { ratio. }\end{array}$ \\
\hline irst 2 weeks & 17.2 & 1. 1 & 4.0 & 11.2 & 1. 4 & 1 to 3.7 \\
\hline rom 2 to & 17.0 & 1.5 & 4.1 & 10.1 & 1.3 & 1 to 3.2 \\
\hline rom 4 to 6 weeks & 11.2 & 0.8 & 2.7 & 7.0 & 0.7 & 1 to 3.3 \\
\hline rom 6 to 8 wee & 8.0 & 0 . & 17 & 5.2 & 0.5 & 1 to 3.8 \\
\hline om $S$ to $10 \mathrm{w}$ & 7.0 & 0.5 & 1.4 & 4.7 & 0.4 & 1 to 4.1 \\
\hline om 10 to 15 weeks & 4.6 & 0.3 & 0.9 & 3.2 & 0.2 & 1 to 4.1 \\
\hline
\end{tabular}

A "ration in accord with the standard given for ducklings might be constituted as follows: Eight pounds of corn meal, 3 pounds wheat middlings, 2 pounds ground barley, 2 pounds old-process linseed meal, 6 pounds animal meal, 2 pounds of fresh bone, and 3 pounds of young green alfalfa."

Feeding Breeding Ducks. - The birds selected for breeders should be kept, ducks and drakes separated, in roomy, shady pastures, where plenty of grass may be obtained, or on free range, and fed a light ration of bran, ground oats, a little meat meal, and grit. A large portion of the ration will come from the grass upon which they may graze. A good mash mixture to feed during this period is 2 parts wheat bran, 1 part corn meal, and 1 part ground oats. Corn, oats, or barley may be fed lightly at noon, although some breeders omit the noon feeding. Water in dishes deep enough so that the nostrils may be cleansed is necessary, and an inverted can should be placed in the dish or a grate placed over it to pre- 
vent the birds from getting into the dish. Water in which the birds may swim is not necessary, although ducks kept

F1G. 204

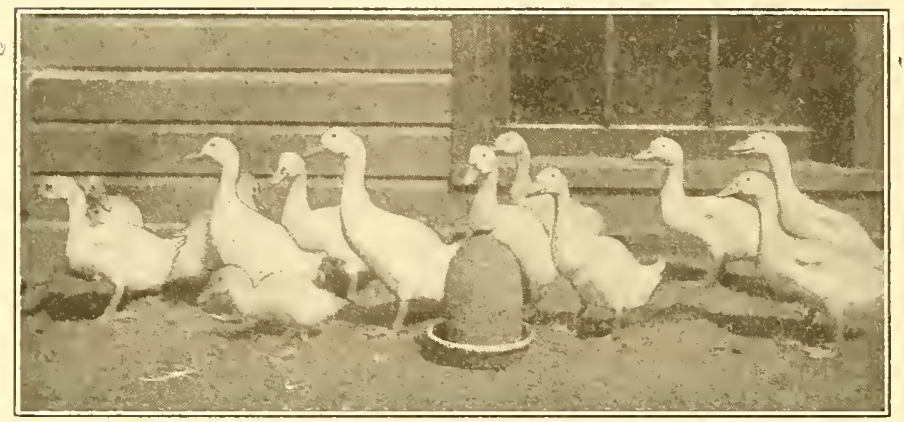

Ducks receiving no animal protein. Notice comparative number and size. (Courtesy of W. P. Wheeler.)

on a sandy soil or thick green sod will keep cleaner if a swimming place is provided.

FIG. 205

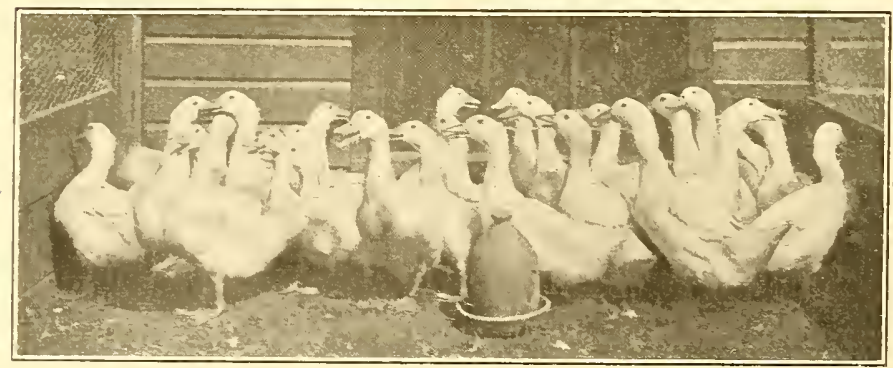

Ducks receiving animal protein. (Courtesy of W. P. Wheeler.)

About the first of November the breeding ducks should be placed in flocks of thirty to forty in the breeding pens and yards and fed for laying by allowing free access to a dry mash, which may be composed of 2 parts wheat bran, 1 part middlings or ground oats, 1 part corn meal, and 1 part beef 
scraps. All the green feed in the shape of cut alfalfa, clover, or chopped roots that they will clean up should be given. Grit and water should be available at all times. If they are kept confined in the pen until eight o'clock in the morning nearly all eggs will be laid upon the floor of the house rather than some in the yard, as ducks usually lay in the early morning.

Feeding Young Ducklings.-After the ducklings are hatched they should be kept without food for thirty-six hours, either in the incubator or under a hen. After removal to the brooder or after thirty-six hours under the hen without feed, the feed for the first week may consist of equal parts of bran, corn meal, and middlings, with 5 per cent. sand in it for grit, fed five times daily. After the third day, 5 per cent of sifted meat scrap may also be added, and green food in the form of chopped lettuce, alfalfa, or clover should be fed freely.

After the first week a good growing ration is 2 parts wheat bran, 1 part wheat middlings, 1 part corn meal, $\frac{1}{2}$ part meat scrap, 5 per cent sharp sand, scalded cut clover, alfalfa, or other green food, as much as they will eat. Feed four times a day.

At the beginning of the eighth week the young ducks should be moved into the fattening shed or kept in a shady place and fed for three weeks on a fattening ration of equal parts wheat bran, middlings, corn meal, and 10 per cent of beef scrap, 5 per cent sharp sand, and green food. It must not be left before them at all times, however, as it is rather concentrated, and they are liable to tire of it.

Special care should be taken that young ducks are not exposed to a hot sun without a chance of shade, nor allowed out in a rain-storm before they are feathered out. Rain while in the downy stage is oftentimes fatal.

\section{GEESE.}

The geese most common on American farms are the Embden and Toulouse. Both are probably descended from the Gray Lag goose-until recently found all over Europe and Northern Asia. The Toulouse owes its name to the city 


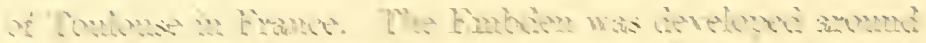

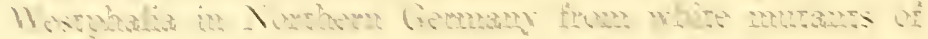
rhe thentwon.

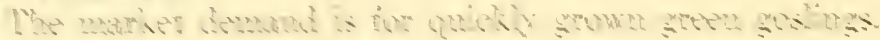

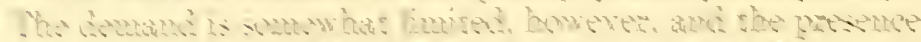

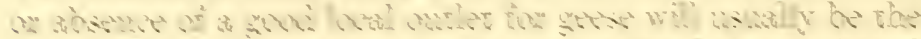

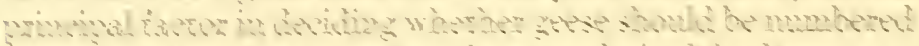

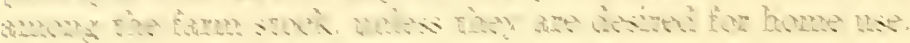

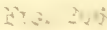

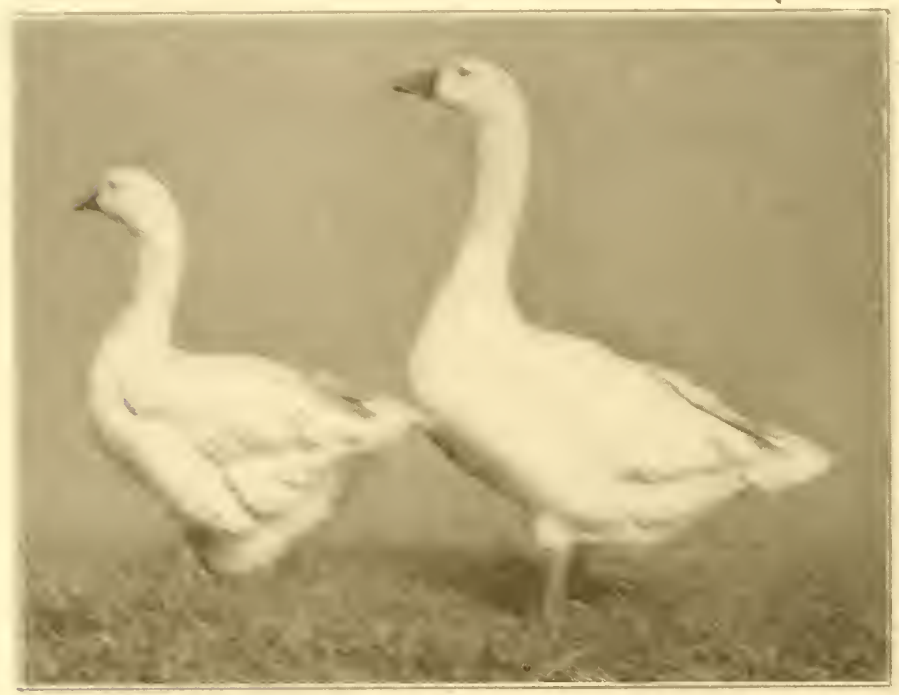

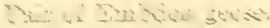

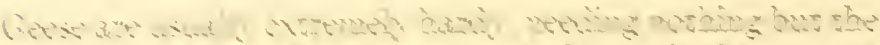

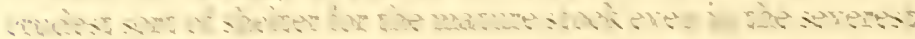

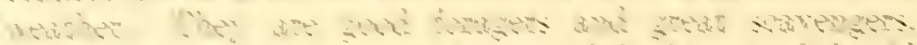

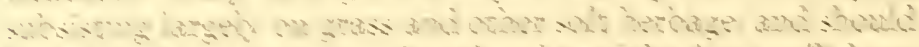

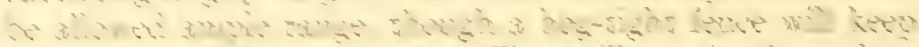

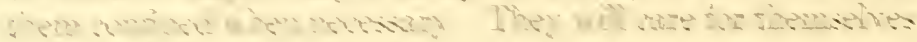

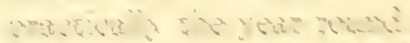

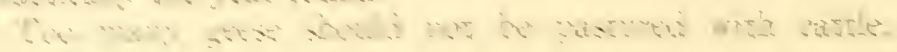




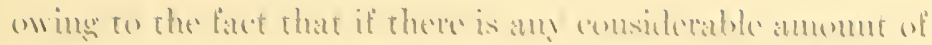

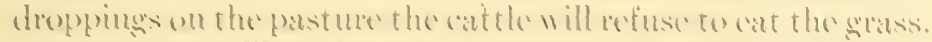

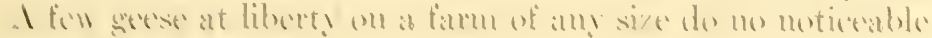
hamm in this resaml.

Whan they ate pastumed on swamplam, which they mag

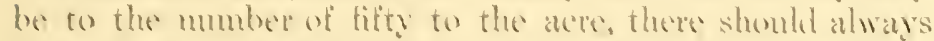
be some high, well-deained land asailable where the birits

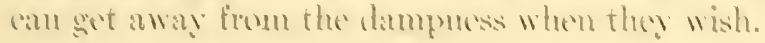

\section{By. $\because(7)$}

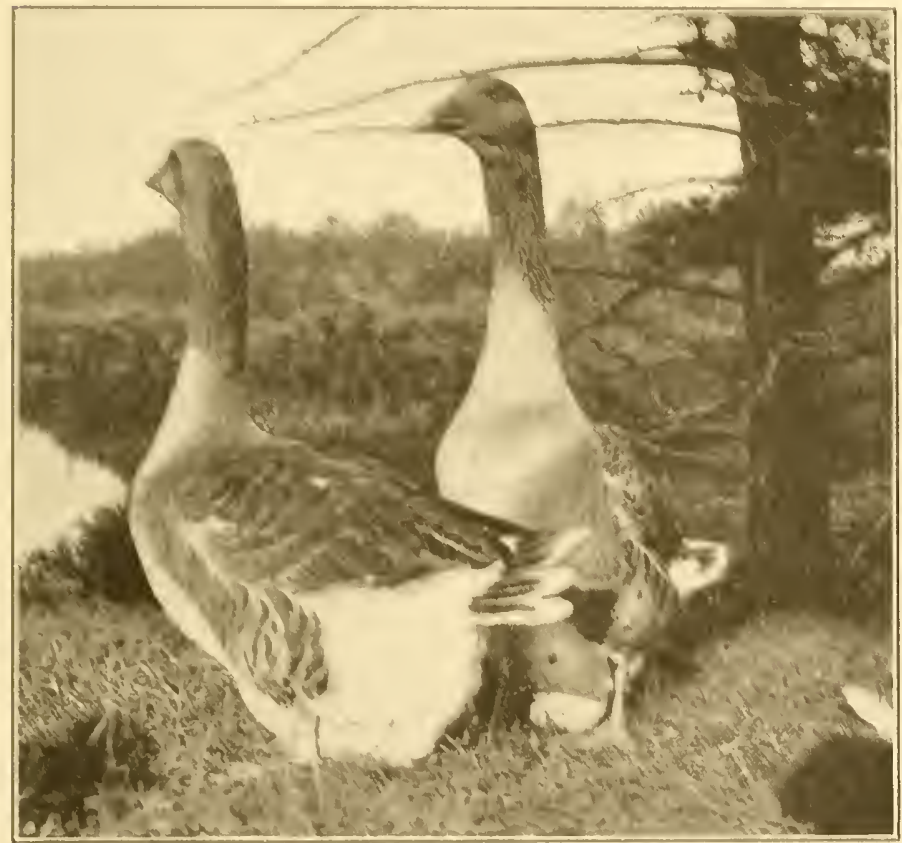

Pair of Toulouse gerse.

'Ther most have shade in warn weather of they sutfor from the heat. If allowed the lmo of the omethat they will comsume the wasted amd spoiled trut, making wains that

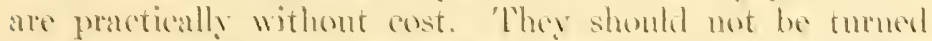
into a newly planted orehard, howerey, as they will imjure the tencter batk of the yommg teess. 
Selection of Breeding Geese.-Geese should not be used for breeding purposes until the second breeding season. The ganders may be used the first season and for several seasons thereafter. For best results not more than two geese should be mated to one gander, though the number is frequently increased to four.

"Ser is diffoult to distinguish in geese. especially when they are young. The sunder is usually somewhat larger and coarser than the gonse and has a shrill ery. while the female has a coarse ory. The male has a heavier. longer neck and a larger head. The ses may be derermined by inspecting the sexual organs or by the action of the geese at mating time. The sphincter muscle which closes the anus of the female is folded and winding or simuous if stretched. While a slight pressure on the corresponding section of the male will make the sexual organ protrude. This test is more easily made on a mature male and in warm weather."

Live Plucking. - The live plucking of geese is not nearly so common as formerly. It used to be quite common to pluck the geese five times a year at intervals of seven weeks. begiming the last week in March. Where it is practised at all now it is generilly confined to the period immediately preceding the moult. They should not be plucked during the breeding season.

Incubation of Goose Eggs.-The first goslings should not be hatched until the grass is green. Incubators have not proved very successul for the hatching of geese, and it is better to allow the geese to set or place the egss under hens. Geese will cover nime or ten egos succestully, while hens of the American breeds should not be given over three of four in conl westher and five or six in warm weather. The length of tme necessary for hatching varies from twentyseven to thirty-three days. but will average about thirty dars.

When they are about due to hatch. If hens are used the nest should be carefully watched and the first goslings taben out as soom as they hatch. wrapped in a woollen cloth. and kepr 
in a warm place. They should be kept away from the nest until the roungest goslings are several hours old, when ther may be given back to the hen. If this is not done the hen is likely to become restless and leave the nest with the older goslings before the late ones are strong enough.

They should be closely confined with their mother until they are three or four dars old, after which they may be allowed at liberty with their mother in a grassy pasture.

Most successful goose raisers make a practice of not allowing the goslings in the water until they are full-feathered on their breasts. Until they are fairly fully feathered they should be sheltered on rainy days. If they are thoroughly wet through and chilled before growing their feathers it is likely to prove disastrous.

Feeding Mature Geese.-When, because of drouth in the summer or during the winter, it becomes necessary to feed mature geese, they should be fed such feeds as mangels, turnips, steamed clorer and the like, supplemented by a mash of equal parts of corn meal, bran, and ground oats. Owing in part, perhaps, to the limited development of the crop, the goose is not able to make very satisfactory use of dry whole or cracked grains. In furnishing any feed to young or old stock there must always be an abundance of drinking water at hand at the place of feeding. Grit, bone, and charcoal should also always be available.

Breeding geese should not be very fat. For this reason geese do better on pasture with stock than about the troughs of the feeding lot. They should be fed grain only semi-occasionally, to prevent their becoming too wild. In the winter, mangels. Swede turnips, clover, or alfalfa hay should form most of their ration. Wherever they are kept they must have plenty of drinking-water, though water for swimming is not necessary. During the breeding season, however. water deep enough for swimming is considered a necessity for successful mating.

Geese lay from trrenty to thirty eggs in a season if not allarred to set. Boxes and barrels should be placed in secluded spots where they will be somerthat hidden by brush. The geese will usually take to them if they are secluded enough, 


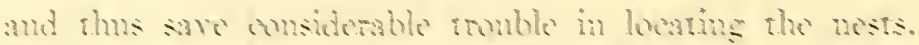

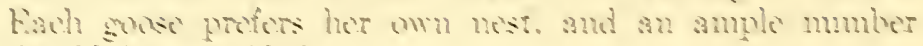
should be provitent.

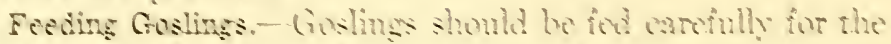

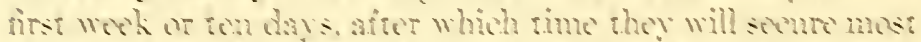

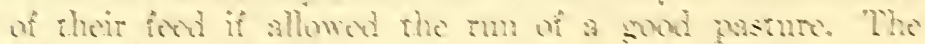

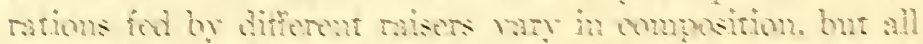

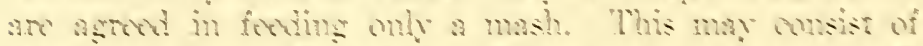

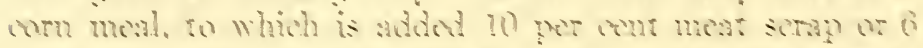

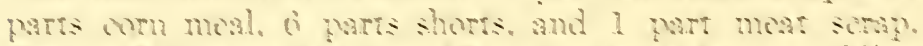

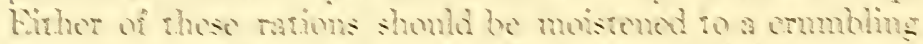

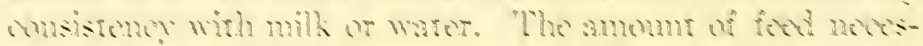

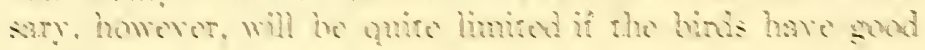
?3:s?mit.

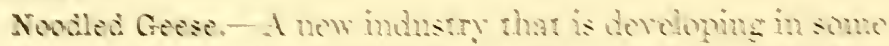

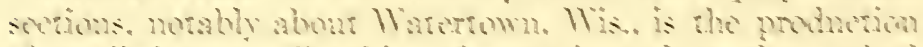

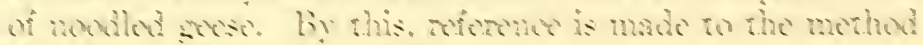
of tarteming hy meshs of "mondes."

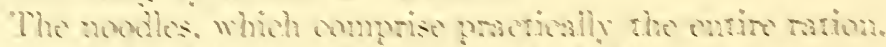

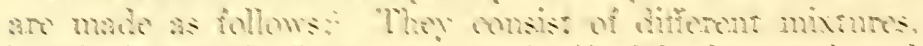

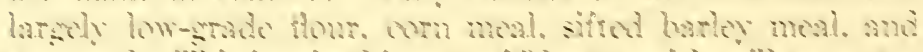

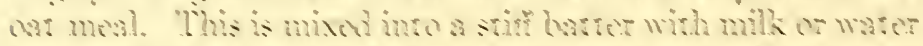

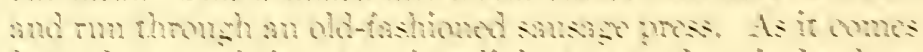

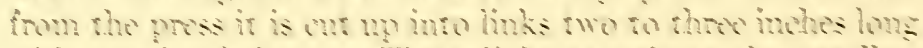

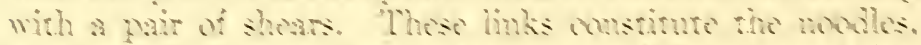

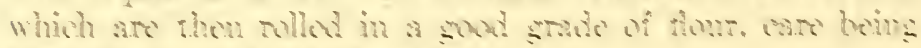

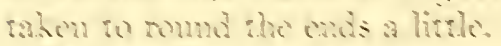

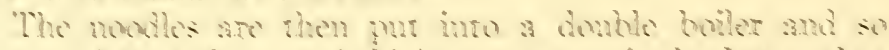
arranght thas they an heht in a wowen wire besket so thas

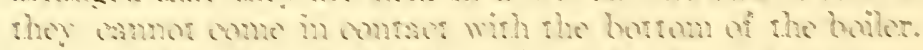

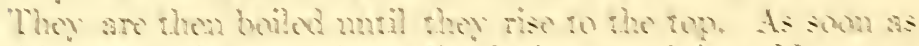

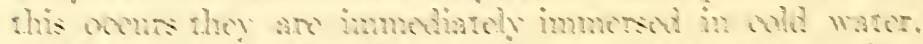

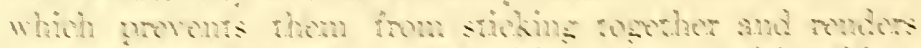

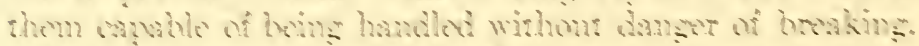

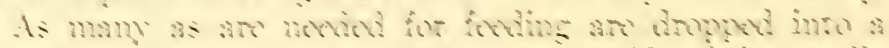

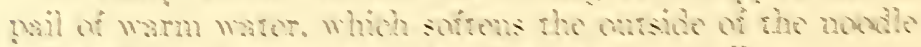

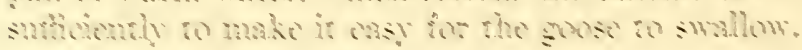

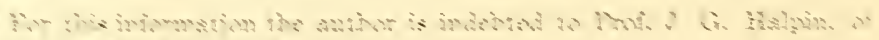

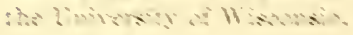




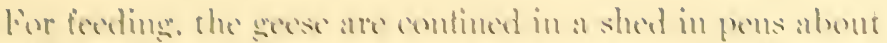

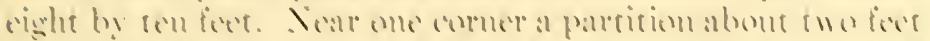

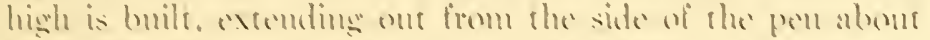

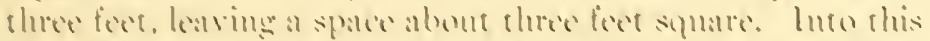

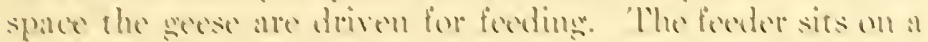
low stoul at the end of this parrition, reathes hate amd leads a between dhe kness of the forder. who opens the mouth wirk the lett hamd while he slips a mondle in with his right.

\section{Vin: :}

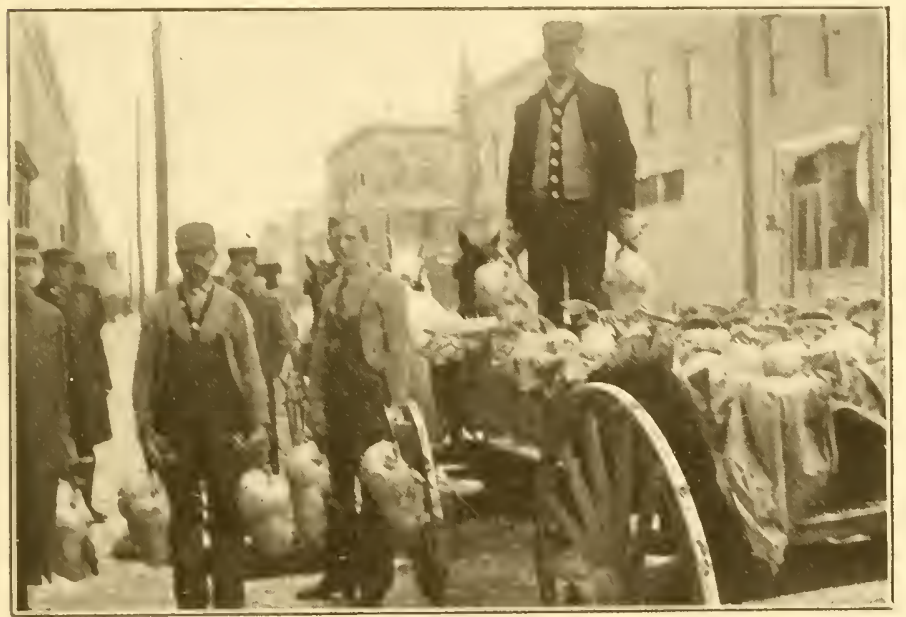

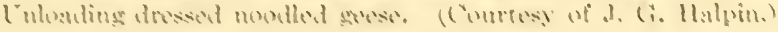

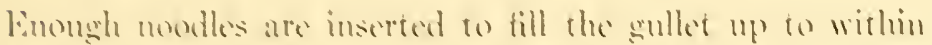
two inches of the throat. Afer teeding she gonses is atlowed to walk out inso the main pen and drink from a tromsh of warm water, in which may be sprinkled a licte corn mest.

A goose shonld never bo moodled mont she has digestod sll rhe mondles from the previous ferding. At tirst the gereso are fed about four times a day. The mumber of ferdings is increased eradually metil the birds are fed every thres homrs. day and night. Girat cale must be taken at all times not to trighten the birds. or they will stampede. 
The feeding period usually lasts from two to three weeks, and the gains made run from 20 to 40 per cent at a feed cost varying from 10 to 20 cents per pound gain. Besides the marked gain in weight secured, the livers of the birds become very much enlarged, and are much prized by epicures, being known under the name "pate de foi gras." The demand for these enlarged livers is not anywhere near supplied, and considerable quantities are imported from France and other European countries. Goose fat, or goose oil, is also in good demand and high in price.

Noodled geese are in demand in the Hebrew sections of the larger cities, and offer a lucrative though very confining three weeks' work, falling usually in late November and early December. 


\section{CHA P TE⿺辶R XIII. \\ PIGEONS AND GUINEA-FOWL.}

\section{BREEDS OF PIGEONS. ${ }^{1}$}

Pigeons are divided into three general classes: (1) Those differentiated by characteristics other than color markings, which include the English Carrier, Pouter, Barb, Short-faced 'Tumbler, and Runt; the latter strangely enough is the largest of the pigeons. (2) Those differentiated by a peculiar arrangement of the feathers, as well as by color markings, which include Turbits, Jacobins, Scandarcons, Frillbacks, Owls, Trumpeters, Fantails, Dragoons, Priests, Brunswicks, Oriental Frills, Florentines, and Homers. (3) Those in which color markings alone are distinguishing characteristics, which include the Nuns, Magpies, Swallows, Helmets, Spats, Archangels, Suabians, Shields, Ice. Pigeons, Starlings, Breasters, Moorheads, Long-faced Tumblers, Porcelains, Hyacinths, Quakers, Lahores, and Mookies.

Of all these breeds the Homer, with its grades and crosses, is the only breed that enters largely into squab production.

Pigeon Breeding.-With pigeons the influences of breeding is confined to a single pair, and the breeding loft should contain only working pairs of breeders. A working pair refers to birds which have voluntarily taken each other as mates. The so-called "hand-mated" birds, by which reference is made to the fact that the birds have been mated by confining them in a mating coop, frequently prove unsatisfactory because the mating proves to be temporary. Voluntary mating is usually for life.

1 This classification is the one offered by Long in "The Poultry Book." 
Mating is accomplished by allowing the unmated birds to occupy a room containing some nest boxes. As soon as a pair is observed to start building a nest together they should be caught, banded, and removed to the breeding loft. Usually about 90 per cent of the birds will mate where upward of one hundred are placed in the matingroom. After a pair is mated the cock drives the hen until she deposits her eggs in the nest. A good driver is likely to be a good breeder.

FIG. 209

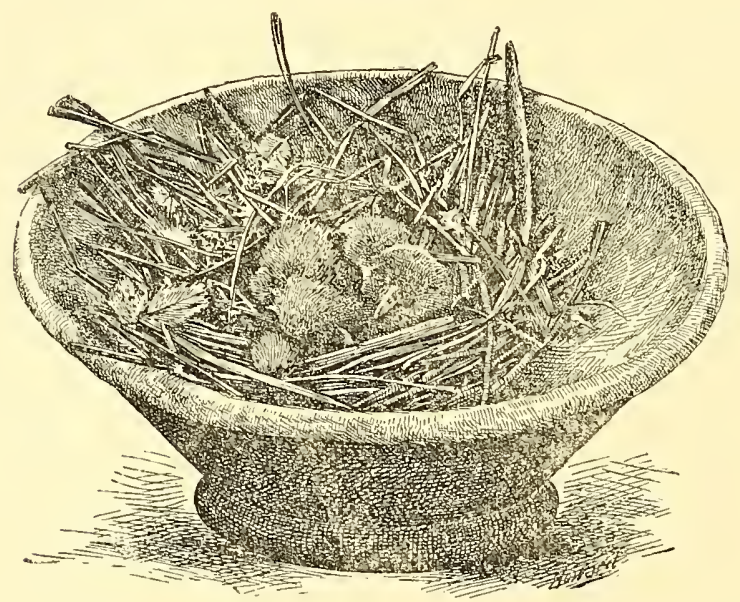

Squabs ("peepers"), twelve hours old.

Two eggs are laid about thirty-six hours apart and usually hatch between sixteen and eighteen days after the last egg is laid. When the eggs are first hatched sex cannot be determined, but if both eggs are hatched and prove to be a pair the cock will usually hatch about twelve hours earlier than the hen. Where two squabs hatch in the same nests of unequal size they should be changed from nest to nest so that the pairs are evened up in size. If this is not done the earliest hatch or largest bird will crowd the smaller one so that it is likely to die. 
Pigeons mature at five months, but are said not to breed until the tail feathers are moulted. In order to hasten the

FIG. 210

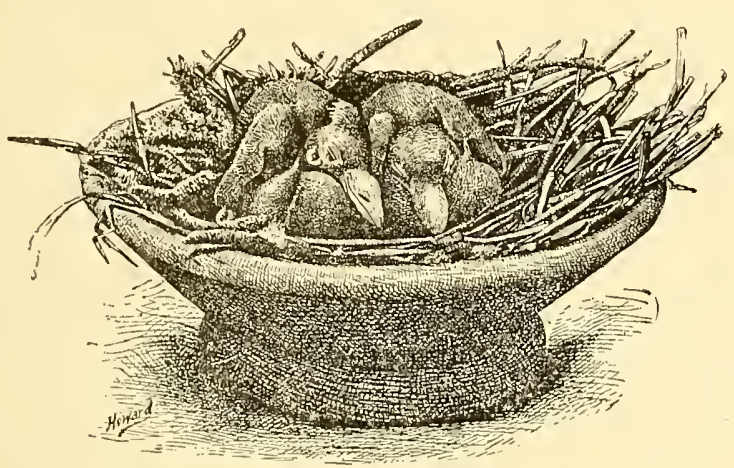

Squabs ("squeakers"), twenty-four hours old.

FIG. 211

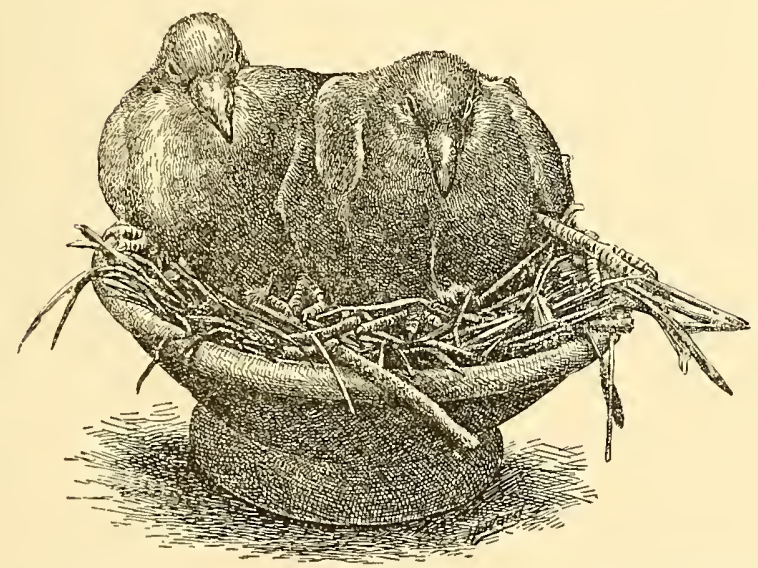

Squabs ("squealers"), twenty-eight days old, ready for market.

breeding it is sometimes customary to pull the tail feathers out at the age between six and nine weeks, at which time they may be placed in the mating-room. 
A young pair will usually not produce more than two pairs of squabs the first year. While unusual, mature pairs sometimes produce as high as twelve pairs in twelve months; the average production probably lies between five and six pairs. Breeders are at their prime at three years, and six to seven years mark the limit of their usefulness.

In squab-breeding the white meat is the most desirable. This white meat may be detected by the white toes, beak and flights, and red legs. Some of the best breeders secure this by crossing a Florentine and Runt and crossing the offspring with a Homer, while others prefer the pure Homer.

Pigeon Houses.-Any outbuilding that is dry and has a board floor may be used for a pigeon loft. It should be sheltered and have a south exposure. It is customary to allow four square feet of floor space per pair of birds. Upon this basis it is possible to house one hundred pairs in a building $25 \times 16$ with a gable 10 feet high. Dryness is so essential that squab breeders frequently erect their houses on posts, giving a clearance of two feet between the ground and floor.

The nests should be placed on the north, east, and west walls, beginning one foot above the floor. This may be done by nailing a cleat on the east and west walls one foot wide and holding a board ten to twelve inches wide one foot above the floor; every ten inches above these other cleats should be laid clear to the roof, after laying boards of uniform width clear to the topmost cleat. Partition pieces $10 \times 12$ may be cut and inserted between the shelves every ten inches. Between these partitions pottery nests nine inches across and four inches deep should be placed.

Good perches may be made by nailing two pieces five inches wide and six inches long at right angles. These perches should be nailed to the wall (as shown in Figure 212) running clear to the top of the house, one perch every nine inches. By placing these at right angles and letting the median line of the upright bisect this angle the necessity of cleaning the perches will be obviated. There should be one perch for every bird. The floor of the house should be kept bare of litter and cleaned at least once a month. 
Tobacco stems cut up into four-inch pieces make the best material for nests.

A flight should be provided, figuring on the basis of a space $25 \times 25$ feet and as high as the house, for fifty birds.

FIG. 212

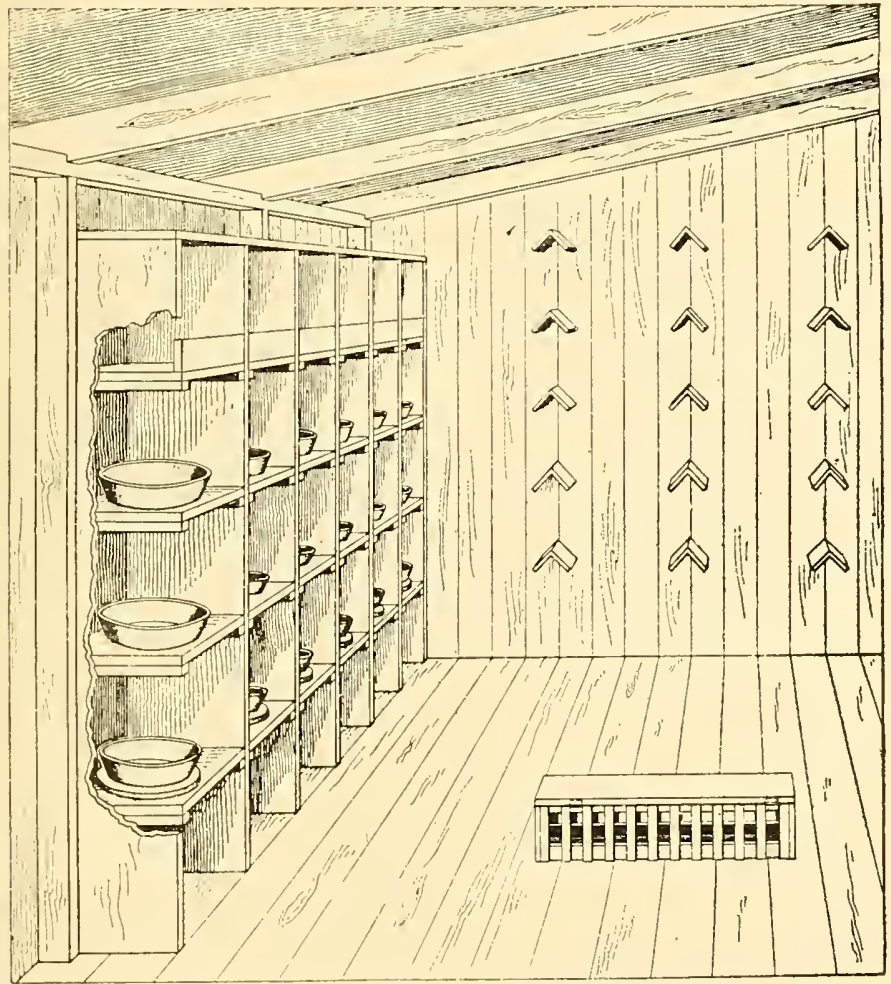

Interior of pigeon pen showing a feed hopper, roosts, nest boxes, and different kinds of nest pans. (Courtesy of Bureau of Animal Industry.)

Feeding Pigeons.-During the first days of its life the squab is fed a cheesy substance regurgitated from the crop of both parents for a period of five to seven days; for the subsequent two weeks partially digested grain is fed in the same 
manner. After they are three weeks old they can usually be fed the same ration as the old stock. This should consist of a variety of feed, such as corn, peas, and red wheat. White wheat seems to have an injurious effect upon the digestive tract and to cause bowel trouble.

F1G. 213

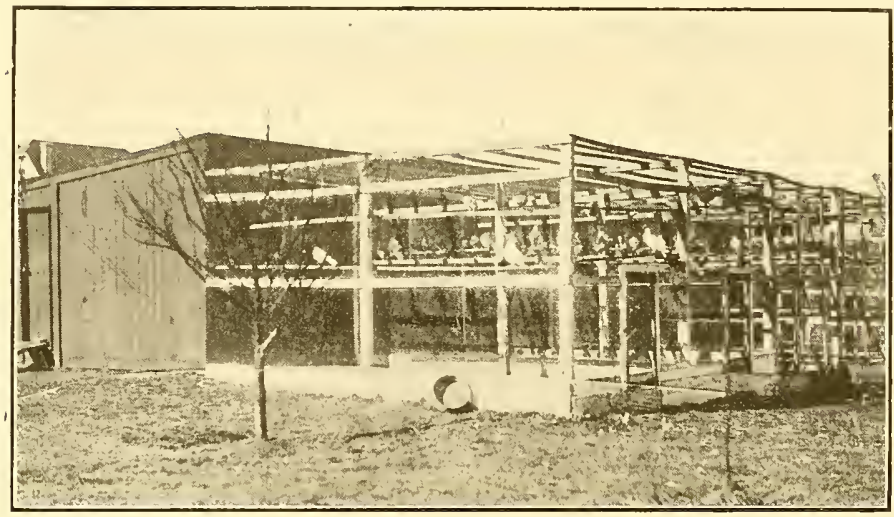

Pigeon house and fly. Note bath pan against fence. (Courtesy of Bureau of Animal Industry.)

A good ration is reported by $\mathrm{T}$. S. Wright, one of the largest squab breeders in the East, to be the following:

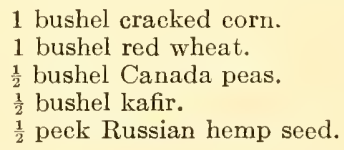

The ration may be fer three times daily on the fioor, allowing one handful for every three birds, or by means of feeding troughs. Care must always be exercised to see that the grain is not musty, for musty feed will kill pigeons just as it does young chicks.

Rock salt, oyster shell, and grit should always be available, and green feed in the form of lettuce, plantain, and water cress should be fed once a day. Aside from the water 
furnished for drinking, and contained in fountains similar to chick fountains, water for bathing should be supplied in pans three to four inches deep. This water should be thrown out as soon as the pigeons have had their daily bath.

\section{GUINEA-FOWL.}

Guineas are quite similar to turkeys in their habits and management. They have never become fully domesticated, are impatient of restraint, preferring to roost out in the

FIG. 214

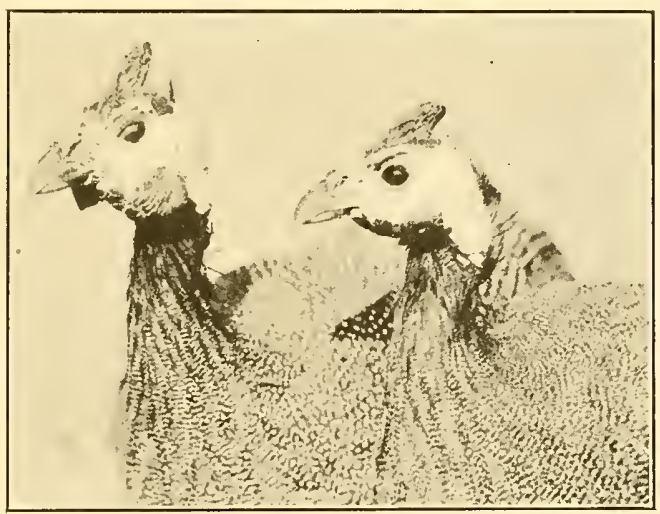

Pearl Guinea-fowl. Male and female. (Courtesy of Bureau of Animal Industry.)

open, though they will frequently roost in the hen-house with the chickens. They are very hardy and usually necessitate little care. Because of their watchful alertness and their loud warning cries in the presence of danger, they are frequently kept on farms to warn the other fowls of danger and to frighten away hawks, crows, and the like. Guineas have only recently been recognized as a standard class of poultry. But one variety, the pearl, has been admitted to the standard, though whites are not uncommon, 


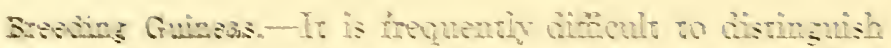
berwern the sexes with sumes-fowl. White the hest fum nishing of the male ane senersily more bevelwed chm in the temalc, the sures? wsy ro rell chem spont is by rhein ery.

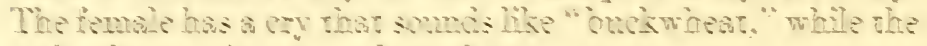

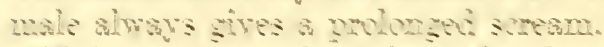

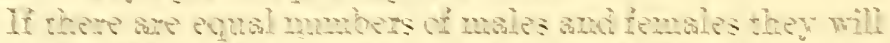

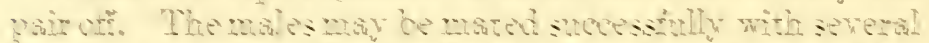

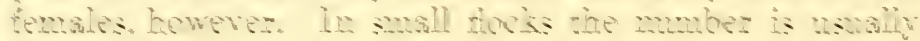
three or form.

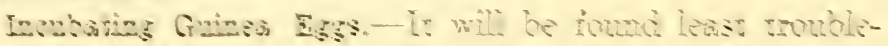

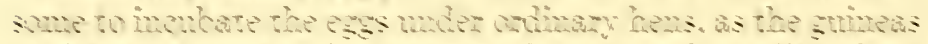

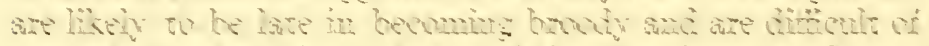

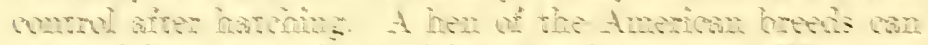

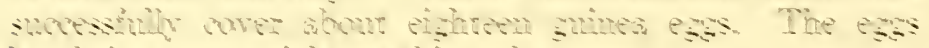

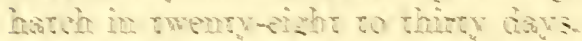

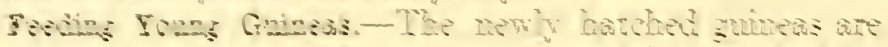

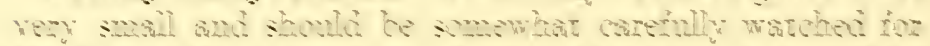

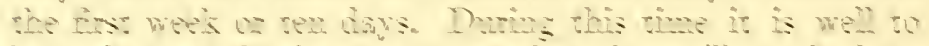
keen chem numed to s mon so rist they will wor be los.

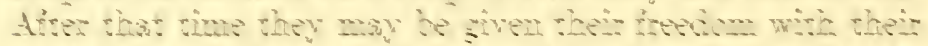

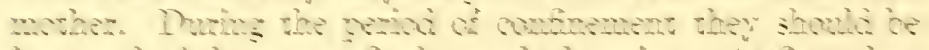

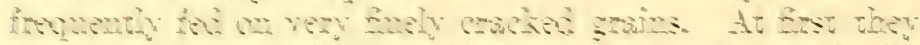

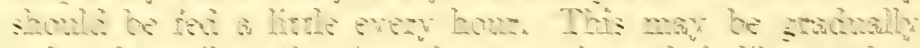

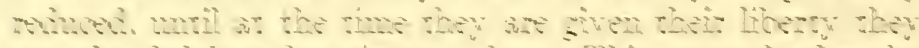

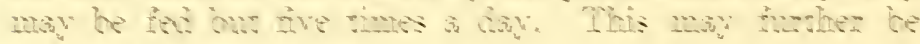
retured a time sues om

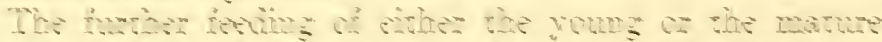

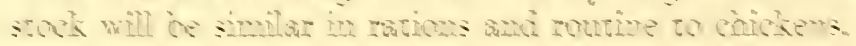




\section{(HAPREX゙ル。

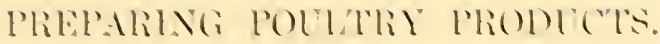

\section{SEASONAL PRODUCTS.}

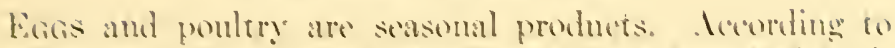

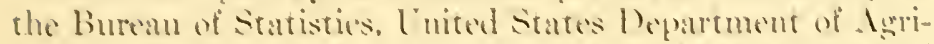

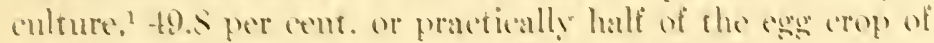
the Luited states is produced in Mareh. April, Mlay and Iume. as shown in 'lable Xl1\%, though duly and lugwst ate usually counted as a part of the engy sagson. 'The Hush (point of highest production) has fallen in April every year tor the

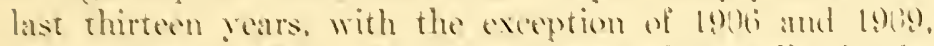
when it fell in May. 'This date is somewht carlice in the southern states than in the northern. "l'he lay in l'ennessed and Kentucky is from December mat ipril. In March and April, sonthern Oho and Missouri stocks appera on the market, helped aloug by 'lexas, southern Mlisomri, and southern Kansas. In the later spring. northern Kansis. lowa, Indiana, lllinois, and the Central States generally lawe their heary producing season, and it is when this ocents that egres are best and most plentiful. Mimesota and Michigan. with a still later season, help out somewhat when the supply of the Central states begius to fail, but the output of hoth the southern and northern con belt is far from adequate to supply the demands of the widespread consmumen public."

'The poulty season begins in dugust and lasts until about the first of damury. In duly and August there ale usually quite heary receipts of broilers. with the heavier roasting chickens coming later. The average number of ponmes of all grades of poultry received cach month thring the last

1 lisllutin No. 101.

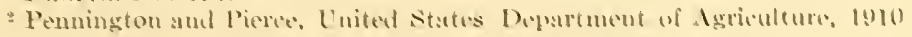
Veror-book, 
four years, at a western packing-house, is shown in Table XLVII which is put in graphic form in Figure 216.

Table NLVI. - The Percentage of the National Egg Crop Prodeced Each Month.

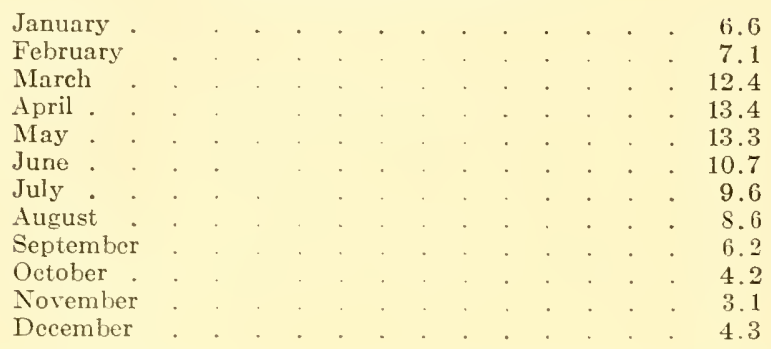

Table Xlil.-The Average Receipts of Potltry at a Western Packing-house for Each Month, Based on the Period 1910-1919 INCLUSIVE. ${ }^{1}$

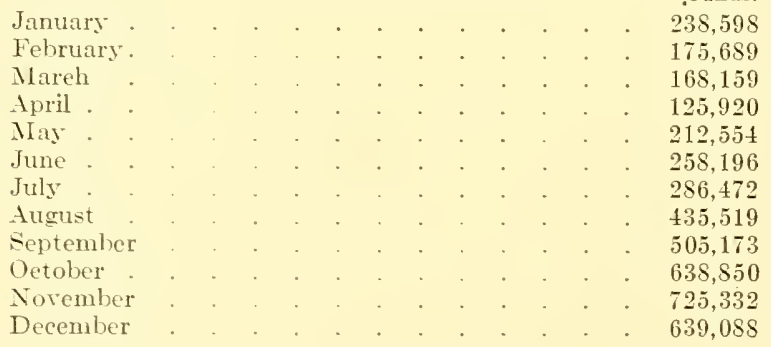

It must be understood that these seasons are longer and are hardly so clearly defined as the seasons for strawberries and regetables. They are sufficiently marked, however, so that during the egg season practically the whole force at a packing establishment is employed in packing eggs. The transition from the egg season to the poultry season is somewhat gradual, but in October and November the whole force is busy packing poultry.

This discussion, of course, applies to the general condition. Both eggs and poultry may be and are produced out of season.

${ }^{1}$ Courtesy of Seymour Packing Company, Topeka, Kansas. 
Some of the specialized poultry farms east and west make a practice of furnishing poultry products out of season and very

FIg. 215

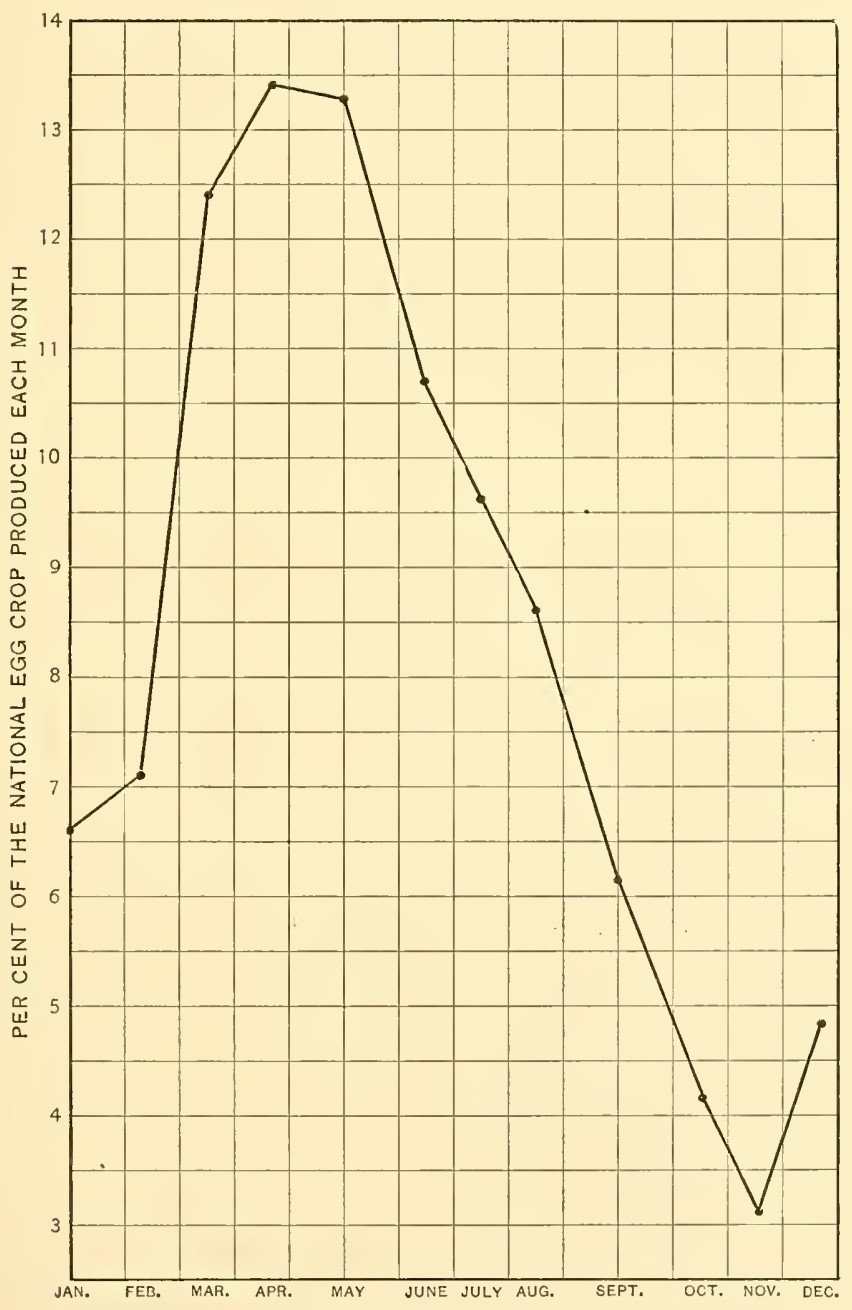

A graphic presentation of Table XLVI. 
many general farms secure a few eggs during the winter, and with a little care and attention may get more. As

FiG. 216

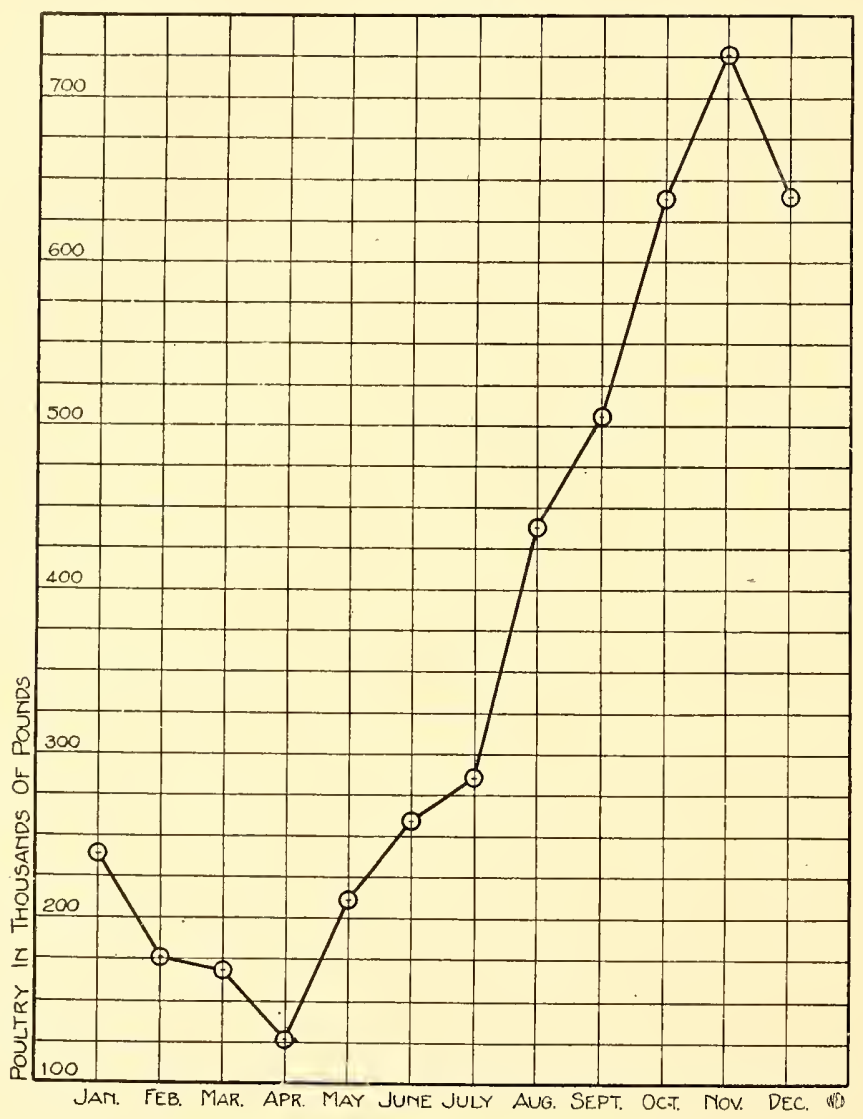

A graphic presentation of Table XLVII.

previously noted, however, farmers specializing on out-ofseason broilers and eggs bear much the same relation to the general production of poultry that truck gardeners who raise 
radishes, lettuce, and tomatoes under glass bear to the general production of vegetables. Fresh winter eggs, like fresh winter strawberries, are out of season products and should be paid for as such. For most persons, the strawberries eaten in winter must be preserved by canning and saved over from the previous season. The eggs eaten out of season by most of the consuming public must also be preserved, usually in cold storage.

The View-point of Preparation.-The preparation of a product depends upon the purpose for which it is intended. As was pointed out in the first chapter, there are numerous channels through which poultry and eggs may reach the consumer. In general, however, both products may be designated for our present purpose as intended for immediate or for future consumption. Immediate consumption refers to those products which are delivered to the actual consumer by the producer without the aid of any intermediate agency. This means retailing by the producer, unless the producer is also the consumer, and is usually referred to as "private trade." When the products are to reach the consumer by any channel less direct, they must be considered as intended for future consumption.

In any discussion of proper methods of preparing poultry products for consumption in those sections where production is greater than consumption, the producer should have two points clearly in mind: (1) the possible distance of the consumer from the place of production and (2) the time that may elapse before consumption. It is the quality of the goods when they reach the table of the consumer, not when first produced, that quickens or depresses consumption and has a marked influence upon the price paid the producer. ${ }^{1}$

1 It is not within the province of this work to discuss marketing save in so far as an understanding of marketing conditions affects the preparation of the products. It may sometimes appear to the producer, however, that as his products are likely to be marketed in a distant city after months in cold storage, his pains in preparing poultry or eggs for consumption are likely to be wasted. If his efforts are not spoiled by the blunder or carelessness of some middleman, it is the middleman who receives the added profit.

Under the present systems of marketing farm products, this is undoubtedly frequently true for all classes of goods. With the growth of the poultry- 


\section{PREPARING POULTRY.}

Most of the poultry produced on general farms is sold alive and is prepared for consumption by the packer. The tendency appears to be for home killing for general consumption to be less and less practised and for the preparation to be made by some one other than the producer. In some cases, however, home preparation is profitable and for private trade is usually necessary. It consists of dressing and packing if intended for general consumption, and may consist of dressing, packing, trussing, and, infrequently, boning if intended for private trade.

Dressing.-A fowl is said to be "dressed" when it has been killed and plucked. For convenience, the operations incident to dressing will be discussed under the topics of (1) killing, (2) bleeding, (3) picking, and (4) cooling and shaping. If any part of the process is not carefully and thoroughly done, deterioration of the product follows promptly. The function of dressing is preservation, or rendering the poultry less perishable, as well as putting it in edible form.

Before the actual dressing operations are begun, the birds should be kept from all feed for twenty-four hours, allowing, however, a liberal supply of fresh water. This will serve to empty the crop of all food. A full crop not only means wasted feed, or selling the feed at the rate per pound received for the carcass, but that spoilage will set in in the vicinity of the crop very much quicker than it ordinarily would or than it will in other parts of the body. The intestines will also be partially emptied, which will generally preclude postmortem defecations caused by handling, and which frequently soil an otherwise attractive carcass.

packing industry on the one hand and coöperative marketing associations on the other, this, however, is becoming less true. The real packer needs and pays for the very best products he can get, and takes care that they do not deteriorate in his eare. In coöperative marketing, the relation between the producer and consumer is made closer, and any benefit derived from marketing superior goods reverts at once to the producer.

In a broad way, however, the statement made above is true even at the present time, and the better the products, the wider will be the consumption and the higher will be the price level. 
Killing.-The method of killing will depend upon the destiny of the bird. If it is for home consumption, the simplest way is by dislocating the head. With this there is no external

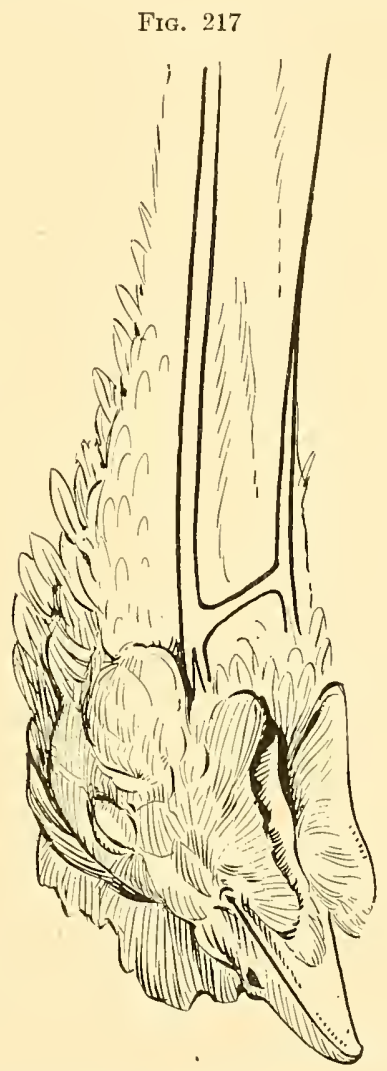

External view of head and neck, showing position of veins. (Courtesy of Bureau of Chemistry.)

bleeding. The blood collects in the pocket formed inside the skin and between the head and the end of the neck. While this method is used commercially in England, it is not in general use in this country because it is thought that the 
bleeding is not thorough enough to make the birds keep well, and further, it does not fit in with the rest of the dressing operations, as practised commercially.

For home use it is convenient because there is no spattering of blood. The bird may be held until the spasmodic actions of the muscles have stopped, instead of allowing the forl to flop about, bruising the flesh. The bleeding is probably more complete than with the old-fashioned methods of mringing the neck or chopping off the head, in both cases bruising the bloodvessels and exposing them to the clotting action of the air, and thereby checking free bleeding.

For private trade where scalding is practised, the killing is done by serering the principal bloodressels of the neck (see Figure 217) and causing the bird to die by bleeding.

In commercial dressing where dry picking is practised, the birds are killed by "sticking," by which is meant the piercing of the brain with a small-bladed knife, for the double purpose of killing the bird and at the same time so paralyzing the feather muscles that dry piching is possible.

Sticking may be accomplished "by running the knife under the eye at such an angle that its point will touch the shull midway between the eyes and a little behind them,"1 or "by placing the knife about half-way down the groove in the roof of the chicken's mouth, and then thrusting it up until the knife reaches the top of the skull."' These two mays of sticking are referred to as "outside" and "inside" sticking, respectively. In both cases the point of the knife should be moved about a little after it is thrust home, in order to destroy enough brain tissue to loosen the feathers thoroughly.

Bleeding.-Pennington and Betts $^{3}$ report that fully 30 per cent. of the poultry received in the New York market is incompletely bled. "Much of it is so badly bled that it results in a loss of from tro to five cents a pound, as compared with the corresponding carcasses which are well bled and in good order. Aside from the bad appearance of incompletely bled chickens, their keeping properties are

1 Pennington and Betts, Bureau of Chemistry Circular No:61.

: Ibid.

${ }^{3}$ Bureau of Chemistry Circular No. 61. 
Fia. 218

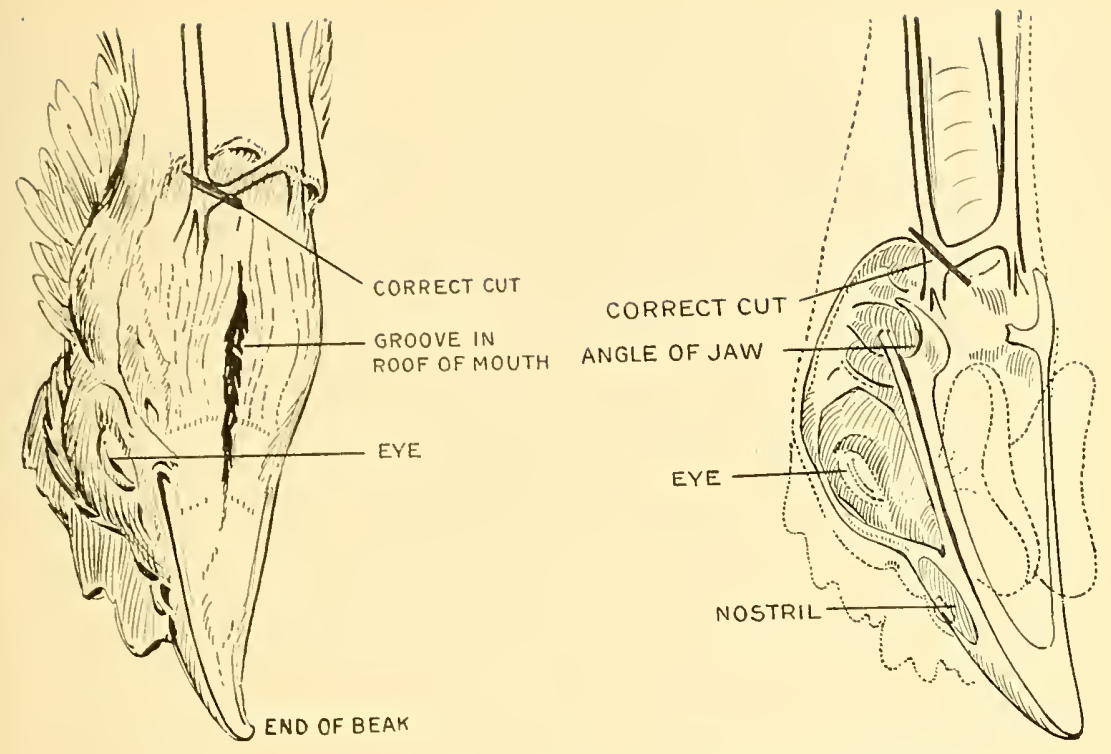

Lower jaw removed, showing position of veins, anatomy of skull, and location of cut. (Courtesy of Bureau of Chemistry.)

FrG. 219

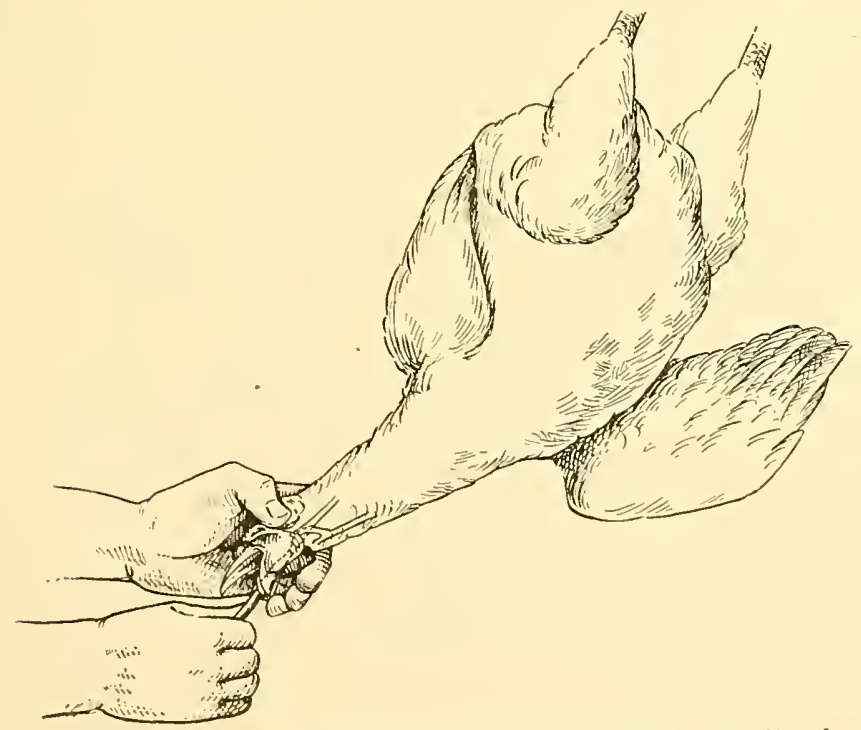

Correct grasp of head at angle of jaw and position of small knife when cutting vein. (Courtesy of Bureau of Chemistry.) 
very inferior. The flesh loses its firmness sooner; its flavor is not so good; the odor of stale flesh and finally of putrefaction comes sooner, and in every way the product is more perishable.

"A very large proportion of the unsightly poultry in our markets, aside from the rubbing and tearing of skins, is caused by an incomplete removal of the blood. This is evidenced by red dots which frequently occur where the feathers have been removed, especially over the thighs and wings; or by small veins which are seen over the breast and in the angles of the wings, or larger veins which mar the appearance of the neck. Generally it is the neck which shows most plainly the presence of blood in the veins, or that a wrong method has been used in an attempt to empty them. The neck is the first part to discolor, becoming first red, then bluish red or purple, and finally green as aging progresses. . . . Not only are the results of bad bleeding observed in certain parts of the body, but the clear, bright color of the flesh : . . is never at its best unless the blood has been completely drained out."'

In dislocating the head and in killing by severing the main bloodvessels of the neck, both killing and bleeding are accomplished in one operation. When killing is accomplished by sticking, the bleeding should be done either before or after sticking, each way having its advocates.

Whether done before or after sticking, or with birds intended for scalding without sticking, great care must be taken, until skill makes care unnecessary, to sever the veins at their point of joining, as shown in Figure 218. Just the location of these veins can only be learned by a careful first-hand study of the head and neck of the fowl itself.

The best knife to use, according to Pennington and Betts, ${ }^{2}$ is one "which is not more than two inches long, one-fourth inch wide, with a thin, flat handle, a sharp point, and a straight cutting-edge."

Picking.-There are two methods of picking (plucking) in general use, known as "scald picking" and "dry picking." 
If the birds are being dressed for immediate consumption and no use is to be made of the feathers, chickens may be scalded and the feathers easily plucked. If reasonable care is taken not to cook the skin, this is both an easy and reliable method. Yellow-skinned birds present a better appearance after scalding than after dry picking if the work has been properly done, because it brings out the color better. Ducks must be scalded or steamed, because no means of sticking them so as to loosen the feathers has been devised. Immediately after scalding, the bird should be plunged in cold water. 'This stops the cooking action of the hot water and renders the bird plumper in appearance.

If the consumption of the bird is to be delayed for any reason, as by shipping, storing, or even awaiting sale in a retail store, it should be dry picked. Even the most careful scalding destroys the delicate but very important cuticle that covers the skin. This cuticle is the fowl's defense against the invasion of microörganisms of all sorts, and if destroyed during the dressing process, putrefactive bacteria quickly gain entrance to the carcass and begin their work of decomposition.

Successful dry picking depends upon the proper sticking of the fowl, which loosens the feathers by paralyzing the control muscles of the feathers. If this is successfully accomplished, for a short time, the feathers may be removed with as much ease as if the bird had been scalded. The cuticle is left uninjured and the carcass will stand holding, shipping, or freezing very much better than when scalded.

There are three ways of dry picking, known as string picking, bench picking, and frame picking, which is a combination of the first two. In the first, the legs are caught in a loop or shackle, and the bird hangs head downward. After sticking, a weighted bloodcup is attached to the fowl's mouth, which helps to hold it steady.

With bench picking, a bench or table is used, as shown in Figure 221. The head of the bird is held by a hook over a hole in the bench, so that the blood may run down into 
a bucket below. The feet are held by a [-shaped shackle, fastened by a rope passing orer a puller. which suspends a weight.

Fis. $2: 0$

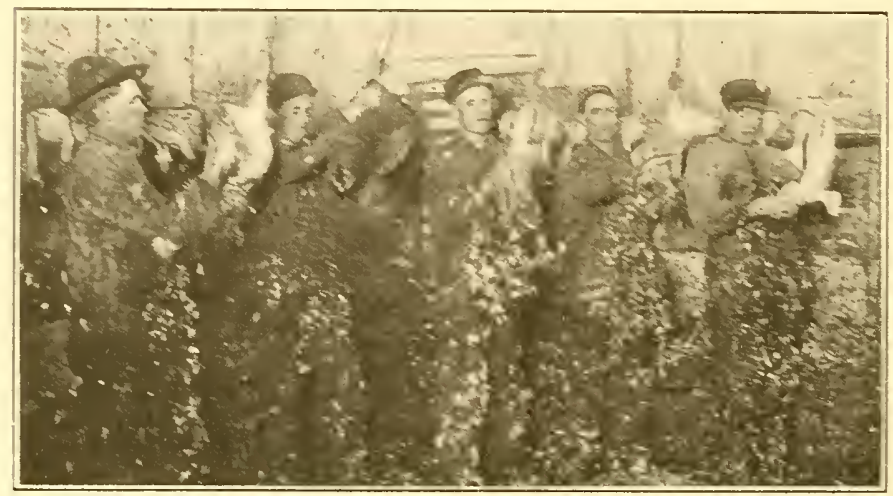

String picking in a commercial estathishmont. Couresy of Iows state College.)

\section{Fici, $2: 11$}

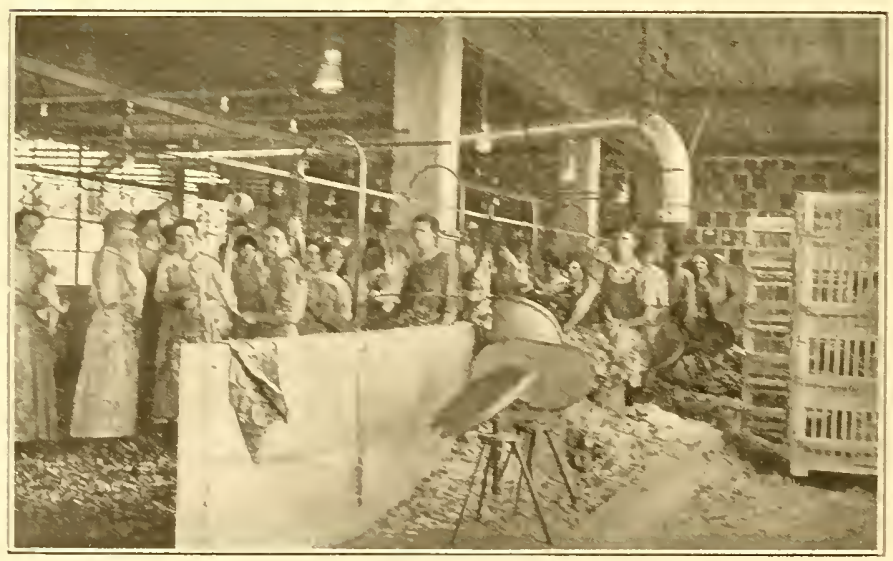

Drosing-room at a jorlory pehing-house. Notice men picing on bewches and the romen piming on strinst. The birds are taken direetly

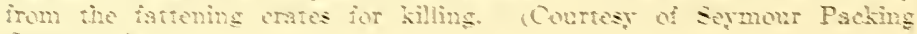
(owpany.) 
With frame picking, the head is held exactly as in bench picking. but the shackle holding the fect. comes from above and is weighted in such a way as to hold the bird's body up off the bench, thus giving the benefit of both methods.

The question of the relative merits of these methods of dry picking is one upon which packers and investigators are not agreed among themselves. The bench has grown in popularity rapidly, beeanse somewhat faster work can be done on it than on the string, and the feathers more easity sorted and saved. The bird is seldom smeared with blood, as in the case of string picking. On the other hand, the government investigators have found that cren when the bench is padded, the eareass is more or less bruised during the convulsions that follow the sticking and in flopping a bird over on its breast to pick its back. It is elaimed that these bruises are not noticeable at first, but that if the carcass is held or stored they become breeding places of bacteria which bring about deterioration. Some of the largest packers in the country, however, whose pack of poultry stands at the very top for quality, use the bench method. With string picking, there is, of course, little chance for bruising, though the picker and the carcass are often covered with blood, and the method does not appear so sanitary. In just how far the frame pieking will displace the other two, remains to be seen.

With either method, the greatest care must be used not to tear or even seuff the skin. In the superficial muscles of the breast taken from a carcass whose skin was ncither torn nor rubbed there are very few bacteria. In both the superficial and deep breast muscles of a fowl with a torn or even a rubbed skin, such numbers of bacteria will be found within twenty-four hours, that a marked change in the chemical composition will already have taken place.

In a well-organized commercial pieking room the work of picking is divided between roughers and pimers. 'The roughers bleed and brain the bird and remove the wing, tail, and larger body feathers. 'The pinners finish the plucking, carefully removing all pin feathers. 
Singeing is not practised when dressing for future consumption, because it tends to soften the skin and injure the keeping qualities.

Precooling.- - It is absolutely necessary that animal heat be allowed to pass out of a dressed bird as soon as possible after it is killed. Bacterial action begins at once. While cooling does not entirely stop it, it does greatly retard it. There are two methods of cooling-dry and wet. When dry cooling is employed, the carcass is simply placed in cold air until the animal heat has all escaped. While it is the common practice to freeze poultry that is to be held any time, care must be taken that freezing does not occur during the cooling process. If it does occur the carcass will not cool out properly. The reason for this is that freezing hardens the outside of the carcass, causing it to act as insulation. And further, it congeals the moisture near the surface and stops the flow of the juices of the body. The juices of the bird continue to flow from one part of the body to another for a considerable time after the bird is killed, especially if one part of the body is colder than another. This affords an opportunity for the internal animal heat to escape at the surface. It is well known among practical packers that with a bird placed in too cold a temperature immediately after dressing, the heat is held within long enough to give the putrefactive bacteria a chance to develop to a sufficient extent to give the bird an offensive flavor when cooked.

The best cooling temperature is between $30^{\circ}$ and $35^{\circ} \mathrm{F}$. To determine when a carcass is cool enough for freezing, insert a small stemmed thermometer into the vent. It should show a temperature of not more than $35^{\circ} \mathrm{F}$. The time necessary for cooling will vary with the size of the carcass.

Wet cooling is frequently resorted to. As soon as the fowl is dressed it is plunged into ice-water. This removes the heat effectively, but Pennington ${ }^{1}$ has found that 4 per cent. of the protein in chicken flesh will dissolve out in an hour. For every ounce of protein dissolved 4.3 ounces of water are absorbed. The practice is to be discouraged, and is coming

${ }^{1}$ Address before Missouri Carlot Shippers of Poultry. Kansas City, 1912. 
to be discriminated against. 'The soaked skin, like the scalded skin, gives entrance to injurious bacteria. Deterioration in taste and appearance soon follows.

The matter of precooling both dressed poultry and eggs before shipment by parcels post to city customers should be carefully looked after. If a refrigerator is not available, the products should be hung down the well in an open bucket, unwrapped, until thoroughly cool. If well cooled before

Fig. 222

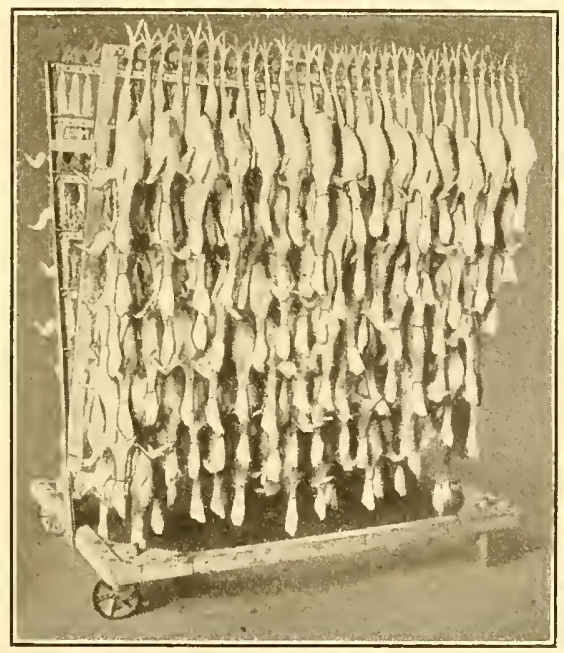

Poultry cooling rack holding 180 birds. (Courtesy of Bureau of Chemistry.)

wrapping, they will arrive at their destination in much better condition. 'This matter has not received the emphasis it should.

Faults in Dressed Birds.-At the central packing plants, birds are discriminated against for the following reasons. When the producer markets his own products he can eliminate each of these defects:

1. The birds are not properly finished. If two birds both weigh 4 lbs., but one is plump, well filled, and thick-fleshed, 30 
while the other is somewhat gangling and scrawny throughout, the former will outsell the latter every time. The second bird should never be marketed until enough flesh has been put on to make him round out.

2. Birds such as were just described are found packed in the same package. The result is invariably that the package goes at a price much nearer that paid for the poorer quality than for the better quality. Poor quality drags down the price much more than good quality can pull it up. Much more will be realized if the good birds are packed together and the inferior ones together. When the inferior ones are all together they gain the advantage that comes from uniformity and are not at the disadvantage of being in direct comparison with better goods.

3. Birds are not picked clean. Too many feathers are left on the neck or a garter or ring of feathers is left around the hock-joint. Often the wings are not picked clean. At times the whole body of the bird must be gone over to remove feathers or pin-feathers. Careful work in this particular greatly adds to the appearance and salability of the product.

4. Birds often reach the grader with some food in their crops. If stored in this condition the flesh around the crop soon turns dark green. It is necessary to remove the contents of the crop. To do this one must make an incision under the shoulder where it will show least. A bird that has had the contents of the crop removed in this way is on a par with a torn bird, as far as keeping qualities are concerned. Birds properly starved need have no food in the crop.

5. Fowls are frequently received with voidings protruding from the vent. With a little manipulation the intestines for some distance back from the vent may be emptied of their contents and the contamination of the other birds in the box avoided.

6. Many birds that are not actually torn have the skin barked or scuffed. Abrasions of the skin of whatever sort result in poor keeping quality.

7. The chickens are not properly bled, as evidenced by the red feather follicles or prominent bloodvessels in any part of the body, followed usually by a purplish discoloration on 
the neck and hips particularly, and frequently extending over the whole body.

Loss of Weight in Dressing.-The dressing percentage of the fowl is not of as much importance as in the larger meatproducing animals. The skill of the cattle buyer, in judging the dressing percentage of animals he buys, often makes the difference between the profit and loss. It should be noted, however, that with poultry, dressing does not refer to the removal of anything except the blood and feathers. The dressing percentage with steers takes into account the removal of all unmarketable parts. The trussing percentage with poultry is more nearly comparable to the dressing percentage with the larger animals.

With poultry the individuals are so small and they are handled commercially in such large numbers that an average loss of about 10 per cent is usually assumed by the packers for birds in good condition, during the months of January to June inclusive. The shrinkage of dressing for the balance of the year is approximately as follows: July, 12 per cent; August, 12 per cent; September, 13 per cent; October, 14 per cent; November, 14 per cent; and December, 12 per cent. It is probable, as the standard breeds become more generally introduced among general farmers, that some discriminations in price will be made in favor of those breeds which dress out with the least loss, other qualities being equal.

In the following tables ${ }^{1}$ are given a comparison of the dressing and trussing percentages of young and old males and females and of several of the common breeds and varieties.

Lee $^{2}$ found, as the result of extended observations of milkfed poultry, that the dressing percentage of the following classes were, respectively, hens 85.6 per cent, roosters 85.3 per cent, springs 87.9 per cent, and broilers 85.7 per cent.

Special Dressings.-Capons should be dressed capon style. By this is meant the style that has become standard and which requires that the feathers be allowed to remain on a considerable portion of the bird. The feathers should be left on

1 Stoneburn, Storrs Bulletin 38.

${ }^{2}$ Bureau of Animal Industry, Bulletin No. 140. 
Table XlVill.-Comparative Dressing and Trussing Percentages.

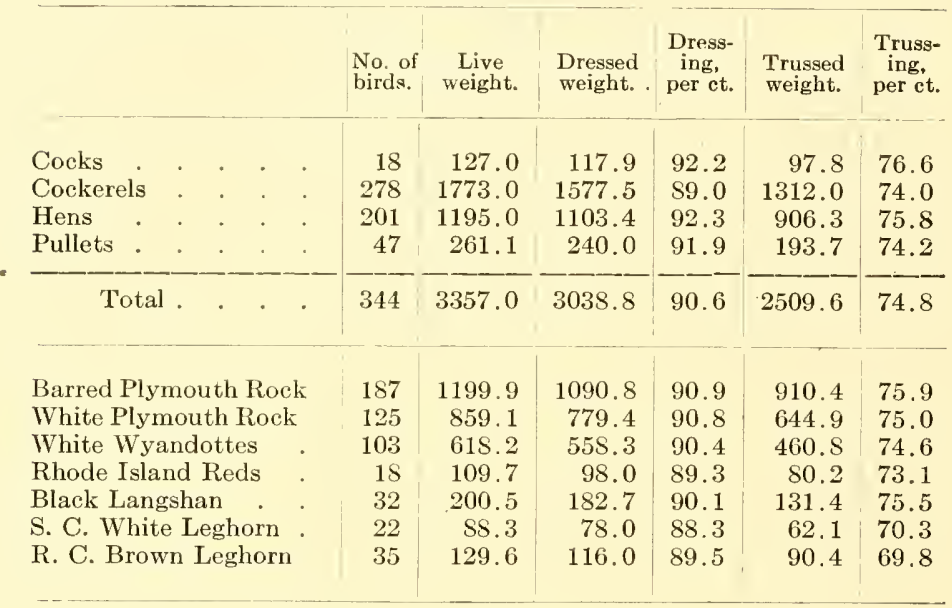

Table XliX.-Showing Comparative Percentage Weight of the Different Parts of the Carcass. ${ }^{1}$

\begin{tabular}{|c|c|c|c|c|c|c|c|c|}
\hline & $\begin{array}{l}\text { White } \\
\text { Wyan- } \\
\text { dotte } \\
\text { Cocks. }\end{array}$ & $\begin{array}{l}\text { White } \\
\text { Wyan- } \\
\text { dotte } \\
\text { Pullets. }\end{array}$ & $\begin{array}{l}\text { White } \\
\text { Leg- } \\
\text { horn } \\
\text { Cocks. }\end{array}$ & $\begin{array}{c}\text { White } \\
\text { Leg- } \\
\text { horn } \\
\text { Pullets. }\end{array}$ & $\begin{array}{c}\text { Light } \\
\text { Brah- } \\
\text { ma } \\
\text { Cocks. }\end{array}$ & $\begin{array}{c}\text { Light } \\
\text { Brah- } \\
\text { ma } \\
\text { Pullets. }\end{array}$ & $\begin{array}{l}\text { Barred } \\
\text { Rock } \\
\text { Cock- } \\
\text { erels. }\end{array}$ & $\begin{array}{l}\text { Barred } \\
\text { Rock } \\
\text { Pull- } \\
\text { ets. }\end{array}$ \\
\hline $\begin{array}{l}\text { 1. Blood } \\
\text { 2. Feathers } \\
\text { 3. Intestines } \\
\text { 4. Head and feet } \\
\text { 5. Bones of body } \\
\text { 6. Giblets } \\
\text { 7. Flesh }\end{array}$ & \begin{tabular}{|r|}
3.57 \\
8.97 \\
6.78 \\
7.78 \\
7.42 \\
4.49 \\
60.99
\end{tabular} & $\begin{array}{l}3.20 \\
6.07 \\
6.62 \\
7.75 \\
6.29 \\
4.64 \\
65.45\end{array}$ & $\begin{array}{r}5.40 \\
8.64 \\
10.13 \\
7.90 \\
6.86 \\
4.32 \\
56.75\end{array}$ & $\begin{array}{r}5.70 \\
8.46 \\
9.91 \\
6.30 \\
6.50 \\
4.46 \\
58.67\end{array}$ & $\begin{array}{r}5.11 \\
9.11 \\
11.11 \\
6.88 \\
6.66 \\
8.00 \\
53.13\end{array}$ & $\begin{array}{r}4.43 \\
9.38 \\
10.16 \\
6.77 \\
6.25 \\
8.07 \\
54.94\end{array}$ & $\begin{array}{r}4.02 \\
8.36 \\
9.91 \\
7.43 \\
7.43 \\
7.74 \\
\mathbf{5 5 . 1 1}\end{array}$ & $\begin{array}{r}4.26 \\
7.87 \\
8.52 \\
6.56 \\
7.87 \\
7.54 \\
57.38\end{array}$ \\
\hline Total. . & 100.00 & 100.00 & 100.00 & 100.00 & 100.00 & 100.00 & 100.00 & 100.00 \\
\hline $\begin{array}{l}\text { No. of chicks } \\
\text { Avg. live weight }\end{array}$ & $\begin{array}{r}16 \\
5.46\end{array}$ & $\begin{array}{r}12 \\
4.53\end{array}$ & $\begin{array}{r}20 \\
3.36\end{array}$ & $\begin{array}{r}12 \\
2.54\end{array}$ & $\begin{array}{r}4 \\
4.50\end{array}$ & $\begin{array}{r}3 \\
3.84\end{array}$ & $\begin{array}{r}2 \\
3.23\end{array}$ & $\begin{array}{r}6 \\
3.05\end{array}$ \\
\hline
\end{tabular}

1 Mairs, Pennsylvania Bulletin No. 87.

2 Does not include giblets.

${ }^{3}$ Does not include bones of head and feet.

${ }^{4}$ Heart, liver, and gizzard. 
the upper half of the neck. The breast and body should be plucked clean up to the large tail feathers. Pick the entire underside of the wing; pick the upper part of the wing, from the shoulder to the first joint. Leave the rest of the

FIG. 223

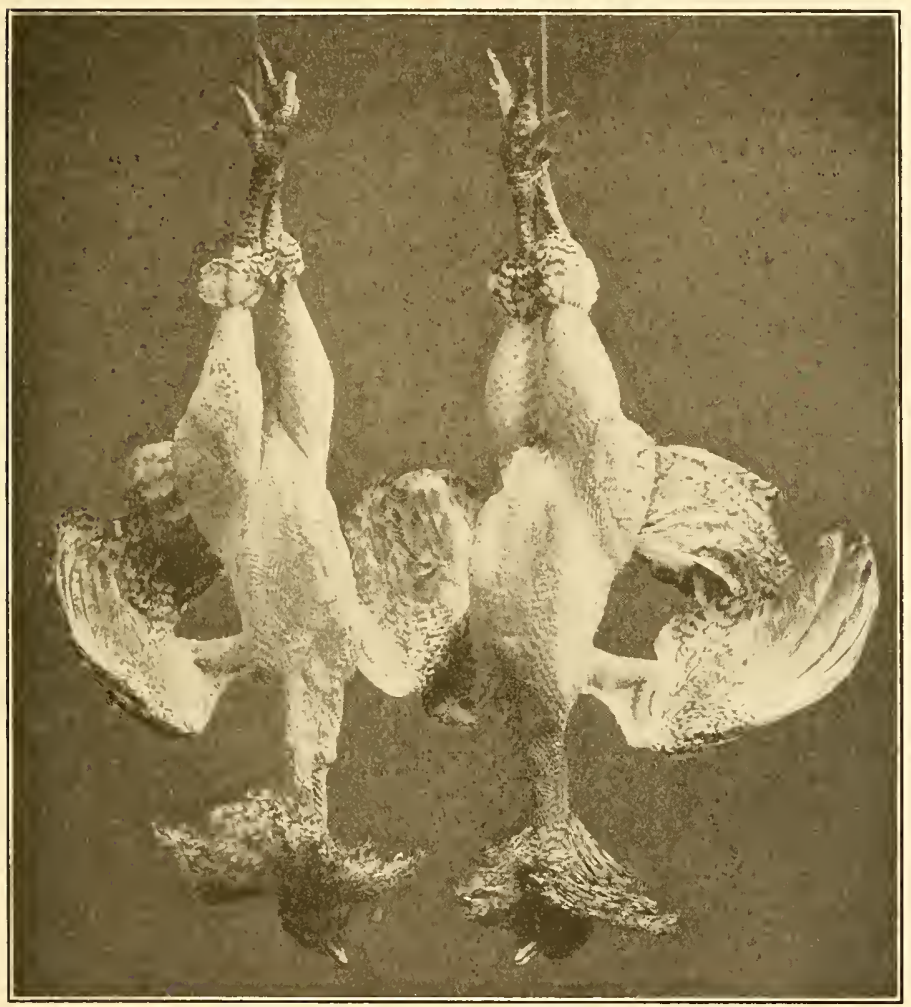

A pair of properly dressed capons.

wing feathers, which include the primary and secondary feathers, and a garter of feathers about the hocks.

Guineas should not be picked. Simply dislocate the head and cool out thoroughly. Pigeons should have the head dislocated and the feathers left on. Squabs (young pigeons) 
should be dry-picked and graded to size. Turkeys and ducks should be picked clean except where special markets desire it otherwise.

Geese should be picked clean. They should weigh 10 pounds or over and be of good quality. Under that weight they are likely to be very red-skinned or dark-colored when dressed. Geese should be packed as soon as properly cooled. If left exposed to the air they take on an oily and disagreeable appearance.

Different classes of chickens are frequently dressed in some special style, as leaving certain of the wing feathers on fowl. Such a means of dressing acts as a means of quick identification of certain classes of fowl not readily distinguished from other classes by the unskilled purchaser.

Feathers.-A by-product of dressing any class of poultry is feathers. There is ready market for all prime feathers that have been properly cared for. As will be seen by the quotations given below, white feathers are by far the most valuable. They should therefore be kept from the colored feathers, and wing and tail feathers should be kept from the body feathers and may be sacked at once. Body feathers should be placed in bins to dry and forked over every few days to keep them from matting. Duck and geese feathers bring a much higher price than the other classes.

Comparative Prices per Pound on the Different Classes of Feathers.

Goose....Pure white feathers . . . . . . $\$ 0.80$

Good average white . . . . . . . .70

Largely gray . . . . . . . . . . . . . 60

Largely gray, scalded . . . . . . . 40 to .45

Long goose-quills . . . . . . . . $\quad .10$

Duck.... Pure white feathers . . . . . . .60

Stained and sealded white . . . . 40 to .50

Dark . . . . . . . . . 38 to .40

Dark, scalded . . . . . . . .35

Chicken...Body, dry picked, all white . . . . .25

Body, dry picked, dark . . . . . . . . . 06

Damp, scalded, musty or very quilly . .02 to $.02 \frac{1}{2}$

Hackles (no quills) . . . . . . . . .15

Rooster tails, long fancy (free from stiff feathers) . . . . . . 1.00 
Turkey...Body, dry picked, all white . . . . $\quad .60$

Body, dry picked, dark . . . . . 10

Tails, dark, no skirts ${ }^{1}$. . . . . . .30

Wings, dark, no shorts . . . . . . .12

Tails, wings and pointers, ${ }^{2}$ no shorts $\quad .10$

Wings and pointers . . . . . . .06

Pointers, dark . . . . . . . . . . . . .

Shorts and skirts, free of body . . . .05

FIG. 224

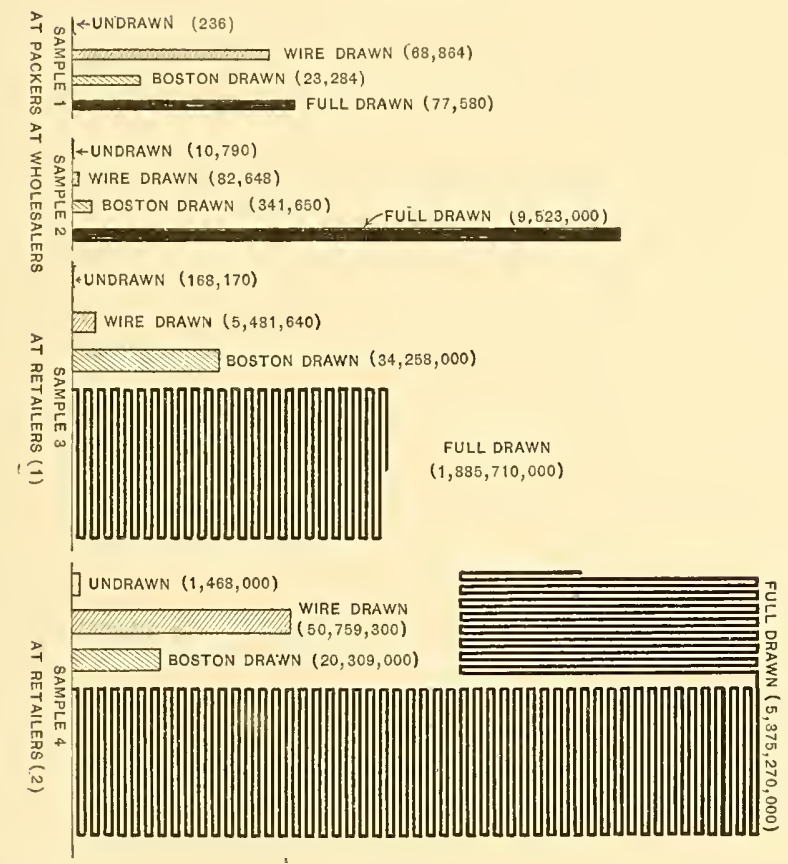

Showing the comparative increase in bacteria in the wall of the abdominal cavity after four different methods of dressing. ${ }^{3}$

Rate of Decomposition of Drawn and Undrawn Poultry.In studying the comparative rate of decomposition in un-

1 Saddle feathers.

${ }^{2}$ Primary wing feathers.

${ }^{3}$ Bureau of Chemistry Circular No. 10. 
drawn poultry and poultry that had been drawn by three different methods, Pennington, Witmer, and Pierce ${ }^{1}$ found that undrawn poultry decomposed more slowly than that which has been either wholly or partially drawn.

The three methods of drawing studied, as described by them, are "full drawn," "wire drawn," and "Boston drawn," as follows:

"For the 'full drawn' specimens the body cavity was opened by a transverse cut across the abdomen, and the vent was removed by cutting around it. The head was cut off and the intestines and viscera completely removed. The heart, liver, and cleaned gizzard, as well as the excess body fat, were put back into the body cavity. The shanks and feet were removed and the hocks were thrust through the opening in the abdomen and the vent.

" 'Wire' drawing consists in pulling out a loop of intestine by inserting the finger through the vent; cutting the loop, and drawing out the gut by careful traction until it breaks at the gizzard. The vent of a bird so drawn presents a normal appearance; the only indication of drawing is the collapsed abdomen.

"The 'Boston' drawing is a modification of the 'wire' in that a circular incision is made around the vent and the intestines pulled through until rupture occurs at the gizzard. The undrawn fowls were shipped with heads and feet on, and had no incisions except for bleeding and braining.

"'The 'full-drawn' poultry decomposed most rapidly, while the 'wire drawn' and 'Boston drawn' stood midway between the undrawn and full drawn in speed of decomposition. Of the latter, the wire drawn, which approached the undrawn condition most nearly, was the least objectionable."

The usual objection to undrawn poultry is that the flesh is likely to be contaminated from the intestines. A graphic representation of the comparative bacterial infection of the abdominal wall in the four methods of dressing, at the packers, wholesalers, and retailers, is shown in Figure 224. 
Grading.-Grading can hardly be spoken of as one of the really necessary steps in preparing poultry for consumption. In commerce, however, uniformity is so universally demanded by middlemen and by consumers who purchase more than a single carcass, that it has become an essential of successful marketing and for practical purposes may be considered among the necessary operations in preparing the products for consumption.

Market Classification of Chickens.-Grades and classes vary somewhat in different parts of the country and with different markets. The classification here given is that used by the Seymour Packing Company of Kansas, the largest exclusive poultry packers in the United States.

The live birds are classified according to sex, size, age, or hardness of bone, into (1) broilers, (2) springs, (3) fowl, (4) stags, (5) capons, (6) slips, (7) roosters.

(1) A broiler is a young chicken of either sex weighing two pounds or under. (2) A spring is a young, soft-boned bird of either sex that weighs over two pounds. (3) A fowl is a hen (female over one year old), or a pullet that shows too much hardness in the breast bone (keel) to be classed as a spring. (4) Stags are cockerels that exhibit too much hardness of bone, development of spurs or comb to be classed as springs, but not enough to be classed as roosters. Capons are cleanly castrated male birds. (6) Slips are birds upon which the operation of castration was not entirely successful. (7) Roosters are cocks (male birds over one year old).

Classification of Other Live Poultry.-Turkeys are classified as young (under one year) and old (over one year) toms, young and old hens. Ducks are usually marketed as green (young) roasting ducks. Geese are classified as young and old, one year the dividing point.

Grades of Dressed Chickens.-The same terms do not alalways refer to the same weights of live chickens as they do when the birds are dressed. The following are the grades used by Seymour Packing Company. While this exact classification will not hold in every section, it is given as representative of the various grades under which dressed 
chickens are marketed. The weights are for a dozen birds instead of one, as in the case of the live-weight classification.

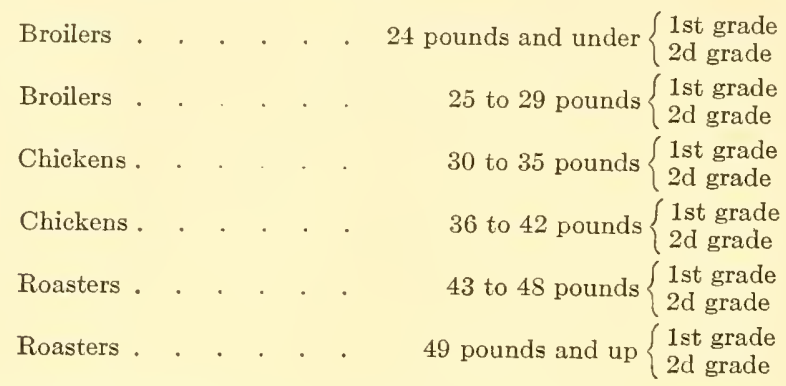

XX Springs unworthy to be placed in the first or second grade, all weights.

XXX Springs unworthy to grade XX, all weights.

All the foregoing come out of the broilers and springs of the live classification.

\begin{tabular}{|c|c|c|c|c|c|c|c|}
\hline Fowl & - & - & . . & . & . & 30 to 35 pounds & $\left\{\begin{array}{l}1 \text { st grade } \\
2 \mathrm{~d} \text { grade }\end{array}\right.$ \\
\hline Fowl & . & . & . & . & . & 36 to 42 pounds & $\begin{array}{l}\text { Ist grade } \\
2 \mathrm{~d} \text { grade }\end{array}$ \\
\hline Fowl & . & . & - & . & . & 43 to 48 pounds & $\left\{\begin{array}{l}\text { lst grade } \\
2 \mathrm{~d} \text { grade }\end{array}\right.$ \\
\hline Fowl & & . & $\cdot$. & . & $\cdot$ & . 49 pounds and up & $\left\{\begin{array}{l}1 \text { st grade } \\
2 d \text { grade }\end{array}\right.$ \\
\hline
\end{tabular}

$\mathrm{XX}$ Fowl unworthy to be placed in the first or second grade, all weights.

XXX Fowl unworthy to be placed in grade XX, all weights.

The foregoing are the fowl of the live-weight classification.

C Roasters, 42 pounds and under.

C Roasters, 43 to 48 pounds.

C Roasters, 49 pounds and up.

The above are the stags of the live-weight classification.

Light capons under 72 pounds.

Heavy capons over 72 pounds.

Slips, mixed weights.

Old roosters, mixed weights.

Torn birds, mixed weights. Chickens and fowls being packed separately: 
Packing.-In the broad sense, packing refers to all of the operations incident to preparing and preserving poultry for use as food. In a more restricted sense, it refers to wrapping it or placing it in suitable packages for shipment or storage.

Heretofore barrels have been used almost entirely for packing poultry. For the better grades, boxes are now almost wholly used. 'These are generally made from what is known as whitewood. Pine is cheaper, but it is likely to impart a piney flavor to the poultry if it remains long in the box. The boxes may be purchased knocked down (K. D.). The lumber is sawed to the exact size desired and comes in bundles of 25 parts each. Special cement-coated $5 \mathrm{~d}$ or $6 \mathrm{~d}$ box nails are used in making up the boxes, as ordinary nails rust if the box is placed in a refrigerator.

At present, in order to obtain the highest price and sell to the best advantage, all classes and grades of poultry, with the exception of culls unworthy to be graded, torn birds, and old roosters which are packed in barrels, should be packed one dozen to the box. Care should be taken not to put the birds into the boxes too loosely; that is, the box should not be too large. It is better to crowd the birds into the boxes, for when they fit snugly they look plumper when the box is opened.

There are very many styles of packing poultry, almost as many as there are different lines of trade. The following standard styles are taken from the "Poultry Packers" Guide:"1

1. Standard Broiler.-Wrap heads; line box with parchment paper. Pack one dozen birds to the box, six birds on each side with feet extended past the centre of the box. The breasts should be up, heads and feet hidden. The head is packed under and to the side of the bird it belongs to, and the feet crossed with those of the opposite bird, and tucked under the opposite bird. Be careful not to draw out the legs too far so that the bird will lose its plump appearance.

2. Standard Export.-Pack in single layer boxes. Line the boxes with parchment paper. Heads not wrapped. Pack

1 Pool Publishing Company, Mason City, Iowa. 
six birds with breasts up; six birds with backs up; heads brought forward and turned sideways so that the eyes show. A box packed in this style has the same appearance on both top and bottom.

3. Standard Roaster Style-All heavy fowl and turkeys should be packed in this style. Some capons are also packed in this style. Boxes lined with parchment paper. Heads wrapped. Pack twelve birds to the box in two layers. Parchment paper between layers. Bottom layer heads and feet up. Top layer heads and feet down. Both layers packed

FIG. 225

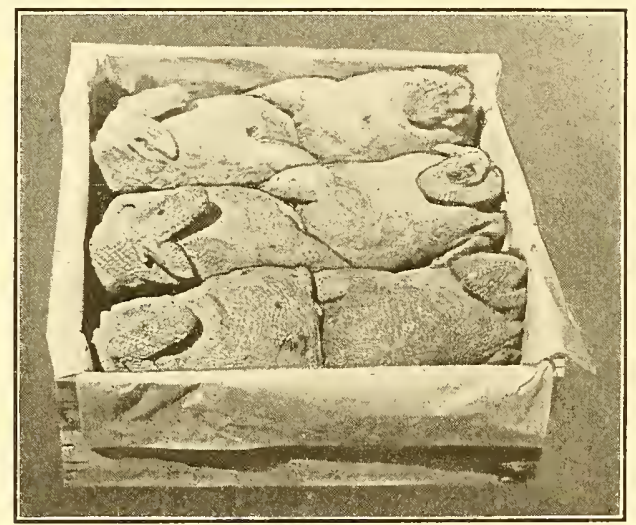

Box of well-dressed roasters.

on both sides and butts locked. To accomplish this three birds are packed with breasts one way and three with breasts the opposite way.

4. Single Layer Roaster Style.-Is used when marketing extra-fine stock for a particular customer. Arrange as in upper layer of the Standard Roaster Style, but pack in a single layer.

5. Standard Duck Style.-Is used for both ducks and geese. Pack in two layers, twelve to the box. Line boxes with parchment paper. Wrap heads. Parchment paper between layers. Lower layer breasts down, feet and heads up. 
Upper layer breasts up, heads and feet down. Both layers packed butt to butt.

6. Standard Capon Style.-Use deep box. Twelve to the box in two layers. Line box. Wrap heads. Parchment paper between layers. Lower layer, breasts down, heads and feet up. Upper layer, breasts up and heads and feet down. Legs crossed with those of the opposite and feet buried.

Stencilling.-If one is marketing a superior product it is decidedly advantageous to the name of the producer to have his name neatly stencilled on the box. In time one may gain a reputation for good goods and his products come into demand. This is particularly true if one comes in close touch 'with the consumer. If one deals through a jobber, he will probably prefer to place his own trade mark or name upon the goods.

For each class of poultry there should be a corresponding number which should appear at the upper left hand corner of one end of the box. This tells the person selling the goods exactly what to find in the box. For instance, the number 5 in the proper corner might indicate that the box contained fancy broilers weighing under $1 \frac{1}{2}$ pounds apiece. The number 43 might indicate fancy spring chickens between 4 and 5 pounds' weight. 'The figures representing the number of pounds net weight should always appear in the lower righthand corner of the end of the box:

$$
43
$$

The foregoing would indicate that there are in the box 12 fancy spring chickens of roaster size and that they weigh 54 pounds net, and are packed in Standard Roaster Style. Unless otherwise noted, it is always assumed that there are twelve birds in a box. This is all that is necessary if one is shipping to a jobber. It is the jobber's reputation that helps to sell the goods and, as before indicated, he places his own trade name or mark upon the box. If one is dealing directly 
with a retailer, however, one should give themselves the benefit of a reputation for high-class products. To do this, more extensive stencilling is advisable.

\begin{tabular}{|ccc|}
\hline 43 & 617 & 12 \\
& White Bird Farm & \\
& Fancy & \\
62 & D. P. Roasters & \\
& $\mathrm{s}$ & 54 \\
\hline
\end{tabular}

In the above-suggested stencilling the numbers 43 and 54 appear as before. The number 62 represents the gross and 8 the tare weights. The number 617 is a serial number by which any particular box may be recognized if any question is raised about it. It also aids in keeping track of the amount of business done. Fancy D. P. Roasters is the trade name by which the ordinary buyer will recognize them. D. P. means dry-picked. Aside from the farm name, there is no more necessary information on the second box than on the first. Giving full particulars, however, fosters confidence with the ordinary retail purchaser. At the same time, if for any reason the goods should be shipped to a wholesaler, the information he desires is there. If the number $4 S$ should appear in place of 43 , the wholesaler might know that he had 12 Fancy Roasters between 4 and 5 pounds the same as in the above case, but that instead of being packed Standard Style, they are packed Single Layer Style. For the retail purchaser this would make no difference. The class numbers may be arbitrarily chosen, or they may be those already in use in a given line of trade.

Determining the Classification.-Late in the fall it becomes difficult to determine whether certain chickens belong among the springs or among the fowls. To determine whether a chicken should be graded among the fowl or roasters, press the rear end of the keel. If it is hard and unyielding it should be classed as a fowl. If soft and pliable, it goes with the roasters. 
The classification of dressed ducks may be gotten at by squeezing the windpipe between the thumb and forefinger. If it can be compressed and flattened with slight resistance, the duck is young. If it is solid like a whip cord, it is an old bird.

Trussing.-For fancy family trade the producer frequently finds it profitable to go beyond the ordinary operations of dressing in the preparation of poultry for the consumer, and to truss the bird. Trussing refers specifically to fastening the legs or wings to the body, but is used here in the broader sense, including all of the common operations of preparing a roasting fowl for the oven. It includes singeing, pulling the tendons, removing the shanks, head and neck, wish-bone, and internal organs, and pinioning the wings and legs. Removing the internal organs is referred to as "drawing." Trussing should be resorted to only when the birds are intended for immediate consumption. A dressed bird with head wrapped ready for trussing is shown in Figure 226.

Singeing.- Singeing refers to the removing by means of a flame the hair-like feathers (filoplumes) which cannot be removed in picking, whether the bird is dry picked or scalded. For this purpose, wood alcohol furnishes an excellent flame because it is smokeless and does not give the meat any taint or odor. The bird should be flamed only as much as is necessary to get rid of the filoplumes. Too much flaming will sear the skin and injure the appearance of the carcass.

Removing the Neck.-To remove the neck, make an incision in the skin at the point on the back of the neck where it joins the body, as shown in Figure 227. Cut the skin along the dotted line, as shown in Figure 227, and then loosen the skin from the neck, as well as the gullet, crop, and windpipe, pulling the latter out from the body as far as possible before pulling them free. Then cut off the head, leaving the gullet and wind-pipe attached to the head, and loose neck skin attached to the carcass.

Now slip the knife down close to the base of the neck, as shown in Figure 228. Cut it on both sides and then across the top. If the ligaments surrounding the neck are carefully cut it can be pulled off easily. 
Taking Out the Wish-bone.-Now place the bird on the rump, fold back the loose skin of the neck, scrape the wishbone bare, and pass the knife-blade under it, as shown in

Fig. 226

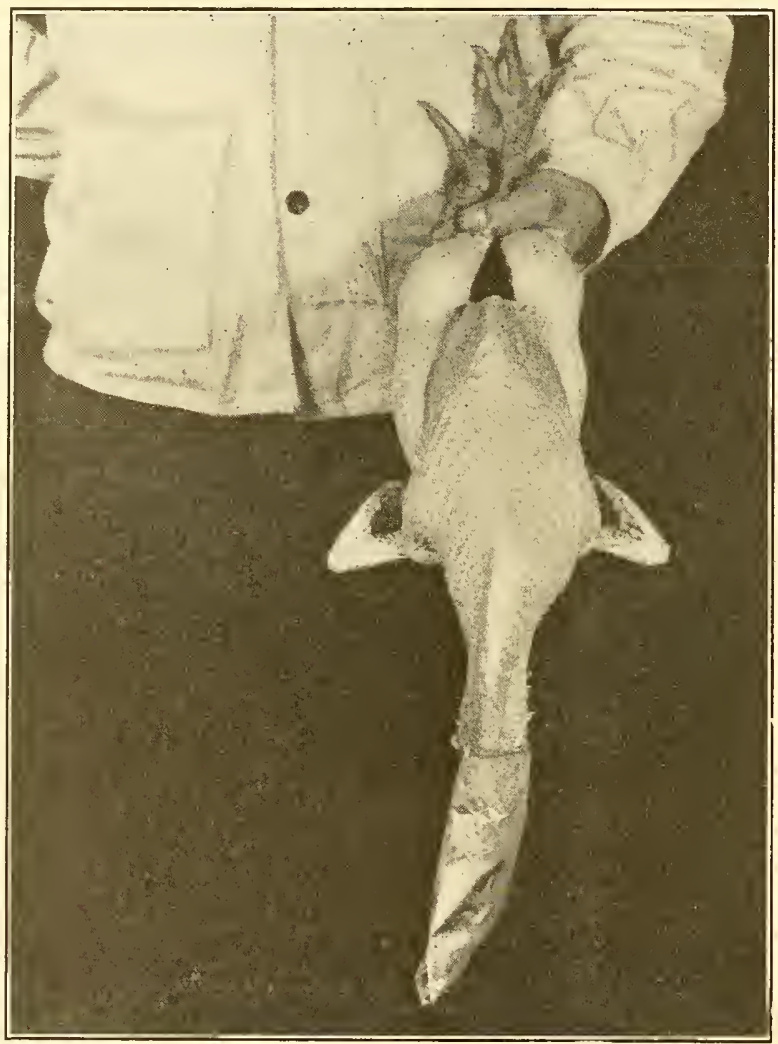

A dressed bird with head wrapped ready for trussing. (Courtesy of F. E. Mixa.)

Figure 229, cutting through the shoulder on both sides. The more thorough the scraping the easier it is to lift out the bone.

A great many more slices of breast meat may be carved off without striking the bone when the wish-bone is out 
of the way. This adds far more to the attractiveness of the bird than one would suppose before trying it. It also makes it possible to draw the bird without tearing.

FIG, 227

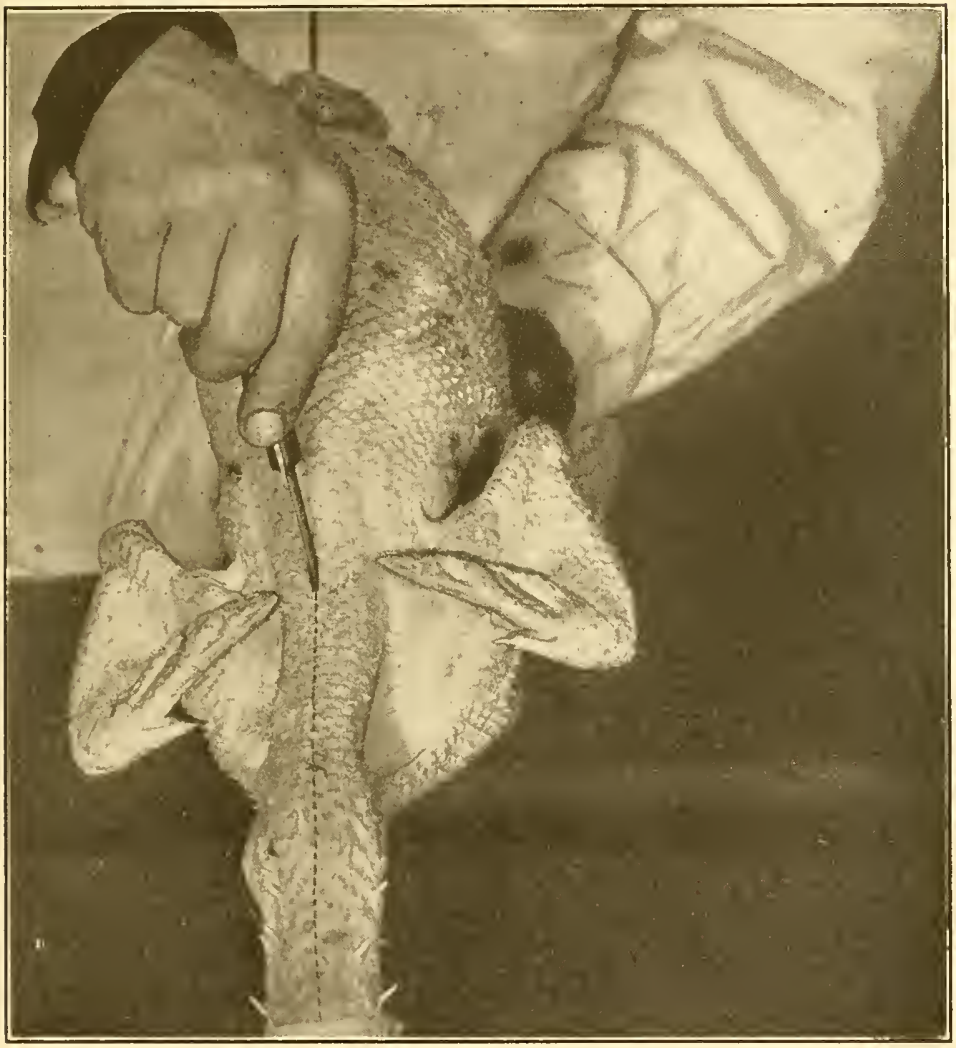

Starting to remove the neck. (Courtesy of F. E. Mixa.)

Pulling the Tendons and Removing the Shanks.-The tendons which connect the muscles of the leg with the toes frequently annoy the consumer by getting between his teeth when he attempts to eat the drumstick. These may easily and quickly 
be remored by making an incision in the shank, as is being done in Figure 230, and passing the knife up and down as far as possible between the hock and the foot. In this incision slip a hook or bent nail and give a steady pull. The beginner will find it easier to pull the tendons one at a time. They are easily seen and separated. With a steady pull they will come out looking like long strings, as shown on the remored shank in Figure 230, learing the drumstick more tender and palatable and fully as desirable as the other dark-meat sections of the fowl.

FIG. 228

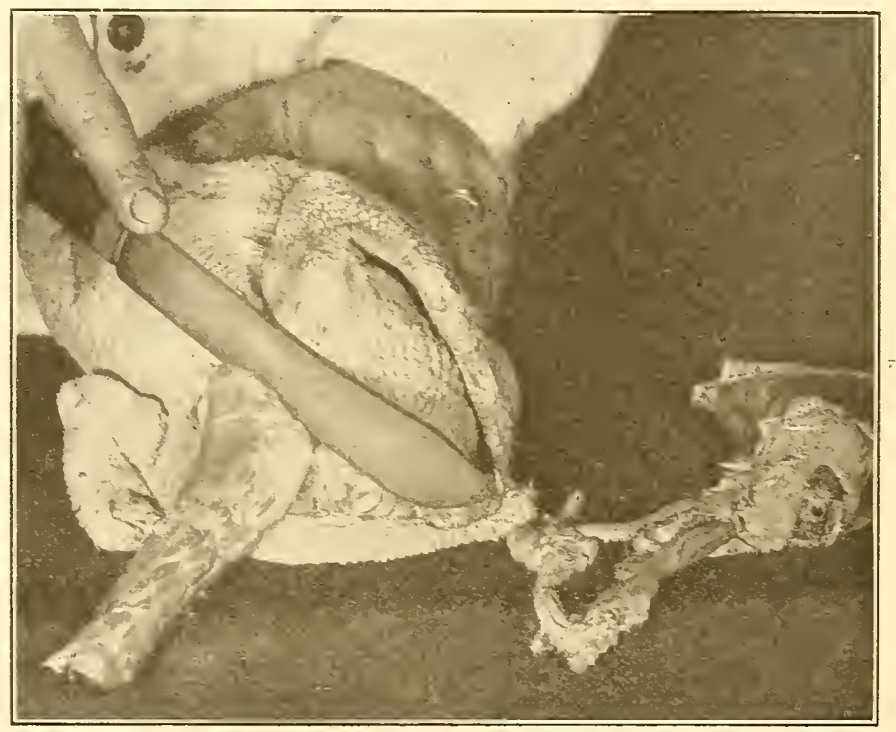

Remoring the neck. (Courtesy of F. E. Mixa.)

After pulling the tendons the shank should be cut off at the hock-joint. If a half-inch of rellow shank skin, which is quite firmly attached to the bone, is left the meat of the drumstick is not so likely to slide up the bone as it generally does in roasting. This makes the carcass appear more attractire on the table when roasted. It will be found, in marketing fancy poultry products, that an attractive appearance often 
makes a marked differenee in the selling price. The appearance of the drumstick is shown at the right in Figure 231, when the shank is properly removed, and on the left when improperly removed, as is likely to be the case when the bone is cut by the use of shears or by forcing with a butcher

FIg. 229

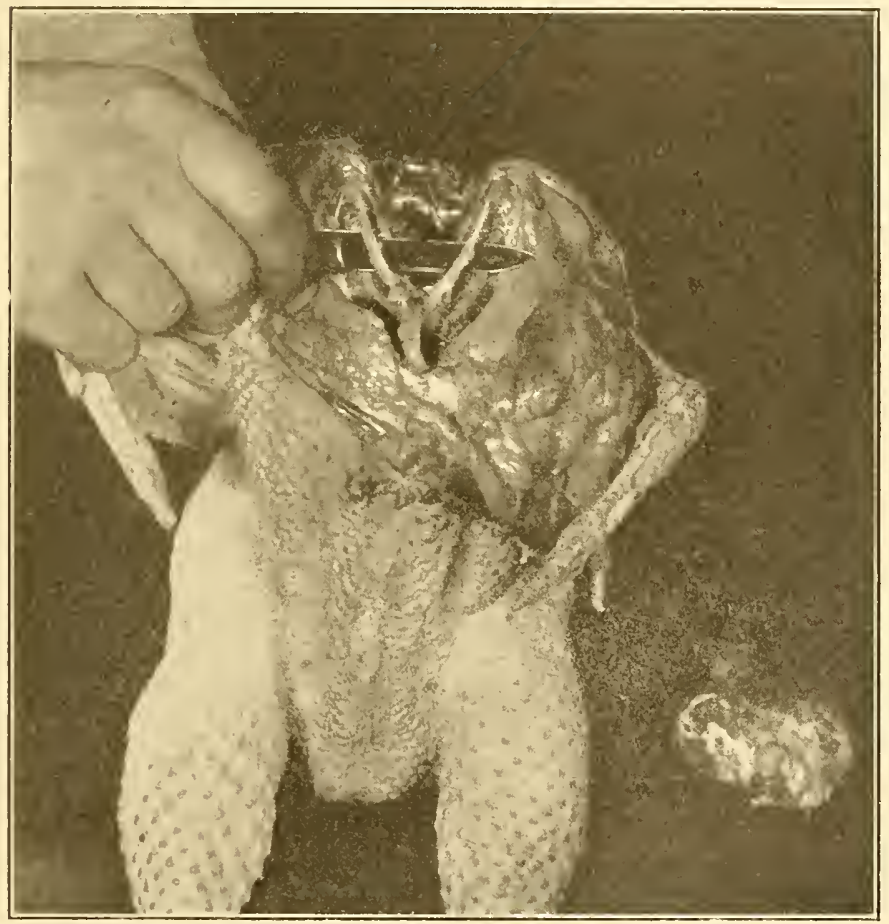

Taking out the wish-bone. (Courtesy of F. E. Mixa.)

knife, instead of simply cutting the ligaments that bind the two bones together at the joint. The latter would be proper in the case of a bird intended for frying. In this ease it is desirable to have the meat slide up the bone, thereby leaving a handle for grasping the drumstick for eating. 
FIG. 230

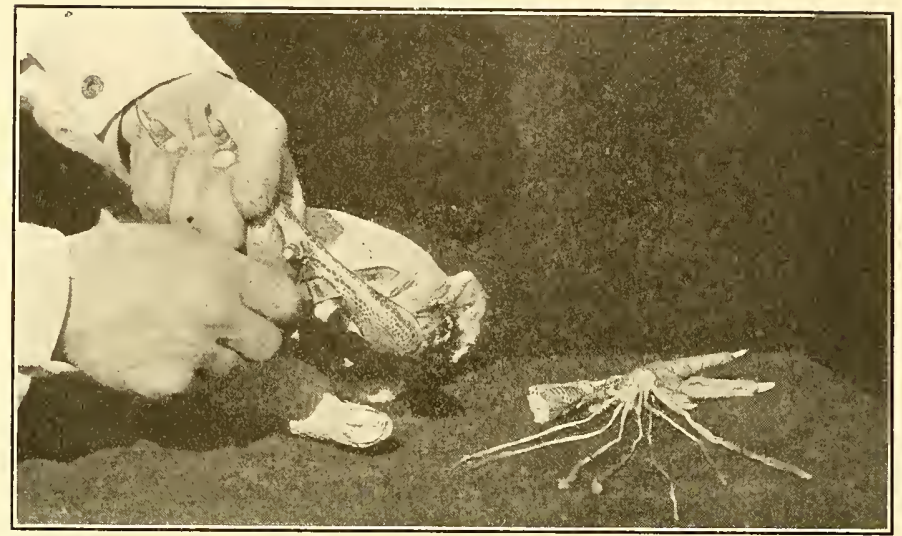

Pulling the tendons and removing the shanks. (Courtesy of F. E. Mixa.)

FIG. 231

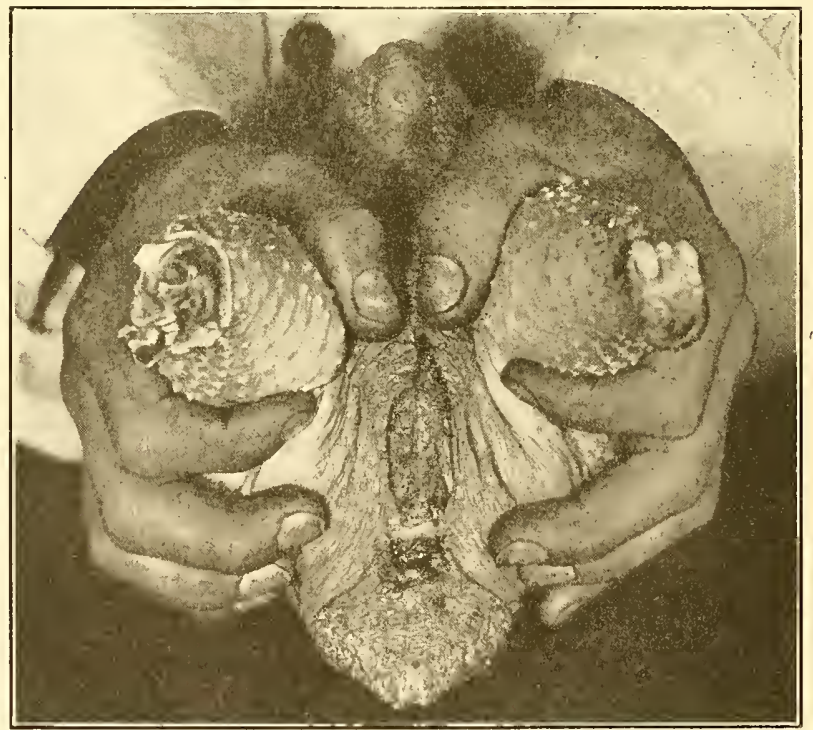

Showing a bird with properly and improperly removed shanks. (Courtesy of F. E. Mixa.) 
Drawing and Trussing.-The bird should be drawn by first making an incision at the side of the rent and cutting

FIG. 232

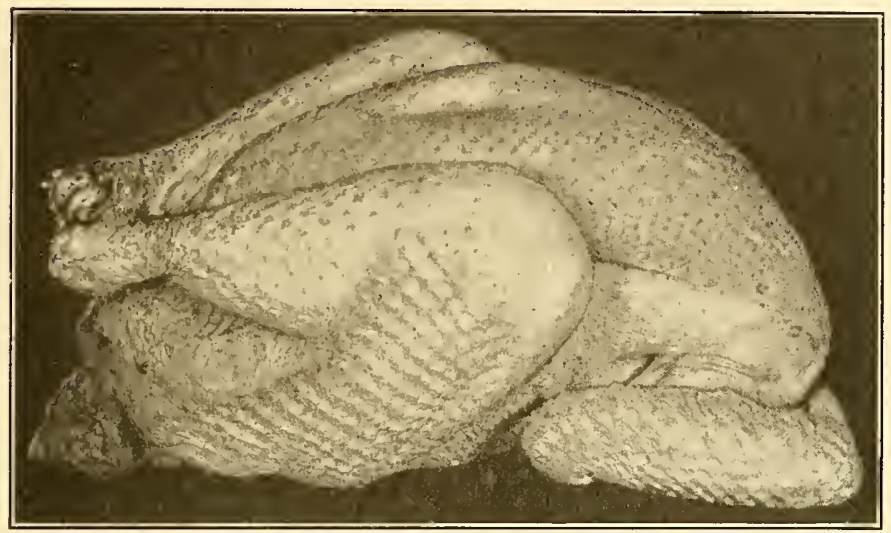

Trussed for the roasting pan, legs tied. (Courtesy of F. E. Mixa.)

FIG. 233

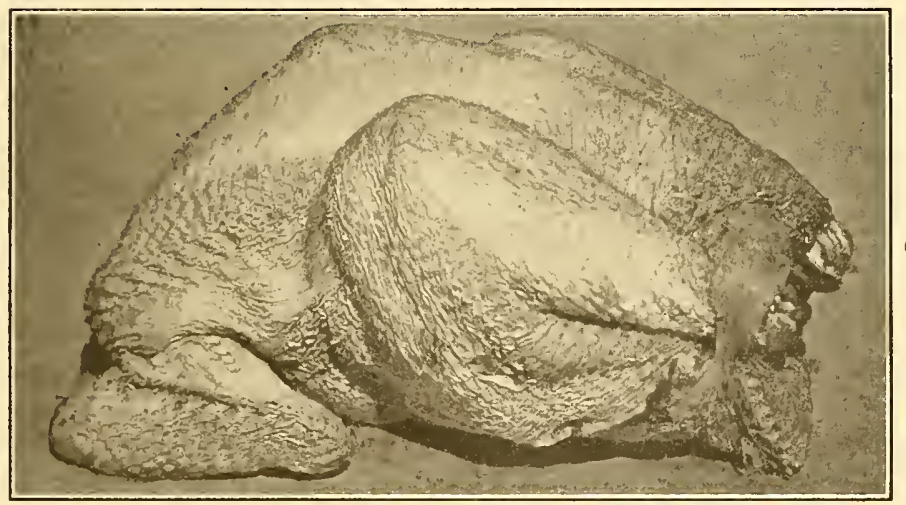

Trussed for the roasting pan, legs slipped through incision in skin (Courtesy of Iowá State College.

completely around it, making the smallest hole possible. Then insert the finger, loosen the intestines, and draw them 
out carefully, breaking them off at the gizzard. Then take a piece of broomstick or a chisel handle and push the gizzard out the opening made by the removal of the neck and wishbone. This avoids the unsightly tearing which must occur when the gizzard is removed from behind. The oil sac should then be removed from the base of the tail.

All that remains to put the bird in shape as an extra-fancy roasting bird is to fold the loose skin of the neck up over the back and lock the wings over it as shown in Figure 232. The drumsticks may be slipped through a couple of incisions made in the skin close to the tail as shown in Figure 233, or may be tied in place as shown in Figure 232.

FIG. 234

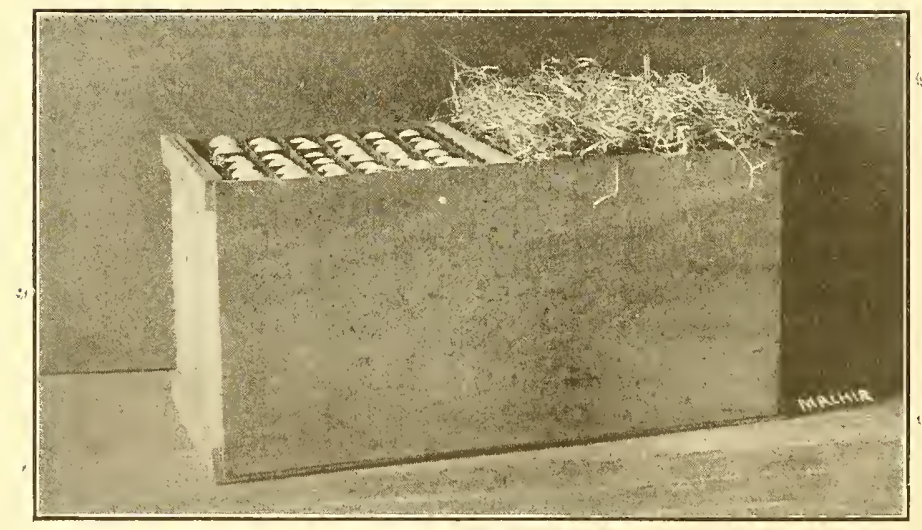

A case holding thirty dozen eggs is the wholesale commercial unit. If properly protected with excelsior before being covered, an egg case is a safe and efficient carrier whether the haul is over country roads or by rail. (Courtesy of Kansas Agricultural Experiment Station.)

\section{PREPARING EGGS.}

An egg is among the most perishable of food products. It is never so desirable for consumption as when it is first laid. Its food value, flavor, and general attractiveness is greater then than at any time later. Aside from cooking and removing the shell, which are points of preparation for which the producer is not responsible, its preparation is complete. 
It is usual, however, for the producer and consumer to be removed from each other by a considerable distance. Some time must elapse after laying, under the most favorable conditions, and at any time of year, before the egg can reach the table of the consumer. During the season of heavy production very many of the eggs must be preserved, by means of refrigeration, for the season of low production.

The producer's problem is to prepare the egg for preservation or, more accurately, to avoid those conditions which are responsible for the deterioration of the product during the time that must elapse between its production and consumption.

What the Loss Is.-Every egg that grades below first-class represents an economic loss that increases as the grade lowers.

These low grades are in a large measure responsible for the wide difference between the price paid to the producer and the price paid by the consumer. The price to consumer would tend to be lower, and the price to the producer would tend to be higher if the preventable loss was eliminated.

Hastings, ${ }^{1}$ after a comprehensive survey of the egg trade in this country, estimated the average annual preventable loss at 17 per cent (or $\$ 45,000,000$ ), distributed as follows:

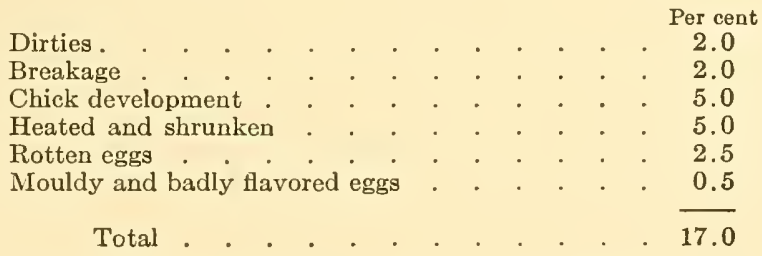

This did not take into account the curtailed consumption caused by poor quality. This estimate is based on the annual loss of which the most occurs during the warm summer months.

Where the Loss Occurs.-Lamon and Opperman ${ }^{2}$ found, as the result of extended observations in Kansas, that when the

1 Bureau of Animal Industry, Circular No. 140.

2 Ibid., No. 160. 
total loss of clean, infertile eggs from the time of laying to their arrival at the packing-house during warm weather was 23.97 per cent of all eggs marketed, 15.5 per cent, or over two-thirds, of the loss was before the eggs arrived in town.

In another test, also made in warm weather, where clean, fertile eggs were used, and the total loss was 42.5 per cent of all eggs marketed, 29 per cent, or over two-thirds, of the loss was before the eggs arrived in town.

Kinds and Causes of Deterioration.-Deterioration comes by shrinkage, liquefaction, germination, bacterial and mould infection, absorption of odors and stains.

The most prolific sources of deterioration are heat, fertility, breakage, dampness, filthy surroundings, and the presence of strong penetrating odors.

Shrinkage.-Shrinkage is caused by the evaporation of the moisture of the egg through the pores of the shell. The amount of shrinkage is noticed in candling by the size of the air cell. The rapidity with which it progresses depends upon the temperature in which the egg is kept, the ventilation and humidity, and the condition of the bloom. Cool temperatures retard it while any injury to the bloom hastens it by opening the shell pores and allowing the easier escape of moisture. While keeping the eggs in a humid atmosphere, or restricted ventilation, would tend to check shrinkage, this cannot be resorted to, owing to the fact that moisture causes injuries that are more serious than shrinkage. If this were not the case, warehousemen could make the storage egg difficult of detection by keeping the cold rooms humid and without ventilation.

Liquefaction.- When a new-laid raw egg is broken into a saucer the thick or viscous albumen is readily distinguishable from the thin or watery albumen. This distinction in the kinds of albumen becomes less marked as the egg becomes older, owing to the fact that the viscous albumen gradually loses its viscosity and becomes more liquid, beginning at the large end of the egg. This condition, which is noticed in what is known as the heated egg, is accentuated by heat, particularly if the egg is fertile. It is usually accompanied 
by a weakening of the yolk membrane, which makes such an egg difficult to poach or fry without the yolk breaking. Such an egg is only fit for general cooking purposes, and not for table purposes. Just what the difference in food value of such an egg is, as compared with a new-laid egg, has not been determined. The deterioration in appearance and flavor, however, can be distinctly noticed, and they make it commercially less desirable.

Infection. 1-Many eggs that are free from bacteria when laid, are subsequently infected because of improper handling. Bacteria under favorable conditions may penetrate the shell by way of the numerous pores, find their way through the shell membranes, and enter the contents of the egg.

As long as an egg is perfectly dry this cannot occur. Where, for any cause, the egg becomes moist, the bacteria and other microörganisms, which are always abundantly present on the shell, grow and move through the pores and finally reach the egg contents.

Dirty nests, particularly those fouled with droppings, are a prolific source of infection. An egg has the same temperature when first laid as the hen laying it. As soon as the hen leaves the nest it begins to cool, and the contents to contract. If the egg is smeared with fresh manure, some of the organisms in it will be drawn through the pores and find their way into the egg. Wiping the egg with a damp cloth only makes matters worse. It dissolves off the bloom, thus opening up the pores, and rubs the organisms into them, leaving the egg moist. It may be that the eggs are then carried to a cool cellar, which will cause further contraction of the contents.

Care must also be taken not to remove eggs from a very cool cellar into the heat of a warm summer day. The moisture vapor of the atmosphere will condense on the cool surface of the egg, causing it to "sweat." Moisture is favorable to the entrance and development of microörganisms whenever it finds its way onto the shell of the egg.

A damp cellar is favorable to the development of mould in

\footnotetext{
1 This statement is adapted from one by Bushnell and Maurer in an unpublished manuscript, Kansas Agricultural Experiment Station.
} 
the content of the egg, which occurs even at cold storage temperatures $\left(29^{\circ}\right.$ to $\left.31^{\circ}\right)$.

Bushnell and Maurer ${ }^{1}$ found that the keeping quality does not necessarily run parallel with the amount of bacterial infection. The keeping quality is determined by the kinds of bacteria present rather than the numbers.

This fact must not lead one to underestimate the significance of infection with regard to spoilage. While not all eggs that contain bacteria will spoil, it is only those eggs which do contain bacterial or other microörganisms that can spoil to any considerable extent. Further, from a practical stand-point, it is impossible to distinguish between different kinds of infection. The only safe practice is to avoid infection in every way possible.

As has been noted in connection with feeding, the bacterial contents of eggs is increased by feeding wet mash as compared with dry mash, and that the furnishing of free range for laying hens brought about a marked reduction in the numbers of bacteria found in their eggs.

The poor packing of eggs for the purpose of taking the eggs to market or for shipping is likely to result in cracked eggs that leak. The contents of one egg smeared over several others not only moistens them, but at the same time furnishes a very excellent medium for the development of bacteria and moulds.

The eggs obtained from different hens also vary widely in their keeping quality. For instance, two hens at the Kansas Experiment Station laid eggs of which only 4 per cent spoiled; while at the same time 33.8 per cent of the eggs laid by another hen spoiled. This is a difference of almost 30 per cent. Unfortunately, we have, at the present time, no practical means of eliminating such hens whose eggs show an exceptional susceptibility to spoilage.

Absorption of Odors.-Eggs, like milk and butter, readily absorb strong or penetrating odors. When kept for any length of time near onions, fish, or citrus fruits, or in a vegetable cellar where there is more or less decay, or even when

${ }^{1}$ Unpublished data, Kansas Agricultural Experiment Station. 
laid in nests recently sprayed with an odorous disinfectant, they will absorb enough of the flavor to taint them very noticeably. While this cannot be detected by the candler, except in extreme cases, it is a real source of loss in that a tainted egg disappoints the consumer and tends to limit consumption. Limited consumption means a lower price.

Stains.-Besides causing increased infection, foul and dirty nests are responsible for numerous soiled eggs. Such an egg can only rank as second-class commercially, even if it is carefully washed.

"A year 'round observation of New York egg receipts showed that over 12 per cent were dirty shelled, and sold for a lower price on this account."' Damp, muddy yards are also responsible for a large number of dirty eggs. When the houses are so crowded that it is necessary to allow the birds to run at large, even during rainy weather, a certain portion of dirty eggs are unavoidable. If the house is properly located with reference to soil and drainage, or the ground surrounding the house is carefully tiled, the number of days when dirty eggs are necessary will be very much lessened.

\section{GRADES OF EGGS.}

The different kinds and degrees of deterioration met with have led to the classification of eggs into generally recognized commercial grades known as firsts, seconds, checks, leakers, spots, blood rings, and rots. The grading is done by means of a "candle." Candle is the name given to an egg tester when it is used in connection with market eggs. It operates on precisely the same principle as the lamp tester usually sent by incubator manufacturers, and usually consists of a tin can with a hole in the side and an electric-light bulb inside, as shown in Figure 235. The use of such a candle necessitates a dark room.

Firsts.-A first is the nearest approach to a fresh egg that is known to the egg trade. Besides being new laid, it must be clean and unwashed, average very close to 45 pounds to

1 Pennington, Open Letter to Buyers and Shippers of Eggs, August 6 , 1913. 
the thirty-dozen case ( $1 \frac{1}{2}$ pounds per dozen), show a very small air cell, and a smooth, strong shell free from cracks. Only firsts are usually considered as fit for storage.

FIG. 235

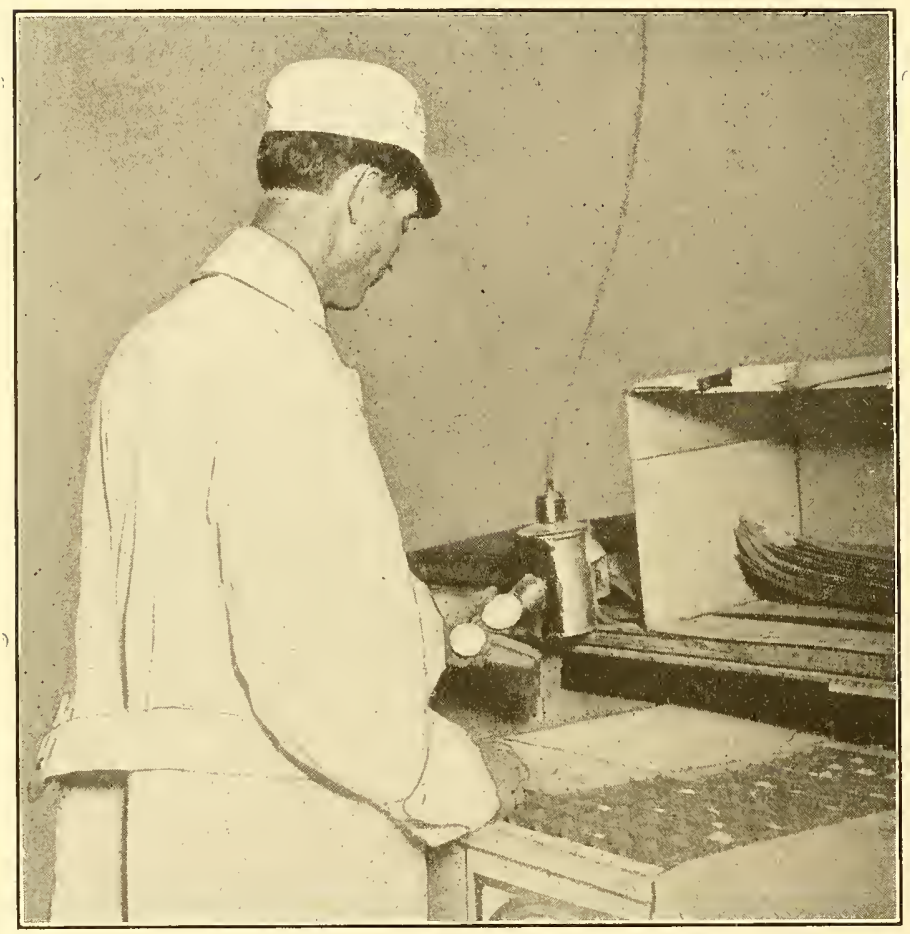

Candling eggs. (Courtesy of H. C. Pierce.)

Seconds.-Second-class eggs are those which are not up to standard in physical qualities or show a more or less marked deterioration in food qualities. The poor physical qualities that cause rejection for the first grade, without regard to its food qualities; are lack of size, being dirty or stained, washed, or having a markedly rough or misshapen shell.

The kinds of deterioration in food quality and which render 
them unfit for successful preservation by storage or preservative compounds are as follows:

1. Weak or Heated Eggs.-With fertile eggs the development of the embryo to a period corresponding to eighteen to twenty hours of normal incubation temperatures brings

'F1G. 236

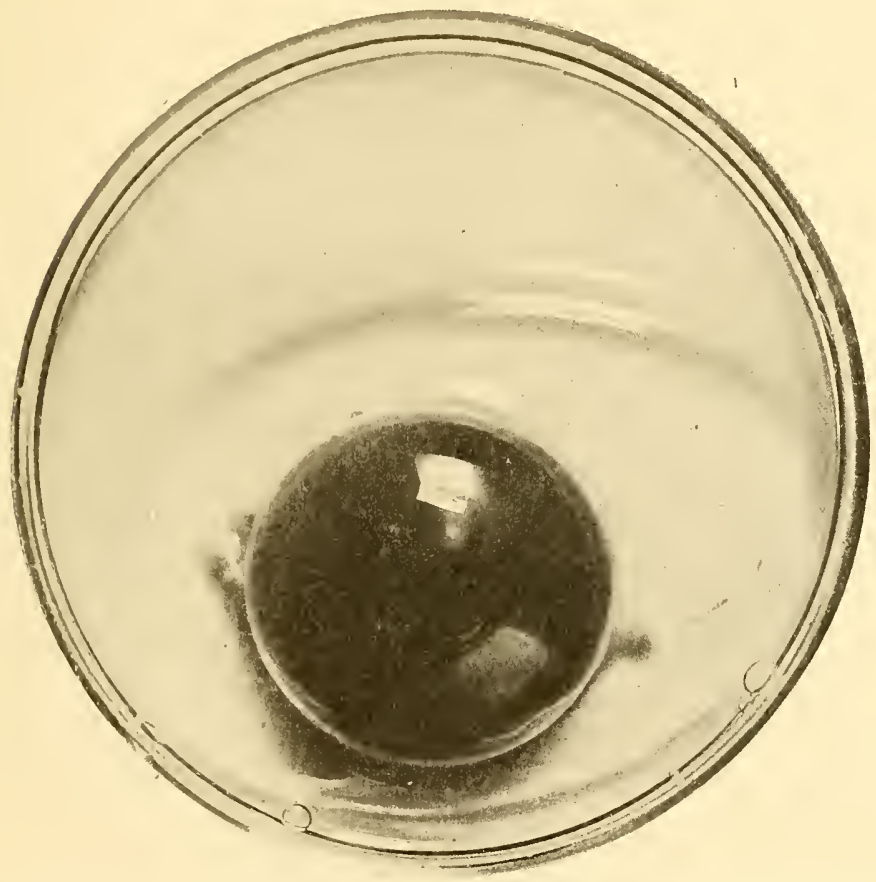

Appearance of a new-laid egg when broken out. Note how the thick albumen "stands up" as compared with the thin albumen which covers the bottom of the dish. (Courtesy of University of Missouri.)

about the condition known as heated. The infertile egg will not show heat so quickly, but in either case the color of the yolk is intensified, the yolk moves about with greater freedom when the egg is rotated, showing that the albumen has become less viscous. While the yolk maintains its relative position 
with reference to the poles of the egg in a new-laid egg, it may move up or down in an egg showing heat. At first it becomes loosened on the side toward the large end of the egg and later from the other side. In an advanced stage of weakness, the yolks may appear swollen, caused by the absorption of water from the albumen.

FIG. 237

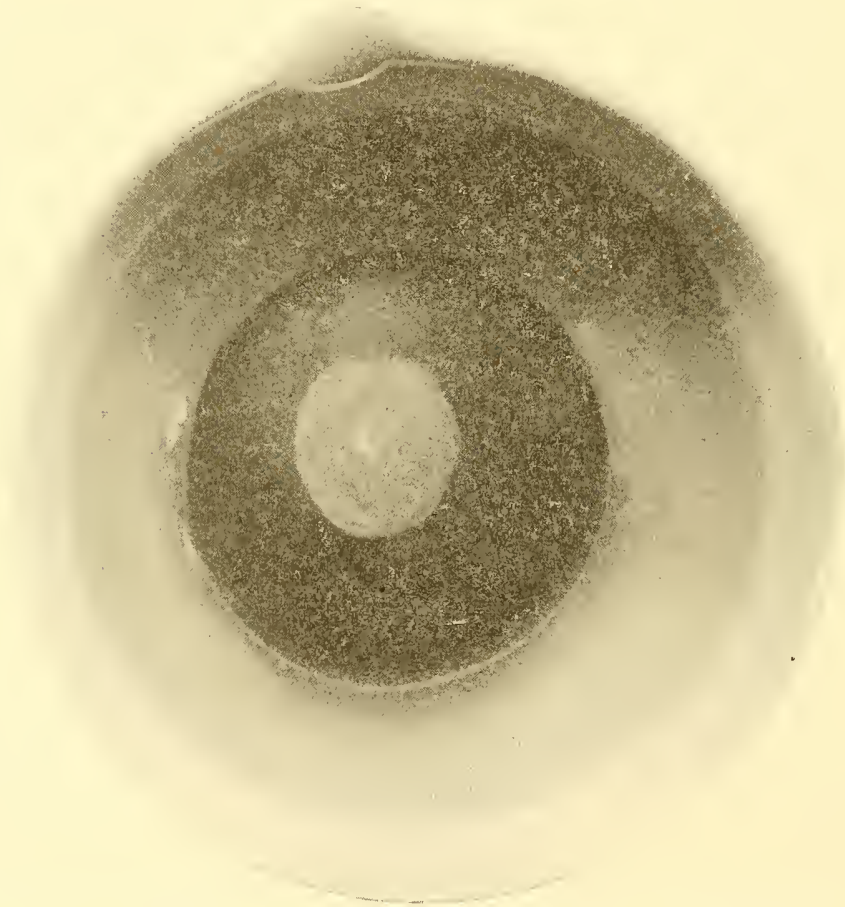

Fertile egg after twenty-four hours of incubation. (Courtesy of Bureau of Animal Industry.)

2. Shrunken Eggs.-These eggs are easily distinguished before the candle by the size of the air cell. The shrink is caused by the evaporation of moisture through the shell. This may be caused by a comparatively short holding in a 
warm, dry atmosphere, or by holding for an extended time under quite favorable conditions.

3. Watery Eggs.-The watery egg is quite similar to the heated egg, save that in addition the inner shell membrane has become ruptured at the large end of the egg, allowing the

FIG. 238

Fertile egg allowed to die after thirty-six hours of incubation, showing a slight blood ring. (Courtesy of Bureau of Animal Industry.)

contents to escape into the space occupied by the air cell, giving a movable air cell.

4. Liver Spots.-Somewhat frequently the rupture of a bloodvessel in the oviduct or the sloughing off of a piece of tissue or membrane causes the appearance of foreign matter 
on the yolk or in the albumen, which appears as a spot before the candle. This should properly be classed among the physical defects. It is not a mark of deterioration, but is a

FIG. 239

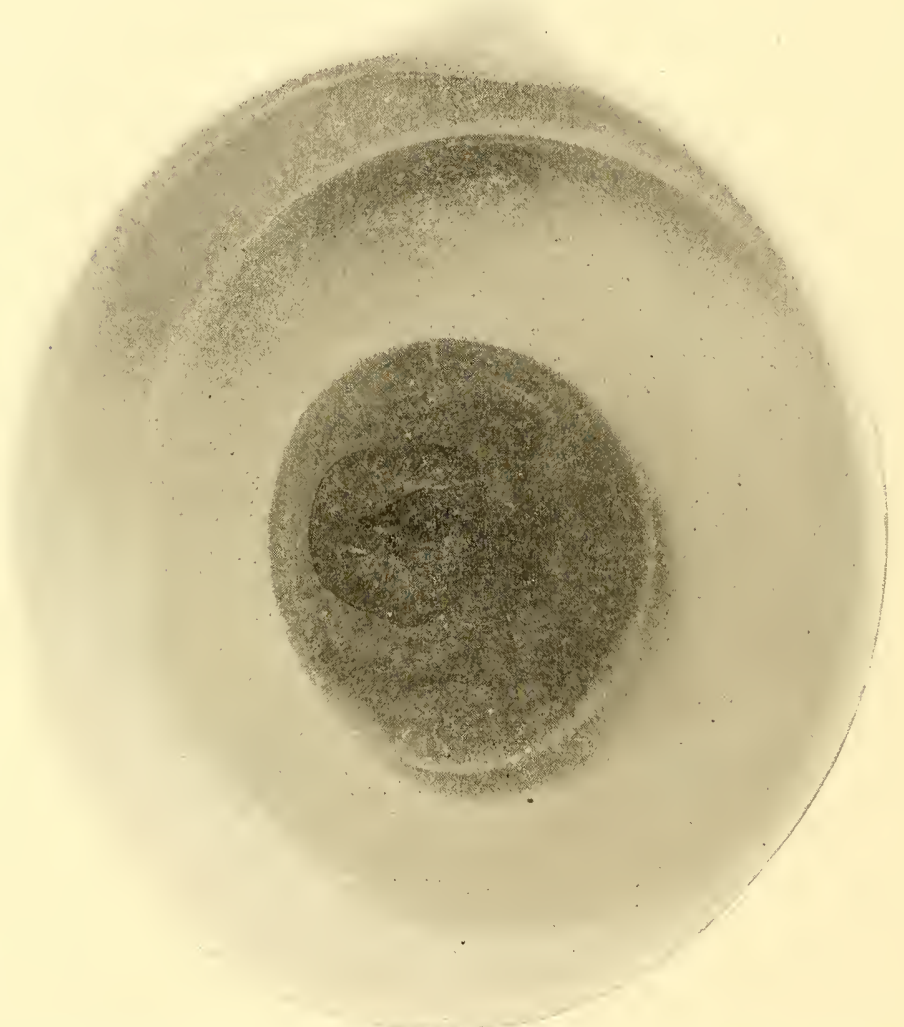

A live fertile egg after incubating forty-eight hours. (Courtesy of Bureau of Animal Industry.)

condition existing in the egg when it is laid. As it is situated in the edible portion, it is classed among the defects in food quality. 
5. Grass Eggs or Green Whites.-Frequently in the spring a condition of the albumen of the egg is met with that causes eggs to be referred to as "grass eggs" or "green whites." This has usually been attributed directly to the increased con-

FIG. 240

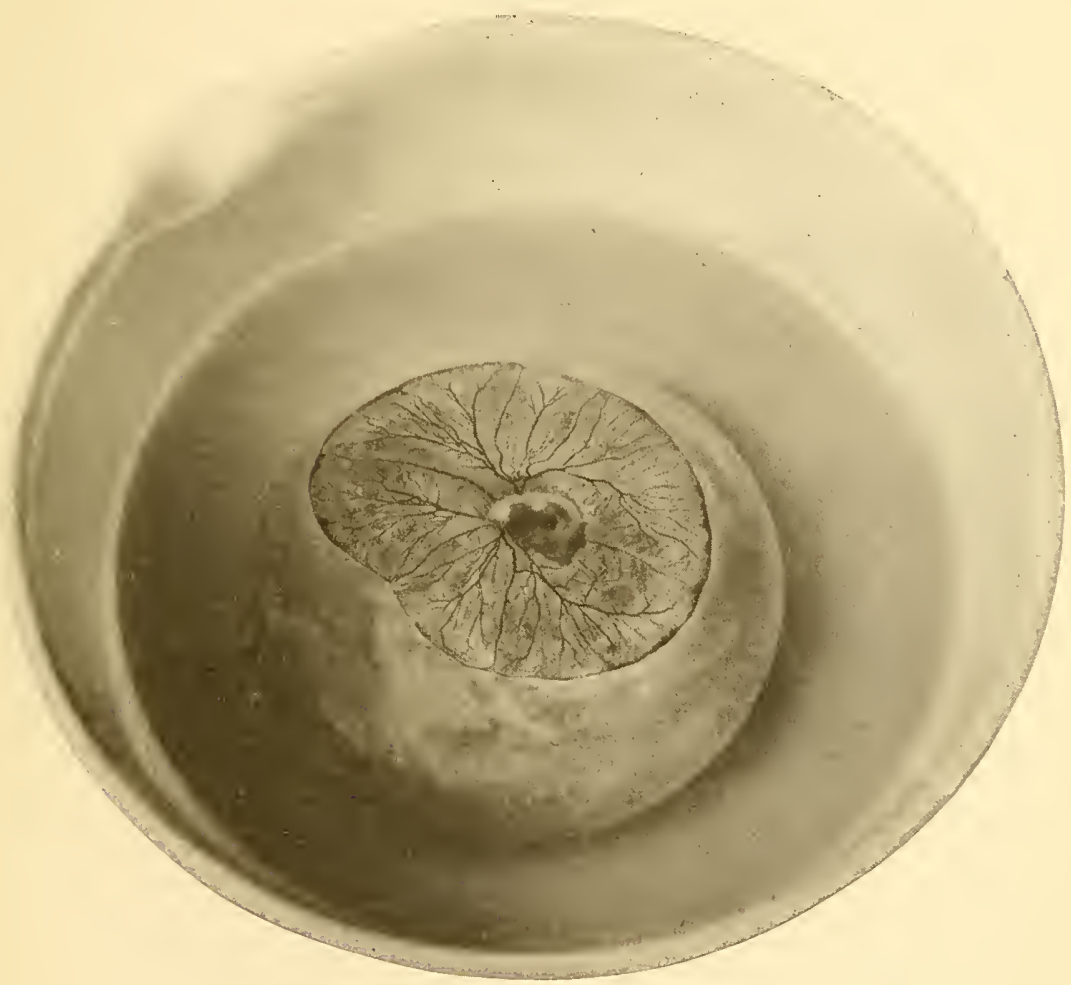

Live fertile egg after seventy-two hours of incubation. (Courtesy of Bureau of Animal Industry.)

sumption of greeness by the layers because they are likely to appear with the product of the spring lay. From the meager evidence at hand, it appears probable that this condition is due to an infection by a pigment-forming organism and due 
only indirectly, if at all, to the increased consumption of green feed. ${ }^{1}$

Checks.-Checks are cracked eggs. Those in which the crack is small and the contents of the egg is still retained are called "blind checks." Where the contents is escaping

FIG. 241

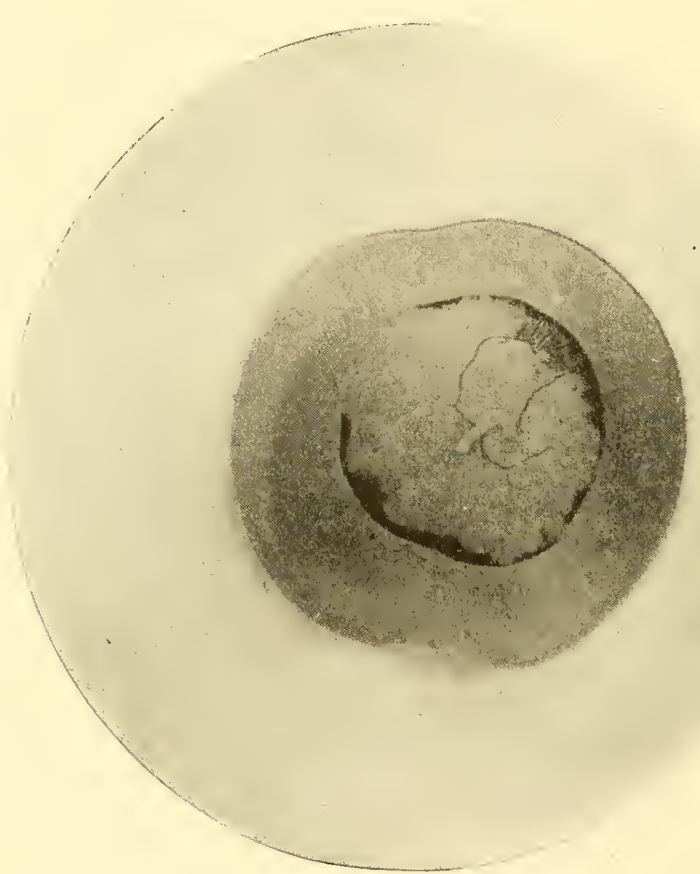

Fertile egg allowed to die after seventy-two hours of incubation, showing a pronounced blood ring. (Courtesy of Bureau of Animal Industry.)

they are designated as "leakers." Such eggs may be perfectly sweet and wholesome, but are extremely perishable, and are good for immediate consumption or to be broken out and dried or frozen.

1 The pigment-forming organism has been isolated by the Bureau of Chemistry, U. S. Dept. of Agriculture. 
Spots.-Eggs in which mould or bacteria has developed in isolated areas inside the shell are called "spots." They are not fit for food. Eggs in which the yolk has adhered to the shell are also classed as spots, being known as stuck spots. These eggs are unfit for food, but may be used for tanning purposes.

FIG. $2+2$

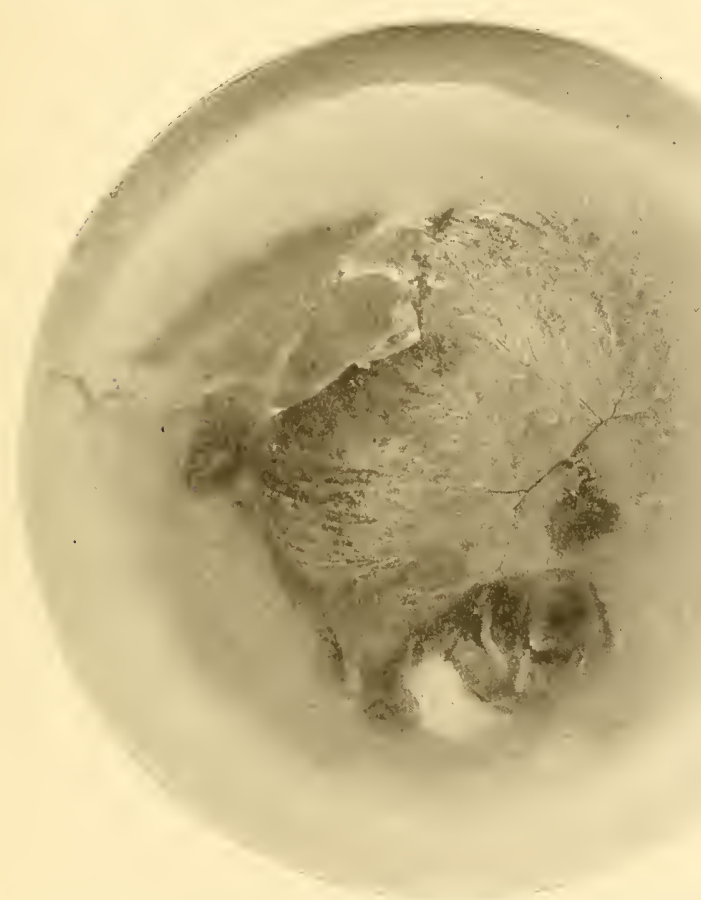

Fertile egg after seven days of incubation. (Courtesy of Bureau of Animal Industry.)

Blood Rings.-Fertile eggs in which the embryo has so far developed as to show considerable blood and then died, the blood is usually left in a more or less imperfect circle surrounding the germ. Before the candle this appears as a pink ring which from its nature has given the name "blood ring" to eggs containing dead germs. These eggs are declared 
by the government authorities to be unfit for human food, and are a total loss, except that in the vicinity of tanneries they may be disposed of at a very low price for use in tanning certain classes of leather goods.

FIG. 243

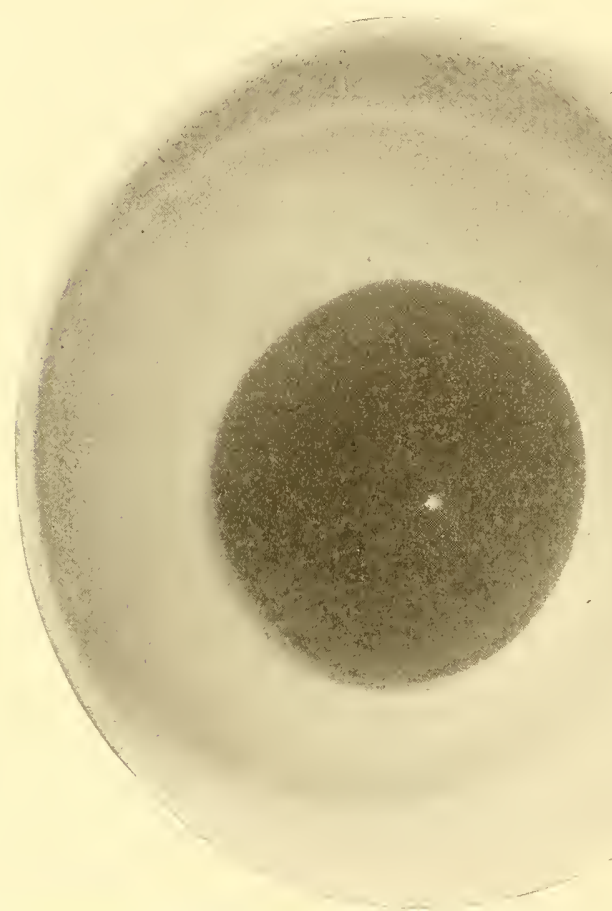

An infertile egg after seven days of incubation. (Courtesy of Bureau of Animal Industry.)

Rots.-Eggs that are so far decomposed through the agency of mould or bacteria as to be totally unfit for food are termed rots. The appearance of rots varies with the kind of organism causing its decomposition. They are severally designated as black, white, pink, and blood rots. All are equally unfit for human consumption. 
Simple Precautions for Securing Firsts.-Almost one-half of the annual hot weather egg loss from low grade and spoiled eggs is traceable to defects in management existing before the eggs are laid and capable of control by the producer. Lamon and Opperman ${ }^{1}$ found, during a test carried on in Kansas and lasting from June 17 to August 26, that by taking the following simple precautions over 97 per cent of the eggs taken to town during that time were graded as firsts:

1. The males were kept from the laying floek. This may be accomplished by caponizing the young males not needed for breeding purposes, or disposing of them as broilers before they reach breeding age. 'The birds reserved for breeding should be confined except during the breeding season, at the end of which they should again be confined or disposed of.

2. The hens were furnished with plenty of roomy clean nests.

3. The eggs were gathered twice daily.

4. They were kept in a cellar that was cool, dry and free from odors.

5. The eggs were taken to market twice a week and carefully protected from the sun on the way to town.

6. All eggs that were small, dirty, misshapen, or found in stolen nests, were kept for home use.

Home Preservation of Eggs.-Commercially, poultry products are preserved most largely by the aid of artificial refrigeration. In the case of eggs, they are also preserved by breaking out of the shell and drying. The dried product is packed in barrels for shipping, but for best results must be kept under refrigeration when held for any length of time. This dried product is soluble and is usually dissolved in water before using.

For home preservation, the most successful method yet devised seems to be with the aid of water glass (soluble sodium silicate). A 10 per cent solution is made by adding one part of the water glass to nine parts of boiled rain-water that has been cooled. March and April eggs, preferably infertile, give the best results. The solution should be put in an open

1 Bureau of Animal Industry, Bulletin No. 160. 
crock or glazed jar and the eggs immersed as they are gathered every day. At least, two inches of the solution should always be above the top layer of eggs. The eggs should be placed in the solution with the large end of the egg uppermost, so that the contents of the egg will not rest on the air cell and rupture the inner shell membrane. Piercing the air cell with a coarse needle just before cooking will prevent the cracking of the shell caused by the expansion of the air cell upon boiling.

While this method is fairly successful for home preservation, such eggs are not considered desirable for general market purposes, because they are unsuited for preservation by the ordinary commercial methods after being preserved in water glass. In most states it is unlawful to expose them for sale without labelling them "pickled" or "preserved" eggs. 


\section{CHAPTER XV.}

\section{POULTRY DISEASES AND. PARASITES.}

Maintenance of Health.-The conservation of vigor and maintenance of health are fundamental problems of poultry production. In the last analysis these constitute but a single problem, for great vigor is only an abundant health. The preceding chapters have been given up, for the most part, to discussing methods of maintaining health, under such divisions as breeding, feeding, and housing.

In proceeding to a brief and practical discussion of the more common poultry diseases, it cannot be too greatly emphasized that constructive breeding, with rational feeding and management, is the first and principal line of defence against disease. This corresponds in a general way to the construction and maintenance of a fireproof building. Flock treatment to prevent the spread of disease that has somehow gained entrance to the flock, corresponds to the efforts of the firemen to save other buildings in the block, for even "fire proof" buildings sometimes burn. Endeavoring to cure a diseased individual corresponds to the efforts to save a badly damaged building from complete destruction, with this very important difference, that while fire in a building may be entirely put out and the damage completely repaired, a bird sick with contagious disease is seldom so completely cured that it does not constitute a source of danger to its flock mates, or so quickly cured that it is capable of complete self repair. A sick fowl may usually be considered as permanently damaged for productive purposes. Comparing the small value of an individual fowl with the serious menace to the entire flock of a bacillus-carrying, cured bird, it is questionable whether it is ever advisable to attempt the cure of birds infected with a contagious disease. 
The following pages are given over, with a few exceptions, to methods of preventing the further spread of disease which has actually gained entrance to the flock and to the control of both internal and external parasites. No pretension is made at a critical discussion of these diseases, nor do those discussed by any means exhaust the list of ills to which fowls are hcir. Only those rather frequently found on general farms. are referred to. For a rather complete and critical discussion, students are referred to Diseases of Poultry by Pearl, Surface, and Curtis, which is the most satisfactory work so far published.

Aspergillosis.-Aspergillosis is a disease that is very generally confused with tuberculosis because the general symptoms are so similar, though caused by a fungus growth on the interior of the air passages. It is usually impossible to distinguish between it and tuberculosis during life. On postmortem examination red patches of fine mould will be found on the interior of the air passages instead of the characteristic lesions of tuberculosis. The origin of this trouble is the presence of the mould, or its spores, in the feed, litter, or surroundings of the birds affected. So far as is known, there is no cure. Where postmortem examination has disclosed the presence of the disease in a flock steps should at once be taken to remove the cause through disinfecting the house, providing sweet, clean litter, and avoiding all feed that is musty or mouldy. Any further birds giving evidence of lack of thrift should be isolated, and if they continue to lose strength should be killed and burned on the assumption that they have contracted the disease.

Blackhead.-For a discussion of this disease see page 425 .

Bumble Foot.-This name is given to an abscess in the ball of the foot or between the toes. It may be the result of a bruise or the penetration of a thorn, or even a piece of straw. It will usually be first noticed through the lameness of the bird. Recovery frequently takes place without treatment, but it is best to catch the affected individual and pull out the one or more pus cores that are generally present. These cores are each covered with a scab, and may usually be 
almost entirely removed without the aid of a knife. If it is not possible to accomplish this, a string should be tied about the leg above the foot to prevent excessive bleeding, and the abscess opened with a knife, and thoroughly cleaned out. The foot should then be wrapped in cloth to prevent its being picked by other birds. If the infection has not become generalized recovery is usually prompt and complete, though a second opening of the abscess may be necessary if the work of removing the pus core is not careful and complete in the first instance.

Chicken Pox.-This disease, frequently referred to as sore head, is usually recognized by the warty excrescences which appear on the face and head gear. These protrusions later become scabby. Investigators are uncertain whether this is simply one form of roup or an entirely different disease. Uncertainty also exists as to the cause, whether it be one or more organisms or a virus. As a usual thing if the scabs are removed promptly upon their appearance, and creoline or any standard stock dip applied, full strength, the trouble will disappear. As in the case of all infectious diseases, the bird should be promptly isolated and not returned to the flock until the trouble has entirely disappeared.

Constipation.-Constipation may occur from a variety of causes. It is far more common among young stock than among the older birds. It may be caused through irritation of the mucous membranes of the intestine or through such obstruction as may result from the eating of a feather, or the accumulation of gravel, or even the accumulation of intestinal worms. Birds usually stand or crouch with ruffled feathers, or move about with more or less difficulty, and make frequent and apparently painful attempts to pass the excrement. Where such cases appear in the flock the whole flock should immediately be purged by means of Epsom salts in the mash at the rate of a teaspoonful per adult bird. With young stock the doses should be modified to suit the age of the stock.

Diarrhea.-The careful husbandman always watches the consistency of the droppings of whatever sort of animals he may be keeping. The normal consistency of chicken 
droppings is such that they hold their shape upon evacuation and do not soil or stick to the dropping board. A variation of feed will usually cause more or less looseness which is not at all alarming. The condition is not referred to as diarrhetic until the consistency of the evacuations is such as to soil the feathers. If no other symptoms appear beyond the diarrhea, and the color is not such as to suspect diseases described elsewhere in this chapter, it may usually be assumed that something is wrong with the feed. The birds should be given salts in a wet mash, at the rate of a teaspoonful per bird and the cause sought out and removed.

Cropbound.-Cropbound or the impaction of the crop is a condition usually brought about through improper feeding. It may occur where birds that have been starved consume a large amount of dry grain, thereby distending the walls of the crop and apparently bringing about a partial paralysis. More frequently it is brought about by the consumption of indigestible material which clogs the opening from the crop into the lower portion of the alimentary tract. This is likely to occur in the spring with stock that has not been supplied with green feed during the winter. When the first green shoots appear, fowls consume considerable dead grass in their eagerness to get the tender green shoots. This grass may become worked into a ball, which is too large to pass through the lower opening of the crop. Not infrequently birds that are changed suddenly to a ration containing oats suffer from this difficulty. A single oat lodged across the ventral opening of the crop may at first act as a mechanical obstruction, later causing irritation and swelling that completely closes the opening.

Where cropbound appears in any considerable number of a given flock the first consideration should be the protection of the unaffected members of the flock through the removal of the cause. If on inspection of the affected birds it is found that oats have caused the difficulty they should be taken from the ration and re-introduced only very gradually. If dead grass picked up in an effort to secure green feed is the cause, a generous supply of succulence should be provided. 
There is no general method of treating the affected birds. Each must have individual attention. In case the condition is brought about through the overeating of dried grains it may be overcome by injecting sweet oil into the crop through the mouth and manipulating the material in the crop until it can be softened and worked out through the mouth. Usually it will save time to give the condition surgical attention. The feathers should be plucked from one side of the neck near the crop until an area of sufficient size is made to allow the making of an incision an inch and a half in length. The skin should then be pulled around so that an incision in the crop itself may be made on the side away from the incision in the outer skin. This incision having been made the contents of the crop should be removed, particular care being taken to see that the lower opening of the crop is entirely free. The interior of the crop should then be washed out with warm water. The edges of the incision in the crop should then be drawn together with stitches of white silk or white cotton thread, each stitch made separately and tied. The outside skin should be drawn together in the same way, and the bird fed on milk for a couple of days. This may be gradually changed to soft feeds, and in a week or ten days the bird will be ready for the regular ration.

Egg Bound.--The condition referred to as "egg bound" in poultry is quite analogous to cases of difficult parturition in larger animals. It may arise from several causes, such as the inflammation of the oviduct, a partial paralysis of the oviduct or the production of an egg so large that it is mechanically impossible for the bird to lay it.

The trouble may be observed by the hens continuing on the nest without clucking, and straining in an effort to exclude the egg. Sometimes this straining will take place off the nest, the bird not infrequently appearing lame or in pain. It is usually possible to insert the fingers, anointed with carbolized vaseline, into the oviduct, and by manipulation with the other hand force the egg out. It is sometimes necessary, however, to insert a wire or awl, and carefully break the shell of the egg, and remove it in parts. 
Eversion of the Oviduct.-Hens or pullets are sometimes discovered on the nest or about the yard with a red or purplish mass protruding from the vent. This condition may be caused by inflammation of the oviduct, followed by straining in an effort to lay an egg. If the bird is discovered before its flock mates begin to pick at the everted oviduct, the bird will usually make a good recovery, if the mass is gently pushed back into place, the finger having been covered with carbolized vaseline. If there is dirt of any kind upon the oviduct, it should be washed off with warm water. 'The birds should then be put in a dark, cool place for twelve hours or more, preferably with the feet fastened in a loop in such a way that the rear part of the body will be slightly elevated. As a usual thing the trouble will not occur again, and the bird may start laying within a day or two. If the difficulty appears more than twice it should be considered chronic, and disposition made of the bird.

Fowl Cholera.-Cholera is a disease caused by a minute organism which finds its way into a healthy flock in numerous ways. Possibly the most frequent is the purchase of an infected bird. The disease is highly contagious, and once it gains entrance to a flock is likely to spread very rapidly. It may be brought in by wild birds of which several species appear susceptible. It may even be introduced by means of dogs, cats, or other animals that have been over areas occupied by infected flocks.

Fowl cholera is not as common in this country as is popularly supposed. It is frequently confused with fowl typhoid, or even acute cases of diarrhea. The most noticeable symptoms are a marked diarrhea, in which the excreta from the kidneys (urates) which usually appear as the white pasty material of the feces, are yellow. While such a symptom does not absolutely prove that cholera is present, it should be considered as a highly suspicious one, and steps should at once be taken to control the disease. Later the color of the urates may change from yellow to bright green. Along with these symptoms the crop is frequently distended and a postmortem examination reveals the fact that the digestive organs are congested and inflamed. Though there 
are numerous cholera "cures" on the market, it is probable that no cure for this disease has yet been discovered.

When an outbreak of cholera is suspected the sick birds should at once be killed, care being taken that none of the blood is spattered about or allowed to drip on the ground, as the blood contains the organisms causing the trouble, and will be a means of spreading the disease. Bodies of the birds should then be burned. Burying is dangerous unless it is very deep and the carcass surrounded with quick lime before being covered. This is due to the fact that skunks or dogs are likely to dig up the carcasses and spread parts of them about the premises, and even insects working about the carcass are likely to spread the disease. Unaffected birds should be removed at once to new quarters that have been thoroughly disinfected with a solution of 1 pound of carbolic acid to 12 quarts of water. This disinfection of the new premises should be repeated frequently and the birds carefully watched for further outbreaks. Any birds showing the least sign of the disease should at once be killed and burned. The litter and droppings from the house where the original outbreak occurred should be carefully burned, the premises about the house sowed with hydrated lime, at the rate of 500 pounds to the acre, plowed, and sowed to a crop. When the difficulty has been brought under control and there are no further outbreaks, it is the part of wisdom to market all birds that were not affected and wait at least one year before attempting to engage further in poultry raising. This is particularly true on the general farm where the birds have the run of the farm, or where the disease is likely to have become widely distributed through the droppings, by the time it is discovered. In such a case it is, of course, impractical to disinfect the whole range, and it will be necessary to depend upon such natural disinfectants as cold, sunlight, and dryness to accomplish the task.

Frozen Headgear.-During extreme weather the comb and wattles on fowls are very likely to be frost bitten. Generally it is not profitable to try to avoid this further than providing proper housing conditions. Such freezing undoubtedly interferes seriously with production for the time being, but 
if the birds are properly housed the birds frozen will be so few that it will not pay to take special pains to prevent freezing. In the case of large wattled males it is sometimes advisable to grease the wattles with vaseline, which offers some protection against their being frozen through dipping in freezing water when the bird drinks. After freezing occurs there is little that can be done beyond anointing the frozen parts with a mixture of vaseline and glycerine, in which there are a few drops of turpentine, and manipulating to restore the circulation.

Gapes.-Gapes are usually noticed through a characteristic gapping accompanied by coughing and the discharge from the mouth of more or less mucus. The trouble is caused by the presence in the air passages of very small parasitic worms. These worms attach themselves to the mucous membranes of the air passages, thereby causing an irritation, and not infrequently an inflammation. They sometimes gather in sufficient quantities to cause suffocation. Where this condition is suspected as a cause of death, the correctness of the diagnosis can be determined by opening the windpipe where the small, thread-like apparently forked worms may be observed. In live birds the presence of the worms may be determined by inserting a loop of horse hair into the windpipe and twisting it to loosen some of the worms and then withdrawing it. If the worms are present, some of them are very likely to be drawn out. The forked or double-headed appearance of the worm arises from the fact that the male and female are permanently joined.

The treatment is to isolate the affected birds and move those not affected at once onto fresh sodded ground. It is sometimes possible to affect a cure of diseased individuals by means of a so-called worm extractor, which may be a looped horse hair, as suggested above, a very fine looped wire, or even a feather that has been stripped of the web except at the extreme end. This treatment is likely to be tedious, and there is no assurance that all the worms are withdrawn. A better practice is to kill and burn affected birds, and move the balance of the flock to fresh ground from time to time until no more cases appear. 
Indigestion.--Indigestion refers to the condition frequently referred to by practical poultrymen as "off feed." The fowls lose interest in their feed and are dull and listless. The most frequent causes are over-feeding, feeding too great a proportion of mash in the ration, or too much concentrates without sufficient green feed. The remedy is largely in finding and removing the cause. Pearl, Surface, and Curtis ${ }^{\mathfrak{l}}$ suggest the advisability of furnishing such birds with a tonic made up as follows:

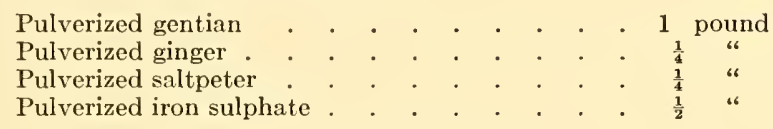

These substances can be procured from any drug store and mixed by the poultryman. Use 2 to 3 tablespoonfuls of the tonic to 10 quarts of dry mash.

Recovery from indigestion may also be hastened by the following treatment: For the first week after the trouble has been discovered add one teaspoonful of Epsom salts to each quart of drinking water. Follow this for two weeks with $\frac{1}{8}$ grain of strychnine to each quart of drinking water.

Leg Weakness.-Leg weakness which is largely limited to growing stock is attributed to too much heat in the brooder and to improper feeding. As would be supposed from the name, it affects the legs and at first the hock joints particularly, which apparently become so loosened that they will bend in any direction. As the trouble progresses, the limbs frequently become spread out, the birds losing control of them to such an extent that they can only scramble about with the body resting on the ground. The appetite remains good, and good recovery is made if the cause of the trouble is removed. The trouble seems really to be that the birds grow in weight faster than they grow in strength.

Where artificial brooding is practiced the temperature should be reduced as low as possible without making the 
birds uncomfortable. At the same time a dose of Epsom salts should be administered, and particular pains taken to see that a considerable amount of granulated bone is consumed. If the birds are being forced, the amount of protein in the ration should be reduced and exercise induced in every way possible. An abundant supply of green feed is frequently very helpful in overcoming this difficulty.

Hart, Halpin and Steenbock ${ }^{-1}$ have recently reported experiments in feeding which suggest that a large per cent of crude fiber in the ration is a preventative of leg-weakness in chicks rearer in confinement and fed a synthetic diet. The fact that the malady was accompanied by loss of appetite and usually terminated fatally in the stock they worked with, suggests the possibility that they were dealing with a different form of leg-weakness than that met with in practical work, where the chicks appear literally to be grown off their feet but maintain their appetite and activity and eventually make a good recovery.

Lice.-There are several species of Jice which infest poultry, and between which, from the practical stand-point, it is not necessary to distinguish. Whenever birds begin to show lack of thrift it is always well to suspect lice, and to make an examination in an effort to discover them. While they infest all parts of the body, they are usually particularly numerous about the vent and under the wings. Masses of eggs or nits may frequently be found attached to the base of the feathers about the vent.

Lice multiply very rapidly, and unless steps are taken to control them, are likely to interfere with both the birds' health and production. With any except the most heavily feathered breeds lice may be kept in control by simply furnishing dusting facilities. Common road dust is very satisfactory, as are also sifted coal ashes. Wood ashes should not be used. Where the dust bath does not control the situation, individual treatment must be resorted to. Sodium fluoride, which may be secured at any drug store will be found satisfactory when thoroughly dusted into the feathers of the infested fowl.

1 Journal of Biological Chemistry, vol. xliii, No. 2. 
Dipping is even more effective. "In using the dipping method all that is necessary is a supply of tepid water and a wash tub. If two persons are to dip at the same time it is advisable to use a large tub. The water should be measured into the tub and three-fourths to one ounce of commercial sodium fluoride added to each gallon of water. It is readily dissolved by stirring. In dipping, it is best to hold the wings over the back with the left hand and quickly submerge the fowl in the solution, leaving the head out while the feathers are thoroughly ruffled with the other hand so as to allow the solution to penetrate to the skin. The head is then ducked once or twice, the bird lifted out and allowed to drain a few seconds and then released. The total time required for an indiridual fowl is thirty to forty-five seconds."1

When the dipping is done on a warm, still day so that the birds dry out quickly no ill effects seem to follow.

Blue ointment (mercurial) has been found satisfactory when worked into the feathers about the vent. The mercurial ointment may be made by thoroughly mixing the following:

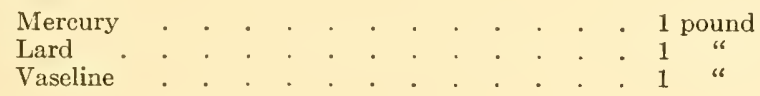

Liver Enlargement.-This condition is sometimes somewhat difficult for the ordinary producer to diagnose in the live bird. It is usually accompanied by an increase in the fowl's weight and frequent evacuations of dark yellow semiliquid feces. It is sometimes accompanied by excessive thirst. With postmortem examination, however, the liver will be found enlarged, mottled in color, easily torn apart, and greasy. This disease is most likely to occur toward the end of winter when the supply of green feed has been deficient.

The treatment consists of feeding the whole flock liberally of succulent feed of some kind, first giving the birds a wet mash containing a teaspoonful of Epsom salts for each bird in the flock.

Mites.-There are more species of mites than lice, but, as in the case of lice, it is not necessary for the practical poultry-

1 Farmers' Bulletin, No. 801, U. S. Dept. of Agric. 
man to distinguish between the different species, aside from the scaly-leg mite mentioned elsewhere. The mite is a tiny, spider-like parasite with piercing mouth parts. It does not live on the body of the fowl as does the louse, but goes upon it from the nest or perch to gorge itself with blood. Mites are most frequently discovered about the perches or nests where they live and breed in the filth accumulating in the cracks and crevices. These tiny parasites multiply rapidly, once the quarters have become infested, and one should be constantly on the lookout for them. When discovered, the roosts and nests should be at once thoroughly sprayed with kerosene containing enough crude carbolic acid to give it a very decided odor. This treatment should be repeated again in nine or ten days if the weather is cool, or in five or six days if it is very hot. The reason for the second spraying is that it is usually impossible to reach with a spray, eggs that have been laid far back in the cracks. It is necessary to spray the second time and sometimes even a third time in order to destroy the mites that hatch out from these eggs. The interval between spraying depends upon temperature, because the eggs hatch more quickly in warm weather than in cool. Mites are found more often in dark houses than in light ones, and cutting windows in a dark house not infrequently proves a means of preventing further infestations.

Poisons.-There are numerous ways in which poultry pick up sufficient poison about the farm to throw them out of condition or even cause death to considerable numbers. Among those most frequently reported are common salt that has been put out for live stock; lead and zinc poisoning, which result from the birds eating paint skins which form on old paint buckets; arsenic, which is the basis of many rat poisons; and copper, which appears in many mixtures for spraying fruit trees. Nitrate of soda used as a fertilizer may be picked up in sufficient quantities to cause difficulty. The symptoms of the various poisons differ somewhat, but usually include loss of appetite, unsteadiness of gait, or extreme nervousness followed by convulsions and death.

The treatment is to first seek out and remove the cause. In the case of poisons from fertilizers it will probably be 
necessary to confine the birds to a grassy pasture where the fertilizer has not been used. The whole flock, including the affected birds, should be given a heavy dose of Epsom salts, which may be followed, in the case of the affected birds, by mucilaginous drinks or strong coffee. A drink suitable for this purpose may be made by boiling flax seed or diluting the whites of eggs with water.

Ptomain Poisoning.- This trouble is usually caused through feeding spoiled or decayed feed. Not infrequently on the general farm a rabbit or squirrel is wounded, but escapes only to die later where the chickens can get at it. It frequently becomes putrid before the birds have finished it, and ptomain poisoning results. It also occurs in warm weather through the feeding of milk where the containers in which it is placed before the fowls are not properly and frequently cleaned and scalded. Enough of the milk dries on the sides of the pan to putrify and cause this difficulty. Its symptoms are usually the partial paralysis of muscles in different parts of the body.

The first evidence of the trouble is an unsteadiness of gait followed by inability to walk, and sometimes later in the form of the so-called "limberneck" with which the bird loses control, more or less completely, of the head and neck.

The treatment consists in removing the cause, giving the entire flock a purgative dose of Epsom salts, and the affected bird a teaspoonful of castor oil, followed by a half grain of strychnine.

Roup.- Roup is the most wide-spread of any disease attacking adult chickens, and is probably second only to white diarrhea in the seriousness of the resulting economic loss. Technically, roup refers to one and possibly two specific diseases, namely, catarrhal roup and diphtheritic roup. Practically, it refers to that group of diseases effecting the mouth, larynx, bronchial tubes, nasal cavities, and the membranes surrounding the eye. These diseases may be technically. divided into common cold, bronchitis, influenza, and canker, but practically such a differentiation is unnecessary from the stand-point of flock treatment, and indeed is impossible for the ordinary producer.

Investigators are not agreed as to whether catarrhal roup 
and diphtheritic roup are in reality separate and distinct diseases, each caused by a specific organism, or whether they are simply two stages of the same disease. Either one or both of these forms is probably caused by an organism, but investigators are not agreed as to whether it is a bacterium or a protozoan in the first place, and those who are sure that it is caused by a bacterium are divided as to which one of several is really specific. Indeed, it appears from the information at hand that roup may be caused by any one of several organisms, just as in the case of pneumonia in the human family. From the practical stand-point, aside from the introduction of a virulent form of disease through the purchase of an infected bird and by other similar means, the causes of the appearance of roup are largely predisposing ones, such as bad housing conditions, consisting of dampness, inadequate ventilation, and crowded quarters, while if anything, more important still is the lack of vitality in the breeding stock.

The symptoms of this general group of diseases designated as roup are well known. It may manifest itself through sneezing or by a watery discharge from the nostrils or eyes, or the first symptom noticed may be a rattling in the throat as the bird breathes. Later on all of these symptoms may put in an appearance, accompanied by a progressive thickening of the nasal discharge, until it entirely closes the nostrils. The discharge from the eye may also thicken to a cheesy consistency, accumulating in sufficient mass to entirely close the eye and have the appearance of a tumor. In the so-called diphtheritic roup, clearly defined patches, commonly called cankers, put in their appearance on the inside of the mouth and on the tongue.

While most of the treatises on poultry diseases recommend certain treatments for birds showing the different manifestations of roup, and almost without exception emphasize the desirability of disinfecting the poultry house whenever roup appears among the birds, practically, it is impossible for the general farm producer to carry out such a program. When roup is discovered in his flock, he should always isolate, kill, and burn the affected individual. This should be done for two reasons. One is that the bird may be 
a source of danger to the remainder of the flock, and second, the very fact that one individual succumbs to infection, while others do not, indicate that it is weaker in some respects than others, and not desirable for breeding purposes.

While the author has made no critical study of roup and kindred affections, a considerable experience with the disease in its various forms leads him to the firm belief that the one or several organisms causing roup are omnipresent, and that any flock of birds is likely to harbor the organisms, and, in fact, most of them do. The matter of an outbreak usually depends upon predisposing causes, and, if at all general, indicates that something in the breeding or the management is radically wrong. Occasionally, no doubt, there may be uttravirulent strains of the organisms introduced, which will be followed by epidemics even under the best breeding and management, but such conditions are rare. The fundamental treatment for this class of diseases is to bred for constitutional vigor, and then be continually alert for its conservation. It is frequently the case that fowls in a single house are affected, when birds of the same breeding in other houses, fed the same ration and cared for in the same way in every particular, are not affected. Under such circumstances, one would be justified in presuming that something was wrong with the house. The only way to overcome such a situation is, of course, to find the predisposing cause, such as dampness or inadequate ventilation, and remedy it.

In certain states where poultry keeping has developed into a specialized industry, notably California, roup vaccines have been developed which afford quite efficient protection against epidemics but which do not impart a permanent immunity.

Scaly Leg.-This is a condition of the shanks and toes caused by the burrowing under the scales of a tiny mite. This burrowing causes an irritation which results in the secretion of material, which, as it accumulates, raises the scales. In extreme cases the scales become covered or disappear, and the secretion so abundant as to appear in large granular lumps on the shanks. The latter condition may be accompanied by lameness.

Unfortunately, individual treatment must be given. The 
legs should be anointed with some penetrating oil, such as the oil of caraway, or with lard, or vaseline, in which there are a few drops of kerosene. Pure kerosene should not be used, because it is almost impossible to keep it from working up into the feathers and scalding the skin. The anointing of the legs should be repeated once or twice a week until the trouble disappears.

Sunstroke.-Although the original habitat of at least a part of the ancestors of our domestic poultry was a very hot country, poultry, and particularly chickens, do not seem very well equipped to stand extreme heat, and heat prostrations are quite frequent. If the birds are discovered soon after the prostration occurs they may sometimes be saved by putting them in a cool place and tying the head in cold wet clothes. It is well to give them as a purgative two teaspoonfuls of castor oil or Epsom salts.

In order to guard against numerous prostrations shade should be provided, and during hot weather it is well to give a wet mash at noon, as this tends to cool the digestive tract and keep the birds quiet during the heat of the day.

Tuberculosis.-This disease is caused by a minute organism which in many respects is quite similar to the one causing tuberculosis in man and other mammals. It seldom appears in anything but adult or very nearly adult stock. It is highly contagious, and may be introduced by means of birds, the English sparrow being particularly susceptible. This disease is serious, not only from the stand-point of economic loss, but because tubercular fowls in all probability form a serious menace to the poultryman and his family. It is popularly understood that a tubercular hen is not likely to lay, but this is not in accordance with the facts. Avian tubercular bacilli have been found alive in eggs that have been poached, and the avian form of the organism has been found along with the form common to the human family in persons suffering from tuberculosis.

In a somewhat exhaustive discussion of tuberculosis, Pearl, Surface, and Curtis ${ }^{1}$ make the following statement: 
"It appears that while fowls are not very likely to contract tuberculosis from domestic animals or from man, yet fowls that have the disease are a serious menace to other animals on the farm as well as to the poultryman and his family." Avian tuberculosis is exceedingly difficult to recognize in its early stages. As the disease advances, however, progressive emaciation may be noticed, accompanied by a feverishly bright eye. This is likely to be accompanied by general weakness and a ravenous appetite. It not infrequently happens that there are tumors, ulcers, etc., and if the disease is localized in the joint there will be lameness. Where tuberculosis is suspected it is always well to kill a suspected case and examine the liver and spleen. In a great majority of cases these will be covered by numerous raised nodules. With many forms of sickness the liver is affected, and may be blotched, but these blotches are usually depressed or raised very slightly. There is a tuberculin test now being used with poultry which is somewhat similar to the tuberculin test used with mammals. A supply of the tuberculin is not likely to be at hand, however, and it is usually advisable as soon as tuberculosis is suspected to ship two or three of the live suspects to the bacteriology laboratory of the State Agricultural College, where the disease can be definitely diagnosed. If the difficulty is pronounced as tuberculosis it is the part of wisdom to dispose of the whole flock, as up to the present time there is no cure for this disease when it has advanced to a point where any of the symptoms noted above have put in their appearance. In case the disease has appeared in valuable breeding stock which it is highly desirable to maintain, specific directions for handling the situation should be secured from the State Bacteriological Laboratory.

White Diarrhea.-This is a disease attacking chicks soon after hatching, usually appearing by the time they are a week or ten days old. It is probably the most serious scourge, from an economic stand-point, with which the poultry raiser has to deal. It corresponds in its seriousness as a menace to poultry production with that of hog cholera in pork production, or contagious abortion with dairy cattle. It appears that this difficulty is caused by a bacterium which finds its way into the digestive tract of the chick in various 
ways. The possibility of the infection being transmitted from a mother to her offspring by means of the yolk material in the egg has already been discussed in its relation to the inheritance of disease (see page 94).

The danger of bringing the disease onto the farm and causing a serious epidemic through purchasing eggs from a breeder whose stock has previously been infected cannot be too strongly emphasized. The same danger presents itself in buying breeding females from a flock where infection has previously occurred.

The symptoms of this disease usually appear between a week and ten days after hatching. The chicks become dumpish and sleepy, tend to stand around, lose their appetites, and not infrequently give a characteristic plaintive cry as if in pain. At the same time there is usually a marked diarrhea, the discharge appearing white and somewhat mucilaginous in consistency. There appears to be no characteristic symptom that can be depended upon as a means to an accurate diagnosis of this disease. Chicks that are suffering from scours as the result of eating grains that have musted or molded in the bin, present symptoms that are very similar. The same is true of another form of contagious diarrhea that is referred to as intestinal coccidiosis.

The loss from white diarrhea is usually heaviest when the chicks are from one to three weeks of age. So far as is known, there is no definite cure. One's whole attention should be directed to preventing its spread to uninfected stock, both young and old, by means of which a similar outbreak may occur during a later season. It is stated by investigators at the Storrs Station where the most important work on this disease has been carried on that infection in baby chicks seldom takes place after they are four days old. That is to say, the birds seldom contract the disease after this age, so that they are themselves inconvenienced. This does not mean, however, that they may not transmit the disease to older fowls. In fact, this forms one of the great difficulties in ridding one's farm of the scourge.

If chicks suffering from this disease are allowed any considerable range, the organisms are likely to be picked up 
by adult females, which in turn become bacillus carriers, likely to transmit the disease to their offspring the following season, as indicated in the discussion on page 94. All eggs purchased from flocks where it is not definitely known that no outbreak of anything similar to white diarrhea has occurred for several years should be hatched in a separate incubator away from eggs that are known to be from uninfected stock. Upon hatching these chicks should be brooded by themselves, confined to a run that can be easily disinfected should the trouble put in an appearance, and so isolated that other stock cannot come in contact with them.

One reason why incubator chicks appear to be more susceptible to white diarrhea than hen-hatched chicks is probably found in the fact that they are hatched in much larger numbers in incubators than under a hen, and a single chick hatched from an infected egg may be the means of infecting a large number of its flock mates, the organisms being distributed about through the incubator by means of the droppings from this chick. If the interior of the incubator is not darkened, the chicks are very likely to pick at the droppings as they begin to get hungry. For this reason, it is usually good practice to keep the incubator darkened until the chicks are taken to the brooder. They should be kept isolated for a period of at least three weeks, after which time one may be reasonably sure that no infection has occurred.

Where the chicks do show symptoms similar to those described above, every chick in the flock should be promptly burned and the entire equipment and run where they were kept, carefully and thoroughly disinfected. The litter, all droppings, and the fringe on the hover should be burned. One should also be careful to disinfect the hands and shoes after having handled the chicks, or been on the ground where infected birds have been.

In disinfecting the run it should be sowed with hydrated lime at the rate of 500 pounds to the acre, plowed and sowed to some crop. The corners that the plow does not reach should be carefully spaded by hand.

Worms.-From the practical stand-point it is hardly necessary to distinguish between the different kinds of 
worms. Generally speaking, they are divided into flat segmented worms known as tape worms, and round worms. Few birds are entirely free from worms of some kind. Where the stock is vigorous they usually cause very little inconvenience. It is usually only in birds that are somewhat lacking in vigor that the worms reproduce with sufficient rapidity to constitute a menace to the host.

The symptoms of worms are so general that it is usually impossible to diagnose their presence unless they are observed in the intestine upon a postmortem examination, or are noticed in the droppings. When worms are observed, it may usually be assumed that the difficulty has permeated the flock fairly completely. Ackert ${ }^{1}$ recommends the following for flock treatment: "To a gallon of a mixture of wheat and oats, add a small teaspoonful of concentrated lye, with sufficient water to prevent scorching. Cook slowly for two hours and cool. Fast the birds to be treated for fifteen hours, then give them all of this mixture that they will eat, providing an abundance of water for them to drink. After twelve to twenty hours give a second dose in the same manner."

During the time of treatment the birds should be confined so that all of the droppings may be collected and burned. About forty-eight hours after the second dose has been given the quarters should be thoroughly disinfected, and, if possible, the birds allowed a grassy run where chickens have not been previously kept. The desirability for this later precaution arises from the fact that with some of the worms the earth worm appears to be a host at one stage in the life-history. It is, therefore, desirable after ridding the fowls of the parasites, by the method suggested above, to have them run on ground where the likelihood of the earth worms being infested is slight. On the general farms where the fowls have free range, as they should have, it is, of course, impossible to accomplish this, and permanent relief from worm infestations can only arise from the breeding of stock of sufficient vigor to prevent any great multiplication of the parasites.

1 Parasitologist, Kansas Agricultural Experiment Station. 
Table L. ${ }^{1}$ - The Average Anndal Farm Income from Poultry.

\begin{tabular}{|c|c|c|c|c|c|c|c|c|c|c|}
\hline \multicolumn{8}{|c|}{ State. } & \multirow{2}{*}{$\begin{array}{c}\text { Eggs. } \\
\$ 11.535\end{array}$} & \multirow{2}{*}{$\begin{array}{c}\begin{array}{c}\text { Carcasses } \\
\text { sold. }\end{array} \\
\$ 7.98\end{array}$} & \multirow{2}{*}{$\frac{\text { Total }}{\$ 19.515}$} \\
\hline Alabama. & . & - & . & . & . & . & . & & & \\
\hline Arizona . & . & & . & . & . & . & . & 112.423 & 43.68 & 156.103 \\
\hline Arkansas & . & . & . & & . & . & . & 17.623 & 9.45 & 27.073 \\
\hline California & . & . & 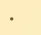 & . & . & . & . & 183.43 & 73.43 & 256.86 \\
\hline Colorado . & 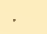 & . & 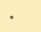 & . & . & . & . & 56 . & 32.45 & 89.02 \\
\hline Connecticut & & . & . & . & & . & . & 96.57 & 46.68 & 143.25 \\
\hline Delaware & & & & . & . & . & . & 82.105 & 48.15 & 130.255 \\
\hline District of $C$ & Colu & $\mathrm{mbi}$ & & . & . & & & 111.94 & 87.07 & 199.01 \\
\hline Florida . & . & . & . & . & & . & . & 26.535 & 16.32 & 42.855 \\
\hline Georgia . & . & . & . & . & & & . & 10. & 9.308 & 19.618 \\
\hline Idaho & . & . & & & & & . & 52 & 27. & 80.09 \\
\hline Illinois & 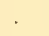 & . & & & & & . & 59 & 17 & 94.644 \\
\hline Indiana . & . & . & & . & . & & . & 58 & 29 & 87.90 \\
\hline Iowa. . & 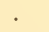 & & ${ }^{\circ}$ & & . & & : & 70 & 33 & 103.953 \\
\hline Kansas . & - & & . & & . & . & . & 68. & 27. & 95.878 \\
\hline Kentucky & 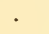 & . & . & & . & & . & 24 . & 17.199 & 41.489 \\
\hline siana & 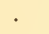 & & . & . & . & & . & 20 . & 11. & 31.342 \\
\hline $\mathrm{Ma}$ & & . & . & & . & . & . & 71 & 26. & 97.967 \\
\hline Maryland & & . & . & . & . & . & . & 5 & 40. & 98.979 \\
\hline Massachuse & & . & . & & . & & . & 138 & 76 & 215.16 \\
\hline Michigan & 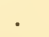 & 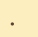 & . & . & . & . & . & 4 & 22 & 71.71 \\
\hline Minn & . & & . & . & . & . & . & 53 & 22 . & 138 \\
\hline Mississippi & 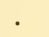 & 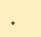 & . & . & . & . & . & 10 & 8. & 91 \\
\hline Mis & & . & . & . & . & . & . & 5 & 32. & 35 \\
\hline Mon & 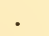 & . & . & . & . & . & . & 78 & 9 & 81 \\
\hline Nebraska & & . & . & . & . & . & . & 50 & 2 & 08 \\
\hline Nevada . & & . & . & . & . & . & . & 113 & 51 & 164.85 \\
\hline New Hamps & shire & & - & . & . & . & . & 8 & 37 & 124.91 \\
\hline New Jersey & & - & . & . & . & . & . & 11 & 106. & 221.49 \\
\hline New Mexico & & . & . & . & . & . & . & 2 & 16. & 44.92 \\
\hline New York & & . & . & . & . & . & . & 72 & 35.115 & 107.775 \\
\hline North Carol & lina & . & . & . & . & . & . & 12. & 11.24 & 24.106 \\
\hline North Dako & & . & . & . & . & . & . & 35 & 20 . & 55.94 \\
\hline Ohio . . & . & . & . & . & . & . & . & 62 & 26.75 & 88.94 \\
\hline Oklalioma & & . & . & . & . & . & . & 34 & 19. & 98 \\
\hline Oregon & & . & . & . & . & . & . & 66 & 31 & 96 \\
\hline Pennsylvani & & . & & . & . & . & . & 67 & 31 & 73 \\
\hline Rhode Islan & & . & & . & . & . & . & 185.79 & 0 & 267.70 \\
\hline South Dako & & . & & . & . & . & . & 57. & 24. & 81.92 \\
\hline South Carol & lina & . & & . & . & . & . & 9. & & 18.75 \\
\hline Tennessee & . & . & . & . & . & . & . & 24. & 14. & 39.44 \\
\hline Texas & . & . & . & . & . & . & . & 20 & 14 & 35.08 \\
\hline Utah . . & . & . & . & . & . & . & . & 48 & 19.45 & 67.62 \\
\hline Vermont . & . & . & . & . & . & . & . & 50 & 25.8 & 76.91 \\
\hline Virginia . & . & . & . & ${ }^{\circ}$ & . & . & . & 30 & 23.16 & 54.03 \\
\hline Washington & & . & $0^{\circ}$ & . & . & . & . & 86.47 & 34.57 & 121.04 \\
\hline West Virgin & & $\theta^{\circ}$ & . & . & . & . & . & 32.24 & 17.09 & 49.33 \\
\hline Wisconsin & & & & . & . & . & . & 45.23 & 21.59 & 66.82 \\
\hline Wyoming & & & & . & . & . & . & 51.51 & 29.18 & 80.69 \\
\hline Average for & & & & & 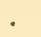 & . & & 60.57 & 31.82 & 92.39 \\
\hline
\end{tabular}

I Compiled from the United States Census Report for 1910. 


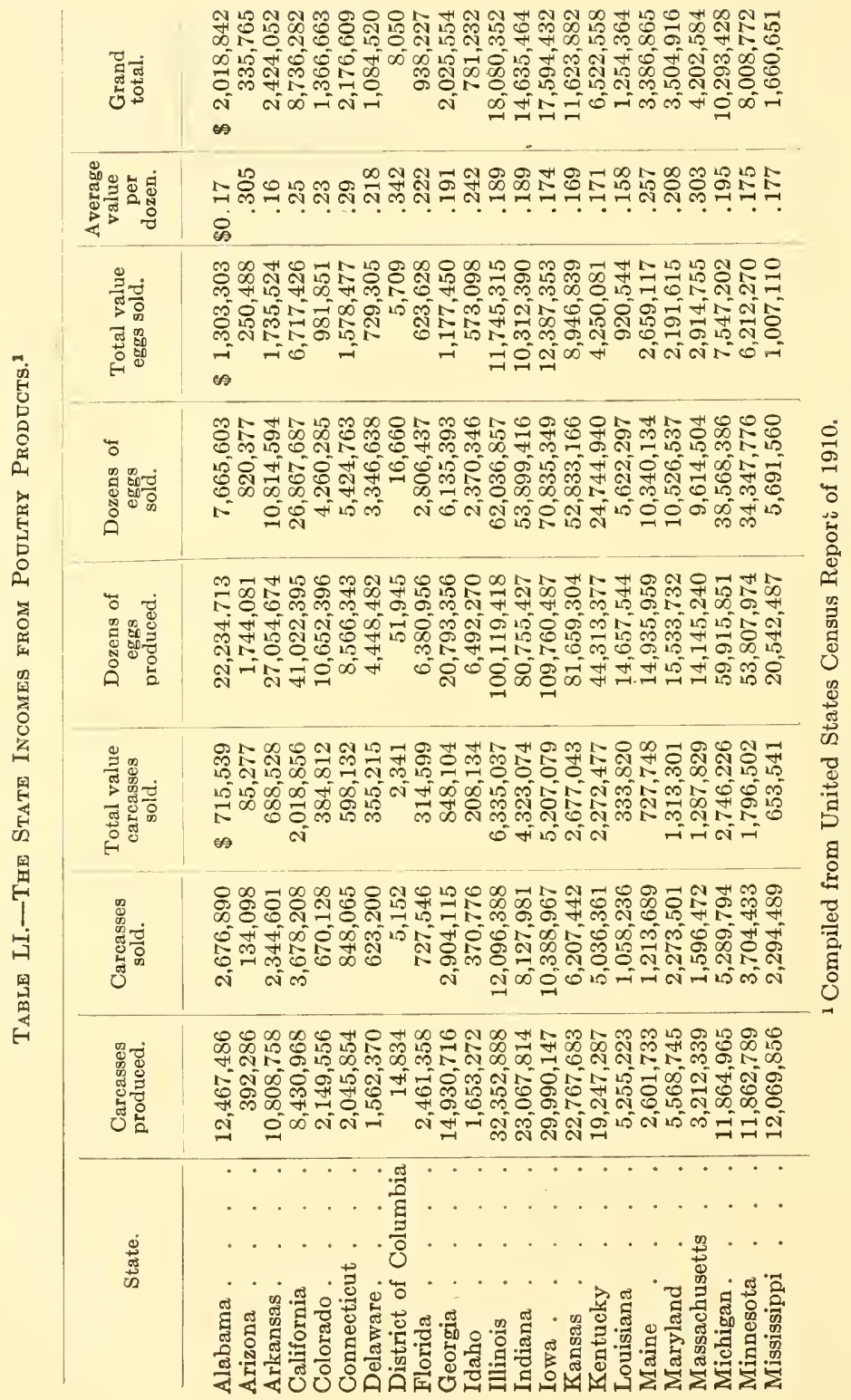




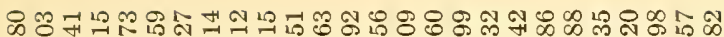

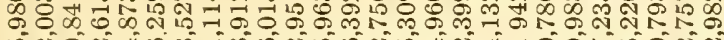
10 ก N

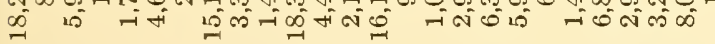

$\Re$

나 ษั่ $\rightarrow$ ำ 15 10 กิ่

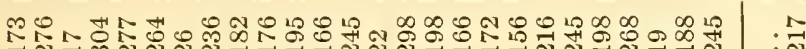

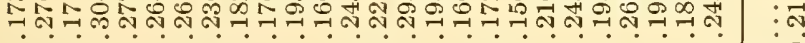

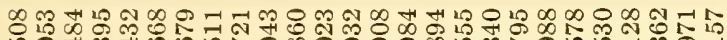

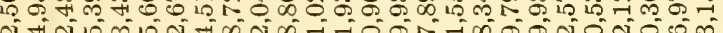
คำ

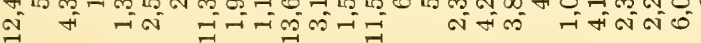

오용 तิ กู 80 $\infty_{\infty}^{\infty}$ is

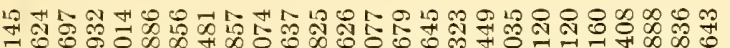
000 10 00 N

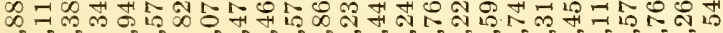

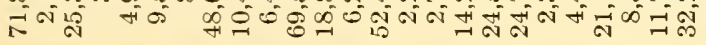

ఇ대

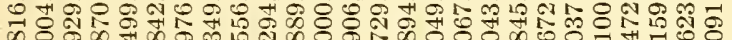

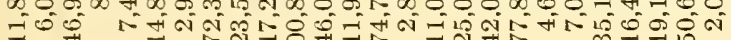
$\exists$ 年

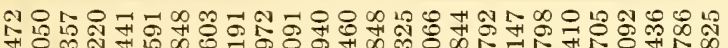

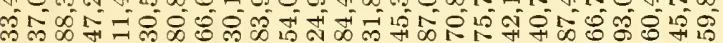
ळ\%

$\infty$ 고 ल से $=10$ के के ले $-1$

年

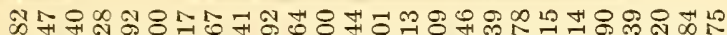

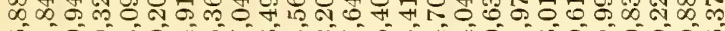

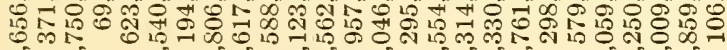

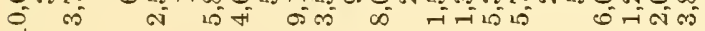

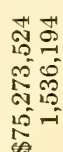
강

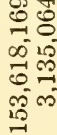

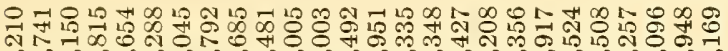
mล హี สำ लं -

估

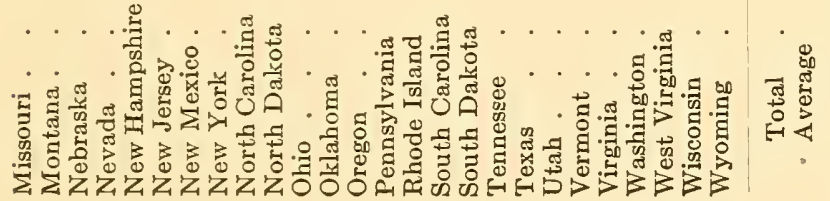


Table LII.-Showing the Number and Value of Poultry Kept in Each State ${ }^{1}$

\begin{tabular}{|c|c|c|c|c|c|c|c|c|c|c|}
\hline & & & & & & & & & Number of fowls. & $\begin{array}{c}\text { Value. } \\
\$ 1,807,239\end{array}$ \\
\hline Alabama. & & & & & · & & . & · & $\begin{array}{l}5,028,104 \\
26876 ?\end{array}$ & $\$ 1,807,239$ \\
\hline rizona. & . & - & . & - & . & 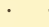 & - & . & 268,762 & \\
\hline Arkansas & . & . & . & . & . & . & . & . & $5,788,570$ & $2,063,432$ \\
\hline California & : & . & . & . & . & . & . & . & $6,087,267$ & $3,844,536$ \\
\hline Colorado. & . & . & . & . & . & . & . & . & $1,721,445$ & $1,012,251$ \\
\hline Connecticut & & . & . & . & . & . & . & . & $1,265,702$ & 988,653 \\
\hline Delaware & & . & 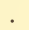 & 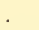 & . & . & . & . & 876,081 & 560,146 \\
\hline District of $\mathrm{C}$ & Colun & mbia & . & - & . & . & . & . & 8,349 & 6,477 \\
\hline Florida . & $v^{\circ}$ & . & $\cdot$ & 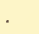 & . & . & . & . & $1,326,271$ & 673,814 \\
\hline Georgia . & ${ }^{\circ}$ & . & . & . & . & . & . & . & $5,328,584$ & $2,088,653$ \\
\hline Idaho & . & . & . & . & . & & . & . & $1,053,876$ & 598,190 \\
\hline Illinois & . & . & . & . & . & . & . & & $21,409,835$ & $11,696,650$ \\
\hline Indiana . & . & . & . & . & . & . & . & $\therefore$ & . $13,789,109$ & $7,762,015$ \\
\hline Iowa . . & . & . & . & . & . & 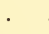 & . & . & 23,4 & $12,269,881$ \\
\hline Kansas . & . & . & $\cdot$ & . & . & . & $\because$ & . & 15,7 & $7,377,469$ \\
\hline Kentucky & . & . & . & . & . & . & . & . & 8,76 & $4,461,871$ \\
\hline Louisana . & 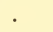 & . & . & . & . & . & . & . & 3,54 & $1,326,614$ \\
\hline Maine & - & . & . & . & . & . & . & . & $1,735,962$ & $1,131,921$ \\
\hline Maryland & & . & & . & . & . & . & . & 2,90 & $1,858,570$ \\
\hline Massachuset & tts & . & $\cdot$ & . & . & . & . & . & $1,798,380$ & $1,492,961$ \\
\hline Michigan & 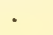 & . & . & . & . & . & . & . & $9,967,039$ & $5,610,958$ \\
\hline Minnesota & . & . & $\cdot$ & . & . & . & . & . & 10,69 & $4,646,960$ \\
\hline Mississippi & . & . & $v^{\circ}$ & . & . & . & . & & 5,07 & $1,846,751$ \\
\hline Missouri . & . & . & . & . & . & & . & 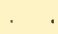 & $20,897,208$ & $11,870,972$ \\
\hline Montana & . & . & . & . & . & . & . & & 966,690 & 436 \\
\hline Nebraska & . & . & . & . & . & & . & . & 9,35 & $4,219,158$ \\
\hline Nevada. & & . & . & . & . & . & . & . & 17 & 93,668 \\
\hline New Hamps & hire & & . & . & . & . & . & . & 924,859 & 649,121 \\
\hline New Jersey & & . & & . & . & . & . & . & $2,597,448$ & $2,221,610$ \\
\hline New Mexico & & . & $\cdot$ & . & . & . & . & . & 531,625 & 256,466 \\
\hline New York & & . & & . & & . & 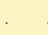 & . & 10,67 & $7,879,388$ \\
\hline North Carol & ina & $\cdot$ & . & . & . & . & . & . & $5,053,870$ & $2,212,570$ \\
\hline North Dako & & - & . & . & . & . & . & . & $3,268,109$ & $1,485,463$ \\
\hline Ohio & . & . & . & . & . & . & . & . & $17,342,289$ & $9,532,672$ \\
\hline Oklahoma & • & . & . & ${ }^{\circ}$ & . & . & . & . & $8,501,237$ & $3,713,943$ \\
\hline Oregon . & & . & . & . & . & . & . & . & $1,823,680$ & 743 \\
\hline Pennsylvania & & . & . & 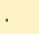 & . & - & - & . & $12,728,341$ & $7,674,387$ \\
\hline Rhode Islang & & . & ${ }^{\circ}$ & . & . & . & . & . & 415,209 & 368,018 \\
\hline South Caroli & & . & ${ }^{\circ}$ & . & . & . & - & . & 2,94 & $1,206,615$ \\
\hline Dakot & & . & • & . & . & & . & . & 5,25 & $2,356,465$ \\
\hline Tennessee & . & . & . & . & . & . & . & . & $8,056,145$ & $3,757,337$ \\
\hline Te: & . & . & . & . & . & . & . & . & $13,669,645$ & $4,806,642$ \\
\hline Ut: & . & . & . & . & . & . & . & . & 691,941 & 327,908 \\
\hline lont & 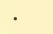 & . & & . & . & & . & & 938,524 & 607,787 \\
\hline Virginia & . & . & - & . & . & & . & . & $6,099,851$ & $3,395,962$ \\
\hline Washington & & . & & . & . & & . & . & $2,272,775$ & $1,367,440$ \\
\hline West Virgini & & . & & . & . & & . & 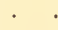 & $3,310,155$ & $1,628,700$ \\
\hline Wisconsin & . & . & 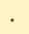 & & . & . & . & . & $9,433,110$ & $4,468,703$ \\
\hline Wyoming & • & . . & & & . & & . & $\cdot$ & 341,050 & 194,078 \\
\hline
\end{tabular}

I Compiled from the United States Census Reports of 1910. 
Table LiII.-The Amodnts of Digestible Organic Nutrients, Total Ash and Crude Fibre, in One Hundred Pounds of the Common Poultry Feedstoffs. ${ }^{1}$

\begin{tabular}{|c|c|c|c|c|c|c|c|}
\hline & & $\begin{array}{l}\text { Nutritive } \\
\text { ratio. }\end{array}$ & Protein. & Fat. & $\begin{array}{l}\text { Nitrogen- } \\
\text { free } \\
\text { extract. }\end{array}$ & Ash. & $\begin{array}{l}\text { Total crude } \\
\text { fibre } \\
\text { (very slightly } \\
\text { digested). }\end{array}$ \\
\hline Barley & & 1 to 6.6 & 9.3 & 1.2 & 58.4 & 2.5 & 4.2 \\
\hline Bran (wheat) & & 1 to 2.5 & 11.0 & 1.48 & 24.79 & 5.8 & 9.5 \\
\hline Buckwheat & & 1 to 8.8 & 6.4 & 2.1 & 51.90 & 2.0 & 11.7 \\
\hline Corn (dent) & & 1 to 8.8 & 8.4 & 4.4 & 64.29 & 1.5 & 2.2 \\
\hline Corn meal & . & 1 to 9.8 & 6.9 & 3.3 & 59.1 & 1.4 & 1.9 \\
\hline Cow peas & & 1 to 2.8 & 17.8 & 1.2 & 47.7 & 3.2 & 3.9 \\
\hline Meat scrap. & & 1 to 0.44 & 65.9 & 13.01 & 0.0 & 4.1 & 0.0 \\
\hline Millet . & & 1 to 10.7 & 6.8 & 3.0 & 61.59 & 2.8 & 8.1 \\
\hline Oats & . & 1 to 7.7 & 8.1 & 4.2 & 53.5 & 3.2 & 10.8 \\
\hline Oat meal & . & 1 to 6.6 & 11.8 & 6.5 & 63.5 & 2.0 & 0.9 \\
\hline Potato. & • & 1 to 14.8 & 0.99 & 0.0 & 14.69 & 0.9 & 0.4 \\
\hline Rye & 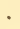 & 1 to 8.7 & 7.5 & 0.48 & 64.6 & 2.1 & 1.5 \\
\hline Wheat & & 1 to 7.3 & 8.9 & 1.11 & 62.58 & 1.8 & 1.8 \\
\hline
\end{tabular}

Table LiV.-The Total Amodnts of the Nutrients Found in One Hundred Pounds of Podltry Feedsteffs, of which the Digestibility for Chickens has not been Determined. ${ }^{2}$

\begin{tabular}{|c|c|c|c|c|c|c|}
\hline & \multirow{2}{*}{$\begin{array}{l}\text { Pounds } \\
\text { of water. }\end{array}$} & \multirow{2}{*}{$\begin{array}{l}\text { Pounds } \\
\text { of ash. }\end{array}$} & \multirow{2}{*}{$\begin{array}{l}\text { Pounds } \\
\text { of crude } \\
\text { protein. }\end{array}$} & \multicolumn{2}{|c|}{$\begin{array}{l}\text { Pounds of carbo- } \\
\text { hydrates. }\end{array}$} & \multirow{2}{*}{$\begin{array}{l}\text { Pounds } \\
\text { of fat. }\end{array}$} \\
\hline & & & & $\begin{array}{l}\text { Nitrogen- } \\
\text { free } \\
\text { extract. }\end{array}$ & $\begin{array}{l}\text { Crude } \\
\text { fibre. }\end{array}$ & \\
\hline Alfalfa meal & 8.8 & 9.0 & 14.3 & 35.8 & 30.1 & 2.0 \\
\hline Brewers' grains & 7.5 & 3.5 & 26.5 & 41.0 & 14.6 & 6.9 \\
\hline $\begin{array}{c}\text { Buckwheat mid- } \\
\text { dlings }\end{array}$ & 12.0 & 4.8 & 28.3 & 42.7 & 4.8 & 7.4 \\
\hline Cottonseed meal . & 7.5 & 6.2 & 44.1 & 25.0 & 8.1 & 9.1 \\
\hline Fishscrap . . & 12.8 & 32.6 & 52.4 & 0.0 & 0.0 & 2.2 \\
\hline Gluten feed & 8.7 & 2.1 & 25.4 & 52.9 & 7.1 & 3.8 \\
\hline Hominy feed & 10.1 & 2.6 & 10.6 & 64.3 & 4.4 & 8.0 \\
\hline Kafir . & 11.8 & 1.7 & 11.1 & 70.1 & 2.3 & 3.0 \\
\hline Milk (butter) & 90.6 & 0.7 & 3.6 & 5.0 & 0.0 & 0.1 \\
\hline Milk (skim) & 90.1 & 0.7 & 3.8 & 5.2 & 0.0 & 0.2 \\
\hline Oil meal (N. P.) & 9.6 & 5.6 & 36.9 & 36.3 & 8.7 & 2.9 \\
\hline Oil meal (O. P.) & 9.1 & 5.4 & 33.9 & 35.7 & 8.4 & 7.5 \\
\hline Rice & 12.3 & 0.5 & 7.4 & 79.0 & 0.4 & 0.4 \\
\hline Silage (corn) & 73.7 & 1.7 & 2.1 & 15.4 & 6.3 & 0.8 \\
\hline Silage (sorgham) & 77.2 & 1.6 & 1.5 & 11.9 & 6.9 & 0.9 \\
\hline Sunflower seed & 8.6 & 2.6 & 16.3 & 21.4 & 29.9 & 21.2 \\
\hline Wheat middlings & 10.7 & 3.7 & 17.8 & 58.1 & 4.7 & 5.0 \\
\hline Wheat shorts & 10.5 & 4.4 & 17.4 & 56.8 & 6.0 & 4.9 \\
\hline
\end{tabular}

1 Adapted from Bartlett, Maine Bulletin No. 184.

${ }^{2}$ Henry and Morrison, Feeds and Feeding, by their kind permission. 


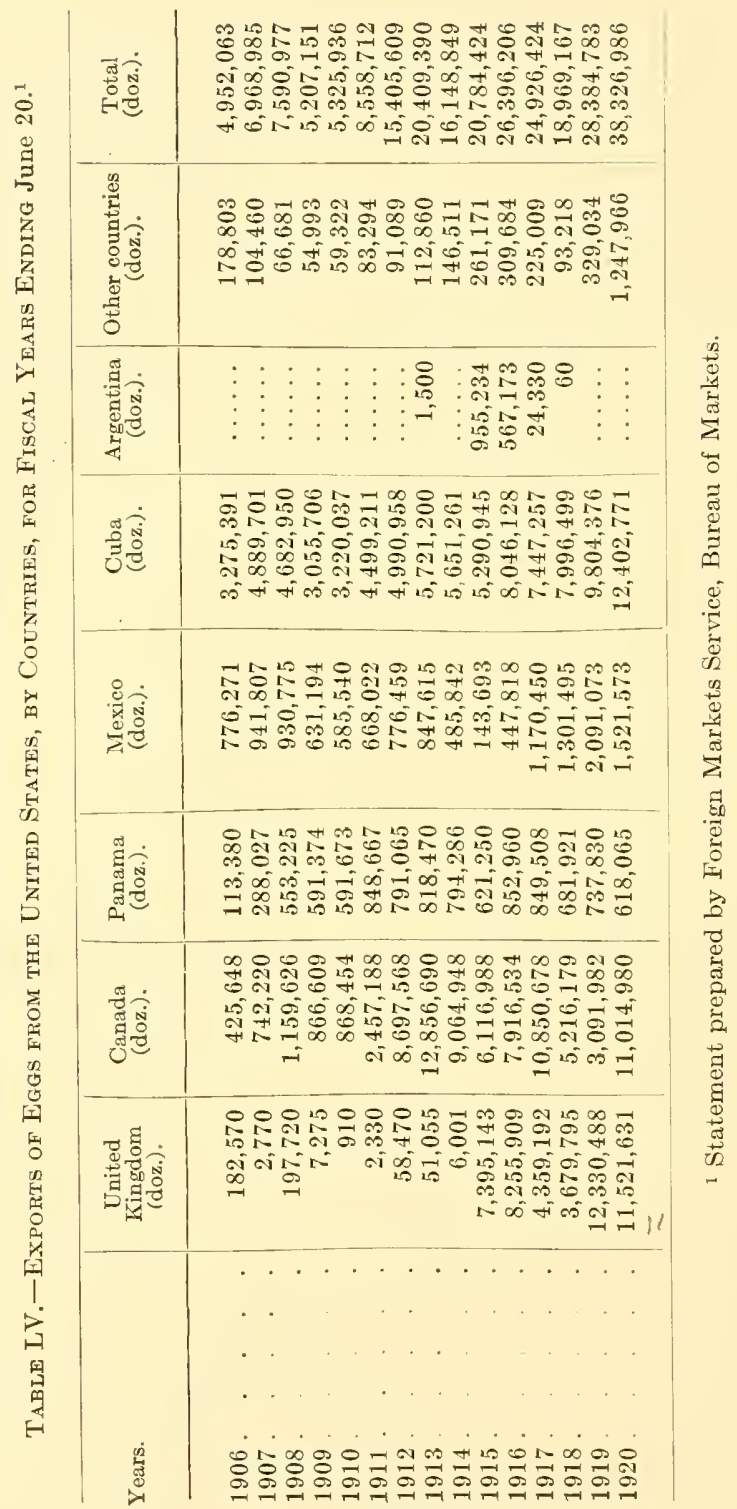




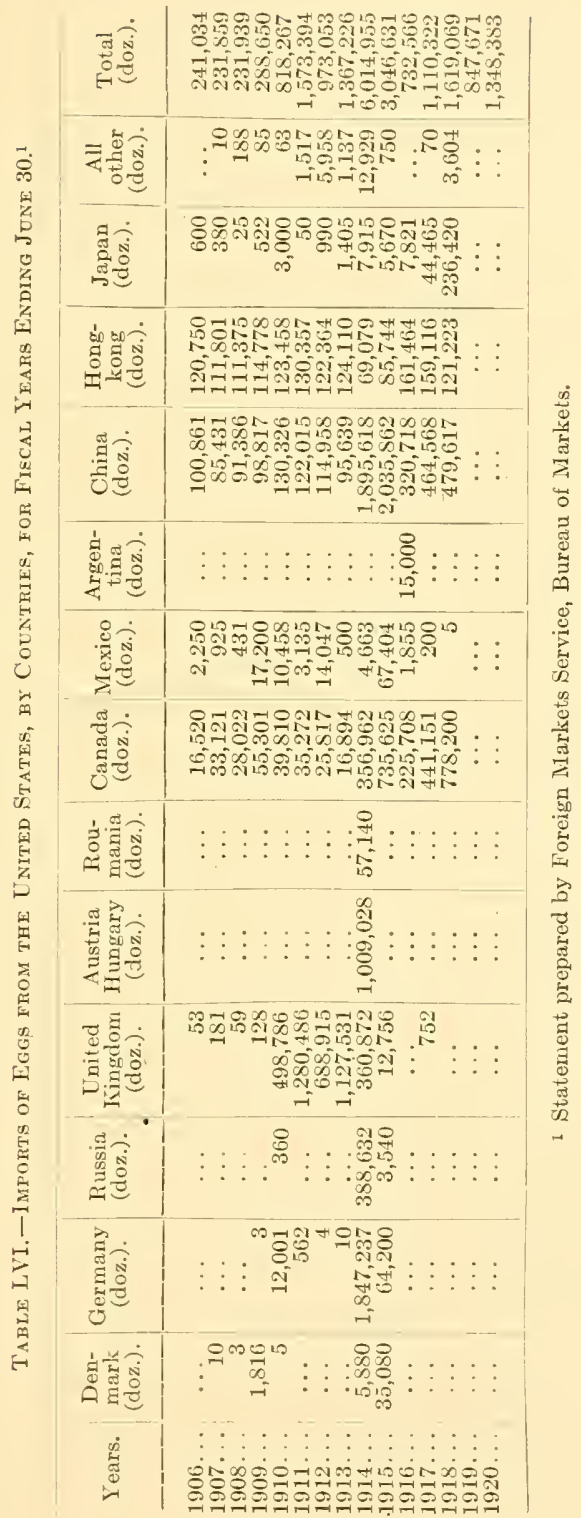


Table LVII.-Exports of Dried and Frozen Eggs for Fiscal Years Ending June 30.

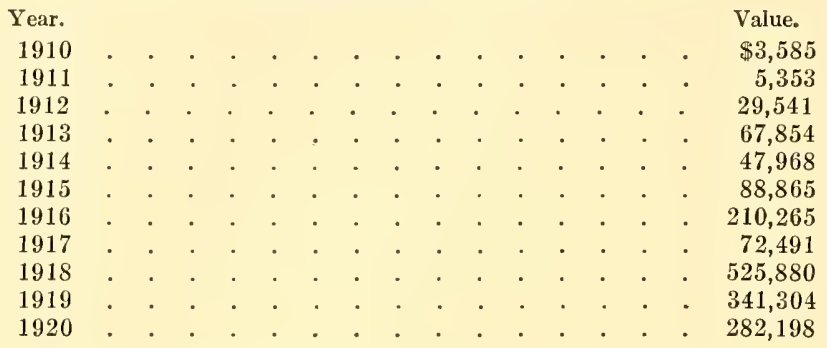

Table LVIII.-Imports of Dried and Frozen Eggs for Fiscal Years ENDiNG JUNe 30.

\begin{tabular}{|c|c|c|c|c|c|c|c|c|c|c|}
\hline Year. & & & & & & & & & $\begin{array}{l}\text { Pounds. } \\
869,923\end{array}$ & $\begin{array}{l}\text { Value. } \\
\$ 56,121\end{array}$ \\
\hline 1911 & : & . & . & . & . & . & . & . & $\begin{array}{l}869,923 \\
433,405\end{array}$ & $\begin{array}{r}\$ 30,121 \\
30,798\end{array}$ \\
\hline 1912 & . & . & . & - & . & . & . & . & 43,822 & 4,430 \\
\hline 1913 & . & . & . & . & . & . & . & . & 228,305 & 36,892 \\
\hline 1914 & . & . & . & . & . & . & • & . & $3,420,412$ & 504,619 \\
\hline 1915 & . & . & . & - & . & . & $\cdot$ & & $3,420,412$ & 504,619 \\
\hline 1914 & . & . & . & . & . & . & . & . & $3,420,412$ & 504,619 \\
\hline 1915 & . & . & . & - & . & . & . & & $8,571,758$ & 798,129 \\
\hline 1916 & . & . & . & • & . & . & . & . & $6,021,672$ & 921,502 \\
\hline 1917 & . & . & . & - & . & . & . & . & $10,317,744$ & $1,732,948$ \\
\hline 1918 & . & . & & - & . & . & . & . & . $14,597,503$ & $4,057,417$ \\
\hline 1919 & . & . & & . & . & . & . & . & $9,085,449$ & $3,143,190$ \\
\hline 1920 & . & . & & & . & 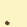 & . & 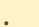 & $24,091,098$ & $8,783,258$ \\
\hline
\end{tabular}

Table LIX.-Total Exponts of Poultry and Game from the United States for Fiscal Years, Ending June 30.

Years.
1906
1907
1908
1909
1910
1911
1912
1913
1914
1915
1916
1917
1918
1919
1920

Value.

$\$ 1,397,004$

$1,086,618$

881,792

848,644

599,548

981,805

697,955

$1,303,399$

913,632

$1,187,771$

$1,561,398$

$1,327,348$

$1,241,144$

$3,799,348$

$1,627,633$ 


\section{N D E X.}

\section{A}

Absorption in intestine, 316 of yolk, 186

Age of breeding stock, 161, 165

Aim in breeding, 109

Air cell in egg, 177, 178, 214 drainage, 255

Albumen, 176 formation of, 177 kinds of, 177

Alfalfa, green, 349 meal, 336

Alimentary tract, 311

Allantois, 184

Alternating yards, 292

American class, breeds of, 75 origin and history of, 76 slaughter tests of, 80

Poultry Association, 56 standard of perfection, 57,59

Amnion, 183

Amylolytic ferment, 314

Analysis of egg, 304 of feeds, 527 of fowl, 304

Anatomy of the fowl, 311

Ancestry of domestic fowl, 49

Anconas, 70

Andalusians, 74

Animal feeds, 322

Annual production, individual variation in, 164

Appendix, 523

Appliances, feeding, $377 \mathrm{ff}$

Area opaca, 180 pellucida, 180 of yards, 291

Artificial brooding, 232, 233 heating of houses, 260 incubation, $197,200 \mathrm{ff}$
Ash content of egg, 301 of fowl's body, 301

in f eeds, 301, 527 use of, 301

Asiatic class, breeds of, origin and history of, 63

Aspergillosis, 504

Aylesbury ducks, 66, 429

\section{B}

Bantams, 65,66

Barley, 336 ground, 337

Barred Plymouth Rock, 78, 145

Barrels for caponizing, 97, 99 packing for, 475

Beets, 350

Bench picking, 461, 462

Bile, 315

Birchen games, 65

Blackhead, 420, 425

Blastoderm, 177, 180

Bleeding, necessity of thorough, 458

Blood, dried, 341 rings, 226, 499

Blue Andalusian, 74

Bone, dry, granulated, 353 green cut, 354

Booted Bantams, 66

Bourbon turkeys, 67

Boxes for dressed poultry, 475

Brahma, $67 \mathrm{ff}$

Bran, wheat, 348

Bread crumbs, 382

Breed, choosing a, 82 defined, 54 standards, 60

Breeder, fancier, 30 
Breeder, production, 30

Breeders, cocks versus cockerels as, 161

hens versus pullets as, 161

management of, $168 \mathrm{ff}$

problem of, 30

Breeding chart, 110, 121

cross-, 109, 132

kinds of, 132

purpose of, 132

definition of, 84

flock, farm, 172

selection of, 173

for production, $142 \mathrm{ff}$

grading, $109 \mathrm{ff}$

line, $118 \mathrm{ff}$

chart for, 110, 121

definition of, 118

purpose of, 119

use of new blood, 121

maternal impressions on, 109

methods of, $109 \mathrm{ff}$

official tests for, 167

pedigreeing methods of, $123 \mathrm{ff}$

records, 126, 129

tests of efficient, 158

Breeds, classification of, 54, 61

ornamental, 61

productive, 61

progenitors, 49

purpose of, 56

standard for, 56,60

Brewers' grains, dried and wet, 338

Broilers, classification of, 473

feeding of, 363,390

season for, 451

standard pack for, 475

Bronze turkeys, 67, 419

Brooder, cool-air compartment of, 241

crowding of chicks in, 243

daily management of, 244

farm types, $230 \mathrm{ff}$

heater for, 234,236

hover, 235,240

number of chicks to a, 243

place of operation, 243

preparation for chicks, 244

proper temperature of, 233

ventilation, 241

Brooding, artificial, 232

natural, 230

principles of, 233

Broody coops, 283
Buckeyes, 63, 75

Buckwheat, 330

bran and middlings, 338

Bumblefoot, 504

Buttermilk, 357

Buyers, classes of, 35,37

\section{C}

Cabbage as a feed, 350

Campines, 65

Canadian geese, 67

Candling, object of, 491, 492

Canker, 515

Cannibalism in chicks, $24 \mathrm{~S}$

Capacity, 133

Caponizing, advantages of, 96 age for, 97

cletails of operation, $96 \mathrm{ff}$

instruments needed, 98

Capons, classification of, 493, 477 making of, 96

method of dressing, 467

as mother's, 232

standard pack, 477

Carbohydrates, definition of, 304 uses of, 304

Catarrh, 515

Ceca, structure and function of, 312,316

Cell division, 180

Cement floor, construction of, 266

Chalazæ location of 177

Charcoal, use of, 355

Checked eggs, loss as, 491, 498

Chick-feeding appliances, $382 \mathrm{ff}$

Chicken, cholera, 508 pox, 505

Chickens, digestive powers of, 320 efficiency of, as compared with other animals, 318,320 grades of dressed, 473 market classification of, 473 number of, $17 \mathrm{ff}$

Chicks, approaches for, 247 baby, 34 care of, in incubator, 228 comparative mortality of incubator and hen hatched, 197 condition of feeds for, 384 day old, 34 depraved appetite of, 248 direction for feeding, $384 \mathrm{ff}$ 
Chicks, drinking fountains for, 412, Creve cœur, 65

414

early versus late hatched, 217

effect of chilling on, 240

first feed for, 229, 382

growing, standard for, 363

methods of marking, 124, 161

pedigreeing, $123 \mathrm{ff}$

sour milk for, $357,384 \mathrm{ff}$

vices of, 248

winginess in, 241

Chinese geese, 67

Cholera, chicken, 508

Class, 54

American, 75

Asiatic, 63

English, 80

Mediterranean, 70

Clay block floor, construction of 268

Cloaca, 316

Clover, cut, 341 uses of, 341

Coal-heated brooders, 235, 236

Cochins, $67 \mathrm{ff}$

Cold storage, cost of eggs for, 25

Colony brooders, $234 \mathrm{ff}$ house, description of, $237 \mathrm{ff}$

Combs, frozen, 509

Concrete floors, 267

Condiments, use of, 339

Constipation, 505

Constitutional vigor, 133 characteristics of, 136 of dam, effect on offspring 135

hatching power as affected by, 141 importance of, 133 influence upon the offspring, 135

Continental class, 65

Continuous house, description of, 283

Cooling dressed poultry, 464

Coöperative marketing associations, 37,39

Corn, 330 meal, 339

Cornish, 64

Cottonseed meal, 339

Cow peas, 332

Cramming machines, 417

Creaminess, 109, 331
Crop, bound, 506

location and use of, 313

Cross-breeding, 109, 132

Crude fiber, 304

Culling, 154

Curtain front, 268 ff

Custom hatching, 34

Cuticle of egg, 177, 194

\section{D}

Dampness, evil of, in poultry house, 256

Dealer, baby chick, 34

Defects, 58

Diarrhea, 94, 519

Digestibility, causes of variation in, 321

Digestible nutrients explained, 300 , 318

Digestion, age, species, and individuality in, 325 coefficients, 318 definition of, 311

Digestive juices, $313 \mathrm{ff}$ tract, diagram of, 312 parts of, 311

Diphtheritic roup, 515

Dirt floor, construction of, 266

Dirty eggs, causes of, 293, 491

Disease, inheritance of, 94

Diseases of poultry, $46,94 \mathrm{ff}$

Disinfectants, use of, 196, 291, 293

Disqualifications, 58,59

Distributer, definition of, 38

Distribution of poultry, 37,38

Divisions of poultry industry, 28

Domestic fowl, origin of, 49

Domestication, effects of, 53

Dominiques, 75

Dorkings, 80

Double mating, purpose of, 171

Drainage, importance of, 253,255

Drake, characteristies of, 431 number of ducks per, 431

Drawing and trussing, operation of, 479,485

Dressed poultry, average price paid for, 24

Dressing, loss of weight in, 467 special styles of, 467

Drink, 329,357 
Drinking vessels, 383, 385, 410, Egg, production, indications of, 413,414

Dropping boards, 283

Dry bone, 353

mash, 336, 380

picking, advantages of, $460 \mathrm{ff}$ methods of, 460

Dryness, importance of́, in house, 256

Duck farming, advantages of, 47 429

Ducklings, feeding of, 435

Ducks, Aylesbury, 66, 429

breeds of, 66,429

care and management of, $431 \mathrm{ff}$

feeding of, $433 \mathrm{ff}$

growing, standard for', 433

housing and yarding of, 432

Muscovy, origin of, 429

number of, in United States, 18

Pekin, for market, $429 \mathrm{ff}$

Runner as egg producers, 429 standard style of pack, 476

Duodenum, 312, 315

Dust wallow, need of, 283

\section{E}

EARLY maturity, 133, 165

relation of, to high production, 165

Economic value of fancy points, 61

Ectoderm, description of, 182

Egg, analysis of the, 303, 304

appearance of fertile, 225

bound, 507

effect of feed on flavor of, 373

formation and fertilization of, 86,90

freak, 90

incubation, development of parts of, 180

periods, 197

lime contents of, 302

packages, 486

position of during incubation,

215

production, 82

average, 147

forcing of, 398. See

Lights.

148

structure of, 175

tester, 226

Eggs, absorption of odors, 490 average price paid for, $22 \mathrm{ff}$ bacterial content of, 374,489 candling of, 491

causes of dirty, 293, 491

demand for, $21 \mathrm{ff}$

as food, 21, 23

hatching, care of, 191

cooling, 208

disinfecting purchased, 196

resting after shipment, 195

selection of eggs for, 188

temperature for holding, 193

time of holding, 193

turning of, 194

during hatching period, 216

warming of, 195

washing of, 194

home preservation of, 501 imports of, 24

infertile, production of, 89

market, deterioration of, 487 , 491

grades of, $491 \mathrm{ff}$

loss in, 487 where it occurs, 487

precautions which will effect improvement of, 486

preparation of, $463-479$

moisture, loss of, during incu-

bation, 210

shrunken, cause of, 488

size of, 190

storage packed, 25, 492

weak or heated, 493

weight of, 190

Embryo of chick, $180 \mathrm{ff}$

Endoderm, 182

English class, origin and history of, 80

Equipment of poultry house, 277

Evaporation during incubation, 210

Eversion of the oviduct, 508 
Exercise, importance of, in feeding, Feeding, wet mash versus dry, 378

External parasites, 512, 513

\section{F}

FANCIER, definition of a, 30

Fancy points, economic value, 61

Farm brooders, types of, $233 \mathrm{ff}$ poultry house, $237 \mathrm{ff}$ income, 20

keeping, advantages of, 39,232

Fasting before killing, 456

Fats, composition of, 305 uses of, 307

Fattening, $400 \mathrm{ff}$ crates for, 415,416 pens, advantages of, 400 rations for, $403 \mathrm{ff}$ results of milk, $401 \mathrm{ff}$ use of tallow in, 404

Faverolles, 65

Feathers, care of, for market, 470 quotations on, 470

Fecundity, $142 \mathrm{ff}$ as affected by comfort, 157 inheritance of, $144 \mathrm{ff}$ object of breeding, 142

Feed, amount of, $366,375,379$ combinations of, $322,370 \mathrm{ff}$ concentrated, 323

consumed by different classes of stock, $375,379 \mathrm{ff}$

Feeding, amount and frequency of, $322,366,375,379$

appliances for, $377 \mathrm{ff}$

basis of, 377

chicks, principles of, 382

ducklings, 433

exercise, necessity of, $37 \mathrm{~S}$

for fattening, 299, $400 \mathrm{ff}$

hoppers, dry mash, $406 \mathrm{ff}$

objects of, 297

practice of, $377 \mathrm{ff}$

problem of, $37 \mathrm{~S}$

production of growth, 298 of heat, 297

purpose of, 297,372

regularity in, 378

shelf for, 282, 284, 407

troughs for, 412

wet mash, $324,374,380 \mathrm{ff}$ $380 \mathrm{ff}$

Feeds, animal, 322, 341, 343, 347 357 classification of, $329 \mathrm{ff}$ digestibility of, $318 \mathrm{ff}$ effects of cooking on, 324 on product, 373

mash constituents, 336 mineral, 353

palatability of, 324,368

succulent, $34 \mathrm{~S} \mathrm{ff}$

stimulating, 339

wetting of, $324 \mathrm{ff}, 374,380$

Feedstuffs, curing of, effect on, 211, 325

effect of age on, 325

Felch's Breeding System, 120

Fences, 291

Fertile egg, appearance of, 225, 493

Fertility, cessation of, 107

time required after mating, 106

Finishing table poultry, 391, $400 \mathrm{ff}$

Fish scrap, 341

Fixtures for poultry house, $277 \mathrm{ff}$

Floor space in poultry house, 243, $263 \mathrm{ff}$

Floors, construction of, 266

Flour, low grade, 346

Follicle, 84

Forcing for egg production, 392 ff, 398

Fowl, cholera, 508

classification of, 474

composition of, 304

origin of domestic, 49

temperature of, 297

Frame picking, 461

Fresh air, importance of, 255, 258

Frosted wattles and combs, 509

Future, limiting factors of, 42

\section{G}

Gali-Bladder, 312

Gallus bankiva, 50

Gapes, 510

Gastric juice, use of, 313

Geese, advantages of, 435

Embden, 435

feeding of, $439 \mathrm{ff}$

live, plucking of, $43 \mathrm{~S}$ 
Geese, market demand for, 436 noodled, 440

number of, 18

selection of breeding, 438

Toulouse, 435

value of, 436

General farm versus intensive conditions, 41

purpose breeds, classification of, 62

Generalized production, 26 ff, 39 reasons for, 39

Generative organs, $84 \mathrm{ff}$

Geographical distribution of poultry, 26

Germ, temperature of development of, $181 \mathrm{ft}$

Gizzard, location and function of, 314

Gluten feed, 342

Glycogen, 305, 315

Goose eggs, incubation of, 438

Goslings, feeding of, 440

Grades of dressed poultry, $473 \mathrm{ff}$ of market eggs, $491 \mathrm{ff}$

Green cut bone, 354 feed, $348 \mathrm{ff}$

Grit, 355

Growth, feeding for, 363, $382 \mathrm{ff}$

Guinea, 449

appearance of male and female, 450

breeding of, 450

feeding of, 450

incubation of eggs of, 450

number of females per male, 450

Gullet, location and use of, 313

\section{H}

Hamburgs, 62, 65

Hardening the chicks, 228

Hatch, taking off the, 228

Hatcher, customs, 34

Hatching, pedigree, 124 power, $139 \mathrm{ff}$

Hen as a food manufacturer, 45 versus Jersey Cow, efficiency of, 318

Hens, breaking up broody, 200 feeding of breeding, 399 hatching with, $197 \mathrm{ff}$
Hens, kind to set, 198

management of setting, 199

physiological efficiency of laying, 318

standard for feeding laying, 364

Hominy feed, 342

Hopper, feed, 406

grit, 411

supply, 405

Hot-air incubators, 204

Hot-water incubators, 204

Houdans, 65

House, care of, 293

drafts in, 260

ease of disinfection, 263

essentials of good poultry, $249 \mathrm{ff}$

evils of moisture in, 256

exposure of, 254

fixtures for, 277

foundation for, 266

lights in, 261

location of, 251

size of, 263

types of, 283

ventilation of, 258

walls and partitions of, 270

warm versus fresh air in, 260

Housing ducks, 432

effect of, on fertility of eggs, 260

necessity of, 249

pigeons, 446

unnatural conditions of, 249

Hover, description of, $233 \mathrm{ff}$

disinfecting of, 243

portable, $233 \mathrm{ff}$

Hygrometer, 224

\section{I}

IMPACTION of the crop, 244,506

Impregnation, artificial, 171

influence of previous, 107

Improvement by selection, $133 \mathrm{ff}$

Inbreeding, $118 \mathrm{ff}$

Incubation, $175 \mathrm{ff}$

Chinese and Egyptian method of, 201

cooling of eggs, 208

comparative reliability of natural and artificial, 197

date of hatching, 217 
Incubation, history of, 200

natural, 198

normal moisture loss in, 210

periods, 197

testing of eggs, 225

turning and cooling of eggs,

$194,208,216,224$

Incubator's, $175 \mathrm{ff}$

best means of supplying mois-

ture, 210

crowding eggs into, 215

disinfection of, 221

efficiency of hens as, 197

first American, 203

hot-air, 204

hot-water, 204

humidity in, 210-221

insurance restrictions on, 229

kinds of, 204

leveling of, 221

mammoth, 20.1

management of, 220

moisture in, 210,224

artificial, 211-224

place of operation, 205

position of thermometer in, 208

preparation of, $220 \mathrm{ff}$

principles of operation of, 205

routine of management of, 220

size of, 201

starting of, $220 \mathrm{ff}$

taking off the hateh in, 228

temperature of, 205

value of, 203

ventilating of, 214

Indications of laying, $148 \mathrm{ff}$

Indigestion, 511

Indoor brooders, requirements of, 233

Infectious entero-hepatitis, 425

Infertile eggs, advantages of, 94, 493,501

Ingredients, size of, 368

Inberitance, $8 \pm \mathrm{ff}$

of constitutional vigor, 135

of disease, 94

of high egg production, 142

Insecticides, 512, 513

Insemination, artificial, 171

Intensive conditions, 41, 46

Intestine, parts of, 315
JAVAS, 63

Junglefowl, description of, 50

$\mathbf{K}$

ITAFIR, 332

Killing, knife for, $45 \mathrm{~S}$

methods of, 57

\section{L}

LA FLeCHE, 65

Langshan, 68

Layers, routine in feeding of, $392 \mathrm{ff}$

Leg weakness, 511

Leghorns, $71 \mathrm{ff}$

Lettuce, 350

Lice, 512

Lights, 261, 357, 379, 393

Limberneck, 515

Line breeding, $118 \mathrm{ff}$

Linseed-oil meal, 346

Liquids, 357

Litter in poultry house, 293

Live poultry, average price of, 21

classification of, 473

Liver, entargement of, 513

location and function of, 315

Longevity, 158

Low-grade flour, 346

\section{M}

Matntenance of health, 503 of life, $297 \mathrm{ff}$

Males, alternating, 170 care of, 169

developing of breeding, 392

disposition of surplus, 172

number of females to, 169

Mammillary layer, 179

Mangel wurtzel, 350

Manure, preservation of, 295 value of, 295

Market eggs, classification of, $491 \mathrm{ff}$ infection in, 489 liquefaction, 488 preparation of, 486 
Market eggs, shrinkage in, 488

Mash constituents, $336 \mathrm{ff}$

Mating, time required for fertility in egg, 106

Meat breeds, classification of, $61 \mathrm{ff}$ fresh, 343

scrap, 343

type, characteristics of, 139

Mediterranean class, origin of, 70

slaughter tests of, 80

Mesoderm, 182

Middlings, wheat, 345

Milk, butter, 357 skim, 357 whey, 359

Millet, 333

Mineral constituents in feeding, $353 \mathrm{ff}$

Minorcas, 64, 71

Mites, 513

Moisture in incubation, 210-224 pan, 224

Molasses, 345

Molt, 152

feeding during, 398

Mouth parts, use of, 311

Muscovy ducks, 66, 429

\section{$\mathbf{N}$}

Nesting material, 198

Nests, care of, $198 \mathrm{ff}$ construction and location of, 198,270

for hatching, 198

trap, 123

Nutrients, $297 \mathrm{ff}$ defined, 300

digestible, required per day, $362 \mathrm{ff}$

digestion and, 320

from animal sources, 322

function of, $300 \mathrm{ff}$

mutual relation of, 306

Nature's supply of, 306

relation of, to production, 300 of vegetable source, 322

Nutrition of poultry, $297 \mathrm{ff}$

Nutritive effect of a feed, 369 ratio defined, 326

OATS, 333 sprouted, 351

Oil meal, linseed, 346

Onions, 350

Open front poultry house, 270

Organic nutrients, 300

Organs, female reproductive, 84 male generative, 95

Orpingtons, 64,80

Ovary, function of, $84 \mathrm{ff}, 91 \mathrm{ff}$ location of, 84 number of ova, 85 parts of, 86

Overerowding, evils of, 248,265

Oviduct, description of, 85 location of, 85

Oyster shells, 356

\section{$\mathbf{P}$}

Packer defined, 36 function and methods of, 36

Packing, methods of, $455 \mathrm{ff}, 475$ stencilling the box for, 477

Pancreas, location and function of, 314

Pancreatic juice, 314

Parasites, external, 512, 513

Pasture of poultry, 349, 351

Pate de foi gras, 442

Pedigreeing, $123 \mathrm{ff}$

Pekin ducks, 66, 429

Pen, size of, 265

Perches, construction and location of, 281

Periods of incubation, 197

Physiological efficiency of fowl, 318

Piano-box house, 250 of reproduction, $84 \mathrm{ff}$

Picking, methods of, 460

Pigeon, best age for breeders, $443 \mathrm{ff}$ breeding of, $443 \mathrm{ff}$

breeds of, 443

classes of, 443

feeding of, 447

houses for, 446

mating of, $443 \mathrm{ff}$

number of, 18

squab breeding, $443 \mathrm{ff}$ value of, 18

Plans for houses, $271 \mathrm{ff}$ 
Plymouth Rocks, 63, 75

breeding of barred variety, $114 \mathrm{ff}$

history of, $75 \mathrm{ff}$

Poisoning, 514, 515

Portable, colony house, 285 hover, 233

and soil fertility, 46

Poultry, average value of, 18 classification of, determining market, 473,478

cooling and shipping dressed, 464

decomposition of drawn and undrawn, 471

definition of, 17

early American, 27, 52

farm consumption of, 21

farms, special, 32,34

faults in dressed, 465

geographical distribution of, 26

grading of, 109, 473

home consumption of, 21

income of ten best states, 20, 21

incubation period of, 197

industry, $17 \mathrm{ff}$

magnitude of, 19

organization of, 28

limits of production of, 42

manufacturing efficiency of, 45

number of farms reporting on, 18

operations incident to dressing, 456

origin of, 49

preparation of products for market, $451 \mathrm{ff}$

preparing of, for market, 456

rank of states as to fowls kept, 27

singeing of, for market, 464,479 statistics, $17,18,19,21,523 \mathrm{ff}$ tendency of the industry, $39 \mathrm{ff}$ in United States, 27

value of farm production, 27

Poults, care and feeding of, 425

Predetermining fertility and sex, 190

Prepotency, mark of, 117

Preservation of eggs, 36, 501

Primitive streak, 180
Producer to consumer, route of poultry products, 37

defined, 32

Products, purpose of preparation, 455

seasonal distribution, $451 \mathrm{ff}$

Protein defined, 302

function of, 302

Ptomain poisoning, 515

Pullets, developing of, 391

spaying of, 105

Pumpkins, 351

Pure bred defined, 57

sires, 109

\section{$\mathbf{R}$}

RACKs for cooling, 465

Range, advantages of, 41, 291

Rape, 351

Ration, balanced, 360

chick, $384 \mathrm{ff}$

composition of, 370

computing of, 365

cost of, 374

definition of, 360

digestibility of, 371

maintenance, 361

nutritive effect, 369

palatability of a, 368

requirements of a, $360 \mathrm{ff}$

typical laying, 396

Record of eighteen farm flocks, 41

Rectum, location of, 316

Red Caps, 64

dog flour, 346

Regularity, importance of, in feeding, 378

Reproduction, $84 \mathrm{ff}, 175$

physical basis of, 84

Reproductive organs, $84 \mathrm{ff}$

female, 84

male, $91 \mathrm{ff}$

Respiratory system, 256

Rhode Island Reds, history and origin of, 80

Rice, 334

Roaster, definition of, $473 \mathrm{ff}$ styles of packing of, 476

Roofing materials, 275

Roosters, classification of, 473

Roosts, 281

Rots, 499, 500 
Rouen ducks, 66, 429

Roup, 515

Rye, 334

pasture, 351

\section{$\mathbf{S}$}

SALT, 355

Scald picking, 460

Sealy leg, 517

Scratch feed, 396

Screenings, wheat, 336

Selection, purpose of, 133

Sex glands, 84 ff

$$
\begin{aligned}
& \text { description of, } 84,95 \\
& \text { function of, } 91
\end{aligned}
$$

Shade and shelter, necessity of, 251

Shanks, removing of, $83 \mathrm{ff}$

Shed roof poultry house, $283 \mathrm{ff}$

Shell, formation of, $89,175 \mathrm{ff}$ layers of, 176 membrane, 88, 176 construction of, 177 oyster, 356

Shorts, wheat, 346

Shrubbery, use of, 253

Skim milk, 357

Sick birds, care of, 503

Silage, 351

Singeing, method of, 479

Slips, classification of, 473,474

Soil, 253 conservation of fertility of, 46

Spleen, 312

Spot eggs, 499

Springs, classification of, 473

Sprouted oats, 351

Stags, classification of, 473,474

Stained eggs, 491

Standard bred defined, 59 pack, 470 of perfection, 57

Stencils, use of, 477

Sticking knife, 458

Stomach, glandular, location and function of, 312,313

Stove brooders, $234 \mathrm{ff}$

Straw loft, 275

String picking, 461

Stud breeding, 171

Succulent feeds, 348

Sugar, 347

Sunflower seeds, 334
Sunlight, importance of, 243,260

Sunstroke, 518

Sussex, 64

\section{T}

TAPEWORMS, 521

Temperature for brooding, $233 \mathrm{ff}$ for incubation, 181, 205, 224

Tendons, pulling of, $481 \mathrm{ff}$

Testers, egg, 225

Toe picking, 248 punching for identification, 161

Tolman house, 289

Tom, number of hens to one, 423

Transportation, facilities for, 45

Troughs, 406

Trussing, 485

Tuberculosis, 518

Turkeys, $67,418 \mathrm{ff}$

blackhead, 425

Bronze, 67, 419

decline of raising, 18, 419

domestication of, 418

farm production of, 420

feeding of market, 428

infectious entero-hepatitis of, 425

nesting of, 424

number of, 18

of hens to tom, 423

round-up of, 421

selection of breeding, 422

White Holland, 67, 419

Turning eggs during incubation, $194,216,224$

Turnips, 353

Type, breed, 54

egg, 158

of houses, 283

meat, 139

vigorous, 136

\section{V}

VARieties, standard, $54 \mathrm{ff}$

Variety defined, 55

Vegetable feeds, 322

Ventilating system of a hover, 241

Ventilation in incubators, 214, 225 necessity of, 215,258 
Ventilation systems, 217

Vigor, cause of lack of, 47, $135 \mathrm{ff}$ importance of, 133

Vitality, importance of, 133

Vitamins, $308 \mathrm{ff}$

Vitelline membrane, 176, 177

W

WALLS and partitions of poultry house, 270

Warmth in poultry house construction, 260

Water glass for preserving eggs, 501

heaters, 414

use of, in nutrition, 301

Watering devices, 410

Watery eggs, 495
Weight of eggs, 190, 491

Wet mash, 324, 380

Wheat, 335

screenings, 336

Whey, 359

White diarrhea, 94, 519

Windows, 268

Wishbone, taking out of, 480,483

Worms, 521

Wyandottes, 63, 75

Y

YARDING ducks, 432

Yards and fences, 291

Yolk, formation of, $84 \mathrm{ff}, 176$ structure of, $175 \mathrm{ff}$

Young stock, growing of, 363, $382 \mathrm{ff}$ 






LIBRARY OF CONGRESS HWHWH 00028510731 